
Aro

BDODTHG LIST.

TAR I 5 S 

S $32.68 k$

\title{
KAMPF UND KRIEG
} im deutschen Drama von Gottsched bis Kleist

\author{
Zur Form- und Sachgeschichte \\ der dramatischen Dichtung
}

Von

Dr. Max Scherrer

$18096 s^{\prime}$

$2.6 \cdot 23$.

Rascher \& Cie, Verlag, Zürich 1919 
s,

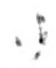


DEN MANEN MEINER MUtTER MEINEM LIEBEN VATER 
N 


\section{Vorbemerkung.}

Plan und Vorarbeiten zu der nachfolgenden Schrift reichen in das Jahr 1913 zurück. Sie ist durch den Krieg zunächst unterbrochen und äußerlich mannigfach gehemmt, innerlich wie ich hoffe aber gefestigt worden.

Einleitung und Kapitel 1-3 sind 1917 als Münchener Dissertation gedruckt.

Für stete, liebenswürdigste Hilfsbereitschaft in der Beschaffung des $\mathrm{Ma}$ terials und in allen bibliographischen Dingen bin ich vor anderen den Herren der Universitätsbibliothek München, insbesondere meinem Freunde Dr. Max Stefl verpflichtet, dessen treue Sorgfalt auch der Korrektur zugute gekommen ist.

Entscheidende wissenschaftliche Föràerung danke ich an dieser Stelle meinen hochverehrten Lehrern Franz Muncker, † Erich Schmidt und Heinrich Wölfflin.

M. S. 
心 


\section{Inhalt.}

Se:te

Einleitung

I

I. Abschnitt: Von der französischen Form zum nationalen Schlachtfestspiel.

1. Kapitel: Gottsched und seine Schule . . . . . . . . . . . . . 8

2. Kapitel: Erste Wirkungen des Siebenjährigen Krieges . . . . . . . 39

3. Kapitel: Klopstocks Hermanns-Schlacht. . . . . . . . . . . . . . 52

II. Abschnitt: Shakespeare und das Kampfstück des Sturm und Drangs.

4. Kapitel: Götz von Berlichingen . . . . . . . . . . . . . . . . 70

5. Kapitel: Die Jugenddramen Klingers . . . . . . . . . . . . . . . 89

6. Kapitel: Das ritterliche Kampfstück bis in die achtziger Jahre . . . . 101

I. Die pfälzisch-elsässische Gruppe ........... 101

2. Die bayerische Gruppe. . . . . . . . . . . . . 113

7. Kapitel: Der junge Schiller . . . . . . . . . . . . . 13i

III. Abschnitt: Die Verfestigung der Form. Stildrama, Kampftheatralik und Theatralsatire.

8. Kapitel: Klingers Reife . . . . . . . . . . . . . . . . . . 167

9. Kapitel: Goethe in den achtziger Jahren . . . . . . . . . . . . 183

10. Kapitel: Die theatralische Ausmünzung der Kampfmotive. . . . . . . . 194

1. Das spätere Ritterstück und das Kampfspektakel . . . . . . . 194

2. Die Höhe der Theaterwirkung: Kotzebue . . . . . . . 206

3. Der Theatergötz . . . . . . . . . . . . 234

11. Kapitel: Romantische Theatralsatire und neue Einkehr bei Shakespeare:

Tieck . . . . . . . . . . . . . . . 238

IV. Abschnitt: Das deutsche Kriegsdrama in seiner Blüte.

12. Kapitel: Die Klassik Schillers . . . . . . . . . . . . . . 260

I. Wallenstein................. 260

2. Die Jungfrau von Orleans . . . . . . . . . . . . 293

13. Kapitel: Die Kriegsdramatik Heinrich von Kleists . . . . . . . 325

14. Kapitel: Faust, II. Teil . . . . . . . . . . . . . . . . . 380

Ergebnisse ....................... . . 392

Anhänge:

1. Die Waffe..................... . . . 395

2. Die Wunde .................... . . 401

3. Das Pferd ..................... 406

Literaturverzeichnis . . . . . . . . . . . . . . . . . 412

Register ......................... . 416 
N" 


\section{Einleitung.}

Goethe führt im 12. Buch von Dichtung und Wahrheit seinen Abriß der Geschichte des Wetzlarer Kammergerichts mit der Bemerkung ein, daß die Beschaffenheit der Gerichte und der Heere die genaueste Einsicht in die Beschaffenheit irgendeines Reichs gebe. Die folgende Untersuchung unternimmt es, unter dem zweiten Gesichtspunkt das dramatische Reich zu mustern und versucht, aus der wechselnden Verfassung der dramatischen Heere und der dramatischen Kriegführung Einblicke in den Wandel der dramatischen Form zu gewinnen. Wie die Kunstgeschichte etwa die Gestaltung eines Kapitells von der altchristlichen Basilika bis zur Renaissance verfolgt und aus der Art wie der kleine Block behauen und geformt wird, die Stilgeschichte der mächtigen Dome liest, so sollte an den Sonderaufgaben, die der Kampf, in seinen Abstufungen vom Einzelgefecht bis zur offenen Feldschlacht, dem Drama stellt, ein Jahrhundert seiner formal-technischen Entwicklung aufgezeigt werden.

Es war natürlich, daß zugleich damit die kriegerischen Sachprobleme, die Fragen der Kampfauffassung, des dichterischen Erlebens des Krieges bis herunter zu der Stellung der Dramatiker zum historischen und zeitgenössischen Heerwesen und seiner Spiegelung in der Dichtung ins Auge gefaßt wurden; sie sind von der formalen Betrachtung ${ }^{1}$ ) nicht zu trennen und haben für sie, angefangen bei der Stoffwahl und noch in den kleinsten scheinbar äußerlichen technischen Prozeduren, entscheidende Bedeutung. Letzten Endes bestimmt das Erlebnis die Formgebung; die dramatische Technik erwächst auf dem Grund der Gesamtstimmung einer Epoche und besteht nur in Zeiten der Erstarrung losgelöst von ihr weiter; auch ein übermächtiger fremder Einfluf setzt schon eine verwandte Disposition voraus. Es gehen demnach im folgenden die Darlegungen über die dramatische Kampfform mit der Untersuchung des kriegerischen Gehaltes Hand in Hand; bei diesem war die Grenze nicht zu eng zu ziehen. Die technische Betrachtung durchmißt, indem sie die wirklichen Lösungen eines reichen Abschnittes der Entwicklung mustert, worin

1) Unter „Form" und „formal“" wird im folgenden durchweg die dramatische Form der Stücke, nicht ihre sprachliche verstanden; also jene, die man auch, im Gegensatz zu der sprachlichen „äußeren", als die ,innere Form" bezeichnet. 
weltliterarische Formagegensätze zum Austrag kommen, nahezu den Kreis der möglichen Formen der Kampldarstellung; die sachliche Betrachtung sollte demgegenuiber Raum genug erhalten, um neben den Grundfragen auch das militärische Kleinwerk, dic spezifisch soldatischen Dinge in ihrem ganzen Umfang z.u iiberblicken und damit ein Cesamtbild der dramatischen Erfassung des Militärischen in den behandelten Epochen - es ist das Jahrhundert, das vom ständischen Heer in die a!lgemeine Wehrpflicht führt - zu erreichen.

In der Abgrenzung des Gebietes war fuir eine Darstellung, die die neuere dramatische Entwicklung, wesentlich das 18. Jahrhundert umfassen sollte, der Ausgangspunkt in der Reform Cottscheds gegeben; für das Kampfproblem ganz besonders dadurch, daß mit der Wiedervereinigung von Bühne und Literatur durch ihn der Prozeß zwischen dem (klassizistisch-französischen) Rationalismus und der ungebundenen (shakespearisch-englischen) Phantasie, der in der Kriegsdramatik hartnäckig durchgekämpft vicrden muß, in eine erste entscheidende Phase eritt. Weniger leicht ist die Grenzlinie nach unten zu ziehen. Ein Ausgleich und damit ein Abschluß wird in der Klassik Schillers crreicht, aber Kleist ist neben ihm für die Krönung der Tendenzen seit dem Sturm und Drang kaum zu entbehren, so sehr er auf der anderen Seite in eine neue Zeit weist. Dagegen steht Grabbe, an den bei der Erwähnung schlachttechnischer Fragen imner zuerst gedacht wird, durchaus jenseits, während der Schlachtakt des Faust II trotz der späten Entstehungszeit, die ihre Spuren hinterlassen hat, naturgemäß noch in die klassische Reihe gehört. Ohne eine spätere Fortsetzung im 19. Jahrhundert auszuschließen, ist die Begrenzung des Stoffes so vorgenommen, daß bis zum Tode Schillers die gesamte Entwicklung. daruber hinaus nur noch das Schaffen Kleists und des alten Goethe erfaßt wird; daß der chronologische Einschnitt dabei gegenüber späteren Stücken von Autoren, dic im 18. Jahrhundert wurzeln, wie Tieck und Kotzebue. nicht ängstlich festgehalten wird, braucht kaum gesagt zu werden.

Als wichtige Vorarbeiten zur Behandlung der kriegerischen Dramatik im 18. Jahrhundert fand ich außerhalb der Spezialliteratur über die einzelnen Autoren und Stücke vor die ältere Schrift von Otto Brahm über das deutsche Ritterdrama, die den umfänglichsten kriegerischen Dramenkreis des letzten Jahrhundertviertels als geschlossene Gattung mustert und seine Motive inventarisiert : auf der anderen Seite die Studie K. H. v. Stockmayers über das deutsche Soldatenstiick seit Lessings Minna, dic den bürgerlichen Zweig der zeitgenössischen Militärstücke untersucht und besonders dort als Unterlage wertvoll wurde, wo sich die Kriegsdramatik großen Stils mit dieser Gattung berührt: in den Räubern, oder mit ihr verschmilzt: im Prinzen von Homburg. Die Probleme der Massenhehandlung, und in diesem Rahmen auch die Kampfszenen, sind neuerdings in Walther Lohmeyers Buch über die Dramaturgie 
der Massen dargestellt worden; für die Bühnentechnik im späteren 18. Jahrhundert liegt Petersens umfassende, über die zeitliche Grenze vielfach zurückgreifende Arbeit über Schiller und die Bühne vor. ${ }^{2}$ )

Über den Krieg als Vorwurf der Tragödie hat sich unter den deutschen Theoretikern des Dramas am bedeutsamsten der Führer der romantischen Kritik, Wilhelm Schlegel, ausgesprochen. Er stellt vergleichend fest, daß der Krieg weit mehr ein epischer als ein dramatischer Gegenstand sei, ${ }^{3}$ ) zugleich aber geschichtlich, daß er dem Schauspiel seit alters zugehöre; denn es ,,kommen schon in einigen griechischen Tragödien Kämpfe und Schlachten vor, das heißt die Vorbereitungen dazu und deren Erfolse; und in historischen - Schauspielen ist der Krieg, diese ultima ratio regum, durchaus nicht auszuschlieBen". Zur Betrachtung seiner dramatischen Erfassung übergehend, findet Schlegel in ihren Haupttypen die große Gegensätzlichkeit der klassischen und romantischen Dichter wieder. „Die Griechen haben sich die Vorstellung von Kriegen und Schlachten auf der Bühne durchgängig untersagt: da ihre ganze theatralische Darstellung auf großartige Würde ging, so wäre es ihnen unleidlich gewesen, daneben eine schwache und kleinliche Nachahmung des Unerreichbaren zu sehen. Bei ihnen werden also alle Gefechte bloß berichtet. Durchaus verschieden war der Grundsatz der romartischen Schauspieldichter: ihre wunderbaren Gemälde waren unendlich größer als ihre theatralischen Mittel der sichtbaren Ausführung; sie mußten überall auf die willfährige Einbildungskraft der Zuschauer rechnen, und durften es also auch in diesem Stücke".

2) An Sonderstudien über das Kriegerische in der Dichtung, fast sämtlich die älıere Zeit betreffend, sind mir bekannt geworden: Frdr. Ha us e n, Die Kampfesschilderungen bei Hartmann von Aue u. Wirnt von Gravenberg, Hallenser Diss., 1885; Frdr. Bode, Die Kampfesschilderungen in den mhd. Epen, Greifswalder Diss., 1909; P. Erfurth, Die Schlachtschilderungen in den älteren Chansons de geste, Hallenser Diss., 1911; O. Leibecke, Der verabredete Zweikampf in der altfrz. Literatur, Göttinger Diss. 1905; K. Albrecht, Der Zweikampf mit blanken Waffen in der deutschen Lit., Burschenschaftl. Blätter, Jahrg. 23. - Die hauptsächliche Literatur aus der im folgenden geschöpft wird, mit den für sie gebrauchten Abkürzungen, ebenso die zugrunde gelegten Gesamtausgaben und Sammelwerke sind am Schlusse verzeichnet; die zahlreichen, mehr beiläufig herangezogenen Schriften werden an ihrer Stelle, ihre Verfasser im Register aufgeführt; in den Zitaten bedeuten arabische Ziffern $(3,12)$ oder arabische, gefolgt von rōmischen (3, XII), Band u. Seite; römische, gefolgt von arabischen (III, 12), Akt u. Szene.

$\left.{ }^{3}\right)$ Uber dramat. Kunst und Litteratur ${ }^{2}$ 3, 202 ff. DNL 143, 230 ff.; noch schärfer, aber beiläufig und darum minder gewichtig gefaBt ${ }^{2}$ 1, 161 (DNL 143, 17) zu Äschylus: „Der Krieg an sich ist kein Gegenstand für die Tragödie, von der bedeutungsvollen Rüstung führt uns der Dichter rasch zur Entscheidung fort." Vgl. dazu O. Nieten, Chr. D. Grabbe, Dortmund 1908 (Schriften der Literarhist. Gesellschaft Bonn 4), S. 352 u. 382, der die Schlachtaufgabe in Hinsicht auf Grabbe als Sphinx für die dramatische Behandlung betrachtet. 
Dic beiden Pole der dramatischen Kriegsgestaltung sind damit umschrieben, und Schlegel hat insbesondere das Prinzip des romantischen - englischspanischen - Schauspiels aus der Tiefe heraus begründet. Im späteren Drama wird dic Kluft zwischen den Grundrichtungen noch erweitert. Die Franzosen, deren Schlegel in diesem Zusammenhang nicht gedenkt, erneuern die antike Tragödic in rationalistischen Geistc, und ihre Kritik, gipfelnd in Boileau. hasicrt die dramatische Form vollends ausschließlich auf die raison, während im Schaffen der Klassiker selhst abweichende, künstlerische Gesichtspunkte allerdings nicht zu unterdrücken sind. Der strikte Gegensatz zu der Behandlung des Kriegerischen durch den ,romantischen" Dichter ist damit erst in der französischen Klassik, am schroffsten in der Theorie, schroff genug in der dramatischen Produktion, noch riicht in ihrem griechischen Urbild gegeben. Während die romantische Kunstweise im Sinne Schlegels, aus der dichterischen Phantasie herausgestaltend und auf die nachschaffende zählend, keine $\mathrm{Be}-$ schränkung kennt, verwehrt der phantasiefeindliche - ungriechische - Rationalismus der tragédie classique alle Darstellung des Krieges. Das äußere Bild ihrer Form gleicht darin dern der antiken Tragödic, der sie auch den Botenbericht als Vehikel der Kamplvergegenwärtigung nachbildet; aber die Geistigkeit ist cine andere, und der Unterschicd prägt sich formal darin aus. daß die Franzosen einen zweiten, unrationalistischen Typus der antiken Kampftechnik. der für die deutsche Entwicklung die größte Bedeutung erlangt, nicht mit übernehmen.

Die Sache der Phantasie in der Kriegsdramatik führt kein Geringerer als Shakespeare selbst. In den Versen des Chorus, der als Vor- und Zwischenredner die kampferfüllte Handlung Heinrichs V. geleitet, liegt eine programmatische Kundgebung beschlossen, die das Verhältnis des romantischen Dramatikers zur Darstellung des Krieges crschöpfend wiedergibt. Shakespeare geht aus von der Erbärmlichkeit des theatralischen Gerüstes, das des großen Vorwurfs - das Aufeinandertreffen zweier mächtigen Monarchien, die Eroberung französischen Bodens steht im Spiel - unwürdig sei; er gibt den kläglichen Raum der Bühne, ihre gegen die Realität stïmperhafte Kopfzahl an Darstellern und das Lächerliche des Theaterkriegs preis:4)

Diese Hahnengrube.

Faßt sie die Ebnen Frankreichs? Stopft man wohl

In dieses $\mathrm{O}$ von Holz auch nur die Helme

Wovor bei Agincourt dic Luft erbebt?

1) Heinnich V.. Chorus vor dem ersten, dritten und vierten Akt, nach Schlegel-Gundolf. Den Prologen billigt auch der neueste Ubenseizer Shakespeares, der sonst die Echtheit des Stückes anzweifelt. des Meisters Hand zu (Shakespeare in deutseter Sprache, Berlin 1908 f. 4. 356). 
O so verzeiht, weil eine krumme Zahl

Im engen Raum ja für Millionen gilt,

Und laßt uns Nullen dieser großen Summe

Auf eure einbildsamen Kräfte wirken.

So muß zum Treffen unsre Szene fliegen,

Wo wir (o Schmach!) gar sehr entstellen werden

Mit vier bis fünf zerfetzten schnöden Klingen,

$\mathrm{Zu}$ lächerlichem Balgen schlecht geordnet,

Den Namen Agincourt. -

Aber er ruft zugleich die Kraft der Phantasie auf, die kargen Andeutungen der Darstellung auf ihre Weise auszugestalten und aus ihnen, den schmählichen Abbreviaturen der Wirklichkeit, das wahre, nur geistig erschaute Dichterbild aufzubauen:

Ergänzt mit den Gedanken unsre Mängel,

Zerlegt in tausend Teile einen Mann,

Und schaffet eingebild'te Heereskraft. ... . Doch sitzt und seht,

Das Wahre denkend wo sein Scheinbild steht.

Auf, auf, im Geist! Seht einer Stadt Belagrung,

Seht das Geschütz auf den Lafetten stehn,

Auf Harfleur mit den Mündern tödlich gähnend...

Der Antrag paßt nicht, und der flinke Lader

Rührt mit der Lunte nun die höllischen Stücke

Die alles niederschmettern... Bleibt geneigt!

Eur Sinn ergänze was die Bühne zeigt.

Es ist bekannt, wie weit Shakespeares Publikum ebenso wie das Publikum der mittelalterlichen Mysterien diesen Forderungen entgegenkam. Dagegen duldet die rationalistische Bühne der Franzosen als Vorführung nur das durchaus der Wirklichkeit Gemäße, das schlechthin Darstellbare; allein die Furcht vor dem Lächerlichen, das Gewissen der französischen Dichter, ${ }^{5}$ ) würde genügen, alle unvollkommene Wiedergabe, die gutwillig für die wirkliche Erscheinung genommen werden soll, auszuschließen.

Die französische Denkweise kommt in dem nachshakespearischen England zum Siege, und ebenso, im Zeitalter Gottscheds, in Deutschland. Die öfters

5) Schlegel, Dramat. Kunst und Litt. ${ }^{2}$ 2, 148 f.; DNL 143, 103; vgl. Voltaire, Discours sur la tragédie Brutus, Cuvres 2, 315. 
als Naivität geringgeschätzte, für den Dramatiker unschätzbare Disposition des alten Publikums, dessen Anspruchslosigkeit wie dicjenige des Kindes aus der Regsamkeit der Phantasie hervorgetht, ist damit verloren. Die lange Reihe der Finwïrfe gegen den Bühnenkampl, die scit den französischen Theoretikern nie mehr verstummen, stammt in Crunde aus dem Lager der Rationalisten, aus einer Ciristesrichtung, die das notwendig dürftige, oft klägliche und geradezu lächerliche der Kampfdarstellung der freien Entfaltung der Handlung zuliebe uicht nuchr zu übersehen vermag. Diese Anschauung bleibt die herrschende. Auch Willuclm Schlegel gibt zu: $\left.{ }^{6}\right)$..Es ist allerdings lächerlich, wenn eine Handvoll ungeschickter Streiter in pappnen Rüstungen durch einige Degen, womit, wie man deutlich sieht, sie sich wohl hüten einander das mindeste Leid zuzufügen, das Schicksal mächtiger Reiche entscheiden sollen" - und selbst er kommt gegenüber der Kriegswelt Shakespeares zu einem überraschend kühl abwägenden Urteil: „Bei allen den erwähnten Nachteilen haben Shakespeare und einige spanische Dichter aus der unmittelbaren Vergegenwärtigung des Krieges so große Schönheiten gezogen, daß ich nicht wünschen kar.n, sie hätien sich deren enthalten." Es entspricht seinem vermittelnden Standpunkt. dalf er schlicflich Fingerzeige für die Inszenierung gibt, die die Schwierigkeiten vor allem durch Verwendung illusionistischer Mittel meiden soll.

Eine breite Grundlage für die ungebundene Entfaltung von Kämpfen, aber auch eine den rationalistischen Widersachern willkommene Blöße und, wichtiger, eine starke innere Gefahr bildet dic vor der Bühne immer rege Schaulust. Der Zustand der älteren englischen Bühne, dic Jugendstücke Shakespeares und das eparische Theater lehren, daß darin die Wurzel der freien Kampftechnik zu suchen ist. Hier tritt al!erdings ein naives, volksmäßiges Element zutage, und als Wortführer der Klassizisten kann sich noch Voltaire nicht genug tun, von der Höhe cines kultivierten Geschmacks herab über die shakespearische Dramatik des Pöbels, für die er doch ein erstes Verständnis anbahnt, herzuziehen. .Les porteurs de chaise, les matelots, les fiacres, les courtauds de boutique. les bouchers, les clercs même aiment passionnément les spectacles; donnez-leur des combats de coqss, ou de taurcaux, ou de gladiateurs. des enterrements, des duels, des gibets, des sortilèges, des revenants, ils y courent en foule" heißt es in der Schrift über das englische Theater, ${ }^{7}$ ) ähnlich wic der römische Klassizist Horaz den ungelehrtesten Tcil des Publikums zaust, weil er mitten im Stück nach Fechtern oder einem Bärentanz schreie. ${ }^{8}$ ) und die Zwischenspicte an den Pranger stellt, worin das Kriegerische

9) Dramat. Kuns: u. Litt. ${ }^{2}$ 3, 207-210; DNI. 143, 233.

7) Du théätre anglaiz (1761). CEuvres 24, 201 (früher betitcle Appel à toutes les nations usw.).

") Ëpiss. II, I. v. 185 \&, : media inter carmina poscunt /aut ursum aut pugiles: his nam plebecula zaudat. 
besonders im Ansehen steht: ,"quattuor aut plures aulaea premuntur in horas, / dum fugiunt equitum turmae peditumque catervae; / mox trahitur manibus regum fortuna retortis, / esseda festinant, pilenta, pettorita, naves, / captivom portatur ebur, captiva Corinthus". ${ }^{9}$ ) Ein übereinstimmender Ausfall Voltaires findet sich noch einmal in der Lettre à l'Académie française: ${ }^{10}$ ) „Partout les spectacles chargés d'événements incroyables plaisent au peuple: il aime à voir des changements de scènes, des couronnements de rois, des processions, des combats, des meurtres, des sorciers, des cérémonies, des enterrements“ - und gegen den kriegerischen Ausstattungsprunk im besonderen prägt er das feine Wort: „Quatre beaux vers valent mieux, dans une pièce, qu'un régiment de cavalerie“, ${ }^{11}$ ) obwohl seine eigene Dramatik dem darin niedergelegten klassischen Prinzip der Verinnerlichung allerdings zuwiderläuft.

Auch Schlegel erkannte, daB die Schaulust und die von ihr geförderte Vervollkommnung der szenischen Mittel für die Kriegsbehandlung des ,romantischen “ Dichters gefährlich werden konnte : ,allein das [der primitiven Kampfwiedergabe] entgegengesetzte Äußerste ist noch weit schlimmer. Wenn es nun wirklich gelingt, das Getümmel einer großen Feldschlacht, die Erstürmung einer Festung und dergleichen einigermaßen täuschend vor die Augen zu bringen, so ist die Gewalt dieser sinnlichen Eindrücke so groB, daB sie den Zuschauer der Aufmerksamkeit unfähig machen. welche ein dichterisches Kunstwerk erfordert; und das Wesentliche wird unter dem Zubehör erdrückt."12). Dieser Vorgang vollzieht sich im Schauspiel de. 18. Jahrhunderts unter dem Einfluß der Oper Hand in Hand mit der Ausbildung des Dekorations- und Ausstattungswesens und führt das Kampfstück bis in die letzte Veräußerlichung im Kampfspektakel. Die freie Kampftechnik ist demnach von der einen Seite her durch die Lächerlichkeit der unzulänglichen, von der anderen durch das Überwuchern der zulänglichen Mittel bedroht. Die zweite Gefahr wächst, je mehr die rationalistischen Ansprüche an sie durch Annäherung der Darstellung an die Wirklichkeit befriedigt werden.

9) Epist. II, I; nach Wieland, der in seinen Anmerkungen Belege aus der römischen Theatergeschichte beibringt: „die Szene bleibt / vier Stunden oft und länger unterbrochen, / indeB das gaffende Parterre mit Zwischenspielen / belustigt wird. Da jagen Reiterei / und FuBvolk hitzig mit gezücktem Säbel / einander durch die Bühne. - Folgt darauf, / gar schön zu sehn! das Schauspiel eines langen / Triumphs; in Fesseln ziehn, die Hände auf den Rücken / gedreht, besiegte Könige daher; / ein rascher Zug von gall'schen Kriegeswagen / und Kutschen voll gefangner Damen und / Bagagekarren rasseln hinterdrein:/ Gerätschaft, Schiffe, Bilder und Gefäße / von Elfenbein, ein ganz Korinth voll eherner / Statuen, wird im Pomp dahergeschleppt".

10) 25 août 1776: II partie; CEuvres 30, $366 \mathrm{f}$.

11) Dissertation sur la tragédie ancienne et moderne (Semiramis), Euvres 4, 500.

12) Dramat. Kunst und Litt. ${ }^{2}$ 3, 208; DNL 143, 233. 


\title{
Erster Abschnitt. \\ Von der französischen Form zum nationalen Schlachtfestspiel.
}

\author{
Warum muß es denn gerade Krieg sein? Krieg ist ein gefährliches \\ Spicl: ich kann schon das bloße Wort nicht leiden; glaubt mir, es \\ liest sich besser davon in Büchern, als dort im Felde zu stehn - \\ Tieck im Blaubart. \\ Erstes Kapitel.
}

\section{Gottsched und seine Schule.}

Gottsched fand bei seinem Auftreten eine verwilderte Volksdramatik vor, in der die rohe Schaulust, dic Voltaire an der englischen Bühne geißelt, in höchster Blüte stand. Ihr Verhältnis zum Kriegerischen ist gekennzeichnet durch dic von den englischen Komödianten eingeführte, seither nicht mehr abgekornmene Verwendung der Blutblase zur Darstellung der Theaterwunden. ${ }^{13}$ ) Dic Kampftechnik im ganzen entsprach ebenso wie dieses Charakteristikum dem Stande des älteren englischen Theaters, der seinerzeit von den Komödianten vermittelt wurde. Die tiefere Ursache der uibereinstimmenden theatralischen Verhältnisse liegt aber in denselben volksmäßigen Forderungen: die Vorfuihrung, auf das Grausame und Blutrünstige ausgehend, findet ihre einzige Grenze in der Beschränktheit der szenischen Mittel. ${ }^{14}$ ) Dieser Tradition gegenüber, in der die shakespearische Phantasiefreiheit allerdings nicht mehr zu erkennen war, bringt Gottsched in entscheidendem. Bruch - wie der Boden schon vor ihm durch a!lmähliches Eindringen der französischen Regeldramatik vorhereitet wurde, spielt hier keine Rolle - das rationalistische Ideal, die

13) Vol. den Anhang Wunde.

19) Fur die Kampfdarstellung bei den englischen Komödianten vgl. Tittmann. Die Schauspiele der enpl. Komödianten. Leipzig 1880. S. LVIll f.; Creizenach. DNL 23, XC f. Die Belege für das ganze älere deutsche Drama sind gesammelt bei Siegfr. Ma uermann. Die Bühnenanweisungen im deutschen Drama bis 1700, Berl. 1911 (Palaestra Bd. 102): engl. Komödianten S. 1241. u. 236; Ayrer 128: volkstüml. Drama 159; Chr. Weise 178; Jesuitendrama 201; Renaissance-Drama $223 \mathrm{f}$. 
Kunstform der gallischen Klassiker zur Geltung. Unter den Gründen, die das historisch bedeutsame Werk gelingen ließen, ist der nicht der geringste, daß Gottsched mit dem französischen Codex einen festgefügten, nach allen Seiten gesicherten Bau, woran es nichts zu rütteln gab, in die Wildnis der überlieferten Formen stellte, daß er ein ausgearbeitetes System, das Regelmäßige an Stelle des Regellosen setzte. Dies wird an den Fragen der Kampftechnik sofort sichtbar.

Von den zwei Wegen, die das horazische Aut agitur res in scenis aut acta refertur dramatischer Gestaltung weist, kennt die klassische Tragödie der Franzosen, wenn Kampfereignisse zu geben sind, nur den einen: den Botenbericht. ${ }^{15}$ ) Äußerlich gesehen hindert die Beobachtung der Einheiten, zumal der des Orts, mehr noch das Gebot der bienséance, welches alle Bluttaten von der Bühne verbannt, die sichtbare Darstellung von Gefechten. In der engumgrenzten Welt der heroischen Tragödie, die nur für wenige bedeutende - Personen Raum hat und die Masse ganz ausschließt, könnten sie ohnehin nur als Zweikämpfe auftreten. Der innere, stilbestimmende Grund, der sie so gut wie völlig fernhält, ist die Konzentration der Aufmerksamkeit auf die seelischen Konflikte. Das äußere Geschehnis für sich bedeutet der französischen Klassik wenig; ihr Interesse ruht auf seinem Reflex im Geistigen. Diese Verinnerlichung allein erlaubt die strengste Beschränkung im Apparat: geschlossene, geradlinige Handlung, Einsetzen kurz vor der Katastrophe, wenig Figuren, geringe Ausdehnung in der Zeit, ein Ort.

15) Während Aristoteles sich über ihn im besonderen nicht äußert, prägt Horaz (De arte poetica v. $182 \mathrm{ff}$.) die fürderhin kanonische Regel: Non tamen intus / digna geri promes in scenam multaque tolles / ex oculis, quae mox narret facundia praesens - in Gottscheds Übersetzung (Crit. Dichtkunst ${ }^{4}$, Leipzig 1751, S. 31): „Doch solltens Dinge sein, / Die man nicht zeigen mag, die darf das Volk nicht sehen:/ Man trägt sie mündlich vor, als wären sie geschehen." Diese Vorschrift geht mit der horazischen Einschränkung von der geringeren Überzeugungskraft des bloß Gehörten gegenüber dem Gesehenen auf Boileau (Art poétique Chant III v. 51 ff.) über:

\section{„Ce qu'on ne doit point voir, qu'un récit nous l'expose: \\ Les yeux en le voyant saisiraient mieux la chose; \\ Mais il est des objets que l'art judicieux \\ Doit offrir à l'oreille, et reculer des yeux."}

Selbständiger spricht sich Corneille aus, der sich im Discours de la tragédie (Euvres 1, 78, vgl. 1, 105) Horazens Regel zu eigen macht, im Discours des trois unités (1, 100) aber, bei der Besprechung der Sonderhandlungen, neben dem Botenbericht noch andere Möglichkeiten der Vermittlung des Außerszenischen sieht: der Dichter soll aus jenen nur die günstigsten darstellen, ,et cacher les autres derrière la scène, pour les faire connaittre au spectateur, ou par une narration, ou par quelque autre adresse de l'art." Vgl. dazu Joh. Böhm, Die dramat. Theorien P. Corneilles, Kieler Diss., Berl, 1901, S. 122. 
Die gottschedische 'Theorie betnächtigt sich dieser Form vom Standpunkt des platten Verstandes aus. Das Problem der Kampfdarstellung ist damit ohne weiteres entschieden; alle Vorführung wird verworfen, weil sie der Wahrscheinlichkeit widerspricht. Jedes Parlamentieren gerade darin hätte überdies als Rückfall in die verhaßte Barbarei der Volksbühne und Zuflucht zu den verabscheuungswïrdigen Wirkungsmitteln der Staatsaktionen gelten müssen. Un so interessanter sind die Annäherungen an jene, die sich in die Schultheorie und in zunchmender Stärke in die Schulpraxis einschleichen.

Gottscheds eigene Äußerungen zur Kampftechnik sind nicht eben zahlreich und mehr beiläufiger Natur; es lag keinc Veranlassung vor, sich über eine Nebenfrage, deren Lösung durch den allgemeinen Grundriß seines Lehrgebäudes deutlich genug vorgezeichnet war, insbesondere auszusprechen. Er gibt etwa in seiner Kritik des corneilleschen "Cid" ${ }^{16}$ ) dem Dichter Beifall. ..daß der Zweikainpf des Grafen mit dem Roderich nicht auf der Schaubühne geschiehet, denn es ist gemeiniglich lächerlich. Man stellet nichts als das Geräusche der Klingen vor". Den Rationalisten stört die ungenügende Bühnendarstellung. Im größeren Zusaminenhang wird der Bühnenkampf gestreift innerhalb der oft diskutierten Schicklichkeitsfrage, wie weit Bluttaten in der Vorführung zulässig seien. Gottsched ist darin noch ängstlicher als seine französischen Lehrmeister. Er tadelt am selben "Cid" (III. 4) ${ }^{17}$ ) - er war auch das Sorgenkind des posterioren Systems Corneilles - daß Don Rodrigue mit blutigem Degen in das Zimmer seiner Geliebten komme, woran der strenge Kommentator Voltaire keinen Anstoß nimmt. Aus seiner Verteidigung von Catos $\operatorname{Tod}^{18}$ ) wird deutlich, daß an einen tödlichen Stich auf der Bühne, weil dabei Blut fließen würde, nicht zu denken ist. Merkwürdig bleibt dieser Zimperlichkeit gegenüber die Anmerkung der Critischen Dichtkunst zu Horazens "Aut agitur" usw. ${ }^{19}$ ). wo Gottsched der Bemerkung, daß die Franzosen auf ihrer Bühnc kein Blut vergießen ließen, die Worte entgegensetzt: .Die Engeländer und wir Deutschen haben dergleichen blutige Dinge gern", immerhin ein Zugeständnis an die nationale Bedingtheit der Kunst und wie eine leise Vorahnung der lessingischen Erkenntnis im 17. Literaturbrief. Die dritte Auflage der Dichtkunst 1742 errichtet freilich an dieser Stelle die War-

19) Beyträge zur Critischen Hislorie usw. 4. 305. 14. Stück, 1736.

${ }^{17)}$ Bevtrăğe 4. 302 u. 306: Fr. Braitmaier. Geschichte der poetischen Theorie u. Kritik von den Diskunen der Maler bis auf Lessing. Frauenfeld 1888-89, I, 135.

13) Schrifien zurn Cato. ..Des Verfassers bescheidene Antwort auf vorhergehende critische Gedanken". Cato. 10. AuR., 1757. S. 110: ..Nur den bloBen Tod, nachdem der todliche Stich shon peschehen war, vor den Zuschauern erfolgen zu lassen, das ist schon eine Verwägenheit. die einigen zästlichen Kunstrichtern verwerflich vorkömmi" usw.

19) Crit. Dichlkunst, I. Auf., 1730. S. 24-25: 4. Aufl. 1751, S. 30. 
nungstafel: „,doch ist es der Wahrscheinlichkeit wegen besser, sich dieser Vorstellungen ${ }^{20}$ ) zu enthalten“.

Derselbe dramaturgische Rationalismus, der mit Cottsched in Deutschland zur 'Herrschaft kam, hatte im Lande Shakespeares selbst Fuß gefaßt. Im Kampf gegen das regellose englische Drama kam dem Leipziger Professor der "Spectator" Steeles und Addisons zu Hilfe, der unter den Werken ist, denen er die Kenntnis der Regeln der Schaubühne verdankt; ${ }^{21}$ ) seine Frau übersetzte die Zeitschrift seit 1739. Es mußte ihm, dem ein zur Regel bekehrter Engländer lieber war als neunundneunzig regelmäßig geborene Franzosen, ${ }^{22}$ ) aus dem Herzen gesprochen sein, wenn der Englische Zuschauer dem Kampfgetümmel, das seine nationale Bühne erfüllte, mit Spolt und Ernst zu Leibe ging. ${ }^{23}$ ) Gegenüber der shakespearischen Beschwörung der Phantasie wies sein krittelnder Verstand ganz im Sinne Gottscheds das Lächerliche auf, das Heeren auf dem Theater anhaftet, wenn sie mit unzulänglichen Mitteln dargestellt werden: „Zwei oder drei Handlanger, und ein paar Lichtputzer ${ }^{24}$ ), machen auf der englischen Bühne eine vollständige Leibwache aus: und, wenn man noch einigen wenigen Trägern rote Röcke anzieht, so können sie mehr als ein Dutzend Legionen vorstellen. " ${ }^{25}$ ) Wie um Shakespeares Chorus zu widerlegen, heißt es weiter: „Es ist der Einbildungskraft der Zuschauer unmöglich, zwanzig Mann in eine unzählbare Menge zu verwandeln, oder sich einzubilden, daß zwei oder dreimal hunderttausend Soldaten in einem Platze von vierzig oder funfzig Ruten ins Gevierte miteinander schlagen können. Dinge von solcher Art sollen erzählet, und nicht vorgestellet werden." Solchen Ausstellungen, die Shakespeare nicht nur mitbetreffen, sondern unmittelbar auf ihn gemünzt scheinen, zum Trotz stellte ihn ein späteres Stück des Spectator allerdings über alle Regeln, und dagegen mußte Gottsched Einspruch erheben. ${ }^{26}$ ) Er wirft in dieser Polemik gegen Shakespeare dem ,Julius Cäsar“ vor, das Stück

$\left.{ }^{20}\right)$ Das Wort in der ursprünglichen sinnlichen Bedeutung, gleich Vorführung.

21) Vorrede zum Cato, 1732; 10. Auf., 1757, 6. Seite. DNL 42, 45.

${ }^{22}$ ) Vgl. z. B. die Freude, womit er (Neuer Büchersaal der schönen Wissenschaften und freyen Künste 7 (1748), 209-38) seiner: Landsleuten zeigt, ,was selbst ein Engländer von der Verderbnis seiner engländischen Bühne denkt" - und den Auszug aus Drydens Essay of dramatic poesy (Das Neueste aus der anmutigen Gelehrsamkeit, Lenzmonat 1753).

${ }^{23}$ ) Der Zuschauer. Aus dem Englischen übersetzt [von Frau Gottsched], Leipzig 1739-43: Gegen den übermäßigen Lärm theatralischer Schlachten, 42. Stück (1, 202); gegen den hohlen Theatcrpomp von Kriegermassen, 36. Stück (1, 167); gegen das anachronistische Schießen das. (1, 168).

24) Im Original noch präziser: „Two or three shifters of scenes, with the two candle-snuffers."

${ }^{25)}$ Der Zuschauer, 42. Stück, 1, 201.

26) „Anmerkungen über das 592. Stück des Zuschauers“, Beyträge 8 (1742), 143 ff. 
hebe vor der Ermordung Cäsars an und daure bis nach der philippischen Schlacht, ${ }^{2 i}$ ) wo Brutus und Cassius geblieben, und wir hören den Tadel, daß diese auf der tragischen Bühne erscheint, mit heraus; ebenso einen ähnlichen. allgemeineren gegen die Kriegsdarstellung, wenn der Crundsatz der Einheit des Ortes ausgeführt wird:2" $)$..Wo man ist, da muß man bleiben; und daher auch nicht in dem ersten Aufzuge in Walde, in dem andern in der Stadt, in dem dritten im Kriege, und in dem vierten in einem Garten, oder auf der Sec sein".

Dic gottschedische Anschauung wurde von den Schweizern geteilt; die rationalistische Verwerfung der dramatischen Schlacht ist einer der wenigen Punkte, worin ihre Theoric, die im ganzen dem Drama nicht allzuviel Aufmerksamkeit schenkt, ${ }^{29}$ ) noch Jahre nach vollzogenem Bruch mit den Leipzigern einig geht. Bodmer äußert sich bei der Abgrenzung der epischen und dramntischen Eigenart, ausgehend davon, daß nicht alles was der Erzählung, zugleich auch der Vorstellung fähig sei: „Dic Erzählung hat z. E. den Vorteil. daß man mit Beschrcibungen der Schlachten einem [epischen] Gedichte von kriegerischem Inhalt ein großes Ansehen geben kann; da die Vorstellung einer Schlacht oder nur eines Zweikampfes auf der Schaubühne schlechterdings lächerlich wäre; weil sie niclit anders als ungeschickt herauskommen kann." ${ }^{30}$ ) Es ist immer wieder derselbe Einwand, der in England, in Leipzig und in Zürich erhoben wird.

Dic wichtigste Kundgebung der Gottschedschule zu der Kampffrage aus der Zeit vor der Schaubühne ist die "Abhandlung von denen auf der Schaubühne sterbenden Personen" in den Beyträgen, die Chri-

2) So von der 3. Autl. (1742) ab in dic Critische Dichtkunst 2. Teil, I. Abschnitt, X. Hauptslück. \$ 16 (4. Auf., 1751, S. 614) übergegangen; die Stelle in den. .Anmerkungen über das 592. Stück" usw.. Beyträge 8, 161-62 hat den Schnitzer „.pharsalische Schlacht”, den die Dichtkunst verbessert. Vgl. J. v. Antoniewicz. Einl. zu Joh. El. Schlegels Ästhetischen und dramaturgischen Schriften DLD 26, LXXXVIII f.

27) Crit. Dichekunst ${ }^{4} 616$.

s) Vgl. Braitmaicr 1. 215: Roland Schacht. Die Entwicklung der Tragödie in Theorie und Praxis von Golteched bis Lessing. Münchener Diss., 1910, S. 13.

20) Crit. Bricfe, Zürich 1746, 2. Brief, S. 79; vgl. B. Seuffert DLD 9. IV f.; augenscheinlich schwebt bei der Stelle Aristoteles vor (Bodmer zitiert ihn S. 86), der beim Vergleich von Epos und Drama eirenfalls ein kriegerisches Beispiel (Ilias 22, 205 ff.) heranzicht: . so würde die Episode von der Verfolgung Hektors aut der Bühne sich komisch machen, wie alle Griechen stille stehen und nicht verfolgen und Achilles abwinkt: im Epos aber bleibt es unbernerkt" (Poetik cap. 24. übers. von H. Stich. Reclam). Bodmer steigert die feine Einzelbemerkung zum allgemeinen. vernunftgegründeten Tadel. - Seine frühere dramaturgische Schrift: Crit. Betrachtungen und freye Untersuxhungen zum Aufnehmen... der deutschen Schaubühne, Bern 1743, ergibt für das Kampluroblem nichts. 
stian Gottlieb Ludwig zugeschrieben wird. ${ }^{31}$ ) Die Schrift, im äußeren Duktus ganz gottschedisch, zeigt bei genauerem Zusehen bemerkenswerte A.bweichungen vom Standpunkt des Meisters. ${ }^{32}$ ) Der Verfasser kennt kein Schicklichkeitsgebot, sein einziger, bis in die letzten Folgerungen geführter Grundsatz ist die „Wahrscheinlichkeit", das heißt die Naturwahrheit. Nur sie legt seinem anderen Prinzip, der ,lebhaften Vorstellung", Beschränkungen auf. Blutvergießen ist nicht zu meiden weil es unschicklich wäre, sondern weil es schwer naturwahr dargestellt werden kann. Daß dieser Theoretiker starke Nerven hat, ${ }^{33}$ ) zeigt seine Empfehlung des Erwürgens auf der Bühne, das vollkommen natürlich zu machen sei, wobei er bezeichnend genug nicht vergißt anzugeben, daß die zu erwartende, aber nicht nachzuahmende Veränderung der Gesichtsfarbe der Kontrolle des Zuschauers entzogen werden müsse. Er neigt deutlich zur Art der Engländer, möchte möglichst viel sehen, und findet die Franzosen - vor Lessing! - „sehr furchtsam“. Es ist fast kein racinescher Held, dem er nicht vorwürfe, er hätte auf der Bühne sterben sollen. Zwar größere Kampfaktionen schließt auch er aus, da sie nicht täuschend vorzuführen sind: „Wenn uns Belagerungen der Städte, ganze Schlachten, die Herabsteigungen der Götter, und dergleichen Dinge vorgestellet werden, so ist es nicht wahrscheinlich genug. Auch ein weitläuftiges Operntheatrum ist nicht fähig, uns einen lebhaften Begriff beizubringen." ${ }^{34}$ ) Aber über den Zweikampf denkt er läßlicher. Im vorhergehenden Stück der Beyträge hatte Gottsched, wie wir sahen, am "Cid“" gelobt, daß der Zweikampf hinten vor sich gehe. Ludwig findet, mit vorsichtigem Ausdruck gegen den Meister, seine Vorführung „nicht nötig“, weil er Nebenhandlung sei. Er nähert sich dem Einwand Gottscheds gegen die Darstellung von Duellen bis zum wörtlichen Anklang, wenn er sagt: „Es ist dieses etwas wider die Wahrscheinlichkeit gesündiget, weil man doch durch das bloße Geklapper der Klingen einen

$\left.{ }^{31}\right)$ Beyträge 4, 390-406, 15. Stück, 1736. Die Zuteilung des Aufsatzes an Ludwig nach Wa ni e k, Gottsched S. 194, ohne Angabe der Unterlage dâzu. GGr ${ }^{2}$ 3, 371 führt nur Ludwigs Ulysses, ADB 19,600 die wichtigsten seiner naturwissenschaftlichen Schriften, deren lange Reihe bei Mieusel Lex. 8, 393 ff. gegeben ist, auf. Bei Jördens fehlt Ludwig. Chr. H. Schmids Bibliographie der deutschen dramaturgischen Schriften (Deutsche Monatsschrift, Berlin 1790 ff., Jahrg. 1794. 1, 123 ff.) verzeichnet den Aufsatz, kennt aber den Autor nicht; auch Antoniewicz. DLD 26, XCII, behandelt ihn als anonym. - Die Darstellungsprobleme des Todes mustert Petersen S. 357 ff. Über den Tod im deutschen Drama von Gryphius bis zum Sturm und Drang handelt Rich. Sexau (Walzels Untersuchungen, 9. Heft, Bern 1906).

$\left.{ }^{32}\right)$ Antoniewicz, S. XCII, stellt nur ihr Verhältnis zu El. Schlegel dar und nennt sie allgemein ".von Gottsched beeinfluBt".

33) Die Beobachtung stützt die Zuteilung an Chr. G. Ludwig innerlich: er war Arzt.

34) Beyträge 4, 391 . 
Zweikampt nicht lebhaft genug vorstellen kann" ${ }^{35}$ ) - er kennt aber immerhin Fälle, wo er gezeigt werden mu B: sofern er zur Haupthandlung gehört. Ebenso könnten Uberfälle ganz wohl vorgeführt werden. Er gibt Mittel an, das Unnatürliche dabei zu mildern und hat richtig gesehen, daß Kämpfe stets schnell abgewickele werden mïssen und nach Möglichkeit überraschend auftreten sollen. damit der Zuschauer nicht zu genau auf Schlag und Stich zu achten vermöge.

Eine erste Lockerung der gottschedischen Strenge ist schon hier zu spüren: sie wird deutlicher in den dramatischen Versuchen seiner Jünger. Die tragischen Produkte der Schule, insbesondere die Stücke der Schaubühne ${ }^{36}$ ) sind die Exempel der Theoric - oder sollten es wenigstens sein; den einzigen Elias Schlegel ausgenommen, handelt es sich in ihrem Umkreis nicht um ein poetisches Bemühen noch so kümmerlicher Art, sondern bloß um ein handwerkmäßiges Verfahren nach dem Rezept. Aber es macht sich doch, sobald man zu übersetzen aufhört und - in den bescheidensten Crenzen - Eigenes bietet, eine unverkennbare Verschiebung des Interesses geltend. Den seelischen Konflikten der französischen Tragödie nachzugehen, waren weder die Gesinnung noch die Mittel fein genug. Der wahre Geist der Klassik des 17. Jahrhunderts konnte durch die Nachahmung ihres dramatischen Gerippes auf unergiebigem Boden nicht gebannt werden. Es besteht von Anfang an ein Zwiespalt zwischen der Gesetzgebung und dem eigenen, wenn auch nur dumpfen Wollen, worin die nationale Tradition noch wirksam ist.

Nun fand Cottsched allerdings selbst an seinen Mustern, deren Problemkreis durch die Formel von der noble et belle passion im wesentlichen umschrieben wird, eines zu tadeln: eben dicse belle passion, die französische Liebe. ${ }^{3 i}$ ) Seine Deutsche Schaubülnne hat denn auch unter ihren - den Cato eingerechnet - zehn Original-Trauerspiclen ein einziges Stück, das in einem Liebeskonflikt aufgeht, Schlegels frühe „Dido“. Umsovicl bezeichnender,

as) Beyträge 4, 397.

36) Die Deulsclue Schaubühne, nach den Regeln der alien Griechen und Römer eingerichtet. Lespzig 1741-45; 2. Aufl. 1746-50. Cher die Entstehungszeiten der darin gesammelten Stücke vgl. Wanick. S. 398 f.

39) Zu vgl., was er über sie mit guter Ironic in der Vorrede zur Schaubühne, Bd. 5 (zur .Panthes" seiner Frau) sagt; es stimmt wiederholt dem Vorschlag Riccobonis bei, die Liebe ganz sus der Tragödie zu vertannen oder nur in tugendhafter Form zu dulden, das. und ..Neuer Büchersal|" I (1745), 270-71: vgl. Waniek S. 186, der Lessings Vorwurf im 17. Literaturbrief entoegnel. Coottsched habe dem .Artigen, Zärlichen und Verlichien" des französischen Dramas nemals dins Wort getedet; ferner Reichel, Coltsched, Berlin 1908 f., 1, 633 und ofter, der (zum Cato) im Apologetenton von der ..proßen. dem franzärischen W'esen von Grund aus widerstrebenden. deutsech empfirulenden Seele" Coollscheds spricht. 
daB auch in diesen innerlich zu behandelnden Vorwurf lautes Kampfgetöse dringt. Die übrigen Stoffe aber sind samt und sonders politischer Natur. Man müßte von einem Verhängnis sprechen, das in dieser Wahl über der Schule waltet, wenn sich darin nicht eine von der französischen abweichende Veranlagung zeigte; im Künstlerischen zwar fast ohne Verdienst, aber historisch als erste Stufe einer Entwicklungsreihe nicht ganz unbedeutend. Man behandelt in einer Form, die der Verinnerlichung der Konflikte ihr Dasein verdankt, Vorgänge so, daß ihr einziges Interesse im äußeren Geschehen läge: Krügers Palastrevolution „Mahomed IV.“, Grimms „Banise“ und Cottscheds eigene „Bluthochzeit“ sind Beispiele; man zwängt Stoffe, die der Masse kaum entraten können, in das karge Figurenschema der heroischen Tragödie: so bleibt das Sozialreformstück Gottscheds, "Agis“, ohne Volk; endlich: man müht sich ab, Vorwürfe voller Kampfaktion, ja eine Schlacht, in die „furcht same" französische Technik zu pressen, die nichts zu zeigen wagt und alles erzählen lassen muß: Pitschels Lagerverschwörung „Darius“" ist kampferfüllt wie die "Panthea“ der geschickten Freundin; der „Hermann“" Schlegels ist eine Schlacht schlechthin.

Voran Ludwig wagt in der Praxis, was er in der Theorie verficht. Sein einzig erhaltenes Trauerspiel, der „Ulysses“"38) bringt wirklich, sofern aus dem späten Druck auf die ursprüngliche Fassung zu schließen ist, einen $Z_{\text {wei- }}$ kampf auf die Bühne (III, 1 u. 2). Die streitenden Freier Antinous und Eurimach werden von ihrem Vertrauten Medon mit einiger Mühe erst getrennt, nachdem sie die Schwerter schon mehrfach gekreuzt haben. Die Klingen sitzen überhaupt im ganzen Stück lose ${ }^{39}$ ) und es wird aus einer Briefstelle Elias Schlegels ${ }^{40}$ ) sehr wahrscheinlich, daß der Druck manche Milderung ins Regelmäßige erfahren mußte. Zwei nicht auf uns gekommene Stücke scheinen sich den Regeln noch weniger gefügt zu haben ${ }^{41}$ ), und Ludwigs ,Asiatische Banise" übertraf Grimms Behandlung dieses Stoffes an Greueln.wohl noch. Friedrich Melchior Grimm ${ }^{42}$ ) macht sich vielleicht des Vorgängers Stück,

38) Ulysses oder der für todt gehaltene aber endlich glücklich wieder gefundene Ehe-Gemahl. Wien, Kraus, 1751; in Die Deutsche Schaubühne zu Wienn, nach alten und neuen Mustern, 3. Teil, Wien, Kraus, 1761 (GGr ${ }^{2}$ 3, 370 gibt, wohl auf Grund eines andern Druckes, 1762 an). Exemplar der Münch. Staatsbibl. - Vgl. Wa niek S. 198-99.

39) Telemach greift II. 3 gegen Eurimach zum Säbel, Penelope hindert ihn; Antinous naiv brutal zu Penelope IV, 2: „Zwingt dich die Liebe nicht, so fürchte dieses Eisen!"

40) An Hagedom 4. Sept. 1743; Hagedorns Poet. Werke, hrsg. v. Eschenburg, 5. Teil, Hamburg 1800, S. 287: „An der Einrichtung des Stückes haben eine große Menge Leute gekünstelt ... Es ist nach der Zeit oft verbessert, und doch niemals gut worden".

4) Waniek S. 197-198.

12) Banise, ein Trauerspiel, 1743. Schaubühne Bd. 4. Grimm ist ungleich bekannter ais 
sicher seine theoretischen Bemerkungen zunutze: er läßt den Tyrannen $(V, 9)$ aut der Szene erdrosseln und zeigt daneben einen Selbstmord; nach der opernhaften Massenszene der dann verhinderten Opferung Banisens dringt eine kleine Soldatenschar init entblößten Schwertern ein $(V, 10)$ - zwar noch kein Bühnenkanupf, aber ein gehöriger Schritt dazu. Nach Ludwigs Vorgang trennt auch Pitschel in seinem .Darius" "4:") einen beginnenden Zweikampf durch cinen Dazwischentretenden; die Wache verhaftet die Führer des Gegenspiels nach schwachem Widerstand. Am weitesten geht Krüger, der alle Scheu vor dem Verdikt des Meisters ablegt und in ,Maho ined IV. "45) zwei Cruppenkämpfe vorführt: IV, 9 überfällt der Obrist der Verschnittenen des alten Serails mit einigen Soldaten den Chef des neuen Serails, V, 3 überwältigt umgekehrt dieser mit Gefolge die zwei Verräter nach heftiger Gegenwehr.

Sowcit wagte man sich unter Gottscheds Augen in seiner eigenen Schaubühıne vor. Der Einfluß des Volksdramas machte sich in solchen Dingen geltend, die Tradition der Staatsaktionen war nicht mit einem Schlag aus der Welt zu schaffen. ${ }^{15}$ ) Diese Einwirkungen wurden unterstützt durch das Streben nach äußserer Aktion, das Mehr-Zeigenwollen, das sich den Franzosen gegenüber kundtat, und das zugleich den dichterischen Fehlbetrag decken mußte. Man fühlte, daß man mit Beschreibungen auf der Bühne nicht wirkte, und zeigte was zu zeigen war. Größere Kämpfe vorzuführen, erlaubte allerdings schon äußerlich die dürftige Kopfzahl der Schauspielertruppen und der zu große Aufwand an Statisten und Kostümen nicht. Hier kam die Beschränktheit der Mittel der französischen Technik gegen die englische zu Hilfe und man gab notgedrungen dem Englischen Zuschauer recht, der im 42. Stück meinte: „Ein guter Poet wird dem Leser einen weit besseren Begriff von einer Armee oder Schlacht in einer Beschreibung geben, als wenn er sie wirklich schwadronen- und scharenweise aufziehen, oder bei einem Gefechte in voller Verwirrung sehen sollte" ${ }^{" 16}$ ) - so wenig man zu dieser dichterischen Vergegenwärtigung befähigt war.

Verfaser der .Correspondance littéraire”. seiner in Paris gefundenen literarischen Lebensunfabe: vgl. Heliner, Literaturgesch. des 18. Jahrhunderts, 72, $422 \mathrm{ft}$.

(3) Theodor Lebereche Pirschel. Darius, ein Trauerspiel. 1741. Schaubühne Bd. 3; 1. 2 u. 3: vgl. Wanick 399 ?.

4) Mahomed der IV. ein Trauerspiel von Benjarnin Ephraim Krüger (.,den man mit Joh. Chr. Krüger [dem Lusispieldichter und Schauspieler] nicht verwechseln darf, da es keine Ehre ist, mit ihon verwechselt zu werden", warnt schon Schmid. Chronol. S. 75), 1744: Schaubühne 5: Wanick 403 !.

¿i) Visl. Wanick S. 406-07: Bélouin. De Cottsched i Lessing. Paris 1909, S. 129.

4) Der Zuschaucr, Leipzig 1739, 1. 203. 
Was abēr auch bei äußerlicher Übereinstimmung in Wahrheit aus der französischen Form geworden war, mag Gottscheds eigene dichterische Praxis zeigen. Er verfällt auf das Gemetzel der Bartholomäusnacht als Stoff zu einer Tragödie. Diesen Vorwurf zu rechtfertigen, verschlägt es ihm wenig, für das aristotelische "Schrecken und Mitleid" als gleichbedeutend "Grausen und Abscheu" zu setzen. ${ }^{47}$ ) Er sucht einen stofflichen Grund, das nationale Schamgefühl dafür, daß die französische Bühne mit dieser allerschrecklichsten Begebenheit in neueren Zeiten, die in allen vorigen Jahrhunderten nichts gleiches habe, nicht viel anzufangen gewu $\mathrm{Bt}^{48}$ ) und beweist damit, $\mathrm{daB}$ ihm die künstlerische Ursache dieser Zurückhaltung verborgen blieb. Er bemüht sich redlich, den unklassischen Stoff in die klassische Form zu zwängen. Die Kämpfe, die das Ende des vierten und den fünften Akt füllen, bleiben hinten. Die französische Technik verlangt aber Berichterstatter, welche ihre Aufgabe mit einiger Wahrscheinlichkeit lösen, und Empfänger, die an dem Mitgeteilten wenigstens insofern interessiert sind, als sie es noch nicht wissen. An beiden Klippen scheitert Gottsched kläglich. Wie sollten die Träger seiner Berichte, die Hugenotten Clermont und Leran, durch das mordwütige Paris, durch Volk und Wachen ungehindert in den Louvre gelangen ${ }^{49}$ ) Wie Heinrich und Condé am Morgen nach der Schreckensnacht (V, 1 u. 2), trotzdem sie sich darum bemüht, noch nichts von ihr wissen, wo doch schon IV, 5 nahe dem Bühnensaal ein Schuß fällt und der Tumult aus den Fenstern wahrnehmbar sein muß?

Die französische Tragödie gibt Kampfgeschehnisse, wenn sie in ihren Bereich fallen, als Vergangenheitsbericht. Die Vorgänge werden erzählt, nachdem sie geschehen sind (acta refertur). Man vermeidet es geradezu, von der Bühne aus eine unmittelbare Beziehung zu ihnen zu schaffen, während sie hinten vor sich gehen. ${ }^{50}$ ) Cottsched will mehr geben. Nicht ohne Effekt erklärt seine Katharina von Medices dem immer noch zaudernden König, als verdächtige Botschaft eintrifft (IV, 5), daß auf ihren Befehl das Mordsignal

47) Vorrede zur Schaubühne ${ }^{2}$ Bd. 6, 5. Seite.

48) Vorrede zur Schaubühne 2 6, 1. u. 2. Seite.

49) Die Parisische Bluthochzeit König Heinrichs von Navarra, ein Trauerspiel. 1745,' Schaubühne 6; V, 3 u. 4; dazu stinumt, daß Leran V, 6 noch einmal auf Kundschaft geschickt wird, zu sehen, was der abgeführte Clermont mache; er wird denn auch verwundet $(V, 8)$.

30) Vgl. etwa Corneilles Cid II, 2-7, Zweikampf; Aktpause III/IV, Schlacht. Im „Horace“ nimmt der Kampf so breiten Raum ein, daß selbst Corneille nicht alle Schwierigkeiten zu überwinden vermochte, weshalb Voltaire (zu III, 4) auf Shakespeare weist (vgl. auch seine Bemerkung zu III, 6). Immerhin sind solche Gebrechen, als zur äußeren Handlung gehörig, bei den Franzosen wie diese selbst von minderer Wichtigkeit, wogegen bei Cottsched und seiner Schule auf die Aktion alles ankommt. 
schon gegeben sei. Ein Schuß bestätigt cs."1) und auch von dem nach Anjous Worten brausend himmelan steigenden Ceschrci des Volkes wird man bei der Aufführung (1746) etwas vernommen haben. ${ }^{52}$ ) Dieses Hereinziehen der außeren Vorgänge schließt zwar hier den Akt wirkungsvoll ab, es erregt aber auch dic Erwartung. Die Handlung flaut ab, wenn Gottsched nach dem kurzen Anlauf im fünften Alt zur französischen Berichttechnik zurückkehrt; um so mohr als ihm wie allen für solche Erzählungen keinerlei dichterische Mittel zu Gebote stehen. Die Franzosen hatten den Bericht zum poetischen Prunkstück ausgebildet und ihm so üher das inhaltlich Mitgeteilte hinaus einen Eigenwert verlichen. ${ }^{3 i}$ ) Bei Gottsched ist er zur Krücke geworden, an der die Handlung mühsam einherhumpelt. Für Clermonts hölzernc Erzählung vom Tode Colignys (V. 3) ist bezeichnend, daß darin die Worte des Admirals eine halbe Seite lang in direkter Rede angeführt werden. Solchen Dingen gegenüber will wenig besagen, daß man es der Mache ansieht, daß Gottsched im Theater gelernt und sich seine theoretischen Einsichten zunutze gemacht hat: auf den langen Bericht Clermonts von dem Einzelschicksal des Führers folgt der kürzcre, als ,fast atemlos" gezeichnete Lerans von dem allgemeinen Morden (V. 4), dann eine weitere Steigerung: der Übergang vom Bericht ins Geschehnis. "Ellicise Mörder mit bloßen Degen und Pistolen" dringen in den Saal um Clermont abzuholen, und seine wickern Genossen lassen ihn widerstands- los aus ihrer Mitte abführen (V, 4). So viel zeigt Gottsched von dem Getümmel der Bartholomäusnacht; zu wenig um theatralisches Leben zu wecken. aber immerhin genug, um auch bei ihm die Durchbrechung der französischen Form zu crweisen.

Sein berühmterer Cato scheidet für diese Betrachtung als unoriginal aus. Dic Kampfhandlung bleibt in dem angelehnten Stück ganz hinten. Im ,.A gi i " ${ }^{\text {54 }}$ ) findet sich $(V, 3)$ hingegen wieder eine Stelle, wo der Pöbeltumult bis in den Bühnensaal dringt. Ähnlich wie in der "Bluthochzeit" die Mörder, wird hier rine Wache gebraucht (V. 6), die schon in Pitschels "Darius" zur stehenden Einrichtung geworden war. Die ersten schüchternen Ansätze zur Darstellung von Massen treten hervor.

Pitschels Stück bezeichnet wohl den Tiefstand der Berichttechnik. In den letzten drei Akten folgt eine Kamplerzählung der anderen. Alle Figuren

“) Voltaire haste 1734 in der. Adelaide Du Guesclin" zum allgemeinen Entsetzen einen Kar:onenschuß, ubrigens nur als Signal, gewagt: vgl. CEuvres 3.77 und Sonnenfels' Urteil, Briefe uber die wienerische Schsubühne 22. Schreiben. Wiener Neudr. 7 (1864), S. 131.

32) Ebenso in Pilschels Darius V, 2 (.,dic Krieger jauchzen ja").

:T) Z. B. Corneille. Hurace IV, 2, Valères Bericht des Sechskamples; das berühmteste Beispiel wohl Racine. Phedre V. 6. Théramenes Berichl von Hippolytes Tod.

y) Agis. König zu Sparta. Ein Tratuerspiel, 1745. Schaubühne Bd.6. 
ohne Ansehen der Person werden zu Berichterstattern gepreßt. Selbst Thamiris, die Geliebte des Königs, muß den Befehlshabern des Heeres von diesem Nachricht bringen (IV, 3), und ihre Vertraute Philaris einen Schlachtbericht beisteuern $(V, 2)$. Patron verläßt als Anführer den Kampf im gefährlichsten Moment, damit der Zuschauer etwas erfahre (III, 3).

Gleiche Not schafft gleiche Auskunft. Es bildet sich für die eigentlichen Kampfstücke der Schule, wie Pitschels „Darius“, Frau Gottscheds

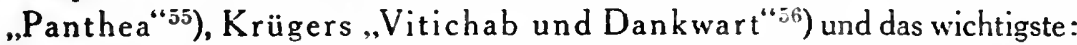
Elias Schlegels ,Hermann“ geradezu ein Rezept heraus, wonach die Kämpfe ins Drama gebracht werden. Neben Pitschel hat Schlegel das meiste zu seiner Ausbildung getan. Wenn man eine Kampfaktion bei währender Handlung ${ }^{57}$ ) mit Wissen des Zuschauers hinten vor sich gehen lief, war die Hauptschwierigkeit für den Dramatiker, Leute auf der Bühne zu halten und durch sie eine gewisse Zeit, die dem Gefecht eingeräumt werden mußte, auszufüllen. Da das Fechten eine Sache für Männer ist, fiel die Aufgabe vor allem den Frauen zu. Ihre Besorgnisszenen sind in allen Stücken anzutreffen, ${ }^{58}$ ) mit Regelmäßigkeit am Aktanfang, weil man mit dem Abgang des Helden zum Kampf, nach stattgehabtem Abschied von der Geliebten, den vorigen Akt effektvoll schließen kann. ${ }^{59}$ ) Die Frauen sind es, welche die Botenberichte entgegennehmen. ${ }^{60}$ ) Von Mannspersonen stoßen zu ihnen fast nur Verräter oder Feiglinge (im Hermann: Segest und Flavius). Wenn der Held einen Kriegsmann zưr Bedeckung der Frauen oder als Befehlshaber für das Lager zurückläßt (im Darius den Hauptmann, im Vitichab den Radogast), so kann auch dieser der Verräter sein (in der Panthea: Araspes). Da die Besorgnis- und Berichtsszenen allein selten ausreichen die Kampfzeit zu füllen (im Darius V, 1-3 nur sie), muß die Intrige mithelfen, die während des Kampfes fortgesponnen wird (im Hermann sowohl wie in Panthea), ohne daß gezwungenere Mittel immer überflüssig würden: in Panthea IV, I muß Nikothris der Panthea nur zum

55) Panthea, Ein Trauerspiel, 1744. Schaubühne Bd. 5.

$\left.{ }^{56}\right)$ V. u. D., Die Allemannischen Brüder, Trauerspiel, Leipzig 1746; im Nachdruck Frankfurt und Leipzig 1748 benutzt. Auszug in Gottscheds Neuem Büchersaal 2, 555-68. Devrient $^{1}$ 2, 198 (mit dem Irrtum: Schauspieler Krüger) über eine Wiener Aufführung 1747; vgl. Waniek S. 550.

5i) Was Corneille im Cid vermieden hatte.

5s) Panthea III, 6; IV, I u. 3 (Schluß); Vitichab und Dankwart III, 1; Darius V, 1 mit männlichem Partner, aber in der Funktion ganz gleich; vgl. dazu Waniek S. 405.

${ }^{59}$ ) Hermann III, 4 u. 5; Vitichab und Dankwart II, 6 u. 7; Panthea III, 5; hier die Besorgnisszene als kurze Nachklangszene noch im Aktschluß (III, 6) und darauf im A.ktanfang; im Darius IV, 8 andere Situation.

60) Darius V, 1-3; Hermann IV, 4; Panthea IV, 4,6 u. 7; Vitichab u. Dankwart III, 3 u. 4. 
Zeitvertreib dic ganz abliegende Geschichte ihres Unglücks ausführlich erzählen.

Die Folge der Berichte ist nach der Schablone auf Unschwung angelegt. Pitschel braucht dieses Mittel nach Corneille (Horace III, 6 u. IV, 2), der danit un so stärker gewirkt hatte, als es ihm zu dem vielberufenen "qu'il mourût" Celegenheit gab, zuerst. Etwas vom Hin- und Herwogen des Kampfes wird dadurch auch in die Berichttechnik hinübergerettet, und ihr einige Spannung gesichert. Ohne daß man das Schlachtgeschehen selbst lenken und motivierend auseinanderlegen muß, wird der Glückwechsel am bequemsten durch Teilberichte, noch cinfacher durch Falschmeldung erreicht. Corneillc ${ }^{61}$ ) läßt seine Julie im Augenblick der Flucht des letzten Horatiers vom Kampf weglaufen und dem Vater die vermeintliche Niederlage berichten. Durch cben dieses Mittel versetzt ungekehrt Pitschel scinc Thamiris in trügerische Siegesfreude (V. 2). Krïgers Siegmar (III, 3) meldet den Verlust der Schlacht zu früh, ähnlich wie Schlegels Flavius (IV, 2), besser motiviert, bedenkliche Nachrichten bringt. Sein Segest sticht dic Frauen nicht ohne Hintergedanken am Schlachtglüc:. Hermanns irre zu machen (IV, 2), der Unglücksbote in der .Panthea" (IV, 4) erstattet seine Falschmeldung als von der Intrige Cedungener. Die stets gläubig aufgenommene Wendung zum Schlimmen gibt Gelegenheit zu leidenschaftlichen Ergüssen; nach ihrer Entladung läßt die alsbald crfolgende Aufklärung die Gesichter um so heller strahlen. Es sind Mittel, die sich bis in die hohe Kunst verfolgen lassen, ${ }^{62}$ ) aber hier strafbar äußerlich gebraucht; so äußerlich, daß der Freudenbote - es sind schließlich Trauerspiele - mehrfach ohne weiteres auch dic Nachricht vom Fallen des Helden bringt (Darius V, 3; Panthea IV, 7), ein Verfahren, von dem sich sogar im ,.Hermann" (Adelheid V, 2) Spuren finden.

Man tut Elias Schlegel Unrecht, wenn man ihn mit den Gottschedischen, dic vor und mit ihm sich um die Behandlung von Kampfstoffen mühen, in Rcih und Glicd stellt. Ihre technische Mache läßt sich zwanglos, so wie es geschehen, rubrizieren, weil der cinzelne keinerlei Originalität besitzt. Was sie an kriegerischen Aktionen geben, soll der dramatischen, noch mehr der theatralischen Bewegung ihrer ohnmächtigen Versuche aufhelfen. Es ist im

6) Der immer wieder hervortretende Einfluß der Horatier hat nichts Auffallendes, waren sie doch seit 1718 durch Claubitz Obersetzung bekannt und im 1. Band der Schaubühne (1741) wieder abgedncti: Wanick S. 398. Georg Behrmanns in Hamburg 1733 aulgeführte Bearteitung im gotsschedischen Cseiste umgeht die Schwierigkeit der Kamptgestaltung durch das Rardikalmittel. daß sie erst nach erfolgtem Sechskampf einsetzt: vgl. Wanick S. 202 f.: Ferd. Heismilller. Hamburgische Dramatiker zur Zeit Coltscheds, Dresden und Leipzig 1891, S. 14.

85) Kriegerischer Glückwechsel z. B. im 1. Akt von Schillers Jungtrau: Falschberichte besonders bei Kleist. 


\section{Elias Schlegel.}

einzelnen belanglos und nur in seiner Gesamtheit, als Ausdruck einer Tendenz, von Bedeutung. Elias Schlegel tut den ersten der entscheidenden Schritte zum nationalen Drama, oder, wenn man will, zu Shakespeare hin, sicher von den Franzosen weg. Die anderen waren von der Intrige ausgegangen; vorfallende Kämpfe wurden von ihr gefordert und dienten ihr. Schlegel wählt als erster die Schlacht selbst zum Vorwurf. ${ }^{63}$ ) Um den Gegensatz mit aller Schärfe, wenn auch übertreibend zu formulieren: seine Intrige, äußerlich denen der Schule ganz gleich, ist nur erfunden, um die nationale Freiheitsschlacht ins Drama zu bringen. Diese im Eingang der vierziger Jahre getroffene Stoffwahl war die stärkste Absage an den Geist der französischen Klassik; in ihr mehr als im fertigen Drama liegt das entwicklungsgeschichtlich Bedeutende. ${ }^{64}$ ) In Frankreich selbst, wo es doch an Reformversuchen der klassischen Tragödie gegenüber nicht fehlte, wagte man auch nur entfernt ähnliches, das doch im Grunde in den Schranken der Tradition blieb, erst ein Vierteljahrhundert später. ${ }^{65}$ )

Gottsched scheint mit gutem Blick gesehen zu haben, daß der Stoff für die französische Behandlungsart, die Schlachten in die Botenberichte verwies ${ }^{66}$ ) - und außer ihr gab es keine - nicht taugte: er riet Schlegel $a b^{67}$ ) und hat

3) Hermann, ein Trauerspiel, 1743. Schaubühne Bd. 4. Hrsg. von F. Mu ncker, DNL Bd. 44; vgl. seine Einleitung S. 111-14.

64) Man sieht es vor allem darin, daß Schlegel das nationale Stoffgebiet erschlossen habe (so auch R. Schacht, Die Entwickelung der Tragödie usw., S. 17 f.). Die doppelt wichtige Wahl ist in noch engerem Sinne symptomatisch dadurch, daß sie gerade auf einen vaterländischen Schlachtstoff fiel.

${ }^{65)}$ De Belloy mit dem „Siège de Calais“, 1765; der Titel läßt mehr Kämpfe vermuten, als in dem Stück wirklich vorkommen. Sie füllen nicht einmal ganz den ersten Akt, werden durchaus nur erzählt und sind nichts als die Exposition für das folgende: eine wahre Orgie von Edelmut und Hochgefühl des Sterbenwollens, die alles, was Cronegk mit „Olint und Sophronia“ darin geleistet hatte, weit hinter sich läßt. Le ssing über De Belloy im 18. Stück der Dramaturgie. - Es sei hier bemerkt, daß die nachklassische Entwicklung der Tragödie in Frankreich für Cottsched und seine Schule nur sekundäre Bedeutung hat. Man hält sich an die Muster Corneille und Racine, in der Theorie neben Corneille und Boileau besonders an den regelstrengen Hédelin d'Aubignac, dessen „Theatralische Dichtkunst", von Steinwehr übersetzt, 1737 erschien und in den Beyträgen 5, 141 mit höchstem Lob angezeigt wurde.

${ }^{65)}$ „Man handelt darin [in den Berichten] von Schlachten zwoer Armeen, die man nicht zeigen kann“", lehrte Hédelin (Dichtkunst S. 309).

87) Schlegel an Bodmer 19. April 1746 (Stäudlin, Briefe berühmter und edler Deutschen an Bodmer. Stuttgart 1794, S. 33): „.. . . der ,Hermann', der unter seinen [Goitscheds] Augen entstanden und ihm nichts zu danken hat, als daß er mir die Wahl dieser Materie und dieselbe Ausführung widerraten“. J. E. Riffert, Die Hermannsschlacht in der deutschen Literatur, Herrigs Archiv 63 (1880), S. 269-70 scheint diese Briefstelle nicht zu kennen und dreht den 
den fertigen ..Hermann" nie recht leiden mögen. Er zieht ihm die frühere .Dido" vor $\left.{ }^{64}\right)$ und spricht vielleicht sogar in der Ankündigung des ..Hermann" in der Schaubühne, bei einer Gelegenheit wo er sonst nur lobte, einen leisen Tadel gegen die Eignung des Stoffes aus wenn er sagt, der Verfasser habe sich die Berichte der Geschichtschreiber zunutze gemacht „so viel es die Regeln der Schaubïhne erlaubter:" ${ }^{19}$ ) Schlegel mußte Gottscheds Abneigung gegen das Stïck besonders empfinden, weil ihm, nach den Worten seines Bruders Johann Heinrich, ${ }^{\circ 0}$ ) keine vou allen seinen Arbeiten mehrern Flciß und längere Zeit gekostet hatte. Der „Hermann“ war daher auch - wie immer die Sorgenkinder die liebsten sind - des Dichters Lieblingsstück. So sauer wurde es ihm, den widerstrebenden Stoff zu meistern, daß er danach eher sechs Trojanerinnen als einen Hermann verfertigen wollte. ${ }^{11}$ ) Man ist versucht an die Mühen zu denken, die ein späterer soldatischer Vorwurf, der .Wallenstein". Schiller bis zu seiner endlichen Bewältigung bereitetc. ${ }^{\text {72) }}$ ) Wo die Schwierigkeit des Unterfangens lag, muß Schlegel während der Arbeit vollkommen eingesehen haben. Aller Vorzug, den die Trojanerinnen vor dem Hermann hätten, stecke in der Materic des Stücks, äußert er, was umgedreht nichts anderes heißt, als daß der Stoff des Hermann ungünstig liege.

Auch Gottsched hat in der ,Bluthochzeit" einen unfranzösischen Vorwurf gewählt. Aber wie leicht war dieser noch auf das Schema der Palastintrige, die sich inncrhalb der vier Wände abwickelt, zu bringen; wie schwer dagegen der Stoff zu einem nationalen Massendrama in eine so gegensätzliche Form zu pressen. Nichts ist lehrreicher, als der Vergleich dos Schlegelschen mit

Sachverhalt um. E. Wolff. Joh. Elias Schlegel. Berlin 1889. S. 42, streift ihn nur. Joh. Rentsch, Joh. El. Schlegel als Trauerspieldichter. Diss. Leipzig 1890. S. 14-15. spricht bloß von der Estfresndung von Lehrer und Schiiler, die über dem fertigen Stück entstand. Waniek. S. 41I, will das hlare Zeugnis Schilegels als spätere Äußerung beiseite schieben. hat aber keine befriedigende Erklärung fur Cottsclieds Haltung, weil er ihren Crund darin sucht, daß der Stoff national sei. was Gottsched allerdings hätte billigen müssen. Die Schwierigkeit ist gehoben. wenn man die Ursache seiner Abneigung vielmehr in der besonderen Disposition dieses nationalen Stoffes sicht: daB es cin Schlachtstoff ist.

6n) Schautnatine ${ }^{2}$ 5. Vorrede 8. his 10. Seite; Wolffs Bernerkung dazu, S. 50, hält kaum Stich.

67) Schaubuhne ${ }^{2}$ f. Vorrecle S. 7-8: Ausfälle Gottschods gegen den Hermann finden sich auch sonst, so mehrfach in den Anmerkungen zu dem, "Auszug aus . . Batteux schönen Künsten". Leipzir 1734.

90) Vorbericht zum Hermann, E. Schlegels Werke, Kopenhagen u. Leipzig 1761-70, 1. 285: vel. Muncker DNL 44, 111 f.

") V'orbericht zu den Trojaserinnen. das. 1. 146; vgl. Cervinus s" 4, 208; die folgende Äußenun Schlegels chendort.

7) An Körner 28. Nov. 17\% (Jon a s. 121) und vielfach in den Briefen. 
Campistrons Stück. ${ }^{\text {i3) }}$ Der Franzose, seinerseits in der Dekadenz der französischen Tragödie stehend, ${ }^{74}$ ) gewinnt aus dem gleichen Sujet einen effektvollen und wechselreichen Liebeshandel. Die Schlacht selbst darf nur einige Szenen des fünften Aktes in Anspruch nehmen. Sie wird von Arminius nach seinem eigenen Geständnis (V, I Ende) veranstaltet pour „,m'ouvrir jusqu'à vous [Isménie-Thusnelda] un glorieux passage", was zu den bekannten Worten des bedächtiger liebenden Hermann bei Schlegel ${ }^{75}$ ) einen starken Kontrast macht. Bei der damit hinreichend gekennzeichneten Verschiedenheit des Geistes will eine Ironie der Entwicklung, daß der Franzose, dem der Kampf nur Ausschmückung der Liebesaffäre ist, in der Tat mehr von ihm vorführt, als der Deutsche, der ihn zum Thema genommen hat. Campistron zeigt Arminius im Gefecht mit der Wache Segests, die ihn verhaften soll und auch entwaffnet, ${ }^{76}$ ) ein Kampfvorgang, der freilich nicht unmittelbar zur Teutoburger Schlacht gehört.

Auf Schlegels Werk liegt der Fluch der Übergangszeiten. Wie symbolisch für seine Halbheit steht der Titel „Hermann“ als ein zugleich vorwärts- und zurückgewendeter Januskopf dem Schlachtstück voran. Die nach dem Helden benannte heroische Tragödie ist noch lebendig. Klopstock wird sein Stück mit Verschiebung nach dem Ereignis hin „Hermanns Schlacht" nennen, in Kleists und Grabbes Überschrift „Die Hermannsschlacht" wird der soziale Vorgang allein zum Ausdruck kommen. Schlegel, der sich innerlich von den Franzosen löst und als erster über Shakespeare zu urteilen weiß, folgt ihrer Technik sogar genauer als die anderen neben ihm. Alles was von der Teutoburger Schlacht bei ihm auf der Bühne erscheint, ist ein Kattenfürst, der mit einigen Soldaten $(V, 3)$ die geschlagenen Römer verfolgen will. Die Situation während der Schlacht hat Mendelssohn, die Einzelbeobachtung zur allgemeinen Er'kenntnis erweiternd, nicht bloß für diesen Fall vorzüglich gekennzeichnet: „Ein Treffen entscheidet das Schicksal Deutschlands; und niemals ist die Bühne so leer von Handlung, als wenn hinter derselben das blutigste Treffen geliefert wird. " ${ }^{77}$ ) Die heftige Aktion rückwärts macht ihr Stocken vorn um so

${ }^{73}$ ) Arminius, tragédie 1684. Euvres de Campistron, Paris 1750, Bd. I; vgl. Wolff S. 45.

i4) Lanson, Histoire de la litt. française, 11. éd., Paris 1909, S. 554.

i5) Hermann III, 4: „Thusnelden liebt er sehr, doch mehr noch seine Pflicht". Wolff, S. 45, ereifert sich sehr gegen Campistron und seinen "W/eiberhelden". Nationale Ausdeutung des Stoffs war von dem Franzosen billig nicht zu verlangen. Als reine Liebesaffäre ist sein Stück sicher geschlossener als das zwiespältige Schlegels. Vgl. auch Rentsch S. 60.

i6) Arminius II, 7: Arminius se défendant au milieu des Cardes: „Ah! traitres, achevez. percez percez mon sein" usw.

77) Fortsetzung des 311. Literaturbriefs 24. Jan. 1765. Schriften, Leipzig 1843-45, Bd. 4. 2. Teil, S. 452-53. Die Rezension ist fast ein Vierteljahrhundert jünger als das Werk. Alle im folgenden benützten Stellen hier. Über die Handlungsarmut vgl. Muncker DNL 44, 113. 
empfindlicher. Schlegel vermag gegen diese Hauptschwierigkeit mehr als andere, üherwinden kann auch $\mathrm{er}^{78}$ ) sie nicht.

Manclie technische Prozeduren des Stücks sind schon im Zusammenhang init der Gottschedschule aufgezeigt worden. Die anderthalb Akte, welche die Schlache in Anspruch ninmt, auszufüllen, wird geschickt eine Möglichkeit genützt, die der Stoff bot: cin Teil des germanischen Heeres, vertreten durch Segest, seinen Sohn Siegmund und den schwächlichen Bruder Hermanns. Flavius, stcht untätig abseits vom Kampf. Ein Stück der Kampfzeit wird zugebracht diese Gruppe zum Eingreifen zu bewegen; ein anderes erhält Flavius für sein Liebeswerben bei Thusnelda eingeräumt. Aber auf alle diese Versuche legt sich der lähmende Eindruck, daß zuviel Zeit vorhanden ist. Man hat es nirgends eilig, obwohl doch das Schlachtgeschehen zum Handeln drängt. Aus der kläglichen Motivierung im einzelnen hat bereits Mendelssohn Segests vergnügtes Spazierengehen im Hain verdienterweise an den Pranger gestellt. Die zu lange Daucr des Kampfes ertötet das Interesse für ihn; es gelingt nicht, dic Aufmerksamkeit Akte hindurch auf eine Geschehniskette zu richten, von der auf der Bühne nichts zu sehen und zu hören ist. Man fragt sich billig. warum bei dieser Technik nicht der größte Teil der Schlacht in den Zwischenakt verlegt wurdc, den schon Hédelin für mühsam Darstellbares, ${ }^{79}$ ) und Corneille zur Unterbringung unbequemer Zeitüberschüsse empfohlen hatte ${ }^{80}$ ) dessen Cid gab überdies das Beispiel einer Schlacht im Zwischenakt (III/IV). Auch darin zeigt sich die Abkehr Schlegels vom französischen Geist und seine Zwischenstellung: Die Schlacht war ihm viel zu wichtig, um sie in einer Aktpause abzutun, sie mußte als Kern seines Stückes einen breiten Raum darin einnehmen. ${ }^{11}$ ) Daß sie am Anfang des fünften Akts nahezu am selben Fleck steht wic am Ende des vierten, empfinden wir heute als unerträgliches Schlleppen. Dic Forderung, dic Handlung müsse im Zwischenakt fortschreiten, ist aber jünger. ${ }^{82}$ ) Cottsched wollte im Gegenteil Comeilles Ideal, daB die

78) Die folgenden Ergebrisse sind denen Wolffs. S. 44, darin gipfelnd, der deutsche Dramasıker habe die franzüsische Technik mit wunderbarem Glück auf den deutschnationalen Stoff angewandt, durchaus entregengesetzt.

5) Dichlkunst 1737, S. 305: .,daB man in die Zwischenzeit der Handlungen [Akte] alles hineinbringr, was dem Poeten zuviel unnütze Mïhe machen, und dem Zuschauer anstößig sein würde". Vgl. die fur Belagerungsstücke benerkenswerte Einschränkung dazu S. 315-16 und auch S. 31 .

$\left.{ }^{60}\right)$ Discours des trois unites, Euvres 1. 114 u. Examen de Mélite das. 1, 141.

11) Rentschs Folgerung S. 60 , daB dies deswegen geschehen mubte, weil Hernanns Sieg das Stück schließt, ist nicht zwingend.

2) Nach Petersen S. 125 scheint Diderot der erste zu sein. der sie formuliert. Uber die zunehriende laolienung des einzelnen Aktes im neueren Drams vgl. Gustav Freysag. Technik des Dremas" S. 168. 
Darstellungszeit mit der für die dargestellten Vorgänge real erforderlichen Zeit übereinstimmen sollte, ${ }^{83}$ ) in absurder Weise auch auf den Zwischenakt angewendet wissen. Die Kontinuität der Zeit, wie sie durch das Gesetz der Szenenverbindung innerhalb des Aktes geschaffen war, sollte für das ganze Stück gelten. Er fand, daß die Schlacht im $\mathrm{Cid}$ zu geschwinde vor sich gehe und $\mathrm{da}$ der Zwischenraum zweier Akte nicht soviel natürlich vorstellen könne ${ }^{84}$ ) und nahm damit dem regelmäßigen Dichter, strenger als selbst die Franzosen, nicht allein für Kampfaktionen auch das letzte Auskunftsmittel. Auf eine andere, allgemeine Crux der Kampfgestaltung weist ebenfalls schon Mendelssohns Kritik des Hermann: es hat seine Schwierigkeit, das Schlachtgeschehen, das vom Drama aus betrachtet wesentlich vom Zufall, jedenfalls von außerdramatischen Gesetzen abhängt, mit dem Räderwerk der dramatischen Motivierungen zu verzahnen; die kriegerische Entscheidung also nicht bloß aus dem Geschichtsbuch, sondern durch das Drama selbst zu begründen und einigermaßen als notwendig erscheinen zu lassen. "Wo die Menschen in Masse gegeneinander wirken, ist der Schein der Zufälligkeit nie ganz zu vermeiden, und das Drama soll uns Entscheidungen zeigen, die aus den gegenseitigen Verhältnissen der Personen, aus ihren Charaktern und Leidenschaften mit einer gewissen Notwendigkeit hervorgehn", umschreibt Wilhelm Schlegel ${ }^{\$ 5}$ ) das für die Kriegsdramatik wichtige Problem. In einem Überblick, wie es Shakespeare damit gehalten, ergeben sich ihm im wesentlichen zwei Typen; der Zufall scheidet für den echten Dramatiker aus; auch auf die nüchtern sachliche, taktische Begründung des Ausgangs läßt sich Shakespeare nicht weiter ein: „Mit großer Einsicht in das Wesen seiner Kunst schildert er das Kriegsglück nicht wie eine blinde Gottheit, die willkürlich bald diesen bald jenen begünstigt; ohne in das Einzelne der Kriegskunst einzugehn, das er doch auch zuweilen berührt, läßt er den Erfolg aus den Eigenschaften der Feldherrn und aus deren Einflusse auf die Gemüter der Krieger im voraus vermuten; zuweilen stellt er den Ausgang in das Licht einer höhern Fügung, ohne doch unsern Wunderglauben in Anspruch zu nehmen: das Bewußtsein einer gerechten Sache und Vertrauen auf den Schutz des Himmels macht die Einen unverzagt, während die Ahndung eines auf ihrem Unternehmen ruhenden Fluchs die Andern - W. Schlegel denkt wohl an Richard III. - niederschlägt." ${ }^{\text {"86) }}$

${ }^{83}$ ) Discours des trois unités, Euvres 1. 113; über die ganze Frage Petersen, S. 112 ff.; $126 f$.

\&4) Beyträge 1736 4, 307 und Auszug aus Batteux schönen Künsten 1754, Teil 3, cap. 6, S. 122.

8) Dramat. Kunst und Litt. ${ }^{2}$ 3, 202. DNL 143, 230.

86) Dramat. Kunst u. Litt. ${ }^{2}$ 3, 203 f. DNL 143, 231; ganz ähnlich lautet die Stelle über Aeschylus $^{2}$ 1, 163 (DNL 143, 17), bei dem er dieselbe künstlerische Besonnenheit findet: ,Mit 
Also cine Motivierung aus den Fïhrercharakteren und eine andere aus der festgegriindeten Weltordnung. Die crste belegt Wilh. Schlegel mit der glänzenden Kontrasticrung der englischen und französischen Heerfürsten vor der Schlacht von Agincourt in Heinrich V., von dem seine Betrachtung ausgeche, und ebenso aus Aeschylus' Sieben gegen Theben. Im ganzen überwicgt aleer in den Historien dic zweitc: für ihre Schlachtentscheidungen genügt Sizakespeare die Anlelinung an das großartig aufgefaßte geschichtliche Gewehchen. Aus der Persönlichkeit des Helden wird der Ausgang am entschiedensten in den Römerdramen genommen. Antonius verliert seine Schlachten in Wahrhcit an Cleopatra. Bei Philippi siegt der tote Cäsar. Einc eigenartige Verknüpfung des Sachlich-Militärischen mit der Motivierung aus dem Charakter gilst Kleist: er läfts seinen überragend gebildeten Hermann mit feinster Berechnung, worin er das "Einzelne der Kriegskunst" durchaus nicht scheut. das verderbliche Netz um die Römer knüpfen und den Schicksalsrest des Schlachtgeschehens mit starkem Glauben bewußt den Göttern anheimgeben (II, 10 Ende).

E!lias Schlegel versucht in ciner Zeit, der andere Mittel noch nicht zu Gebote stehen, den Sieg der Cherusker lediglich im Tatsächlichen, in der Führung der Intrige zu begründen. .Damit der Ausgang des Gefechts, auf welchen hier alles ankommt, nicht ganz vom Zufall abhänge, läßt der Dichter die Deutschen geschlagen, zuletzt aber von dem Sohn des verräterischen Segest mit den Truppen, welche ihm sein Vater untergeben, in dessen Abwesenheit verstäskt werden, und ihre Feinde besiegen." (Mendelssohn). Hermanns Verdienst am Sieg wird durch diese Anlage der Schlacht stark geschmälert. DaB Schlegel den Umschlag $(V, 2)$ nur durch einen ganzen Rattenkönig von Unwalırscheinlichkeiten erreicht, hat weniger Bedeutung als das völlige Scheitern der französischen Form an dieser Aufgabe. Nirgends zeigt sich die Technik dünner und olnmächtiger. Die nachträgliche Erzählung des wichtigsten Ereignisses der ganzen Handlungskette, des Eingreifens Siegmunds, wirkt nach so vielen Berichten matt und unglaubhaft, jedenfalls nicht überzeugend. Dazu komm?, daß Schlegel für das spezifisch Militärische, für das Taktische der Schlacht, das bei seiner Art der Motivierung entscheidend mitsprechen müßte, im Gegensatz zu den späteren Bearbeitern des Stoffes wenig Verständnis an den Tag legt. Dieser Teil der Berichte gibt kein Bild, und damit fällt die einzige Stütze eines zwingenden Ausgangs. Alle diese Mängel lassen Goethes

grofer H'eisheit schilden der Dichier hier lin den. Persern'] und in den Sieben vor Thebe den Auszane der Kämpfe nicht als rufalliz. wie er fast immer beim Houner erscheint (denn dem Zufall soll cinmal in der Tragödic nichts cingeräumt werden). sondern durch übermütige Verblendung auf der eirren. durch besonnene MaBigunz auf der andern Seite voraus bedingt". 
Urteil über die Eröffnungsvorstellung des Leipziger Theaters 1768, der Hermann sei ,,ungeachtet aller Tierhäute und anderer animalischen Attribute sehr trocken abgelaufen" ${ }^{87}$ ), vollkommen begreiflich erscheinen. Schlegel kam über die gottschedische Technik wesentlich nicht hinaus, und diese vermochte seinen kühn gewählten Vorwurf nicht zu bewältigen. Der erste Versuch, die Schlacht dem neuen Drama zu gewinnen, mißlang.

Entwicklungsgeschichtlich bedeutend sind immerhin zwei Kunstmittel, die Schlegel zuerst braucht: er baut die Frauenszene während der Schlacht (IV, I) zu einer im Effekt fast reinen Stimmungsszene aus; nicht an Shakespeares oder Kleists Stimmungskunst zu messen, welche die Schlacht gewaltiger zu gestalten vermag als alle Vorführung von Kämpfen es tun kann, aber doch von diesen höchsten Leistungen nur in der Stärke, nicht in der Art verschieden. Hier verrät sich der Dichter, der alles was die Gottschedschule zusammengereimt hatte, weit hinter sich läßt. Aus der nächtlichen Natur ${ }^{88}$ ) erhebt sich Adelheids Beschwörung der Schatten der Väter, die ihrem Volk im Freiheitskampfe beistehen sollen.

Schlegel weiß auch sonst die poetischen Momente der Kampfhandlung herauszuholen ${ }^{89}$ ) und auf gehobene Aktschlüsse nicht in der ledernen Weise der Schule Bedacht zu nehmen..$^{90}$ ) Freilich macht sich gerade in der ${ }^{\circ}$ Frauenszene IV, 1 das dialektische Element als Feind der Stimmung geltend, und Mendelssohn sah vollkommen richtig, daß die Poesie Schlegels mehr eine Tochter der Vernunft als der Einbildungskraft war. Hierin ist er ein Geistesverwandter Lessings, mit dem er sich darin berührt, daß er als erster eine Form der Kampfvergegenwärtigung verwendet, die sich bei jenem in charakteristischer Art wiederfindet. Die Frauen sprechen vermutungsweise von der Schlacht ${ }^{91}$ ) und schildern sie so in hypothetischer Rede dem $\mathrm{Zu}$ schauer: ein geschicktes Mittel, den Kampf ohne irgendwelche Beziehung mit dem Schlachtfeld, wenn auch nur im allgemeinen, zu beschreiben. Überflüssig zu sagen, daß Schlegels Alexandriner die unübertreffliche Prosa Lessings an Intensität der Vergegenwärtigung nicht erreichen kann. Aber die Verwandtschaft ist deutlich und findet sich wie in dieser Einzelheit in der Art und Weise des Schaffens überhaupt. ${ }^{92}$ ) Der Vorwurf, den der junge Goethe gegen Emilia

87) Biographische Einzelnheiten: Leipziger Theater 1768. Werke 36, 226.

88) „Siehst du der Sterne Heer durchs Laub der Äste schimmern - “"v. 1081.

${ }^{89)}$ So III, 5 das Schlachtgebet der Fürsten.

${ }^{90)}$ III, 5: IV, 4, Kampfabgang der Frauen.

${ }^{21)}$ „Wie viel wird Hermanns Arm schon hingestrecket haben...

Wie mancher tapfre Schritt wird, Deutschland zu befrein,

Schon über Schanzen, Feind und Tod gestiegen sein." v. $1093 \mathrm{ff}$.

92) Vgl. Lessings bekanntes Selbstbekenntnis im letzten Stück der Dramaturgie. 
Galotti erhebt, daß man mit halbweg Menschenverstand das Warum von jeder Szene, von jedem Wort auffinden könne, ${ }^{93}$ ) trifft mit Schlegel das ganze vorlessingische Drama. Nur daß die Mühsal der Rechnung, wic dic Analyse der Kampftechnik gezeigt hat, überall fühlbar bleibt, und das intellektuelle Vergnügen, das Lessings fehlloser Mechanismus gewährt, nirgends aufkommen kann.

Die anderen Stücke Schlegels stehen an Bedeutung für die Entwicklung dem Hermann gegenïher zurück. Von den Arbeiten, die noch auf der Schule entstanden, ist Neues am allerwenigsten zu erwarten. Daß die "Dido" ${ }^{\circ 4}$ ) cinen überraschend starken Kampfhintergrund hat, wurde schon erwähnt. Der Nachdruck liegt aber hier im Gegensatz zum Hermann noch auf der Herzensangelegenheit, der sich die Gefechtsaktion unterordnet. Es ist aber kaum zufällig, daß sic schon in diesem Werk einen so breiten Raum einnimmt, ${ }^{93}$ ) wenn die Technik sie auch noch zu bewältigen vermag.

In ."Canut "96) crwächst dieser eine andere, eng umgrenzte Aufgabe: das Duell. Ludwig und Pitschel hatten rasch entstehende Zweikämpfe auf der Bühne begonnen und getrennt. Schlcgel läßt sein förmliches Duell nach erfolgter Forderung hinter der Szene austragen, wobei der Zwischenakt, trotzdem er sich dazu anbictet, wieder ungenützt bleibt. Die Absicht ist deutlich: der Zweikampf soll im Drama zu starker Geltung gebracht werden; wenn er ihn nicht zeigen darf, muß wenigstens die Aufmerksamkeit auf ihn gerichtet sein, während er unsichtbar vor sich geht. ${ }^{97}$ ) Auch das retardierende Moment vor seinem Beginn, das Dazwischentreten Estrithens II, 5 dient dazu, das Ereignis zu unterstreichen. Schlegel verwendet neben einem Teilbericht więder die hypothetische Kampfvergegenwärtigung (Estrithe III, I). Weil es nur zwei Personen in Anspruch nimmt, bereitet das Duell nicht die gleiche Schwierigkeit. die Zwischenhandlung auszufüllen, wic die Schlacht. Immerhin ist Schlegels Rechnung nicht ganz aufgegangen: statt einzugreifen, hält der König in dringender Situation eine unzeitige Rede - ein Einwurf, den schon Johann Heinrich mit unzugehörigen historischen Gründen zu entkräften suchte. ${ }^{98}$ )

- An Herder Mfitte Juli 1772, Briefe 2, 19.

4) Dido ein Traverspiel. 1744. Schaubühne Bd. 5.

*) Lybierkrieg: I. 5 Heranziehen der Lybier gemeldel; II, 2 Verleidigungsbefehl Didos; III. 3 Bereitschafumeldung: III. 4 Sturmdrohung des Lybiers: IV, 5 Bitte um den Befehl zum Kanpt: V, 2 u. 3 Kainp?berichte: das Eingreifen des Aeneas erst in der Umarbeitung: Vorpericht Werke 1. 71 Gefecht gegen Acneas: IV, 3 Kampfhericht.

"6) Canut ein Traserspiel. 1747 in den ."Thealralischen Werken" erschienen; Werke 1761 \&.. Bd. 1 .

") In dem früh entworfenen. öfter umgearbeiteten .Orest und Pylades" (gedruckt erst 1761 un ersten Band dez Werke) wird der Kampt hinter der Szene II. 3 hörbar.

") Vorterichi zum Canut. Werke 1. 213. 
Augenscheinlich nahm Elias diesen unwichtigen Mangcl gegen den Vorteil seiner Anordnung, das Duell als bewegtestes Ereignis seiner Handlung, soweit es die strenge Technik erlaubte, hervorzuheben, gern in Kauf.

Für Schlegels Úbergangsstellung im allgemeinen ist charakteristisch, daß er mit seiner Einsicht ungleich weiter kommt als seine Werke vermuten ließen. ${ }^{99}$ ) In der Theorie ist ihm nanches aufgegangen, was er als Schaffender noch nicht in die Tat umzusetzen vermochte. Sein Interesse ist hier aber auf Gegenstände gerichtet, die unseren Fragen fernliegen, vor allem auf die Charakterisierung. Úber spezifisch Technisches findet sich wenig. Seine Dramen lehren, wie er sich darin von Gottsched meistern ließ, auch als er innerlich andere Wege eingeschlagen hatte. In der Abhandlung „Von der Nachahmung“" braucht er beiläufig ein Beispiel aus unserem Gesichtskreis: Zu den Dingen, die ein Vorbild nachahmen können, obwohl sie ihm ganz unähnlich sind, ,gehört ein theatralischer Stich, wenn der Degen durch die Brust zu fahren scheint, und doch nur zwischen den Armen hindurch gehet" ${ }^{100}$ ) Ist damit ein Kampfvorgang gemeint, ${ }^{101}$ ) so hat er davon in seinen Dramen keine Anwendung gemacht, und auch diese Kleinigkeit würde sich in das allgemeine Verhältnis von Theorie und Praxis fügen.

Schlegels vornehme Zurückhaltung in theatralischen Dingen, die bei aller Verschiedenheit eine gewisse Geistesverwandtschaft mit den Klassikern Frankreichs erkennen läßt - er steht ihnen als der einzig schöpferisch Veranlagte zugleich am nächsten und am fernsten - kontrastiert mit der Effekthascherei der Gottschedschule, die durch die Regel nur mühsam im Zaum gehalten wird, aufs schärfste. Entgegen allen immer noch hochgepriesenen Mustern werden in ihr krasse Wirkungsmittel mehr und mehr beliebt. Der Zwiespalt konnte den Gegnern in der Zeit des sinkenden Ansehens der Schule nicht verborgen bleiben. Nur ein Jahr nach Vollendung der Schaubühne fielen zwei Abtrünnige, wohl Kästner und Mylius, im Hamburgischen Correspondenten (1746) über Krügers „Vitichab und Dankwart" her, wie es scheint mit sehr viel mehr Witz als die plumpe Verteidigung des Verspotteten aufbringt. ${ }^{102}$ ) Der Streich galt übrigens mehr Gottsched selbst; er sollte in dem Jünger, der ihn in sub-

${ }^{99}$ ) Vgl. Antoniewicz DLD 26, XI, besonders für die Einheit des Orts; R. Schacht S. 17 u. 25.

100) Werke 3, 147; bei Antoniewicz S. 146.

101) Es kann auch, trotz dem „Degen", an einen Selbstmord gedacht sein.

${ }^{102}$ ) „Nöthige Ablehnung des Scherzes wider die Allemannischen Brüder, welchen ein paar lose Freunde aus Leipzig in dem Hamburg. Correspondenten einrücken lassen." Wittenberg 1746. Benutzt in einem Druck Frankfurt u. Leipzig Anno 1748 (48 S.); das zitierte auf Seite 40. Da mir der Jahrgang 1746 des Hamburg. Correspondenten nicht zugänglich war, beruht die Darstellung nur auf dieser Verteidigungsschrift, die aber aus der Rezension manches zitiert. - Wa - 
misser Zuschrif: vor seiner Tragödie versichert hatte, daß er seinen Vorschriften darin möglichst gefolgt sei, getroffen werden. Uns interessiert hier nur der cine Vorwurf, den die Kritiker gegen Krügers Stück erheben: „Ich bin mit Zwcikämplen, Todesurtcilen, Mordtaten, Todesfällen, Ohnmachten, bis zum Erstaunen nach meiner Herren Rezensenten Meinung freigebig" - in der Tat eine hübsche Liste der Effektmittel, mit denen man in Gottscheds Gefolge die Stücke aufputzte. Das Drama ist ganz und gar von Schlegels Hermann abhängig, dem dic Situation (Römerschlacht) und die Wege zu ihrer Lösung (Intrige, Schlachtwendung) ohne Scheu entnommen sind. Im Gegensatz zu Schlegel will Krüger aber darïber hinaus durch Kampfvorgänge auf der Bühne wirken, wie sie in scinem Mahomed IV. nachgewiesen wurden. ${ }^{103}$ )

Den völligen Bankerott der gottschedischen Dramatik bezeichnet fast ein Jahrzehnt später Schönaichs „Versuch in der tragischen Dichtkunst ${ }^{\prime}{ }^{10 t}$ ) Das Organ Cottscheds zeigt die vier neuen deutschen Originale mit den üblichen Lobsprüchen an und bemerkt noch dazu, sie seien recht geschaffen, um die jetzt Mode werdenden Ubersetzungen aus dem Englischen, welche das Theater in die alte Verwirrung zurückzustürzen drohten, aus dem Feld zu schlagen. ${ }^{105}$ ) Wic unregelmäßig diese Paladine der RegelmäBigkeit wirklich waren, hat der Rezensent nicht gesehen, oder nicht sehen wollen. Aber die Gegner hatten scharfe Augen. Lessing zwar beschränkte sich auf eine verächtliche Abfertigung der pöbelhaften Schreibart des Barons, dem er im übrigen zuerkannte, daß er in seiner clenden Dichterei die mechanischen Regeln so ziemlich zu beobachten wisse. ${ }^{106}$ ) Der junge Nicolai jedoch packte den Gegner gerade hier an und wies init Behagen auf, wie verschieden von den Lehren des Meisters die Stücke des Schülers geraten waren. ${ }^{107}$ ) ..Darüber erstaune ich, daß er [Gottsched], der den Opern die Unregelmäßigkeit vorwirft, und durch einen seiner Schüler, der engländischen Tragödien Blut, Mord und Grausamkeit

niek S. 526 sucht die Verfasser der Rez. in J. A. Schlegel und Gärtner; dieser spätere Druck nennt aber Kästner und scinen ..halben Stubenbursch Milius" mit großer Bestimmtheit. Vgl. auch Wianick S. 492-93.

$\left.{ }^{100}\right)$ Vitichab u. Dankwart I. 2 ungestüme Forderung zum Zweikampf (ohne Austrag): II, 3 Eindringen einer bewaftrelen Cruppe, die Vitichab töten will; Radogast deckt ihn mit dem Leib.

109) „Bestetrend aus vier "Traucrspielen, nämlich Zayde. Mariamne. Thussnelde, Zarine." Bresslau 1754. Ex, der kel. Bih. Berlin. Vgl. Otto La dendorf. Christoph Otto Freihr. v. Schön sich. Leipriger Diss. 1897. S. 29-37.

$\left.{ }^{105}\right)$ Das Neurste usw. 1755, S. 63-64.

100 Berlinische Zeitung 22. Febr. 1755; Schriften 7.10.

107). Bricte uber den itzigen Zustand der schönen Wissenschaften in Deutechland", Berlin 1755. H. Brict. S. 124-25. Berliner Neudr. 111. Scrie. 2. Bd., S. 91: vgl. Ladendorf S. 35. 
vorwerfen lässet, dennoch Deutschland zu vier Originalstücken Clück wünschen kann, in deren einem [Thusnelde und Hermann V, 6] eine Schar Römer über die Bühne gejagt wird, denen Hermann mit dem Schwerte folgt, und in einem andern [Mariamne IV, 3] ... ein Held den Kopf eines Feindes getragen bringet." Die Beispiele ließen sich leicht mehren. Die „Mariamne“ ist auch sonst reich an Greueln, und was die "Zayde“ an Erdolchungen zustande bringt, ist für ein Stück eine respektable Leistung.

Für die Kampfdarstellung im besonderen, die Nicolai zuerst aufs Korn nimmt, war die Situation in der Tat so, daß Gottsched nur ein Jahr bevor Schönaichs Stiicke erschienen, im „Neuesten“ Drydens Verdikt gegen Bühnenkämpfe gebracht hatte, noch dazu mit einer Stelle, die vollkommen auf Schönaich paßte. ${ }^{108}$ ) „Vermittelst dieser Erzählungen vermeiden die Franzosen den Tumult, dem wir in England unterworfen sind; wenn wir Zweikämpfe, Schlachten und andere solche Vorstellungen auf den Bühren leiden: die daher den Kampfspielen gleichen, wo man um Preise ficht. Was ist aber lächerlicher, als ein Kriegsheer mit einem Trummelschläger, dem fünf Mann folgen, vorzustellen; die der Held des Widerparts vor sich herjaget? oder einen Zweikampf zu sehen, wo der eine durch zwei oder drei Stöße eines Rappiers ermordet wird, dessen Spitze, wie wir alle wissen, so rund ist, daß man in keiner Stunde damit jemanden entleiben würde?" ${ }^{109}$ )

Schönaich gewinnt aber aus solchen Dingen seine besten Wirkungsmittel. Gerade Kämpfe kann sich seine gänzlich veräußerlichte Dramatik nicht entgehen lassen. Er tut alles, sie möglichst wirksam zu machen. In der Verschwörungsgeschichte von "Zarine und Stryangäus" (III, 3-5) begegnen sich die feindlichen Führer bei Nacht in Waffen. Mit einem Begleiter wieder allein. faßt Stryangäus Verdacht. Durch die unheimliche Dunkelheit „rauschet ein Pfeil", dem mehrere folgen; die Verschworenen stürzen herein, ihr Führer fällt aber von Stryangäus' Hand. In diesem Augenblick ,erscheint die Königin gewaffnet, mit einer Menge Fackeln“; ihr höchst effektvoll gedachtes, überraschendes Auftreten trennt die Kämpfenden.

Mehr als diese immerhin bezeichnende Stimmungsmache interessieren die Kampfvorgänge in "Thusnelde und Hermann", weil sich dieses Stück

${ }^{108}$ ) „Drydens Gedanken von der französischen und englischen Schaubühne“" Das Neueste usw. 1753, S. 220-21; dieser Auszug aus ,An Essay of dramatic poesy“ 1668 (das im folgenden zitierte in Dryden. Works ed. Sco:t and Saintsbury, Bd. 15, London 1892, S. 323-24) ist sehr einseitig. Das Lob Shakespeares u. dgl. wird in Cottscheds Zeitschrift natürlich unterschlagen. Lessing übersetzte ein größeres Stück des Essays Theatral. Bibliothek 4. Stück, XIII (die angezogene Stelle Schriften 6, 274).

$\left.{ }^{109}\right)$ Die oben S. 11 beigebrachte Äußerung des Spectator, ebenso das oben S. 6 ziticrte Urteil

A. W. Schlegels decken sich mit den Bemerkungen Drydens im einzelnen. 
in die Arminiusrcihe stellt. 'Sein unmittellarer Vorläufer, Mösers "Arminius" von 1749, setzt erst nach geschlagener Schlacht ein, scheidet also hier aus. Schönaich hängt im wesentlichen von Schlegel ab; um so auffälliger sind die Punkte, worin er über ihn hinausgeht. Die spärliche Technik der personnages wird durchbrochen. Der ..Lieutenant von der kön. polnischen und churf. sächsischen Reiterey", wie sich Schönaich auf dem Titelblatt des „Hermann” schreibt (2. Aufl. 1753), gibt der Masse als Kampfgefolge einigen Anteil am Drama. Wie das Personenverzeichnis der ..Zarine" .medische und sacische Kriegsbedienten" und gar "Eine Menge Verschworner" fordert, hat hier Germanicus (IV, 3) eine große Gefolgschaft: ${ }^{110}$ ) V, 6 flieht die von Nicolai signalisierte Römerschar, von den Germanen verfolgt, über die Bühne, während Schlegel $(V, 3)$ nur einige Katten hatte auftreten lassen. Schönaich gibt damit zum erstenmal ein wechselseitiges Schlachtgeschehnis: Freund und Feind gleichzeitig. Sein Stück ist auch sonst so angelegt, daß beide Parteien auf der Bühne erscheinen. Bei Schlegel hatte sich die ganze Handlung auf germanischer Seite vollzogen, und Varus war in einer einzigen Szene - die Schönaich nachahmt - zur Unterhandlung aufgetreten (II, 5). Hier halten die Römer gerade während der Schlacht die Bühne besetzt $(V, 4-6)$, was wieder eine der Halbheiten des Ubergangs bedingt, die sich in diesen Jahren auf Schritt und Tritt aufdrängen. Wenn man beide Gegner vorführt, kann man nicht mehr, oder nur noch mit $Z$ wang, an dem einen Ort festhalten. Die shakespcarische Technik wechselt ihn mit den Partejen. Schönaich übernimmt den unverrückbaren Hain Schlegels, wenn er ihn auch durch die Vorschrift, da $B$ man in der Tiefe beide Läger sehen solle, der Kampfsituation näherbringt; dennoch will er die wirksamen Momente hüben und drüben zeigen. ${ }^{11}$ )

Wie im Schauplatz, ist die Beziehung zur Schlacht auch sonst enger geworden: die lllusion, daß sie unmittelbar hinter den Kulissen vorgehe, soll auf ganz unfranzösische Wcise durch akustische Mittel erreicht werden. Man hört den lang anwährenden Tumult, bis man die fliehenden Römer zu Gesicht bekonamt; aus dem einzelnen Schuß in Gottscheds Bluthochzeit ist bereits ein ganzes Kampfgetöse erwachsen. Nicolai hatte recht; mit solchen Kronzeugen konnte man den Engländern den Prozelb nicht mehr machen. Man war ihrem dramatischen Libertinismus, so regelmäßig man sich auch gebärdete, selbst nahegerückt.

"I0) Es ist demnach nicht ganz. richtig, wenn Lohmeyer S. 37 der Cottschedschule die Masaenverwendung in Bausch und Bogen abspricht.

111) z. B. IV, 2 Kamplschwur der germanischen Fürsten; V, 5 Kampfbefehl des Germanicus. Ein Kampfvorgang noch III, 5: Flavius greift gegen seinen Bruder Hermann zum Degen C.. Er ziehs das Schwert: und alles ziche. Inguionar falls dem Hermann. Sterlin dem Flavius in den Arm"). 
Das Stück ist Schönaich dann über den Kopf gewachsen; innerhalb der Regelschranken, die er, obwohl weitherzig genug, schließlich doch beobachtete, konnte er mit der Schlacht nicht fertig werden. Er bricht deshalb an der spannendsten Stelle, nach der Meldung, daß Thusnelda von Germanicus geraubt sei, kurzweg ab und schließt das Drama mit der merkwürdigen Vertröstung auf den nächsten Kampftag, aber immerhin patriotisch.

Will man sich gesammelt vergegenwärtigen, was die Schule Cottscheds in der dramatischen Kriegsgestaltung gesündigt hat, so greift man am besten zur Parodie. In dem theatralisch stark interessierten Wien, wo der Kampf zwischen der neuen regelmäßigen Tragödie und der überkommenen extemporierten Komödie besonders heftig ausgefochten wird, schickt Josef Kurz (Bernardon) als schlagfertiger Verfechter der heimischen Tradition die "Prinzessin Pumphia" ${ }^{a 12}$ ) gegen die gespreizte Kunstdramatik ins Treffen; gleichviel, ob sie ein einzelnes Stück aus der gottschedischen Werkstatt aufs Korn nimmt oder die Richtung im ganzen persifliert, ${ }^{113}$ ) jedenfalls ist darin mit gutem Witz die Summe der Blößen gezogen, die den mühseligen Regeldramen anhaften, und ihre Kampftechnik, gestützt auf die lokale Überlieferung. besonders liebevoll vorgenommen.

Die gedruckte Parodie, noch dazu einer so weit zurückliegenden Kunstform, kann natürlich nur ein schwacher Abglanz der lebendigen Aufführung in jenen für das Für und Wider erhitzten Tagen sein, wo die Spitzen und Stacheln der Kurzschen Posse die tragischen Geburten trafen, die soeben es ist bei einigen schwer begreiflich - in vollem Ernste die Bretter beschritten hatten. Der Spaß hat inzwischen sein bestes Publikum verloren und wird kaum anders zünden können, als wenn ihm die Lektüre von einem Dutzend der klappernden Schulstücke vorangegangen ist, worin der Leser, nach Nicolais treffendem Wort über die Komödien, ${ }^{114}$ ) beständig Gefahr läuft nach allen Regeln Aristotels eingeschläfert zu werden. Kurz beksmmt

112) Eine neue Tragoedie, Betitult: Bernardon Die Getreue Prinzessin Pumphia, Und HannsWurst usw. Aufgeführt 1756 u. offenbar gleichzeitig, aber ohne Datum, gedruckt. Die Datierung $\mathrm{GCr}^{2} 3,374$ beruht auf einem handschriftlichen Eintrag in Cottscheds Exemplar, der die Komödie auch im Nöthigen Vorrat 2, 289 f. unter den Trauerspielen des Jahres 1756 aufzählt; dann gedruckt im 2. Bd. der Wiener Deutschen Schaubühne 1767; neu hrsg. von A. S a u e r. Wiener Neudr. Heft 2 (1883); vgl. seine Einleitung S. IV u. Ferd. Raab, Joh. Jos. Felix v. Kurz, genannt Bernardon, Frankfurt a. M. 1899, S. 110.

${ }^{113}$ ) Sauer, Wiener Neudr. 2, V läßt die Frage offen, Raab S. 112 sieht das Urbild in Grimms Banise, die 1752 in Wien gegeben wurde; $\mathrm{CGr}^{2}$ 5, 303 vermutet, daB Clavels Mordtragödie La Mort de Nadir ou de Thomas Koulikan usw. - die augenscheinlich den Stoff geliefert hat - parodiert sei.

114) Briefe über den itzigen Zustand usw. S. 118; Berliner Neudr. III. Serie 2, 86. 


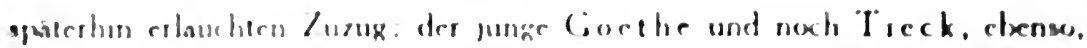
naher semer Regun. Ketzeline setzen sich mit der Alexandrinertragodie

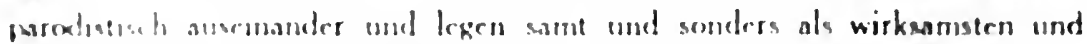

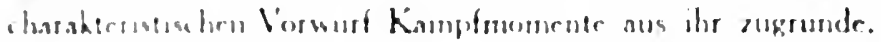

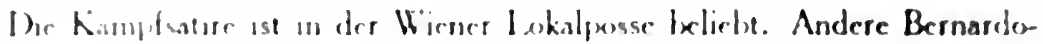
maden wareln in ihr. Phalupp Hafuet fuhrt cine spabhafte .Bataille" auf und shater lalie sich Sinhaneder alubliche Wirkungen nicht entgehen. ${ }^{35}$ )

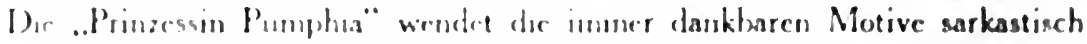
de lromserung des Mutes. Auferste Feigheit ist ja auch cine komische Starker Hanswursts: hier rriff sie parodistisch das MiBurrhältnis von Rede und Tun des acgelminlighen Kriegshelden. die der französischen Technik gemäB nfers ver grolispreherisehen Worten auf der Bühne gar niche zum Schlagen hinter the henumen: soversichere Kulican die ihn anklagende Pumphia, nachdem or prahlerisete Siegerreden gehalten. sciner villigen Unschuld an der Clurwondume libes Vaters (1. 3): ..Ach sehweige doch! ich habe nichts getan./

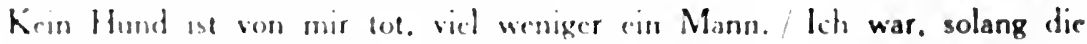

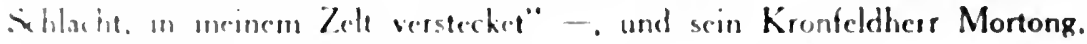
den er homploth mit pomphaftem Loh uberschiittet: ..Konn her, umarme

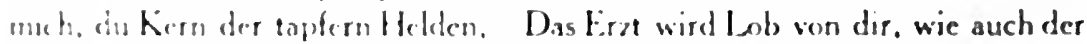
Mlarmer makden". gesteht ireuherzig: ..Herr! mir war Angst dabei, dann es kung hutak an!" Von der Lngefibhlichkejt seiner aclbst und der Truppen Iest dirser Kuluan l. A leschwichtigend Zcugnis ab: ..Ich, land mein Kriegeshere, nur lielen mu: die Rula": noch egoistischer lalit sich der König Ahas-

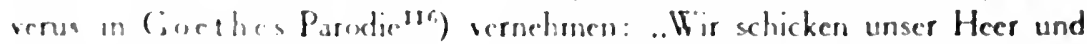

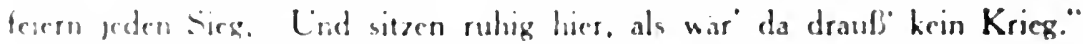

Wits: ist wn Ki:r die kënigliche Fishrertatigkejt in der entbrennenden

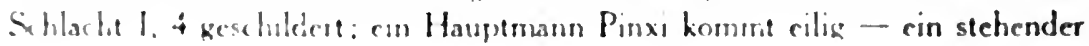

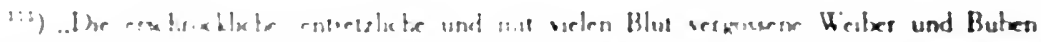

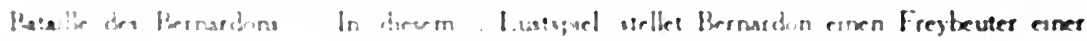

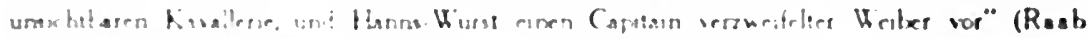

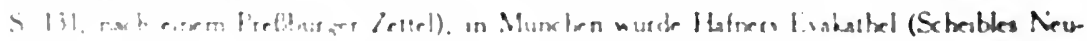

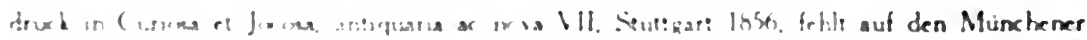

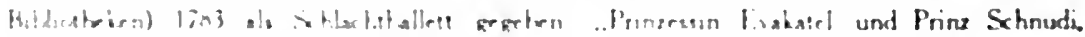

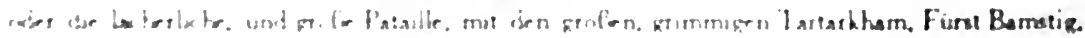

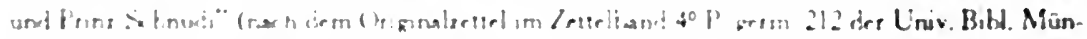

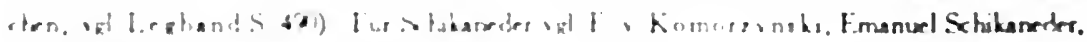
bet!n |all. S io

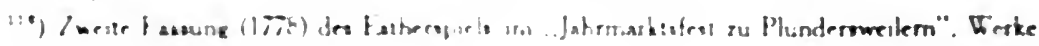
10. it 
Auftritt der Alexandrinertragödie - den Kampfbefehl zu holen; aber bevor Kulican noch ein Wort geäußert, läuft er mit der Versicherung schon wieder ab: „ich hab dich schon verstanden, / Sobald du Herr nur sprichst, ist Hülf' und Rat vorhanden" - worauf erst der König, jetzt völlig zwecklos und ins Blaue hinein, mit seinem Vemichtungsbefehl losbricht: „Gleich haut die Hunde tot ..."1177)

Die Satire des Kampfabgangs, der unvermeidlichen, effektvollen Prozedur der Gottschedschule steuert Ti eck bei; in Jeremias' Marionettentheater, ${ }^{118}$ ) wo nacheinander das heroische und das bürgerliche Trauerspiel, das Schicksals- und Rührstück erscheinen, ist die alte getragene Gattung durch eine Situation aus dem Belagerungsstück vertreten. Einem bedrängten König gelingt es nicht, die Bürger zur Verteidigung zu bringen -- „Und kellerwärts verkriecht sich mannhaft der Soldat" - er zieht selbst sein Schwert und nimmt einen von der nacheilenden Königin lebhaft bewunderten Abgang zum Treffen; indessen der auch nach dieser fürstlichen Mutäußerung skeptische Bote allerdings schon das Jubelgeschrei der Feinde hört.

Besonders verwundbar war die gottschedische Kampftechnik in ihrem Meldeverfahren. Bernardon hat ihren trockenen Gefechtsbericht nicht übel bloßgestelit, indem sein König Cyrus ,ein Papier aus dem Sack nimmt“ und es kurzerhand vorliest: das ist der klassische Botenbericht, abgefaßt in zwanzig skurrilen Alexandrinern. ${ }^{119}$ ) Ubrigens war sein Autor natürlich so wenig wie Cyrus selbst mit im Treffen und schreibt nur nach dem Hörensagen, wie der Sosias Molières und Kleists - es liegen alte Cloriosus- und Hanswurstmotive zugrunde - seinen Schlachtbericht memorieren muß, um trotz heimlichem Schinkenmahl im Zelt als Augenzeuge bestehen zu könner. ${ }^{120}$ ) Ebenso hat Pumphias Gemahl Faustibus der Schlacht vorsichtig aus der Ferne angewohnt,

11i) Den hohlen pathetischen Ausbruch des pseucoheroischen Stils geißelt auch - außerhalb der Kampfsituation - Goethe, dessen Ahasverus mit dem künstlichen Umschlag des Alexandrinerstücks aus tyrannischem Cleichmut plötzlich in die schrecklichste Angst fällt und befiehlt, wahllos alles hängen zu lassen; Werke 16, $25 \mathrm{f}$.

${ }^{118)}$ ) Prinz Zerbino, Wüste; Schriften 10, $200 \mathrm{f}$.

$\left.{ }^{119}\right)$ II, 2; der schablonenmäßige, durch nichts begründete Glückumschwung wird 1, 4 gemeldet, I, 5 die glückliche Beendigung des Kampfes und komische Beute.

120) Moli è r e, Amphitryon v. $196 \mathrm{ff}$.: „N"importe, parlons-en et d'estoc et de taille. / Comme oculaire témoin: / Combien de gens font-ils des récits de bataille / Dont ils se sont tenus ioin?" Eine lustige Theateranekdote von einem völlig mißglïckten Kampfbericht in einer halb extemporierten Haupt- u. Staatsaktion erzählt Joh. Chr. Brandes, Lebensgeschich.te, Berlin 1799 f., 1, 160-63, von der Seuerlingischen Gesellschaft in Lübeck (urn 1750). Der König, ein bei der Truppe neuangekommener Schauspieler, gerät mit der Aufforderung an seinen Kronfeldherrn. die Schlacht zu berichten, unglücklicherweise an einen mecklenburgischen Bäckergesellen, de: 
berichtet aber II, I in einer pomphaften Rede von einigen dreißig Alexandrinem von seiner heldischen Haltung - nachdem er sich falstaffisch furchtsam überzeugt hat, daß ihn niemand bedroht.

Die heroische Schlachtschilderung des Römerdramas parodiert noch Kotzebue in seiner einaktigen Tragödienposse .Cleopatra“", ${ }^{121}$ ) die den shakespearischen Stoff, zum Teil dieselben Szenen, die Kotzebue selbst in der "Octavia" (1801) nachgebildet hatte, zugleich mit den Formen des gottschedischen Schlachtstücks verhöhnt. Auch hier ist Cäsarion, der der Mutter berichtet, nur ..von weitem" dabei gewesen. Kotzebue ahmt insbesondere die überspitzte Antithese des zweischenkligen Alexandriners bei den Gottschedischen boshaft nach (8. Szene): ..Ach liebe Frau Mama! verloren ist die Schlacht! / Augustus hat gesiegt - Ezypten gute Nacht!" Noch beißender bein Auftreten des geschlagenen Antonius, der sich den Helden der .,Schaubühne" verzwcifelt ähnlich einführt (9. Szcne): „Da kormm ich aus der Schlacht, wie cin begossner Hund. / Erschossen ward mein Heer, ich aber bin gesund."

Im Eingang der Pumphia wendet Kurz die stcreotype Fluchtszene, die wir noch eben bei Schönaich angetroffen haben, ins Komische. .Das Theater stellet durchaus ein Lager vor, inwendig läßt sich unter Trompeten und Pauken cin Lärm von streitenden Soldaten hören; es laufen etliche persische Soldaten über das Theater, alsdann kommst König Cyrus und sein Feldherr Sigelvax ganz ängstlich nachgeloffen." Der großz Cyrus flucht, selber laufend was ihn die Bsine tragen, auf die Fliehenden, und sein General versichert im Davonrennen, ,dein Feldherr stehet schon“"

Ureigenstes Wiener Gebiet betritt die Parodie mit der anschließenden Geißslung des Theatralgefechtes, in Wien Combattement genannt. Es war ein Erbstück der schaufrohen Volksbühne, die sich an bewaffneten Zusammenstößen ergötzte auch wenn sie mit den bescheidensten Mitteln inszeniert wurden. Wic sehr es stehende Formen angenommen hatte, beweist der Wiener Schauspielertarif, wonach als Nebengefälle, das heißt Extravergütungen für den Darsteller, .jedem Duellanten in den Combattements 34 Kreuzer" zustunden. ${ }^{122}$ ) Wir haben gesehen wie dieses Combattement, der Kampf um

zur Aushille als Statist mittut. Auf wiederholtes Drängen des Herrschers, den Hergang doeb zu erählen, bricht der Biedere in außerster Verlegenheit endlich los: .Ik kann et nich segzen. Herr König. ik bin by de Slacht nich mit wesen".

121) Ersidruck im Almansch dramatischer Spiele 1833. Werke Bd. 1.

${ }^{122}$ ) Devrient' 2, 207 1.: ..Zufallige Gedanken über die Schsubühne zu Wien" in Das Neueste aus der anmurigen Gilehrsankeit 1763, S. 635: ..M 1 n erwăge nur ein wenig, was tăglich auf unserer Bühne ... die Bezshlung einzelrner Torheiten der Schauspieler kosten, wenn sie r.ast jeden Sehlag, den sie wathrend ihrer Vorstellungen aushalten, jeden Fall ader Hexenluz in die 
des Effekts willen, zuerst unter der Form des Duells, bei Schënaich schon in größeren Gefechtszenen, sich auch in die gereinigte Traoc̈die wiedtr einschlich; es tritt später sogar bei einem so strengen Autor wie Ayrenhoff in die Erscheinung. Wenn Kurz es ironisierte, licß er demit vor allem die spektakelfreudigen Wiener über eine eigene Schwäche lachen, der noch zu Anfang des 19. Jahrhunderts der Götz von Berlichingen zum Opfer fiel. ${ }^{123}$ ) Die ausnehmende Magerkeit, womit das Gefecht dargestellt wird, richtet sich aber deutlich gegen das neue Kunstdrama, das die Wirkurg von Kämpfen nicht missen wollte, aber mit den Mitteln aus schlechtem Gewissen gegen die Regeln ärgstlich tat.

Die Satire der Pumphia-Schlacht (I, 1-2) beruht durchgängig auf einem krassen Mißverhältnis der hochtrabenden Versreihen zu dem, was eine dünne Technik vorzuführen gestattete. D $\in m$ durch $O_{F \in r}$ und $S_{p} \in k$ takel verwëhnten Wiener mußte der Abstand besorders fühlbar sein. Es entsteht nach der Fluchtszene ,abermal ein großer Lärmen, dann kcmmen 4 Buben, 2 als Tartarn, und 2 als Perser gekleidet, diese halten ein Combattement; die Tartarn überwinden die Persier, welche als tot auf der Erden liegen bleiben, die Tartarn aber, bei entstandenen Lärmen, laufen davon". Jetzt tritt Kulican mit seinem Feldherrn auf, ,nebst etlichen Buben, welche tartarische Soldaten vorstellen“. An das Kampfgefolge der Cottschedischen erinnert die ausdrückliche Vorschrift: „alle haben die bloße Säbel in der Hand“. Der König gebietet der grausen - durch die zwei Bubenpaare geschlagenen - Schlacht Einhalt: „Hört nur zu morden auf, genug ist Blut vergossen" - und er treibt die Parodie der Darstellerzahl ins Croteske, indem er angesichts der beiden Toten versichert, er könne ,als Sieger jetzt auf tauserd Leichen gehen, / Der Wahlplatz ist bedeckt, man kann darauf nicht stehen" ${ }^{124}$ ) Es darf in der Schlachtposse

Lüfte, den sie etwa tun müssen, mit besonderer barer Bezahlung vergütet bekommen". - J.v. Son nenfels, Briefe über die wienerische Schaubühne, 1768, Zwey und funfzigstes Schreiben, Wiener Neudrucke 7 (1884), S. 315: „Das Fliegen, die Arien, eine Maulschelle wurden dem Schauspieler unter den Namen Nebengefälle (Accidentien) besonders bezahlt. Es war also sehr natürlich, daß ein Schauspieler [Kurz-Bernardon] sich und den Seinigen viel zu singen, viel zu fliegen gab, und seine Stücke auf Maulschellen arbeitete, wovon er sich gewiß die meisten zuschrieb". Der Prügeltarif ist auch erwähnt in [H. Blümner] Gesch. des Theaters in Leipzig 1818, S. 100.

123) Henslers allerdings nicht mehr erfolgreiche Bearbeitung 1808 wollte der Neigung des wienerischen Publikums durch ein von der Kritik getadeltes ,immerwährendes Aneinanderhäufen von Gefechten ohne Wahl und Zweck" entgegenkommen; E. Kilian, Goethe-Jahrbuch 14 (1893), $276 \mathrm{f}$. und Dramaturg. Blätter 1 (München 1905), 176.

124) Ebenso ist I, 4 nach Pinxis Meldung das Feld von den drei vier fünf anrückenden Feinden ,schon überall bedeckt". 
nicht fehlen, daß schlicßlich auch dic beiden Opfer der Bataille wieder lebendig werden; als inan sie auf Pumphias Befehl begraben will, wird offenbar, daß sie sich gleich Falstaff nur tot gestellt haben, und sie laufen jetzt, um die unliebsame Kricgserfahrung reicher, was sic können: ..Schlägt man auf einen hin, so schlägt der andre her. / Dasmal in Krieg gewest, mein Lebtag nimmermehr". König Kulican blickt ihnen bewundernd nach und bemerkt nach einer alten Soldatenweisheit: .Wic listig ist der Feind, das war ein tapfrer Mann, / Den man noch vielc Jahr zum Streiten brauchen kann". 


\section{Zweites Kapitel.}

\section{Erste Wirkungen des Siebenjährigen Krieges.}

Zwei Jahre nach den kampflustigen, frischen „Briefen“" sah sich Nicolai veranlaßt, seine Gedanken über die Tragödie systematisch zu ordnen und als programmatische „Abhandlung vom Trauerspiele" dem Preisausschreiben der neugeschaffenen Bibliothek der schönen Wissenschaften zugrunde zu legen. ${ }^{1}$ ) Die Schrift entstand mühsam und geriet nicht zu seiner Zufriedenheit. ${ }^{2}$ ) So leicht seiner spöttischen Kritik das Einreißen des Alten geworden war, als es ans Aufbauen gehen sollte, mußte er erfahren, daß alle festen Richtlinien fehlten. Wo es sich um die Form des Dramas handelt, ist die Abhandlung ganz besonders unsicher und schwankend, wie auch der über ihr entstandene Briefwechsel über die Tragödie, den Nicolai mehr zwischen Lessing und Mendelssohn vermittelte, als daß er selbst daran teilnahm, dafür kaum etwas ergibt; er wird hauptsächlich über die ästhetischen Probleme der Tragödienwirkung geführt. Den Formfragen gegenüber hat die Theorie noch keinen sicheren Standpunkt gewonnen. Nicolai kommt über die Angabe kleinlicher Mittel, wie den Regeln, die bei ihm im wesentlichen noch durchaus zu Recht bestehen, ein Schnippchen zu schlagen sei, nicht hinaus; er bleibt damit in der von Corneille gewiesenen Richtung befangen, die bei den Späteren zu wahren Taschenspielerstücken der Regelinterpretation ausschlägt. Neu und auf Lessing deutend ist der Vorwurf gegen die Franzosen, sie zeigten aus übertriebener Delikatesse auf ihrer Bühne zu wenig. Auf der anderen Seite wird aber den Engländern die übermäßige Anwendung der Ortsveränderung noch recht gottschedisch verwiesen: sie verrate eine große Unwissenheit in der Art, einen Plan zu machen, oder wenigstens eine sehr große Nachlässigkeit. ${ }^{3}$ )

Von den zum Wettbewerb eingereichten Stücken gehört das eine, gegen Cronegk unterlegene, Brawes „Freygeist", 4 ) der bürgerlichen Reihe an,

1) Bibliothek der schönen Wissenschaften und der freyen Künste Bd. 1, Stück 1, Leipzig 1757.

2) An Lessing 2. März 1757; Lessing, Schriften 19, 67; vgl. ihre Charakterisierung bei Min or, Lessings Jugendfreunde DNL 72, 284-87.

3) Bibliothek der schönen Wiss. 1, 34-35, DNL 72, 341-42.

4) Erstdruck im Anhang zum 1. u. 2. Bd. der Bibl. der schönen Wiss., Leipzig 1758. 
die von Lessings Miß Sara Sampson ausgeht. Dieser neue Zweig des Dramas kennt den Kampf nicht wie die hohe tragische Gattung als fast ständige Aufgabe, sondern mehr nur als gelegentliches Intermezzo, das der cine oder andere Stoff mit sich bringt, und dann, wie die alte heroische Tragödie, und auch aus ähnlichen Gründen, fast nur als Zweikampl. Die Gruppe der bürgerlichen Stücke bleibt daher, einiges für die allgemeine Entwicklung besonders Wichtige und Symptomatische ausgenommen, hier außer Betracht.

Zu diesen Fällen zählt der Zweikampf zwischen Clerdon und Granville im .Freygeist" (IV, 2-6). Er geht hinten vor sich, wie es die alte Regel forderte. Bei gleichem äußeren Habitus hat sich aber innerlich eine Umwandlung vollzogen; die Cottschedianer wurden nur durch den Regelzwang zurückgehalten. alles an die Rampe zu zerren was Effekt versprach. Brawe verfügt über die dichterischen Mittel, die Fessel nicht mehr als solche empfinden zu lassen. Er behält das Duell hinten nicht aus Ängstlichkeit, sondern weil er es der Phantasie viel eindringlicher zu malen vermag, als die mannigfach gehemmte Darstellung es vor Augen bringen könnte. Bei ihr verlöre er die unheimliche Spannung auf das hinten Geschehende, und sie erreichte nie den Eindruck der mit Selbstanklagen untermischten Erzählung des Verlaufs durch Clerdon. Die ausschweifende Schilderung des Kampfes in diesem Bericht, der mit seinen zügellosen Gefühlsausbrüchen den Genieton vorwegnimmt, geht weit über alle Möglichkeiten der wirklichen Darstellung eines Zweikampfes hinaus. ${ }^{5}$ ) Die poetische Wiedergabe des Gefechtsvorgangs trägt es hier zum erstenmal der Typus wird in der späteren Entwicklung bedeutend - über die szenische davon.

Das gegensätzliche Verfahren schlagen die Kampfszenen in Cronegks .Codrus" ${ }^{\text {" }}$ ) ein, der gegen Brawe den Preis errang. Der weitgereiste Freiherr kannte das Pariser Theater aus eigener Anschauung und blicb ihm auch im Alexandriner treu, während Brawe sein bürgerliches Stück in Prosa schrieb. Ganz wie Schönaich sah sich Cronegk aber genötigt, der Leere seiner Handlung durch Theatereffekte zu Hilfe zu kommen. So gelangt auch er dazu, einen überraschenden Überfall vorzuführen (1ll, 6 u. 7). Während einer Unterredung, die Codrus mit dem feindlichen König Artander hat, vernimmt er crstaunt verdächtiges Geräusch und Waffengetümmel. Der Gegner greift zum Schwert, Codrus will sich zur Wehr setzen, als feindliche Soldaten eindringen, die seinen Vertrauten, welcher vergeblich gegen ihre Ubermacht

e) Auch A. Sauers strenge Kritik des Stücks billigt diesem Kamplbericht große Wirkung zu: J. W. von Brawe, der Schüler Lessings. Straßburg 1878 (Quellen und Forschungen 30), S. 32.

") Gedruckt neben dern .Freygeist" in Anhang zum 1. u. 2. Bd. der Bibl. der schönen Wiss. 1758. 
ficht, vor sich hertreiben. Beide werden überwältigt und gefangen, während draußen die Stadt sich ergeben muß. In V, 9 und 10 braucht Cronegk die stärksten Stimmungsmittel, um deren Befreiungskampf zu versinnlichen: nachdem das Orakel verlesen ist, donnert und blitzt es, ${ }^{7}$ ) plötzliche Nacht bricht herein, schreckliches Klaggeschrei erfüllt die Luft, ein wildes Geräusch wird hörbar. So vorbereitet soll die Meldung der Niederlage (,Herr alles ist verloren") katastrophal wirken; der König zieht mit seinem ganzen Gefolge blank und stürzt sich ins Getümmel. Man sieht, Cronegk scheute sich nicht vor Kampfgeschehnissen. Der Grund, warum er das Hauptereignis der Handlung, Codrus' Opfertod, nicht auf der Bühne vor sich gehen ließ, kann nicht hier liegen. Er selbst nennt dafür die Beobachtung der Ortseinheit, ${ }^{8}$ ) welche die Vorführung in der Tat hindert sofern man an der Überlieferung festhält, wonach sich Codrus als Bauer verkleidet von den Wachen am Tor niedermachen läßt. Die Unschicklichkeit dieser Verkleidung selbst ${ }^{9}$ ) wird kaum die Ursache sein, da Cronegk ganz im Sinne des Feilschens um historische Treue und Regelzwang den Weg zur Umgehung der Schwierigkeit angibt: Codrus braucht schließlich nur unbekannter Weise, nicht gerade als Bauer vermummt, erstochen zu werden.

Cronegk und Brawe werden von Zeitgenossen und Späteren gleichmäßig als dem deutschen Drama zu früh Entrissene, die ihr Bestes erst noch hätten leisten sollen, betrauert. ${ }^{10}$ ) Es kann aber kein Zweifel sein, bei wem das Vorwärtsdrängende, Entwicklungskräftige lag. ${ }^{11}$ ) Brawes zweites Stück, der „Brutus“, 12) überrascht durch seine fortschrittliche Haltung und zählt zu den Werken, welche in der Geschichte der Kriegserfassung Epoche machen. Brawe wählt wie Schlegel ein Schlachtereignis zum Vorwurf. Das patriotische Interesse am Freiheitskampf, Urgrund und Ziel des „Hermann“, bleibt den philippischen Kämpfen jedoch fern. Die Intrige tritt deshalb hier sogar

7) Obwohl Cronegk nach vielfältigen Erfahrungen besorgte, das deutsche Parterre würde dabei - wohl auf Kosten des Theatermeisters - lachen. Gedanken über das Trauerspiel Codrus, Bibl. der schönen Wiss. 1, 90.

8) Gedanken usw. S. 91.

9) Wie Minor DNL 72, 133 annimmt.

10) So z. B. Jördens 1, 357 u. 205.

11) Lessing stellt gegenüber $\mathrm{Chr}$. F. Weiße im 81 . Literaturbrief fest, daß Brawe „,das größere tragische Genie war"; augenscheinlich in seinen Fußtapfen erkennt Chr. H. Schmids Biographie der Dichter, Leipzig 1769, ihm (1, 132 u. 152) vor dem allerdings ebenfalls hochgehaltenen Cronegk (1, 68 u. $129 \mathrm{f}$ ) die Palme zu; ähnlich [Küttner] Charaktere teutscher Dichter und Prosaisten, Berlin 1781, 2, 300 f. u. 305 f.

12) Geschrieben 1757, gedruckt erst 1768 von Ramler und K. G. Lessing: Trauerspiele des Herm Joach. Wilh. von Brawe, Berlin 1768; hrsg, von Minor DNL 72. 
starhes herwe und der. Shlachestoff wird in des alen Wease in cinen Familien-

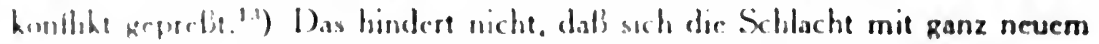
fmpress fubllmor mache. Vor anderem hat die erstaunlich vorgeschrittene duherrase Se Siruche daran Antril. Der funffubige reimlose Jambus schliebt eure neur Wirle auf. Alles was die Nexandrumertragoelic an Kampfechilderung und liewanderm geleistet hatte, erscheint notxen Brawes Diktion gespreizt

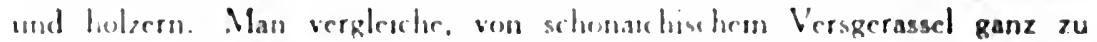

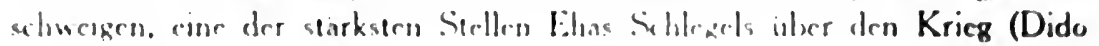
V. I Barce):

Cewaht uns Krieg und Fod. fur Frieden ohne dich.

Cowahr uns alles das, wovor wir Wealer zlltern.

Der Krieger Feldeeschere, die Furche von Iasngen Mittern.

Der Walfen geausen Klang. erhizzer Arme Wut.

Zerschlagner Mauern Fall, erwiurger Menschen Blut.

Was auf den Wallen Ciraun, in Hausern Sirrein erwecket.

Vias allen schrecklich ist und dich an mindsten schrecket.

Aus allem, was uns draut, wabl uns die kleinste Not.

W'ahl unsern Unergang. und meide deinen Tod -

mut dem was Brawe, ohne Entsprechung der Situation, aloer vor eine nicht unahnliche Aufgale gestelle, als Kamptaufforderung an den Feldherm zu geben imstarde ist (Brutus III. 6 .Messala):

Komm. Brutus! Alles ist zur Rache Roms.

Zum Kampif leceit, und deinem Heer feble nur

Sein grobes Schrecken, du. - Niche Heere bloB.

Der Erdkreis scheint zum Sircit compört. Ein Meer

Von Staub verdrängt den Tag - Der Waffen Glut

Durchbricht dic hange Finsternis und strahlt

Enesceen un sich her. Voll Ungeduld

Wunsche aus den Fesseln sich der wilde Krieg.

Dir scimen Ungestum noch landigen.

Komm, zeige drinem Heer dich und den Sieg.

Der Reınzwang, das Verhangnis der deutschen Alexandrinertragödic. mag einige der gestelaten Hortgefuge lxei Schlegel auf dem Cewissen haben. und daB auch Brawe rin Sohn sciner Zcit war. labe schon in dieser kurzen Stelle de Schlegel verwande, epigrammatische Fassung der Siblußzecile erkennen: das andert niches daran, dab der hohltonenden Rhetorik des Coottschedschülers gexentiber in dirser machewillen Bildersprachor Brawes rin ganz neues und

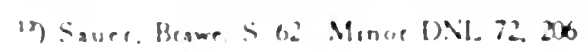


vielleicht das erste innere Verhältnis zu der "großen Welt des heitern Krieges“ (H. v. Kleist) zu spüren ist, ein Erleben, das mit aller Deutlichkeit vorwärts auf den Sturm und Drang weist.

Hier zum ersten Male ist der Bann gebrochen, der bisher auf allem Kriegerischen in den Dramen lag. Daß Gottsched, der zu der Armee in keiner anderen Beziehung stand, als daß er als junger hochgewachsener Mann vor ihren Werbern geflüchtet war, ihm nichts abzugewinnen vermochte, ist nicht weiter verwunderlich; wohl hatte auch seine Zeit Kämpfe gesehen die Bände der Schaubühne fallen in die Jahre der ersten beiden schlesischen Kriege - aber der Lärm der Schlachten war kaum bis in die Gelehrtenstuben gedrungen. Wenigstens verraten die Stücke der Schule nichts davon und zeigen, daß man den Krieg nur vom Hörensagen kannte. Bei Schönaich freilich, der selbst Offizier war, und dem Waffenhandwerk sogar eine Schrift widmete, ${ }^{14}$ ) sollte man erwarten, daß dies in den Stücken nicht bloß in der Verwendung von ein paar Statisten und einigen kümmerlichen Effekten, sondern auch in einem geistigen Verhältnis zum Kriege zum Ausdruck käme: aber die Schranke zwischen dem Leben und dem Dichten war noch unübersteiglich und in seinem Heldengedicht „Hermann" fanden die Gegner gerade die Schlachtschilderungen des Spottes besonders würdig. ${ }^{15}$ ) Jetzt aber erregte das gewaltige Schlachtgeschehen des Siebenjährigen Krieges die Gemüter mächtig, und trotz der ständischen Wehrverfassung zum ersten Male allgemein. In Ewald von Kleists Ode an die preußische Armee vernahm man neue Töne; die zum Ruhme des großen Preußenkönigs erstehende Kriegslyrik ist zugleich Ausdruck und wiederum Anregerin des lebhaftesten Interesses an den militärischen Vorgängen. Gleims Grenadierlieder ${ }^{16}$ ) und ihr Anhang bilden manche Mittel der Kampfschilderung aus, die auch für das Drama wichtig werden. Der lebendige Krieg gewinnt Anteil an ihm.

Als Brawe an den „Brutus“ ging, war der Lobositzer Sieg errungen, während er daran arbeitete wurde die Prager Schlacht geschlagen, wurde Kollin durch Roßbach und Leuthen wettgemacht. Unter dem wenigen, was wir von seinem

$\left.{ }^{14}\right)$ „Freie Gedanken über einige Theile der Kriegskunst", Frankfurt und Leipzig 1758. Jördens 4, 613 .

$\left.{ }^{15}\right)$ A. Stern, Beiträge zur Literaturgesch. des 17. u. 18. Jahrhunderts, 1893, „Ein gekrönter Dichter" S. 111. Ebensowenig würde man nach dem französischen "Arminius" schließen, daß ein Campistron Feldzüge mit Auszeichnung mitgemacht hat (Grande Encyclopédie 8, 1141, Lan s on).

16) Vgl. A. Sauers Einleitung zu ihrem Neudr. DLD 4, IV ff.; Xl f. Die volks- und kunstmäßige Kriegslyrik mustert, nach seinem früheren Vortrag (Kriegsdichter des Siebenjährigen Krieges und der Freiheitskriege ${ }^{2}$. Altona 1863), H. Pröhle im 2. und 3. Abschnitt seines Buches: Friedrich der Große und die deutsche Litcratur, Berlin 1872. 
Leben wissen, steht sein naher Umgang mit dem Major von Kleist in dieser Zeit. ${ }^{17}$ ) Hier wird sich der Student für kriegerische Dinge begeistert haben, vielleicht noch mehr als der Soldat selbst, der auch das Drückende seines Standes ausgekostet hatte.

$\mathrm{Zu}$ der persönlichen Anregung muB auch literarische getreten sein; Stellen des „Brutus" wie die oben angezogene ${ }^{18}$ ) muten - für den jungen Dichter ehrenvoll genug - fast shakespearisch an, ohne daß allerdings unmittelbare Spuren in Werke des Briten hineinführten. Es scheint sicher, $\mathrm{da} B$ Brawe den Cato Addisons englisch gelesen hat. ${ }^{19}$ ) Von dieser Seite wäre also kein Hindernis, da $B$ er nicht auch Stücke Shakespeares, noch bevor Lessing ihn proklamierte, im Original hätte kennen lernen können. Doch läßt sich diese Annahme durch nichts weitcr stützen. Man wird daher, da Brawe gerade für seine neue Erfassung des Kampfes weder bei Addison, dessen Cato allerdings ganz anders auf ihn gewirkt hat als auf Cottsched, noch auch bei Lessing viel gewinnen konnte und, unbeschadet seiner Begabung, in einem Lebensalter, das auch Größere noch als Gefolgsmänner sieht, und in einer Zcit, die sich erst mühsam aus der Nachahmung zu eigenem crhob, der Anregung wohl bedurfte, auf andere englische Vorbilder des Brutus, ${ }^{20}$ ) am ehesten Milton, ausblicken müssen.

Sci dem wie ihm wolle. Brawe ist auf $\mathrm{dem}$ Wege zu Shakespeare. Wenn man von seiner Kampfszenenreihe (III, 6 bis IV, 4) die beengende Zeltleinwand wegreißt und sie in Shakespeares weites, wechselndes Schlachtfeld stellt, wird es deutlich, trotzdem alle Masse fehlt und von Gefechten nichts crscheint. ${ }^{21}$ ) Wie er auf der anderen Scite der Tradition, die sein

17) Jördens 1. 205: Sauer, Brawe S. 6.

18) Vgl. auch den Schlachibericht IV, 2 (Tribun):

Die Taptersten entflichn. Nur Brutus steht.

An diesern Tag ein Halbgott, nicht ein Mensch.

-..........

Aul dem Gefilde voller Tod allein

Und unbesiegt steht Brutus; wider ihn

Gerüstet eine W'elt...

Dazu vgl. Shakespeare I Heinrich IV: V. 1: „Sie bieten einer Welt in Waffen Trotz", und S chiller Jungtrau I, 10: "Nicht eine Welt in Waffen fürchten wir"; für das kraftvolle ,steht Brutus" Räuber 11. 1: .Fünt Regimenter muBien neben ihen wechseln, er stand. Feuerkugeln fielen rechis und links. Euer Sohn stand" usw.

19) Souer. Brawe S. 73. Das dem Brutus in englischer Sprache vorangesetzte Motto aus Popes Prolog zu Addisons Stück spricht schon dafür.

20) Saver S. 70-76. Minor DNL 72, 206.

2) Bei der einzigen Wiener Auffühnung von 1770 (Devrien t² 237) wurde denn auch zum mindesten der SchluB in Freien gespiclt. Sonnenfels gibt die Aufstellung des Heeres 
Stück in allem Außeren regiert, noch dienstbar ist, zeigt seine Motivierung des Ausgangs der philippischen Schlacht, verglichen mit derjenigen Shakespeares. Den vordeutenden Traum des Brutus, Cäsars Erscheinung, entnehmen beide der Überlieferung. ${ }^{22}$ ) Shakespeare gibt ihn körperhaft (IV, 3), Brawe läßt ihn erzählen (I, 2). Für Shakespeare ist mit der grandiosen Stimmungsszene, die durch eine trübe Ahnung des Cassius kurz vor dem Kampf noch vertieft wird, die Schlacht so gut wie entschieden. Sie muB nach diesen schicksalsmäßigen Vorklängen verloren gehen, und der Dichter bemüht sich nicht weiter um eine äußere Begründung ihres Verlaufs. Wohl aber gestaltet er sie breit und reich um ihrer selbst willen. Brawe hingegen gibt die Motivierung im Sachlichen: Marcius geht mit seinen Truppen zum Feind über. Wie früher bei Schlegel, so herrscht auch hier noch die Intrige. Das Kampfereignis ist noch immer Teil von ihr, Mittel zum Zwecke einer bestimmten Handlung, das heißt Intrigenführung, noch nicht selbst Zweck, und demnach - denn das ist die innere Begründung der Technik - auch noch nicht selbst Handlung, sondern immer wieder nur Bericht. Das neuartige Erleben des Kampfes, hier und dort durchbrechend, ist noch nicht formbestimmend geworden. Der Abstand zwischen der beschwingten Kampfdiktion und der nachhinkenden Kampftechnik wird um so augenfälliger, als das neue Wort auch die neue Tat verlangte.

Die Motivierungen des ersten, traditionell gebauten Schlachtaktes ${ }^{23}$ ) sind zwar besser als die hergebrachten; der Kampfbericht läßt alle Vorgänger hinter sich; der Dichter weiß den Vorteil, den die verlorenen Schlachten vor den gewonnenen auf dem Theater haben, in dem Auftritt des zusammenbrechenden Brutus ${ }^{24}$ ) zu nützen. Es verdrießt aber nach der bewegten Szenenreihe doppelt, wenn nun das Intrigenstück wieder in sein Recht tritt, statt $\mathrm{da} B$ die Handlung in einem Zuge zur Katastrophe geführt würde, wie es die Lage fordert. Während die Truppen auf Leben und Tod fechten, nimmt sich der General Zeit, im Zelt seinen Familienhändeln breitspurig nachzugehen. ${ }^{25}$ )

dazu an, die mit wenigen Statisten eine große Menge vortäuschte: Über die Vorstellung des Brutus, 1770; Gesammelte Schriften, Wien 1783-87, 9, 81 .

$\left.{ }^{22}\right)$ Plutarch, Leben Caesars, cap. 69; Leben Brutus', cap. 36.

${ }^{23}$ ) IV; Besorgnisszene - Meldeszene; die erste, sonst den Frauen gehörend, in dieser Männertragödie von einem greisen Senator bestritten.

24) IV, 4; die Situation ist derjenigen des geschlagenen Antonius bei Shakespeare (Antonius und Cleopatra III, 9) verwandt.

2i) ,So möchte ich es fast dem Brutus für Feigheit auslegen, daß er sich, sobald es etwen unglücklich geht, sich in sein Zelt zurückzieht, hier eine Zeitlang schwatzt, und sich dann wie ein Verzweifelnder in die Schlacht und endlich in sein Schwert stürzt", rügt schon Chr. H. Schmid, Biographie der Dichter 1, 146. 


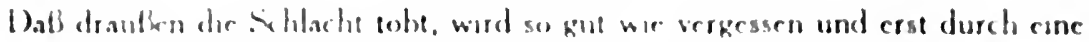

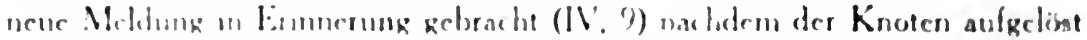

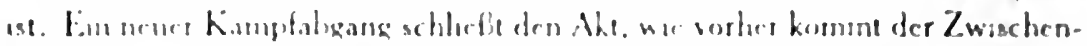

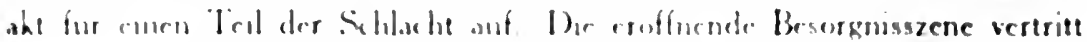
dann run Verewriflungesmenolog won Brutus verrateruschem Sohn. der im

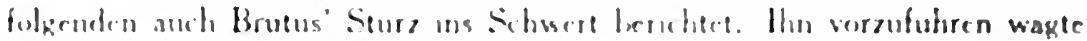
Brawe nexh niche. Er ladit den Todwunden nat des Weise Costecheds hercin-

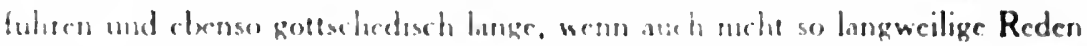

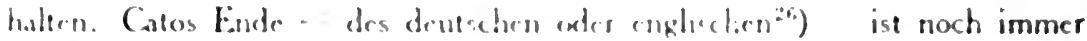
vorbildlich.

Brawe golt der leteraturgestheher als Shiuler Leesonges schlechthin, und der Brutus word beanders eng an das lessingisahe Kicomis-Frapment an-

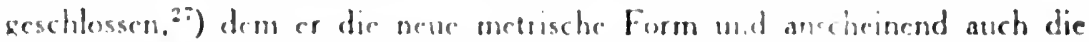

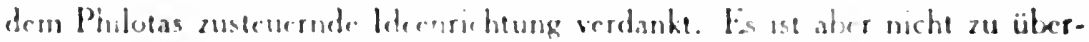

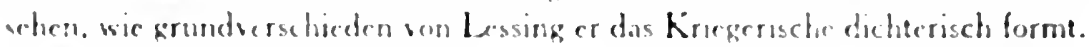
Ferade das Enewicklungsstarke in seiner Arffassusg kesunte er dern Meister usche aldermen. Der lmpetus sciner Kampfrede, die sich weitatmig in breitem Chwong ersiete. hat mit der besonnenen. Kargen und kurzangebundenen Doktion Lessings gerade im Kleonnis mur wenig zu tun. Die darin offenbare

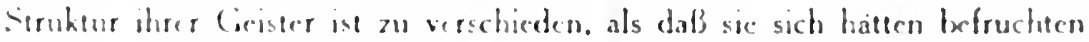
komnen. I monngs ganze Produktion liegt in der stengen Schlichetheit ihrer Formgebung vor uns. Die Betracheung der Kampllehandlung darin erweist

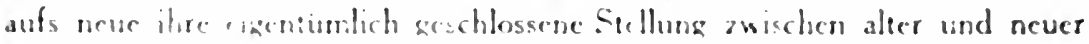
Klassik. Von Brawe haten wir nur einen Anlang. Man möchee aber allein nach sciner vorwates deutenden Kampiauffassum: urmules. dab sich sein poetisches Temperament. wenn er gelebt hatke, der jungen Generation angeschlossen haben wurde, au der ihn sein Cieburtsdamm hall, schon stelle.

Auf der anderen Site ist freilich die Erscheinung Brawes ohne den kritiechen lorgang Lessings niche an denken. Er wie die panze Entwicklung der

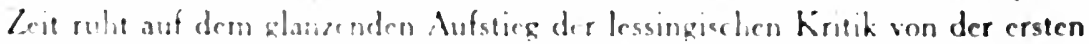

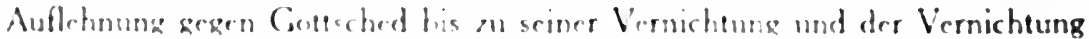

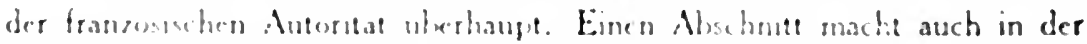
Cocechube des Kamplproblems der denkwisdige 17. Literaturbrief vorn Februar 1759. Mit coner dem uncrbetlichen Systematiker senst niche eigenen. fast herebresch anmutenden Finsicht in die natomale Bedingtheit der Kunst rehe t !rsong in ihm das R-formwerk Colferheds durch dic Erklarung. .edat) wir metir in den (irsh huzack der Englander als der Fianzosen cinschlager".

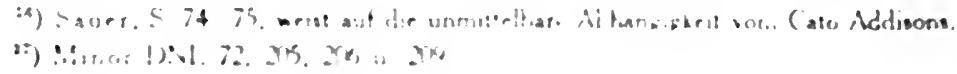


und proklamiert das erlösende Wort: „daß wir in unsern Trauerspielen mehr sehen und denken wollen, als uns das furchtsame französische Trauerspiel zu sehen und zu denken gibt" ${ }^{28}$ ) An dem Mehr-Sehenwollen ist die Kampfdarstellung in vorderster Linie interessiert. $\mathrm{DaB}$ man mit einer solchen Auslegung die Äußerung nicht preßt, beweist ein letzter ohnmächtiger Vorstoß der Gottsched-Partei in den „Briefen die Einführung des englischen Geschmacks in Schauspielen betreffend. "29) Neben der Verspottung von Lessings FaustFragment werden hier im 2. Brief zur Verhöhnung der neuen Richtung Stücke aufgezählt, die recht shakespearisch, englisch und wild geraten seien, darunter: „Die Zerstörung Jerusalems, tragisch, mit Harlekins Lustbarkeiten. Hier tummeln sich die idumäischen und römischen Husaren brav herum ${ }^{30}$ ) eine hungrige Mutter frißt vor den Zuschauern ihr eigen Kind, ${ }^{31}$ ) und unter einem entsetzlichen Feuer aus groben und kleinem Geschütze singen die Juden: Wenn wir in höchsten Nöten sein“. Der hoffnungsvolle Kandidat aus Herrn Niemands [Lessings] Schule erfindet etwas eigenes, indem er den ganzen Milton dramatisiert, und „dies Stück hebt sich an vor Erschaffung der Welt, mit dem Falle Satans und seiner Engel; mit der himmlischen Schlacht, die sie in die Hölle stürzet". Man schob also Lessing in die Schuhe, daß seine Forderung solche Dinge - mögen sie immerhin parodistisch übertrieben sein - in sich schlösse, und zeigte zugleich, daß man Kämpfe in der Theorie noch immer zu den größten Sünden gegen die Regelmäßigkeit rechnete.

28) Schriften 8, 42.

29) Mit dem Untertitel: ,wo zugleich auf den XVII. der Briefe die neue Litteratur betreffend, geantwortet wird". Frankfurt u. Leipzig 1760. Die Schrift war mir nicht zugänglich, doch ist der Auszug in "Das Neueste“" usw. 1759. S. 916-23 (die im folgenden zitierten Stellen auf S. 920-21), den Koberstein ${ }^{5}$ 5, 309 Cottsched selbst zuweist, ausreichend. Über die Verfasserschaft, woran der ganze gottschedische Kreis teil hat, vgl. die Venweise bei HolzmannBohatta 1, 262, Nr. 7604; Waniek S. 335 Anm. u. 633-34. Der Hinweis Chr. H. Schmids, Chronol. S. 134, auf Joh. Gottfr. Gellius -ist in seiner Bibliographie deutscher dramaturg. Schriften (Deutsche Monatsschrift 1794, 1, 93 ff.) unter Nr. 48 wiederholt; die Teilnahme Gellius' an den "Briefen" wird aber weder bei Meuse 1, Lex. 4, 79-82, noch $\mathrm{GGr}^{2} 4,213$ verzeichnet. Eingehend erörtert die Verfasserfrage dieser "Briefe“ auch W'. Creize nach, Versuch einer Geschichte des Volksschauspiels vom Doktor Faust, Halle 1878, S. 77 Anm. 1).

30) „Nur Ifflande und Kotzebue mit Landwehr und Landsturm, oder verdünnte und verdummte Schiller mit marschierendem Militär und sprengenden Kosaken" hatte Bren ta no ein halbes Jahrhundert später in einer Überschau über die patriotischen Schauspiele wirklich zu Hagen; Dramaturgischer Beobachter, Wien 1814, abgedruckt bei Monty Ja cobs, Deutsche Schauspielkunst, Leipzig 1913, S. 191.

31) Der Anklang an Horazens Mahnung, De arte poetica v. 185, Nec pueros coram populo Medea trucidet, ist deutlich. 
Das Werk Lessings, das nahezu gleichzeitig mit der ersten Reihe der Literaturbriefe entstand, ist der Philotas (1759). Der Mann, der die Franzosen durch die Engländer stürzt, den die Feinde als Apostel der wüsten Formzerstörung kreuzigen, schreibt diesen denkbar strengen Einakter, auf den am chesten das Wort Herders von der antiken Simplizität paßt. Es ist durchaus kein Werk des Ubergangs, sondern, in merkwürdigem Gegensatz etwa zu Schlegel, eine stilreine Leistung in klassizistischen Formen, womit sich Lessings so gebildeter Geist in einer vorwärtsdrängenden Zeit eigenrichtig behauptet. Der Stoff hätte zur Entfaltung theatralischen Apparates, zu Kämpfen und Aufzügen Anlaß genug gegeben. ${ }^{32}$ ) Was aber Gottsched dunkel vorgeschwebt haben mochte, als er sich aus dem Wust der entarteten deutschen Dramatik in die französische Regelstrenge hinüberrettete, was seiner und seiner Getreuen Unfähigkeit aber unerreichbar war, ist hier unter unmittelbarer Einwirkung der Antike Ereignis geworden: Genaueste Beschränkung in allem Äußern; Abwandlung der Konflikte nur im Scelischen; daher Einsetzen kurz vor der Lösung, wenn alle Prämissen schon vorliegen. Es ist nicht daran zu denken, da $B$ in dem kargen Raum dieser wenigen Szenen der Kampf, worin Philotas gefangen wird, als das Ereignis a quo hätte vorgeführt werden können. Lessings Drama wurzelt überhaupt mehr als in der Aktion im Wort. In ihm gibt er sich ganz aus, und seine Schlachten werden nicht körperhaft auf der Bühne, sondern in der Dialektik seiner Sprache geschlagen.

Es ist bei Elias Schlegel darauf hingewiesen worden, daß Lessing die Kampfvergegenwärtigung in hypothetischer Form zur Meisterschaft ausbildet Das bewundernswerteste Stück dieser Art findet sich in dem Vorläufer zu Philotas, dem Klconnis-Fragment (I, 2). Die ficbernde Angst des Königs um seinen in den Kampf gezogenen Sohn gebiert hier eine körperhafte Vision des in Gefahr Fechtenden, dem der Vater Hieb und Parade angibt, als ob er im Getümmel neben ihm stünde. ${ }^{33}$ ) Der Philotas zeigt in anderer Situation etwas durchaus Ähnliches. Der junge Held steigert sich selbst in die Illusion des Gefechtes hinein (8. Auftritt), mit dem gedoppelten Zweck, den König und Strato über sein Vorhaben zu täuschen und selbst im Rausche der Begeisterung den Mut zur Ausführung des Todesentschlusses zu finden. Auch hier bewältigt Lessing den Kampf durch das Wort und verschmäht eine

33) Erich Schmids, Lessing 21,351 spricht von der naheliegenden Aufforderung zu Massenszenen im Lager. Die haltlose Kombination A. Böhtlingks (Shakespeare und unsere Klassiker 1. Lessing und Shakespeare, Leipzig 1909. S. 50 f.), die slrenge Formgebung beruhe auf Lessings Absicht, das Stück Friedrich dem Croßen als Mahnwort mundgerecht zu machen. bedart keiner Widerlegung.

23) E. Schmidı "1, 346 zählt diese Fieberphantasie des Euphaes zum Besten, was Lessing überhaupt geschaffen. 
naheliegende reale Erneuerung der Gefechtssituation, indem sich Philotas etwa auf den König stürzen und von Stratos oder anderer Gefolgsmänner Streichen fallen könnte. Eine solche Möglichkeit wird mit größter Zurückhaltung dadurch leise angedeutet, daß Strato, als Philotas das Schwert zieht, zwischen ihn und den König tritt.

In so gemessene Form ist hier der Niederschlag der gleichen Zeitereignisse gefaßt worden, die bei Brawe stürmisch am engen Regelrock rütteln. Was im Philotas von friderizianischen Kriegen steckt, ist der Geist, der Führer und Truppen trieb. Antiker Gesinnung verwandt, ließ er sich ohne Zwang in antikes Gewand kleiden. In diesem Sinn kann das Werk ,kriegatmend“ heißen, ${ }^{34}$ ) obwohl vom Toben der Schlacht darin nichts zu hören ist. Dem wirklichen Krieg abgelauscht ist übrigens mancher frische Einzelzug: die Spannung, mit der Philotas hinter jedem Hügel und hinter jeder Krümmung des Tals den Feind vermutet, konnte Kleist dem Freund als Erlebnis eines Patrouillenrittes heimgebracht haben.

So wichtig der Siebenjährige Krieg für die Entwicklung der deutschen Literatur im ganzen geworden ist, so gering sind doch seine unmittelbar augenfälligen Wirkungen gewesen. ${ }^{35}$ ) Die Tragödie insbesondere steht dabei an letzter Stelle. Der Philotas war nur eine dramatische Kleinigkeit. Brawes Brutus trat überhaupt erst nach einem Jahrzehnt ans Licht und erlebte eine einzige, späte Aufführung. Der Höhepunkt der Wirkung des Krieges auf das Drama, ${ }^{36}$ ) die „Minna von Barnhelm“, liegt auf bürgerlichem Gebiet. Der tragische Autor, der das Jahrzehnt von 1760-70 - worin Wielands Shakespeare erscheint - beherrscht, Christian Felix Weiße, ist ein Mitläufer, in dessen Stücken das Erlebnis der Zeit keinen Widerhall findet. Er schreibt bis in die sechziger Jahre hinein Alexandrinertragödien, die wie in allem anderen so auch in ihrer Kampfbehandlung völlig den gottschedischen Status zeigen und als letzter Verfall seiner Schule aufzufassen sind. ${ }^{37}$ ) Die Häufung von Greueln, welche die Wirkung um jeden Preis sichern sollen, erreicht hier ihren Gipfel. Von den Engländern nimmt er sich höchstens den Freibrief dazu. So schwelgt „Richard III.“" ${ }^{\text {" }) ~ i n ~ d e n ~ S c h e u ß l i c h k e i t e n ~ d e s ~}$

34) Gervinus ${ }^{5} 4,417$.

${ }^{35}$ ) Cervinus 5 4, 244 nennt es einen Spott, daß er nichts Wichtigeres als die Bardendichtung hervorgerufen habe - wobei deren ursächlicher Zusammenhang mit dern Krieg erst noch in Frage steht.

$\left.{ }^{36}\right)$ Wilhelm Scherer, Gesch. der deutschen Literatur ${ }^{12}$, S. 449. Stockmayer S. 3.

37) Beytrag zum deutschen Theater, 5 Bde., Leipzig 1759-68; vgl. Bélouin, De Cottsched - Lessing, Paris 1909, S. $147 \mathrm{ff}$.

38) Beytrag usw. 1. Teil, 1759; Neudruck von Minor DNL 72; umgearbeitet in der 2. Auf- 
Prinzenmordes, der im vièrten Akt hinten peinvoll umständlich vorgenommen wird, während Mutter und Schwester vorne zittern. Damit nicht genug. füllt die Erzählung des Verbrechens in widerlicher Ausführlichkeit noch den letzten Akt. Die Kampthandlung, Richmonds Anrücken und Sieg, Richards Tod, wird in der hergebrachten Weise durch Meldungen gegeben, ebenso ein leicht vorzuführender Tumult in „Krispus": dessen Uberwältigung durch die Wache III, 6. Zu erwähnen ist nur, daß hier (IV, I) wie in ,Mustapha und Zeangir" ${ }^{39}$ ) ein stummes Kricgsgefolge als stehende Einrichtung erscheint, schüchterne Vorbereitung der künftigen Massentechnik, wie schon bei Schönaich und Cronegk. Im letztgenannten Stück wagt der Sultan in komischer Ängstlichkeit nicht anders umherzugehen, als von einer Wache mit gezückten Schwertern ungeben, die hin und wieder in Aktion treten muß.

Wie sehr auch die folgenden zwei, äußerlich fortschrittlichen weil jambischen Stücke in der Tradition stecken, ${ }^{10}$ ) kann die ,Befreiung Thebens" ${ }^{(41}$ ) zeigen. Auch hier, wie so oft in der Gottschedschule, ein Verschwörungsund Kampfstoff in das Schema ciner Familientragödie gezwängt, die durch lange Frauenszenen kümmerlich genug auf vier Akte gestreckt, das politische Ereignis bis zum fünften zurückdrängt. Hier sollen dic Unterdrücker beim üppigen Gelage von den Verschwörem, die sich als Jungfrauen verkleiden wollen, niedergemacht werden, zu welchem Ende Weiße den Ort verändert. Dem rauschenden Ensemble cines Piccolomini-Gastmahls steht man aber noch fern; auch diese zu breiter Entfaltung lockende Aktion wird in eine dünne Szene zu zweien eingefangen, in die nur der Lärm der befreienden Tat dringt. Erst die Sieger zeigen sich und enteilen zu dem schwereren Stück Arbeit: dem Kampf um die Stadt. Wieder stellt sich dic Unzuträglichkeit französischer Technik ein; Männcr sind in dieser Situation, die alle Fäuste nötig hat, nur mit kläglicher Motivierung auf der Bühne zu halten. Kampf und Sieg werden dann V, 6 nicht ungeschickt, aber in der alten Weise ohne rechte Anteilnahme des unkriegerischen Autors in geschraubten Bildern berichtet. Noch eine Kleinigkeit ist hervorzuheben: V, 4 geht Aspasia an die innere Türe des Zimmers und schildert zurückkommend den Anblick der ermordeten Prasser ein eister Ansatz zur Bcobachtung hinten vorgehender Dinge von der Bühne aus, ein Mittel, das für dic Kampftechnik soglcich bedeutend wird.

Lage des Beytrags 1. Teil. 1765; diese Ausgabe neugedruckt von D. Jacoby und A. Saver DLD 130. Zugrunde liegt die ursprïngliche Fassung.

29) I. 3; 11. 3; V. 1-3. Ḱrispus im Beytrag 3. Teil, 1764: Mustapha im 2. Teil, 1763.

10) Vgl. Minor DNL 72, XVIII, wo das Hergebrachte stärker belont ist als in seiner Monographie Chr. F. WeiBc, Innsbruck 1880, S. 225-30.

4) Beytrag 3. Teil, 1764. 
Die weiteren Stücke Weißes interessieren hier nicht mehr. Der durchgehenden Umwendung ins bürgerliche Drama, die Shakespeares „Romeo und Julia“ unter seinen Händen erfahren mußte, fielen auch die vorkommenden Kämpfe zum Opfer. Sie werden erzählt soweit sie unentbehrlich sind.

Im ganzen würde man von dem Verfasser der "Amazonenlieder“, die immerhin einige frischere Töne treffen, auch im Drama mehr Organ für das Kriegerische erwarten; daß er sich aber darin selbst von Shakespeare nicht aus der Enge der Überlieferung befreien läßt, beweist auch für jene, daß sie nicht aus lebendigem Empfinden geschöpft, sondern nur aus literarischer Anregung gemacht sind. Träger der Entwicklung ist der stets der Anlehnung bedürftige Weiße, der es zu einer eigenen Form nie gebracht hat, nicht gewesen. 


\section{Drittes Kapitel. \\ Klopstocks Hermanns Schlacht.}

Der Ruhm, den Deutschen das erste wahrhaft kriegerische Schlachtstück gegeben zu haben, gebührt einem Manne, dessen Leistungen auf dramatischem Feld gern in Bausch und Bogen verworfen oder wenigstens über die Achsel angeschen werden. Klopstocks Hermanns Schlacht, 1769 gedruckt $^{1}$ ) ist die eigentliche, spätgereifte Frucht der friderizianischen Schlachten, das entscheidende kriegsdramatische Werk an der Schwelle des Sturm und Drangs. Seit Schillers vernichtendem Urteil $^{2}$ ) viel gescholten, tritt der Bardiet, den die Intention des Dichters ausdrücklich „für die Schaubühne“" bestimmtc, ${ }^{3}$ ) trotz allem was gegen ihn cinzuwenden ist, als überraschend neuartiger und fördernder Versuch zur Lösung des Schlachtproblems in die Entwicklung.

Was bei Schlegel vorschwebte, sich aber dem Intrigendrama gegenüber nicht durchzusctzen vermochte, die Schlacht als solche zum Thema und Ziel des Dramas zu machen, ist hier in einem bis auf Grabbe singulären Fall Tatsache geworden. Klopstock gibe weder eine Tragödie, in der die Schlacht Katastrophe, noch ein Schauspiel, worin sie wie bei Schlegel krönende Tat einer Befreiungshandlung wäre; um sie allein ist es ihm zu tun, er verherrlicht den Teutoburger Kampf und wählt dazu die dramatische Form. Sein Bardiet könnte als Festspiel zu einer Jahrhundertfeier von Arminius' Sieg geschrieben sein; so, als Schlachtfcier, ist cr zu würdigen. Der besondere Kunstwille schuf sich ein besonderes Gewand. Die Zeit bot noch immer das französische, das Klopstock bereits in mehreren Dramen ohne Glück getragen hatte. Die Art, wic er es jetzt für dic Schlachtaufgabe umkrempelt, ist entwicklungsgeschichtlich sehr bedeutsam.

Seiner lyrischen Natur ist die Schlacht mehr Zustand als Aktion - womit

1) Hamburg und Bremen 1769. Hrsg. von R. Hamel. DNL Bd. 48.

$\left.{ }^{2}\right)$ An Goelhe 20. Mai 1803.

3) Wenn wir dies nicht aus dem Titel und sonst (Muncker, Klopstock, S. 403) wüBten. würde es das Werk selbst in einern bezeichnenden Zug verraten: im Lanzentanz Sz. 3, wo das szenisch schwer durchzuführende Lanzenwerfen vermieden und die Vermeidung motivien wird. Als cine Schwierigkejt für die Aufführung, die bis zur Vollendung durchgeprobt werden soll, hebt Cleim (An Klopstock 26. März 1769, abgedruck। DNL, 48. 30) diesen Lanzentanz ausdrücklich hervor. 
dem dramatischen Leben des Werks freilich das Urteil schon gesprochen ist. Handlung verschmäht er so sehr, daß er als einziger von den Bearbeitern des Stoffs alle Prämissen des Freiheitskampfes beiseite wirft. Andere Lösungen gewinnen aus deren Aufbau und Steigerung ihre besten Wirkungen, ${ }^{4}$ ) er setzt in kühner Weise mitten in der Schlacht selbst ein und bleibt ihre Begründung schuldig. Ein solches Verfahren spricht aller formstrengen Kunstübung Hohn und bedeutet, wie die Erhebung der Schlacht zum ausschließlichen Inhalt, die stärkste Absage an die französische Tradition. Ihr ist ein Drama ohne streng abgesetzte Teile, deren jeder seine feste Bestimmung zugewiesen erhält, undenkbar. Klopstock unterschlägt die Exposition und zieht auch die andere Konsequenz: er gibt die Akteinteilung auf und bewegt sich frei in einer ungegliederten Reihe von Szenen. Daß Ort- und Zeiteinheit festgehalten werden, stellte ihn dagegen wieder in die Tradition, wenn es nicht aus der festspielmäßigen Grundrichtung des Stücks fast notwendig hervorginge, worin wiederum Klopstocks lyrisches $T \in$ mperament wirks $a m$ ist. Shakespeares Schlachten sind nach dem Prinzip des Wechsels gebaut, die Hermannsschlacht Klopstocks nach dem des Beharrens; wie in Ort und Zeit, so auch in Rücksicht der Partei: nur die germanische Seite bestreitet die Handlung, Römer treten erst als Gefangene auf. Der Lyriker löst die Aufgabe von der Stimmung aus, wie sie der Brite von der Aktion und Schlegel mit den Franzosen von der Intrige aus gelöst hatte. Es zeigt den ganzen Unverstand des Bearbeiters, der das Stück nach anderthalb Jahrzehnten für das Theater retten wollte, ${ }^{5}$ ) $\mathrm{da} B$ er der Sache genug zu tun glaubte, wenn er die Bardenchöre strich. Sie sind nichts mehr und nichts weniger als das Formprinzip dieses SchlachtOratoriums, ${ }^{6}$ ) und so unmöglich sie von der Bühne herab sein mögen, das Werk fält ohne sie ohnmächtig zusammen.

Es war ein geistvoller Einfall Klopstocks, auf alle illusionistische Darstellung der hinten vorgehenden Schlacht zu verzichten und dafür dieses Schlachtorchester auf die Bühne zu stellen. Er gewinnt damit einen für die festgehaltene französische Technik unschätzbaren Vorteil, der seine Anlage überhaupt erst möglich macht: Barden und Druiden sind ihr unverrückbarer Mittelpunkt und zugleich der wirkende Gegenpol der rückwärtigen Aktion, die, wie wir mehrfach gesehen haben, die Figuren mit magnetischer Kraft von der Bühne abzuziehen pflegt. Durch Klopstocks Anordnung erhält die sichtbare Szene

4) Vgl. Muncker S. 395-96.

$\left.{ }^{5}\right)$ Joh. Gottfried Dyk, Hermanns Schlacht. Ein heroisches Schauspiel in drey Akten. Das berühmte Bardiet des Herm Klopstock für die Bühne eingerichtet. Leipzig, Dyk, 1784.

6) Schon der Rezensent der Allg. deutschen Bibl. (Bd. 12, II, S. 26) fand, daB neben anderm „der Unstand, daB Siegmar den Barden auf einem Felsen ihre Stelle anweist . . . dem Gedichte gleichsam die Einheit des Orts, und seine ganze Form mitgeteilt" habe. 
cine dauernde, nachdrückliche Besetzung, woran sich die wechselnden Personen schließen können.

Die innere Bedeutung der Barden ist, daß in ihren Gesängen das ganze Schlachtgeschehen beschlossen liegt. Der Lyriker Klopstock hat kein Verlangen Getünmel vorzuführen und fügt sich hier wie von selbst in die französische Regel, die für Schlegel cine Fessel gewesen war. Seine Schlacht tobt in den Chören aus, deren Empfindungsgehalt durch überreich eingefügte Stimmungsszenen aufgenommen wird. Ihrer unseligen Breite gegenüber ist das, was man an Schlacht a ktion vermittelt erhält, fast spärlich. Dennoch hat gerade hier Klopstock für dic Entwicklung das Beste geleistet: er führt der Kampftechnik mit cinem Schlage eins ihrer von nun an wichtigsten Mittel, die Beobachtung, zu.

Durch sie wird die Schlachtgestaltung auf einmal aus ihrer überlieferten Enge befreit. Jetzt war man imstande, die Aktion aus der Vergangenheit, worin die Berichttechnik sie festgchalten hatte, in die Gegenwart zu versetzen, nach welcher die Bühne so dringend verlangt. Die Teichoskopie setzt neben das acta refertur cine neue Möglichkcit, eine außenstehende Handlung dem Zuschauer zu vermitteln: die Mitteilung während sie geschieht, ein dum agitur. refertur. Alle Versuche innerhalb der alten Form konnten der Gegenwartsforderung nur nahekommen, keiner sic erfüllen. Man löste den cinen großen Bericht der französischen Klassiker nach vollendeter Handlung in kurze Teilberichte bei währender Handlung auf: es konnte schließlich doch nur Geschehenes erzählt werden; man versuchte es mit Schilderung des unsichtbar vorgehenden Kampfes in hypothetischer Redeform, das Mittel blieb auf wenige Fälle beschränkt. Von da zur Beobachtung war nur noch cin kleiner Schritt. Die optische Bzzichung zwischen dem Sprechenden und den Vorgängen muBte geschaffen werden, er mußte sie sehen. Damit gewann man ganz neue Darstellungsmöglichkeiten und einen mächtigen Anreiz für die Phantasie des Zuschauers. Das Ziel war fürderhin, die Beobachtungen so zu gestalten, daB dieser die Dinge mit eigenen Augen zu sehen vermeinte.

In der scheinbar rein technischen Angelegenheit liegt cine wichtige Wandlung im Wesen des Dramas beschlossen. Man kam aus den französischen vier Wänden in die Weite der Schlachtfelder, von einem halben Dutzend sichtbarer und greifbarer Figuren zu unbestimmbaren, nur noch in der Phantasic zu umfassenden Massen. man wandte sich im cinzelnen wie im ganzen vom $\mathrm{Be}$ grenzten ins Unbegrenzte, vom Rationalen ins Illusionäre. Es ist mit einem Wort die Wendung zum Sturm und Drang. Klopstock ist als ihr Angelpunkt für die Lyrik erkannt. ${ }^{7}$ ) er greift aber auch schr bedeutend in die Entwicklung des Dramas ein. Zum kommenden Geschlecht stellt ihn schon sein Verhältnis.

7) W. Scherer" S. 426. 
oder besser Mißverhältnis zur Bühne. Die ganze Zeit des Rationalismus von Gottsched bis auf Weiße nahm in ihrer Produktion die allerängstlichste Rücksicht auf Aufführbarkeit. Keine Frauenrolle wurde geschrieben, für die eine Besetzung nicht schon vorhanden war, kein Statist gefordert, der in den Listen der Theater nicht bereits geführt wurde. Klopstock ist der erste, der, den Spieß umdrehend, dem Theater Aufgaben stellt, und darin durchaus der Eröffner der Geniezeit, daß er, ohne mit der vorhandenen Bühnentechnik zu rechnen, ein eigenwilliges Werk bildet. Sofern er dabei immergültige Gesetze der dramatischen Form zum eigenen Schaden verletzt, ist er der Vater aller neueren Buchdramatiker geworden, derjenige, der die von Gottsched mühevoll geschaffene Verbindung von Literatur und Bühne wiederum zerriß, aber doch auch der erste frei schaffende Künstler nach einer Zeit des Mecharisierens der Poesie. Das erklärt mit die Wirkung, welche Hermanns Schlacht ausübte ohne je aufgeführt zu sein.

Eins wird für uns vor allem wichtig: die neue Raumvorstellung. Die Cottschedischen kannten nichts anderes als das Ceviert der Schaubühne. Klopstock entdeckt für das deutsche Drama das Lokal. ${ }^{8}$ ) Ein neuer entscheidender Schritt von den Franzosen weg ist damit getan. Corneille war dazu gekommen, von jeder Bestimmung des Lokals überhaupt abzuraten. ${ }^{9}$ ) Noch in Lessings Nathan wird von Palmen wohl gesprochen, aber man atmet ihre Luft nicht. ${ }^{10}$ ) Auch hier ruht das Interesse noch, wie in der französischen Tragödie, auf den personnages. Klopstock geht als erster von der Einzelpersönlichkeit in das Grenzenlose des Naturganzen. Er hat einen neuen Sinn für die Außenwelt des Dramas, wenn er auch an dem einheitlichen Ort festhält; dieser ist ihm nicht die Bühne, sondern die naturhafte Wirklichkeit selbst. Die berauschende Entdeckung, die die Theorie an Shakespeare zu machen im Begriff war, nimmt er als Schaffender voraus. Was er als Lyriker für die Ausbildung des Naturgefühls getan hatte, trägt im Bardiet reiche Früchte. Die Gottschedschule hatte für Schlachtfelder keinen Blick. Ein Bild der Örtlichkeiten, wo gefochten wird, erhält man nie. Matt und allgemein gehalten ist selbst der Hain Schlegels, des einzigen, der Ansätze zur Naturpoesie zeigt. Klopstock jedoch vergegenwärtigt das Lokal zur Greifbarkeit ${ }^{11}$ ) und entwickelt Gelände und Gefechtsaktion, unzertrennlich wie sie für die Taktik sind, eins durch das andere.

8) Knapp vor ihm erfaßt Cersienberg im ,Ugolino“ (1768) aus verwandter Anschauung heraus ein allerdings eng begrenztes, bühnenmäßiges Lokal, den Hungerturm, mit allen grauenvollen Besonderheiten seiner Erscheinung.

9) Discours des trois unités, Guvres 1, 120; Discours de la tragédie, Euvres 1. 96; vgl. Petersen S. $79 \mathrm{ff}$.

10) Gundolf, Shakespeare unủ der deutsche Geist, S. 145.

11) Vgl. Muncker S. 392. 
Merkwürdig, wie das technische Mittel gleich zur Hand ist, dem neuen dichterischen Gehalt Ausdruck zu schaffen. Nur die Verwendung der Beobachtung gibt dic Möglichkeit, das Lokalgefühl bei festgchaltener Ortseinheit dramatisch auszumünzen. Die Art, wie es geschicht, setzt aber nicht nur ein neuartiges Empfinden für den Boden, worauf gekämpft wird, sondem auch für die Fechtenden selbst voraus. Das hohle, übersteigerte Kricgsgelärm der von Gerstenberg und Klopstock ausgehenden Bardendichtung in einer durchaus friedlichen Zeit ist verdientem Spott anheimgefallen. Die Schlachtpoesien Klopstocks selbst aber erwachsen aus einem ticfen Verhälenis zu Kampf und Waffentat. Das Kriegslied von 1749 allein wäre dafür Zcugnis genug; vollends die Bardenstrophen in Hermanns Schlacht quellen aus cinem starken Erleben des Kriegerischen von seinen Stimmungswerten aus. Daneben überrascht die nahe Vertrautheit mit den kleinen und kleinsten Vorgängen des Gefechts, die nur durch übermäßig herausgestellte kriegshistorische Gclehrsamkeit und das seltsam gespreizte Germanenwesen, einen letzten Ableger gottschedischen Heldentums, zu stark belastet wird. So genauen Einblick in die Geschehnisse des Feldkriegs konnte Klopstock kaum allein aus Büchern gewinnen. Das muß Frucht der Zeiterfahrung, des Siebenjährigen Krieges sein, trotzdem ihn der Dichter zum geringsten Teil in der Heimat miterlebte und keine Zeichen besonderer Anteilnahme gab. ${ }^{12}$ ) Es stimmt zu dieser Annahme, daß Klopstock mit dem Gcdanken spielte, cinige preußische Bataillons, die sich in jenen Feldzügen besonders hervorgetan hätten, durch eine Aufführung des Bardiets zu belohnen, ${ }^{13}$ ) selbst also eine enge Beziehung zwischen Krieg und Werk sah.

Der technische Einfall, Vorgänge hinter der Szene durch Leute auf der Bühne wahmehmen und dem Zuschauer mitteilen zu lassen, scheint auf der Hand zu liegen. ${ }^{14}$ ) Dennoch hat ihn eine ganze Periode nicht gefunden, obwohl sie seiner für zahlrciche Schlachten sehr bedurft hätte. Es ist aber nicht der Bühnengriff, der in erster Linie in Frage steht, sondern der in ihm wirksame Formgrundsatz. Daß die Cottschedianer nicht beobachten lassen, ist allerdings ein neuer Beweis wie unselbständig sie im Technischen die Franzosen

12) Muncker S. 210.

15) An Ebert 14. Juli 1770. Lappenberg. Briefe von und an Klopstock, Braunschweig 1867. S. 229. In einem früheren Brief (An Ebert 18. Febr. 1769) versichert er, in alter Zeit wäre er hinter dem Fünten, dem der Freund den Bardiet vorlesen soll, in der Schlacht gewesen, und zwar nicht so sehr aus Bardenpflichl, als aus Neigung. $V_{8} l$. auch den enthusiastischen Brief Gleims (An Klopstock 26. Marz 1769. DNL 48, 30): .Ach, daB ich Kaiser, daB ich Kaiser wäre, diesen Bardiet aufführen zu lassen mit den Kosten des peloponuesischen Krieges, eine Million ใür die Probe!"

14) Lohmeyer S. 66 bemerkt zum ..Cö̈z". daR dieser Kunstgrift so naheliege, dab sogar Klopstock davon Gebrauch mache. 
kopieren. Diesen jedoch verbietet das klassische Kunstgesetz, das die Handlung mit strengem Rationalismus auf die sichtbare Szene beschränkt, sie ins Illusionäre weiterzuspinnen. Von hier aus wird es begreiflich, wie schwer, ja unmöglich es den unzweifelhaften Begabungen, einem Schlegel, einem Brawe fiel, das Joch zu ihrer Zeit abzuschütteln, wiewohl es ihnen an Helfern nicht gebrach.

Klopstock braucht die Teichoskopie im deutschen Drama als erster im großen Maßstab und sogleich mit Meisterschaft. In der ersten Szene und weiterhin hält Horst für den alten Siegmar, dessen stumpfgewordene Sinne den Dienst nicht mehr tun, Ausschau; was er sieht und hört teilt er dem Fürsten, meist durch Fragen aufgefordert, rasch und prägnant mit; nicht als etwas Fertiges in schöner Form dargeboten, wie es die spätere Klassik geben wird. nur als Stoff in den Dialog hereingeworfen, der es erst in Frage und Antwort zu einer Erkenntnis modelt. Oft gibt der Beobachter als einfacher Soldat nur die mit Auge und Ohr erhaschten Tatsachen. Die höhere Einsicht des Empfängers, des erfahrenen Führers, man möchte sagen des geschulten Offiziers, zieht aus ihnen die Schlüsse. Klopstock hat hier Feinheiten, die gewürdigt sein wollen. Trefflich die Beobachtung der römischen Reiterpatrouille zu Anfang, die zugleich exponierend die Stellung des Kattenheers ergibt, für das Gesagte charakteristisch, wie erst Siegmar die Flüchtlinge, die Horst zu Ende der ersten Szene sichtet, richtig als Patrouille der Legionen zur Wegerkundung feststellt. Dieses Eingehen auf die militärischen Dinge, wie es sich am besten an kleinen Zügen erweist, läßt einsehen, warum ein fürstlicher Heerführer ${ }^{15}$ ) sich für das Stück interessierte. Man ist hier zum erstenmal versucht, auf ein späteres Sinnbild enger Beziehungen zwischen Poeten und Martismännem hinzublicken: den Soldatendichter Schiller unter den Erfurter Offizieren. ${ }^{16}$ ) Über den Schlachten der Gottschedischen wird kaum ein Soldatenherz höher geschlagen haben.

Von besonderer Wichtigkeit ist ein anderes zeitgenössisches Zeugnis eines soldatischen Dichters über Hermanns Schlacht: Gerstenbergs Rezension in der Hamburgischen Neuen Zeitung. ${ }^{17}$ ) Während andere Besprechungen im allgemeinen loben, ${ }^{18}$ ) faßt hier ein Mann der neuen Generation den Stier bei den Hörnern. Er fühlt heraus, was das Neue, das Epochemachende an dem Kampfstück ist: die unmittelbare, packende Vergegenwärtigung der Schlacht.

15) Carl Wilhelm Ferdinand von Braunschweig, der Neffe Friedrichs des Großen. Muncker S. 403; vgl. Klopstocks Briefe an Ebert aus der ersten Zeit nach dem Erscheinen der Hermannsschlacht (Lappenberg S. 216, 219, 222, 224 f., 227).

16) Vgl. K. Berger, Schiller ${ }^{5} 2,645$.

17) 175.-178. Stück, 6.-10. Nov. 1769; hrsg. von O. Fischer DLD 128, Berlin 1904.

18) Allg. deutsche Bibl. Bd. 12, II, S. 24-32. 
Er hat als Erster gesehen, was die Entdeckung des Lokals gegenüber der französischen Verblasenheit heißen will. Er mißt Klopstock an den größten Mcistern und findet außer bei Shakespeare und den Griechen nirgends ein solches Muster, wie sich der Dichter in die Lage seiner Fabel ganz hineinzusetzen hat. .. Wenn inan z. E. folgende Stellen liest" (Gerstenherg druckt ein großes Stück der ersten Szene mit dem ersten der oben angeführten Beispicle ab), „so sicht man nicht allein die Schlacht mit allen ihren Lokalumständen in dem Geiste des Dichters gegenwärtig, sondern wir selbst, die Leser, finden uns mitten in sie hineingeriuckt." ${ }^{19}$ ) Gerstenberg erkennt weiterhin den Gewinn der alten schleppenden Berichttechnik gegenüber: „Das sind die großen verborgnen Schönheiten einer erfindungsreichen Exposition, wodurch sie Klarheit und Leben erhält; da ist kein Flickwerk von Erzehlung und ellenlanger Beschreibung: lauter kurze $Z$ üge, wie sic mit Nachdruck aus dem Gemälde hervorspringen, und die das Auge gerade über den Punkt hinführen. auf den alles ankömmt."

Auf die besondere Lagerung des Stoffes, dessen Tendenz er rühmt, geht Gerstenbergs freudige Anerkennung freilich nicht ein, so wenig wie auf die Schwierigkeit, das ganze Stück in dieser Weise zu bauen. Es ist klar, daß die Teichoskopie allein, die auch bei möglichster Umsetzung ins DialogischAktionelle am Ende doch nur ein schilderndes, ruhendes Element bleibt, dazu nicht ausreicht. Klopstock muß auf den Botenbericht zurückgreifen, dem er das minder Wichtige und alles, was einige Ausfïhrlichkeit verlangt, anvertraut. Neben sporadisch eintreffenden Meldungen nimmt er einen stehenden Berichterstatter (Kedmon) in seinen Sold. Die bedeutenden Wendungen der Schlacht bleiben aber durchaus der unmittelbareren Wahrnehmung von der Bühne aus aufbehalten.

Der Vorteil macht sich geltend, daß der Dichter jetzt über zwei Mittel. Bsobachtung und Brricht verfügt, die sich auf die mannigfaltigste Weise ablösen und stützen können. Im Eingang der dritten Szene meldet der früher auf Kundschaft geschickte Horst das Einschwenken der ersten römischen Kohorte ins Tal. In der nun folgenden Beobachtungsreihe erreicht Klopstocks ..geistige Phantasie" (Mendelssohn) zugleich mit gefechtsmäßiger Spannung eine staunenswerte Anschaulichkeit. „Kommen noch mehr Kohorten. Horst? - Noch einc kömmt sehr blutig und sehr langsam." Durch die knappste Fassung der Worte hindurch, die jede Silbe wägt, glaubt man zu sehen wie die Kohorten halten, um Manipeln gegen den flankierenden Wald anzusetzen.

19) Di.D 128, 282. Ähnlich faBr Chr. H. Schmid in Klotzens Bibliothek sein Lob zusemmen: ..Klopstock dichtet als wenn er selbst mitgefochten hälte." Deutsche Bibliothek von Klotz. Bd. 4. Halle 1770, S. 404: vgl. auch S. 431. 
Dadurch in der Bewegung freier geworden, rückt die Hauptkolonne, durch folgende, beim Halten auf sie aufmarschierte Abteilungen gedrängt, nunmehr mit drei Kohorten sichtbar, schneller vorwärts. Das mit Ungeduld erfragte Erscheinen des Adlers der ins Tal dringenden Legion in der Tiefe der Kolonne ist das Zeichen zum höchsten Moment: dem Kampfabgang Siegmars. Man sieht noch wie auf germanischer Seite die Katten sich langsam wie ein dicker Nebel in den Vorderbusch ziehen - dann setzt das Kampforchester mit mächtigem Getön ein.

Ein anderer großer Augenblick der Beobachtung ist die letzte Wendung der Schlacht zum Sieg in der achten Szene. Er findet die Technik nicht minder auf der Höhe ihrer Aufgabe. Vom ersten zweifelnden Ausruf eines Einzelnen: „Sie weichen“, wächst die Zuversicht des Sieges mit trefflicher Steigerung bis zu dem Freudenschrei einer ganzen Gruppe von Beobachtern: „Sie fliehn!" Zwei Botschaften, die erste kurz, die zweite ausgeführter, bringen Schlag auf Schlag die Gewißheit, daß die Freiheitsschlacht gewonnen ist.

Diese Dinge sind es vor allem, welche die Zeitgenossen nach dem Zeugnis der Rezensionen mitrissen. Man stand hier vor etwas ganz Neuem, das wie eine Offenbarung wirkte. „Mit eben dem Eindruck, welchen ein neues oder seltenes Phänomen des Himmels auf den Sternkundigen macht" kommt Chr. H. Schmid von der Lektüre. ${ }^{20}$ ) Wenn man erwägt, was alles Hermanns Schlacht geleistet hat, wird man solche Stimmen, die sich mehren ließen, trotz dem heute feststehenden Gesamturteil verstehen können.

Die Zeit empfand das Werk als vollkommen original. Diesen Eindruck nachzuzeichnen, durfte die Frage nach fremder Anregung bis hierher verspart werden. Wir vermuten in Klopstock kaum noch einen bahnbrechenden Neuschöpfer auf dramatischem Gebiet und sehen uns besonders für das, was er im Technischen als erster bringt, nach Vorbildern um, ohne dabei sein neues Verhältnis zum Kriegerischen im mindesten anzutasten. Der Gedanke an Shakespeare, der jetzt schon im Hintergrunde der Entwicklung steht, tritt zurück: die dichterische Struktur beider ist zu verschieden. Wir sahen schon oben, wie gegensätzlich die Formprinzipien ihrer Schlachten sind. Gelegentliche Berührungen im einzelnen würden dagegen nicht aufkommen auch wenn sie deutlicher wären. Zudem tritt die Teichoskopie, wie später zu zeigen sein wird, bei Shakespeare nur beiläufig auf. Ein sehr viel geringerer englischer Dramatiker ist von amerikanischer Seite als vermutlicher Anreger Klopstocks

$\left.{ }^{20}\right)$ Deutsche Bibliothek von Klotz 4,399; seine Rezension ist viel besonnener als Kober ste in 5, 369 glauben machen will. Sie darf sich neben das stellen, was Gerstenberg geschrieben hat, wenn auch gewiß Jördens' Urteil „,meisterhaft" (Lexikon 3.43) für sie zu hoch gegriffen ist. 
namhaft gemacht worden: William Mason. ${ }^{21}$ ) Neben ihm kommen weithin sichtbare antike Vorbilder in Betracht, deren Einwirkung darum von vornherein ungleich wahrscheinlicher ist.

Masons .Caractacus". 1759 und öfter erschienen, ${ }^{22}$ ) wie die frühere .Elfrieda" "2:1) ,.written on the Model of the ancient Greek Tragedy", ist seinerseits cin Versuch, das antike Drama zu erneuern. Es sind demnach zwei Fragen zu beantworten, dic eine: ob Klopstock seine Kampftechnik an den Griechen schult, die andere: wenn dies der Fall ist, ob er unmittelbar oder durch Masons Vermittlung bei ihnen lernt. Es handelt sich für uns nicht um die Erneucrung des griechischen Clors im allgemeinen, ${ }^{24}$ ) die beiden gemeinsam ist, sondern um die besondere, in der deutsclıen Entwicklung alleinstehende Lösung des Schlachtproblems durch Klopstock. Sie ist im wesentlichen in den "Sieben gegen Theben" des Aeschylus vorgebildet. ${ }^{23}$ )

21) John A. Walz. An english Parallel to Klopstock's Hermannsschlacht. Modern Language Notes 21, 51-54, Baltimore 1900.

$\left.{ }^{23}\right)$ Die (nach $W_{a} \mid z$ ) 4. Auflage des Stücks am zugänglichsten in: Poems by William Mason, M. A., London 1764.

23) die für die deutschen Elśriede-Diamen (E. Schmidt, Charakteristiken ${ }^{2}$ 1, 443f.). vor allem für Bertuchs Bearbeitung 1773 von Bedeutung ist. Auch Klinger nennt Mason als Vorgänger in der Beliandlung des Stoffes (Rieger, Klinger, 2, 36).

20) Vgl. daruber K. Burdach. Schillers Chordrama und die Geburt des tragischen Stils aus der Musik. Deutsche Rundschau Bd. 142, wo S. 258 ff. der Zusammenhang mit der musikalischen Entwicklung (Oper u. Singspiel) dargelegt und S. 409 f. über die Theorie des Chors gehandelt wird. Die dabei beruhrten Fragen der Potenzierung der Wirkung durch den indirekten Eindruck (Reflex) neben der sichtbaren Handlung gehen unmittelbar auch die Teichoskopie - ob innerhalb oder außerhalb des Chors - an, nur daß in ihr der Reflex, statt neben die sinnenfällige Darstellung, an ihre Stelle tritt.

$\left.{ }^{2}\right)$ Der Zusaminenhang ist, soviel ich sche, bisher nicht gewürdigt worden. Munckers Aufsätze .Klopstocks Verhältnis zum klassischen Altertum". (Augsburger) Allgemeine Zeitung 1878, 26. u. 29. April, 3. Mai, schließen Klopstocks Dramen von der Betrachtung aus. Eigene Zeugnisse Klopstocks fehlen. Von den Zeitgenossen hat der belesene Chr. H. Schmid die Parallele geseten. ohne sie auszuführen: er will Klopstocks Werk .,mit nichts als mit der Thebaide des Aeschylus vergleichen" (Deutsche Bibliothek 4. 436); auch Gerstenberg zicht neben Shakespeare die Griechen zum Vergleich heran. Die Bedeutung der "Sieben" als Kriegsdrama hat A.W. Schlegel schart hervorgehoben; es ist das einzige Stück, das er (Dramat. Kunst u. Litt. 2 3. 202; 204: vgl. 1, 161 ; 163) zum V'ergleich mil der shakespesrischen Kricgsdramatik heranzieht. Klopstock ging schon für den ..Salorno" ülxer die Franzosen auf die Griechen (Sophokles) zurück (Muncker S. 353: vgl. auch S. 392: die Handlung von Hermanns Schlacht entwickle sich wie diejenige der griechischen Tragödic in einem großen Zuge, ohne Aktgliederung). DaB Klopstock im allgemeinen mit den griechischen Tragikern weniger vertraut was als mit den Epikern (Muncker \$. 532), ist kein Hindernis. Gekannt hat er Aeschylus sicher, wohl schon, wenn auch nur fluchtig. von der Schulpforte her. Zudem wies Cold ha ge $n$ s Ubersetzung gerade um die Zeit, als Klop- 
Hier wie dort dasselbe Formprinzip: die Anlage als Schlacht-Oratorium; der Kampf hinten, das Schlachtorchester (wozu bei Klopstock auch die Druiden rechnen) als fester Pol vorn. Seine Funktion dieselbe: es ist Träger der Beobachtung und der Stimmung. Es vermittelt dem Hörer das Sachliche der Schlacht und münzt ihren Gefühlswert aus. ${ }^{26}$ ) Bei Aeschylus (Frauenchor) mehr in leidender Weise, bei Klopstock aktiver, die Schlacht geradezu regierend (Männerchor). Die monumentale Stimmführung des Griechen im dreigeteilten Chor erreicht Klopstock allerdings nicht. Bei jenem horcht ein Teil der Thebanerinnen im Vordergrunde nach der Schlacht und fragt; der zweite beobachtet von der Höhe des Hügels, antwortet und schildert; der dritte liegt betend vor den Götterbildern. Sie vereinigen sich in angstrollem Flehen um den Sieg. Die Simplizität dieser sich rhythmisch wiederholenden, szenisch und funktionell gleich eindringlichen Anordnung ist den Bardenchören fremd. Die Anlage aber ist im Grund dieselbe.

Im weiteren Verlauf müssen sich die Wege trennen, wenn auch in Klopstocks Kedmon der Bote des Aeschylus wiedererkannt werden mag. Der Grieche läßt diesen Boten in epischem Nacheinander des gleichzeitig Vorgehenden erst jetzt die feindlichen Helden schildern und Eteokles in großer Szene die Kampfbefehle geben. Dramatisch gerechnet, käme dies viel zu spät. Der neuere Dichter ist ans dramatische Miteinander gebunden und muß die ganze Kampfzeit (die Schlacht ist bei beiden längst entbrannt) mit Bühnenvorgängen ausfüllen. Hier treten seine Episoden ein. Es ist der Punkt, wo Klopstock aufs neue seine Zuflucht zu der abgetakelten Intrige nehmen muß. Die Zankszene Segests, die Besorgnisszene Thusneldens sind wie rudimentär aus Schlegels geschlossener Handlungskette übriggeblieben. Auch der übersteigerte Auftritt Siegmunds gehört zu diesem Flickwerk, das überdies das Fehlen der Exposition fühlbar macht. Um die von Szene zu Szene neu auftretenden Personen nur mangelhaft in den Zusammenhang zu bringen, muß sich der ganze Bardiet mit expositionellen Bestandteilen schleppen. Die großen Linien des Aeschylus gehen in den Füllseln unter. Sein Vorbild hat aber Klopstocks Formbildung höchst wahrscheinlich bestimmt: die Gemeinsamkeit des Baus ist zwingend.

Anders steht es um Masons Caractacus. Ob Klopstock im Stofflichen

stock an die Hermannsschlacht ging, auf die „Sieben gegen Theben“ besonders hin. Sie erschien 1767 in der "Griechischen und römischen Anthologie in deutschen Übersetzungen“... von Goldhagen, Brandenburg 1767-68, 3 Teile (Degen, Literatur der deutschen Übersetzungen der Griechen, Altenburg 1797, 1, 20; die bibliographischen Angaben [Kayser, Ersch und Cruber, I. Sektion 73, 274 u. ADB 9, 333] gehen auseinander. $\mathrm{CGr}^{2}$ 5, $258 \mathrm{Nr}$. 5). Die „Anthologie“ scheint heute selten zu sein und war mir nicht zugänglich.

29) Vgl. zu dem schon angeführten bei Klopstock besonders die zweite Hälfte der 3. Szene. 
aus ihm geschöpft hat, beschäftigt uns hier nicht. Die Ubereinstimmung im Druiden- und Bardenwesen hat in der Tat viel Bestechendes. Formal beherrscht der Chor die Szenc ähnlich wie bei Klopstock. Aber gerade das Entscheidende der Schlachtgestaltung, den beobachtenden Chor, hat Mason von Aeschylus bis auf Ansätze nicht übernommen. Der Caractacus ist überhaupt nicht Schlachtstück im Sinne Klopstocks, sondern Intrigenstück mit Kämpfen im Sinne Schlegels. Erst in letzten Drittel fallen zwei Gefechte vor, die in der alten Weise durch ausführlichen Botenbericht wiedergegeben werden. Es ist richtig. $\left.{ }^{27}\right)$ und stellt Mason gegen das Vorige wieder in eine Reihe mit Klopstock, daß seine Barden die Kämpfer durch ihren Gesang ermutigen; eine Beziehung zwischen Chor und Schlacht ist also auch hier geschaffen. Es finden sich ferner Ansätzc zur Beobachtung, besonders des Geländes; sie werden aber für die Schlachttechnik nicht fruchtbar gemacht. Die genaue Vergleichung dicser Dinge ergibt als Resultat, da $B$ es zum mindesten nirgends notwendig ist, auf Masons Stück zurückzugreifen. Dic Anlage des Bardiets ist diejenige des Aeschylus. Dic Bcobachtung, die Klopstock dem deutschen Drama als technische Neuerung zuführt, hat er nicht von Mason lernen können. Der Caractacus scheidet demnach für die Entwicklung der deutschen Kampftechnik so gut wie ganz aus; mag auch die ein und andere Kleinigkeit herübergekommen sein, sofern Klopstock das Stück überhaupt gekannt hat, er fand darin für seine Schlachtgestaltung nichts, was ihm die Antike nicht reicher geboten hätte.

Für dic Teichoskopie ist noch das berühmteste Beispiel antiker Mauerschau nach Homer, dic zweite Szene der "Phönissen" des Euripides, heranzuziehen. ${ }^{2}$ ) Antigone hält mit ihrem Erzicher von der Zinne des Palastes Ausschau nach dem dräuenden Heer ihres Bruders. Das Zwiegespräch der beiden bringt Ordnung in das Wogen des blitzenden Gefildes, die Führer stellen sich in scharfem Umriß vor das geistige Auge des Hörers. Hier konnte für die Technik von Frage und Antwort, deren treffliche Ausbildung bei Klopstock überrascht, und ebenso für die vergegenwärtigende Beschreibung manches gewonnen werden. Der kleine Umstand, daß des Euripides Einleitung der Teichoskopie bei Klopstock (Szene I) wiederkehrt, ist nicht zu übersehen. Horst erscheint, spricht mit dem noch hinten befindlichen Siegmar und hilft ihm dann herauf; ganz so der Erzieher und Antigone.

$\therefore$ Walz S. 52.

20) Der Zusammenhang der Teichoshopie in der griechischen Tragödie mit dem Epos - von den Mauern des belagerten Troja herab überblickt man das Kampffeld - ist in Aeachylus' halb epischer Anlage noch vollkommen deuslich. Der Auftrill der Phönissen nähert sich am meisten jener Stelle im drilten Cesang der llias, wo Helens ihrem Schwiegervater die griechischen Helden von der Mauer aus beschreibt. 
Die Beziehungen der Hermannsschlacht zu der griechischen Tragödie erschöpfen sich nicht in der Erneuerung des Chors und der Úbereinstimmung ihres Baus mit den "Sieben“ des Aeschylus; gemeinsam ist ebenso das, was der Teichoskopie zugrunde liegt, die Ausweitung und naturhafte Anschauung des Raumes. Klopstock dachte sich als seinen Schauplatz viel mehr die Roßtrappe als eine Bühne, und diese Wirklichkeitsvorstellung stimmt durchaus mit den Verhältnissen der antiken Skene überein, wo die Darstellung unter freiem Himmel in Luft, Sonne und Staub - wenn Atossa im Viergespann erschien - vor sich ging. Die französische, auf modernen Gesellschaftsformen beruhende, in den geschlossenen Saal gebannte Tragödie ist darin von den Griechen in den Fundamenten der Auffassung getrennt. Klopstock steht jenen ebenso nahe wie ihr fern. Es ist merkwürdig, wie die antike Bühnenvorstellung bei den Franzosen, obwohl sie ihre Crundsätze scheinbar festhalten, verengt wird und konventionell erstarrt. Der stehende Ort der Handlung der tragédie classique, ,une salle“, kann zwar noch als Analogon des attischen Königspalastes gelten, und der Unterschied läge dann nur in der zimmermäßigen Geschlossenheit gegenüber der Freilichtszene; diese führt im Gegensatz zur modernen Illusionsbühne sogar eine ähnliche Realität der Ausmaße mit sich wie sie der französische Rationalismus fordert. Wessen aber das griechische Theater trotz der Gebundenheit an die szenische Wirklichkeit in Licht und Luft fähig ist, lehrt eben die Teichoskopie. Den Franzosen ist der Bühnenraum Teil des realen Theatersaales, und ihre Tragödie wird im Crunde als gesellige Veranstaltung im Salon - daher können $\mathrm{Zu}$ schauer ohne Störung einer lilusion auf der Bühne Platz finden - gespielt; diese Anschauung verbietet es, den außerszenischen Raum zur Handlung heranzuziehen und mehr als beiläufig in der Vorstellung wachzurufen; denn die Konvention, die dem Spiel im Saal in bescheidenen Grenzen die Täuschung zubilligt, gilt kaum für jenen, und man würde Gefahr laufen daran zu erinnern, daß außerhalb der vier Wände die Treppen und Gänge des Hauses, worin tragiert wird, sich befinden. Dagegen durfte der griechische Dichter es wagen, vermittelst der Ausschau ein Heer in die allen Zuschauern bekannte und bewußte reale Landschaft zu stellen und so den szenischen Schein in die Wirklichkeit hinüberzuspielen, ${ }^{29}$ ) ohne daß offenbar sein illusionsfreudiges Publikum den rationalistischen Einwand erhob.

Ganz ähnlich würden die Verhältnisse gewesen sein, wenn der scherzhaft geäußerte, aber ernsthaft zu wertende Wunsch Klopstocks, der seine Absichten am besten kennzeichnet, in Erfüllung gegangen wäre: „Hermanns Schlacht unter freiem Himmel im Harz, just auf einem solchen Felsen am Tale

${ }^{29}$ ) Andere Beispiele dafür gibt A. W. Schlegel, Dramat. Kunst u. Litt. ${ }^{2}$ 1, 86. 


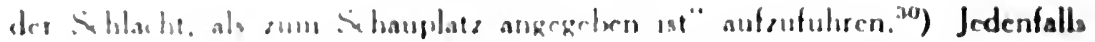

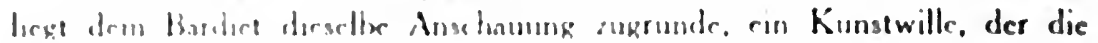

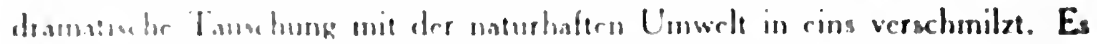

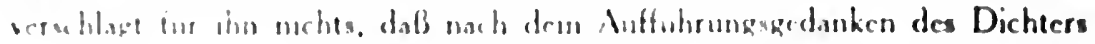

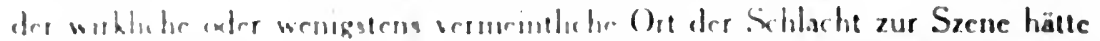

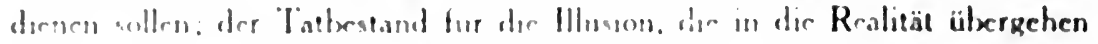
wll diese ware immer das mextrone. 31 dem vorgetauschten historischen

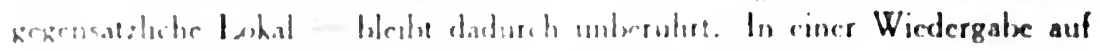

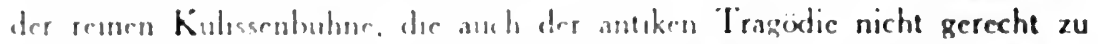

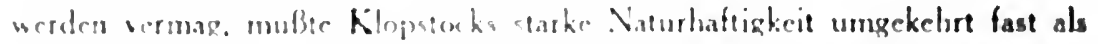

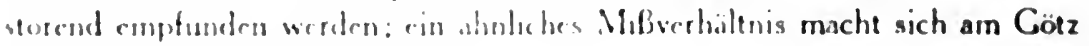
von Berlechingen wralich gelendi.

Acschilus homant al. Dramatiker is.s Krieges un dieselbe Zeit, wo Klop-

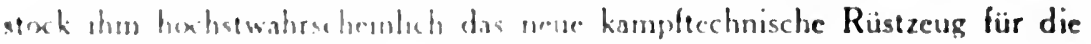

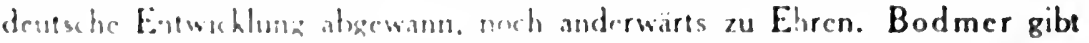
m scmem . . Kurl von Burgund", ) rine genauc Erncucrung der ..Perser".

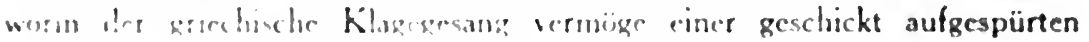

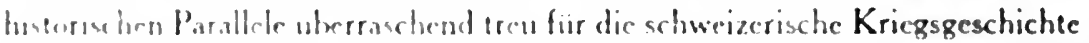
adputers waret: an die Siclle der Nicderlase des Xerxes tritt dicjenige Karls des Kuhnern. Bextmers Stuk hlieb ohne alle Bedeutung. aber der Versuch altern int netren dem Werk Klopsterks erwahnenswert. Ganz besonders, weil Jie Hermannshliache mach ihrer kimsterischen Absiche dem aeschyleischen

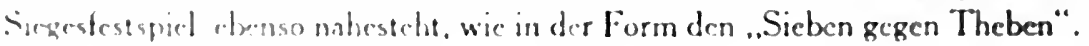

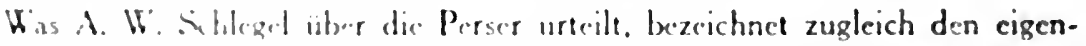
reheigen Charahter des kopstockischen Bardiets viel prägnanter als Lessings Prhannte $X .8$-rung: ${ }^{32}$ ) .. Indesecn, wäre es auch ke in rechtes Drama, so ist es dexh ran stellert Siegesgerang der Frcibeit".

Blickt mu von den dargelegten engen Bezichungen der Hermannsschlache zum anthern D):ams aut thre Vorsünger zurtick, so zeigt sich interessanter.

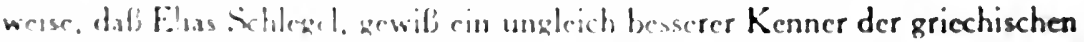

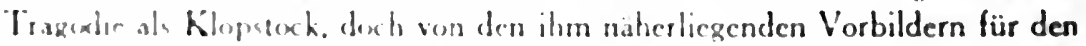
.Hermanu" urnh hemen Cirlirauch machen konnte: dic Diktatur der Fran-

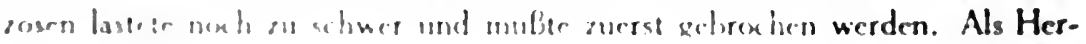

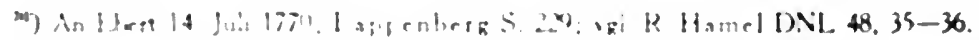

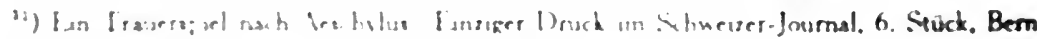

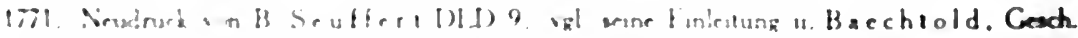

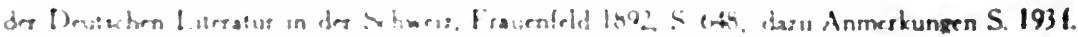

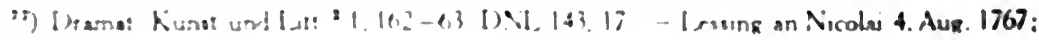
(1) 64.6 
manns Schlacht entstand, war Lessing daran, sie in der Dramaturgie durch die neue Erfassung der Griechen zu stürzen.

Dem Werk Klopstocks sollte hier keine ästhetische, wohl aber eine technisch-historische „Rettung“ zuteil werden. Die künstlerischen, vor allem die dramatischen Mängel liegen am Tage. Dem Schlachtstück insbesondere ist vorzuwerfen, daß das Schlachtgeschehen in keiner Weise in die Handlung verzahnt ist. Nichts begründet die Wendungen des Kampfes, der ziellos hin und her wogt. Was Schlegel durch die Führung der Intrige erreicht hatte, fiel der lyrischen Anlage Klopstocks zum Opfer; sie bot die Möglichkeit, den Kampfausgang mit Stimmungsmitteln, nach Art der Vorklangsszenen Shakespeares, zu motivieren: so hatte Mason den Ausgang durch ein Opfervorzeichen vorbereitet. Klopstock sah davon $a b$, wie es scheint, um nicht die einzige Überraschung seiner Handlung, den Umschlag des Schlachtenglücks zugunsten der Germanen, preiszugeben.

Die historische Bedeutung von Hermanns Schlacht dürfen diese Ausstellungen nicht verdunkeln. Wir sahen, wie sie als etwas Vorwärtsweisendes, erstaunlich Neues in die deutsche Entwicklung trat und was für stattlichen Zuwachs an Gehalt und Ausdrucksmitteln sie ihr brachte. Darauf ruht der große Erfolg des Werks so gut wie auf dem rein Lyrischen. Im ganzen gesehen ergibt sich folgendes Bild: Ein Lyriker unternahm hier den denkwürdigen Versuch, die Schlacht, den Zusammenprall bewegter Massen, eine Aufgabe welche die Aktion an sich ist, mit seinen Mitteln auf einem ihm wesensfremden Gebiet zu lösen. Sein Formgesetz, das Beharren, ist das genaue Gegenteil dessen, was Vorwurf und Gattung heischen. ${ }^{33}$ ) Dagegen bringt er ein starkes Verhältnis zum Kriegerischen mit. In Anlehnung an die Antike findet er den Weg einer Lösung, indem er die äußere Aktion mit neuer Technik in der Illusion vorgehen läßt und sie dafür im Geistigen, in Gedanke und Stimmung abwandelt, in gewissem Sinne die französische Reflextechnik vollendend, aber zugleich ihren Rationalismus vernichtend. Das so entstandene Werk, äußerlich von französischem Gepräge, neigt vielfach zum kommenden Geniedrama. Daher bekennt sich auch der Wortführer der Genies, Lenz, in den ,Anmerkungen übers Theater" ausdrücklich zu dem Dramatiker Klopstock, nennt ihn in einem Atem mit Shakespeare: „Die Italiener hatten einen Dante, die Engländer Shakespearen, die Deutschen Klopstock, welche das Theater schon

${ }^{33}$ ) Wie wenig darüber mit Klopstock zu rechten ist, zeigt sein Ausfall gegen Herder, der den Bardiet ohne Handlung fand. Mit einer Begründung, die auf einem ebenso eigentümlichen. als bezeichnenden Begriff der dramatischen Handlung fußt, konnte er ihm entgegensetzen : „Auch die Barden sind handelnde Personen; denn sie helfen siegen. Und nur, mein Wertester, nicht nach den Zwecken und Mitteln in „Oedipus“" oder „Lear", sondern im „Hermann“. An Herder 5. Mai 1773, Lappenberg S. 250. 
aus ihrem eigenen Gesichtspunkt ansahen, nicht durch Aristoteles' Prisma ... Was Shakespeare und Klopstock in seinem Bardiet getan, wissen wir alle" ${ }^{34}$ ) und riihmt scine Vergegenwärtigung der Schlacht noch insbesondere: „welche Wo'lltat des Genies. Sie auf die Höhe zu führen, wo Sie ciner Schlacht mit all ihrem Getiinmel, Jammern und Grauen zusehen können ohne Ihr eigen Leben. Gernütsruhe und Behagen hineinzuflechten, ohne aul dieser grausamen Szenc Aktcur zu sein". ${ }^{35}$ )

Das Neuartige in Hermanns Schlacht wird durch nichts mehr ins Licht gesetzt als cinen vergleichenden Hinweis aut ein gleichzeitiges, stoffverwandtes Stück. Ayrenhoffs ,Hermanns Tod" $:^{36}$ ) wobei nicht verschwiegen werden soll, daß die Wiener Sonderentwicklung zu dieser Zeit gegenüber der allgemein deutschen überhaupt zurück ist. ${ }^{37}$ ) Was sich in dieser an neucm Leben geregt hatte, ist für Ayrenhoff nicht vorhanden. Sein Stück stellt sich durchaus in die Reihe, die wir von Gottsched über die Schaubühne zu Schönaich verfolgten. Wie dieser klammert er sich äußerlich an die Regeln und sündigt heimlich gegen sie, weil auch er nach dem Effekt geizt. Wie dieser zieht er die Masse herein und fordert als „Comparsen" deutsche Soldaten und Gefolge, Liktoren und römisches Kriegsvolk. Die soldatischen Verfasser ${ }^{38}$ ) (Ayrenhoff war damals Grenadierhauptmann, zuletzt Feldmarschalleutnant) wollen wenigstens Truppen um sich sehen. Wie Schönaichs Schauplatz, so zeigt derjenige Ayrenhoffs ,,in der fernsten Tiefe ein Lager". Eine vorgeführte Kampfsituation - die Schlacht selbst verlegt Ayrenhoff in den Zwischenakt von IV z.u V - ist bei beiden der Höhepunkt der Handlung. Wie in des Gottschedschülers .Zarine" die Königin, trennt bei ihm Thasnelda die aufeinander-

$\left.{ }^{34}\right)$ Anmerkungen übers Theater, Neudruck von Th. Friedrich, Kösters Probefahrten 13 (1908). S. 127.

a) Das., Friedrich S. 123-24; die Stelle kann auf niemanden als auf Klopstock gehen, der dann im folgenden (vgl. die vorige Anm.) auch genannt wird; sie paßt inhaltlich, selbst wenn man cine starke Sorglosigkeit des Ausdrucks bei Lenz in Rechnung setzt, weder auf Shakespeare. noch auf den Götz: bei beiden werden keine eigentlichen Schlachten, insbesondere nicht "mit all ihrem Gelümmel. Jammer und Grauen" beobachtet, und etwas Bestimmtes hat nach der Fassung der Stelle sicher vorgeschwebt: zu Hermanns Schlacht stimmt sie, und man wird dort in der Tat auch zu Anfang .,aut die Höhe geführt".

se) Unter diesem veränderten Titel 1770 erschienen: Sämtliche Werke, neue verb. u. verm. Auflage in $6 \mathrm{Bdn}$.. Wien 1803. Bd. 1. Als ..Hermann und Thusnelde" 1768 aufgeführt. Auf diese Aufiführung bezieht sich die im folgenden angezogene ausführliche Kritik von Sonnenfels (B r efe über die wienerische Schaubühne, sechstes bis neuntes Schreiben). Uber Ayrenhoff vgl. W. Montag. Münstersche Beiträge zur neueren Literaturgesch. Nr. 6, 1908.

97) Vgl. Devrient' 3, 123 u. 2, 197.

$\left.{ }^{23}\right)$ Vgl. Sonnenfels Neudr. 7, 33 f.: Riffert, Die Hermannsechlacht in der deutsechen Literatur, Herrigs Archiv 63, 285. 
prallenden Parteien. Und endlich, wie den Vorgänger, so ereilt auch ihn ob solchen äußerlichen Bühneneffekten die Kritik. „Ich mache dem Dichter keinen Vorwurf aus dem Theaterstreiche: diesen Vorwurf macht sich ein Mann wie er natürlich selbst, sobald er seine Arbeit bei kaltem Blute in die Hand nimmt " meint Sonnenfels, ${ }^{39}$ ) der dem wienerischen Bühnengefecht, wie wir es in der Prinzessin Pumphia satirisiert fanden - "Combattement, wie das theatralische Kunstwort heißt" - scharf zu Leibe geht und mit einem Hieb auf das Wiener Theaterpublikum spottend anmerkt, daß sich freilich so ein Ding vortrefflich wohl ausnehme und vermögend sei, in Wien einem ganzen Stücke den Schwung zu geben. ${ }^{40}$ ) Er selbst jedoch schließt sich früher gehörten Stimmen an und verabscheut ,das Geklirr der hölzernen Spieße, und alle das Pappengefecht, welches auf der Schaubühne immer possierlich lassen muß".

Klopstocks Schlachtenwelt stand solchen Kulissenkämpfen fern. Ein Blick auf ihn zurück zeigt, wie groß die Kluft ist. Die alte Schule kannte den Kampf in der Tat nur als „Combattement“. Er gestaltet ,die blutige schöne Todesschlacht" zum erstenmal um ihrer selbst willen.

Seine eigenen späteren Bardiete, die zudem erst verjährt erschienen, treten dem ersten Wurf gegenüber trotz mannigfacher Fortschritte, hauptsächlich der Charakterisierung, zurück. Klopstock hat sich in ihnen sozusagen selbst ausgeschrieben. Die Bardietform war durchaus für und mit der besonderen Schlachtaufgabe des Teutoburger Ringens konzipiert. ${ }^{41}$ ) Was folgte, war im Grunde Anwendung der erstarrten Form auf Stoffe ganz anderer Struktur, wie das sonst Nachahmern eigen ist. Dafür nur ein Beispiel: Der Chor, in

39) Briefe usw. 7, 53. Ayrenhoff verteidigte sich gegen ihn temperamentvoll; vgl. Jördens 1, 70 u. 72 und Sonnenfels' Replik Briefe 7, $186 \mathrm{f}$.

40) Ähnlich läßt sich später in München Lorenz Westenrieder in einem Rezept, wie man. ,,den gräulichen Shakespeare ausgenommen“, für den größten Schauspieldichter gehalten werden könne, vernehmen: „man . . . lasse seine Personen sich stoßen, schlagen, das Herz bis an das Kinn heraufseufzen, in Ohnmacht fallen, sterben, lasse noch obendrein Soldaten durch die Bühne rennen und ein paarmal trompeten, und am Ende halte man einen herrlichen Einzug “ usw.; Baierische Beyträge zur schönen und nützlichen Litteratur 1779, 2, 990 . Ein ganz verwand:es Verdikt richtet übrizens A y r e n h off selbst in späteren Jahren (1783) gegen das kriegerische Spektakelwesen, in der Zueignungsschrift zu seiner streng klassizistischen „Kleopatra“ (Werke 1803, 2, 132): „Wie könnte . . . eine Tragödie gefallen . . . worin . . . weder Gespenster noch Hofnarren Teil an der Handlung haben; noch Gefechte, Leichenzüge, Militärexekutionen und dergleichen anziehende Schaustücke das Auge des Zuschauers weiden, oder Trompetenschall und Kanonendonner das Trommelhäutchen seines Ohrs erschüttern.“

11) Damit hängt zusammen, daß Klopstock keine faßbare Definition des Bardiets, die auf alle gepaßt hätte, zu geben vermochte; vgl. Muncker S. 389. 
Hermanns Schlache formbestimmend, ist in .Hermann und die Fürsten" last nur noch lyrischer Schmuck, der auch fehlen kënnte, und wirkt nur einmal bedeutender auf die Handlung cin.") In "Hermanns Tod" ist er vollends zur opernhaften Einlage geworden. Dies urd endercs hängt entscheidend von der Verschiebung des Interesses ab, die sich in Klopstock vollzog. Der erste Bardict war eine Schlachtefeier. Das Ereignis als solches stcht im Mittelpunkt, nicht der Held. Erst aus dem geformten Werk wird der Plan einer Hermann-Trilogic erwachsen sein. Hermanns Charakter und sein Schicksal, etwas wie die Tragik des genialen Menschen, sind fürderhin der Inhalt, der den folgenden Bardieten ganz ardere Wirkungen verleiht, als sie von Hermanns Schlacht ausgehen. Wie sehr dagegen die Kampfaktion, die doch ursprünglich der Bardietform allein den Sinn gab, zurücktritt, zeigt am deutlichsten „Her$m$ anns Tod". ${ }^{44}$ ) Auch hicr hinter der Bühne Kemplvorgänge, die den Hauptteil des Stückes füllen. Aber hier undenkbar, den Helden bis gegen den SchluB hinten fechten und erst dann auftreten zu lassen, wie im ersten Stück. Er muß vielmehr unter den bedenklichsten Motivicrungen auf der Szene gehalten werden, etwa einer Wunde wegen, von der Thusnclda dann doch glauben kann, er habe sich auf der Jagd gestreift (14. Szene). Aller kempftechnische Fortschritt geht damit verloren. Man steht wicderum auf Schlcgels Standpunkt. Dessen Scgest war während der Schlache ,vergnügt und ruhig durch den Hain geirrt". Klopstocks Hermann riskiert sogar ein Schläfchen, indessen seine Leute auf Leben und Tod fechten. Demit sich vorne die schlachtfremde Handlung abwickeln kann, muß dic allzu enge Beziehung zu den Kämpfen hinten vermicden werden; die Beobachtung fällt dem zum Opfer, während sie im zweiten Bardict noch gute Dienste leistet. $\mathrm{DaB}$ der SchluB aus der Spannung auf den hinten vorgehenden Endkampf Hermanns und seiner Getrcuen große Wirkung zicht, wicgt die Mängel der gesamten Anlage nicht auf.

In ,Hermann und die Fürsten" handelt es sich nur um kurzen Kampf. den schnell abgeschlagenen Nachtangriff der Germanen auf das römische Lager (Szene 13-16). Ein Einzelbeobachter vermittelt ihn den Frauen und Brenno, unablässig gefragt, meist in raschen, atcmlosen Sätzen. Der Chor, der in Hermanns Schlacht den feierlich gemessenen Gang bedingt, fehlt hier. Gespräche der Fraucn, Brennos und Ingcmars, der verwundet heraufgeführt wird, füllen die Pausen der Beobachtung. Kattwald rettet die Frauen. Die Niederlage der Germanen führt cinen Trupp Römer auf die Bühne. Wenn darob die Kampftechnik lockerer und beweglicher erscheint, ist doch kaum

12; Ein Bardiel für die Schautuhre. Hamburg 1784. Sümll. Werke, Leipzig 1823 f., Bd.9.

(2) In der 7. Szene necks das Heidenlied Arres Eifessucht auf Heimann urd stimmt ihn um ") Ein Bardiet für die Schaubuhne. Hamburg 1787. Sämt]. W'erke Bd. 10. 
an shakespearischen Einfluß zu denken..$^{45}$ ) Die Beobachtungstechnik ist die von Hermanns Schlacht, nur daß sie hier, der veränderten Situation gemäß, gesammelter und darum dramatischer und suggestiver auftritt, wo sie dort über eine lange Schlachtdauer verstreut war. Für verfolgende Kriegertrupps gaben uns schon Schlegel und Schönaich Beispiele. Wahrscheinlicher als die Einwirkung Shakespeares, für den die genaue Untersuchung des einzelnen gar nichts aufbringt, möchte diejenige der allgemeinen Zeitrichtung sein. Gerade die Kampfszenen scheint Klopstock erst geschrieben zu haben, nachdem der Götz erschienen war. ${ }^{46}$ ) Möglich, daß dieser auch ihm die Zunge etwas löste. ${ }^{47}$ ) Er hätte dann von Goethe, der kampftechnisch, wie gleich zu zeigen sein wird, von ihm lernte, seinerseits wieder gelernt.

45) Muncker stellt die Frage S. 400.

46) Vgl. Muncker S. 397.

47) Vgl. technisch etwa Götz V, Hauptmanns Zelt, Wolf: „Fort fort! Alles verloren. Unser Hauptmann erschossen. Götz gefangen“" mit Klopstock, Hermann u. die Fürsten Sz. 15, Eine andre und entferntere Stimme: „Hermann schlug fort! Der Tribun ist tot! Sie sind durch!" 


\title{
Zweiter Abschnitt. \\ Shakespeare und das Kampfstück des Sturm und Drangs.
}

\author{
Viertes Kapitel. \\ Götz von Berlichingen.
}

Die augenfälligste, freilich an sich betrachtet auch äußerlichste Wandlung, welche die Form des deutschen Dramas von ,Hermanns Schlacht" zum „Götz" durchmacht, ist die Sprengung der Ortseinheit. In der Tat prägt sich in ihr eine Grundwendung der deutschen Dramatik aus. Wir haben gesehen, wie Klopstock das Erleben der Umwelt von der Lyrik ins Drama herüberbrachte. In einem singulären Fall, einem rechten Beispiel der Übergangshalbheit gelang ihm das, ohne daß er die ererbte Ortseinheit der Franzosen verließ. In Wahrheit aber war mit der Ansiedelung der Teutoburger Schlacht auf liebevoll gestalteter Scholle der französischen Ortslosigkeit das Urteil schon gesprochen. Das Naturgcfühl, aus mannigfachen Quellen in der Lyrik entwickelt, war im Begriff, das Drama zu erobern und von Grund auf neu zu bilden. Goethe tut im Götz mit aller Kühnheit der Jugend den Schritt, wozu Klopstock nur zögernd den FuB gehoben hatte. Damit wird die Absage an die Franzosen vollkommen: Shakespeare regiert dic Stunde.

Lessings Dramaturgie bereitet für itn den Boden, und kurz vorher proklamieren in ganz anderer Weise Gerstenbergs Literaturbriefe seine Größe. Das Erlebnis der Jungen an Shakespeare, das uns hier angeht, ist von Herder in seincm genialen Aufsatz ${ }^{1}$ ) formuliert worden: es ist die Entdeckung des Lokals. Wir sahen wie Gerstenberg als erster Klopstorks Verdienst darum erkannte; er ist auch der erste. der es an Shakespeare ahnt.") Herder nun erfaßt den neuen Weltteil der Poesie mit tiefem Gefühl. Er hat hinreißende Worte für den Zauber des Lokals, das bei Shakespeare, völlig individualisiert, die Handlung umschließe wie die Hülse den Kern. Er zieht die Erfahrung

') Shakespear. V'on deulsctier Ant und Kunst, DLD 40 41, insbesondere S. 67-70.

") Gundolf S. 192-93 schliele es in den umfassenderen Begriff ..Kolorit" ein. 
des Alltags dafür heran, wie unauflöslich die Umwelt, ein jeder Umstand des Lokals, des Wie und Wo und Wann, nit unserem Erleben verknüpft sei. Die Franzosen simplifizieren die Erscheinung bis sie auf ihr Brettergerüste paßt. Shakespeare gibt eine lebendige Welt mit allem Urkundlichen ihrer Wahrheit. Herder prägt für alles das, was zu einer Handlung gehört, und sie erst zu einer bestimmten Begebenheit macht, Ort, Zeit und die Fülle der äußeren Umstände, den Ausdruck „Lokalgeist". Er häuft mit der Freude des Entdeckers die Beispiele jener eigentümlichen Intensität des Seins aus Shakespeares Werken, wo das Größte wie das Kleinste sich zum völligen Ganzen einer Begebenheit zusammenschließt, die nur da und so geschehen kann, und wo sich, nach Herders erschöpfendem Ausdruck, aus Szenen und Zeitläuften aller Welt, wie durch ein Gesetz der Fatalität, eben die hierherfindet, die dem Gefühl der Handlung die kräftigste, die idealste ist. Von Herders Belegen dieses „Lokalgeistes" fältt sachlich die Eingangsszene des Hamlet in unseren Gesichtskreis: „Schloßplatz und bittre Kälte, ablösende Wache und Nachterzählungen, Unglaube und Claube - der Stern - und nun erscheint's!", eine grandiose Formung soldatischer Nachtwache, deren weithin wirkendem Eindruck wir bei großen und kleinen Geistern mannigfach begegnen werden. „Je größer die Gewalt ist, mit welcher der Dichter durch die Poesie in unsere Einbildungskraft wirkt, desto mehr äußerliche Aktion kann er sich erlauben, ohne der Poesie Abbruch zu tun; desto mehr muß er anwenden, wenn er die Täuschungen seiner Poesie mächtig genug unterstützen will.“ Mit dieser feinen Bemerkung des 84. Literaturbriefs nimmt Moses Mendelssohn $^{3}$ ) die andere große Entdeckung des Sturm und Drangs an Shakespeare vorweg: die Aktion. Hier ist der Punkt, wo sich in der Entwicklung des Kampfdramas die Wege scheiden. An Aktion bot Klopstock nichts, in der Handlungslosigkeit gehört er zur alten Schule. Was die Franzosen über die von ihrer Kunstform geforderte Beschränkung hinaus in Handlungsarmut gesündigt haben, darüber sind nicht deutsche Stimmen, sondern diejenige Voltaires selbst zu hören. ${ }^{4}$ ) Seine eigene Produktion trifft allerdings das Mendelssohnsche Wort, ins Negative gewendet, so gut wie die Stücke der Cottschedschule: wo die Dichterkraft fehlt, bleibt alle äußerliche Aktion hohles Geklapper. Wer den Kampf, das Aktionelle in gesteigertster Form, dichterisch nicht meistert, dem hilft es wenig, wenn er dafür einige Komparsen aufeinander rennen läßt.

Bei Shakespeare fand die neue Zeit, deren Erleben sich vom Epischen ins Dramatische gewandelt hatte - „Handeln ist die Seele der Welt" ruft ihr

3) Ges ammelte Schriften, Leipzig 1844, 4, II. Abt., S. 17.

5) Discours sur la tragédie Brutus, Euvres 2, 314; 211 Tancrède das. 5, 496; Commentaire sur Corneille: zu Horace III, 4. 
Stimmführer Lenz aus ${ }^{5}$ ) - Aktion im höchsten Sinn in beglückender Fülle und berauschte sich daran, aus langer Kerkerhaft befreit. Der junge Coethe folgt dem Briten bezeichnend genug auf das Feld, wo sich seine Aktion am stärksten entfaltet: das kricgerische. Mit dem Götz, der dic Entwicklung weithin bestimmt, erklimmt das deutsche Kampldrama, wenn man die Intensität des kriegerischen Erlebens zum $\mathrm{Maß}$ nehmen will, in jähem Anstieg einen Gipfel.

Wenn dem Theaterbesucher von heute Shakespeares starke Vorliebe für Kampfvorgänge, nicht zum mindesten der veränderten Bühneneinrichtung wegen, gelegentlich lästig fällt, pflegt man gewissermaßen zur Entschuldigung des Dichters anzuführen, daß er damit eine Konzession an das Publikum seiner Zeit, das den Spektakel liebte, gemaclst hätte. Man verkennt dabei, dab man in Shakespeares Tagen einen Degen an der Seite trug, der oft locker genug saB; daB der Renaissancemensch auch außerhalb des kriegerischen Ausnahmezustandes in die Lage kam, sich persönlich oder doch in kleinerem Verband seiner Haut zu wehren, eine Aurgabe, die uns Heutigen die Polizei abgenommen hat. Die Zeitstimmung der clisabethanischen Epoche war kriegerisch auch ohne besondere Ereignisse. Aber auch diese fehlen nicht: mit dem Auftreten Shakespeares fällt der Sieg über die Armada Philipps II. fast auf das Jahr genau zusammen. ${ }^{6}$ )

Ungleich wichtiger als diese äußere ist jedoch die innere Begründung der shakespearischen Kämpfe: scine Liebe zu Gefechten entspringt seinem diktatorischen Bedürfnis nach dramatischer Bewegung, seinem Willen zur Aktion. Im wilden Dahinbrausen eines Kampfes tut er sich Genüge, es ist ihm eine Lust, die Elemente zu cntfesseln und scine Schöpferkraft an ihnen zu messen. Die Größe seines Gestaltungsvermögens verlangt nach den gewaltigen Ereignissen von Sieg und Heldentod. Hier, im Kamplgeschehen, haben die

¿) Uber Görz von Berlichingen. Werke Bd. 4. München 1910, S. 223.

9) Vgl. Lohmeyer S. 48: G. Freylag ${ }^{3}$ S. 210. Nachiräglich (die Ausarbeitung des Abschnittes murde durch den Ausbruch des Krieges unterbrochen. aber 1915 zu Ende getührt) kann ich hier und öfler aut den von Rudolf Brol a nek am 23. April 1916 in Weimar vor der deutschen Shakespeare-Geselischaít gehaltenen. dann in Shakespeare-Jahrbuch (Bd. 52, Berlin 1916) erschienenen Vortrag ..Shakespeare über den Krieg" verweisen, wo S. XXII-XXVII über die Quellen der shakespearischen Kriegsanschauung - die wunderbar genug nicht auf persönlicher Kenntnis fuBt - gehandelt wird. Brotanek hält ihre literarischen Gundlagen, die er in der Bibel, der Antike und den englischen Vorgängern Shakespeares nachweist, für bedeulsamer als die historisch-kulturellen. - Leichter wiegende Streifzüge durch das Gebiet, im Charakter von Zitatenlesen mit verbindendem Text, sind aus demselben Anla B. der Gegenwartsbezichung von Shakespeares 300. Todestag. öfter unlernommen worden: so von Josephine Graf-Lomtano. Der Krieg in Shakespeares Schilderung. Rechams Universum 1916. Heft 28. 563-66. 
mächtigen Gefühle, Begeisterung, Treue, Aufopferung, Triumph und Verzweiflung Raum. Er braucht das außerordentliche, überalltägliche, das Heldenschicksal. Gewiß steht er mit seinen Bühnenkämpfen in einer Tradition, worin das äußerliche Schlachtgelärm den kriegerischen Gehalt überwucherte. Er selbst zahlt dem nur lärmenden Getümmel, das der Spectator später geißelt, in frühen Werken seinen Tribut und wendet sich in einer Kundgebung des Alters - dem Prolog zu Heinrich VIII. - mit deutlichen Worten von ihm ab. ${ }^{7}$ ) Aber sie sind kein Widerruf, nur eine Einschränkung gegen den Chorus Heinrichs V., denn sie sprechen nicht von der dichterischen, sondern einzig der sträflich theatralischen Kampfdarstellung.

In den reifen Schöpfungen gestaltet Shakespeare unser kriegerisches Teil mit einer Kraft, die die deutsche Entwicklung durchaus in ihren Bann schlägt. Man steht hier vor jener Universalität seiner Kunst, welche die Geniezeit so gewaltig packte: daß er nicht die oder jene Seite des menschlichen Seins, nicht das oder jenes Weltbild gibt, sondern die Erscheinung in ihrer Totalität, Mensch und Welt selbst. Das ließ Herder sagen: „eine Welt dramatischer Geschichte, so groß und tief wie die Natur; aber der Schöpfer gibt uns Auge und Gesichtspunkt, so groß und tief zu sehen!" und seinen Schüler Goethe: "Und ich rufe Natur! Natur! nichts so Natur als Shakespeares Menschen." ${ }^{8}$ ) Es ist jene allumfassende Gestaltung, worin jeder Stand und jeder Lebenskreis, der König wie der Bettler, der Gelehrte wie der Handwerker, der Feldherr wie der Troßknecht das Spezifische seiner Daseinsform, das völlig ihm Gemäße zum eigenen Erstaunen findet. Der Kriegs mann ist dabei am allerwenigsten zu kurz gekommen, ${ }^{9}$ ) und Shakespeare hat das soldatische Erleben vom titanischen Heldenschicksal eines Antonius bis zu dem Kampf-Bramarbasieren des miles gloriosus Falstaff, vom Kern des Soldatentums bis zu seinen äußerlichen Formen und kleinsten Erlebnissen wie restlos ausgeschöpft.

Für diese Kriegswelt des großen Briten ist die Zeit nunmehr reif geworden. Das deutsche Kampfdrama zehrt von dem Schatz, den der Götz erschließt, bis zur Penthesilea und der kleistischen Hermannsschlacht und darüber hinaus immerfort; dergestalt, daß man, wie die Geschichte einer Bibelstelle, bei der kanonischen Geltung Shakespeares seit dem Sturm und Drang auch die Geschichte einer seiner soldatischen Formungen, etwa der Schildwachszene des Hamlet, schreiben könnte.

7) „Nur die allein. / Die sich an Spaß und Unzucht gern erfreun, / Am Tartschenlärm. die nur der Bursch ergötzt / Im bunten langen Kleid, mit Gelb besetzt, / Sie sind getäuscht; mit Wahrheit groB und wichtig. / Darf, Edle, niemals Schattenwerk so nichtig / Als Narr und Kampf sich mischen, sonst entehrten / Wir uns und euch -.."

8) Zum Schäkespears Tag. $\mathrm{DjG}^{2} 2,140$.

9) Vgl. Brotanek S. XXXVII. 
Mit den Worten .,Verzeihen Sic, Dichter und Soldat, es immer dem unsoldatischen Dichter, wenn er etwa die schlimme Seite des Krieges und der Krieger allzusehr übertrieben hätte" entschuldigt Lessing im 36. Literaturbrief seinen Logau bei dem fiktiven Adressaten, einem bei Zorndorf verwundeten Offizier. Scit dem Eingeständnis Horazens über seine unrühmlichen Erlebnisse bei Philippi ${ }^{10}$ ) war dic Eignung der Dichter zum Kriegshandwerk verdächtig. Das Poetengeschlecht konnte insgesamt, gemäß dem horazischen „militiae quamquam piger et inalus, utilis urbi," "') als unsoldatisch gelten. Opitz stand nicht an, im .,Lob des Krieges-Cottes "12) im Anschluß an den Römer für seine Person zu erklären: „Ein Fechter bin ich nicht; ich kann wohl wettelaufen / Wann Feind fürhanden ist - " und für die Dichterfamilie im ganzen geltend zu machen: „Poetenvolk ist heil, ist leichte wic ein Feuer, / Geht durch -“".

Die scharfe Trennung von Leier und Schwert ${ }^{13}$ ) besteht, nachdem das Vollmenschentum der Renaissance untergegangen ist, durch Jahrhunderte. Wir sahen, wie der soldatische Lebenskreis den Stubendichtern der Gottschedschen Schaubühne durchaus fernlag, noch mehr aber, daß er selbst in der Produktion derjenigen, die ihr Leben in ihm verbrachten, höchstens in Äußerlichkeiten wirksam wird. Es wäre nach den Stücken eines Schönaich und später noch Ayrenhoffs kaum zu erschließen, ob der Verfasser Offizier oder Pastor war - so fremd dem eigenen Dasein ist damals dic nach Mustern betriebene, unpersönliche Dichtung. ${ }^{14}$ )

Der Siebenjährige Krieg hatte die Verhältnisse gewandelt. Bei Brawe, bei Lessing im Philotas ist trotz dem Zurückdämmen alles irgendwie aktuellen Cl:arakters das Zeiterleben zu spüren. Die Kriegserfahrung der Gegenwart beginnt letendige Züge für die Darstellung weit zurückliegender kriegerischer Vergangenheit zu leihen. Klopstocks Hermannsschlacht schreitet darin weiter, und wir erkannten den Offizier im Rezensenten Gerstenberg eben daran, daß

i9) Carm. 13. 7. Fur seine von je angezweifelle Tapferkeit setzt sich Lessing in den ..Rettungen des Horaz" (Werke 5. 2i4: 29j-98) gewichlig ein: nach ihn bricht Wieland in den Anmerkunģen zu seiner Chersetzung der Episteln (Klassiker des Altentums, I. Reihe, Bd. 6. München u. Leipzig 1911. S. 347-48, vgl. S. 249) für sie eine Lanze.

i1) Epist. 11. 1 v. 124.

2) V. 486 f.: 521 : DNL, 27, $86-87$.

13) Den tatenlosen jungen Dichter, der vorn Krieger für sein Gedicht lernen muß, schildert Coethe in Tasso v. 428 f.; den Mann der liedeswerten Tat kontrastient die Prinzessin v. 801 f. mit deren Sänger, der sie auf die Nachwelt bringt.

11) Daß Dichter aus dem Soldatenstand übrigens regelmäßig sein müssen, erkliart ein SpeB Brentanos. in dessen Custav Wasa (1. 15) sich ein Tollheitsanfall eines Offiziers im Theater im Cegensalz zu einem zivilistischen - in eine Schlachischilderung in Ottaverimen entlidt: das RegelmäBige komme bei ihnea vom Reglement und der Taktik. 
ihn die neue Lebendigkeit ergreift. Die Vorstellung vom unsoldatischen Poeten widerlegt der preußische Major Ewald von Kleist durch einen edlen Soldatentod, wenn er auch im Leben selbst noch zu fühlen bekam, daß es unter Offizieren eine Art von Schande war, ein Dichter zu sein. Einen Ausgleich zwischen Leben und Dichten kann er nach den Verhältnissen dieser Übergangszeit noch nicht finden: todesmutige Soldatenbegeisterung der neuen und die ängstliche Anschauung der alten Zeit vom Krieg als einer den schönen Künsten feindlichen, rohen Macht durchkreuzen sich in seiner Poesie. ${ }^{15}$ )

Aus demselben Siebenjährigen Krieg, der den Dichter Kleist fallen sah, ist uns eine Szene erhalten, die an der Schwelle der neuen noch einmal die alte Zeit strengster Observanz, zum Symbol verdichtet, vor Augen führt: des zahmen Gellert Erlebnis mit dem Husarenleutnant, das der erschreckte Poet mit liebenswürdigem Humor selbst erzählt. ${ }^{16}$ ) In seine Leipziger Studierstube dringt eines Tages ein ungeschlachter Martissohn, mit drohenden Augen, kotigen Stiefeln, blutigen Sporen und barbarisch gezopftem Bart ein entsetzensvoller Anblick; aber er entpuppt sich seinem Äußern zum Trotz als ein glühender Verehrer der Gellertschen Schriften, der weder zu plündern kommt - diese bittere Erfahrung machte im gleichen Krieg Freund Rabener ${ }^{17}$ ) - noch einen Verhaftbefehl bei sich führt, sondern dem Lieblingsdichter bloß seine Huldigung zu Füßen legen will. Immerhin zittert dieser bei seiner Umarmung, und als der Soldat ihm als Anerkennung für sein Bücherschreiben Beutestücke anbietet und zugleich, anpreisend, ihre Geschichte erzählt, läuft es dem Poetlein eiskalt über den Leib. Er weist dem Kriegsmann seine Bücherschränke, als das Gewchr mit dem allein er umzugehen wisse, und hat schließlich keine andere Empfehlung an seinen General auf dem Herzen, als die Bitte um Frieden - die bei dem Berufssoldaten nach den Verhältnissen der Zeit kaum ein geneigtes Ohr finden wird. Der ganze Auftritt ist in den "Zwey Briefen" im Kupfer festgehalten: der Poet im langen Magisterrock, die Hand auf den

15) Vgl. Meyer-Benfey, H. v. Kleist 2, 519; E. v. Kleists Stellung zum Kriegerischen is ${ }^{t}$ anläßlich seines 200. Geburtstages am 7. März 1915 aus der Gegenwart heraus mehrfach gewürdigt worden; vgl. z. B. O. Walzels Gedächtnisartikel, Leipziger Tageblatt $1915 . \mathrm{Nr} .119$.

$\left.{ }^{16}\right)$ Zwey Briefe, der I. von C.F. Gellert, der II. von G. W. Rabener, Leipzig und Dresdien 1761, S. 4-10. Vgl. Jördens 2, 59 u. Muncker, Bremer Beiträger Bd. I, DNL 43, 8.

1i) Zwey Briefe usw. S. 24: „Das schmerzet mich am meisten, was ich durch die Plünderung verloren habe; unsere Freunde, unsere Hülfsgenossen, unsere apostolisch-katholische Erretter, Leute die sich das größte Gewissen machen würden am Char-Freitage Schweine-Braten zu essen, die plündern uns selbst in der größten Beängstigung, und brechen die Keller auf, in welchen man vor der Wut der Flammen und der Feinde noch etwas retten können, und man soll auch nicht einmal davon reden; das ist zu grausam! Sagen sie es auf mein Wort in Warschau nach, daß uns die Feinde zwei Drittel verbrannt. und unsere Freunde ein Drittel gestohlen haben" usw. 
Büchern, der Soldat, martialisch genug, mit der Knute und ungeheurem Schleppsäbel.

Das neue Fühlen führt der tatfrohe Sturm und Drang zum Siege. Die junge Generation hat zum Kriege kein anderes als ein freudig bejahendes Verhältnis, ja eine wahre Sehnsucht nach ihm. .In Krieg" verlangt Lenzens Reinhold Strephon mit vielen anderen Sturm- und Dranghelden, ${ }^{18}$ ) die die Gluthitze ihres Innern in Kampf und Waffentat auskühlen wollen. „Krieg war meines Herzens Ruf" gesteht der ritterliche König Edgar noch in Klingers Elfricde. ${ }^{19}$ ) Schillers Moor stellt schwachherzige Schulweisheit mit bitterer Klage dem freien Heldentum der Antike gegenüber: „Schöner Preis für euren Schweiß in der Feldschlacht, daß ihr jetzt in Gymnasien lebet und eure Unsterblichkeit in einem Bücherriemen mühsam fortgeschleppt wird. Kostbarer Ersatz eures verpraßten Blutes -."

Wie ihre Helden, die Gestalt gewordenen Träume des eigenen Innern, dürsten die Genies nach kriegerischem Tun, trotzdem, oder besser weil die Zeit friedlich ist. (.Uberall Friede, schändlicher Friede", klagt Strephon). Jetzt fällt auch im Leben die Schranke zwischen dem Dichter und dem Soldaten: ein Lenz lernt als Hofmeister der Herren von Kleist in Straßburg das Soldatenwesen aufs gründlichste kennen und betreibt leidenschaftlich in um. fänglichen Entwürfen Militärreformen, welche die Wehrmacht auf nationaler Crundlage und ebenso die Taktik neu begründen sollen; ${ }^{20}$ ) er wirft in den ..Soldaten" grelle Schlaglichter auf die soziale Seite des Standes. Der junge Goethe rechnet beim Götz auf den Beifall der Kriegsleute. „Hier schick ich Ihnen ein Drama meiner Arbeit. Sein Glück muß es unter Soldaten machen" schreibt er in einem Geleitbrief des Stücks. ${ }^{21}$ ) In Klinger endlich vollzieht sich geradezu das Bündnis des Degens mit der Feder, wie es Huttens Losung .,litteris et armis” feiert, wie es Wilhelm Schlegel für die Blüte der spanischen Dramatik schön auseinandersetzt. ${ }^{22}$ ) Ewald von Kleist hatte unter

16) „Die Freunde machen den Philosophen" II, 3. E. Schmidt, Lenz und Klinger, Berlin 1878, S. 30: vgl. Brahms reichie Zusammenstellung über den Tatendurst der Stürmer. Ritt. S. 191 .

19) Basel 1783: IV. 4. Werke 1. 249 u. 252.

20) Coethe. Dichtung und Wahrheit. 14. Buch: Werke 28, 249; E. Schmidt, Lenz und Kolinger S. 19 u. 22: ders.. Lenziana. Abhandlungen der preuß. Akademie 1901. S. 988-89; vgl. K. Freyes Einkeitung zu Lenz" "Uber die Soldatenehen", Leipzig 1914, S. I ff. und die Anmerkungen, das., S. 102 ff.

21) An Demars. [Frankfurt Juli 1773]. Briefe 2. $x$.

23) Dramsi. Kunst und Litt. ${ }^{2}$ 3, 364-65. Aus der Liste spanischer Dichter und Soldaten. die Schlegel samt ihren Feldzügen verzeichnet, seien nur der Invalide Cervantes. Lope und Calderon hesvorgehoben. Der Ahnherr der neueren deuischen Dichter und Soldaten - als 
der Verbindung gelitten, jetzt verleiht sie der Dichtung Klingers den freudig ritterlichen Charakter, wie er die Spanier auszeichnet. Klinger ist geborener Soldat. Wieland findet ihn ,für jede Civil-Bedienung zu groß", und will ihn als Leutnant unter den Preußen sehen. ${ }^{23}$ ) Die Sorge um Anstellung im Heeresdienst erfüllt seine Jugendjahre und zeitigt manches abenteuerliche Projekt, ${ }^{24}$ ) bis er die Erfüllung heißer Wünsche zu erhaschen glaubt und als Leutnant eines kaiserlichen Freikorps begeistert in den bayerischen Erbfolgekrieg zieht. Die träge Führung des Feldzuges enttäuscht den Tatenhungrigen aber, und er sieht sich bald genug von der trügerischen Kriegeswoge wieder an Land gesetzt ${ }^{25}$ ) endlich tut sich ihm in Rufland die Offizierskarriere auf, die ihn allerdings nicht m.ehr in den $\mathrm{Krieg},{ }^{26}$ ) aber zu hohen militärischen Stellen im Friedensdienst des Kadettenkorps führt.

Dieser überzeugteste Soldat unter den deutschen Dramatikern ist nicht der einzige. Eine besondere Fügung will es, daß die Größten der künftigen Zeit, Schiller und Kleist, nicht nur dem Stande entsprossen sind - Klinger ist der Sohn eines einfachen Konstablers - , sondern beide seine harte Schule durchgemacht haben; ein Sachverhalt, der für die deutsche Kriegsdramatik entscheidende Bedeutung hat. Wir werden den soldatischen Problemen, die sich aus den biographischen Umständen entwickeln, begegnen.

Dem frühen Sturm und Drang liegen sie noch fern; er wirft sich mit der ganzen Frische einer jungen Neigung in die Gestaltung kriegerischer Tat, die ihn aus seinem Evangelium Shakespeare in berauschender Fülle lockt. Als stärkster Ausdruck und zugleich mächtigster Anreger des Erlebens der jungen Ceneration ersteht Goethes „Götz von Berlichingen“..2i) Man

Urvater dieses Typus überhaupt kann Aeschylus gelten - ist der Landsknecht unter Kaiser Maximilian und Liederdichter Jörg Graff. Neben ihm stehen Renaissancegestalten wie der Berner Dichter, Maler, Staatsmann und Soldat Niklaus Manuel. Ein anderer Landsknecht, der zweimal wider den Türken zieht, Valentin Schumann, verfaßt als Schwankdichter das "Nachtbüchlein“. - Ins bürgerliche Soldatenstück hat der jüngere Stephanie eine reiche Standeserfahrung mitgebracht; er beginnt als preußischer Husar und bringt es, von den Österreichern gefangen, bei ihnen bis zum Oberleutnant; Koberstein 5, 331; vgl. Stockmayer S. 12 u. 14.

$\left.{ }^{23}\right)$ Rieger I, 154.

2i) Rieger 1, 155; 262; 266;268; 303-04; Klingers Bemühungen sind kurz zu übersehen in K. Freyes Einl. zu Sturm und Drang, Dichtungen aus der Ceniezeit. In vier Teilen. Berlin usw., o. J., (Gold. Klassikerbibl.) S. LXIV-LXV.

25) Rieger 1, 267--71; 287.

26) Rieger 2, 74-75.

27) Götz von Berlichingen mit der eisernen Hand. Ein Schauspiel. 1773. Zugrunde gelegt ist für diese zweite, wie für die erste Fassung (Geschichte Gottfriedens von Berlichingen mit der eisernen Hand dramatisiert [1771]) der Abdruck in Hir zel-Mor ri s' Der junge Coethe (DjG) Bd. 2 u. 3. 
hat ihn trefflich das literarische Roßbach genannt: $\left.{ }^{28}\right)$ dic Niederlage der Franzosen ist mit ihm vollkommen. Wir sahen wie Klopstock dem deutschen Kampfdrama das Schlachtfeld gewann; Götz gewinnt ihm die Welt - im Thema zu bleiben: die Welt des Kriegerischen. Sic kann sich frei in Raum und Zeit entfalten, nachdem die kerkermäßig ängstliche ${ }^{2 y}$ ) Ortsschranke gefallen ist. Was Herder an Shakespearc erlebt, gestaltet Gocthe: jeden Vorgang in körperlicher Umwelt, umhüllt von Luft und Licht, in seiner ihm völlig gemäßen Atmosphäre. Klopstock ist in allen diesen Dingen Vorztufe, Geethe die Erfüllung.

Es handelt sich bei ihm nicht wie bei Shakespeare um Kampfentscheidungen von weltgeschichtlicher Tragweite, noch wie bei Klopstock um die Befreiungsschlacht eines Volkes. Aber nicht die sachliche Bedeutung der Ereignisse. sondern die Intensität ihres Erfassens gibt den Ausschlag. In Goethes Gestaltung stchen die Plänkeleien um Jaxthausen und die Gefechte seiner kleinen Reitertrupps jenen mächtigen Geschehnissen nicht nach. Die Gewalt des kriegerischen Geistes reißt hier wie bei Shakespeare mit.

Gegen Klopstocks Hauptschwäche, seine stagnierende Gesamtanlage, hat Goethe aus ganz anderem Erleben sein sieghaftes Tempo zu setzen. Die Beweglichkeit der Handlung wird durch ihre Ausbreitung im Raum mächtig gefördert. Wo Klopstock weite, öde Strecken zu überwinden hat, wechselt Gocthe die Szene und führt überall dorthin, wo etwas geschieht. Während Klopstock eine der realen angenäherte Kampfzeit durch allerhand Fïllsel mühsam ausstopfen muß3, gibt Goethe mit kühner Momenttechnik nur das wesentliche, den Kern der jeweiligen Aktion, und überläßt alles andere den irrealen Szenenzwischenräumen, welche Wochen so gut wie Stunden umfassen können - im äußersten Gegensatz zu der sogenannten Einheit der Zeit, die in ihrer idealen Form nichts anderes ist als der kontinuierliche Zeitablauf in einem Tempc, das der Realität möglichst nahe kommt. Auf diese Weise geschieht es, daB der Götz, der in seiner inneren Gesamtform, als Historic, epischbiographisch geblieben ist, doch zugleich in seiner Einzelform die größte Überwindung des Epischen und seine völlige Umsetzung ins Aktionelle erreicht. Der mühselige Trott des klopstockischen Schlachtkleppers ist zum brausenden Galopp eines edlen Streithengstes geworden. Auf dem Theater freilich ist für ihn kein Raum, und der Götz vollendet damit auch diese andere Tendenz von Hermanns Schlacht: dic Abwendung von der Bühne. Klopstock geht auch als Buchdramatiker, allerdings erst halb entschieden. Coethe voran, der jetzt alle Schranken sprengt und in völliger Unbekümmertheit um das Theater dramatisiert.

28) Weissenfels, Goethe im Sturm und Drang 1. 341.

a) Coethe. Zum Schäkespears Tag. DjG:2. 138. 
Diese Richtung des Götz hat Tieck am feinsten erfaBt ${ }^{30}$ ) und insbesondere auseinandergesetzt, wie Goethe von seiten des Lokals - auf dem von Klopstock eingeschlagenen Pfad - weiter schreitet als dem Dramatiker überhaupt zusteht. Er zwinge auch die szenischen Überschriften von Schenke, Feld und Lager, in die er nicht minder Poesie lege, in seinem Gedichte mitzuspielen, er versetze uns, statt als Zuschauer vor das Schauspiel, mit in dieses hinein und gebe die Wahrheit selbst statt des Scheins der Kunst. Die szenischen Anweisungen des Götz sind in der Tat nur zu Unrecht als solche zu bezeichnen, sie stehen als epische Bestandteile, dem dramatischen Roman zugehörig, für die Phantasie des Lesers da und können vom Regisseur nicht in Dekoration umgesetzt werden. Hierin scheidet sich Goethes Kampftechnik grundsätzlich von derjenigen Shakespeares, der stets für das lebendige Theater, wenn auch für eine anders beschaffene Bühne und vor allem für eine regere Zuschauerphantasie schreibt. Seine Lokalität ist restlos durch das Wort, als „gesprochene Dekoration“" gestaltet, wie das Wort überhaupt die ganze Umwelt des Dramas gibt; er bedarf weder des Behelfs der szenischen Anweisung noch wesentlicher dekorativer Unterstützung. Einen bequemen Prüfstein für die Theatergerechtheit gibt hier wie anderswo die Verwendung von Pferden in Kämpfen ab, die Shakespeare vermeiden muß, ${ }^{31}$ ) während Goethe auch darin keine Beschränkung kennt. ${ }^{32}$ )

Diese Bühnenmäßigkeit des shakespearischen Dramas ist der folgenschwerste Unterschied, der sich aus dem Vergleich des Götz mit ihm ${ }^{3 \hat{s}}$ ) für die Kampftechnik ergibt. Bei Goethe und einigen seiner Nachfolger liegen die Dinge so, $\mathrm{daB}$ manches der theatralischen Darstellung völlig hohnspricht, anderes aber eminent bühnenmäßig empfunden ist. Eins schließt das andere nicht aus. Die Raumvorstellung des Dichters schwankt, der Leser fühlt sich hin- und hergeworfen; bald hat er festen Bühnenboden unter sich, aber wenn er zugreifen

30) Professor Emmrich in Jungen Tischlermeister, Schriften 28, 255.

31) Heinrich V., Chorus vor dem ersten Akt: "Wenn wir von Pferden sprechen, denkt, ihr seht sie / Den stolzen Huf ins weiche Erdreich prägen“. Niacbeth IIl, 3 wird das Auftreten von Pferden absichtlich motivierend umgangen, ebenso in der Schlacht in Richard III: V, 4 "Ihm fiel sein Pferd und doch ficht er zu FuB" usw.

39) $\mathrm{DaB}$ das Theater an der Wien den Götz 1809 gerade deshalb als bühnenfähige „RっBkomödie" aufführen werde, war nicht abzusehen; rgl.den Anhang Pferde. Ein Hamburger Rezensent meinte dagegen ausdrücklich. da8 das Stück ,nicht für die Schaubühne bestimmt sei, . . als welche die Vorstellung von Pferden und manchen andern Dingen nicht leiden würde" (Frdr. Winter, Die erste Aufführung des Cötz v. B. in Hamburg. Litzmanns Theatergesch. Forschungen 2 (1891), S. 25).

23) Er ist am eingehendsten unternommen von Minor und Sauer, Studien zur Coethephilologie, und Weissenfels 1, $347 \mathrm{f}$. 
will, weitet sich der Raum zu einer nur noch in der Natur selbst gegebenen Landschaft. Klopstock verleugnet darin, trotzdem er ins Freie geht, noch nicht die festen Begriffe der alten Schule; sein Naturschauplatz ist scharf umgrenzt und durchaus als gesondert von der umgebenden Raumweite, die durch die Teichoskopie erfaßt wird, empfunden. Die Vorstellung eines Bühnenvierecks herrscht überhaupt im gesamten dramatischen Schaffen, auch dem freiesten, buchmäßigsten, strenger als man vermuten würde. Wenn auch kleinere Grenzüberschreitungen häufig vorfallen, ${ }^{3 \cdot}$ ) cin völliges Verschwimmen des Bühnenraumes in die schrankenlose Natur, wie man es an manchen Stellen im Götz und besonders auf den Schlachtfeldern Grabbes schwindelnd beobachtet, ist selten.

Der junge Goethe gibt im dritten $\mathrm{Akt}^{35}$ ) mit ciner Kühnheit, worin ihm nur Grabbe gefolgt ist, eine ganze taktische Reiteraktion. Selbitz faßt die Reichstruppen, denen gegenüber Götz frontal hält, in der rechten, Lerse in der linken Flanke im Galopp. Die Bühne ist zum Schlachtfeld erweitert. Cleich die folgende Szene dagegen zeigt in der Verwendung der Beobachtung. kraft deren Klopstock an der Ortseinheit festzuhalten vermochte, die genaueste Beschränkung auf das Theater; sie konnte daher als cinzige aus der Reichsexekution schon in den frühesten Bühnenbearbeitungen des Götz, der Berliner Einrichtung Kochs und der Hamburger Schröders, beibehalten werden ${ }^{36}$ ) Es ist der vielgenannte Auftritt des verwundeten Selbitz, ,Eine Höhe mit einem Wartturm": Tiecks Schulmeister erklärt ihn nicht ohne Darstellereitelkeit als den schönsten im ganzen Stück, und er war Tieck selbst sichtlich ganz besonders ans Herz gewachsen ${ }^{37}$ ) Man führt ihn allgemein auf die Szene Shakespeares im Julius Cäsar V, 3 zurück, ${ }^{38}$ ) wo Cassius den Pindarus vom Hügel Ausschau halten läßt. und sieht den besten Beweis einer Anlehnung darin, daß sie nur äußerlich sei: bei Shakespeare gibt die Beobachtung das treibende Motiv zu Cassius' Selbstmord ab, bei Coethe ist sie bloß schildemd. ${ }^{39}$ ) Das gerade

34) Für den jungen Schiller gibı Petersen S. 181 f. Beispiele.

35) III. 12 u. 13. Die Zählung nach Minor u. Sauer S. 126 für die Fassung A (I771). Die Frage, ob, oder besser wie weit Coethe beim Cötz an die Bühne gedache hat oder nicht, wird durch die inneren Zeugnisse in Werk selbst, in erster Linic die Raumvors:ellung, unzweifelhaft entschieden, während die von Frdr. Winter. Theatergesch. Forschungen 2.13-15 beigebrachten auberen Belege nicht weiterführen.

56) E. Kilian. Coethes Götz von Berlichingen auf der Bühne. Dramaturg. Bläter I (1905), S. 169-71: das ausführliche Programm seiner Einrichtung, das Schröder dem Publikum in die Hand gab, ist abgednuckt bei Frdr. Winter.

37) Der junge Tischlermeister. Schriften 28, $248 ; 214$.

20) Minor u. Sauer S. 278-79; Brahm. Ritt. S. 151; von der Hellen, Coethes Werke. Jubil. Ausg. 10. 283: Morris, DjG2 6. 206.

39) Ein Reat der Funktion der Szene bei Shakespeare kann in dem ..So stirb Selbitz" Coethes gesehen werden: Cassius: „O Memme, die ich bin, so lang zu leben”". 
stellt diesen an Klopstocks Seite, der zweifellos neben Shakespeare auf die Szene eingewirkt hat. ${ }^{40}$ )

Die Beobachtung ist mehr ein Kunstmittel der geschlossenen als der offenen Form, wenn auch allerdings keins der französischen Tragödie; (diese kennt sie höchstens in der dem Rationalismus einzig gemäßen, kümmerlichen Anwendung: der Ankündigung von Auftretenden). Wer auf seiner Bühne alles sichtbar werden läßt, bedarf ihrer nicht, oder höchstens beiläufig als eines Griffes unter vielen. So ist es kein Zufall, daß Shakespeare in der Unmenge seiner Kämpfe nur ganz seltenen Gebrauch von ihr macht. Als ausgebildeter Typus - ein Beobachter, der einem anderen meldet - steht die angeführte CassiusSzene einzig da. ${ }^{41}$ ) Nah verwandt, wenn auch mit einiger Veränderung, ist ihr der monologische Auftritt des Enobarbus in Antonius und Cleopatra III, 8. Das Motiv, daß der Beobachter nicht mehr sehen will, weil es schlecht steht, tritt hier stark hervor. Sonst findet sich nur entfernteres, ${ }^{42}$ ) darunter auch eine unmittelbare Nachbildung der antiken Teichoskopie in Troilus und Cressida I, 2, wo Pandarus als Kuppler der Cressida die heimkehrenden troischen Helden schildert, die Shakespeare aber zugleich leibhaftig über die Bühne gehen läßt.

Das Drama strenger Form dagegen ist auf die Beobachtung angewiesen. Wir trafen sie in der antiken Tragödie und bei Klopstock und werden verfolgen, wie sich die deutsche Klassik das Mittel dienstbar macht. Shakespeare becient sich seiner mehr beiläufig in einer Stelle von wenigen Versen, in gedrängter Kürze. Klopstock hat es umständlich ausgebildet, und der junge Goethe lernt von beiden. Die Übereinstimmungen seiner Szene mit Shakespeare sind bereits gemustert. ${ }^{43}$ ) An Klopstock ist sicherlich die Technik von knapper Frage und Antwort geschult. Shakespeares Beobachter meldet, einmal aufgerufen, in fließender Rede. Das Gemeinsame mit Hermanns Schlacht liegt allerdings

10) Die Tatsache stellt schon Weissenfels 1, 354 fest. Andere Einflüsse der Hermannsschlacht bringen Minor u. Sauer S. 167-68 und Weissenfels 1, 346 u. 510 zur Sprache.

41) Das technische Motiv kann daher nicht schlechthin (Petersen, Säkularausg. von Schillers Werken 6, 401 f.) ein shakespearisches heißen. - Nach der Bühneneinrichtung der Shakespearezeit stand der Beobachter auf der Zinne (dem Balkon der Shakespearebühne); auf diese beziehen sich die szenischen Anweisungen: Pindarus ascends the hill; dann: Pindarus above und schließlich: Pindarus descends.

42) Ant. u. Cleop. IV, 12 geht Antonius um Ausschau zu halten ab und berichtet zurückkommend. Heinrich V: IV, 8 sichtet der König eine Reiterschar auf einem Hügel. Lear IV, 6 täuscht Edgar dem blinden Gloster den Blick von schwindelnder Klippe auf Meer und Strand hinab vor.

43) Minor u. Sauer S. 279. Ubersehen ist dort, daß Selbitzens "Reit einer hin und fluch und wetter sie zurück" dern "Wenn du mich liebst, Titinius, so besteig / Mein Pferd" usw. entspricht.

Scherrer, Kampf im deutschen Drama. 
mehr in der Art des technischen Verfahrens als in einzelnen Anklängen. Einige Parallelen zeigen ebenso die Anlehnung als ihre Grenzen. ${ }^{44}$ ) In Gocthes Szene wird das Interesse auf den einen Punkt gesammelt; Klopstocks Beobachtungen, die an sich zum lebendigsten scines Bardicts gehö:en, verzetteln sich auf eine weite Strecke. Ganz Goethe eigen ist das unvergleichliche Tempo des Auftritts, die Atemlosigkeit womit geschildert wird, wie auch die Intensität der Anschauung. Hier zeigt sich die überlegene Dichterkraft, die alle Anlehnung nur zu einem äußerlichen Ding macht.

In der sachlichen Motivierung der Beobachtung steigert der Götz hinwiederum ein Motiv Klopstocks. Der Dramatiker sicht sich stets in die Notwendigkeit versetzt zu begründen, wanum er einen Beobachter anstellt, und den Empfänger der Meldung nicht mit eigenen Augen sehen läßt. Je spannender die Beobachtung gestaltet wird, um so eher drängt sich dem Zuschauer die Frage auf. An anderer Stelle trifft sich Klopstock in dieser Motivierung mit Shakespeare. ${ }^{43}$ ) Goethe bildet einen der beiläufigen Züge von Hermanns Schlacht zuın Hauptmotiv aus: der todwunde Siegmar fragt nach dem Stand des Kampfes. ${ }^{46}$ ) der aber vorher schon dem noch Unversehrten, wie auch dem Oberdruiden Brenno, gemeldet wird. Neu und für die Teichoskopie im engeren Sinne charakteristisch ist im Götz die Warte; aufs glücklichste aus Klopstock weitcrgebildet die Belebung der Szene bis in die kleinsten Züge: wie etwa der Knecht hinaufklettert. An anderer Stelle schickt Götz den Georg auf den Weg hinaus, um mit dem $\mathrm{Ohr}$ an der Erde nach Pferdegetrappel zu horchen. wie Siegmar den Horst das Ohr an den Felsen legen läßt, den Huf der Rosse zu belauschen. ${ }^{17}$ ) In solchen, dem früheren Drama völlig verschlossenen Kleinigkeiten, wo der Boden, auf dem gefochten wird, mitagiert, liegt eine neue Welt. und es ist wichtig. den goethischen Realismus hier auf Klopstock fußen zu sehen.

Neben der Selbitz-Szene stehen noch eine Reihe von Stellen, an denen

"5) Klopstock Sz. 1, DNL 48, 60, Horst: .Einer fält von einem W'urfspieB aus dem Busch! nun noch einer, noch ciner, Siegmar!". zu Goethes Knecht: ..Da flieht einer nach dem Wald. Noch einer! Ein ganzer Trupp." - Klopstock Sz. 3 S. 77. Siegrnar: ..Sichst du den Adler noch nicht ?” - Horst: „O Sirgmar! Siegmar! eben seh ich ihn!”. zu Selbitz: ..Sichest du Cötzen?”... Knecht: .Ich sehe Cölzen. Ich sehe Georgen!"; (dazu noch Klopst. Sz. 3 S. 82, Ein Barde: .W'ir helfen siegen! Ich sch es! Ich sch's!"). - Klopstock Sz. 8 S. 108. Druide: „Sie Aiehnl sie fiehn auf allen Seiten!", zu Goethes Knecht: .STeg! Sieg! sic tliehn!"

4) Cassius: .Ceh. Pindarus, stcig höher auf den Hügel / Mein Aug war immer schlecht". - Siegmar. 1. Sz.: ...Mein Auge reicht so weit nicht mehr. Blick hinab..."

st) Sz. 7. S. 100: die Parallele ist auch bei Weissenfels 1. 354, mit cincm Irrtum in bezug auf die Selbitz-Szene, verzeichnet.

47) 1. 2: vgl. auch V. 1 vom Zareunerbuben: .Er lag die halb Nacht auf der Erd bis er Pferde häre". Klopstock. Szene 1. S. 60. 
Goethe die Beobachtung mit Meisterschaft handhabt. ${ }^{43}$ ) Angesichts der lockeren Form des Götz widerspricht dies scheinbar der oben gegebenen Charakteristik dieses technischen Mittels. In Wirklichkeit zeigt es aber gerade, worin sich Goethes Kampftechnik von derjenigen Shakespeares unterscheidet. Sie scheint wohl noch aufgelöster und geht in der Tat an einzelnen Punkten über alle Aufführungsmöglichkeit hinaus, bewahrt aber innerlich gegenüber Shakespeare eine große Zurückhaltung. Die „Geschichte Gottfriedens dramatisiert" läßt nicht ein einziges Mal beide kämpfenden Parteien zugleich die Szene einnehmen und führt noch viel weniger Kämpfe selbst vor. Alle diese Dinge, die bei Shakespeare häufig sichtbar werden, bleiben der Beobachtung und dem Bericht aufbehalten. ${ }^{49}$ ) $\mathrm{DaB}$ sie uns dennoch völlig greifbar sind und der Cötz im ganzen durchaus als die Erlösung des Kampłdramas aus aller Enge zu gelten hat, liegt in der vollendeten Körperhaftigkeit und dem sprühenden Leben dieser Schilderungen. Der epische Kampfbericht ist in ihnen fast rein aufgehoben und in seiner gedrängten Fülle selbst Aktion geworden. ${ }^{50}$ )

In der Zurückhaltung gegen Shakespeare liegt auch der Punkt, wo der Unterschied der Fassungen, der Geschichte Gottfriedens von 1771 (A) und des Götz von Berlichingen von 1773 (B), der bisher vernachlässigt werden durfte, ins Gewicht fällt. B ist bei größerer Geschlossenheit kampftechnisch freier und hat neuerdings von Shakespeare gelernt. Sie drängt die Adelheid-Handlung zugunsten der Kampfhandlung zurück. Der Bauernkrieg, in A stückweise abgerissen, wird jetzt in großem Zuge durchgeführt ${ }^{51}$ ) und durch die neue

48) Inhaltlich und technisch am wichtigsten III, 23, die Knechte am Rüstschrank, welche die Uberwältigung Götzens beim Abzug aus der Burg am Fenster beobachten. Ferner III, 20, wo Lerse einen herumziehenden Reichsmusje aus dem Fenster erlegt, vgl. Shakespeare, I Heinrich VI: I. 4, wo der Büchsenmeister von Orleans ein Stück auf die englischen Beobachter gerichtet hat. - V, 5 sieht Götz Miltenberg brennen; III, 9 der Ritter den filehenden Reichstrupp auf das Lager zukommen. I, 4 beobachten die bischöflichen Diener am Fenster das Einreiten Färbers zum SchloBtor. - Verwandt III, 18, Götzens Unterhandlung mit dem Reichsherold. Georg hat die Piken der Reichsvölker im ersten Sonnenstrahl blinken sehen. Die Fassung von 1773 steuert noch bei: V, 6, Zigeunerinnen beobachten brennende Dörfer. Geringfügigeres $(V, 1$ untergehende Sonne blutrot) ist übergangen.

49) Minor u. Sauer sprechen S. 154 von der ,ängstlichen Technik“, nach der Goethe alles eigentliche Geschehen auf der Bühne im Götz vermeidet.

50) III, 8 faßt Georg in zwei Sätze, wie Götz den Offizier der Reichsexekution angerannt habe. III, 14 berichten Götz, Georg und Lerse, sich ablösend.

51) Eine cinzige Jaxthausenszene, (V, 4), welche den bedenklichen Schritt Götzens beleuchtet, unterbricht die Kampfszenen-Reihe. Das Streben, die Kampfhandlung in einheitlicheren FluB zu bringen, zeigt sich ebenso A III, 8 = B III, 7 Wald an einem Morast, wo durch die kleine treffliche Änderung, daB Götz den Reichsknecht zum Gefangenen macht und Georg übergibt, drei vorher abrupte Szenenfragmente in eins verschmolzen sind. 
Szene B V. I Flucht, vor einen weiten Hintergrund gestellt. .Tumult in einem Dorf und Plinderung" wird hier gezeigt wie V, 5, wo Weislingen und seine Reiter in die mit Götz hadernden Bauern brechen. ..Tumult und Schlacht." ${ }^{2}$ ) A hatte die Nicderwerfung des Baucrnaufstands (V. 6, Weislingen) nur erzählt. Schon vor dieser Entscheidungsszene räumt B dem Gegenpart der Bauern ganz in der Art Shakespeares, der vor der Schlacht fast ständig die Parteien wechselweise vorführt, ${ }^{53}$ ) einen Auftritt ein: die Szene ,Berg und Tal, eine Muihle in der "Tiefe", wo Weislingen mit Reitern sich über seinen Zuzug und die Lage melden und den $W^{\prime}$ cg weisen läßt.

Den bedeutendsten Zuwachs crhält die Kampfhandlung durch dic Umordnung der Zigcunerszene, ${ }^{5.1}$ ) die in A der Adelheid-Reihe angehört. Jetzt rückt sic Coethe in den Schlachtzusammenhang, dem er damit einen gewaltigen Ausklang gewinnt, statt daß in A der letzte Kricgszug Götzens matt abbrach. Die Funktion der Zigeunerauftritte hat nun viel Ähnlichkeit mit derjenigen der ersten beiden Hexenszenen im Macbeth, ${ }^{55}$ ) welche, unbeschadet ihres besonderen Handlungszweckes, die dïster unheilschwangere Stimnung der Schlacht durch die entfesselten Naturgewalten unverglejchlich eindringlicher formen. als es durch reale Kamplvorgänge geschehen könnte. Shakespeare lät es denn auch an der Atmosphäre der Schlacht, die den Kampfbericht des blutenden Hauptmanns näclutig hebt, genug sein und behält ihre Geschehnisse wider scine Gewohnheit hinten. Die gleiche Stimmungsgewalt der Natur stellt jetzt Gocthe in den Dienst der Kampfhandlung. Das Dahinbrausen des wilden Jägers über das nächtige Zigeunerlager steigert die Hetze von Weislingens Reitern hinter Götz her ins Titanische; das Toben der Natur trägt die Stimmung der Verfolgung, bis das gehetzte Wild in ihrem Tumult zusammenbricht. Was nun folgt, das letzte Aufflackern des Widerstands, wie sich die „,wilden Kerls, starr und treu“ für Götz einsetzen, der Strom der Feinde aber über sie weggeht, stellt sich in der gesammelten Knappheit und der mitreißenden Schnelle des Geschehens dem Besten an Kampfgestaltung in der ersten Fassung an dic Seitc. Es ist eine der Stellen, wo wie nirgends sonst in dem neuen Rhythmus das neue Erleben des Sturm und Drangs fühlbar wird, und man rückblickend erkennt, welchen Abschnitt der Götz in der dramatischen Bewältigung des Kriegerischen macht.

Das Soldatische wird auch sonst mit neuen Sinnen erfaft. Die kleinen und

62) Vgl. Minor u. Sauer S. 154.

$\because 7$ Z. B. Ant. u. Cleop. 111. 7 u. 8: IV, 10 u. 11; Macbeth V. 5 u. 6.

i) Eine andere Auffassung uber diese Änderung Goethes als die hier vorgetragene vertritt Weissenfels S. 380 .

¿) Die sachliche Verwandischaft verzeichnen Minor u. Sauer S. 281. 
kleinsten Züge, Dinge, die früher niemand gesehen hatte, zeigen das am deutlichsten. Wackere Reitergesinnung kann sich nicht prächtiger äußern als in den Worten des Knechtes über den weiblich zarten Carl: „Der wird nicht sein Vater, sonst ging er mit in Stall," ${ }^{56}$ ) denen gegenüber die hundsföttische Denkart der Reichsvölker: ,jeder wirds von sich schieben, Kaiser und Reich zu gefallen Arm und Bein dran zu setzen" - aus dem Mund eines Offiziers! - doppelt niederträchtig erscheint. ${ }^{57}$ ) Auf die innere Verfassung dieser Truppe wirft das Schelten des Knechts auf den Vorgesetzten, der für sich furagieren läßt indessen sie hungern, ein helles Schlaglicht. Wie es sonst um sie steht, erweist sein geplagter Kamerad, dem der falsche Alarm in die Gedärme geschlagen hat. ${ }^{58}$ ) Wie aus den Erfahrungen des Patrouillendienstes geschöpft ist die Bemerkung des zweiten Offiziers, dem der Hauptmann den Beobachtungstrupp nicht anvertrauen will, er habe einen landeskundigen Knecht unter seinen Leuten. Wenn bei der Belagerung Jaxthausens ohne alle Phrase die Viktualien knapp werden (B III, 18 und 20), muß man sich an das gestelzte Heldengerede eines Cato von Utica in nicht ganz unähnlicher Lage erinnern, um zu ermessen wie weit der Weg ist, den das Kampfdrama seither zurückgelegt hat. Wie körperhaft Bekleidung und Bewaffnung bei allen Vorgängen mitgesehen sind, mag eine gelegentliche Erzählung Georgs (B III, 13) erweisen, der einem Reichsknecht seinen Dolch in die Gedärme stieß, „wie sich sein Harnisch in die Höhe zog". Die neu erwachte Empfindung für die Waffe kommt in Götzens Mahnung an seine Leute, zum Abzug die besten Büchsen mitzunehmen, und deren Auswahl durch die Knechte am Rüstschrank, schön zum Ausdruck.

Dieser unerschöpfliche Reichtum des soldatischen Details, die Intensität in der Erfassung kriegerischen Seins entstammt derselben Wurzel, aus der das Naturgefühl, die Empfindung für das Lokal, Kolorit, Luft, Licht und Farbe erwächst: der neuen Sinnlichkeit der Zeit. ${ }^{59}$ ) $\mathrm{Da}$ sie sich gerade am Kriegerischen genugtat, darf man nach einer Schöpfung wie dem Götz allein und

$\left.{ }^{36}\right)$ I, 3; gleichgültig, ob der dazu angeführte Satz der Lebensbeschreibung ( $\mathrm{DjC}^{2} 6,200$ ) angeregt hat oder nicht.

$\left.{ }^{37}\right) \mathrm{V}_{\mathrm{g}}$. dazu das vorzügliche Bild des jämmerlichen Reichskriegswesens, wie es bis in die Tage des jungen Coethe bestand, bei Karl Biedermann, Deutschland im 18. Jahrhundert, Leipzig 1854 ff. 1, 39-47. Jähns, KW 2, 1530 ff. u. 3, 2191 ff.

58) B III, 7; diese aus der Kriegsgeschichte bekannte Wirkung der Aufregung vor der Schlacht findet sich natürlich auch in der Wiener Posse, so in dem vorgelesenen Karnptbericht in Kurz ${ }^{*}$ Prinzessin Pumphia II, 2: „Ein tapfrer Reiter wurd auf seinen FuB getreiten, / Und einer lieff davon, dann ihm war was vonnöten".

${ }^{39}$ ) Vgl. W'eissenfels 1. 328 f. Gundulf S. 192 f. stellt Gerstenjerg als ihren ersten Träger dar. 
ebenso nach seiner weiten Nachwirkung als einen Zug germanischen Wesens, das sich selbst gefunden hatte, deuten.

Beduirfte die Welt des Krieges, die der Götz auftut, und seine freie Technik noch einer Folie, welche sie recht hervortreten läBt, so wäre Lessings „Emilia Galotti" gegen sie zu halten, die mit dem Erscheinungsdatum 1772 zwischen den beiden Fassungen des goethischen Werks liegt. Die Formgegensätze der zwei disparaten Werke prägen sich auch auf kampftechnischem Gebict aus, denn Lessing bringt in interessanter Weise eine Kampfepisode in die vier Wände seines bürgerlichen Dramas. Es handelt sich um den Überfall auf Appianis Wagen, den Marinellis Helfershelfer III, I auszuführen haben. Nichts ist für die mathematisch scharfe Rechnung lessingischer Technik charakteristischer, als wie er sich hier aus der Affäre zieht. Indessen hinten der Anschlag betrieben wird, führt Marinelli den Prinzen auf den Gedanken eines gewaltsamen Raubs der Emilia, und kaum entbindet ihn dessen Wort von der Verantwortung, so fallen die für Appiani tödlichen Schüsse; wie wenn der Regisseur Marinelli nur auf die Klingel zu drücken brauchte. Auf die erstaunte Frage des Prinzen beschreibt der gewandte Kammerherr vermutungsweise den Verlauf, und indem Lessing noch einige Beobachtung aus dem Fenster an $\left\{\right.$ ügt ${ }^{60}$ ) und den Bravo Angelo den Hergang erzählen läßt, hat er die Spannung des Vorgangs seinem technisch geschlossenen Stück, das nur einen Botenhericht erwarten ließe, gewonnen. Eine Welt trennt diese künstliche Koinzidenz von Geschehnis und Schilderung. ${ }^{61}$ ) die alle gegebenen Mittel bewundernswert incinanderarbeitet, von den losgebundenen Kampfszenen des Götz.

In dem Werk Goethes hat das Erlebnis der neuen Generation seine höchste Gestaltung gefunden. In seiner Wertung als Frucht der allgemeinen Stimmung der Jugend soll allerdings nicht vergessen sein, daß der Geniale hier wie überall vorangeht. Er schaft die Zeitstimmung ebensosehr als er, ihre Keime zur frühesten und zugleich kräftigsten Blüte entwickelnd, in ihr wurzelt. Der Götz. erst ruft eine ganze Cattung des Kampfdramas, das Ritterstück, hervor. Es wird sich zeigen, wie dessen Entwicklung lange Jahre braucht, um seine Anregungen einigermaßen zu verarbeiten. Hier ist noch der Stand der Kampftechnik jener Zeit in den Niederungen zu belegen. Ein Jahr nach dem Ritter mit der eisernen Hand erscheint Schummels "Eroberung von Magde-

e) III, 2 der langsam zurückfahrende Wagen von Marinelli. III. 3 die nahende Emilia vom Prinzen geschildert. Lessing verwendet das Mitel auch später im Nathan, besonders Il. 4.

(i) Eine technische Parallele dazu bietet der Tod des Helden in Aeschylus' Agamemnon. den Kassandra aul der Bühne schildert, während sich hinten der Mord vollzicht. Die Koinzidenz ist hier vermöge des Wundertiaren. durch ihre Sehergate, erreicht. Vgl. G. Freytag ${ }^{3}$ S. 67 und Petersen S. 3581 . 
burg“ ${ }^{62}$ ) ein allerdings auf älterer Vorlage beruhendes Belagerungsstück von lokalem Interesse; an sich völlig belanglos, sei es als Gradmesser des allgemeinen Niveaus herausgegriffen. Vom Publikum ist es - nicht zu dessen Ehre - wie es scheint für etwas dem Götz Verwandtes genommen worden. ${ }^{63}$ ) Ein geiler Bösewicht, der kaiserliche Oberst Curban, betreibt in Magdeburg zugleich den Verrat der Stadt an Tilly und seine Werbung um die Tochter des schwedischen Kommandanten, die ihn wütend abweist. Inmitten der Greuel, welche die eindringenden Kaiserlichen verüben, will er sich dadurch an ihr rächen, daß er die Begnadigung von tausend Bürgern von ihrem Entschluß abhängig macht, sich schimpflich an Pappenheim auszuliefern. Durch einen edeldenkenden Untergebenen vor Tilly entlarvt, geht er seiner Sirafe entgegen, indes die hart mitgenommene Stadt Pardon erhält. Man sieht, eine rohe Verbindung von Liebesintrige und Greuelstück, ${ }^{64}$ ) auf dankbarem lokalgeschichtlichem Hintergrund, ganz in der alten Weise und dazu äußerst stümperhaft gefertigt; am ehesten, aber nicht ohne Abstand, etwa neben Weiße zu stellen, dessen Befreiung von Theben eine ähnliche Aufgabe des

62) Nach der Rezension der Gött. Gel. Anzeigen 1774, Zugabeband S. 283: o. O., o. V. 1774. Zugänglich im „Theater der Deutschen“ Bd. 15, Königsberg und Leipzig 1776; die Verfasserschaft ist nicht völlig gesichert. V. Rohwedel, den Holzmann u. Bohatta, Bd. 2 Nr.1790, und $\mathrm{CGr}^{3}$ 4, I S. 666 nennen, scheint nur für die handschriftliche Fassung von 1768 in Betracht zu kommen, die vorliegende Druckbearbeitung aber, für die Schummel nur als Herausgeber zeichnet, ihm zu gehören. Ohne weiteres teilt sie ihn Carl Ludw. Costenoble, der es wissen konnte (Tagebücher 1, 99, Schriften der Gesellsch. f. Theatergesch. Bd. 18, 1912) zu, und liefert zuglcich ein Zeugnis für die Langlebigkeit des Stücks, das sich auf der Magdeburger Bühne erhielt. bis es durch Friedr. Ludw. Schmiàts Behandlung des Stoffes „Der Sturm von Magdeburg“ (1. Aufführung 1799) abgelöst wurde: „Am 10. Mai [1797] wurde die Eroberung von Magdeburg von Schummel aufgeführt. Solange ich denken kann, wurde dieses Stück von den jedesmal anwesenden Schauspielern in meiner Vaterstadt produziert, und mit großem Interesse. Und - sonderbarwir Einheimischen, zur Stadt gehörigen Darsteller vermochten bei wirklich fleißiger Vorführung keine Teilnahme zu erregen." Unter Schummels Namen streift auch W. Kawerau, Aus Magdeburgs Vergangenheit, Halle 1886 S. 175 das Stück, wogegen es in Hippes Artikel über Schummel in der ADB 33, 59 ff. u. in W. Gie rkes Monographie, Berner Diss. 1915, S. 12 ff. fehlt.

63) Der 15. Band des „,Theaters der Deutschen“ druckt es neben dem Götz ab. Schmid, Chronol. S. 219, bemerkt zu einer Aufführung des Stücks, es hätten drei Hände daran gearbeitet ohne einen Götz herauszubringen. In Hamburg behauptete es neben der glänzenden Aufführung des Götz seinen Platz (Litzmann, F. L. Schröder 2, Hamburg u. Leipzig 1894, S. 143), ohne $\mathrm{daB}$ ihm hier der jeder Stümperei günstige Lokalsinn zu Hilfe kam, und wurde in der Zeit rom 17. Nov. bis 2. Dez. 1774 viermal aufgeführt, während der Götz vom 24. Okt. bis 2. Dez. auch nicht mehr als fünfmal gespielt werden konnte.

64) III, 6 erschlägt ein Kroat ein von der Mutterbrust gerissenes Kind an einem Stein, wogegen schon der Göttinger Rezensent auf die horazische Mahnung hinweist. 
Kampfes um eine Stadt zu lösen hatte. ${ }^{65}$ ) Von götzischem Kriegsgeist hat Schummel nicht die Spur, nur cinige Griffe sind der neuen Entwicklung kläglich genug abgeguckt, ${ }^{66}$ ) wie auch Shakespeare mit einer wahnsinnigen Ophelia (III, 10) und einer düster prophezeihenden „Melancholica" unleidlich verzerrt hereinragt. Das Stück kann immerhin zeigen, was nach dem Erscheinen des Götz im Kampfdrama noch möglich war und neben ihm Beifall fand.

6) Man trift bei Schummel wieder die traditionellen Besorgnisszenen der Frauen (in 1I). und jene immer wieder fortrennenden Boten, von denen einmal einer nur auftritt (II, 8) um zu versichern, daB er eile.

${ }^{60}$ Die Beobachtung wird mehrłach in den Dienst der Kampthandlung gestellt: II. 7 sehen die Frauen durchs Fenster auszieh.ende Bürgerhaufen, 11, 8 aufsteigenden Dampl, II. II wie ein Verwundeter (der Catte und Vater) gebracht wird. - Die Knabenszene IV. 2 steht in der Tradition, die von Philotas über die Söhne Ugolinos und Klopstocks Opferknaben zu Goethes Georg fühn 


\section{Fünftes Kapitel. \\ Die Jugenddramen Klingers.}

In Goethes Kreis zurück und zugleich zum Chorführer seiner Nachfolge tührt die Betrachtung dessen, was Klingers Dramatik an Kampfform und -gehalt geleistet hat. Wie bedeutsam die Rolle ist, die das Militärische in seinem Leben spielt, wurde bereits erwähnt. Die Spuren sind in seinen Stücken überall zu finden, denn jetzt hat das Leben im Gegensatz zu früher den stärksten Einfluß auf das Dichten, und der Mann, der von sich sagen konnte: „Ich fühl daB ich dazu gemacht bin, mit diesem Herzen, diesem Körper, "1) erlebte seinen kriegerischen Beruf. Der Götz ist Goethes einziges Kampfdrama geblieben, während Klinger weit über den „Otto“"2) hinaus Kriegerisches gestaltet, am großartigsten in antikem Gewand in den Szenen von Pyrrhus' Leben und Tod. Zeitgenössische militärische Verhältnisse, wie sie Lenz in den "Soldaten“ zur Darstellung brachte, spielen in den bürgerlichen "Sturm und Drang“"3) herein, der eine vorfallende Bataille, wie nicht anders zu erwarten, in den Zwischenakt (von IV zu V) verweist. Den fünften Akt eröffnet eine Besorgnisszene der Frauen bei noch währendem Schiefen; ein Schlachtbericht schildert V, 5 die Vorgänge. Die modernen militärischen Kunstwörter, die sich in Klingers Sprache gelegentlich finden, sind hier besonders am Platze. $\left.{ }^{4}\right)$

Der Otto eröffnet die Reihe der Ritterdramen, die von Götz ausgehen..$^{5}$ ) Klinger übertrumpfte mit ihm den goethischen Kriegshelden durch eine Gestalt von übertitanischem Ausmaß, die als ein wahrer Schlachtengott zermalmend durch die Kämpfe schreiten soll. So schildert ihn der junge Gebhard, der Nachkomme Georgs im Götz (II, 6), in hingegebener Begeisterung. Nur daß Otto gerade in den Gefechten, die ins Stück fallen, keine Gelegenheit

1) Rieger 1, 155.

2) Leipzig 1775; Neudruck DLD 1, Heilbronn 1881; Dramat. Jugendwerke 1.

3) O. O. 1776; Dramat. Jugendwerke 2.

4) Vgl. R. Philipp, Beiträge zur Kenntnis von Klingers Sprache und Stil in seinen Jugenddramen, Freiburger Diss. 1909, S. 83: Bataille; S. 84: Campagne, Conquête; S. 96: crepieren: S. 105: Volontär.

5) Vgl. Brahm, Ritt. S. 73 ff., der besonders über Ottos Abhängigkeit von Götz und Shakespeare handelt, und Rieger $1.37 \mathrm{ff}$. u. $62 \mathrm{ff}$. 
bekommt, sein Heldentum zu bewähren, und seinen Schlachtdurst zumeist in Monologen austoben muß.

Es handelt sich in dem von Motiven strotzenden Drama um die Fehde des alten Herzogs Friedrich und der bischöflichen Partei, der sein Sohn Konrad angehört, gegen dessen unbotmäfigen Bruder Karl. Klinger macht sich im ganzen die Kampftechnik Goethes zu eigen. Wie dieser zieht er in der bewegtesten Weise alle Register der Kampfdarstellung, Bericht, Beobachtung, Vorführung, und wechselt die Mittel sogar gelegentlich ohne ersichtlichen Grund, wohl nur um des quirlenden Lebens willen. ${ }^{6}$ ) In der Kampfvorführung selbst geht er nach dem shakespearischen Vorbild weitcr als Coethe, der die entscheidende Phase des Gefechts vom Wartturm hatte beobachten lassen. Klinger führt in Schlacht und Tumult selbst hinein, und kühner als es die Bauernkriegsszene des Cötz von $1773(\mathrm{~V}, 5)$ tut, wo Weislingen hinter den Flielienden nur den Verfolgungsbefehl gibt. Hier werden von beiden Seiten Worte zusammen mit Hichen ausgeteilt und Shakespeares Technik selbständig weitergebildet. ${ }^{7}$ ) Dieser gibt die Kämpfe zumal in den Historien fast ausschlieflich pantomimisch. Aus der allgemeinen Schlacht schälen sich die Zwiegefechte der Führer heraus;") sie sind uft redend eingeführt, aber dann spricht der einfache Soldat nie zugleich, was mit der aristokratischen Scheidung der höheren Stände vom Volk in Shakespeares Auffassung zusammenhängt. In Klingers Schlachtgewirre gerät Bischof und Reuter. Fürst und Knecht mit Wort und Waffe aneinander. Wie Shakespeare hebt dagegen auch er einen Einzelkampf (Herzog-Walldorf) durch dic szenische Anweisung aus dem Getümmel heraus. An Shakespeare angelehnt ist die Art, wie der Herzog den Gegner erschlägt, darauf durch Öffnen des Visiers feststellt, wer er ist, und ihm ein kurzes Gedenkwort widmet. ${ }^{9}$ )

Für diesen Nachruf aus Freundes und Feindes Mund, der in der Ehrung des toten Gegners die Großartigkeit shakespearischer Auffassung - so wie sie

c) II, 10 beobachien zwei Reuter den Kampfauszug Karls vom Fenster (vgl. Goethes Knechie am Rüstschrank). und wollen auf den Turm, wo man's besser sehe; einer ist aber nach ein pas monologischen Worten Ottos von dort schon wieder zuriick und meldet, was er gesehen.

7) L. Jacobowski. Klinger w. Shakespeare. Dresden 1891. führt S. 42 Klingers Schlachtrechnik zu eng nur auf das Vorbild in Macheth V. 4-7 rurück.

") 7. B. I Heinrich V1: I, 5. 'Yaltoo-Pucelle: Ill Heinrich VI: II, 4. Richard-Clifford: I Heinrich IV: V. 3 u. 4. Blunt-Douglas: Douglas-König Heinrich-P'rinz Heinrich: PercyPrinz Heinrich: Falstaff-Douglas: (daß von hier oder aus Richard III. der Name Blunt bei Klinger stammt, bemerkt Brahm mil anderen Nachweisen des Namens, Ritt. S. 87 Anm. 2); vel. auch Coriolan I. 8, Coriolan-Aufidius. und Macbeth V, 7. Macbeth und der junge Siward: Macduff und Macbeth.

") V'. (ohne geraue Entsprechung) I Heinrich IV: V. 3 
schon Aeschylus in den Persern in erstaunlicher Unbefangenheit bewährt mit am schönsten zeigt, geben die Römerdramen und Historien viele Beispiele; in Feindes Nachruf ${ }^{10}$ ) allerdings mit einer Einschi änkung dem nationalen, französischen Feind gegenüber. Ihm wird die Großheit der Gesinnung nicht zugebilligt, und Shakespeare läßt den Bastard von Orleans bezeichnend genug die Leichen der beiden Talbots verunglimpfen, wenn auch der Dauphin dagegen einschreitet. Die Pucelle spricht nicht minder rüd von ihnen. ${ }^{11}$ ) Auch der Bürgerkrieg kann so unversöhnlichen $\mathrm{Haß}$ zeitigen: die Yorkschen Prinzen schreien dem schon agonisierenden Clifford ein wildes Rachelied in die Ohren, ${ }^{12}$ ) worin dieselbe ungezügelte Leidenschaft und primitiv-barbarische Roheit dem Feind gegenüber lodert, welche die Kriegshelden der llias an den Tag legen; auf der anderen Seite legt allerdings Homer, darin der aeschyleischen Auffassung verwandt, den feindlichen Troern einige der rührendsten Szenen in den Mund.

Der shakespearische Freundesnachruf erklingt am erhabensten über dem gefallenen Cäsar und, in der Kampfhandlung der Römertragödie, in vierfacher Steigerung an Cassius' Leiche ${ }^{13}$ ); in Macbeth verschmäht der alte Siward in heldischer Seelenstärke, um seinen Sohn zu klagen. Im AnschluB an die Gedenkrede auf Percy wird das Motiv auch ins Komische gewendet: Falstaff, aus dem maskierten Tod wieder aufstehend, bedankt sich für Prinz Heinrichs Gedächtnisworte. ${ }^{14}$ )

Der Nachruf Shakespeares hat sein Cegenbild in den Nekrologen der griechischen und französischen Klassiker, die aber das Kampfereignis und den Tod des Helden neben der Klage um ihn mitführen; während die englische Bühne das Ereignis selbst zeigt und für die getragene Rede nur den Preis des Gefallenen aufbehält. Das Verweilen bei ihm tut hier einem ästhetischen Bedürfnis des Abschlusses und rückblickenden Ausruhens nach vollzogener Aktion Genüge. Sachlich steht der shakespearische Nekrolog den gesprochenen Verlustlisten nahe, die am Ende der Schlacht konventionell die vornehmen

$\left.{ }^{10}\right)$ I Heinrich IV: V, 4; Coriolan V, 5 ; Jul. Cäsar V, 5; Ant. u. Cleop. V, I; vgl. auch Brotanek, Shakespeare-Jahrbuch 52, XXX-XXXI. Im deutschen bürgerlichen Soldatenstück, in den konventionell verfestigten Verhältnissen des modernen Berufsheers, entspricht der freien Anerkennung des Feindes das Achtungsverhältnis zwischen gegnerischen Offizieren, das aus der gemeinsamen Standesehre hervorgeht; vg!. Stockmayer S. 40.

11) I Heinrich VI: IV, 7; A. Böhtlingk, Shakespeare und unsere Klassiker III: Schiller, Leipzig 1910, S. 305, versucht umsonst. ihre Äußerungen durch ganz eigenwillige Interpretation zu ihren Gunsten umzudrehen.

12) III Heinrich VI: II, 6.

13) Jul. Cäsar III, 1 u. 2; V, 3; vgl. II Heınrich VI: V, 2.

14) Macbeth V, T; I Heinrich IV: V, 4. 
Gefallenen namhaft machen, ${ }^{13}$ ) und ist sicherlich mit aus ihnen erwachsen.

Durch Klinger tritt die britische Form des Nachrufs in die deutsche Entwicklung ein und herrscht in ihr, bis die Klassik in formschönen, feierlich stilisierten Todeserzählungen die Botenberichte der Franzosen und Griechen erneuert. Charakteristisch shakespearisch ist in scinen knappen Gedenksätzen die Betrachtung, die das ganze Leben des Gefallenen in zwei Worte faßt: $:^{16}$ ) bei Shakespeare findet sich an verwandter Stelle geradezu eine kurze Biographie. die Talbot dem eben getroffenen Salisbury ${ }^{17}$ ) noch während seines Todeskampfes mit ins Grab gibt.

$\mathrm{Da} B$ Klinger im Otto den Kampf vorführt, entspringt durchaus seinem Aktionsbedürfnis. Es ist um so viel bezeichnender, als die Situation - einc als Frauenbedeckung zurückgebliebene Schloßbesatzung, an ihrer Spitze Otto - der Bewältigung der Kampfvorgänge durch Beobachtung und Bericht entgegenkommt, wie spätere verwandte Fälle zur Genüge ausweisen. ${ }^{18}$ ) Auch Klinger nützt sie im übrigen und gibt, während Cocthe in den Händeln mit der Reichsexekution mit seinen Szenen-Ausschnitten in der Kampflinie bleibt, Reflexe bei den Zurückgeblicbenen: Ottos Lechzen nach Gefecht (II, 9 u. 10), Adelheidens Besorgnis (II. 12). siegflehende Reuter (II, 15). Die entscheidende Wendung des Treffens erscheint mit einem Übermaß an Aufwand sogar doppelt; einmal sichtbar und darauf von Otto auf einer Anhöhe beobachtet. ${ }^{19}$ ) Eine Verfolgungsszene, nach dem Götz gebildet, schließt ab. ${ }^{20}$ )

Es war bei Goethe die Rede vom Mitagieren von Pferden. Hier hat Klinger neues zu bieten. Goethe erfaßt sie allgemein vom Tempo, von der Bewegung

15) Richard III: V. 4 und öfter in den Historien: vgl. auch Brotaneh S. XXVIII.

16) ..Nun Walldorf fahr wohl, fahren Verräter wohl. Ich macht dich groß und klein." Das ..Fahr wohl" an das shakespearische fare-well anklingend. Verwande Klinger. Elfriede. 1783. Ende: .lahre hin. wir sind auspesöhni" usu:

1i) I Heinrich VI: I. 4: ..In dreizehn Schlachten siegte Salishury. / Heinrich den Fünften zog er auf zum Krieg. / Solang Trompete blies und Trommel schlug. / Lieb nie scin Schwert in Feld zu schlagen ab."

16) Maier. Sturm von Boxberg 1778 II. 4-1II, 2: Schiller. Jungtrau V. 10-13.

19) $\mathrm{Vgl}$. zum Schluß der vorgeführten Schlachiszene II. 13 (Adelbert: ..Cnädiger Herr, geht alles verloren") Götz B V. 7 (..Fort fort! Alles verloren. Unser Hauptmann erschossen. Cötz gefangen"). und Klingers Stilpo IV. 15: ..Fluchı! Flucht! Stilpo gefangen." - Für die leiden. schaftliche monologische Beobachtung Ottos II. 16 vgl. die Stelle des Enobarbus. Ant. u. Cleop. III. 6. Im Ausdruck lehnt sich Klinger stark an die Selbitz-Szene an.

so) Diese und andere Parallelen siehe bei Brahm. Rilt. S. 92. Eine weitere Fluchsszene folgt V. 9: ..Zu Plerd! zu Plerd! Durchgehauen! Durchgehaum I" (Vgl. die vorige Anen.). 
aus, sie fegen durch seinen weiten Kriegsraum. ${ }^{21}$ ) Klinger verrät in einer Szene, die uns den Otto mit am nächsten bringt, - sie hat schon dem Rezensenten des Teutschen Merkur am meisten gefallen ${ }^{22}$ ) - reiterliche Vertrautheit mit dem Tier. Horst (der Name mag vom Schlachtgefährten Siegmars bei Klopstock stammen) hat bei scharfem Ritt hinter Konrad her ein Eisen verloren, Otto schilt und wettert mit dem treuen Gaul und erhält den rechten Grund zum Fluchen dazu, als ihn eine Hexe lahm gehen macht. Das Pferd ist hier, die stürmerische Derbheit abgerechnet, mit inniger Liebe gesehen und fast als handelnde Person gegeben. Klinger hat ein ganz besonderes Verhältnis zu ihm. ${ }^{23}$ ) Die Gestaltung der soldatischen Dinge erfaßt nun auch das Streitroß; die neue Kunst erobert sich die Welt des Krieges immer weiter. Man sieht in die Tätigkeit einer Kavalleriepatrouille: der Hauptmann läßt II, 6 seinen berittenen Erkundungstrupp absitzen, um sich geräuschlos anzuschleichen, „daß die Kerls die Gäul nicht trappen hören“. Gebhard und Rudolph bleiben nur unwillig als Pferdehalter zurück.

In solchen Dingen tut Klinger eigenes dazu, im ganzen bleibt er im Otto freilich dem Götz zinsbar; wenn auch überall und gegen spätere Nachahmer doppelt fühlbar wird, wie er die Kampfwelt Coethes aus eigenem Empfinden nachzuschaffen vermag. Er überwindet denn auch die Abhängigkeit bald; die ,Szenen aus Pyrrhus' Leben und Tod" ${ }^{24}$ ) zeigen ihn von dem Einfluß des Freundes befreit auf ganz anderen Wegen. Hier, in der Weite der antiken Welt, hat Klingers kriegerisches Teil, von Shakespeare befruchtet, seinen stärksten Ausdruck gefunden. Es war eins seiner liebsten Stücke, ${ }^{25}$ ) und wenn es ihm nicht gelungen ist, seine riesenmäßigen Gestalten zu einem geschlossenen Werk zusammenzuzwingen, so hat er doch in einigen ehermen Szenen den Geist des Krieges mit einer Wucht gebannt, der nur weniges an die Seite zu stellen ist.

Wir sahen wie Elias Schlegel einen ersten, unverächtlichen Versuch machte, das Kriegerische durch die Stimmung zu bewältigen, wie der Lyriker Klopstock diese zum Prinzip der Gestaltung erhob, wie der Götz von 1773 den kriegerischen Clanz seines Helden in der nächtigen Zigeunerwelt verlöschen ließ. Hier baut Klinger weiter. Es muß ihm zum starken Erlebnis geworden sein, wie Shakespeare den Krieg vielleicht - sicher, hätte Klinger sagen müssen -

21) Vgl. für den Rhythmus etwa das „Wir haben gejagt! wir haben gefangen!" I, 3; bei Klinger nachtönend: „Das war gejagt, wir haben sie gesehen“ II, 7.

29) II, 3; Merkur 1775, 3, 179.

23) Vgl. darüber den Anhang Pferde.

24) Im wesentlichen 1775 geschrieben, 1776-79 an verschiedenen Stellen gedruckt. Neudruck Dramat. Jugendwerke 2.

$\left.{ }^{25}\right)$ Rieger 1, 107. 
am gewaltigsten durch die Stimmung der Nacht gestaltet. Neben dem grandiosen Bild der über den Heeren brütenden Nacht in Heinrich V. (Chorus zum 4. Akt) steht die nächtliche Vorklangsszene zur philippischen Schlacht in Brutus' Zelt, steht der wüste Schlachttraum Richards III. Eine Gattung von Auftritten wiederholt sich bei Shakespeare unter mannigfaltigen Formen in nicht zufälliger Weise: die nächtlichen Postenszenen. Sie sind, verschieden in Stellung und Funktion, die starken Träger shakespearischen Kriegsgeistes. dem die umgebende Natur auch sonst, und die Nacht als ihre geheimnisvollste Erscheinung am tiefsten, ihre Stimmung leiht. Der Bereich der Postenszenen geht vom einfachen Vorgang der Schildwachablösung, der gerade in seiner körperhaften Sachlichkeit die stärksten Stimmungswerte birgt (Hamlet I, 1). bis zu der entscheidungsschweren Vordeutung des Schlachtgeschehens. Was die Wachen in Antonius und Cleopatra IV, 3 erleben - Gott Herkules verläßt in Zeichen und Wundern das Heer - besiegelt Mark Antons Untergang, so hell sein Stern auch noch darauf am ersten Schlachttag, im Niedergehen, strahlt." $\left.{ }^{26}\right)$

Wir werden Nachbildungen dieser Postenszenen Shakespeares mannigfach antreffen. Klinger geht mit einer großartigen Formung, wohl angeregt, aber doch aus eigener Kraft voran. Die Nachtwache der Pyrrhussöhne vor dem Zelt ihres Vaters dart sich neben Shakespeare stellen, das gewaltige Bild des wachenden, schweigenden Recken Ptolomäus, in dessen Rüstung der Mond spielt, neben das Bild Hagens und Volkers, wie sie vor Etzels Saal sitzen. Das Heldische ist hier wie dort gegenwärtig. Wie dann Alexander und Helen das schlafende Heer bis zur äußersten Wache, die unzähligen Zelte bis zum steilen Berg hin übersehen und Alexander erschauernd den Gedanken faßt: "Ich denk, ich schlag' einmal bei Nacht. Es muß herrlich und fürchterlich sein“", feiert das Kriegerische in Klingers Seele seinen höchsten Triumph. Diese Empfindung für den Nachtkampf, den die kriegerische Entwicklung erst in

20) Andere nächeliche Postenszenen: Ant. u. Cleop. JV. 9 (Cäsars Lager): König Johann V.6: aus Hcinrich V: IV. I gehört der Anruf, wic er bei den Schildwachen üblich ist, hierher: femer I Heinrich VI: 1J. I, wo die aufgeführten Posten in der Folge vom Feind überwäligt werden: wie III Heinrich VI: IV, 3. Die Stimmung von in der Nacht gespannt wachenden Vorpostenkelten, die sich nah gegeniberstehen, geben vier Verse aus dern Chorus Heinrichs V: IV meisterlich: ..Von Lager halli zu Lager. durch der Nacht / Unsaubern Schoß, der Heere Summen leise. / DaB die gestellien Posien fast vernehmen/Der gegenseitigen Wacht geheimes Flüstem." Den Postenszenen verwand ist, wie Cassius und Casca sich in der Gewitternacht Jul. Cäsar J. 3 anrufen; anzufügen die nächiliche Lagerszene Heinich V: III, 7 und eine Schildwachszene bei Tag. Coriolan V. 2. - Cher Shakespeares Stimmungsszenen vgl. A. Brandl. Zur Szenenführung bei Shakespeare, Sitzungsberichte der preuß. Akademie 1906, S. 630-44, und B. Blaese. Die Stimmungaszenen in Shakespeares Tragödien. Berliner Diss. 1910; vgl. auch Brotanek S. XX. 
unseren Tagen zu einer Hauptkampfform gemacht hat, getragen vom Sausen des Windes und Rauschen des Stroms, hat etwas von antiker Größe. ${ }^{27}$ ) Gewiß, Klinger übertreibt gelegentlich und übersteigert das Titanische, das Shakespeare etwa im Antonius mit gewaltigem Maß, aber mit Maß geformt hat, bis ins Groteske. Der Schlachttraum des Pyrrhus, dessen Herumwerfen im Schlaf das Zelt wanken macht, dessen Schnauben die Feinde schreckt, gehört hierher wie die zwei Zentner schwere Rüstung, womit der alte Alcim zu aufdringlich prahlt. ${ }^{28}$ ) Aber das Übermaß der Leiber wird hier, in der antiken Welt, die unserm Alltag gänzlich entrückt ist und in unserer Vorstellung für übermenschliches Heldentum Raum hat, erträglicher als in dem uns nähern Otto; das große Wollen Klingers, das trotz allem in den Dingen steckt, tritt hier reiner in die Erscheinung.

Der Geist des Krieges ist weiter mächtig im Kontrast Pyrrhus' des Helden und Demetrius' des Lüstlings. Die einfachen Soldaten verachten diesen ob seiner weibischen Schwelgerei und gehen, unwiderstehlich angezogen von stolzem Feldherrntum, zu Pyrrhus über. ${ }^{29}$ ) Der alte Alcim aber darf die Wiedergeburt seines Herrn zum Krieg erleben und reckt sich selbst noch einmal in der verjüngenden Kraft dieses Vorgangs zu vergangener Heldengröße auf. Die Charakterwandlung des Demetrius steht in der allgemeinen Richtung des Sturm und Drangs, an Stelle des Lebensgenusses die Tat zu setzen (Faust). Klinger gestaltet den Gegensatz in seiner schärfsten Form: im Umschwung

$\left.{ }^{27}\right)$ Ein zweites stimmungsgewaltiges Nachtstück, außerhalb der kriegerischen Welt, liefert der spätere Klinger im IV. Akt der Medea in Korinth, wo nach Medeens feierlicher Klage an den scheidenden Vater Helios mit dem Herabsinken der Nacht ihre finsteren Kräfte durchbrechen, sie aus der Beschwörung Hekates den Gedanken des rächenden Kindermords empfängt, und die Tat mit grausenvoller Dämonie vollzieht. Vgl. Rieger 2, 102-03 u. 105.

28) Traum: Pyrrhus I, Neudr. S. 361 u. 362; den Traum überliefert Plutarch; als poetisches Motiv (Schlachttraum Richards und Richmonds) war er in Richard III: V, 3 zu finden. - Rüstung: Pyrrhus II, S. 377 u. 380; die Bemerkung Dramat. Jugendwerke 2, 457, daß die Figur des Alcim von Klinger erfunden sei, ist irrig. Plutarch erzählt die Geschichte seiner Rüstung, im Leben des Demetrius cap. 21. Klinger hat ihr Gewicht echt stürmerisch auf das doppelte gebracht, indem er aus den griechischen Talenten deutsche Zentner machte.

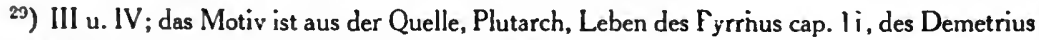
cap. 44, entwickelt. Auch Shakespeares Antonius erscheint nirgends größer als in den Worten des Überläufers Enobarbus IV, 6 (der allerdings, umgekehrt wie bei Klinger, vom Helden abgefallen ist). Die Technik, den Kriegsherrn durch sein Feldlager ins Große wachsen zu lassen, deutet auf Wallensteins Lager, wie die Art, den Fürsten erst spät, nachdem die Exposition sein Heldentum ins hellste Licht gesetzt hat, aus dem Zelt treten zu lassen, auf einen anderen Torso der deutschen Kriegsdramatik: Kleists Guiskard, weist. Die innere Verwandtschaft mit ihm wird später zu würdigen sein. 
aus cinem Leten unter .. Weibern, Flöten, Wein und Freude" (S. 379) in heldisches Beginnen. Wenn irgendwo, so ist hier deutlich, daB ihm Tat im höchsten Sinne kricgerische Tat bedeutet.

Mit den Pyrrhius-Szenen hat Klinger neben die Welt des Götz etwas Eigenes gestellt und. da Goethes antike Pläne ganz liegen blieben, seinerseits eine Provinz Shakespeares erobert. Er setzt damit auch die Tradition, die von Klopstock her kommt, fort. Der feierliche Schwung seiner Sprache, der gelegentlich sogar ein Vers unterläuft, klingt mannigfach an die Diktion des klopstockischen Bardiets und seiner Cliöre an. ${ }^{30}$ ) Ihre Gesinnung dem Kriegerischen gegenüber ist nicht minder verwandt, wie selır auch Klinger gegen Klopstock (von Shakespeare) befreit erscheint. Es herrscht die grofe, getragene Auffassung des Heldentums, bei Klopstock nicht selten kühl und gespreizt, bei Klinger gelegentlich übersteigert. Daß Klopstock in der Kunst der Stimmung vorangeht, wurde schon berührt. Beide haben cine besondere Auffassung der Waffe und einen ausgeprägten Sinn für das Akustische des Kriegsgeräts. ${ }^{31}$ )

Als lockere Fragmente sind die Pyrrhus-Szenen bedeutender durch die Bewältigung des Kriegerischen in Geistigen als im Technischen; immerhin sahen wir, daß sie auch dort, in der Art wie der Held groß gemacht wird, Unverächtliches leisten. Die Beobachtung dehnt die Szene vor Pyrrhus' Zelt zum weiten Lagerfeld und gibt der Illusion Mond. Wolken und Gebirge zu sehen. Es wurde gezeigt, welchen Eindruck die shakespearische Gestaltung der Nacht auf Klinger machte. Wie darin, hat er auch sonst seine Kunst, menschliche Handlung durch Vorgänge in der umgebenden Natur zu stimmen, an Shakespeare geschult. ${ }^{32}$ ) Die Teichoskopie ist dazu, anders als bei dem

20) Pyrrhus 1. S. 367 ganz hlopstockisch: ..Ein lieblicher, starker Ton ist das Klirren der Walfen. Ein herrlicher Rut der Ruf zur Schlacht" usw. Riegers Bernerkung 1. 109 ist wohl dahin zu wenden, daß Klingers Sprache in Pyrrhus nicht bloß ..gerignet war, seinen Freunden von der klopstockischen Schule zu imponieren". sondern daß sie Klopstocks Einfluß selbst erfahren hat. Man glaubt ihn noch aus der Medea I zu vernchmen, wo Klingers unmittelbarer Anreger Stolberg mit den freien Rhythmen seiner Aeschylusübersetzung und der Sprache seiner eigenen antikisierenden Dramen (Rieger 2, 103 u. 97 f.) wohl mehr Mittler zwisehen Klinger und Klopstock, als selbständiger Neubildner ist.

a1) Vgl. den Anhang Waffe. Der Todeswagen, vor dem Varus geht, rasselt Walhalla vorbei (Hermanns Schlachı. Szene 3 S. 79); die Kette der Eroberer klirrt (Sz. 6 S. 94: Sz. 11 S. 125); die Walfen. Beile und Lanzen tönen (Sz.6 S. 94; II S. 125 und sehr oft). Klinger: „Rasselt, meine Walfen. klirrt mir V'ergessen zu" (Pyrrhus I. S. 367, noch zwcimal wioderholt S. 368): Waffen rasseln durch die Dämmerung S. 370. sollen Alexanders Ceist Dank zurasseln S. 371 ; vgl. das Zitat der vorigen Anm.

s2) $\mathrm{V}_{8}$ l. die Zusammenstellung bei Jacobowski S. 14. 
Briten, die stehende technische Prozedur, die den vier Wänden der Bühne die freie Natur gewinnt. ${ }^{33}$ ) In einem Stück, das wie die „Zwillinge ${ }^{\text {“34) mit }}$ genauer Bühnenrücksicht geschrieben ist, bestreitet das Mittel, von Klinger nun schon virtuos gehandhabt, auch diejenigen wichtigen Momente der Handlung, die nicht vorzuführen sind. II, 1 beobachtet Guelfo mit Grimaldi zum Fenster hinaus die Anfahrt der Karosse seines fürstlichen Bruders mit Eltern und Braut. ${ }^{35}$ ) Der Vorteil der Beobachtung, daß das Ereignis schon mit seinem Reflex erscheint, wird hier so weit getrieben, daß Guelfo vor Erregung eine Pistole abschießen muß. Zur höchsten spannenden Wirkung führt Klinger diese Reflextechnik in der Gestaltung des entscheidenden Ereignisses des Stückes, Ferdinands Ermordung (IV, 3). Sie wird wiederum durch Teichoskopie vermittelt. Man hört ein Pferd im Hof, es ist reiterlos, der alte Guelfo, der es kennen muB, gibt den geängstigten Frauen keine Antwort; es ist Ferdinandos, Kamilla entdeckt Blut am Sattel, sie ahnt die fürchterliche Wahrheit, die Grimaldi dem verstörten Guelfo dann ins Gesicht schleudert. ${ }^{36}$ )

In dem technisch freien "Grisaldo“(37) dagegen hat der Kampf als Vorführung wieder Raum, und Klinger läßt sich den Anschlag auf den in Isabellas Armen weilenden Helden, der sich mit dem wackeren Bucklichten Ballona aus Feuer und Feind heraushaut, nicht entgehen (III, 4). Das Stück ist ebenso nach der Seite des kriegerischen Gehalts bedeutend; der sieghafte Grisaldo gehört zu den triumphalen klingerischen Kriegernaturen. ${ }^{38}$ )

Auch die Verschwörung des ,Stil po“"39) tobt in einigen Kampfszenen aus, die im raschen Wechsel der Parteien (IV, 13 u. 14) und dem Führer-Einzelkampf (IV, 15 Pandolfo-Rinaldo) die shakespearische Schule verraten. Klinger ist ihr diesmal im Gegensatz zum Otto auch in der theatermäßigen

23) Otto II, 2 verziehendes Gewitter, Sonne, Regenbogen; Zwillinge II, 5 Kamilla und Guelfo am Fenster: Feuerwolken des Abendhimmels; III, 3 Guelfo am Fenster: schwarze Wolken und Sturm; IV, I Kamilla (sieht hinaus): lieblicher Morgen. Grisaldo I, I Sarazenenkönig am Fenster: .Sonne i" usw.

34) Hamburg 1776, im 1. Bd. von Schröders Hamburgischem Theater. Dramat. Jugendwerke 1 .

${ }^{35}$ ) Vgl. den Vorgang bei Lessing, Emilia Galotti III, 1-3. In Elfriede III, 1 läßt Klinger das Heranreiten des königlichen Jagdtrosses von den Frauen ebenso vom Fenster aus verfolgen.

35) Vgl. für die Beobachtung noch Otto II, 6: „Sieh im Gebüsch - da - dort - sieh ein Haufen Volks beim Feuer" und Prinz Seidenwurm III, 10, der Prinz zum aufrührerischen Volk zum Fenster hinaus.

27) Berlin 1776. Dramat. Jugendwerke 2.

33) Vgl. Rieger 1,130 u. 140.

s9) Basel 1780 (geschrieben 1777). Dramat. Jugendwerke 3.

Scherrer, Kampt im deutscben Drama. 
Beschränkung im Apparat gefolgt. - Alle diese Dinge treten aber an Intensität der Gecstaltung des Kriegerischen hinter den Pyrrhus-Szenen zurück. Wic Klinger in seinem reifen Schaffen, im Konradin, in der allgemeinen Entwicklung der Kampftechnik stehend, eine Schlacht meistert, ist später zu verfolgen.

Das Konkurrenzstück seiner Zwillinge, Leisewitzens .Julius von Tarent ${ }^{* 10}$ ) hat - auch von dieser Seite lessingischer Beschränkung verwandt - an Kämpferischem nur ein Duell aufzuweisen (Cuido-Aspermonte I, 3), das in manchem Betracht auf das spätere des Don Carlos mit Alba bei Schiller (II, 5) hinweist. Aber auch Leisewitz steht unter dem Bann shakespearischer Postenszenen; die nächtlich unheimliche Totenwache zweier Soldaten an Julius' Leiche $(\mathrm{V}, 1)$ mit ihren Gesprächen über umgehende Geister gehört zur Nachfolge der Terrassenszene im Hamlet.

Völlig in diese vergaft hat sich Ludwig Philipp Hahn, der seinen ,Aufruhr

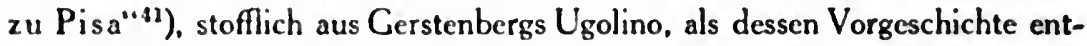
wickelt, mit einer Postenszene bei Nacht eröffnet und schließt. Shakespeare wird damit schon ganz äußerlich nachgeahmt; was bei ihm Folie meisterlicher Stimmungskunst ist, welche das nüchtern Expositionelle der Szene ganz aufsaugt, steht nun als lecrer Rahmen, dem der Inhalt fehlt, und soll nichts als ein gewöhnliches Expositionsgespräch zu interessanterer Erscheinung aufputzen. ${ }^{4}$ ) Die Postenszene vor dem Hungerturm am Schluß bringt wenigstens ein paar nicht unlebendige Schildwach-Redensarten. ${ }^{43}$ ) Im ganzen besteht für Hahns Kampftechnik die rühmende Bemerkung von Schubarts Vorbericht, da $B$ er die französische Mechanik des Theaters nicht verachte, ebenso zu Recht wie Eschenburgs Tadel, er sei in manchen kleinen Umständen der mechanischen Einrichtung der shakespearischen Regelunkenntnis zu weit

(0) Leipzig 1776. Hrsp. von R. M. Werner, DLD 32.

") Ulm 1776; vgl. R. M. Werner, L. Ph. Hahn. Quellen und Forschungen 32, 1877.

17) Dafür bezeichnend. daB der Schildwache Hahns (I. I), obwohl nichts besonderea vorréallen ist noch vorfallen wird, .., was in den Cliedern sticki”. ganz cinfach von scinem shakeapearischen Kameraden her (Francisco: .I am sick at heart," nach Wieland: .Mir ist gar niche wohl"). Ebenso auBerlich übernimmt Hahn I. 3 (Werner S. 24) aus Shakespeares zweiter Terrassenszene (1.5) das Motiv, den Freund von einer Stelle zur anderen zu ziehen. Ferner Hahn: ..es ist ganz frisch" wie Shakespeare I, I nach Wieland: ..es ist bitterlich kalt" und I. 5 (nach Wieland I. 7) ..es ist eine beiBende, scharfe Luft" usw. - Hahn: .. War deine Wache ruhig?" wie Shakespeare I. 1 (nach Schlegel wörtlich so), nach Wieland: .Habe ithe eine ruhige Wache gehabt?" Auch Hahn braucht den Wier da?-Anruf wie Shakespeare zweimal für verschiedene Personen.

43) V. 12: .. Wer da! ... redet respektierlicher mit der Wache ... - nicht viel gerisonniert oder wis geben Feuer aul euch ... wer dal ... Tretet näher, dab wir euch sehen." 
gefolgt. $\left.{ }^{44}\right)$ Hahn läßt einerseits III, 6 den Ugolino nach französischer Weise zum Kampf abholen und den Boten zugleich dessen Verlauf berichten, weiterhin die Information durch eine neue Botschaft an Ugolinos Weib ergänzen, ${ }^{45}$ ) auf der anderen Seite aber führt er III, 7 doch in den Kampf hinein.

Die Art, wie dies geschieht, zeigt deutlich, was Hahn am Gefecht fesselt, und warum er gerade die Schildwachszenen Shakespeares nachahmte. Ihm liegt nicht der Kampfauftritt im großen, sondern die Einzelszene, und zwar die Einzelszene in niedriger Sphäre. Klinger gibt bei verwandter Lage der Dinge - ein Stadtkampf hier wie dort - in den Stilpo-Auftritten die Führer in den entscheidenden Momenten, nach jener großen Auffassung Shakespeares, daß im Geschick des Feldherm dasjenige der Armee beschlossen liegt. Hahn hat nur Organ für den Soldaten, als Schildwache und als Raufer, und er nimmt ihn durchaus von seiner derben Seite. Sein Feldherr Ugolino ist nichts als grotesk, seine Kriegsknechte aber, wenn auch roh, doch lebendig. Es ist bezeichnend zu sehen, wie der Durchschnittsmensch Hahn sich aus der shakespearischen Kriegswelt nur eine ganz kleine, unwichtige Provinz - mag sein aus eigener Erfahrung - anzueignen vermag: die pöbelhaften Raufszenen. Die Balgereien der Soldaten Hahns mit feigen Bürgern (III, 7), die mit komischem Einschlag meist unblutig ausgehen, nehmen zum mindesten ihren Freibrief aus Shakespeare; ${ }^{46}$ ) ein Soldat, der sich im Kampfe listigerweise getroffen stellt, hat an Falstaff (I Heinrich IV: V, 4) - nebenbei auch bei Bernardon - einen Vorfahr. Auch der Ton, den seine Soldaten den Vorgesetzten gegenüber anschlagen, erweist, daß Hahn den Krieger nur von seiner volksmäßig-rüpelhaften Seite kennt. ${ }^{47}$ ) An Technischem ist noch anzumerken, daB auch er einmal von der Beobachtung aus dem Fenster Gebrauch macht: Francesco betrachtet II, 8 das Einmarschieren der feindseligen Prozession in den Hof.

Man sieht, er bringt neue und alte Mittel durcheinander und schwankt

4) Allg. Deutsche Bibl. 34, 487.

45) Werners Bemerkung S. 29, es liege hier eine Nachahmung jener bei Shakespeare so zahlreichen Wartturm- u. dgl. Szenen vor (wir sahen oben, daß sich streng genommen nur die eine Cassius-Szene nachweisen läßt) hält genater Prüfung nicht stand.

6) Vgl. etwa Lear, der auch sonst (Werner S. 20) eingewirkt hat, II, 2.

47) Werner bringt dafür S. 25 zwei Beispiele aus I, I und II, 5 bei; die Erfurtische Gelehrte Zeitung 1776 (von Werner S. 33 zitiert) hebt freilich das eine im Gegenteil rühmend hervor und hat insofern recht, als sie sich wie Hahn selbst auf den Standpunkt des gemeinen Soldaten, gegen den Feldherm, stellt. Werners Bemerkung S. 17, Hahn sei keiner individuellen Züge tähig, bedarf für die Figuren des niedrig-derben Kreises der Berichtigung. Die Soldaten, Bürger und Senatoren, wie etwa die Weiber. III, 2, sind ihm nicht übel geraten. 
zwischen der uherlicferten und der erst errungenen Gestaltungsweise als ein recher Mitlaufer hin und her. Der Cö̈z ist für ihn noch wenig fruchebar gewerden: or halt sich metir an shakespearische Brocken. Anders stehe es. zum mindesten im Stofflichen. mit Hahns folgendem Stück. dem Robert von Hohenechen aus dem Jahr 1778, das den Eintritt des deutschen Ritterdramas nach Ciocthes Cözz und Klingers Otto bezeichnet. 


\section{Sechstes Kapitel.}

\section{Das ritterliche Kampfstück bis in die achtziger Jahre.}

\section{Die pfälzisch-elsässische Cruppe.}

Es ist ein merkwürdiger Sachverhalt, daß eine Familie so handfester Bühnenstücke wie die Ritterdramen sich an ein Vorbild anschließt, das dem Theater so wenig Rechnung trägt wie der Götz. Goethe hat kein zweites, bühnengerechtes Ritterstück versucht und ist später an der Aufgabe, das erste theaterfähig zu machen, selbst gescheitert. Auch Klingers Otto kennt die Schranken der Aufführbarkeit nicht. Mit Hahn und Jakob Maier nun begibt sich die ritterliche Gattung in die Grenzen der Bühne. Der erste Autor, der ausspricht, daß daraus manche Beschränkungen entstehen müssen, ist Babo; $\left.{ }^{1}\right)$ vorhanden aber sind sie von Anfang an und dort gerade am fühlbarsten; denn man weiß die Mittel noch nicht zu handhaben, um das was der Vorführung widerstrebt, dennoch für sie zu gewinnen.

Die weitverzweigte Familie der Ritterstücke, ihre Abhängigkeit vom Götz und unter sich selbst, hat Brahm mit starker Betonung der Stellung Törrings untersucht. ${ }^{2}$ ) Für uns lautet die Frage und demnach die Auswahl und Gruppierung des Materials anders. Die an den Götz anschließende Gattung hatte historisch - wenn sie sich über kahle Nachahmung und ein ödes Breittreten erheben wollte - die Aufgabe, die befreiende Tat ihres Urbilds dem gespielten Stück fruchtbar zu machen. Goethe hatte dem Drama mit genialem Wurf die Weltweite gewonnen, ohne bei diesem umstürzlerischen Beginnen auf die Bedingungen der Aufführung zu achten, und natürlich auch ohne darauf achten zu können und zu wollen. Jetzt gilt es, diese Weite in die geschlossenere Form hinüberzuretten, in dem Gesichtskreis unserer Betrachtung insbesondere: den Kriegsgeist, der in dem losgebundenen Gang des Götz eine hinreißende Gestaltung gefunden hatte, mit den geringeren Möglichkeiten des Bühnen-

1) Vorrede zum Otto von Wittelsbach, München 1782: „Ich schrieb dies Stück für die Bühne, und eigentlich für die vaterländische. Daher die Einschränkung in mancher Situation, die in einem bloB zum Lesen geschriebenen Drama größer entworfen und ausgeführt hätte werden können."

2) $\mathrm{Zu}$ seiner Arbeit sind im folgenden die Rezensionen von Werner, AfdA 7, 417-39; Seuffert, Deutsche Literaturzeitung 1880, S. 416 f., und Koch, Literaturblatt f. germ. u. rom. Philol. 1881, 49-52, wie A. Hauffens Einleitung "Das Ritterdrama“, DNL 138, überall ma Rate gezogen. 
stücks zu bannen. Das ist zum Teil eine Angelegenheit der Technik, zu deren Entwicklung Goethe wie Klinger ja eine Fülle von Anregungen gegeben haben, zum größeren aber doch Sache des Erlebens, des Verhältnisses zu Kampf und Krieg, die kein Dramatiker mit allen technischen Griffen überzeugend bewältigen wird, wenn er nicht innerlich teil an ihnen hat. Sollte der Verlauf erweisen, daß die ersten Versuche dieser Bewältigung, am Götz gemessen, kläglich gescheitert sind, so darf das nicht abhalten, weiter zu blicken und das Gemeinsane des vielfach redlichen Bemühens auch der geringeren Köpfe mit dem Streben der Führenden zu erkennen, das sich in der krönenden Formkunst der Klassik, der Reife Schillers und dann Kleists, vollendet.

Das Jahr 1778 bringt zwei Ritterstücke, beide pfälzischer Herkunft und auch sonst nah verwandt: Jakob Maiers .,Sturm von Boxberg."3) und Hahns "Robert von Hohenecken" $\left.{ }^{4}\right)$. Die Priorität scheint aus äußeren und inneren Gründen Maier zuzugehören und Hahn sein Stück schnellfertig nachgeahmt zu haben..$^{5}$ ) Der Tatbestand des Sturms von Boxberg dem Götz gegenüber ist der, daß die Intrige wieder in ihr Recht eingesetzt wird, oder vielmehr, angesichts der späteren Leistungen Maiers, daß er im Wesentlichen noch durchaus im Gefolge des alten Intrigenstücks ${ }^{6}$ ) bleibt. Klinger hatte sich im Otto, der locker biographischen Anlage des Götz entgegen, zur Intrige zurückgewandt und damit cinen Weg beschritten, der zum Bühnenstück zurückführen mußte, und ihn auch zurückgeführt hat ; wenn er freilich dadurch, $\mathrm{da} B$ er die Verwicklungen über Gebühr häufte, der Aufführbarkeit vorerst keinen Vorschub leistete. Maier, als ein bescheidenes Talent, verhält sich gerade umgekehrt. Die formale Erscheinung des "Sturms" steht im ganzen da, als ob ein Götz nie gewesen wäre. Der Pfälzer ist weit entfernt davon, durch dessen Freiheiten kühn gemacht, nun etwa selbst über die Schnur zu hauen; er muß sich vielmehr die Bereicherungen, die Gocthe dem Kriegsdrama, worauf es ihm doch ankam, gebracht hatte, mit chrlicher Mühe nach und nach, in einem folgenden Stück und eincr späteren Bearbeitung des ..Sturms“" erst aneignen. Dem Drama von 1778 bedeutet der Götz kaum mehr als eine neue Stoffwelt, die Maiers Neigung und Zwecken zupaß kommt. Es ist kein unwichtiges Beispiel, wie die Tradition der Kampfdarstellung noch eine im Sachlichen so deutliche Nachahmung Goethes im Bann hält.

In Frage stchen die Gefechte um Boxberg und der Sturm auf diese Burg: aber Maier hält sich noch ganz an die vier Wände gebunden und scheut alles was darüber hinausginge, in der strengsten Weise sogar die Beziehung zu dem

3) Mannheim 1778.

9) Leipzig 1778 (Exesnplar der Kogl. Bibl. Berlin).

3) Brahm. Ritt. S. 99: dazu Werners Rez.. AldA 7. 433-34.

") Vgl. Brahms Analyse, Ritr. S. 95 f. 
hinten Vorfallenden durch Beobachtung.') Das Theater ist ihm noch das Zimmer, nicht die Welt. So muß der Leiter der Kämpfe, der Burgherr Rosenberg, mit dem alten Elend der Motivierung im Gemach festgehalten werden und hier seinem kernhaften Kampfzorn in eitel Reden Luft machen. Das Verfahren des Berichtens ist das seit den Zeiten Gottscheds wohlbekannte, ${ }^{8}$ ) und in gottschedischem Geiste behandelt ist auch die Kampfentscheidung: als reine Effektszene. Indem der Lärm des Burgsturms näher und näher schwillt, steigert sich III, 1 der Konflikt von Vater und Sohn um das Fräulein von Detten bis zu dem Grad, daß sie sich Schwert gegen Schwert gegenüberstehen, statt als Burgherren dem eindringenden Feinde die Spitze zu bieten. Der trennt sie denn auch als Sieger in diesem Augenblick höchster theatralischer Spannung. Der Vorgang, als das einzige was von den Kampfgeschehnissen auf der Bühne erscheint, kennzeichnet das Intrigenstück mit aller Deutlichkeit. Das ist, mit dem Wiener Ausdruck, Combattement, Kampf um des Effekts willen, hier im Dienste des Familienkonflikts, und meilenfern vom Götz, wo er Selbstzweck war und nichts weiter zu leisten hatte, als ein frisches männliches Reiterleben, erfüllt von wackerer Reitertat, zu vergegenwärtigen.

Dieser Sachverhalt, der sich nur durch die Macht der Tradition des gespielten Dramas dem Götz gegenüber erklären läßt, ist bei Maier auffälliger als bei jedem anderen. Denn jede Seite des „Sturms" und dann der „Fust von Stromberg" zeigt, daß es ihm recht sehr um das Kriegerische des Mittelalters, um Rittertum und Fehdewesen zu tun war, und daß er viel mehr in diesen Dingen lebte, als nach der versagenden technischen Bewältigung der Kampfhandlung im ersten Stück zu schließen stünde. Er nähert sich der kriegerischen Welt des Götz von einer besonderen Seite: von der chronikalischen Gelehrsamkeit aus. ${ }^{9}$ ) Goethe hatte die Lebensbeschreibung Berli-

7) Der alte Rosenberg tut nur seine Absicht kund, den Kampf vom höchsten Schilderturm zu verfolgen (II, 4 u. 7). Unsicher ist eine Monologstelle III, 3 : „Drüben liegen sie an der Mauer“" wo er die "Helden alten Schlages“ aber doch wohl nur mit dern geistigen Auge erblickt.

8) Wie bei Klopstock Kedmon, so ist hier der Reisige Blink als ständiger Meldebote in Pflicht genommen. Bemerkenswert nur III, I, wie der Gefechtsbericht, als vor den Beginn der Szene fallend, gespart wird und nur aus seinem Reflex, dem Wutausbruch Rosenbergs, zu erschließen ist; aber durch das Unleidliche wettgemacht, daß darauf III, 2 der junge Rosenberg selbst als Verwundeter ausgiebig erzählen muß, wodurch beide Führer dem Kampf entzogen werden.

9) Goethe beschwert sich (An Schiller 14. März 1798) über den „archivalischen Aufwand“ in Sturm. Zum Fust meint Schiller später (An Goethe 20. Febr. 1802), er gebe eine ganze und sprechende Vorstellung des Mittelalters, wenn sie schon offenbar nur der Effekt einer bloßen Gelehrsamkeit sei. So wohlwollend hat er freilich nicht immer geurteilt; vgl. darüber Petersen, S. $105-06$. 
chingens genützt soweit es ihm gut schien. Jedenfalls hatte er ihr nichts entnommen, was nicht seine Anschauung durchdrang und als ein Lebendiges, Gegenwärtiges hinstellte. Wie er darob von den einen als in der Geschichte grundgelehrter Mann bewundert, von andern aber über historische Sachverhalte zurechtgewiesen wurde, erzählt er selbst im 13. Buch von Dichtung und Wahrheit. Das Kriegerische war ihm Bewegung, Handlung, Leben im stärksten Sinn. Bei Maier treffen wir das Wissen vom Kriege, die aus Exzerpten gewonnene Kenutnis sciner Erscheinungsform im Mittelalter, seiner Gebräuche und Waffen. Dieses Wissen ballt sich, entgegen der schlichten Natürlichkeit Goethes, nicht selten zu gelehrtem Schwulst zusammen ${ }^{10}$ ) und bleibt fast immer anschauungslose Schuliveisheit. Man erhält eingehende Schilderungen des Technischen der Kampfzurüstung (II, 5), hört kriegshistorische Lektionen über die Anstalten zur Berennung einer Burg. Schirmkörbe, Igel und Katzen (III, 4), und ihre Verteidigungsmöglichkeiten, Wälle, Wehren, Gräben, Schütten, laufende und andere Hölzer (III, 7), Bollwerk und Vorburg (III, 3 u. 4). ${ }^{11}$ ) Das Lokal der Kämpfe, zumal die Burg, wird darum in der Vorstellung aber nicht körperhaft, obwohl die mannigfachen Teile der mittelalterlichen Feste mit rechter Buchgelehrsamkeit immer wieder genannt werden. Guethes Landerwerb geht auch für das geistige Bild, nicht bloß für die Bühnenerscheinung, verloren. Mit dern $\mathbb{W}$ esen des Sturm und Drangs und seiner Erfassung des Kriegerischen hat diese Kriegsgelehrsamkeit wenig gemein, denn gerade das Kennzeichnende. das innere Verhältnis zum Kampf, fehlt ihr; nur daß allerdings der neue Wirklichkeitssinn, die Freude am Gegenständlichen schließlich auch dem historischen Schnörkelwesen zugrunde liegt und damit auch die Erscheinung Maiers notwendig aus der Zeitrichtung hervorgeht.

10) Man vergleiche etwa die Art, wie sich zwei Leute vorstellen: Gö̀ z B III, 6. Götz: „Gebt mir euren Namen”. - Lerse: "Franz Lerse”. Sturm I, 5, Rosenberg: .Wer bist du?" v. Detten: .Mehr Glimpf, ich bin ein edelgeborner, wappen-, lehen- und turnierfähiger Ritter. der unter einer purpurnen Helmdecke einen gekrönten Turnierhelm mil sieben stählernen Reiten auf drei Schirmkörben führt". - Wenn irgendwer, so redet dieser Ritter wie ein Buch.

") Auf ahnlichen Wegen geht ein moderner Dramatiker. Gerhart Hauptmann im Florian Geyer, der das Zeitkolorit ebenfalls in der Hüufung von verschollenem chronikalischem Wortschatz und archaisierenden Formen sucht: .Unsere Mauem sind lest, die Gräben tief: Zwergzäune sind ufgerichti, ein Lichtzaun ist gemacht. Zwinger. Tor. Turm sind in gutem Stand" (Vorspiel; Werke, Berlin 1912, 2, 74): ..als daB ich gute Kundschatt hab und glaublich bericht : bin, daB alle Hauten der Bauern uf Würzburg zu ziehn und daB, solanse die Welt steht, kein solches Reisen. Webern und Inhaufenziehen gewesen ist mit Panieren. Schwein spießen. Flegeln, Hellebarden. Handrohren. Wägen und Hakenbüchser" (Vorspiel. das. 2, 67): „Mauerbrechend Ceschütz. Bruder, als thr zu Rothenburg habt: es fehlt uns an guten Stücken: schafft uns Eure zwo Notschlangen herbei" (Akt 1, das. 2. 80; vgl. 2.95) usw. 
Mit dem Herzen kommt er dem Soldatischen nur von einer beschränkten Seite, der volkstümlichen, bei; er stellt sich in dieser einen Hinsicht, freilich überlegen, neben seinen Landsmann Hahn, dessen Aufruhr, wie wir sahen, dieselbe Neigung zeigt. Die nicht zimpferliche Reuterszene II, 6, in der Blink mit der Zofe Adellheid schäkert, gehört hierher, und man ist wieder bei Hahns Derbheit, wenn der Wächter vor der Fräulein Zimmer (II, 4) sich mit Knebelbart und Schlachtschwert vorkommt wie eine alte Wehmutter, die ihre Kundschaft verloren hat. Am deutlichsten tritt diese Tendenz Maiers in Blinkens Schilderung des flotten Reuterlebens bei Suff und Sang im pfalzgräflichen Lager (II, 5) zutage, die auf einer Chronikstelle beruhen mag, in der frischen Fassung aber genugsam erkennen läßt, daß der Autor daran teilhat. Sie weist auf andere Erzählungen froher Reiterschaft, wie diejenige des ersten Jägers bei Tillys Heer in Wallensteins Lager, vorwärts. Die Freiheit zu Realismen dieser derben Art, welche die Umarbeitung von 1785 noch vermehrt, ${ }^{12}$ ) kommt Maier natürlich aus dem Götz, dem auch eine Reihe von beiläufigen Zügen entstammt; ${ }^{13}$ ) sie dürfen nicht dazu verführen, daß man den Nachdruck auf diese kleinen Übereinstimmungen legt; das für uns wichtige ist im Gegenteil zu sehen, wie wenig die Form des Götz bei sachlicher Anlehnung noch wirksamgeworden und wie verschieden der Weg ist, der hier zum Kriegerischen führen soll.

Ein ganz anderes Bild zeigt Hahns Ritterdrama. Man kann kaum sagen, daß darin überhaupt ein Weg gesucht wurde, dem Kriegerischen beizukommen, obwohl der "Robert von Hohenecken" sich der Technik des jungen Goethe geneigter zeigt als die Boxberger. Neben Maiers manchmal schwerfälliger, manchmal schulmeisterlicher, im ganzen aber doch tüchtiger und solider Art steht Hahns Stück als eine leichtfertige Nachahmung des Cötz; es ist unrichtig, die beiden Leistungen in ihrem Wert oder Unwert als einander würdig zu bezeichnen. ${ }^{14}$ ) Leichtfertig verfährt $\mathrm{Hahn}$ in dem Stück, das seine Dramatik völlig bankerott zeigt, deshalb, weil er die wackere Ritterwelt, die Goethe erschlosser hatte, ohne irgendein Gefühl für ihren Gehalt aufzubringen, nach der Weise der Spekulanten auf billigen Erfolg ${ }^{15}$ ) schnell bereit zu einem süßlich-faden Liebeshandel ummodelt. Maiers Intrige liegt zwar auf eben dem Gebiet, aber sie ist nicht so unleidlich sentimental gefaßt und erfüllt vor

12) I, 4 die Zudringlichkeiten der Reisigen gegen die gefangenen Frauen; I, 7 die Ausplünderung des Schulmeisters Breidmann, die aus seinen Taschen eine höchst armselige Habe zutage fördert usw.

13) Brahm stellt eine Liste, die sich noch vermehren ließe, Ritt. S. 97-99 zusammen.

14) Brahm, Ritt. S. 101.

15) Die Zeitgenossen rühmen das Stück auch wirklich weit über Gebühr. Vgl. Werner, L. Ph. Hahn S. $67-68$. 
allem das Stïck nicht allein, sondern hat ihr Gegengewicht in dem derbschrötigen Rittertum eines alten Rosenberg, der dem kämplerischen Teil vorsteht. Welchen Schlages dagegen die Ritter Hahns sind, wird am deutlichsten dadurch offenbar, daß er doch um des dankbaren Gegenstands willen eine ganze Kampthandlung, Uberfall, Belagerung und Burgsturm gibt und sie, aus Maiers Zimmer herausgehend, zum 'Teil auch vorführt. Man sieht also einen Ritter, der auf Fiauenraub auszieht (III, 6), im entscheidenden Augenblick aber seine Knechte machen läßt und selbst cinen gefühlvollen Monolog hält; einen Belagerer, der, statt seine Anstalten zu fördern, unten am Wall zu dem Verteidiger um seine Geliebte emporwinselt (IV, 5); endlich einen Burgherrn, der in der Phase des Sturmes (V. 6), indessen seine Leute ihr Leben an die Abwehr setzen, als flügellahmer Selbstmordkandidat herumschleicht. In dieser Weisc, geistig und technisch gleich kläglich, hält sich die ganze Kampfaktion, obwohl sie sich enger an Götz anschließt als diejenige Maicrs. ${ }^{16}$ ) Die Verhältnisse sind zudem, vielleicht aus Rücksicht auf eine mögliche Aufführung. äußerst kleinlich. Robert hat in der Burg kaum ein Dutzend Leute, der Belagerer scheint nicht über das doppelte zu verfügen $(V, I)$, und der pfälzische Hauptmann stützt sich gar $(V, 3)$ auf ein Hilfskorps von drei Mann. Nun entscheidet zwar der Aufwand an Truppen und Kampfgeschehnissen, wie der Cötz lehrt, in keiner Weise. Doch reiht sich bei Hahn dieses kümmerliche Aufgebot durchaus in das allgemeine Mißverhältnis zum Kriegerischen cin und kennzeichnet sein Machwerk auch von dieser Seite als einen Parasiten der Cattung, als ein Ritterstück ohne alle kämpferische Gesinnung. Einige nicht ganz üble Figuren der niedrigen Sphäre, zu der Hahn schon im Aufruhr einzig Geschick bewies, Reitersknechte und Bauern. ${ }^{17}$ ) wiegen den jammervollen Eindruck seiner Helden nicht auf.

16) Dies gilt für die Kampftechnik gegen Brahms allgermeine Bemerkung. Ritt. S. 102. Es sei nur angernerkt, daB Hahn bei der Belagerung wie Goethe beide Parteien weehselnd vorführt, indes Maier sich auf die eine beschränht, und zu Brahms Parallelenliste S. 102 noch hinzugelügt: Hahn verwendet I, 5 einen verwundeten Knecht als Berichtemptänger wie Coethe den Selbitz, freilich hier ohne Beobachtung, die er aber sonst öfters (I, 2 und ausführlich III, 9) braucht. - Die Erzählung V. 5 von der Köchin, die wütend, daß sie ihr den Wasserstein aus der Mauer gerissen und (zur Verteidigung) über die Schanze hinabgewälzt haben, dem Adelbert heiBles Wasser auf den Kopf schültet, ist nicht unverständlich, wie Werner S. 66 sagt, nur wenig zugehörig. Sie soll zweifellos ein besonders lebendiger Zug in Bild sein, wie man sie am Cotz schätzen gelernt hatte.

17) Wie er I. I u. 2 die eröftnende Trinkszene des Coótz nachahmt (Brahm, Ritt. S. 102). so tut er sich II, 2 aut den besoffenen Velten und durch das ganze Stück auf den reichen Fettwanst Schlick viel zugute. Was die Knechte und Buben etwa in Meldungen frisches haben. koram ihnen durchweg aus dern Götz. Ein polternder plälzischer Hauptmann (besonders I, 7 
Eine eigenartige und zu der allgemeinen Entwicklung vielfach gegensätzliche Stellung in der Nachfolge des Götz nimmt ein französisch geschriebenes Stück, "La guerre d'Alsace" von Ramond de Carbonnières ein, das aber nach seiner Art völlig zum deutschen Ritterdrama rechnet und ihm durch eine frühe Übersetzung unter dem Titel „Hugo VII." ${ }^{19}$ ) auch wirklich gewonnen wurde. Kritiker französischer Zunge schätzen es wenig, ${ }^{20}$ ) es ist jedoch für unser Thema von Belang und soll hier den zahlreichen Erscheinungen des Jahres 1780 vorangehen, einmal weil es schon im Winter 1776/77 entstanden ist und ferner deshalb, weil es sich von allen Stücken, die der Götz hervorgerufen hat, am engsten an diesen anschließt. Darum steht es natürlich auch in der französischen Dramatik ganz einsam und geradezu als Kuriosität da, zu der selbst von relativ so tumultuösen Kampfstücken wie dem um fünfzehn Jahre früheren De Belloys ${ }^{21}$ ) kein Weg führt. Das Verhältnis von Vorbild und Nachahmung hat in diesem Fall gegen die Zeit Gottscheds ins genaue Gegenteil umgeschlagen, läßt aber hier nicht minder als dort erkennen, wie sehr die Formmöglichkeiten des Kampfproblems national bedingt sind. Die singuläre Erscheinung auf französischer Seite konnte nicht anders als auf elsässischem Boden, unter der persönlichen und literarischen Einwirkung des jungen Goethe, entstehen.

Ramonds „Hugo“ er weist sich als reines Kampfstück, viel ausschließlicher dem Kriegerischen gewidmet, als der Götz selbst. ${ }^{22}$ ) Indessen Craf Hugo

und III, I) ist nur grotesk. Welcher Art der Realismus Hahns ist, mag der Zug II, 5 zeigen, wo der Köhler den sehnsüchtigen Robert den noch warmea Platz fühlen läßt, wo das Fräulein gesessen (!).

18) Basel 1780; Brahm verzeichnet den vollständigen Titel, ohne darauf einzugehen, Ritt. S. 106; Hauffen DNL 138, XI; Erich Schmidt bespricht das Stück anhangsweise in Heinr. Leop. Wagner2, Jena 1879. S. 119 u. 120. GGr ${ }^{34}$. III, S. 151 o) hätte vor allem darauf hinweisen müssen, wenn er Ramond, wie es geschehen ist, einbeziehen wollte. Erst nachträglich werde ich durch die Einleitung von M. Desceltes zum Neudruck des "Rheinischen Mosts“ (Leipzig 1904), die aus Ramonds unveröffentlichten Memoiren schöpft, auf das Programm des Fürstlich Waldeckschen Gymnasiums zu Corbach 1887 aufmerksam, worin Ferd. Heymach über Ramond handelt. Er erzählt S. 15-18 ausführlich die Handlung des Hugo und vergleicht ihn darauf dem Inhalte nach mit Götz, schenkt aber der Form keine weitere Aufmerksamkeit.

19) Regensburg 1781; sie ist benutzt.

$\left.{ }^{20}\right)$ Louis Morel, Werther au théâtre en France, Herrigs Archiv 118, 360 nennt es „une adaption assez maladroite de Goetz de Berlichingen".

21) Vgl. oben S. 21 Anm. ${ }^{65}$ ). Die "Belagerung von Calais" war auch in Deutschland, 1766 von"Ackermann in Hamburg "mit erstaunlicher Pracht" aufgeführt worden; Schmid. Chronol. S. 158; Devrient 2, 155.

22) Die nicht kriegerischen Partien am bischöflichen Hof sind ganz im Epischen stecken geblieben. 
den Bischof von Straßburg befehdet und in mehreren Treffen schlägt, erregen unbotmäBige Vasallen in seiner eigenen Burg Exem (Egisheim) Aufruhr. Es gelingt aber einigen Getreuen, die Frauen, auf die es abgesehen ist, in den festesten Teil des Schlosses zu retten und ihn gegen die Belagerung zu halten. Hugo selbst fällt zu Straßburg dem verräterischen Bischof bei trügerisch eingeleiteten Friedensverhandlungen zum Opfer; die Frauen werden durch den Liebliaber Ottiliens aus dem bischöflichen Lager, dem sie selbst das Leben gerettet haben, entsetzt, aber er findet in den Schlußkämpfen gegen die Empörer den Tod, und die Geschichte gewinnt damit einen traurigen Ausgang. Denn eine Geschichte, eine Art dramatischer Chronik $^{23}$ ) zieht in aller $\mathrm{U}_{n-}$ gebundenheit des Götz in den losen Szenen vorüber. Man atmet wieder die freie Luft des Sturm und Drangs und man spürt sie in ganz besonderer Weise: Ramond setzt Goethes Eroberung der Ortlichkeit für ein beschränktes Gebiet und mit weit geringerer Kraft, aber mit ganzer Liebe fort - wic er später als Reiseschriftsteller der Entdecker der Pyrenäenlandschaft geworden ist.

Seine Welt ist die mittelalterliche Burg, die nirgends mit so viel Anteilnahme mit allen ihren trauten Winkeln und wiederum mit dem Wuchtigen ihrer Erscheinung zum dramatischen Schauplatz gewonnen worden ist, wie von ihm. Ihr Gehalt hat sich ihm auf ganz andere Weise aufgetan als etwa Maier, er schöpft ihre Kenntnis nicht aus dem Papier, sondern hat sie auf Streifzügen durch das burgengesegnete elsässische Land gesehen, gegen den Abendhirmel und im Morgengrauen und in ihrer lastenden Masse bei Nacht; er bringt diese Erlebnisse von gestern und heute frischweg nach der Art der Stürmer in sein Stiick, das ihm am Ende aus nichts anderem als gerade aus ihnen erwachsen ist. ${ }^{2 \cdot}$ ) So sind Mauer und Turm, Waffenplatz und verschanztes Tor, der steile Burgweg und die Brustwehr gegen das Tal für ihn Schauplätze von ganz anderer Bedeutung als in den meisten Ritterstücken, wo mit ihnen als toter Staffage geschaltet wird, während er sie fast als handelnde Person nimmt.

Er ahmt nicht schlechthin die Umwelt des Götz nach, wohl aber hat ihm dieser die Augen für die Burgen seiner Heimat geöffnet - ähnlich wie Goethe auch das Straßburger Münster für die Welt entdeckte. Eigenes Erleben und literarische Anregung wirken durcheinander; so ragt etwa Gerstenbergs Hungerturm als ".Turm der Vergessenheit" (IV S. 140) in Ramonds Stück herein. Daß er vielfach aus der Natur selbst schöpft, crweist der Umstand,

23) E. Schmidt, H. L. Wagner ${ }^{2}$ S. 120.

24) Es sei .,conçu au milieu de ces rujines imposantes dont jai ranimé les anciens habitants“* ist Ramonds eigene Außerung. die Heymach S. 15 aus der Widmung der französischen Ausgabe, die ihm vorlag. beibringt. 
daß das Lokal kaum je ohne Licht und Luft, als etwas das ihm unerläßlich zugehört, gesehen ist. Die Tageszeit wird in vielen szenischen Anweisungen mitgenann $t^{25}$ ) und dabei manche Abstufung des Übergangs erfaßt, die dem Drama vor dem Götz verschlossen war. Gewiß ist vieles mehr nur in diesen Uberschriften, die wie bei Goethe zur Handlung gehören, als im Stück selbst gegeben; aber der Sinn dafür ist doch geschärft.

Shakespeare ist neben Goethe wie bei Klinger gegenwärtig. Auf ihm ruht die auffällige Bevorzugung der Nacht, ${ }^{26}$ ) die einen großen Teil der Szenen umbüllt, während die Aufmerksamkeit auf das Wetter, zumal eine wüste Sturmnacht mit Wind und Wassernot (V, S. 193), neben dem berühmten Beispiel, das Lear dafür aufstellte, auch im Götz vorgebildet ist. Was Ramond hier und anderwärts ${ }^{2 i}$ ) gibt, geht stark über das stehende Effektmittel von Donner und Blitz hinaus und gehört aufs engste in das neue Verhältnis zur Natur. Aus Shakespeare werden wiederum, und ganz besonders liebevoll, die nächtlichen Postenszenen nachgebildet. Eine Wache am Straßburger Stadttor (V, S. 175) sieht Geister wie ihre Kameraden auf der Terrasse von Helsingör; ein anderer Posten wird recht hübsch in der Ausübung seiner Pflicht, die sich gegen einen Genossen wendet, mit dem er noch gestern beim Wein gesessen, von diesem ausgezankt (IV, S. 116); eine dritte Schildwache aber, da sie sich nicht gefügig zeigen will, in einer trefflich knappen Szene (III, S. 108) kurzerhand über die Brustwehr ins Tal gestürzt.

So sehr die Nachfolge Shakespeares im ganzen den Hugo wie den Götz der Bühne unfaßbar macht - Ramond beharrt hierin im Gegensatz zu seinen Mitstrebenden im Ritterdrama ganz in der Weise Goethes und des klingerischen Otto - so gibt sie ihm gerade in einer Schildwachszene (IV, S. $146 \mathrm{ff}$.) die stärkste Bühnenwirkung; ähnlich haben wir auch im Götz Szenen wie die des verwundeten Selbitz angetroffen, die eminent bühnenmäßig gestaltet sind. Es ist die erste Formung des vorgeführten Sturms auf eine Burg, der wir begegnen, und nach der technischen Bewältigung dieser schwierigen Aufgabe, im Anschluß an Shakespeare, gleich auch die beste. ${ }^{28}$ ) In dunkler Nacht, vor

25) 11, S. 51 : „Bei Sonnen Untergang“" S. 57: „Beim Anbruch des Tages“; III, S. 76: .Einen Augenblick vor Sonnen Aufgang“; S. 78: „Der Tag bricht an“; usw.

28) II, S. 69; III, S. 107; IV, S. 146 usw. „Eine finstere Nacht“ III, S. 74; , Eine tiefe Nacht" V, S. 193; "Eine sehr finstere Nacht" III, S. 109; auf den Zusammenhang mit Shakespeare macht schon E. Schmidt, S. 120, aufmerksam. Auch der Sternenhimmel „mit dem Wagen Gestirn gerade über uns" spielt mit (V, S. 176).

27) V, S. 173; IV, S. 133.

$\left.{ }^{28}\right)$ Vgl. Brahms Zusammenstellung der Erstürmung von Burgen im Ritterdrams S. 151, die aber gerade nicht nach dem dramentechnisch wichtigen, ob der Sturm gezeigt oder auf irgendeine Weise umgangen wird, scheidet. E. Schmidt bemerkt zu den Dramatisierungen des Kohl- 
Tagesgrauen sammelt sich die Sturmtruppe unten an den Mauern des Weckmund; er soll in aller Stille, ohne Gewehr und SpieB, nur mit dem Beil überfallen werden. Als man die Leitem anlegt, gellt jedoch von oben der wache Postenruf $W$ er da! in die Finsternis, mit einem nach Shakespeare ${ }^{29}$ ) gebildeten illusionären Mittel sich noch zweimal, und jedesmal entfernter, wiederholend; nichts könnte den Eindruck der völlig körperhaften, ringsum wohlbehüteten Burg schlagender geben, als diese cinfache, ganz bühnengemäße Prozedur. Auf den Annuf unheimliches Schweigen - und dann, losbrechend, auf einen Schlag der Alarmschrei aller Wachen: Ergreift die Waffen! Die Úberrumpelung mißlungen, der Sturm aber, cinmal angesetzt, doch durchgeführt, Gefecht und Geschrei. Fackeln. Stcine und brennendes Pech von oben, brechende Leitem unten. Ausfall und Tumult - man wird zugeben, daß hier der kriegerische Vorgang sicherlich mit Effekt, aber gewiß nicht hohl zur Wirkung kommt, wenn auch die Szene leider nicht in der Fülle ihrer Bewegung schließt. Der Sinn für das Akustische in der Nacht tritt in Ton und Pause stark hervor.

Ebenso bühnengerecht wie dieser Burgsturm erweist sich die große Beobachtungsszene des Eingangs (I, S. 1), die das erste Treffen mit den Bischöflichen vermittelt. ${ }^{30}$ ) Neben dem goethischen Vorbild mag hier auch Klopstock Pate gestanden haben. An den Götz lehnt sich Ramond in allen soldatischen Dingen vielfach an, ${ }^{31}$ ) nur da $\mathrm{B}$ er mit Klinger in der Vorliebe für das Kampfgetümmel (IV. S. 148-150 und V. S. 206 ff.) über ihn hinausgeht. Dabei ist zu beachten, wie er sich bemüht, die bloße Kampfpantomime durch das Wort zu überwinden - ein Bestreben, dem wir weiterhin begegnen werden.

Bei alledem ist der Hugo wichtiger durch das, was er will, als das, was er wirklich geleistet hat. Es soll durchaus nicht geleugnet werden, daß die $\mathrm{Ge}$ -

hass (Kleists Werke 3, 140), daB Begebenheiten wie die Stürmung der Tronkenburg nur zu ohnmächtigem Ringen mit der epischen Gewalt führten. - Ranond scheint der gelungene nächtliche Uberfall Talbots auf Orleans, I Heinrich VI: II. I vorzuschweben, wo aber die Schildwachen, über ihren Dienst murrend, ihre Pflicht schlecht versehen und die französischen Cenerale sich danum nachher die Verantwortung für die mangelhafte Sicherung gegenseitig zuschieben.

29) Dort (Jul. Cäsar IV, 2 beim Auftreten des Cassius) für die Illusion einer tiefen Marschkolonne gebraucht, welcher das Halt!, das der Spitze auf der Bühne gebolen wird, entlang lauft, sich weiter und weiter entfernend. Man stöße in solchen kleinen Zügen immer wieder auf die erstaunliche Vertrautheit Shakespeares mit militärischen Dingen. Kleist verwendet das Mittel ganz gleich. Hermannsschlache V, 1.

20) Vgl. Brahm, Ritt. S. 152.

"1) I. S. 8 vorübersprengende Reiter, ebenso III, S. III, eng an Cö́z B III, II u. 12; III, S. 109 Verstecken von FuBknectiten im Gebüsch wie Götz III, 7 i das Ertrinken eines Knechits. V. S. 194 ist dercelben Szene nachgebildet (auch bei Klinger, Otso II. 9); unw. 
staltungskraft Ramonds seine hochgesteckten Ziele bei weitem nicht erreicht; doch sind die Tendenzen für sich bemerkenswert genug. Ramond geht für seinen kriegsdramatischen Versuch an der Seite Klingers noch einmal mit Entschlossenheit über Goethe auf Shakespeare zurück, während es die andem am Götz genug sein lassen. Als Ruinenkenner und Burgenfreund hat er das innige Verhältnis zum Lokal der Ritterzeit, das ihnen fast durchweg fehlt. Obwohl er sich nicht in die bühnenmäßige Form fügt, löst er eine der technischen Aufgaben des Ritterdramas, indessen sich etwa G. Meißner wohl in der Vorrede zu seinem gleichzeitigen "Johann von Schwaben "32) mik der Rücksichtslosigkeit der Bühne gegenüber brüstet, weil das seit dem Götz augenscheinlich zum literarischen guten Ton gehört, ${ }^{33}$ ) in Wahrheit aber eine völlig bühnengerechte, herkömmliche Palastintrige in stofflich neuer Einkleidung liefert, welche die Entwicklung in keiner Weise fördert.

Viel mehr hätte dies die dichterisch reichste Erscheinung des Ritterdramas in der Ceniezeit, Maler Müllers "Golo und Genovefa" leisten können, wenn sie nicht erst ganz spät, nach einem halben Menschenalter, ans Licht getreten wäre. ${ }^{34}$ ) Obschon die eigentliche Kampfhandlung darin keinen großen Raum einnimmt und die Interessen andere sind, kann man sagen, daß Friedrich Müller in der einen Seite seines Werkes alles das ans Ziel bringt, was Ramonds schwächere Kräfte auf halbem Wege liegen lassen mußten. Ein Stück, ganz in der freien Form des Götz und doch der Bühne ungleich näher, erfüllt von prächtigem Rittersinn, der sogar das Ende des unrühmlichen Colo verklärt, ohne daß es sich in auseinanderstrebenden KampfszenenReihen vertäte, und endlich voll der köstlichsten Natur, ${ }^{25}$ ) Luft, Licht und Farbe - eine ganze ritterliche Welt mit Schloß und Turm, Garten und finsterem Wald, Mohrenkrieg und Cottesgericht. Der Maler Müller sieht die Welt wie Goethe mit Künstleraugen und formt sie mit Künstlerhänden, indessen der Liebhaber Ramond die Dinge mehr nur fühlte, als selbst zu gestalten vermochte.

Wie dieser den Burgsturm, so meistert Müller mit überlegener Kraft die

32) Leipzig 1780; vgl. Brahm, Ritt. S. 103; nach Seufferts Rez. S. 416 war das Stück schon Jahre vor seinem Erscheinen, 1776, fast gleichzeitig mit demjenigen Ramonds, fertig.

23) Selbst der junge Schiller gibt die Räuber „für nichts anders als eine dramatische Geschichte“ aus (Vorrede 1781).

34) Nach B. Seuffert, Maler Müller, Berlin 1877, S. 144 ausgearbeitet in den Jahren 1776-81. Veröffentlicht erst von Tieck in seiner Ausgabe von Müllers Werken Bd. 3, Heidelberg 1811; hrsg. v. A. Sauer, DNL Bd. 81 ; von K. Freye, Sturm und Drang, Dichtungen aus der Geniezeit, 4. Teil.

25) Damit zusammen hängt die genaue Ortsbestimmung (vgl. Seuffert S. 170), von Klopstock zuerst, nach ihm von Coethe und dann Ramond betätigt. 
andere stehende Aufgabe der Technik des Ritterstücks: das Turnier, ${ }^{3}$ ) und zwar ganz im Theatersinne durch Beobachtung, die wiederum in der erzeugten Illusion mehr gibt, als es die Vorführung selbst tun könnte. Wie sehr er dabei die Bühne im Auge hat, beweist auch hier der Umstand, daß die Verwendung von Pferden durch kunstvolle Anordnung der Szene umgangen wird. Den Kampf zu Roß vermitteln die Zuschauer, der Kampf zu Fuß erst wird im Augenblick der Entscheidung in ein paar rasch hin und wider geführten Stößen sichtbar, als die fast sportmäßige Spannung des drängenden Zuschauerhaufens ihre Höhe erreicht hat. Man erklettert dic Mauern, steigt einander auf die Schultern und hört doch mehr nur was geschieht, das Aufeinanderrennen der Rosse und ihren dumpfen Fall, als man es zu Gesicht bekommt; höchstens daß über die sich reckenden Köpfe hinweg die wehenden Helmbüsche zu erspähen sind. Aus der aufgeregt quirlenden Menge lösen sich die Gärtnerseheleute als besondere Cruppe ${ }^{3 i}$ ) es ist ein feiner Zug der gesteigerten Erwartung, daß der nachforschende alte Adolf keine sichere Auskunft über den Stand des Kampfes erhalten kann, dessen Wogen in jeder Zeile der kurzatmigen Szenen meisterlich zum Ausdruck kommt.

Maler Müller bildet mit dieser, seit Klopstocks Versuch nicht mehr angewendeten Massenbeobachtung die Selbitz-Szene des Cötz ${ }^{38}$ ) aufs glücklichste und völlig frei weiter. Seine Richtung zur Bühne verrät sich auch sonst, wie bei Klinger in den ihr gewidmeten Stücken, durch reiche Verwendung der

se) Es tritt meistens als Cottesgericht aul, unter welcher Rubrik Brahm. Ritt. S. 161, eine Liste gibt. Lohmeyer, S. 306 Anm. I. bringt noch zwei weitere Fälle bei; vgl. auch S. 307 Anm. 12 und Petersen. S. 257. - Ubersehen scheint bisher, dab auch dieser, im Ritterstück mit großer Wichtigkeit behandelse Vorgang in Shakespeare sein Vorbild findet. Richard II: I, 3 wird eir dann allerdings verhinderter Cotteskampt mit allem Zeremoniell (Fragen an die Cegner, Gerichtsbann. Waffnung) eingeleitet. In Lear V. 3 findet sich das Motiv des unbekannten Kämpfers, dem man den Kampf weigern darf. II Heinrich VI : II. 3 bringt den Vorgang in plebejischer Sphäre: der Waffenschmied und sein Geselle fechten mit Stangen vor dem König um die Wahsheit ihrer Aussage. - Ein Cottesgericht, das nach stimmungsstarker Vorbereitung aul der Bühne. hinten zum Austrag komms, auch bei Klopstock. Hermann und die Fürsten Sz. 8-11; eine vom Ritterstück weitab stehende klassische Turnierschilderung in Coethes Tasso II. I; ein turnierartiges allegorisches Ritterspiel am Hofe Elisubeths wird bei Schiller. Maris Stuart II, I. beschrieben; vgl. daru Bellermanns Ausgabe von Schillers Werken 3. 431. Ober die Turnierszene des Warbeck (Dramat. NachlaB hrsg. von Kettner 2, 127 u. 165 f.) vgl. Lohmeyer S. 144.

37) Vgl. auch Lohmeyer S. 87.

28) Seuffert erwahnt sie S. 164 als Vorbild, ohne sonst auf die technische Seite des Stücks näher einzugehen. Auch B. Colz, Pfalzgräin Genovefa in der deutschen Dichtung, Leipzig 1897. streift sie S. 63 nus. 
Beobachtung, ${ }^{39}$ ) die besonders die Umwelt auf Schritt und Tritt heranzieht. Warum Müllers Werk trotz alledem dem Theater fernbleiben mußte, ist hier nicht zu verfolgen.

Wie Goethe hat er farbiges soldatisches Detail, eine Fülle lebensfroher Kleinigkeiten des ritterlichen Daseins zu geben. Mit Klinger ist ihm der Sinn für das Streitroß gemeinsam. In der Lektion über die ritterlichen Dinge, die Adolf seinem künftigen Tochtermann Karl auf den ersten Ausritt mitgibt, wie Polonius seine Regeln über Lebensart dem Laertes auf die erste Reise, nimmt die Mahnung über Pferdebehandlung den breitesten Raum ein. ${ }^{40}$ ) Der Offizier Goethes sorgt durch einen landeskundigen Knecht für das Wegfinden. Müllers Karl ist auf der Heimkehr im finstern Wald unerfindlich irrgeritten (IV, 3) und muß seinen Knecht auf einen Baum steigen lassen, wie auch Ramonds Reiter (V, S. 193) sich in Nacht und Regen um die verlorene Orientierung streiten. Die exponierende nächtliche Szene Müllers am Tor (I. 1), mit lautem Pochen und einem verschlafenen Wächter an Macbeth gemahnend, führt gleich mit dem ersten Schritt mitten in die ritterliche Welt, die Stimmung des Aufbruchs zum Mohrenzug vor Tag und die Sammlung der Kontingente dazu hinein. Solche Intensität der Vergegenwärtigung trennt immer und überall die Werke der Meister von den Mitläufern einer jeden Gattung der Kunst, und um so schärfer, je genauer man die kleinen und kleinsten Züge ins Auge faßt. So hohes Lebensgefühl, wie es sich gut in einem sachlich eng umgrenzten Erlebniskomplex wie dem kriegerischen verfolgen läßt, ist geringen Köpfen fremd, was sie auch sonst leisten mögen; die Art, in der Müller eine wackere Damaszenerklinge mit einer Seele begabt, ist Geist von diesem Geist, und man möchte ihren Liebhaber, den alten Burgvogt Adolf, so sehr die Ausdehnung seiner Figur der Ökonomie zuwiderlaufen mag, ${ }^{41}$ ) allein um sie nicht missen. Froher Kriegssinn lebt nicht minder in der prächtigen Jagd im Grünen im fünften $\mathrm{Akt}_{,}{ }^{42}$ ) und sie ist, nach Lerses Wort, , ,doch immer was, und eine Art von Krieg".

\section{Die bayerische Gruppe.}

Die reiche Welt Müllers ist der weiteren Entwicklung des Ritterstücks zu ihrem großen Schaden verschlossen geblieben. Sie ruht nach Maiers und

39) Zum Fenster hinaus I, 2, DNL 81, 5 u. IV. 5, S. 94; Oberjäger und Förster beobachten den Pfalzgrafen, wie er ein Schmaltier jagt V, 10, S. 152; Sehen und Hören verbunden IV, 12. S. 113, Hören auch I, 4, S. 16; viel Naturbeobachtung: Gegend bei Nacht II, 4, S. 44; Herbst V. 3. S. 135 u. 136; Himmel IV, 15, S. 123; Mond I, 2, S. 6; Sterne IV, 12. S. 114.

c) Vgl. den Anhang Pferde.

11) Seuffert S. 170; Uber Müllers Verhältnis zur Waffe siehe den Anhang Waffe.

(2) Vgl. Seuffert S. 157.

Scherrer, Kampf im deutschen Dtama. 
HahnsVersuchen vorwiegend auf der bayerischenCruppe der Ritterdramatiker. ${ }^{\star 3}$ ) Hier geht Längenfeld mit einem im weitern Sinne historischen Drama, .Ludwig IV., genannt der Bajer" voran. ${ }^{41}$ ) Es setzt sich mit dem Kriegerischen umfänglich auseinander und ist uns deshalb wichtig, weil es dieses in verschiedenen $F$ assungen ${ }^{45}$ ) nicht unerheblich verschieden bewältigt;

43) Ober sie Brahm, Ritt. S. 107-122; Legband S. $407 \mathrm{ft}$.

44) Einem Wink Seufferts (Rez. zu Brahm. Deutsche Literaturzeitung 1880. Sp. 417) tolgend, räume ich ihm neben dem ungleich hekansteren Törring und Babo einen besserep Platz ein, als Brahm. Ritt. S. 108. Sein Stück erscheint als erstes seiner Art in Bayern im Druck (vgl. die Vorrede 1782, C), erlebt innerhalb drcier Jahre, allerdings wohl zumeist seiner antikirchlichen (Gervinus ${ }^{5} 4,653$ ) und patriolisch anti-österreichischen Tendenz (vgl. die Vorrede. Werners Rez, zu Brahm, AfdA 7, 425, und Hauffen, DNL 138, IX u. S. 10; Legband S. 407) wegen drei Auflagen. Nicolai (Reise durch Deutschland usw. 6 [1785], S. 699) hebt es rühmend aus dem Brass der "Nationalstücke" hervor und führt S. 700 das bayerische Aufführungsverbor gegen die Ritterdramen darauf zucke man sah dessen V'eranlassung in dieser anti-österreichischen Stellungnalume (Werner und Hauffen das.: vgl. Brahm, Ritt. S. 62). bis Legband S. 417-18 den wahren Sachverhalt auf Grund der Akten feststellen konnte: die Würde des bayerischen Kurhauses, die sich durch eine Bühnengestalt wie den Fürstenmürder Otto von Wittelsbach verletzt sah, sollte durch das Verbot geschützt verden.

4) Ihr Unterschied ist bisher nicht verfolgt worden. Es existieren: A: München, Crätz, 1780. die Brahm allein kennt; B: Miinchen. Crätz, 1782, die „verbesserte, vom Verfasser selbst besorgte Ausgabe". snit geringen Abweichungen von $\mathrm{A}$ und Besserungen im einzelnen, aber ohne Milderung der Tendenz; die bösen Reden über Papst und Maultasche erhalten z. B. I, 3 sogar noch verdeutlichende Zusätze. Dieser Druck scheint bisher unbekannt, er fehlt bei Kayser. GGr "5, 359. Holzmann u. Bohatta und Hayn. Thesaurus libronm Phil. Pfister Monacensis, 1888; auch Baader (Lexikon verstorbener bayerischer Schriftsteller 2, 162), die einzige mir bekannte Quelle über den Verfasser, der bei Meusel, Lex, und in der ADB fehlt, verzeichnet diese Ausgabe nicht; endlich C: München, Strobl, 1782, gezählt als ,zweyte und verbesserte Auflage". mit dem wichtigen Vorbericht, eine stark verbreiternde Umarbeitung. die sich bemüht. Ludwig IV. außer im Crtöse der W'affen auch im Kreise seiner Familie zu zeigen; die Ausfälle sind an vielen Stellen gemildert; lag W'erner (AfdA 7, 426) vor, dem jedoch A nicht zugänglich war. Die Hof- und Stastsbibl. München besitzt alle drei Drucke. - Zur Namensform: Baader und nach ihm Brahm schreibe Lengenfelder (Joh. Nepornuk) - korrigiert von Werner und Seuftert - der Mann selbst unterzeichnet sich unter der Vorrede zu C Längenfeld; augenscheinlich ein spittes Beispiel der noch nicht abgeschlossenen Verfestigung der Eigennamen (-feld. aber der-felder), die zu massenhaften Doppelformen geführt hat. Legbands Register spaltet den Autor irrig in zwei: Lengenfeld, den Verfasser des "Ludwig der Bajer" (S. 408) und J. N. Lengenfelder, den Verfasser der "Neven Vestalinnen”. Nünchen 1777 (S. 35 f.), eines busen Klosterstücks voll der schärfsten Angriffe auf das Nonnenwesen; möglich. daß die dadurch erregte Sensation dem Erfolg des ..Ludwig" zugute kam, wenn die Vesfasserschaft Längenfelds unter der Hand bekannt wurde. Die Ausfälle des .Ludwig" erscheinen gegen diese beiBende Klostersatire sahm. - Largenfeld ist jung verdorben und gestorben. 
bei geringer Kraft wird darin ein für die Zeit bezeichnendes und auch sonst anzutreffendes Streben deutlich. Die kriegerische Handlung des Stücks, neben der die politische, das Heiratsprojekt des Kaisersohnes mit Margaretha Maultasch von Tirol herläuft, umfaßt die Vorbereitungen zur Waffenentscheidung im Lager Ludwigs sowohl wie in demjenigen des Cegenkönigs Friedrich von Österreich, und darauf die Schlacht bei Mühldorf selbst. Auch Längenfeld exponiert durch eine Schildwachszene, allerdings bei Tag (B I, l), und verwendet sie im Verlauf (III, 1) noch einmal. An militärischen Kleinigkeiten ist anzumerken, daß Friedrich vor dem Treffen (III, 3) eine improvisierte Karte studiert, und daß zur Erkundung des feindlichen Anmarscies (IV, 1) ein "Seherohr" - für das 14. Jahrhundert etwas verfrüht und darum wohl in C fallen gelassen - gebraucht wird. Der Schlacht sucht Längenfeld auf dreifache Weise beizukommen: durch Beobachtung, Reservestc!lung und Vorführung.

Von österreichischer Seite verfolgt (IV, 1) eine Führergruppe vom Hügel den Aufmarsch des kaiserlichen Heers, die eigene Schlachtordnung und den Beginn des Kampfes: Cruppenbeobachtung, wie sie Klopstock geübt hatte und wie sie noch eben bei Maler Müllers Turnier anzutreffen war. Längenfelds Sache ist dabei weder große Spannung noch packende Anschaulichkeit, wohl aber, von der Seite des Verstandes, kundiges Detail. ${ }^{46}$ ) Nachdem die Österreicher die Heerhörner haben ertönen lassen, springt die Handlung $(I V, 2)$ zur bayerischen Partei über; ihre Reserve, an der Spitze die ungeduldig harrenden Führer, nimmt nun die Szene ein, indessen hinten die Schlacht tobt. Diese Anordnung, die schon Elias Schlegel und nach ihm Klopstock vorgebildet haben, wird Klinger in ungleich bedeutenderer Weise als Längenfeld der Schlachtgestaltung im „Konradin" zugrunde legen; zur Voliendung führt sie später, zugleich mit der Technik der Offiziersbeobachtergruppe, Kleist im Prinzen von Hombuıg. Lär.genfeld setzt eine Vielheit von Mitteln in Bewegung - man sucht zu erspähen was möglich ist, sehnt Botschaft herbei, erhält sie, bespricht die Lage, beklagt die Toten, wägt die Aussichten - ohne das zu erreichen, was die Situation einzig verlangt: Spannung. Diese Lösung

16) Man ist zuerst in Ungewißheit über den Gegner, sieht dann die feindliche Kavallerie schwenken und schlieBt, da sich Glied für Glied aus dem Staub schält, daB sie auf Grasboden übergeht. Die schablonenhafte Verwendung der Staubwolke in der Kamplbeobachtung fürderhin (vgl. Brahms Zusammenstellung, Ritt. S. 152) scheint innerhalb des Ritterstücks von Längenfeld auszugehen, der dem Wind und Staub (vgl. auch IV, 2) die gröBte Rolle zuerteilt. In C hängt der Sieg fast davon ab, daB man dem Gegner den Wind abgewinnt. Das Motiv der Staubwolken als zuerst Gesichtetes ist freilich so alt wie die Teichoskopie selbst: schon in Aeschylus' Sieben gegen Theben (Reclamsche Ausgabe S. 8) verrät dichter Staub, ..ein stummer, doch sichrer Bote“, nahende Reiter. - Wind. Wetter und Wasser, wie bei Ramand, III, 1 Ende. 
kann ihm daher in ihrem trägen Trott auch nicht genügen, et will mehr und vor allem Bewegung und Aktion geben und führt als erster Ritterdramatiker nach Klinger in die offene Feldschlacht selbst hinein. An dieser Aufgabe scheiternd, hat er nichts zu geben als die ungestaltete Kampfpantomime, ${ }^{47}$ ) die ihn zudem, als ausgebreiteter Kampf zu Roß vorgeschrieben, mit der Bühne gänzlich entzweit. Eine lange szenische Anweisung, worin die Großen beiderseits mannigfaltige Heldentaten verrichten und die Situation dadurch entschieden wird, daß die bayerische Reiterreserve den Feind im Rücken faßt. bedeutet nichts anderes, als daß der Dramatiker Längenfeld das Heft aus der Hand gibt und kurz entschlossen erzählt, was in der Schlacht vorfiel. An beliebiger Stelle, nachdem der Gegenkönig entwaftnet und gefangen ist, erteilt er seinen Personen dann wieder das Wort.

So weit hat die Befreiung des Kriegsdramas durch den Cötz untergeordnete Talente geführt. Freilich hatte auch Goethe die Gattungsgrenzen mit Weisungen, die sich nur an die Phantasie des Lesers wenden können, verletzt ${ }^{48}$ ) aber er verstand zugleich, jeden einzelnen Augenblick, den seine Cuckkastentechnik aus der Kampfaktion herausgreift, mit dramatischem Leben bis zum Springen zu füllen und die Gefechtshandlung insgesamt durch das mitreißende Tempo zwingend zu gestalten. Hier dagegen ist die Schlacht in ihrem ganzen Bestand, als fortlaufende Ereigniskette, nüchtern und kunstlos vorgeschrieben und die dramatische Aufgabe gerade dort liegen gelassen, wo sie so schwierig als interessant wird. An Wirkung im zirkusmäßigen Sinn, wie sie das spätere Ritterstück anstrebt, denkt Längenfeld dabei nicht; seine Kampfpantomime hat auch als solche keinerlei Verdienst; der Bühne fremd, beruht sie nicht auf der naiven Schaulust der Menge wie das Wiener Combattement oder die stummen Kampfszenen in den frühen Werken Shakespeares, sondern nur auf dem Versagen anderer Mittel.

Daß Längenfeld selbst sie als Verlegenheitsauskunft empfand, wird dadurch bewiesen, daß er sie zu überwinden trachtet. Die Umarbeitung $C$ bemüht sich, den Schlachtverlauf mit dem Wort zu meistern, kommt aber damit nur halb zustande, indem sie (C IV, 4) die erste Hälfte der Pantomime dialogisiert vorweg ni mmt, den Rest aber $(C I V, 6)$ fast unverändert stehen läßt. Immerhin nähert man sich damit dern, was Klinger im Otto versucht hatte, und erkennt,

67) Brahm druckt Rirr. S. 109 einiges daraus ab, woraut sich Lohmeyer S. $84-85$ stützt. Des pentomimische Abbrechen des Lagers III, I, das Brahm auch anführt, gehört deshalb niche vollig hierher, weil es während eines Schildwachgespräch, vor sich geht.

4) Etwa: "Selbitz (hinter der Höhe hervor in Calopp)". Uber die Mischform des dramatischen Halbromans, die C'bergangsstufen zum gespielien Drama und die romanhaten Reste in den Bühnenanweisungen vgl. Pelergen S. 4-8. 
so weitab Längenfeld von Maler Müllers kunstvoller Beschränkung auf die Bühne bleibt, doch sein Streben nach festerer Gestaltung der Kampfszenen. Wie die Fassung $C$, gemäß der allgemeinen Tendenz der Umarbeitung, auch die Vorbereitungen zur Schlacht ausbaut, Lücken ausfüllt und die Handlungskette folgerichtiger abwickelt, kann im einzelnen hier wegbleiben. Mit vielen seiner Genossen teilt Längenfeld den Sinn für das Volkstümliche: streitbare Bäckerknechte (C IV, 2 usw.) liegen ihm sichtlich näher als königliche Kriegshelden.

Von der technischen Seite her mit Längenfeld verwandt, aber mit viel mehr Organ für das Kriegerische ausgestattet, erweist sich Graf Törring in seinem ersten Werk, ,Kaspar der Thorringer" ${ }^{49}$ ) dessen Held sich gleich mit dem entschiedenen Bekenntnis einführt: „Ohne Feder schreibt man nicht, und ohne Schwert regiert man nicht: es gibt Schulfüchse, es muß auch Soldaten geben - Soldat bin ich!" ${ }^{50}$ ) Der Zusammenhang mit dem Cedankenkreis der frühen Stürmer ist deutlich, und so schilt denn auch Kaspar mit Strephon bei Lenz: „Friede, und immer Friede! Verdammt! - O Zeit meiner Jugend, in Waffen und Fechten hingebracht! Da lebte ich, da galts!", und klagt wie der eingeengte Herr Jaxthausens : , Jagen und immer Jagen! Müßiggang und immer Müßiggang! . . Kaspar, jetzt irrst du, wie der wilde Jäger, in deinen Försten“, statt daß es in den kampferfüllten Jugendjahren, wo der Name Thorringer noch ein Feldgeschrei war, kriegerischen Ruhm zu ernten gab. ${ }^{51}$ ) Die Helden

4) Brahm vermutet, Ritt. S. 108, Längenfeld habe den Kaspar in der Handschrift gekannt und sei von ihm beeinfluBt.

50) 1, 2; vgl. dazu Lessings Paul Werner: „Nein, Soldat war ich, Soldat muß ich wieder

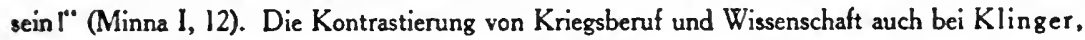
Elfriede IV, 4; für die Tendenz der Genieperiode gegen tatenloses Celehrtentum siehe Brahm, Ritt. S. 190-93.

51) Vgl. Brahm, Ritt. S. 34; die Gegenüberstellung von Jagd und Krieg läßt sich nach der schon angezogenen Szene im $\left.\mathrm{Cö̈tz}_{(\mathrm{Dj}} \mathrm{D}^{2} 3,260\right)$, wo aus braven Reutem brave Jäger geworden sind (,aus Stiefeln machen sich leicht Pantoffeln“), und die Jagd doch immer als eine Art von Krieg gilt, durch das Ritterstück weiter verfolgen. Nach Törring ist es SpieB, der in „Klara von Hoheneichen" I. 4 (vgl. Brahm, Ritt. S. 135) den Ullo sagen läBt: ..Ah, wohl uns. Ritter, daB es einmal wieder was Ernstliches gibt; mußten uns schon lange nur an Bären und Wölfen üben" : die Jagd als Ersatz des Krieges im Sinne Lerses kehrt in Tiecks Genoveva (Schriften 2,241) wieder: „Hat man / Nicht Krieg, so muB man Jagd gar fleißig treiben"; in der gehobenen Sprache Schillers, mit dem antiken Bild, in Braut v. M. v. 912 f.: „Denn die Jagd ist das Gleichnis der Schlachten, / Des emsten Kriegsgotts lustige Braut". Als Deportierter bricht Kotzebues Graf Beniowski (Werke 4,89), dem der Couverneur eröfnet: „Die Jagd wird in Zukunft lhre einzige Beschäftigung sein", feurig froh aus: „Jagd und Waffen I des Krieges Bildl und mindestens ein Traum von Freiheit!" Klingers ritterlicher König in Elfriede (I, 2) ist ein kecker Reiter und frischer Jäger, der nach dem Schottenkrieg mit Wölfen kriegte und das Land säuberte: in- 
Törrings stelien mit dieser mannhaft-ritterlichen Gesinnung am meisten den klingerischen nahe und gleichen ihnen auch in dem freudigen Selbstgefühl kraftroller Körperlichkeit.

Wenn die Textüberlieferung des „Kaspar" nicht ein so böses Kapitel wäre, $\left.{ }^{52}\right)$ licße sich an ihm trefflich nachweisen, wie weit das Kampfstück nun schon aus der stubenhaften Enge eines Maier herausgetreten ist, wie schr es sich aber auf der anderen Seite, gegenüber der Zügellosigkeit des Götz, doch der Bühne nähert - Tendenzen, die wir nach der einen und der anderen Richtung auch bein Maler Müller antrafen. Zwar ist Törring wile Längenfeld vorerst noch ein gut Teil der Theaterfeindlichkeit des Götz eigen, und der Kaspar bedarf wie dieser und andere einer Bühnenbearbeitung; sie braucht jedoch, wie der geschickte Bearbeiter von $A$ erwiesen hat, keineswegs so tief ins Fleisch zu schneiden wie die eigene Goethes von 1804. Zwar die große Kampfpantomime vor der brennenden Burg $(E I V, 6)$, worin Törring ebenso schwelgt wie Längenfeld, der sie möglicherweise nachgeahmt, dann aber immerhin weitergebildet hat, wo die Waffentaten cinzelner Adeliger sich ohne Hilfe des Wortes aus dem allgemeinen Zusammenptall der Hecre schälen und sogar wiehernde brennencie Rosse gehört werden sollen, muß natürlich fallen..$^{53}$ ) Die Kampthandlung im ganzen erleidet aber dadurch, daß (A IV, 4) nur das Anricken des Thorringers hörbar und die Schlacht selbst in den Zwischenakt verlegt wird, keine starke Einbuße.

Törring weiß sie in anderen Auftritten auch schon mit bühnenmäßigen

dessen der mit ihm in Kontrast gesetzte, weichlich-empfindsame Ethelwold die Jagd nicht liebt und während des Krieges zu Hause blieb. Im Anschluß an die Antike, vielleicht auch Tasso. bildet Kleist die Jagdgleichnisse bedeutsam aus (vgl. E. Schmidt in Werke 2. 455 f. und Berthold Schulze, Kleists Penthesilea, Progr. Groß-Lichterfelde 1912, S. 15 f., der sie als Leitmotive verfolgt): so rast Achilles. Penth. v. 213 f.. ., scit in der Forst des Krieges / Dies Wild sich, von so seltner Art, ihm zeigtc". Dazu Hermannsschlacht v. 18 ff.: ..Statt die Legionen mutig aufzusuchen, / In seine Forsten spielend führt er uns. / Und liBt den Hirsch uns und den Ur besiegen." Besonders bildkräftig Hermannsschl. v. $145 \mathrm{ff}$.: ,.könnten wir [statt den der Jagd] Des Krieges ehrnen Bogen spannen, / Und, mit vereinter Kraft, den Pfeil der Schlacht zerschmetternd / So durch den Nacken hin des Römerheeres jagen -."

$\left.{ }^{32}\right)$ Brahms Angaben, Ritt. S. 23, bedürfen sehr der Ergänzungen Werners, AfdA 7, 427. dessen Zeichen ich, soweit sie in Betracht kommen. um nicht wieder neue einzuführen, beibehalte. Der Kaspar, 1779 fertig, erscheint erst 1785, anonym und ohne den Willen Törrings. $\mathrm{O}=$ Klagenfurt 1785 (von Brahm zugrunde gelegt): $E=$ Leipzig und Wien 1785, scheint $\mathrm{O}$ sehr nahe zu stehen. $\mathrm{A}=$ Frankfurt und Leipzig 1785. die Theaterbearbeitung. in der Werner den besten Text vermutet: ihre Vorrede nimmt für sich ausdrücklich Korrektheit in Anspruch. Sie ist neben $E$ benutzt, während $O$ auf den Münchener Bibliotheken fehlt; die späteren Nachdrucke, die Werner zu denen Brahms beibringt $(B=$ Augsburg 1791: $C=0.0 .1817)$ sind belanglos.

z) Vgl. Brahm. Ritt. S. 28. 
Mitteln zur Wirkung zu führen, so vor allem in Kaspars Entschlußszene (E IV, 4). An der Spitze des Heeres nach Landshut unterwegs, um den Gegner ins Herz zu treffen, erhält er Nachricht, daß dieser seinerseits sein Stammschloß Thorring bedrohe. Erst im Angesicht der Brandröte seiner Burg läßt sich der starre Patriot bewegen, die Interessen seines Landes seinen eigenen vorerst nachzusetzen und Weib und Kind zu retten - zweifellos eine theatralisch treffliche Fassung dieses Führerkonfliktes, wenn auch Kaspars kalter Stoizismus unserem Gefühl fremd bleibt. ${ }^{54}$ ) Wie beweglich Törrings Technik bereits ist, zeigt gleich die folgende Szene E IV, 5, die in A fehlt. Sie löst den Botenbericht von Thorrings Bezwingung in eine nächtliche Begegnung im Wald auf, hinter dem die Lohe der brennenden Burg emporsteigt; ein Ritter und ein Knecht rufen sich in der Weise der shakespearischen Schildwachen an; ${ }^{55}$ ) ihr lebhaftes Gespräch führt in die Meldung des Knechts hinein. Wie ein verwandter Auftritt bei Ramond (III, S. 88) tragen auch die beiden hübsch gegeneinander abgesetzten Rastszenen im Eingang des vierten Akts, die heitere Ruhe des Siegers neben der bedrü̈kten des Besiegten, shakespearische Züge. ${ }^{56}$ ) In solchen Dingen offenbart sich überall schon im „Kaspar" àer gute Bühnenblick Törrings. Im gleichen Stück, das eine so monströse Schlachtpantomime vorschreibt, läßt er ihn ganz theatermäßig illusionistische Mittel finden, um nächtlicherweile ausmarschierende Truppen (E III, 4) durch Trommelschlag und Gespräche der Bürger der Einbildungskraft vorzutäuschen; so entgehen ihm auch dankbare Momente, die Fackelszene im Gewölbe (E I, 8) und besonders der Schwertschwur (E III, 6) nie.

Dieser ausgesprochene Theaterinstinkt führt nun das Ritterdrama in der "Agnes Bernauerin "57) im eigentlichen Sinn zur Bühne zurück. Anders als Maier, der aus ihrer überlieferten Enge nur allmählich loskam, ist Törring

54) Vgl. über die Szene auch Brahm, Ritt. S. 27-28. Cassius, Jul. Cäsar V, 3, sieht seine Zelte brennen, Götz V, 5 Miltenberg, die Zigeunerinnen V, 6 andere Dörfer; in Ramonds Hugo wird III, S. 108 eine Brandröte beobachtet. Brahms Anmerk. Ritt. S. 28 (vgl. Werner AfdA 7, 437) bringt aus dem anonymen „Franz von Sickingen“" (aufgeführt 27. Febr. 1783 in Mannheim) eine von Schiller in der Rhein. Thalia (Werke hrsg. von Goed. 3.516) bewunderte, Törring eng verwandte Situation bei.

${ }^{55)}$ „Halt! Wer bist du? - Eure Losung zuvor I - Um die frag ich euch“ usw. Die Parallele zu Götz, die Brahm, Ritt. S. 35 oben hierin zu sehen glaubt, hält nicht Stich.

56) Shakespeare selbst oder zum mindesten die außerhalb Götzens von ihm herführende Entwicklung ist gegen Brahm, Ritt. S. 30 nicht nur für das Geisterhafte, sondern auch das Kriegerische bei Törring von Bedeutung. An einer Stelle, wo sich beides berührt, der Vordeutung des Kampfausgangs durch den Geist E III, 7, scheitert er allerdings, da ihm gebrochene Farben kaum zu Gebote stehen.

57) O. O. [München] 1780; Neudruck von A. Hauffen, DNL 138. 
durch die freic Form hindurchgegangen und hat sich dann, ihre Vorteile nach Kräften herübernehmend, erst wieder eine aufführbare gezimmert; mit dem Unterschied von Müller, daß es sein Werk, ein mit aller Festigkeit, dic das Theater verlangt, gefugtes Bühnenstück, wirklich zu einem großen Bühnenerfolg brachte. ${ }^{38}$ ) Das zum Bild eincs Jahrhunderts, ja zum Weltbild erweiterte lockere Lebensbild Götzens war im "Kaspar", indem der biographische Ausgangspunkt immerhin beibehalten wurde, zu einer fester umgrenzten Handlungsreihe verengt worden. In der "Agnes" tritt wiederum die scharf umrissene Begebenheit in ihr Recht. Der Kaspar ist vor allem darin Ritterstück, daß er ganz auf dem männlich-ritterlichen Charakter seines Helden ruht, indessen die Agnes als Konfliktsstück auch in anderen Lebenskreisen, etwa dem bürgerlichen, vor sich gehen könnte. Sic hat nun zwar mit dem Ritterdrama dieselben Kampfaufgaben. Turnier und Burgsturm gemein, aber nicht so vordringlich wie in den vorangehenden Kampfstücken, sondern mehr nur beiläufig und, wie in Maler Müllers Genovefa, als Teile einer großen, anders gerichteten Handlung.

Dennoch läßt sich an der Bewältigung dieser Dinge gerade jetzt manches sehen. Der Kampf zwischen dem unbegrenzten Darzustellenden und den beschränkten Mitteln der Darstellung, zwischen der Welt als dem Inhalt dramatischen Gestaltens, wie sie der Sturm und Drang erschlossen hatte, und dem Theater als dessen Erscheinungsform, der Kampf, der dann zur klassischen Form führt, hat ernstlich begonnen. Der Stürmer wechselt die Szene sobald sie ihn beengt und regiert schrankenlos in Raum und Zcit. Nun aber bedeutet Veränderung des Schauplatzes mit einem Male nicht mehr bloß eine neue Uberschrift, sondern Fallen des Vorhangs, ${ }^{59}$ ) Umbau der Dekoration, Abreißen der Stimmung, und man muß mit allen hemmenden Realitäten der Bühne rechnen, wo man bisher mit Sonne, Mond und Sternen frei geschaltet hatte. Die Technik gewinnt im Augenblick der Umkehr die höchste Bedeutung. Sie wird stehenden Aufgaben gegenüber, wie sie das Ritterstück gerade in seinem kämpferischen Teil stellt, allerdings bald zur Routine erstarren müssen; in der Tat tritt dies schnell ein. Um so bemerkenswerter sind die ersten Lösungen der Kampfprobleme, die bewußtermaßen für die Bühne gesucht wurden.

Agnes Bernauer soll $(\mathrm{IV}, 7)$ in Abwesenheit ihres herzoglichen Beschützers von den Leuten des alten Herzogs in wohlverwahrter Burg überfallen und aufgehoben werden. Wir sahen, wie Ramond den Burgsturm mit ihm sonst nicht eigenen, bühnengemäßen Mitteln als Kampfhandlung zur Geltung brachte. Im weiteren Verlauf des Ritterstücks wird der Vorgang dann, meist als Panto-

58) Deriber Brahm, Ritt. S. $60-66$.

8." ${ }^{\circ 0}$ Petersen S. 144 datiert seine durchgreifende Anwendung von 1774 ab. 
mime, zum theatralischen Schaugepränge, und die brennende und zusammenstürzende Burg, das Glanzstück des Theatermeisters, ${ }^{60}$ ) bleibt bis zum Käthchen von Heilbronn ein Charakteristikum der Gattung. Maier führt den Sturm auf Boxberg, welcher der ersten Fassung seines Stücks zu Unrecht den Namen gegeben hatte, in der zweiten breit vor, und Törring selbst ließ sich im Kaspar wenigstens den Augenblick seiner Vollendung, Brand und Plünderung, nicht entgehen. ${ }^{61}$ ) Hier überall ist das Verlangen wach, die Vorgänge, gleichviel ob sie wichtig oder unbedeutend sind, sichtbar vor Augen zu haben ; ${ }^{62}$ ) eine Forderung, die den geringeren Zweig des Ritterstücks, der ihr um jeden Preis stattgibt, schnell zur Veräußerlichung führt.

Auch der Burgsturm der Agnes, wo die Situation etwas anders liegt, wäre von dieser Richtung zweifellos als gute Prise erklärt worden. Törring schlägt jedoch einen anderen Weg ein. Er verzichtet auf die äußere Aktion, die er im Kaspar ausgebreitet hatte, aber nicht aus Ängstlichkeit wie Maier im ersten „Sturm", sondern weil er die Wirkung mit geschlosseneren Mitteln erreicht: er ersetzt, ganz ähnlich wie das an ihrer Stelle die Beobachtungstechnik tut, das Sichtbare durch das bloß Geahnte, das klar Erkennbare durch das unheimlich Drohende, die Aktion durch die Spannung. So geringfügig die paar Szenen (IV, 8-11) der Agnes scheinen mögen, so bezeichnend sind sie doch. Man kennt den geplanten Anschlag auf die Bernauerin und wird durch ihre dumpfe Angst beim Abschied von Albrecht auf das nahende Unheil vorbereitet. Der Ton des unterhandelnden Tuchsenhausers schärft sich an ihrem Widerstand mehr und mehr, er warnt, sie beginnt zu verstehen, das Verhängnis bricht herein. Die Herzoglichen überwältigen ihre Getreuen in wütendem Gefecht. Die treffliche Wirkung ist mit den einfachsten Mitteln erreicht; der ganze umständliche Geisterspuk im Kaspar bringt nichts so Beklemmendes hervor, wie hier das simple Läuten der vermeintlichen Mittagsglocke und Ritter Tores „Es ist Zeit“. Der Hergang der Überwältigung Voheburgs bleibt dabei völlig im Dunkeln ${ }^{63}$ ) nicht darauf kommt es nunmehr an, sondern auf die gesammelte

$\left.{ }^{60}\right)$ J. Ch. Lobe zu Coethe über eine Berliner Aufführung von Kotzebues Deodata (welches Stück damit gemeint ist, gelang mir nicht festzustellen): „Es war kein dramatischer, aber ein vollkommener Panoramengenuß ... Die Eroberung und Verbrennung einer Burg erschien mir als das Vollkommenste, was die Bühne zu leisten fähig sei." Goethes Gespräche² 2, 476.

$\left.{ }^{61}\right)$ Uber die gute Wirkung berichtet Schütze, Hamburg. Theatergeschichte S. 622: „auch brachte der 4mal im Januar [1789] gegebne Kaspar der Thorringer, in welchem, außer andern Ergötzlichkeiten für die Sinne, die Burg Thorrings im letzten Aufzuge sehr künstlich brannte, der Direktion einen Teil dessen ein ..."

62) Vgl. für den Kaspar Brahm, Ritt. S. 30.

45) Erst V, 5 berichtet der sterbende Zenger, daB die Feinde an Zahl überlegen (hundert gegen fünfzig) waren. 
Spannung des Ereignisses, dic dem Drama mehr geben kann als scine Vorführung als Schaustück. Maier hatte scin Interesse für den Vorgang an sich schon durch die Wahl des Titels bekundet, ith aber vorerst nicht zu zeigen gewagt. Das mag für die innere Verschiedenheit ihres Verfahrens zeugen, denn äußerlich ergibt sich bei beiden ein ähnliches Bild der.Kampfbewältigung. und Törring nähert sich damit üherhaupt wieder der Zeit vor dem Götz.

Freilich nur in diesem einzelnen Fall. Wie wenig er sonst auf die farbige Kriegswelt Goethes Verzicht zu tun gesonnen ist, zeigt das Turnier, das er als erster auf die Bühne bringt, eine ganze Tradition eröffnend, ${ }^{6 / 1}$ ) die auch hier wicder ins Äußerliche führt. Bei ihm erhält die Szene einen starken dramatischen Akzent im Streit des Vaters und Solnes vor versammelter Ritterschaft und der Menge des Volks. Das Tumieren der Ritter ist nur Auftakt dazu und demgemäß als einleitende Pantomine, bloß durch die Anweisung „Kämpfe”." gegeben. Sie sind zu Fuß gedacht; das Zeremoniell wird olne gelehrte Aufdringlichkeit vorgeschrieben. Der Dialog setzt erst ein, als sich die allgemeine Aufmerksamkeit dem jungen Herzog zuwendet, den die Marschälle von den Schranken zurückweisen, und das Turnier durch diesen Zwischenfall unterbrochen wird. Technisch steht diese Anlage derjenigen Maler Müllers ohne Zweifel nach; doch war bei jenem der Zweikampl und sein Ausgang der eigentliche Mittelpunkt des Auftritts, während Törring das Kampfspiel nur als reichen Hintergrund braucht und in ihm der Bühne cin besonders buntes Stück der ritterlichen Welt gewann, die ihm schon nach seiner Familienüberlieferung nahe stand.

Gleichzeitig mit Törring bemüht sich in Österreich Alois Blumauer, später als Satiriker ungleich bekannter geworden, um eine dramatische Formung des ritterlichen Zweikampfs. Seine "Erwine von Steinheim", ${ }^{5}$ ) ein auch motivisch wichtiges Stück, ${ }^{66}$ ) breitct ihn im fünften Akt mit großem Zeremoniell aus. Die Dicnstleute erwägen die Aussichten des Waffengangs; dann

6) Brahm. Ritt. S. 42; Lohmeyer S. 86; Hauffen DNL 138, 9.

4) Wien 1/80, im 5. Bande des k. k. Nationaltheaters; Brahm. Rilt. S. 139 setzte das Stück nach einem späleren Nachdruck irrig ins Jahr 1790, obwohl schon Meusel, Lex. und nach ihm Wurzbach 1, 443 das richtige Datum verzeichnen, und wurde damit seiner Bedeutung nicht gerecht; beides stellt Werners Rez.. AfdA 7, 420 u. 434 richtig. Benulzt in der Ausgabe von Blumauers sämll. Werken, h:sg. von Kistenfeger, Bd. 9. München 1827.

60) Der heimkehrende Kreuzfahrer findet sein Weib in neuer Ehe und erlangt vom Kaiser die Bewilligung zum gottesgerichtlichen Kampf, worin der (ehrenhafte) Nebenbuhler ihn wider Willen tötet. Gegen die von W'erner (vgl. Hauffen. DNL 138, XI u. 13) behauptete Abhängigkeit von Babos "Oda oder die Frau von zween Männern" von Blumauers Stück siehe Legband S. 265 f.: vgl. auch Jos. Zorn. Die Motive der Sturm. und Drangdramatiker, Bonner Diss. 1909. S. 15 . 
werden. Ritter und Zeugen umständlich auf das Ritterbuch vereidigt und die übrigen Vorbereitungen zum feierlich geregelten Gottesurteil, wie das Prüfen der Turnierwaffen, vorgenommen. Beim Gefecht selbst aber versagen Blumauers dramatische Mittel; es muß eine ganze Weile lang stumm nach der Anweisung geführt werden. Der epische Charakter der dramatisierten Erzählung, ${ }^{67}$ ) der sich auch sonst in den fast durchweg langen Reden und weitschweifigen Verhandlungen ausprägt, tritt dabei stark zutage. An Törrings Beweglichkeit und noch viel weniger an Maler Müllers packende Vergegenwärtigung des Gottesgerichts reicht diese noch befangene Dramatik nicht heran; viel eher stellt das belehrende Ausbreiten historischen Wissens sie neben Maier. Als erster Versuch in der neuen Richtung aus einem ihr bisher verschlossenen Bezirk ist das Stück immerhin unverächtlich.

Will man ermessen, wie viel Längenfeld und besonders Törring geleistet und wie hoch das anzuschlagen ist, was sie dem Götz abgewonnen haben, braucht man nur das Stück eines Mannes, der sich dann der bayerischen Gruppe anschließt, aus dem selben Jahr 1780 neben sie zu halten: Die „Römer in Téutschland" ${ }^{68}$ ) von Babo; demselben Babo, der ein paar Jahre darauf mit dem Otto von Wittelsbach so erfolgreich in die neue Richtung eintritt. Er hatte als vielgewandter Bühnenschriftsteller, als der er sich noch lange Zeit bewährte, bereits 1776 mit dem militärischen Drama in zwei Akten "Arno“ am bürgerlichen Soldatenstück teilgenommen und ihm wichtige Anregungen gegeben, ${ }^{69}$ ) und darauf 1779 einen steifen "Dagobert der Frankenkönig“ geliefert. ${ }^{70}$ ) Die „Römer in Teutschland" sind Kampfstück insofern, als darin wie bei Schlegel und Klopstock, deren stoffliche Tradition Babo aufnimmt, die Befreiung Deutschlands vom römischen Joch vor sich geht, allerdings nicht in einer Feldschlacht wie dort, sondern durch geheime Verschwörung. Man weiß, daß München ähnlich wie Wien in den siebziger Jahren anderen Städten gegenüber in der dramatischen Entwicklung zurückstand. ${ }^{71}$ ) Nach

67) Eine längere Vergleichung des Trauerspiels mit seiner Quelle liefert Joh. Frdr. Schink in seinen Dramaturgișchen Fragimenten Bd. 3, Graz 1782, S. 761-95.

${ }^{68}$ ) Der erste Druck München 1780 ist auf den Münchener Bibliotheken nicht vorhanden und daher der Nachdruck Frankenthal 1780 benutzt. Die erste Aufführung in München schon 1779 (Grandaur, Chronik des Kgl. Hof- und Nationaltheaters S. 23), und zwar am 22. Aug. (Westenrieder, s. u.; Legband S. 430).

${ }^{69}$ V Vl. über „Arno“" Hauffen, DNL 138, 12 u. Stockmayer S. 41, 46 u. 95-9, wo er an Bedeutung neben Möllers Graf Walltron gestellt wird; Legband S. 408.

70) Über ihn kurz Brahm, Ritt. S. 112; Hauffen, DNL 138, 12; ausführlich Legband S. 279-82, vgl. 267 Anmerk.

71) Der Theaterrezensent des Teutschen Merkurs urteilt $1775(2,274)$ über sein Theater: "es ist noch ganz in der rohesten Kindheit, und noch sieht man geringe Hoffnung, dab es voll- 
einem Stück wie demjenigen Babos - es erhielt vielen Beifall und behauptete sich lange Zeit im Repertoire ${ }^{72}$ ) - möchte man schließen, es hätte das erste Sturm- und Drang-Jahrzehnt völlig verschlafen, wenn nicht ein Törring fast gleichzeitig auf den Plan trätc.

Die „Römer" lehnen sich zwar in Tendenz und Sprache vielfältig an Klopstock an, sie gehören aber innerlich weit mehr in dic Cottsched-Schönaichsche Gruppe als neben dessen Schlachtfestspiel. Kriegerisches ist in der von Intrigen und Konflikten strotzenden Familientragödic alten Schlages, ${ }^{73}$ ) in der ein unerkannter Sohn die hauptsächlichste Rolle spielt, wenig zu finden; soviel die Helden, der übergeschnappte Römerhasser Hatto und Willmar, der ins Groteske gefallene Horst Klopstocks, von Tod oder Freiheit reden. Der Befreiungskampf der Germanen wird in der schüchternsten Personnages-Technik abgemacht, die von dem Massenaufgebot Törrings in der Turnier- und der Ertränkungsszene der "Agnes" stark absticht. Zwei Germanen nehmen den römischen Feldherrn, der nächtlicherweile natürlich allein lustwandelt. IV, 4 gefangen, und als darauf zu einem Schwertgruß ans Vaterland doch noch einige Krieger versammelt werden müssen, wird ängstlich dazu bemerkt, daß nur eine Reihe auf die Bühne komme, die übrigen aber innerhalb der Szene blieben. Im „Otto" dagegen schreibt Babo, anspruchsvoller geworden, beim Kirchgang des Herzogs (1) hundert Mann nur an Leibwache vor, die Fürstlichkeiten, Ritter und Landstände ungerechnet. In dieser cinen, an Klopstocks Stimmungskunst geschulten Szene der "Römer", wo die Cermanen das lodernde Fanal der Freiheit betrachten - ein Augenblick, den Kleist zur höchsten lyrischen Wirkung bringt - bricht Babos Bühnenbegabung durch das weithin hölzerne Stück; sie kann den raschen Aufschwung, den er im Otto nach einmal empfangener Anregung nimmt, allein erklären."

kommener werden möchie". Ausführlich dargelegt sind diese Zustände samt ihren Cründen und den besonderen Verhältnissen, welehe für die Ubergangszeit daraus folgen, bei Legband S. 258-59: 296-97.

72) Westenrieder, Baierische Beytrăge 1779, 2, 992: Legband verzeichnet vom 22. Aug. 1779 bis Nov. 17878 Auftührungen.

т) Vgl. Westenrieders Rezension, Baierische Beytrăge 1779, 2. 997 . Wie Schönaichs .Thusnelde und Hermann" nülzt Babo das alte lohensteinische Motiv, daB der römische Feldherr - hier Drusus, dort Germanicus - der feindlichen Fürstin nachstellt.

"1) Fördernd für das Verständnis ist daneben die Einsicht in die Eigenart des darnaligen Zustandes in Bayem, wie sie Legband S. 2\%-97 für das Allgemein.Geistige darlegt. Auch innert der dramatischen Form prallen hier die Gegensätze, die der Norden in der Entwicklung zweier Generationen ausfocht, in derselben Generation, ja im selben Autor schroff aufeinander. Als sich die bayerische Dramatik zu regen anfing. lag neben der goltschedischen Form schon die des Cötz vor, und man war vor die Wahl gestellt, sich eklektisch der einen oder der anderen anzunchlieben. 
Merkwürdig bleibt er immerhin, denn „Otto von Wittelsbach" 75) ist an den „Römern" gemessen eine ganz erstaunliche Leistung und ein rechtes Beispiel dafür, wie viel ein mittleres Talent vermag, wenn es durch große Vorbilder auf den rechten Weg geleitet wird. Babo hat an dem dramatischen Libertinismus der siebziger Jahre, wie seine Römer übergenug ausweisen, nicht teilgenommen. Die Aufführung seiner Stücke lag ihm stets als erstes am Herzen, ob er sich nun mit dem Dagobert ${ }^{26}$ ) in französischer Technik versuchte oder im Otto ein freies Ritterstück gab. Er tritt in die vorschreitende Entwicklung in dem Augenblick ein, als Törring das Ritterdrama eben der Bühne gewonnen hatte. Fest auf ihrem Boden stehend, gibt er den Kampfvorgängen, die den Cötz, Klingers Otto und Ramonds Hugo erfüllen, ebensowenig wie Törring in der Agnes Raum, weiß aber den frischen Reitergeist jener kriegfrohen Werke seinem Stück ungeschmälert zu erhalten. Sein Otto bleibt ein wackerer Streiter auch wenn er weniger zum Schlagen kommt, und man glaubt ihm seine hübsche reisige Selbstcharakteristik: "Ich reite spornstreichs durch mein Leben und finde keine bleibende Stelle, bis mich der Tod aus dem Sattel hebt." Mit vieler Beweglichkeit bringt Babo die Örtlichkeit zur Geltung ${ }^{77}$ ) und versteht sein Bild des Reuterlebens durch kleine Züge eindringlich zu machen. Das Siegel des Uriasbriefes schmilzt unterm Koller des wackern Wolf bei raschem Ritt (III, S. 123); ein Schwert erinnert den Kaiser (III, S. 130) an Ottos gerade Art.

Die Einschränkung der Kampfvorgänge zeigt sich am deutlichsten darin, daß die Heldentaten, die der Wittelsbacher als unerkannter Ritter zu Bamberg verrichtet, nicht an die Rampe gelangen: Babo behält das Turnier im Gegensatz zu Törring hinten, ob es ihm nun für die Aufführung zu schwierig oder als Bühnenvorgang zu leer vorkam. Jedenfalls ist der unfehlbare Hieb und Stich des Unbekannten besser zu schildern als darzustellen, und Babos Anordnung gewinnt zudem den Vorteil, daß Ottos Hintreten vor den unruhigen

75) München 1782. Neudruck von Hauffen, DNL 138.

$\left.{ }^{76}\right)$ Die Vorrede (benutzt nach der Ausgabe München 1787) verspricht sich von dem Stück auf der Bühne mehr Wirkung als beim Lesen. Für die Vorrede zum Otto s. o., S. 101 Anm. 1).

77) Akt I, DNL 138, 95, eine rasche Aufbruchszene am SchloBtor; die Burg Wittelsbach bei der Ubergabe, IV. S. 159; schon vorher IV, S. 150 durch stimmende Beobschtung ins Cesichtsfeld gerückt: Reuß: „Cnädiger Herzog? was ist das für ein Schloß, nach dem ihr so hinstarrt? es prangt gar hoch über die ganze Gegend, als wär es die Krone des Landes". - Herzog: .Wittelsbach!" Seine Ruinen (vgl. Brahm, Ritt. S. 113) dann in V. - Landschaft aus dem Fenster gesehen IV, S. 141 : „Vater, wo liegt Frankfurt?” - Otto (zeigt durchs Fenster): „Da. weit hinter jenen Bergen nordwärts!" 
Kaiser $\left.{ }^{i s}\right)$ stärker einschlägt, als wenn man ihn vorher in dessen Gegenwart fechiten sähe. Das Interesse an dieser bühnenmäfigen Wirkung trägt es hier wie beim Burgsturm der Agnes über die Freude an Kämpfen schlechthin davon. Die Trehnik zeigt sich der Aufgabe, das Turnier zu umgehen, gewachsen, und es geschicht ohne Zwang. An ritterlichen Gebräuchen wird bei der Verteilung des "Dankes" in Saal gerade noch genug gegeben - mehr würde in jene unfruchtbare Gelehrsamkeit hineinfuihren, die in Babos lebendiger Darstellung sonst fehlt.

Wo cin Kampfvorgang dagegen wirksame Elemente in sich birgt, darf er nicht wegbleiben. Wie Cötz Jaxthausen, so übergibt Otto seine Burg Wittelsbach den Vollziehern der Reichsacht nach einer dem goethischen Vorbild im cinzelnen nachgeahmten Kapitulations-Verhandlung..$^{9}$ ) Goethe hatte den Augenblick der treulosen Überwältigung Götzens blitzartig durch die paar Worte der beobachtenden Knechte crleuchtet. Babo führt diese Anregung bezeichnend für dic Art, wie jede Kleinigkeit Goethes dem Theater fruchtbar gemacht wird - zu einer längeren Bühnenszene aus (V, S. 160). Das Tor wird geöffnet, Ottos Leute ziehen auf sein Geheiß ab, der Führer der Exekution stellt sie. Da ihnen die Klingen olmehin locker sitzen, steigert sich die Spannung bis nahe ans Handgemenge, als Otto mit Kindern, Brüdern und Getreuen erscheint. Die Herzoglichen wollen den Ächter anfallen, alles zieht, die Bayern decken ihn mit ihren Lanzen; er allein bleibt inmitten der Erregung von ihr unberührt und schafft sich durch die Größe seines Elends, im Scheiden von Burg und Vaterland, selbst bei den Häschern Achtung. Das Kämpferische wird hier, wo nur scine Spannung, nicht das Dreinschlagen gegeben ist, zu einem theatralisch äußerst wirksamen Mittel, und man sieht vie seine Bewältigung - im Theatersinne - seit Türrings und Längenfeids Schlachtpantomimen fortgeschritten ist.

Ein Blick auf einen wilden Schößling am bayerischen Stamm. Anton Nagels „Bürgeraufruhr in Landshut" ${ }^{80}$ ) bestätigt dies durch den Kon-

i8) Bei Philipps plötzlichem Aufbruch schwebe deutlich derjenige des Claudius (Hamlet III, 2) vor; ( laudius wird durch die ,Mausefalle". Philipp durch die bloße überraschende Cegenwart des Beleidigten entlarvt. Die Reden, welche Babos Otlo danach führt, sind ganz im shakespearischen Ton gehalien.

7) Vgl. Brahm, Ritt. S. 114 u. 151. Otto fahrt wie Götz über den Text der Auffordenung auf. Bei Shakespeare gebören Unterhandlungen besonders mit Stadt-Festungen zum Bestand der Kriegsgeschehnisse. Brahm nennt S. 151 Richard II: III, 2; ich füge an König Johann 11. I: Heinrich V: III, 3: I Heinrich VI: IV, 2 und V, 3; III Heinrich VI: V, I: Coriolan I, 4.

s0) Im gleichen Jahr wie Babos Orto, München 1782, erschienen. Brahm, Ritt. S. 118-120; Lohmeyer S. 88-90: Hauflen. DNL 138. VIII. Nicolai, Reise usw. 6 (1785), S. 699 nennt das Stück ..ein wildes Ding, das aber ein pasr starke Szenen hat". 
trast. Stofflich zwar in der Nachfolge Törrings stehend, setzt dieses wüste Stück doch keinesivegs dessen Richtung zur Bühne hin fort, sondern ersättigt sich zuchtlos an aller Freibeuterei der ,dialogisierten Geschichte“. Nagel, im Formalen überall ein völlig ungeratener Bruder etwa Ramonds, der seinen Shakespeare nicht talentlos, aber wahrhaft greulich verzerrt, beschränkt sich merkwürdig genug nur in zwei Dingen: er bewahrt beim buntesten Ortswechsel die Einheit der Zeit, indem er die Vorgänge einer Nacht in eine Unzahl von Verwandlungen preßt (wodurch die Folge der Ereignisse natürlich außer Rand und Band gerät), und er verengt die vaterländische Tendenz der bayerischen Stücke zu einem kläglichen Lokalpatriotismus. Wie im übrigen geringere Köpfe, hat er starke Beziehungen zum alten Greueldrama und übertrifft einen Schummel an Grellheit um Bedeutendes. An Kampftechnik braucht er für seine dramatischen Fetzen in lockerem epischem Zusammenhang nur wenig aufzuwenden. Er führt kunstlos und roh - das heißt Shakespearismus in diesem Zerrbild der Sturm- und Drangdramatik - vor, was ihm gut dünkt, Zweikampf, die Überwältigung der Bürger durch Waffenknechte, eine Hundemeute (S. 104), Geraufe (S. 161) und besonders, gegen den Schluß, das große Morden in Landshut (S. $170 \mathrm{ff}$.) als Schreckenspantomime, bei der ihm alle Raumvorstellung verschwimmt. ${ }^{81}$ ) Auch der nächtliche Sturm auf die Trausnitz (S. 147 ff.) soll, wie bei Ramond, sichtbar werden; dem Realismus, zu dem der Götz Mü: gemacht hatte, gemäß untergraben die Steinmetzen mit Mauerbrechern die Ringmauer; als die Aktion endlich in Zug kommen soll, Leitern angesetzt werden, Ziegel herunterrasseln und Feuerbrände bereit sind, bringt jedoch der Altbürgermeister die biedern Bayerherzen von ihrem sündlichen Vorhaben gegen den Landesherm ab.

Dabei kann man Nagel doch nicht schlechthin unfähig schelten. Er besitzt eine zwar rohe, aber dennoch hin und wieder zwingende Gestaltungskraft, er ist ein verwildertes und völlig dem Krassen verfallenes Talent. Bequem liegt ihm als einziges technisches Mittel die Beobachtung, die er auf Schritt und Tritt, bei einer Lagerszene (S. 136), beim Anrücken von Thorringers Heer (S. 176) und anderer Truppen (S. 161 u. 186) und in der Mordnacht (S. 164) anwendet. Auch Gruppenbeobachtung ${ }^{82}$ ) findet sich, wie Nagel überhaupt durch seine Verwendung des Volkes in einer Unzahl von Rollen hervorsticht. ${ }^{\$ 3}$ )

81) Vgl. Lohmeyer S. 89, der die Bühnenvorschrift abdruckt.

${ }^{82}$ ) Eine Handwerkergruppe verfolgt S. 62-65 von unten, wie der Herzog mit seinem Baumeister auf dem schwindelnd hohen, noch eingerüsteten Martinsturm herumklettert und auf schwanker Leiter beinahe abstürt - das Motiv, das den Baumeister Solneß Ibsens in atemloser Spannung schließt.

20) Vgl. Lohmeyer, S. 88 u. 90. 
Liest man in seiner Kampfpantomime von Steinkugeln, Doppelhaken, ledernen und hölzernen, mit eisernen Reifen beschlagenen Haubitzen und Feuerkatzen, so fühlt man sich an die museumsmäßigen Kenntnisse cines Jakob Maier erinnert, von dessen tüchtigem, geregeltem Wesen dieser Flackergeist sonst so sehr absteht.

Aus der bayerisehen Familie ist noch ein Stück aus dem selben Jahr 1782. Lorenz Hübners .,Hainz von Stain der Wilde" ${ }^{\text {"H4) }}$ ) von Bedeutung; nicht um poetischer Verdienste willen, die ihm ganz abgehen, sondern weil es eine besondere Tradition der weiten ritterlichen Gattung fortsetzt. Man könnte innerhalb des Ritterstücks ein eigenes Burgenstück unterscheiden. Goethe entdeckt das Lokal mit Saal, Küche und Schloßhof Jaxthausens, mit dem Wartturm in Gebüsch und Wald. Ramond bildet es mit der größten Liebe aus; seine Handlung knüpft an eine bestimmte Ruine an und ist eingestandenermaßen aus ihrer Anschauung herausgestaltet, wie später des jungen Tieck Ritterdrama aus dem sonderbaren und finsteren Eindruck erwächst, den ihm die Burg Berneck im Bayreuthischen gemacht. ${ }^{85}$ ) Kleists Strahlburg mit dem Platz am äußeren zerfallenen Mauernring, ,.wo der Zeisig sich das Nest gebaut. Der zwitschernde, in dem Hollunderstrauch", ist uns allen gegenwärtig. Neben diese letzte Verklärung mittelalterlicher Burgenwelt in der ritterlichen Gattung darf sich nun freilich Hübners gut gemeintes, aber stümperhaftes Stück nicht stellen. Nur seine ehrliche Freude am alten Gemäuer ordnet ihn hinter Ramond in diese Reihe ein. Was auf den Gipfeln, im Götz und Käthchen, zu einer poetischen Verherrlichung des besonderen Kriegslokals führt, macht sich hier in der Niederung als naive Lust an historischem Krimskrams behaglich; mit lehrhafter Nebenabsicht, denn Hübner stellt sich auf dem Titel der späteren .Camma" nicht umsonst als Professor vor. So beschreibt er denn in der Vorrede zum "Hainz" den historischen Schauplatz, den er sich gewählt hat Stein an der Traun ${ }^{86}$ ) - in seinem gegenwärtigen ruinenhaften Zustand aus genauer Kenntnis und erzählt von den Gefängnissen, unterirdischen Gängen und der Köpfstätte dieses, einer Lokaltradition zufolge, ${ }^{87}$ ) wüsten Raubritternestes. Aus eigener Machtvollkommenheit gibt er der rekonstruierten Burg einen Burghof mit Warten und ergänzt an seinem Lokal auch die Zugbrücken, denen in seiner Handlung eine wichtige Rolle zugedacht ist. ${ }^{88}$ ) Die Einheit

4) München 1782. Brahm nur kurz, Ritt. S. 122; 133-34; Hauffen, DNL 138, VIII.

8) Schriften 11, XXXVII.

${ }^{86)}$ Bei Altenmarkt unweit Trostberg, in der Gegend des Chiemsees (Bezirksamt Traunstein).

"7) Die Sage erzähtt Elisa von der Recke. Tagebuch, Berlin 1815, 1. 21 ff. (Werners Rez., AfdA 7, 437).

89) Die Zugbrücke als Requisit des Ritterstücks fordert später in Kotzebues .Johanna vod Montfaucon" A. W. Schlegels Spott heraus. 
des Ortes, die er, angesichts seiner sonstigen Weise wunderlich genug, zu halten verspricht, interpretiert dieser Burgenfreund als die Einheit aller denkbaren Schauplätze derselben Burg, wie Corneille ${ }^{89}$ ) wenigstens zwei Schauplätze derselben Stadt zugebilligt hatte.

Mañ wird für das Burgenwesen Hübners den unmittelbaren Einfluß Ramonds durchaus behaupten können. Der Hugo, 1781 in Regensburg deutsch erschienen, lag den bayerischen Autoren nahe und konnte durch seine Richtung im ganzen anregen, wie auch eine Fülle von Einzelzügen liefern. Zudem hatte Babo aus Burg und Ruine Wittelsbach ${ }^{90}$ ) bereits starke theatralische Wirkungen zu ziehen verstanden. Daneben wirken die Vorbilder bei dem sichtlich belesenen Hübner durcheinander; singende Knechte im Burghof (II. 1; bei der Heimkehr III, 1), die übrigens recht frische Reuterlieder zum besten geben, weisen auf den Götz; der Nachruf, den Hainz dankbar einem im Treffen gefallenen Knecht hält (III, I), samt der Anordnung ehrenvoller Bestattung, eher auf Shakespeare; ihn wird man auch in der ausgedehnten Postenszene (IV, 2) auf den Warten am Tor in der Abenddämmerung unmittelbar erkennen, obschon Ramond sehr Verwandtes bereits nachgebildet hatte. Der scharfe Wind von der Helsingörer Terrasse her pfeift auch den beiden "Skartleuten“" Hübners, wie den Posten Hahns um die Ohren, die Kälte - dies als Beispiel hübnerischer Diktion - schüttelt ihnen den Steiß, daß er klappert, und der Schauder, der ihnen über den Rücken läuft, weissagt nichts Gutes. Gerade diese letzte Funktion der Postenszene, das stimmungsmäßige Vordeuten eines unheimlich drohenden Ereignisses, verrät das shakespearische Vorbild.

Die Katastrophe selbst, die Überrumpelung des Weiberräubernestes, das durch Verrat fällt, geht als Pantomime mit Geschrei und einigen Rufen der Führer rasch vorüber $(V, 1)$. Das Bühnengeschick in der Anordnung zeigt gegen Törrings Kaspar ${ }^{91}$ ) Fortschritte, die offenbar auf dem Einfluß Ramonds beruhen. Die Szene ist der Burghof; eine Fackel gibt das Zeichen über die Mauer nach außen; man hört von dort das Röcheln der erstochenen Wächter, hört die "Fallprücke“ niederrasseln und sieht die Angreifer in die Verwirrung der unbewehrten Knechte stürzen, die das „Lärmhorn“ zu spät zu den Wafíen ruft; darauf über die innere Fallbrücke, die sich ebenfalls durch Verrat senkt, in den Schloßkern, die „Felsenburg“ eindringen. Es ist kein Zufall, daß der Bühnenpraktiker Kotzebue später in .Johanna von Montfaucon“" zu einer verwandten Anlage greift: sie gewährt den bewegten Eindruck des Gefechtes

89) Discours des trois unités; vgl. Lessing im 44. Stück der Dramaturgie. Petersen S. 95.

90) Der Otto war (Legband S. 437) am 23. u. 25. Nov. 1781 über die Nalionalschaubühne gegangen und hatte dann das allgemeine Aufführungsverbot vaterländischer Stücke veranlaßi.

21) Trotz Brahm, Ritt. S. 134.

Scherrer, Kampf im deutschen Drama. 
mit dem geringsten Ausmaß wirklicher, leidiger Bühnenkämpfe; man erkennt auch bei cinem Hübner, wie sich die Ansätze zu ciner bühnengerechten Schlachtpantonime fortbilden. Für die Technik der Beobachtung beweist die Art, wie er sie nach Bedarf handhabt, ${ }^{92}$ ) daß das Mittel urn diese Zeit bereits Gemeingut geworden ist. Wie überall in den Niederungen der Ritterdramatik fahren bei Hübner nicht die Helden - Hainz selbst ist ein unleidlich sentimentaler Bösewicht - wohl aber die Knechte gut. Für grobschlächtiges Reuterwesen reichen die Mittel, allem Anschein nach der Kreis eigener Erfahrung und besonders die derbschrötige Sprache zu. Szenen dieser Art sind auch im „Hainz" die lebendigsten.

Was sie leisten, danken diese untergeordneten Autoren der festen Tradition einer geschlossenen Gattung. Neben dem Ritterstück wird dies besonders in der Familie der bürgerlichen Soldatendramen deutlich, die eine Reihe schr brauchbarer Theaterstücke geliefert hat. In seinem späteren vaterländischen Schauspiel "Camma, die Heldin Bojoariens" ${ }^{\text {(23) }}$ sicht sich nun aber Hübner durch einen von außen kommenden Machtspruch, das bayerische Aufführungsverbot, von dem festgetretenen Pfade weggewiesen und muß in dic Wirmis grauer Vorzeit abirren. ${ }^{9}$ ) Zwar Schauplatz und Kostüm bleiben im Crunde dicjenigen des Ritterstücks; Camma wohnt mit ihren Bojern in einer Burg mit Tor, Fallgatter und Lärmhom; cin Herold fordert sie ${ }^{\mathscr{L}}$ ) mit Trompetenstoß zur Schlacht ins freie Feld (II, S. 4I ff.). Daneben aber muß das Bardenwesen, dem sich Hübner durch den Stoff nähert, Züge leihen: Klopstock steuert in diese ritterliche Welt einen Druiden, Ossian einen Fingal bei, der bei den Bojern die Charge eines "Rottmeisters" bekleidet; man hört sogar Töne aus dem Soldatenstück durch, wenn der greise Bojerfürst

s2) III, I erspäht Siegfried vom Torgitter der Felsenburg herab in Staubwolken den heransprengenden, verworrenen Haufen der heimkehrenden Sieger, samt einem Trupp von Gefangenen; IV. 2 die Posten verdächtiges Waffengeflimmer in Gebüschen usw.: in Brahms Statistik der .Beobachtung von Vorgängen hinter der Szene“. Ritt. S. 151 f., ist der Hainz übergangen.

93) München 1784. Brahm. Ritt. S. 121-22.

24) Hübners Vorwort selbst legt diesen Sachverhalt dar: Brahm S. 122. Die Bemerkung Legbands S. 408, daßB der Heldengeist Bojoariens in der Camma noch einmal ziemlich unverhültt in einem vatertändischen Stoff gepriesen werden konnte. srifft wohl für den Druck zu, für die Aufführung jedoch tilgte der Zensor nach dem Ausweis des Theaterzeltels (18. Dez. 1783, im Zettelband $4^{\circ} \mathrm{P}$. serm. 212 [I] der Univ.-Bibl. München) jede Bezichung aul das engere Vaterland: Camma ist die Heldin aus Teutschlands Vorzeiten. die Bojer sind in Cherusker verwandelt usw. Vielleicht. daß die Aufführung dieses vaterländischen Stücks trotz des Verbots überhoupt nur ..zum Eesien der Armen" (so auf dem Titelblatt des Druckes) durchschlüpfte. Es wurde bis 1798 (Legband S. 504 u. 526) zehnmal gespielt.

s), Vgl. Brahm. Ritt. S. 151 . 
Morganor (II, S. 38) sich weigert, vom Kampf fern zu bleiben, weil das seinem ,alten Soldatenherzen“" zu wehe tun würde.

Gleich wunderlich und haltlos wie das Kostüm ist die Technik; sie pendelt zwischen dem Götz und der Weise Klopstocks hin und her. Das Heer wird zwar aufgeboten (II, S. 41), aber die Schlacht hinten gehalten. Für eine Besorgnisszene an ihrer Stelle liefert Klopstock das Motiv des waffensehnsüchtigen Knaben (II, S. 44 ff.), der nicht mehr Kind heißen will, begierig mit dem Säbel eines Kattenboten spielt (II, S. 49-50) und in seinem Tatendrang von ihm vertröstet werden muß. Das Ergebnis der Schlacht weissagt der hellsichtige Druide (II, S. 46) noch während sie geschlagen wird - die Technik der Koinzidenz in plumpster Form. Aus dem Ritterstück wiederum tummeln sich unter den bojoarischen Großen ein paar grobe Kriegsgesellen, von denen einer, der alte Pipin (III, S. 71), v sm Römerkrieg nicht übel erzählt, wie er wohl tausendmal aus seinem Helme Pfützenwasser getrunken und an seinem Schwert Hammelfleisch gebraten habe. Die Diktion im ganzen offenbart, besonders aus fürstlichem Frauenmunde, ${ }^{96}$ ) eine erschreckende Plattheit; Schinks Klage, ${ }^{97}$ ) daß die Pfalzgrafen, Herzöge und Könige eine Sprache reden, als ob sie in der Schenke groß geworden wären, uid sich gebärden, als ob sie eben aus dem Stalle kämen, trifft auf die Stücke dieser Sphäre ebenso zu, wie Wilhelm Schlegels Spott, ${ }^{98}$ ) daß in ihnen nichts altdeutsch sei als vermeintlich die Roheit.

Ans Ende der kriegerischen Dramen aus der bayerischen Gruppe seien hier, zugleich zurück- und vorgreifend, drei Städte-Belagerungsstücke gestellt. 1778 gab der als Lustspieldichter fruchtbare Graf Törring-Seefeld eine „Belagerung der Stadt d'Aubigny" "99) die als heroisches Konfliktstück voller Edelmut noch der französischen Schule nahesteht, trotzdem die Form mit Ort und Zeit im ganzen bereits freier schaltet. Immerhin hat hier aus der neueren Entwicklung die Postenszene bereits Eingang gefunden und füllt die Zeit, die der hinten vor sich gehende Kampr beansprucht. Zwei Soldaten besprechen sich auf Wache vor dem Zelt des Marschalls (III, 1) - einer mutig und unbekümmert, ungern dastehend während andere fechten, der andere über Recht und Unrecht der Parteien räsonnierend.

Ein Jahr nach Anton Nagel läßt Max Blumhofer ein neues und von dem ersten sehr verschiedenes Landshuter Drama erscheinen: „Die Schweden in

96) Camma schlägt die Werbungen Alarichs (I, S. 20-21; II, S. 42) im unverfälschten Domestikenton ab und schickt ihm, Teutschlands Heldin, „den Korb entgegen zur Morgengabe“ usw.

97) Dramaturg. Monate, Schwerin 1790, 3, 752.

98) Dramat. Kunst und Litt. ${ }^{2} 3,415-16$.

99) Uber sie Legband S. 275-77. 
Bayern oter die Bürgertreue ${ }^{\circ 100}$ ). Es verherrlicht lokalpatriotisch den Opfersinn der Landshuter Bürger und steht nach Form und Tendenz der Magdeburger Belagerung Schummels nahe, nur daß das Rührselige das Grausame in den Hintergrund drängt. Festspielmäßig wird ein Massenaufgebot zu Kanpfaufzïgen verwendet. ${ }^{101}$ ) In eine fernere Vergangenheit, die aber darum nicht mincler zu cinem Loblied auf hayerische Kriegstüchtigkeit, wie es das ganze bayerische Ritterstück durchklingt, dienen muß, schweift Einzinger von Einzings .Eroberung der Stadt Jerusalem im Jahr 1099"102) ab: das Belagerungsstück aus den Kreuzzügen zeichnet sich durch den naivsten Anachronismus der Diktion aus: trotz der Versicherung echten Zeitkostüms im Vorwort reden Kreuzfahrer wie Türken durchaus die französisierende Militärsprache des 18. Jahrhunderts. ${ }^{103}$ )

Gleichzeitig mit der Blïte der ritterlichen Gattung in Bayern und von ihr beeinfluft, tritt Jakoh Maicr in der Pfalz mit einem zweiten Ritterstück, dem .Fust von Stromberg", ${ }^{10.1}$ ) hervor. Es zeigt gegenüber seinem ersten. das formal und geislig an die ältere Tradition gebunden ist, vor allem ein neues und fruchtbringendes Eingehen aul das Urbild der Gattung, den Cötz. Erst jetzt führt dieser den scliwerfälligen, aber soliden Maier ins Freie und läßt ihn seine dranatische Geschichte in der Zeit und besonders im Raum entfalten, ohne daß3 darum die Ansprüche der Bühne gefährdet würden. Jeder Akt des Fust erfordert mit Regelmäßigkeit zwei Schauplätze - cin Mittelweg zwischen der neuen Ungebundenheit und der alten Ortseinheit, den die Theaterpraxis dieser Zcit häufig cinschlägt - und zwar mit einziger Ausnahme des V. Aktes eine Szenerie in Freien neben einem geschlossenen Raum. ${ }^{103}$ ) Die Fehde Fustens mit den Äbtischen entwickelt sich nun in Busch und Feld, im Verhack an der Hecrstralie, bei Kapelle und Schenke. Der gelchrte Ballast ist zwar nicht gewict:en, ja er hat mit dem weiteren Eindringen des Autors in die Historie der Ritterzeiten zugensmmen; jedoch beschwert er die Handlung weniger als im Sturn von Boxberg, weil Maier ihn gemäß den didaktischen Absichten.

${ }^{109}$ ) Munchen 1783. Brahm. Ritt. S. 120 (unter .Blaimholer". wie der Name auf manchen Drucken auch erscheint): Grandaur. Chronik S. 28; Legband S. 441: 335.

(10)) Akt II, S. 38 sammeln sich die Bürger unter ihren Fahnen auf dern Marktplatz; man hört die Landshuter Stücke feuern: Schwertschwur und Kampfabgang. Den IV. Akt leitet ein grober Aufzug der Truppen Custav Adolfs im schwedischen Lager ein.

${ }^{102}$ ) Frankfurt u. Leipzig 1790. Von Brahm übergangen: als Nachtrag zu ihm behandelt von Lezband S. 403-11.

105) Reiche, ergö̈zliche Belege bei Legband. S. 409 u. 410.

104) Mannheim 1782. Brahm S. 127-29.

$\left.{ }^{103}\right)$ Fast derselbe regelmäBige Wechsel innerhalb ine Aktes findet z. B. in Blumhofers . Schueden" statt 
die die Vorrede vertritt, ${ }^{100}$ ) in einen besonderen, starken Anhang von vorwiegend kulturhistorischen Anmerkungen ausschift.

Dazu haben die kriegerischen Dinge - der neuerliche Anschluß an Götz ist darin überall sichtbar - an Anschaulichkeit und Frische gewonnen. Indessen man I, 2 auf einen klösterlichen Weintransport lauert, ${ }^{107}$ ) erhalten die Buben eine Lektion im praktischen Reuterdienst. Der Sinn für das Pferd als Wesensteil der ritterlichen Welt ist Maier erst hier aufgegangen. ${ }^{108}$ ) Nach dem Überfall, den er nach der Natur der Sache nicht zeigen kann und durch eine anderweitige Szenenreihe deckt, mustert Ritter Steinach (II, 5), nachdem für die Verwundeten gesorgt ist, die Waffenbeute; er biegt prüfend die Klingen und erfindet sie als "schlechte Lumpen-Pfaffenware“; eine davon wird ihm gleich darauf in kurzem Zweikampf, wozu er sie in der Hand behält (IiI, 6), von Fust zerhauen, er selbst gefangen. Die Freude am Waffenwesen, die sich in solcher Kleinmalerei äußert, an Maiers Landsmann, den Maler Müller gemahnend, dient damit zugleich der dramatischen Motivierung; sie tritt $\mathrm{V}, 1$ noch einmal hervor: Steinachs Reiter schärfen in der Wachtstube ihre Klingen und mustern die Schneiden.

Für die Kampftechnik im einzelnen hat der Götz neben der Einleitung der Belagerung von Fustens Burg ${ }^{109}$ ) besonders das Vorbild für eine lebendige Beobachtungsszene geliefert: das Erspähen des Wagenzuges (I, 2), der dem Abte weggenommen werden soll. Die unmittelbare Anlehnung an Goethe ist vollkommen greifbar; seine Motive werden aufgenommen, seine Anregungen ausgeführt, ${ }^{110}$ ) ohne daß die Tradition, die sich in der Beobachtungstechnik

106) Vgl. Bra hm, Ritt. S. 94.

107) Wie Götz auf Weislingen, ebenfalls im Eingang des Stücks; einen Überfall Cötzens auf Nümberger Kaufmannsfuhrwerke führt Goethes Theaterbearbeitung von 1804, II, II, ein."

108) Er tritt dann auch in der Umarbeitung des „Sturms" hervor, während sich in der Fassung von I778 neben der einen, dem Götz nachgeahmten Stelle III, 3: „fand man uns mehr im Stalle als bei der Kunkel" (Brahm S. 98) darüber kaum beiläufig etwas findet: II, 5 ,im Odenwald wächst Kraft für die RoB ..."

109) IV, 2 Burg in Gefechtsbereitschaft gesetzt; IV, 3 ankommender Zuzug; IV, 6 Meldung vom Anrücken der Feinde; V, 7 Unterhandlungsbegehren. Andere Einflüsse bei Brahm, Ritt. S. 128.

$\left.{ }^{110}\right)$ Die Szene kommt in Brahms knapper Zusammenstellung S. 152 zu kurz. Wie Selbitz' Knecht auf die Warte, muB' der Bube mit seinen „Luxaugen” auf einen alten Baum klettern. Die Ausschau wird hübsch durch ein anderes aus dem Götz entwickeltes Motiv, akustische Beobachtung, eingeleitet. Ratgald erlauscht mit dem Ohr an der Erde (Götzens Weisung an Georg) das Klappem der Räder und das dumpfe Klingen der Schellen; der ausguckende Bube will kampflustig herunter, um mitzutun, muB aber vorerst auf seinem Posten ausharren. Hören auch I, 6: „... ein Getös aus der Ferne wie eine Mannsschlacht". Bewundernde Beobachtung von Fusts Burg I, 2 (ähnlich wie in Babos Otto): „Ein herlicher fester Bau, mit seinen hohen Türmen, schönen Mauern und Warten!" 
seit ihm ausgebildet hatte, merklich in Frage käme. Dafür ist Maier in dem Hauptstück seiner Kampthandlung, dem Cottesgericht, dem bayerischen Ritterstiick. Törrings Agnes, verpflichtet. ${ }^{111}$ ) Dort konnte er den Verlauf seiner Szene mit der Verweigerung des Rechtes zum Kampf und den daraus entstehenden Tumult vorgebildet finden, wenn auch die besondere Weise der Durchführung sein Eigentum ist.

An diesem Gottesgericht, in einer Welt formelhafter Rechtsbräuche und peinlicher Kampfsatzungen, rüstet sich Maiers Hang zu chronikaler Gelehrsamkeit ein Fest, wie er sich sonst etwa an umständlichen Erörterungen über Eherecht, Ebenbiirtigkeit und Deszendenz (IV, 3) ersättigt - alles Dinge, die den Titelbeisatz des Fust: ,Mit den Sitten, Gebräuchen und Rechten seines Jahrhunderts" zur Genüge rechtfertigen. Törring hatte es am farbigen Glanz des Rittertums genug sein lassen und das historische Motiv, das Zurückweisen des jungen Herzogs von den Turnierschranken, nur zu dem dramatischen Zweck eingeführt, den Konflikt zwischen Vater und Sohn zum Ausbruch zu bringen. Maier ist es deutlich um den Brauch des Gotteskampfes an sich selbst zu tun, und er breitet sein ganzes Wissen davon aus. Die Kämpfer müssen einen .gestabten schweren Eid" schwören, keinen Trug anzuwenden, die „Kreiswärtel" walten ihres Aintes, Sonne und Licht wird geteilt, der Herold gebietet Frieden - kurz es herrscht jene Freude am Gegenständlichen, worauf der Erfolg des Ritterstücks als Gattung recht eigentlich beruht, jenes sachliche Interesse an dem bestimmten historischen Vorgang, das noch ein zeremonieller Cotteskampf in Richard Wagners Lohengrin durch reiche Bühnenerscheinung befriedigt. Die Mannheimer Aufführung suchte den nach Kräften gerecht zu werden: .Diese Vorstellung wurde soviel als möglich mit aller der Eigenheit gegeben, darin sie geschrieben ist", berichtet Iffland. ${ }^{12}$ ) Maiers Aufwand erreicht freilich nur eine kühle tristorische Treue, hat aber gerade damit auf vicle Nachfolger autoritativ gewirkt. ${ }^{113}$ ) $\mathrm{Ob}$ er von Blumauer, der als erster mit einer Dramatisierung des Gottesgerichtes hervorgetreten war, Anregungen empfangen konnte, steht dahin; ${ }^{114}$ ) innerlich berührt sich beider Art, nur daß Maiers Anlage - dies im AnschluB an Törring dramatischer ist: der ausbrechende Streit und Tumult hindert die Durchführung des Gefechts, während es sich bei Blumauer in die Pantomime ver-

111) Brahm legt die Parallelen Ritt. S. 128 dar.

112) Theatral. Laufbahn. DLD 24, 53.

133) Vgl. Brahm S. 162.

144) Brahm S. 161 irrt in Maiers Priorität infolge des Datierungsfehlers bei Blumauers Stück. Dieses war 2. B. in München 1781 aufgeführt und gedruckt worden (Leg band S. 265; vgl. immerhin S. 438). 
lieren müß.115) Mit Maler Müllers kunstvoll gemeistertem Gotteskampf, der wirkungslos im Pulte ruhte, kann sich keine der beiden Szenen messen.

Für die immer weitergreifende Lizenz des bühnenmäßigen Ritterstücks gegenüber Kampfvorgängen ist die Umarbeitung charakteristisch, die der bedächtige Maier seinem „Sturm von Boxberg“ 1785 angedeihen ließ; offenbar aus dem Wunsch heraus, seinen Erstling den neueren Erscheinungen der Gattung an Wirksamkeit ebenbürtig zu machen. Die neue Fassung ${ }^{116}$ ) entstand ziemlich oberflächlich durch zwei Hauptänderungen, die beide den Stand der Kampfhandlung betreffen. Die in A erzählend nachgeholte Vorgeschichte, die Gefangennahme der Pfalzgräflichen, wird dramatisiert und als neuer Halbakt (B I, 1-7) dem früheren Stück vorangestellt; den ganzen Schluß setzt Maier ebenso aus dem Bericht in Handlung um, und der Sturm auf Boxberg erscheint nunmehr als großes Kampfspektakel auf der Bühne. Dazwischen aber bleibt das alte Intrigenstück - das ist das äußerliche des Verfahrens fast völlig unangetastet, und die abschließenden Versöhnungsszenen von A fügen sich nach der vorgeführten Erstürmung gleichfalls unverändert an. Die umgearbeiteten Auftritte zeigen in manchen Zügen, wie der Fust, ein neuerliches Eingehen auf den Götz, ${ }^{117}$ ) der Maiers Produktion auch hier noch bestimmt.

Bemerkenswert für die Entwicklung ist der Sachverhalt des Burgsturms. Während die führenden Bayern, Törring und besonders Babo, aus den Kampfpantomimen der frühen Götz-Nachfolge bereits einen Weg zu dramatisch wirksamerer Ausmünzung der Gefechte gefunden haben, öffnet Maier jetzt erst der Theaterschlacht Tür und Tor. Der zurückhaltendste der älteren Ritterdramatiker erweist sich damit zu guter Letzt als Förderer des spektakelnden Ritterstücks, dem wir späterhin begegnen werden. Er baut nunmehr (B III, 11), anspruchsvoller als Hübner, der die Überrumpelung vom Schloßhof aus gezeigt, und Törring, der bloß ein brennendes Thorring verlangt hatte,

115) Zu ihr greift Maier IV, I beim Raub Berthas aus der Kapelle, worin sie von den Häschern in längerem stummem Spiel beschlichen wird.

${ }^{116)}$ Neue für die Bühne eingerichtete Auflage, Mannheim 1785, = B (die erste Fassung $1778=$ A). Brahm streift sie nur, S. 129 u. 100-101.

${ }^{117}$ ) So gleich die exponierende Szene in der Schenke unten am Schloßberg B I, I, die doch wohl über Hahn (vgl. Brahm S. 100) unmittelbar auf Goethe zurückgeht. Charakteristisch für das Nachbilden auch des Einzelsten ein kleiner Zug: die Aufforderung Remingens B I, 3 ,Werft ihnen die Armbrusten an die Hälse! Mit bloßer Wehre über sie her!" (nochmals B IlI, 11) ist zweifellos aus den Worten Georgs von der verlorenen Armbrust Götzens (,Ihr warft sie dem Feind an Kopf") im I. Akt entwickelt; jener spontane Einfall des scharfen Handgemenges, den Goethe einem Satz der Lebensbeschreibung Götzens entnahm ( $\mathrm{DjG}^{2}$ 6, 199), wird hier sondcrbar genug zu einer gewissermaßen reglementarischen Kampfsitte remacht. 
seine praktikable Bühnenburg mit umständlichen Anweisungen auf steiler Höhe vor dem Zuschauer auf: Tor. Türme und Warten Boxbergs, von denen Feuerzeichen aufsteigen, ${ }^{118}$ ) einen mit Pallisaden verwahrten Absturz, den jäh ansteigenden Burgweg, Wall und Schanze. Die Bezeichnungen sind weniger gelehrt als im ersten "Sturm" und das Lokal schon deswegen anschaulicher, weil es hier für die Bühne vorgeschrieben, statt nur vom Zimmer aus geschildert werden mußte. Maier hat vor dem Theater bei den Aufführungen seiner Stücke gelernt. Den verkürzten Maßstab in der Darstellung aller dieser Gegenstände, trotz der in sie gestellten unverkürzten menschlichen Figur, muß Inan der Dekoration freilich zubilligen, wie es auch Maiers Zeit tat; sonst hättc seine Feste Boxberg auf keinem Theater Platz.

Gegen sic führt er nun scine Pfälzer zum Sturm, während dic Boxberger den Burgweg von oben her mit Steinen bewerfen. Einen Hauptmann Sturmfeder läßt er mit seinem Haufen auf der Bühne schlechtweg exerzieren. ${ }^{119}$ ) Indessen Luz Schotten befiehlt, von hier aus Bresche zu schicßen, soll ein neuer, weniger verlustreicher Sturmversuch von einer anderen Seite - unsichtbar - unternommen werden. Maier behält das Spektakel immerhin in der Hand und führt es rasch zur effektvollen Krise. Als zum Hauptsturm angetreten wird, erscheint oben der alte Rosenberg und macht Arstalt, den Kampfpreis, das geraubte Fräulein von Detten, vom Wall herabzustürzen. Luz Schetten iiberwindet einen Augenblick des Zagens und feuert seine Leute dennoch an; eben jetzt aber dringen oben seine Kuechte aus der Burg, die sie von rückwärts genommen haben, heraus und überwältigen den Frauenräuber, che er sein Vorhalsen ausführen kann. Der innere Zusammenhang mit der ersten Fassung ist hier ganz eng; dasselbe Motiv vom Abstürzen des Fräuleins. nur in anderer Verbindung, führt in beiden Fällen die Kampthandlung zu einem spannenden Gipfel: dort zum Konflikt des Vaters und Sohnes angesichts des cindringenden Feindes, hier zu der Situation des ohnmächtigen Angreifers. dem der Verteicinger hohnlachend die Geliebte überm tödlichen Alggrund zeigt. Der Theatereffekt, der im Götz durchaus fehit, ist das Ziel des Kampfes, ob er nur als Lärm ins Zimmer dringt, oder als große Massenszene an Wall und Tor sich austobt. Darin stcht auch der zweite "Sturm." - weniger der „Fust" - und seine ganze Nachfolge im späteren Rittcrstück dem vorgoethischen Kempldrane trotz der Verschiedenheit der Form inncilich nabe.

116) Vgl. B I, 2, wo ein Turmknecht "Feuer aussteckt, und allenthalben reisige Knechte zu den Schutzgattern herausschauen".

110) B III, 11: .Den Fähnleinknecht in die Mitte! SchlieBt den Haufen!" usw. 


\section{Siebentes Kapitel.}

\section{Der junge Schiller.}

Uberblickt man die Entwicklung der dramatischen Erfassung des Kriegerischen vom Erscheinen des Götz von Berlichingen bis in die achtziger Jahre, so ergibt sich zunächst, daß die Trennung von Literatur und Bühne, die Goethe vollzogen hatte, aufgehoben wurde und dem Theater aus dem goethischen Werk eine ganze neue Gattung erwuchs, welche die vorher gültige Bühnenform einschneidend veränderte. Dabei hatte aber im Grunde nur das Theater, und keineswegs die Dichtung gewonnen. Im tieferen war ein Ausgleich nicht gefunden worden. Die Leute, welche das Erbe des Götz von der Seite der praktischen Bühne aus antraten, können wohl das Verdienst für sich in Anspruch nehmen, seine Kriegswelt der lebendigen Darstellung angepaßt zu haben Theaterbearbcitung im weitesten Sinn -, soviel auch auf dem Weg vom freien Gedicht zu den Kulissen verloren ging; aber sie zehren doch zumeist von Goethes Gut und wußten aus der Darstellung von Kämpfen kaum mehr als theatralische Wirkungen zu ziehen, die dann in das langgepflegte Kampfspektakel auslaufen. Die im eigentlichen Sinn dramatische Kampfgestaltung ist dadurch nur wenig gefördert worden. Auf der andern Seite haben die vom Götz ausgehenden, dichterisch bedeutenden Begabungen, die auch im Kriegerischen Eigenes zu geben hatten, ein Klinger mit dem Otto und den Pyrrhus-Szenen, ein Friedrich Müller, wohl im einzelnen zu jener beigetragen, aber umgekehrt den Weg zum Theater nicht gefunden. So fehlte der Entwicklung immer noch der Mann, der, die kühne Einseitigkeit Goethes überwindend, der Dichtung und dem Theater zugleich ihr Recht gegeben hätte. Achtungswerte Schritte dazu haben wir zuletzt in Bayern bei einem Törring und Babo beobachtet; natürlich bleiben sie in den Schranken ihres begrenzten Talentes; der letztere tritt überdies erst auf nachdem das Werk, das in jedem Betracht und so auch in der Kriegsdramatik das bedeutendste seit dem Götz ist, „Die Räuber“, erschienen war.

Schillers Erstling hat neben der kampftechnischen für unsere Entwicklung eine hervorragende inhaltliche Bedeutung. Der Offizierssohn, Zögling württembergischen Militärakademie und Regimentsmedikus - Schillers An- 
stellung in der Armee erfolgte kurz vor dem Erscheinen der Räuber') - greift als erster Dramatiker die große soldatische Frage der Zeit auf. Das unmittelbare Erleben des Kriegerischen war mit dem Sturm und Drang durchgebrochen und das Leben ins Dichten getreten; damit begann auch der gegenwärtige Zustand der Wehrmacht in dic Poesic zu wirken. Die Armee, früher der Gegenstand konventioneller Verherrlichung - wo es Konflikte gab, wie bei Ewald von Kleist, fanden sic in die Dichtung keinen Eingang - wird den jungen Dramatikern zum Lebensproblem. Coethe ausgenommen, haben die bedeutendsten Köpfe der neuen Generation, Klinger, Lenz, Schiller, später der dem Sturm und Drang vielfach verwandte Heinrich von Kleist höchst persönlich zu ihr Stellung zu nehmen. In der sozial gerichteten Dramatik des jungen Schiller gewinnt dieses Verhältnis dichterischen Ausdruck. Neben die dramatischen Gestaltungsaufgaben von Krieg und Kampf tritt damit in den Räubern ein Neues: dic Auscinandersetzung mit den historisch gegebenen Wehrverhältnissen der Gegenwart.

Auch der Götz kannte diese Fragen schon. Dem Bild der - historisch richtig gesehenen - Reichsvölker leiht der Mietsoldat des 18. Jahrhunderts Züge, die er in der Tat mit dem des 16. gemein hat. Aber Goethe steht den soldatischen Einrichtungen noch mit der reinen Freude des Gestalters gegenüber; sie sind ihm nicht zur eigenen Lebensnot geworden. Bei Klinger ist das bejahende Verhältnis, das er als geborener Soldat zum Stand hat, durchaus fühlbar. Er sieht ihn als Optimist an, der zutage tretende Mängel als selbstverständlich zugehörig in Kauf nimmt, und betrachtet ihn von Anfang an als seine eigentliche Bestimmung. Er ist bezeichnend genug der einzige dieser soldatischen Poeten, der dem Soldatenberuf treu bleibt und den Ausgleich zwischen stürmerischer Kriegsdichtung und militärischer Dienststellung findet. Lenz dagegen, selbst nicht Soldat, wenn er es auch in Weimar zu werden hoffte, aber mit dem Leben des Standes gerade in seinen schlimmen Seiten innig vertraut, ohne dic robuste Offiziersbegeisterung Klingers, dafür mit einem scharfen Blick für das soziale Elend der Gemeinen ausgerüstet, bohrt sich tief in die unheilvollen Schäden der bestehenden Wehrverfassung ein und tut ihre Morbidität als Dichter und Th.eoretiker ${ }^{2}$ ) packend dar. Sein sicherer Instinkt sieht sie schon jetzt dem Untergang zusteuern. ${ }^{3}$ ) Lenz gibt

2) Frankfurt u. Leipzig 1781. Vgl. Weltrich. Schiller 1. 329.

2) Die Soldaten. Eine Komödie. Leipzig 1776 - Uber die Soldatenehen. Geschrieben 1776. Veröffentlicht von K. Freye, Leipzig 1914.

2) Der bereits von K. Freye (S. VII-VIII) hervorgehobene. der Vorhersage nahe Ausblick aul eine kommende Niederlage der friderizianischen Armee (besonders S. 18-21 der Schrift) ist für 1776 überraschend reif: umsomehr als dieses stindisch erstarte Heer dann wirklich einer von grober Idee beseelten, aus neuem Geist geschaffenen Armee, wie sie Lenz fordent (S. 9: 12: 
damit die Hauptdokumente zu dieser militärischen Zeitfrage, die mit den Räubern aus der Sphäre des bürgerlichen Dramas heraus und in die Kriegsdramatik eintritt.

Es verlohnt sich, von hier aus einen Blick auf Lessing zurückzuwerfen. Stockmayers Untersuchung über das deutsche Soldatenstück ${ }^{4}$ ) beschränkt sich so scharf auf die erschöpfende Musterung der Nachfolge der Minna von Barnhelm, daß sie die lenzischen Soldaten, ihren eigentlichen Widerpart, unberücksichtigt läßt; sie datiert daher einen Umschwung in der dramatischen Spiegelung des Militärstandes erst von dem späteren verabschiedeten preuBischen Offizier Julius von Voß.5) Die grellen Schlaglichter, die dieser nach der Katastrophe auf das preußische Heer von 1806 wirft, ${ }^{6}$ ) hat Lenz der ständischen Armee im ganzen schon dreißig Jahre früher und um so viel kühner aufgesetzt. Die beiden ungehörten Warner und abgewiesenen Reformer haben manches gemeinsam; nur daß die positiven Vorschläge in Lenzens Reformplänen der gründlichen Einsicht in das Heerestechnische entbehren und, wie schon Goethe bezeugt, ${ }^{7}$ ) sich öfters ins Utopische verlieren, so sehr sich Lenz unablässig über die luftigen Projektenmacher erheben will. Aber sie bergen doch auch viel Zukunftstarkes, und der darstellende und anklagende Teil der jetzt vorliegenden Schrift $^{8}$ ) ist sehr gewichtig und steht zusammen mit Lenzens Soldatenkomödie als Markstein in der Entwicklung.

Lessings Minna hatte das Soldatentum aus dem Hochgefühl einer kriegerischen Glanzzeit heraus verklärt ${ }^{9}$ ) und ohne eitle Schönfärberei doch von seiner edelsten und liebenswürdigsten Seite genommen. Der Major von Tellheim hat den höchsten Begriff von seinem Metier, das er nur auf nationaler

16; 28 usw.) erlag. Es schmälert sein Verdienst nur wenig, daß er für seine Gedanken Gewährsmänner hat: er trägt sie mit der Uberzeugungskraft von Selbstdurchfühltem vor.

4) Eine gute Ubersicht gab vor ihm Hauffen, DNL 138, XXXI-XXXIII.

5) Stockmayer S. 85. Nach seiner Darstellung S. 33-34 hat die oppositionelle Stellung, die Merciers „Deserteur" (vgl. S. 92-94) zum Subordinationsproblem einnimmt, in Deutschland keine Nachfolge gefunden. Lenz hat mit dem Franzosen immerhin das gemeinsam, daB er zum herrschenden Militärsystem in Gegensatz tritt. - Auch Klinger nimmt übrigens mit einer Figur, die Stockmayer übergeht, dem wackern Kapitän in den „Falschen Spielern“ von I781, am Soldatenstück teil. Vgl. Rieger 2, 17.

") Vgl. die "Geschichte eines bei Jena gefangenen preußischen Offiziers" 1807; das Lustspiel „Loos des Genies" 1809 u. die Posse „Der Kommandant à la Fanchon“ 1807; G. Ellingers Einl. zu Voß' Faust, Berliner Neudrucke II. 2, 1890, S. II ff.

7) Dichtung und Wahrheit 14. Buch, Werke 28, 249.

8) Eine Übersicht der sechs Pakete lenzischer Handschriften auf der Berliner Königl. Bibliothek, die das Soldatenwesen betreffen, gibt K. Freye in den Anmerk. S. 102-103.

9) Vgl. E. Schmidt, Lessing ${ }^{2}$ 1, 459-63. 


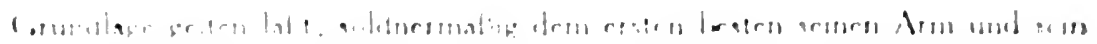

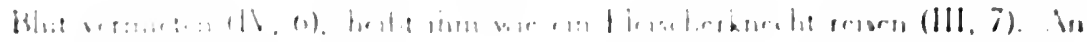

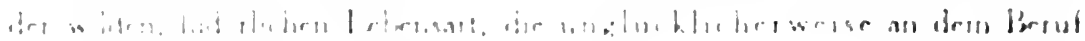

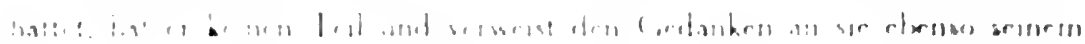

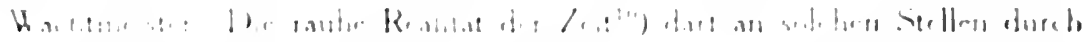

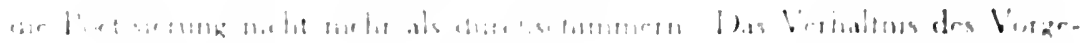

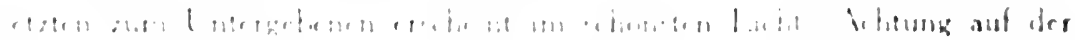

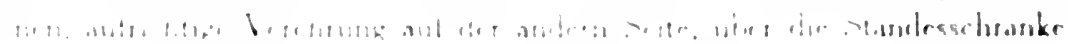

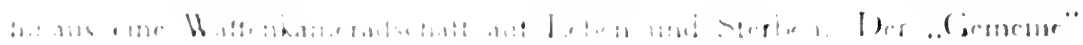

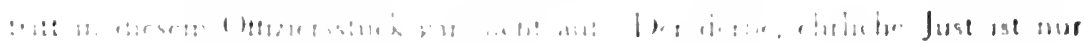

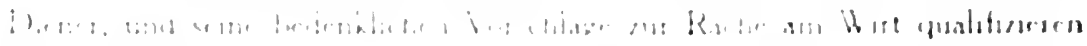

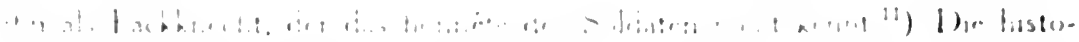

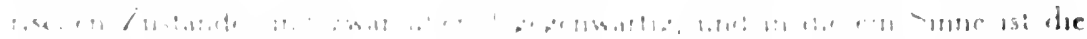

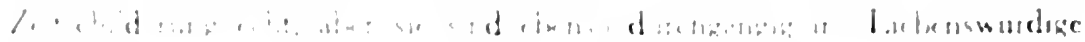

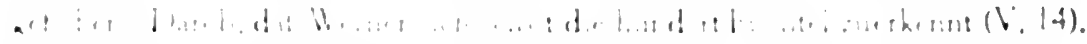

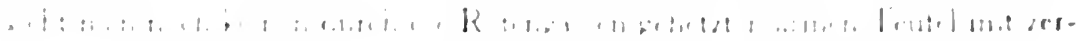

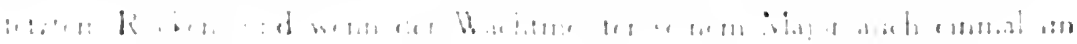

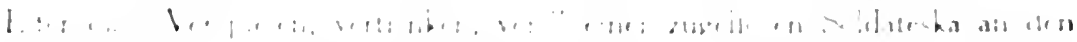

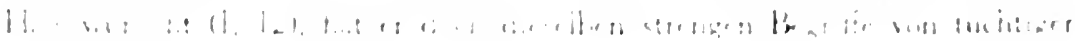
$1,1+1,1,1, n,+1,1+1$

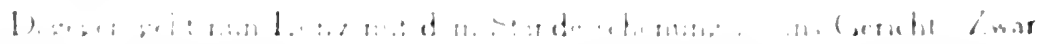

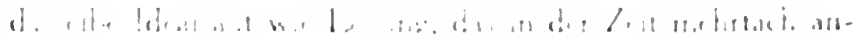

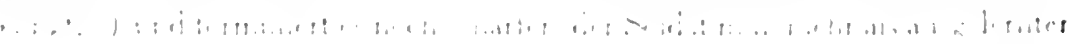

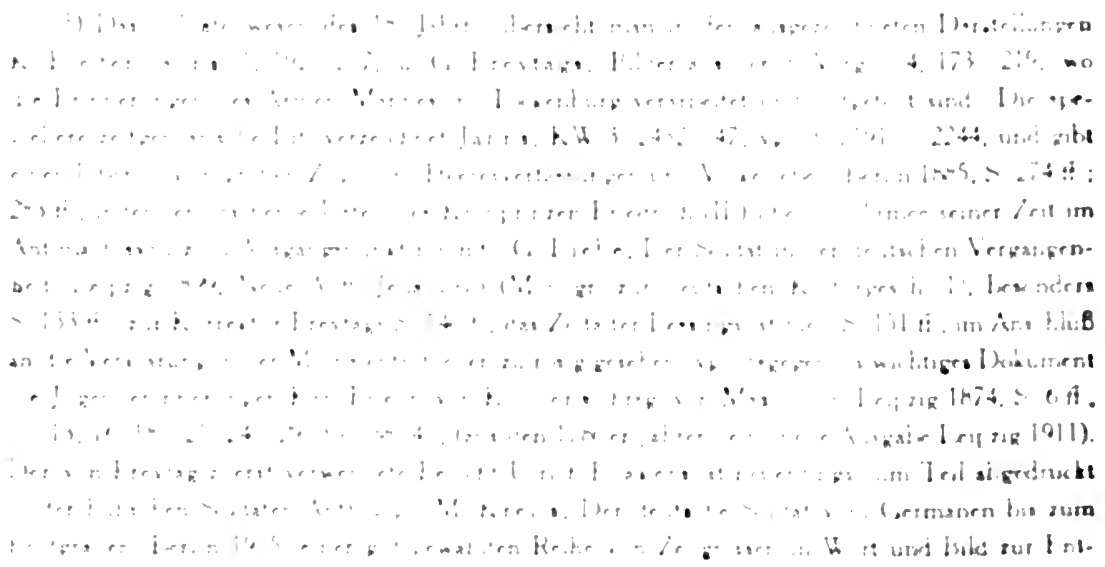

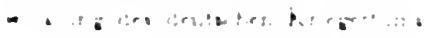

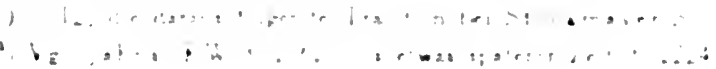


Mörder, er soll Verteidiger des Vaterlandes $\operatorname{sein}^{13}$ ) - aber nur um seine trostlose wirkliche Verfassung damit in Kontrast zu setzen. Er schildert das Elend der Gemeinen, denen ihr Brot und ihre Schläge täglich zugemessen werden, ihr verachtetes Dasein, das sie durch kümmerlichen Nebenverdienst fristen müssen, den Haß der Bürger, die Qual des Dienstes mit seiner rastlosen Überexerziererei und den unmenschlichen Strafen, die ausgemergelten Körper, die all diese Not, zu der sich das Laster gesellt, schafft - und nennt den Soldaten, der unter der Fülle dieser Beschwerlichkeiten seufzt, gewiß die elendeste Kreatur, die jemals auf zwei menschlichen Beinen gestanden hat. Er macht nicht halt vor den Zuständen im Offizierskorps, das aus Männern, die ihre Untergebenen achten, nicht unbärtigen Buben gebildet werden soll, die ihre Lust darin finden, alte würdige Soldaten zu prügeln. Er geht dern lockeren Zeisig zu Leibe, dem die Liebeshändel keine Zeit lassen, ernstlich an seinen Beruf zu denken und sich in ihm auszubilden; er vergilit den Spieler nicht und den unwissenden jungen Soldatenschinder, der seinen Unverstand in Sachen des Dienstes durch übermäßige Härte bedecken will, aber schließlich auch nicht den wackeren Offizier, der nur durch den öden maschinenmäßigen Betrieb des Dienstes den freudigen Mut zu seinem schönen Handwerk verloren hat. Er stellt endlich die Frage nach dem Sinn und Wert des ganzen Systems und erkennt, daß die Furcht des Soldaten vor Strafe, die Seele der gegenwärtigen Taktik, im Handgemenge versagen muß, wie er über die nur äußerlich gebesserte moderne Kriegszucht skeptisch denkt. Wo fände in Lessings froher Soldatenwelt, die auch einen "trefflichen Krieg" in Persien gelten läßt $(V, 1)$, eine Anklage Platz wie die, daß unsere meisten Kriege Schauplätze unserer Schande und privilegierte Straßenräubereien seien, daß die Soldaten ihre Waffen gegen wehrlose Weiber und Kinder richten ${ }^{14}$ )

13) Uber die Soldatenehen S. 13; vgl. S. 40-41; daß die Schrift zwischen deutschen und französischen Verhältnissen schwankt und ihren Erfahrungsgehalt aus dem Straßburger Boden zieht, spielt bei den gleichartigen Zuständen der Berufsheere des Jahrhunderts für uns keine Rol.e. Die literarische Hauptquelle Lenzens, die er oft zitie $t$ und durchweg benutzt, ist der in jener Zeit epochemachende "Essai général de tactique" des Comte de Cuibert, London 1770 und häufig; eine Londoner Ausgabe von 1772 zeigt der Teutsche Merkur, März 1773, S. 263, rühmend an und weist auf die demnächst erscheinende deutsche Übersetzung (Dresden 1774) hin. Der „Essai“ ist mit der ganzen Lit. verzeichnet und in ausführlichem Auszug wiedergegeben bei Jähns, KW 3 , 2059 ff.; vgl. 2236; 3. 2432 f.; 2584 ff.

$\left.{ }^{14}\right)$ Die sprunghafte, stürmerisch dispositionslose Schrift streift ein und dasselbe willkürlich an dieser und jener Stelle; die Fundorte werden hier insgesamt, in der Reihenfolge wie sie angezogen sind, vermerkt: S. 20; S. 32, 98; S. 33, 59; S. 87, 98; S. 57-59, 61; S. 19, 41, 44, $45,76$. 81 ; S. 44, 25-26, 38, 46; S. 61; Offziere 41-43, vgl. „Die Soldaten" III, 4; 34; 61-62. -Kriegszucht S. 27 u. 15; S. 22-23. Unmensch lichkeit S. 90 u. 91 ; Lenz erhofft von dem ehrlich vertheirateten Soldaten eine schonungsvollere Kriegführung 
Lenzens Soldatenstück stellt auf verengtem Gebiet die Zustände nicht minder grell dar als die Reformschrift. ${ }^{15}$ ) Der Wachtmeister Lessings nimmt seine harmlose Renommisterei über galante Abenteuer (III, 10) mit Tellheims ernsthaftem Grundsatz zurück: „Das muß ein Schurke von einem Soldaten sein, der ein Mädchen anführen kann." Lenzens soziales Drama zeichnet ein ganzes Milicu solcher Schurken, die als professionelle Mädchenjäger das andere Geschlecht als leichte Beute ansehen (II, 3 u. 4), ja zur Leichtfertigkeit durch ihren Stand verpflichtet sind (III, 10); von denen einer endlich die Verführte mit kalter Niedertracht ins Verderben stößt $(V, 3)$. Der rohe Ton dieses Offizierskreises, worin die übelsten Streiche getrieben werden (III, I u. IV, 2) und die miserabelsten Manieren herrschen (IV, 9), gibt dem der künftigen Räuberbande Schillers nichts nach. Die Not der Gemeinen, die sonst in dem Stücke keinen Raum hat, ${ }^{16}$ ) macht sich immerhin in dem Aufschrei des verzweifelten Soldaten Stolzius Luft (IV, 10), der dem Offizier gegenüber zum Gift greift: ,Und müssen denn die zittern, die Unrecht leiden, und die allein fröhlich sein, dic Unrecht tun?"

Lenz steht mit so düsterer Abschilderung und so aufwühlender Polemik nicht allein. In der Deutschen Chronik fragt im selben Jahr 1776 der wackere Kämpe für die Geringen und Rechtlosen, Schubart: .Ist's wahr, daß unsre Kricger bloß um niedern Sold gedungne Sklaven sind?", und schickt in völlig lenzischer Auffassung ihres Metiers wenig später einem toten Soldaten den mitfühlenden Stoßseufzer ins Grab nach: ,.Du kommst in ein Land,... wo der Geist des Friedens über dir säuselt, und dir einen Posten anweiset. auf dem du all deinen Kummer, dein Ächzen unter dem Degen deines Befehlshabers, deinen Mangel, dein trauriges Negerleben bald vergessen haben wirst!" ") $\mathrm{Er}$ ist in Gedichten wie dem .Bettelsoldat" der Sänger des Loses der "Gemeinen" und begrüßt mit Jubel verwandte Klänge, so den

is) Uber den Zusammenhang der beiden vgl. Freyes Einl. zu dieser, S. II-IV.

16) Im 19. Jahrhundert nimmt der an Lenz anknüpfende Georg Büchner dieses Thema im "Wozzek" auf. In Lenz" dramatischer Phantasei .Der Engländer" (Leipzig 1777) apostrophiert Robert Hot, der sich hat anwerben lassen, um als Schildwache der Geliebten nahe zu sein, seinen neuen Stand: ..Habe die Soldaten und ihre Knechtschaft und ihre Pünktlichkeit sonst ärger gehaßt wie den Teufel" (I. 1); das Deserteurproblern spielt herein. Aus Liebesgram geht auch David in dem Entwut .Der tugendhafte Taugenichts" unter die Soldaten; II. I vgl. 1II. I. eine Werberszene: III, 3 wird ein Treffen der Preußen und Österreicher vor Lissa in grabbescher Liz nz mil weechselseitigem Pelotonfeuer. Handgemenge und Flucht dargestellt: danach stellt Johann als Gemeiner Betrachlungen üher den Mut der Offiziese hinter der Front an.

$\left.{ }^{1 i}\right)$ Teutsche Chronik, Ulm 1776. S. 250: Leben u. Gesinnungen 2, Stuttgart 1793, S. 246 (geachrieben 1778/79). 
herrlichen "Soldatenabschied" Maler Müllers, ${ }^{18}$ ) worin der Pfälzer so echte Töne traf, daß Schubart dem Lied kein schöneres Lob wußte als das, die Soldaten würden es künftig wirklich singen, wenn sie von ihrer Trauten Abschied nehmen: „Wo ich fall', scharrt man mich nieder, / Ohne Klang und ohne Lieder, / Niemand fraget, wer ich bin.“ Die Not des Standes, das „,heiß und schwere Lebensjoch" spricht Schubarts späterer, tiefempfundener „Totenmarsch", aus dem Erlebnis des Soldatenbegräbnisses erwachsen, in poetischer Milderung ergreifend aus - schönstes Zeugnis für die soziale Sendung des Sturm und Drangs, seinen Beruf für die Schwachen und Bedrückten.

So hatte sich der Soldatenstand der neuen Gesinnung dargestellt, bevor Schiller auftrat. Der Karlsschüler konnte von der unveröffentlichten Schrift Lenzens nichts wissen; ob die veröffentlichte Komödie unter die Zöglinge eingeschmuggelt wurde, ist zweifelhaft; Schubarts Chronik allerdings mußte ihnen schon durch ihren Kameraden Ludwig, seinen Sohn, zugänglich sein. Jedenfalls aber ist das, was der Dichter der Räuber zu dem Zeitproblem äußert, Frucht eigener Wirrnisse. Schiller nennt ein starkes soldatisches Erbteil sein eigen, das ihn durch sein ganzes Schaffen hindurch nicht verläßt; man hat es mit Recht auch in seiner beherrschten Lebensführung gefunden..$^{19}$ ) Er formt in den Räubern mit aller Begeisterung der Jugend ein soldatisches Ideal, aber und dies hätte seinen militärischen Herrn, den Herzog, billig mehr alterieren müssen, als der aus ihnen entstehende Graubündner Handel - nicht innerhalb des historisch gegebenen Soldatentums. Der höchste sittliche Wert kriegerischer Gemeinschaft, die Soldatentreue bis in den Tod, tritt nicht im organisierten Heer, sondern unter einer Bande von Mordbrennern in die Erscheinung. Schon

18) Teutsche Chronik 1776, S. 751.

19) Trefflich auseinandergesetzt bei Weltrich, I, 14 f. u. 540. Die militärische Laufbahn des Vaters, seine Kriegszüge und die daraus quellenden Jugendeindrücke Schillers untersucht Ernst Keller, Joh. Kaspar Schillers Jugend und militärische Dienstjahre, Progr. Freiburg i. Br. 1885; Weltrich 1, 4-8; 19 f.; 733 f. Mit „Schiller als Kriegsmann“" [deutlicher: Kriegsdichter] beschäftigt sich ein aus schöner Soldatenbegeisterung heraus geschriebener Aufsatz des Generalmajors Albert Pfister, Marbacher Schillerbuch 1 (1905), S. 61-72, sachlich nur den Wallenstein betreffend, im Charakter einer Festrede. Als Beispiel, wie Schiller als Kriegsdichter dem lebendigen Krieg fruchtbar gemacht wird: Paul Kannegießer, Sch. u. das deutsche Volk in Waffen. Eine Gedenkrede an die Soldaten Straßburgs, ZfdU 28 (1914) S. 801-07; populär für Veruundete gehalten. Aus der Literatur des Tages sind neben der Kriegs-Anthologie E. M. Kronfelds. Krieg u. Soldat in der Spruchweisheit, München o. J. [1915], die auf S. 43-55 auch eine Reithe von Schillerschen Kriegszitaten aneinanderreiht, zu nennen: W. Widmann. Fr. Sch. u. der Weltkrieg 1914/15, Stuttgart 1915, wo eine noch umfänglichere Zitatenlese zum Dienst der Stunde gepreßt wird, und Th. Birt, Sch. der Politiker im Lichte unserer großen Gegenwart, Stuttgart u. Berlin 1916, die über Schiller den Kriegsdichter S. 24-28 feuilletonistisch handelt. fact is 
in Goethes geschichtlichem Bild hebt sich die staatliche Militärmacht übel genug von der wackeren Gefolgschaft des freien Ritters ab, die sich aber dort im offenen, ehrlichen Krieg schlägt. Schiller legt das soldatische Ideal geradezu in eine Gesellschaft von Räubern, die sich, so schlimm sie sonst sein mag, im Augenblick höchster Gefahr durch Korpsgeist und Treue heldisch erhebt. ${ }^{20}$ ) Die reguläre Arnnce spielt der Bande gegenüber, gleich der früheren Reichsexekution. den ruhmlosen Polizeibüttel. Es ist denkwürdig, mit was für Augen der Eleve der herzoglichen Kadettenschule, der sich zu einer Stellung im Berufsheer vorbereitet, dieses anschaut. "Sie setzen ihr Leben an zehen Kreuzer; fechten wir nicht für Hals und Freiheit?" - so mißt der Kämpfer für eigene Rechnung verächtlich den geworbenen Söldling, der mit seinem Blute schachert, wie Lenz fragt: .Was sollen wir ihm [dem Angreifer] entgegensetzen? Sold, den wir unsern Soldaten austeilen, drei Groschen des Tages?" "21) Wie im Götz wiegt die Úberzahl der nach der Natur der Sache feigen .Mietlinge" leicht. und was dort ein "Reichsmusje", heißt hier ein "Kommißbrotritter". ${ }^{22}$ ) Die neue Schärfe Schillers in der Kontrastierung beruht darauf, daß er die Gegenwart im Auge hat: das Söldnertum der eigenen Zeit wird als militärische Erbärmlichkeit an den Pranger gestellt. Zugleich anch als der kümmerliche und ehrlose Stand, den Lenz gezeichnet hatte: das „zum Kalbsfell schwören“ rangiert unter den Aussichten, die sich der aus der Gesellschaft ausgestofenen Rotte noch auftun, hinter dem Schuldturm, dem Tagelöhnen und dem bettelnden Bänkelsängerdasein. Die Lage der armen Tcufel, die unter der milzsüchtigen Laune des Korporals das Fegfeuer zum voraus abverdienen und beim klingenden Spiel der Spießruten nach dem Takt der Trommel spazieren gehen, wird hicr erschreckend deutlich; durch die Gaunerkniffe des Werbers Spiegeiberg, der mit seiner erlesenen Schar an Falstaffs edle Kompagnie

20) Vgl. Weltrich 1, 374.

21) Räuber 11, 5. Werke 2, 80 ${ }_{31}$. Uber die Soldatenehen S. 14: vgl. im Götz: ..jeder wirds von sich schicben. Kaiser und Reich zu gefallen Arm und Bein dran zu setzen" (DjG23, 226) und ..... nicht mehr als ihnen der Kaiser Pflaster gibt, die Wunden zu heilen, die sich ihr Mut holen könnte" (das. 3, 252-53). Dieser Szene im Heilbronner Rathaus ist Kabale u. Liebe II, 7 verwandt: Walter hält die Gerichtsdiener, welche der Präsident (wie Goethes Rat) umsonst anfeuert, mit einem ..Wag es, sie anzurühren, wer nicht auch die Hirnschale an die Gerichte vermietet hat" in Schach - wiedenum, wie in den Räubern, das Vermieten von Leib und Leben als erniedrigend emplunden. Ohne diese Spitze steht der Götz-Szene nahe Fiesko IV, 9.

:2) Götz. DjCz 3. 227, 228, 231, 235 u. 243: Räuber 2. $80_{23 .}$ zs. з2: S. 82. Fiesko V. 5: ..Miellinge hüpfen hinter seinem Namen, und sein Weib sollte zaghaft tun?" Nach Schiller häufiger: Jul. v. Soden. Heinrich IV. (1784) I.6: „Recht sol Pfui der Mietlinge, die heut den Franken, morgen den Sachsen dienen." Klinger, Roderico. 1790, IV, 4: „Der feige Mietling verlabt im Kampl die Fahne, zu der er geschworen hat -." 
gemahnt, blicken die unsaubern Praktiken durch, ohne die die Regimenter ihren Ersatz nicht beschaffen konnten. ${ }^{23}$ )

Schiller setzt sich später noch einmal unmittelbar mit dem Heerwesen des 18. Jahrhunderts auseinander: er brandmarkt in „Kabale und Liebe“ (II, 2) als sozialer Ankläger dessen dunkelste Seite, den Soldatenverkauf, mit unerhörter Kühnheit als Infamie. ${ }^{24}$ ) Hier steht er zweifellos auf Schubarts Schultern, der in der Deutschen Chronik den Kampf gegen dieses Schandmal des Despotismus unermüdlich und mit glühendem Eifer, bald offen als furchtloser Mahner, bald versteckt in allen erdenklichen Einkleidungen, Andeutungen, Seufzern und Winken, geführt hatte. Der als Patriot empfindlich für die Schande war, daß deutsches Blut für eine Lands- und Domänenware geachtet wurde, daß deutsche Männer, für Sold und Lohn gedungen, in fremdem Dienst gegen deutsche Kolonisten fochten; der als Freiheitskämpfer die Wehrkraft der Heimat zum feilen Werkzeug gegen die Freiheit der Neuen Welt mißbraucht sah, als Politiker die Sorge über die Entblößung des eigenen Landes von Waffenfähigen sich nicht verhehlte, der sich aus menschlichem Mitgefühl der staatsrechtlichen Frage annahm, ob ein Reichsstand seine Truppen ohne Zustimınung des Reichsgerichts ins Ausland leihen dürfe; der endlich gegen allen Jammer und alle Schmach sich rührend an den schwachen Trost klammerte, daß diese unglücklichen Söhne des Landes sich wenigstens - sei's für eine fremde und dazu schlechte Sache - des deutschen Namens würdig geschlagen hätten. Als "Probe der neusten Menschenschatzung" war in der Deutschen Chronik eine Liste des Soldatenschachers zu lesen, worin die beteiligten Fürsten mit Ausgaben und Einnahmen, das heißt verkauften Menschen und empfangenen Talern, verzeichnet stunden. Dər eigene Land ssherr blieb nicht verschont, und die Gerüchte über seinen Aateil - der Handel kam nicht zustande wurden unterstreichend vermerkt. ${ }^{25}$ )

23) Räuber I, 2, Werke $2,37_{22} ;$ II, 3; 2, 66 12 ff.: $68_{26}$ ff.; zu $70_{12}$ f. vgl. Lenz, Soldatenehen S. 58. - Shakespeare, I Heinrich IV: IV, 2.

24) Eine tabsllarische UUbersicht über den Soldatenhandel nach Amerika gibt Biedermann I, 205, nach Schlözer; Jähns KW 3, 2208 ff.; ders., Heeresverfassungen usw. S. 234-87. Eine stark polemische Gesamtdarstellung an Hand der Akten lieferte Fr. Kapp, Der Soldatenhande] deutscher Fürsten nach Amerikı, 2. Aufl. Berlin 1874; ihm gegenüber. schönschminkend, die Einl. zu M. v. Eelkings kriegshistorischer Arbeit Die deutschen $\mathrm{H}$ Ifstruppen im nordamerikanischen Befreiungskriege, 2 Teile, Hannover 1863 („Die Subsidientraktate“). Ein unverdächtiger und entscheidender Zeuge ist Friedrich d. Gr., dessen scharfe Verurteilung des Menschenwuchers von Kapp S. 156-64 eingehend untersucht wird; vgl. Jähns, Heeresverfass. S. $284-87$ u. Bellermanns einlißliche Anmerk., Schillers Werke 2. 435-37; Eelking 2, 165.

$\left.{ }^{25}\right)$ Die Teutsche Chronik ist Kapps Untersuchung, wofür sie eine wichtige Quelle gewesen wäre, entgangen; er zieht von Schubart nur Gedichte heran, S. 206 u. 93. Von den Schiller-

Scherrer, Kampf in deutschen Drama. 
Schiller nun leiht der Zeitungspolemik Schubarts die Wucht des drarnatischen Pamphlets. Schärfer hat deutsche Dichtung kaum je Abrechnung gehalten als in jener Szene, worin aus der Front der verschacherten Truppen, die hohnvoll Freiwillige heißen, ein paar vorlaute Bursche rebellisch vortreten, der gnädigste Landesheir sie aber vor versammelter Carnison niederschießen und dazu die Trommeln rühren läßt, damit der Allwissende das unglückliche Volk nicht soll beten hören. ${ }^{26}$ ) Wiederum fält cin grelles Streiflicht auf die Stellung des jungen Dichters zu der Militärmacht seiner Zeit, dic ihm durch den eisernen Zwang der Karlsschule tief verhaßt geworden war. Er stellt sich hier, auf dem sozialen Boden, völlig neben Lenz. ${ }^{27}$ )

Kommentatoren hat Düntzer (Erläut. 15/16, 2. Aufl. S. 160) und beiläufiger E. Schmidt (Sökularausg. 3. 454) auf sie verwiesen. Die Hauptstellen stehen, in der im Text beobachteten Reihenfolge, im Jahrg. 1776, S. 330; 6; 218. - 375; 703; 82. - 157; 662. - 227; 662. - 532 f.: 546 f. Liste der Verkäufe 194; Württemberg 200; 225; 270. Vgl. die Charakteristik der Chronik von Ad. Wohlwill, Schnorrs Archiv 6 (1877), S. 385 u. 387.

${ }^{26)} \mathrm{Vgl}$. Kapp S. 202 f. Shakespeares Richard III. läßt IV. 4 Tusch blasen und die Trommeln rühren, damit der Hımmel nicht höre, wie die fürstlichen Frauen ihn, des Herrn Gesalbten, lästern. In Schubarts .Fürstengruft” (1781, DNL. 81, 377) heißt es: |Die Fürsten| „Die das Gewissen, jenen mächt' gen K'läger. / Der alle Schulden niederschreibt, / Durch Trommelschlag. durch weische Trillerschläger / Und Jagdlärm übertäubt." Im .Kaplied” von 1787 (DNL 81. 431): ..Ist hart! - drum wirble du. Tambour, / Den Generalmarsch drein. / Der Abschied macht uns sonst zu weich - -". Bei G. Büchner. Der hessische Landbote, 1834 (Schriften, Berlin 1909. 2. 141): .,Mit ihren Trommeln übertäuben sie [die vom Fürsten gepreßten Soldaten] eure Seufzer. mit ihren Kolben zerschmettern sie euch den Schädel" usw. - E. Keller S.26, vgl. Welt rich I, 4 ff., bringt für den Auftritt eine Episode aus dem Leben von Schillers Vater bei: Widerwilliger Auszug der Württemberger gegen Friedrich d. Gr. - Abschiedsszenen der nach Amerika Ausziehenden sind geschildert bei Schubart, Chronik 1776 S. 737, bei Eelking 1, 172 und in einem Briefe Caroline Schlegels, An L. Gotter 16. April 1782 (Caroline, hrsg. v. E. Schmidt. Lapzig 1913, 1, 62; Kapp S. 206).

$\left.{ }^{27}\right)$ Weiteren Spiegelungen des Soldatenhandels in der Literatur ist nach Kapp S. $204 \mathrm{ff}$. Duntzer S. 160 f. nachgegangen. Neben Schubarts dort herangezogener "Fürstengruft" Ist als dichterisches Dokument das "Kapli d" samt seinen Nachbarn (DNL 81, 430 fi., vgl. 303) wichrig. dem er aber die anklagende Schärfe nach seiner Lage nicht geben durfte; sie kommt dafür in den zugehörigen Brielsiel en zu W'ort (Schulart an Himburg 22. Febr. 1787; an s. Sohn 26. Aug. 87; 28. April 87; an s. Cattin 24. Nov. 86; bei D. Fr. Stra u B. Schubarts Leben in seinen Brielen”. Bonn 1878, 2. 196; 240; 209; 177). Uber die Angelegenheit - die Verschacherung des württemberg. sog. .Kapregimentes" an die Holländisch-ostindische Compagnie - vgl. St rauB2 2. 1241. Die Anwerbung für Amerika steht im Hintergrund von Lenzens ..Waldbruder", im anurikanischen Krieg spielt Kilingers ..Sturm und Drang", dessen Held Wild in die Neue Welt gekcormen ist, um die Kampagne als V'olontär mitzumachen (1, 1). Klinger selbst jubelt als cingeflesschter Berufssoldat über die Aussicht. in englischem Sold don zu fechten (an Schleiermacher 11. Aug. 1776; Rieger 1. 398), oder auch, gleichviel, im Dienst der Kolonien gegen 
Aller kriegerische Clanz, den er dem Berufsheer, wie er es sah, so gründlich aberkannte, liegt dafür auf Moors Bande; sie wird Schiller zum Gefäß der soldatischen Ideen, die in ihm, dem Offizierssohn, im Gegensatz zu der bedrückenden soldatischen Außenwelt erwachsen waren. Eine wüste Gesellschaft, die doch auf dem Urgesetz alles Kriegswesens, der unweigerlichen Disziplin beruht. Hierin ist Schillers Soldatennatur ganz offenbar: er verherrlicht die Disziplin, so kehlzuschnürend er sie selber empfunden hatte. Kein kriegserprobter General kann über einem in eiserner Zucht großgewordenen Heer das befehlende Wort autoritativer handhaben als der jugendliche Räuberhauptmann Schillers, wenn er unter seiner Bande Musterung hält: „Wer überlegt, wann ich befehle?" ${ }^{28}$ ) Aber freilich, er stellt die Mannszucht auf eine neue Grundlage : diese Subordination schreibt sich nicht aus der rohen Gewalt, dem äußern Machtmittel, nicht aus dem symbolischen Stock des Korporals her, sondem aus männlich freier Unterordnung unter den Besten, und der Eid, auf dem sie ruht, bindet den Herrn gleich wie den Knecht. Die Stunde kommt, wo die Getreuen, ihre Narben weisend, den Hauptmann an seine Schuld mahnen, und ihren Anspruch auf ihn gültig erheben; aber vorher auch die Stunde der Gefahr, worin das Räubergesindel sich trotz aller lockenden Amnestie auf Leben und Sterben um den vergötterten Führer schließt, und der einzige Spiegelberg eine hundsföttische Memme bleibt. Was dieses freie und doch soldatisch straffe Verhältnis an Edlem birgt, hat Schiller in die Stellung des ersten Gefolgsmannes, Schweizers, zum Räuber Moor gelegt. Er steht neben

England (Rie ger 1, 155 f.; 191 f.; 262; 266); ja er soll sogar, als dies gescheitert ist, das unsaubere Geschäft des Werbers für die Mietstruppen übernehmen (Rie ger I, 303 f.). Zu Goethes zahmer Anspielung im "Neuesten von P'undersweilern”, 1781 (A. Schöll in den Grenzboten 1870, Heft 22; Kapp S. 204; Köster in Jubil.-Ausg. 7, 358) muß der Brief an Carl August (26. Nov. 1784) gestellt werden, worin Coethe - ein denkwürdiger Kontrast zu der Anklage Schillers im gleichen Jahr - über ein Angebot der Holländer im Geschäftston berichtet: „Die Bedingungen klingen ganz gut, ich lege sie bei“ - und unter diesen Bedingungen figuriert auch die schlimme Sondervergütung für die Leute, die nicht zurückkommen, wofür der Holländer offeriert: für den Reiter samt Pferd 300, für den Infanteristen 100 fl. holländisch (Briefw. Carl Augusts mit Goethe I, Berlin 1915, S. 47 u. 49 f. Briefe 6, 395 u. 470). - Eine Geißelung des Soldatenhandels findet sich noch in einer dramatischen Satire Blumhofers (vgl. Le gband S. 324 Anmerk.): „Die Luftschiffer" usw.. Nördlingen 1787, wo unter den in ewiger Qual büßenden Geistern der Abgestorbenen auch ein Fürst angetroffen wird, der Millionen von Soldaten verkauft hat und den Erlös verpraßte und verschlemmte. - Um etwas Verwandtes handelt es sich bei dem Kriegsschwindel des Dorfrichters Adam bei Kleist: die Regierung der vereinten Staaten soll danach beabsichtigen, die Milizen widerrechtlich außer Landes in den mörderischen Kolonien zum Heil der Haager Krämer zu verwenden (v. 1915 ff.; Variant v. 119 ff.), wofür man einen vagen Präzedenzfall geltend macht (Vabant v. 420).

${ }^{28}$ ) II, 3 S. $79_{21}$; vgl. dazu Mirior 2, 32. 
dem Hauptmaun gleich wacker wie Lerse neben Götz, aber mehr Kamerad als jener, der sich im bezahlten Dienstverhältnis findet; im befreiten Sturm und Drang natïrlich ledig der Standesschranke, die in Lessings Soldatenwelt herrscht, aber trotz des genialisch ungebundenen Tones im Grunde nicht minder diszipliniert als Tellheims Wachtmeister, dem auch schon ein und das andere freie Wort gegen seinen Major entschlüpft, und durchaus fern der stürmerischen Unhotmäßigkeit eines Otto bei Klinger. Neben der gründlichen Opposition. die Schiller dem Soldatentum seiner Zeit macht, sind diese inneren Úbereinstimmungen mit der verklärenden Behandlung Lessings nicht zu übersehen. Schweizer hat dem Freund und Führer im heißen Kampfgewühl das Leben gerettet - die Grundlage der echten Kricgskameradschaft, die ebenso zwischen Tellheim und Werner das unzerreißbare Band knüpft ${ }^{29}$ ) - und seine Kameradentreue ist rührend auch im Verstiegenen. Hier konnte der Karlsschüler, anders als in der Licbeshandlung des Stücks. Selbsterlebtes geben. Nichts lebendiger und schöner als der kleine Freundesdienst des Wasserschöpfens mit Gefahr von Hals und Bein, ein Erlebnis von heißem Marsch, wie es so unmittelbar im späteren Schiller nicht mehr stehen dürftc. ${ }^{30}$ ) Sicherlich ist daneben die Auffassung dieses Verhältnisses von Moor und Schweizer jugendlich überhitzt und streift das Groteske, etwa wenn der Kamerad zum Lohn aufopferndster Treue die heiligen Locken des alten Moor zu berühren gewürdigt und durch das Rächeramt geehrt wird, wie noch kein Sterblicher vor ihm (IV, 5), und so darf man dem ganzen kriegerischen Räuberwesen nicht allzu genau nachrechnen. Die Ubertreibungen im Zahlenmäßigen sind offenkundig, der Sieg der achtzig Banditen über die 1700 Regulären geht über alles menschenmögliche, auch wenn man deren Kumpfkraft völlig geringschätzt. Zwar hat der Dramatiker Schiller es verstanden, den Erfolg im Eindruck dennoch glaub-

2) Rauber IV, 5. S. 135, Minna III, 7: die Episode von dem böhmischen Reuter, dem Schweizer den Kopf spaltete, als er schon über Moor den Säbel zuckte, lautet ähnlich wie diejenige Werners, der den Hieb auffing, welcher Tellheim den Kopf spalten sollte.

$\left.{ }^{20}\right)$ III. 2, S. 9321. u. 96, 1 ; zum Ausdruck Schillers sind beigebracht Psalm 22, 15 f. und Klopstock. Messies 10,707. Zum Motiv: Plutarch. Leben des Brutus cap. 51 (E. Schmidz). Die einzelnen Zirge wiederholen sich naturgemäB in der Tradition der kriegerischen Dramatik. Klopssocks Hermann (Hermannsschlache. 11. Szene, DNL 48, 116 u. 117) verlangt nach getaner Kampfesarbeit nach einem kühlen Trunk, der ihm im Helm geholt und gereicht wird wie Moor im Hut, woraul schon Minor. 1. 316, in anderm Zusammenhang hinweist; ebenso Odyseus in der achlachtheißen W'elt von Kleists Penthesiles (v. 12 u. 139; vgl. 1400). Zur Pflege eines Verwundeten: Käthchen II, 9 der Phöbusfassung: ein stimmungsschwerer Trunk am Quell, Schroffenstein IV, 4 v. 2224 ff. - Das Trinken aus demselben GefäB als intimste Kriegskameradachaft zwischen Tellheim und Werner, Minna III, 7: zwischen Wallenstein und Oktavio. Tod 7. 1697. 
haft zu machen. Er kann es wagen, einen verzagten Räuber sogar, von vielen Tausend Husaren, Dragonern und Jägern, welche die Anhöhe umschwärmen, faseln zu lassen, und selbst Schweizers ungeheuerliche Renommage von den fünfzig gegen seinen großen Nagel ist in dieser Welt am Ort. Schlimmer steht es schon mit den konkreteren Angaben. Die Räuber verfügen mit ihren fünf Paar Pistolen und drei Kugelbüchsen pro Mann über eine Fülle des Schießzeugs, die uns an Karl May gemahnt; der eine Tote Roller wiegt gegen die dreihundert erlegten Feinde entschieden zu leicht, während die Bande insgesamt gegenüber der zwanzigfachen Exekution doch noch als Masse gelten konnte. ${ }^{31}$ )

Alle diese Dinge bis zu den scheinbar unleidlichsten unter den Verstiegenheiten hängen aufs engste mit der geistigen Haltung zusammen, die Schiller überhaupt, und auch in seiner gebändigten Reife, zum Kriege einnimmt. Seiner Geistesrichtung im ganzen ist die pathetische Kriegsauffassung gemäß, die sich auf Crund seiner unbegrenzten Wirkung, so wie er sie formte, einem ganzen Zeitalter eingeprägt hat. Sie stößt mit der realistischen Coethes am schrcffsten bei ihrem ersten Auftreten zusammen, besonders sinnfällig, weil die Kampfhandlung der Räuber derjenigen des Cötz in manchem verpflichtet ist. ${ }^{32}$ ) Wir sahen, wie Schiller den Kontrast des freien Kriegertums zu dem Lohnsoldaten verschärft. Es gibt aber in den Räubern immerhin eine Stelle, wo auf dieses verächtliche Mietlingsheer urplötzlich ein Strahl ganz anderen Lichtes fällt: „Und draußen stehn Siebenzehnhundert, unter Musketen ergraut" - in diesem Augenblick nicht mehr Kommißbrotritter, sondern rühmliche Veteranen, eine formidable, nach einem Vers G. Kellers von der Gewohnheit Eisenfaust in Schritt und Tritt gelenkte Kriegsmacht gegen das Häuflein der Räuber, von denen keiner auf Wink und Kommando zu fliegen cder nach Kanonenmusik zu tanzen weiß. Schiller gibt hier (II, 3, Moor zum Pater) um des einen prachtvollen pathetischen Gegensatzes willen, um das große Wort des Moments die ganze Vorstellung von den erbärmlichen Schergen des Gesetzes, die er sich autgebaut hat, preis; er verkehrt seine Auffassung dem Getragenen zuliebe jäh ins Gegenteil. Der Vorgang ist in Goethes schlichter Kriegswelt, deren festen, simplen Ton keine hohen Worte durchkreuzen, undenkbar. Die Reichsexekution erscheint in jedem Augenblick

31) II, 3, S. $81_{24}$ u. III, 2, S. 97 ; vgl. zum letztern E. Schmidt, Säkularausg. 3, XVI. Eine ähnliche Ubersteigerung der Zahlenverhältnisse weist $\mathrm{Brahm}$, Ritt. S. $34 \mathrm{f}$. in Törrings Kaspar nach, der von 400 Mann (statt wie im Götz 150) einen einzigen entkommen läßt. Zu den Übertreibungen überhaupt Weltrich 1, 373.

32) Die Ubereinstimmungen des äußern Verlaufes und übernommene Einzelmotive mustert Minor, ZfdPh 20 (1880), S. 67-68; vgl. dazu seinen Schiller, 1, 309-10; E. Schmidt, Säkularausgabe $3,429$. 
als das, was sie ist, und Coethes Auffassung des Krieges im ganzen geht im Götz nirgends aus dem Realistischen, ja Derben heraus. Die große Gegensätzlichkeit seines und des schillerischen Geistes drückt sich damit auch in dem engen Gesichtskreis der Kriegsgestaltung scharf aus.

Schiller hängt zwar wie die ganze Dramatik der Geniezeit der Natürlichkeitsrichtung des Götz an. Aber daneben bricht bei ihm zugleich an allen Enden die Neigung zum Pathetischen und Heroischen durch. So stehen in dieser Kampfwelt neben den kühnsten Realismen Züge feierlich erhabener Art, und neben der Redeweise des Alltags wuchtig einherschreitende Worte. Die heillose Diebsbande, an der kein Haar ist, das nicht in die Hölle fährt, ist doch zugleich der Hort der Treue bis in den Tod. Ihre Erhebung ins Heroische hat einen allgemeinen Zwiespalt zur Folge. Der Mordbrenner Schweizer, der schließlich den Galgen stündlich riskiert, kann wie der rechtschaffenste Veteran zürnend fragen: „Ist uns darum der helle Schweiß über die Backen gelaufen, daß wir aus der Welt schleichen wie Hundsfötter?", der Räuber Moor gar von dieser Handvoll Schelme feldherrnmäßig sagen: „Ich fühle eine Armee in meiner Faust" :13) Der grundlegende Unterschied vom Götz liegt schon in der scheinbar rein äußerlichen Steigerung der zahlenmäßigen Úberlegenheit des Exekutionsheers: ${ }^{31}$ ) er ist am deutlichsten dort, wo es sich um ausgesprochene Reminiszenzen ${ }^{35}$ ) handelt.

23) II, 3 (S. 86 $6_{30}$ u. $88_{19}$ ): IV. 5 (S. 124 28 ): Moors Wort hervorgehoben von E. Schmidt. Säkularausg. 3. XVII. Im übrigen nur ein paar Beispiele: die Räuber müssen "fechten wie angeschossene Eber" (S. $81_{35}$ ), sie folgen dem Hauplmann in den .Rachen des Todes" (S. $81_{19}$ ): sie wollen über die Feinde her ..wie die Sündllut und auf ihre Köpfe herabfeuren wie Wetterleuchten“" (S. 80 $0_{32}$ ). Dicht daneben: sie sollen , .nicht wissen, wo sie die Ohrfeigen herkriegen” (S. 82, ). .daß ilmen die Kurteln schuhlang herausplatzen" (S. $81_{18}$ ) usw.

34) Bei Goethe ist es rund 500 Mann stark; um 100 schmilat es in den ersten Plänkeleien (DjG 2 3. 234), mit 400 tritt es ins Gefecht, 150 stellen sich danach beim Appell (das. 239), auf 200 wird es wiederum beim Anzug auf Jaxthausen geschätzl (S. 240). Demgegenüber verfügt Götz immerhin über cin wackeres Häufchen eigener Leule, .dergleichen wenig Fürsten beisammen gesehen haben" (S. 227). Sickingen schickt 20 Reuter (S. 227 u. 234; im Gefecht scheiren es mehr), Selbitz kommt mit 50 Mann (S. 231), insgesamt also sicherlich eine Schar von über 100 Knechten. Die Zuzügler halten sich im Kampt schlecht und zerstieben anscheinend. so daß Gölzens Macht vor der Belagerung einschließlich der blutigen Verluste stark unter 50 Mann sinkt (S. 240), deren Kampfwert ihm zudem verdächtig ist (S. 238). Ersatz zu schaffen miBlingt (S. 239).

${ }^{3 i}$ ) Zwei der von Minor, ZfdPh 20,68, aufgewiesenen Parallelen sind interessanter durch den Kontrast als durch die Úbereinstimmung: $\mathrm{C}^{\prime}$ ötz $\left(\mathrm{DjC}^{2} 3.234\right)$ : .so fallt ungesäumt in die Seiten. Wir wollen sie patschen." Räuber S. $81_{30}$ :.. Wir andem, wie Furien, fallen ihnen in die Flanken." Der Gegensatz der Auffaseung ist durch das .ppatschen" dort und die ..Furien" hier schart bezeichnet. - Auf die Frage..Wie stehts Pulver?" heißi's im Cötz bedächtig (S. 242): .So ziemlich": 
Die Kriegspathetik der Räuber steht in manchem der Auffassungsweise Klingers nahe ${ }^{36}$ ) sie scheidet sich aber doch auch von ihr trotz verwandter äußerer Züge durchgängig. Das Kraftgenialische schlechthin, wie es Klingers Art bestimmt, ist in letzter Linie ein Ausfluß robuster Körperlichkeit; der reckenhafte Klinger steckt überall in seinen Kriegshelden. Körperliche Kraftprotzen kennt das Ritterstück zur Genüge. Diese Entwicklung geht schließlich wiederum von der gesunden Lebensfülle der Gestalten im Götz aus, die von Klinger gesteigert, auch übersteigert, vom niedern Ritterstück nur noch vergröbert wird. Die schillerische, getragene Auffassung hat geistigere Wurzeln; sie hebt den Krieg aus der Kraft der Phantasie ins Großdichterische, wie auch ihr erst die geistigen Probleme des Soldatentums aufgehen.

Die Richtung ins Pathetische verursacht in der Kriegshandlung der Räuber noch mehr Schwankungen; weil sie, noch ungezügelt, ohne das Ganze zu bedenken, stets nur den Augenblick ergreift und ihm die höchste Fülle der Empfindung geben will. So stirbt Roller den schönen Soldatentod (III, 2, S. 96 ${ }_{31}$ ), obwohl Diebe nicht fallen können, wie Helden fallen (II, 3, S. 87 $7_{25}$ ). Den schlimmsten Streich hat sie dem Autor in der Szene des verkappten Hermann (II, 2) gespielt. Schiller braucht für seine Intrige einen gefälschten Gefechtsbericht. ${ }^{37}$ ) Sein Dichterfeuer geht mit dem schönen soldatischen Gegenstand durch, und was nur ruchloses Mittel in der Hand von Bösewichtern sein sollte, schwillt ihm wider Willen ${ }^{\circ}$ zu einem hinreißenden Stück Kriegspoesie an, das jetzt in der dramatischen Funktion, die es noch zu erfüllen hat, unser Gefühl unerträglich betrügt und zudem aller Voraussetzungen ermangelt. Woher sollte der „hölzerne“ Franz, woher Hermann solche Töne nehmen? Gewiß braucht der Dramatiker hier einen starken Akzent, aber die Todesnachricht für sich hätte in einfacherem Gewand den alten Moor niederwerfen können, und eine bedächtige Technik würde wohl die Personen auf der Bühne betrogen, aber nie die Empfindung des Zuschauers auch nur einen Augenblick irregeführt haben. In Wahrheit geht hier der Dichter, erfüllt von dem Bild dieses großartigen Soldatentodes, mit in die Irre. Der Fälscherkniff wird ihm selbst auf der Höhe des Auftritts zum Ernst, und es ist schwer zu sagen, wie sich der

in den Räubern grandios (S. $8 \mathrm{I}_{22}$ ): „Pulver genug, die Erde gegen den Mond zu sprengen.“ Die Sache liegt anders, aber die Antwort in Jaxthausen hätte nicht so lauten können, auch wenn ganze Tonnen voll vorhanden wären.

36) Einflüsse des „Otto“ in den Räubern und Fiesko, die hier ohne Belang sind, sucht O. Erd mann, Rez. zu E. Schmidt, Lenz und Klinger, AfdA 5, 379.

37) In Schubarts Erzählung wird Karl bei Freiberg - die Pragerschlacht setzt erst Schiller ein (E. Schmidt, Säkularausg. 3, 426) - verwundet; der Bruder unterschlägt den Brief. den Karl aus dem Lazarett an den Vater schreibt. Ein verwandter Falschbericht findet sich später bei Kleist, Homburg II, 5. 
Schauspieler demgegenüber benehmen soll. Der Bruch in der zwiespältigen Szene wird empfindlich, wenn nach den gehobenen Worten vom Ende des Wackern das plumpe Spiel mit Porträt und blutbeschriebenem Schwert eingreift. ${ }^{38}$ ) Dazu stimmt dieses Meisterstück eines Kampfberichtes nicht. Es sprengt den dramatischen Rahmen, so echt dramatisch es an sich und in der Wirkung auf die Hörer ist; denn der Kriegsdichter Schiller verleiht ihm einen Sonderwert, der ihm nach seiner Funktion nicht zukommen darf.

Der Zusammenhang nit der Kriegslyrik des jungen Poeten liegt zutage. Hier klingen dieselben Töne an, die das Schlachtgedicht der Anthologie auf 1782, "In ciner Bataille, von cinem Offizier" durchbrausen, jene stärkste Formung, welche dic exerzierte Schlacht des 18. Jahrhunderts in der Poesie gefunden hat. ${ }^{39}$ ) Dort der schöne wilde Takt der wogenden Angriffsschlacht, hier das eiserne Beharren festgewurzelter Verteidigung. Der Karl des Berichtes, der unter dem großen Schwerin den Ted auf dem Bette der Helden sucht, steht mit seiner Fahne unerschüttert als Fels in der Brandung des Treffens, ${ }^{40}$ ) und Schiller hat die heldische Festigkeit durch das große Crescendo des wicderholten .,er stand" zu triumphaler Wirkung geführt. Dieser treue Fähnrich stand während fünf Regimenter neben ihm wechselten, er stand während die Kartätschen ihn umhagelten, er stand noch mit zerschmetterter

28) Die Einheitlichkeit der Szenc ist nur mit größtem Zwang zu retten; wer den Todesbericht unbefangen liest, wird sicherlich nicht zu der künstlichen Parallelstellung W. Bormanns (StvgIL 5. Ergànzungsheft, S. 99) kommen, der in ihr nur die "abgeleierte Lügenbotschaft" sieht, die als Cegenstück zu der .,hergeleierten Entrüstung" des Paters aufzufassen sei. Auch Minors Lob der Charakteristik (1, 350, der vermummte Hermann verändere nicht bloB äuBerlich den Ton. sondern rede auch die Sprache cines Kriegsmannes) will hierher nicht passen; vielmehr steht der Tenor dieses überquellenden Teilstücks isoliert außerhalb der Welt Franzens und Hermanns und spricht wohl für dig dichterische Kraft, aber mehr gegen, als für eine sorgfältigere Charahterisierung.

3v) Später leicht überarbeitet: .Die Schlacht”. Vgl. Weltrich 1. 540-41; an Kraft der Gestaltung und atemraubender Vergegenwärtigung der Kamplvorgänge eins der bedeutendsten und sicher überhaupt das wirksamste aller Kriegsgedichte: man muB nur selbst den Versuch semacht haben, es soldatischen Zuhörern, etwa den Mannschaften einer Kompagnic vorzutragen, um zu wissen. wie der kriegerische Funke darin zündet. - Vgl. aus der Anthologie noch „Graf Eberhard der Creiner". wo aus der W'elt der "Bataille" unter anderm ein blïcherisches .MarschI Kinder! In den Feind!" seitsam in ein Treflen des 14. Jahrhunderts hineinklingt. - Das episodische Moment, das auch in der ..Schlacht" einen Einzelvorgang aus dem allgemeinen Kampigewühl auflitzen Lißt, steht in Hermanns Gefechtsbild dem Zwecke gemäß obenan. Dem .Sein letzter Seufzer war Amalia“" entspricht das ..Crüße mein Lottchen. Freund " in jener Episode genau.

- $\rightarrow$ Das fechtermäBige Feststehen auf sicherem Grund schön bei Shakespeare, aus dem Munde des Kriezers, der den Antonius vom ungewissen Schlagen auf schwankem Schiff abmahnt: .Wir sind gewohnt zu siegen fest auf Erden / Und fechtend FuB hei FuB" (Ant. u. Cloop. III, 7). 
Rechten, die Fahne in der Linken, und die hingegebene Bewunderung des Weibes bricht jauchzend aus: „Hört ihr's? er stand“" - bis er - der Übergang ist meisterhaft - am Abend der Schlacht, unter Kugelgepfeife niedergesunken, gefunden wird. ${ }^{41}$ ) Hier läßt sich die Kriegspathetik Schillers, die den ganzen Bericht trägt, noch einmal an der anders gearteten Auffassung Goethes messen. Wie dessen Valentin, so stirbt der wackere Fahnenträger ,,als Soldat und brav“ in aller Schlichtheit; aber Schiller steigert seinen Tod doch zugleich ins Heroische hinauf: „Bald darauf hauchte er seine große Seele dem [voraufgegangenen] Helden zu."

Nach der Seite der Kampftechnik hin zeigt sich bei den Räubern ein merkwürdiger Sachverhalt. Sie gelten der allgemeinen Vorstellung nach sicherlich als spektakelvolles, ungebärdiges Stück, und der junge Autor selbst ist der erste, der ein Übermaß von Kampflärm statuiert: „Nehme ich das Schießen, Sengen, Brennen, Stechen und dergleichen hinweg, so ist es für die Bühne ermüdend und schwer", äußert sich seine Kritik der Aufführung. ${ }^{42}$ ) Die Theatertradition hat dem kämpferischen $T$ eil in der Tat eine übergroße Liebe zugewendet. Voran ging Schikaneder als erfolgreicher Unternehmer großer Theaterspektakel, die zwischen Bühne und Zirkus die Mitte halten. Seine Aufführungen der Räuber stellten die Bataille zwischen den Banditen und dem Militär und danach Brand und Einsturz des Moorschen Schlosses als dankbarste Hauptszenen heraus. ${ }^{43}$ ) Ähnlich läuft eine lärmende Liebhabervorstellung des Stückes ab, die Tieck im Jungen Tischlermeister mit ausgezeichneter Ironie schildert. ${ }^{44}$ ) Nach der Meinung seiner robusten ländlichen Kunstfreunde muß den zweiten Akt ,eine große wirkliche Schlacht mit Schießen und Hauen beschließen", und es soll dabei ,ein Toben geben, daß den Leuten das Herz im Leibe lacht". Das greuliche Spektakel vollzieht sich, sorgsam eingeübt, zur allgemeinen Zufriedenheit. Die Andeutungen des Textes werden ausgestaltet, die Räuber teilen sich entsprechend dem Gefechtsbefehl Moors in die Kampfaufgaben; die Regulären dringen an, unter Schießen von nah und fern, Geschrei und Hörnergeschmetter wird mit Säbel und Bajonett gefochten. Fast haben die Räuber gesiegt, als mit effektvollem Umschwung

4) Eine verwandte Vorstellung in Brawes Brutus IV, 2: „Nur Brutus steht" usw. (vgl. oben S. 44 Anmerk. ${ }^{18}$ ). Zum Ausdruck noch Räuber V, 2 (S. 154 24 ): „Da wir dir standen wie Mauren, auffingen wie Schilder die Hiebe" usw. Zum Bau der Worte E. Schmidt, Säkularausg. 3, 427. Nach dem Inhalt hat Hermanns Bericht Beziehungen zu den im Soldatenstück zahlreichen Schilderungen soldatischer Bravourstücke, z. B. Babos Arno I, 2, vgl. Stockmayer S. 5.

42) Anhang zur Selbstrezension, Werke (v. Goedeke) 2, 375; Weltrich 1, 412.

42) v. Komorzynski, Schikaneder, Berlin 1901, S. 18; Petersen S. 249 u. 471.

44) Schriften 28, 337; 347-48; 355-56; 359; 362. Petersen S. 249. 
Moor selbst mit seinen Getreuen, von der Ubermacht gedrängt, erscheint. Das Cefecht erreicht seine ohrenbetäubende Krise und jetzt, während von allen Seiten geschossen wird was aus den Rohren geht, entscheidet das Eingreifen des theatralisch glanzvollsten Hilfstrupps: die ganze Koppel der Jagdhunde. die der alte Förster dazu abgerichtet hát, bricht mit Geheul auf die Soldaten los, und Doggen und Bullenbeißer wüten in ihren Gliedern, bis sie sich zur Flucht wenden und der Sieg der Banditen vollkommen ist.

Diese stark satirische Pantomime der Tieckschen Erzählung verwirklichte Immermann auf der Düsseldorfer Bühne, indem er über fünfzig Soldaten zuzog und das Pulver nicht schonte. Man sollte in sciner, in halber Verspottung Schillers inszenierten Räuberschlacht Moor mit den Getreuen leibhaftig im Getümmel fechten sehen. Er stutzt Tiecks Phantasicbild theatermäßig zu; für den Ausfall der kaum zu realisierenden Mcute entschädigen neue, stark aufgetragene Bühneneffekte. Nach Immermanns eigenem Bericht ${ }^{45}$ ) zerlegte er die Schlacht mit doppeltem Clückwechsel in drei Aktionen, die auf der kunstvoll verbauten Bühne vorgingen: Ein einleitendes Tirailleur-Geplänkel läßt die erfolgreichen Freischärler zu kühn vorgehen; von der gegnerischen Hauptmacht gefaßt, wird Moor mit den Haupträubern auf einem hohen Felsstück cingeschlossen, aber von den Seinigen herausgehauen. Indessen der Kampf hinten forttobt, plündern vorn Spiegelberg ${ }^{46}$ ) und Schufterle als Marodeure die Erschlagenen, und auch der Pater Unterhändler wird mit zerrissener Kutte der Galerie preisgegeben. Die Exekution zieht vermeintlich siegreich auf - als plötzlich von allen Seiten wütendes Gewehrfeuer der noch im Hinterhalt liegenden Rärber auf sie einschlägt und das Gefecht neu entbrennt. Dezimiert, retten sich die Regulären auf den hohen Weg und auf ein vorragendes Ruinenstïck. Jetzt werden alle Register wüster Theatralik gezogen. Während draußen ein Pulverkarren donnernd in die Luft geht und die Räuber unter Schlachtgeheul anstürmen, bricht das Mauerstück ab und fährt samt den Soldaten prasselnd in den Abgrund. In rotem Schein zeigt sich die Apotheose der Sieger: Moor, auf Schweizer gestützt, die Leiche Rollers. Was an Feinden übrig ist, schlachten die Räuber mit langen Messern ab.

Das große Schlachtspektakel Immermanns ist auf den Theatern zwar nicht seiner Ausdehnung und seinem Aufwand, aber seinem Geist nach langhin herrschend geblieben. Der zweite Aktschluß der Räuber geht kaum ohne kräftige Gewehrsalve und öfters nicht ohne auftauchende Soldaten ab, obwohl

4) Memorabilien 2. Teil, 'Tagebuch. Dez. 1836. Werke (Hempel) 19. 138 6. Abgedruckt bei M. Jacolss. Deutsche Schauspielkunst. Leipzig 1913. S. 130-31. Petersen S. 249-50.

46) Andere Theatermätzchen Spiegelbergs bei Kilian, Dramaturg. Blätter 2. München 1914. 188. 
der Dichter nur auffordernde Hörner, Lärm und Getümmel verlangt. Einen Schein von Berechtigung gewinnt diese Inszenierung ${ }^{47}$ ) allerdings aus anderen Stellen des Stücks, die zumal die Schüsse nicht aussparen. ${ }^{48}$ ) Die „Räuber" sind im Gebrauch theatralischer Mittel überhaupt nicht ängstlich. Die Mäßigung, die Schiller bei den Kämpfen selbst gleich im ersten Wurf an den Tag legt, ist demgegenüber fast erstaunlich.

Neben der Räuberschlacht in den böhmischen Wäldern ${ }^{49}$ ) steht die Erstürmung des Moorschen Schlosses (V, 1) in Frage. Beide Kampfereignisse meistert Schiller im scharfen Gegensatz zum Götz ohne Verletzung der Bühnenform, vielmehr ganz aus ihr heraus; ohne Anspruch auf Weite des Raumes innerhalb der Grenzen des Theaters. Den kämpferischen Aufwand des Ritterstücks läßt er beiseite und schwelgt in keiner Schlachtpantomime. Dramatische Mittel bestreiten die Szenen: die Spannung tritt entscheidend in die Kampfgestaltung ein. Sie hatte früher in äußerlichster Weise die alte, enge Form regiert, worin sich Kämpfe nur nach ihrem theatermäßig spannenden Gehalt geltend machen konnten. Klopstocks breite Schlachtanlage war ihr nicht mehr günstig, und der frühe Sturm und Drang warf sie vollends über Bord. Ihm kam es auf die restlose Vergegenwärtigung des einzelnen Vorgangs an, er war zu untheatralisch gerichtet, um nach spannender Verknüpfung zu streben. Der Götz gibt die einzelne Kampfszene zwar in einem atemversetzenden Tempo, aber er zerhackt ihre Folge viel zu sehr, als daß sich die Handlung zu einem einheitlichen Zug zusammenschließen könnte; es war ihm um das Kampfgebraus, nicht um den Zusammenprall dramatischer Gegenmächte zu tun. Schiller verstand hierin Shakespeare, der mit der größten Kunst die gewitterschwere Atmosphäre vor der Schlacht schafft ${ }^{50}$ ) besser, ja er drängt als geborener Theatraliker seine Wirkungsmittel ungleich enger zusammen. Seine

47) Sehr scharf geht Kilian a. a. O. 2, 188 mit ihr ins Gericht.

48) Der Hauptmann kündigt sich nach einer eingeführten, martialischen Sitte verschwenderisch mit drei Schüssen an: II, 3 (S. 74) u. IV, 5 (S. 125): hier auch die Antwortschüsse der Räuber. Er schießt über die Schläfer, um sie zu wecken IV, 5 (S. 133); dagegen ist beim Sturm auf Moors Schloß V, 6 nur der eine Schuß vorgeschrieben, womit Schweizer sich entleibt (S. 148). Die auf dem Theater stets aufregende Drohung eines Schusses V, 2, wo ein Räuber auf Amalia zielt (S. 156); ebenso in der Theaterbearbeitung IV, 8, wo Franz Hermann gegenüber zur Pistole greift, dieser ihn aber mit seiner auf jeden Fall bereitgehaltenen Waffe kaltblütig in Schach hält eine Theatersituation, die sich in der Kriminaldramatik mannigfach wiederholt. Verwandt Fiesko 1, 9: der abgefeimte Mohr findet beim Mordanschlag auf Fiesko in dem raffiniert sich hütenden Grafen seinen Meister.

49) Zu ihr vgl. Petersen S. 250; Lohmeyer S. 105.

$\left.{ }^{50}\right)$ Die Hauptbeispiele sind Richard III: V, 3 ff.; Jul. Cäsar IV, 3 ff.; Ant. 11. Cleop. IV, 2 f.; vgl. Brotanek, Shakespeare-Jahrbuch 52, XXI 


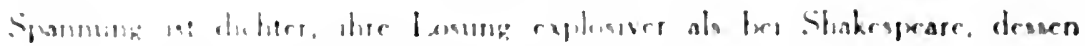

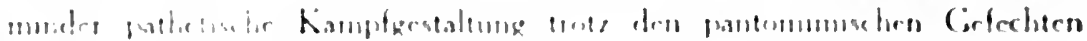

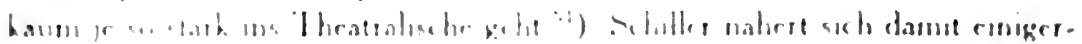

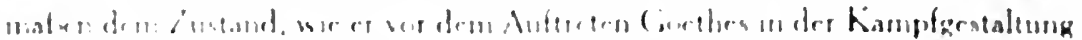

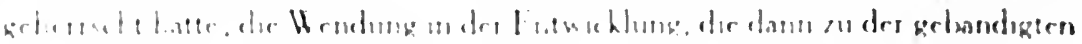

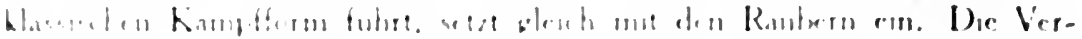

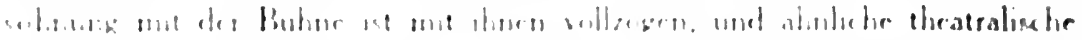

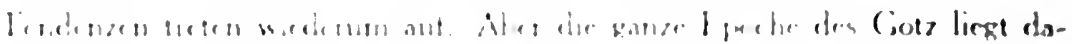

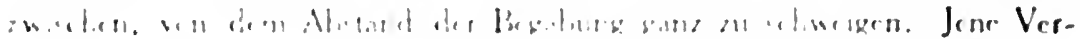

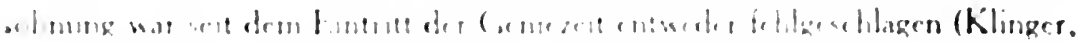

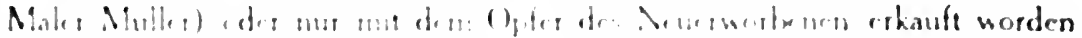

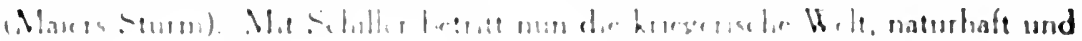

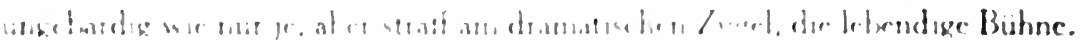

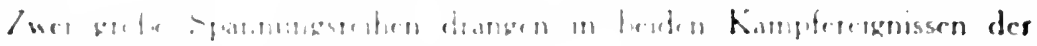

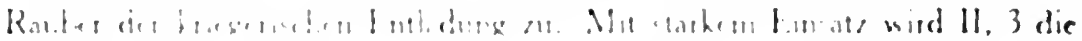

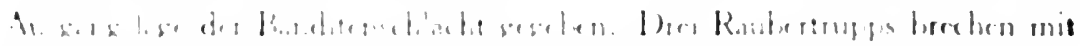

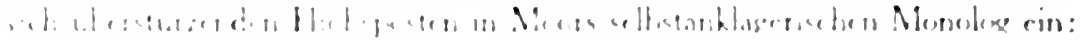

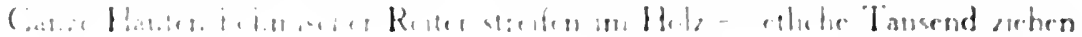

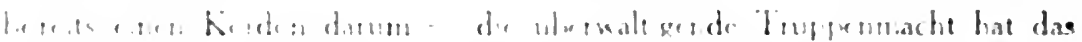

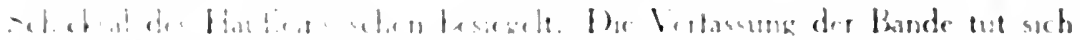

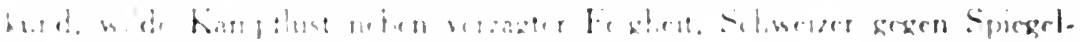

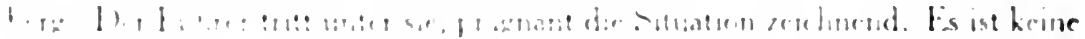

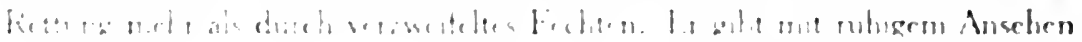

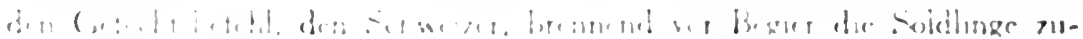

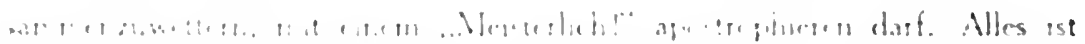

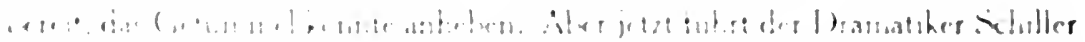

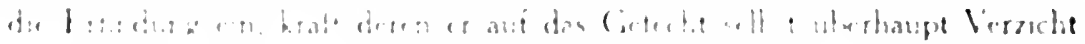

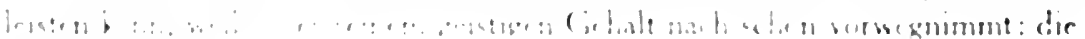

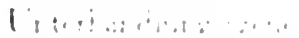

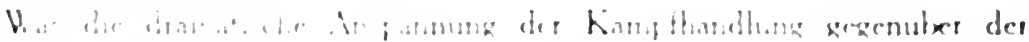

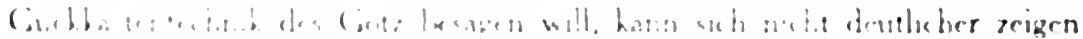

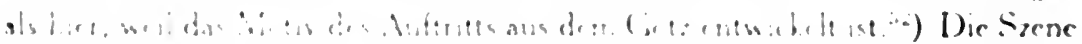

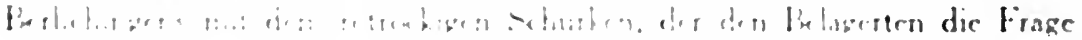

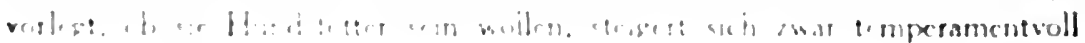

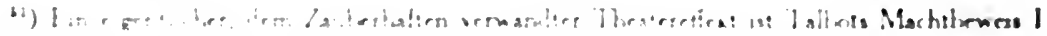

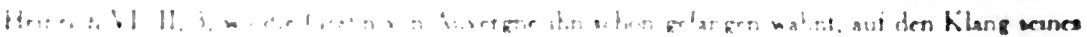

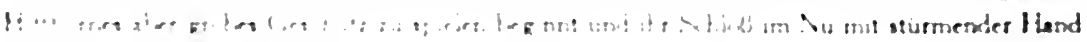

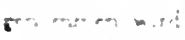

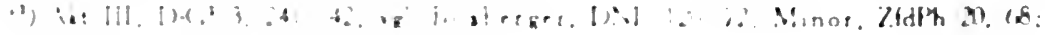

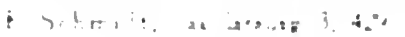


genug zum drastischen Ausruf; aber sie will nichts weiter sein, als ein Ausschnitt aus der Belagerungsgeschichte, ein Stück lebendigster Gestaltung für sich, ohne dramatische Verknüpfung und Folge. Schiller stellt das Motiv in den großen Zug seiner Handlung und gewinnt aus ihm die dramatische Gegenmacht. Der Pater tritt auf, als nur noch die Schlacht selbst bevorzustehen scheint, er ist zwar nur eine klägliche, aber immerhin eine Vertretung der Bataillone, die draußen jedes Haar auf seinen Schläfen bewachen, des Truppenaufgebots, das ja seinerseits nur durch die Zahl Gewicht hat. Seine Worte schärfen sich an Moors Trotz, die Spannung steigt Stufe um Stufe, und mit ihr wächst die feindliche Heeresmacht immer drohender heran. Als die fadenscheinige geistliche Beredsamkeit versiegt, übernimmt Moor selbst den Part des Unterhändlers und führt ihn nun mit einer meisterhaft erfundenen dramatischen Ironie zum Gipfel. Der Pater wies dem Mordbrenner mit Emphase den von Reitern der hohen Obrigkeit umsäumten Gesichtskreis, nun braucht Moor stolz das Wort von den Siebenzehnhundert, unter Musketen ergiaut, und läßt im Augenblick der höchsten Steigerung die Kriegsmacht selbst zum einzigen Mal - sichtbar werden: „Höret, wie ihre Hörner tönen! Sehet, wie drohend ihre Säbel daherblinken!" Jetzt erfolgt auf die entscheidende Frage des Hauptmanns triumphal der Umschlag, die höchste Soldatentreue bricht sich jauchzend Bahn. Damit ist die Schlacht aus dem Ethos heraus schon gewonnen, noch ehe eine Büchse geknallt hat, und es kann niemand über ihren Ausgang im Zweifel sein. Der Dichter streift ihn später (III, 2) bloß noch. Sachlich ist es nichts' weiter als ein Kampfabgang, was Schiller gibt, der Vorgang, den schon die Gottschedzeit effektvoll ausgestaltet hatte. Ein Rückblick lehrt, was aus diesem Element und der abrupten Unterhandlungsszene Goethes in dramatischer Durchdringung geworden ist und zugleich, $\mathrm{da} B$ die Bühnenschlacht der Theatertradition hier, wo die Technik sie überwunden hat, am wenigsten Platzrecht genießt.

Ein Meisterstück dramatischen Kampfbaus ist nicht minder der Sturm auf das Moorsche Schloß im V. Akt. Schiller erfaßt den Vorgang wie die strenge Technik vom Zimmer aus, während die freie Richtung des Ritterstücks, wie Maiers umgearbeiteter "Sturm" zeigt, nicht mehr gesonnen ist, auf seine Bühnenerscheinung zu verzichten. Auch hier wiederum Mäßigung; so nimmt ihn gleichzeitig und mit gleichem Ziel Törrings Agnes. Aber die neue geschlossene Anlage ist nicht mehr Fessel, sondern straffste Zusammenfassung der dramatischen Kräfte. Es erwächst aus ihr bei Schiller jene gesammelte Spannung und jene mächtige Steigerung im Herandringen des drohenden Verhängnisses, die weder in der früheren, engen Form noch in der losgebundenen Kampftechnik ihresgleichen hat. Der kriegerische Vorgang gibt seinen dramatischen Gehalt restlos her. Einzig auf diesen bedacht, geht Schiller 


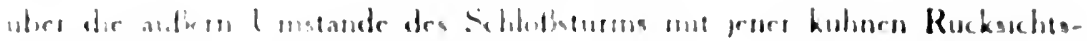

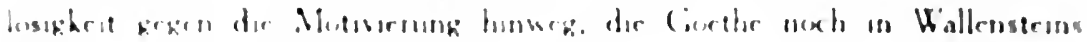

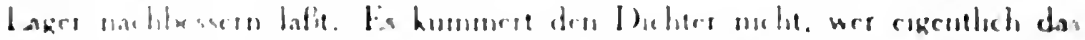

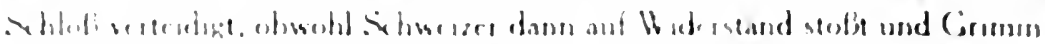

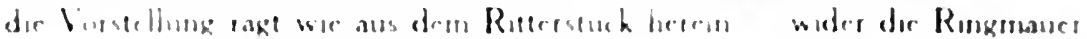

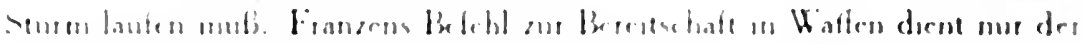

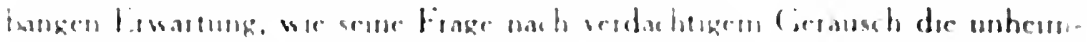

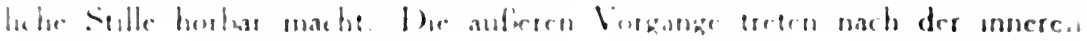

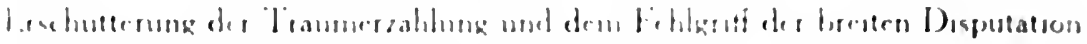

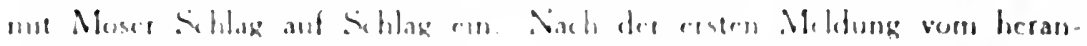

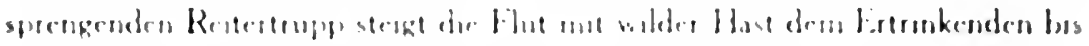

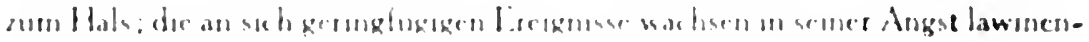

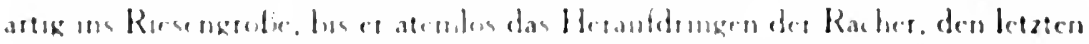

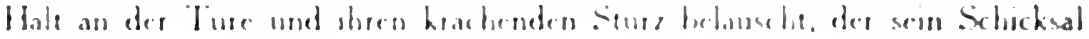

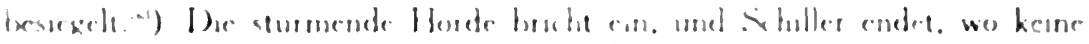

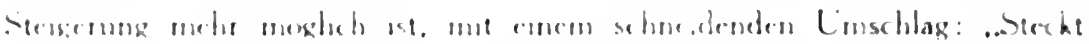

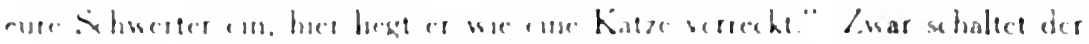

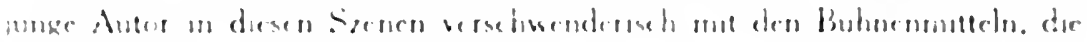

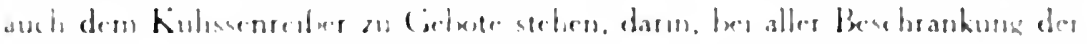

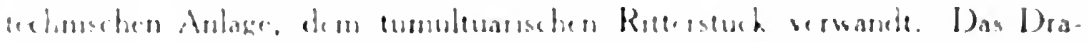

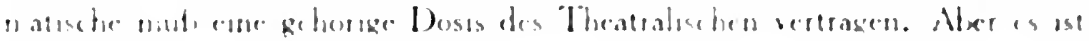

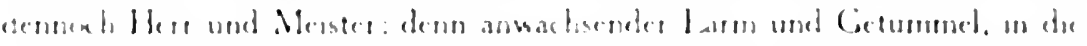

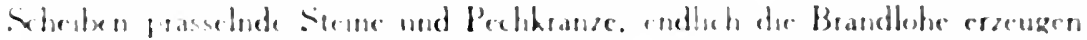

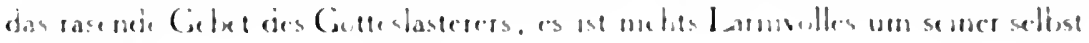
nillen da.

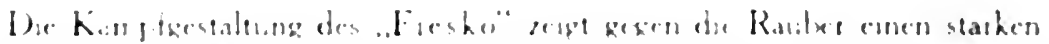

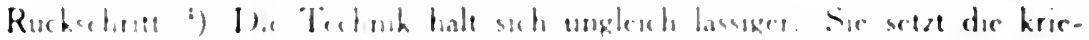

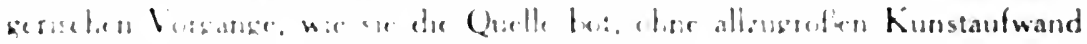

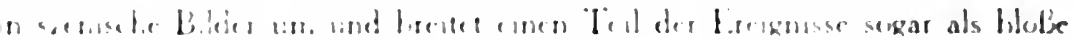

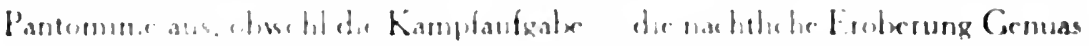

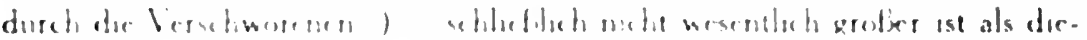

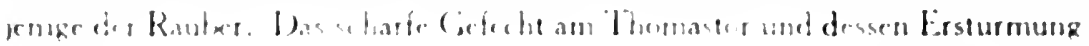

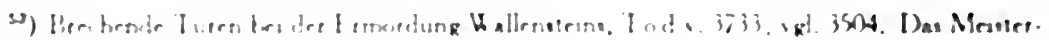

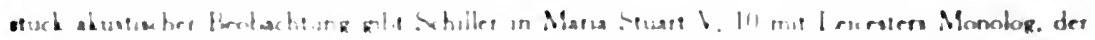

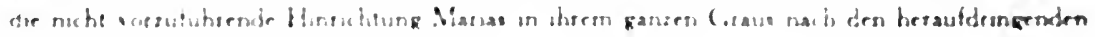
(orpaustion irsti

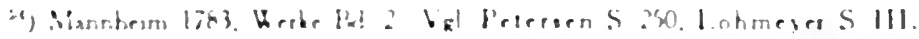

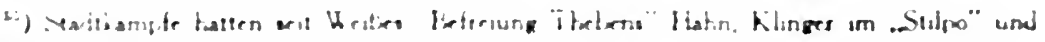
angel latiendes 
(V, I) wird nur durch eine szenische Anweisung gegeben. Die Raumvorstellung, die Schiller diesen Vorgängen zugrunde legt, schweift über das der Bühne mögliche hinaus, wenn sie auch Theatereindrücken des iungen Dichters entsprungen sein mag. ${ }^{56}$ ) Er macht sich jetzt, im Gegensatz zu den großen Szenenreihen der Räuber, die shakespearische Freiheit der Handlungsführung zunutze. Im ganzen wird man gegenüber der dramatischen Durchbildung im ersten Stück, trotz bedeutender Züge im einzelnen, den Eindruck des Skizzenhaften nicht los.

Die Verwandtschaft der Kampfgestaltung im Fiesko mit derjenigen des Ritterstücks ist mehrfach betont ${ }^{57}$ ) und in den Anforderungen an das Dekorative und der pantomimischen Gefechtsaktion in der Tat offensichtlich. Der Zuschauer soll die kriegerischen Geschehnisse der Nacht über das hinaus, was enger zur Handlung gehört, zu Gesicht bekommen. Obwohl der Fiesko darin von allen Stücken Schillers am weitesten geht, legt er immerhin auf diese Dinge nicht entfernt den Wert, den das Ritterstück dieser Richtung ihnen zuschreibt, das einen Burgsturm, ein Turnier um seiner selbst willen in aller Breite vorführt. Er steht darum mit seiner Kampfführung im Grunde Shakespeare und seiner unmittelbaren Nachfolge, etwa den Stilpo-Szenen Klingers und auch dem Cötz, näher als der seither ausgebildeten, tumultuarischen Ritterdramatik. Dies lehrt auch die Behandlung des Ortes. Schiller behält zwar die eine Straße Genuas, die aber darum die große sein und vom Palast Dorias durch das Thomastor bis in den Hafen reichen muß, durch den ganzen Akt aus Rücksicht auf die Bühne bei, baut aber innerlich seine Auftritte auf den shakespearischen Ortswechsel von Szene zu Szene auf. Durch diesen Zwiespalt sieht er sich genötigt, das Theater an den Szenenschlüssen immer wieder frèi zu machen, weil sich die Personengruppen nicht begegnen dürfen; eigentlich müßte der Ort mit ihnen wechseln. ${ }^{58}$ )

Die Übersicht über das Kampfgeschehen hat Schiller dadurch erleichtert. daß er den Kampfplan den Ereignissen vorweg entwickèln läßt, ein Mìttel, zu

58) Petersen leitet S. 195-96 die geforderte übermäBige Bühnentiefe von Erinnerungen an das Ludwigsburger Theater $a b$, das die Perspektive in die freie Natur zu öffnen pflegte. Naturhafte Weite schwebt z. B. in einer Vorschrift wie derjenigen V, 4 vor: ..Kalkagno fern mit Verschworenen".

${ }^{67)}$ Petersen S. 250; Lohme yer S. 111. Andere Beziehungen zum Ritterstück bei Brahm. Ritt. S. 147 und Minor, 2, 39 u. 57.

58) Von den 17 Szenen des Kamp autzugs schließen sich aneinander 9-13 u. 15-17; daneben scharf verbunden nur 2-3 (Aufeinandertreffen der Gegner); durch eine künstliche Prozedur 5-6; die andern enden alle shakespearisch mit einem "Eilen ab" - .Gehen fechtend ab" "Ziehen unter Trommelschlag weiter" usw. Petersen berührt diesen Sachverhalt in seiner ausführlichen Behandlung des Szenenwechsels bei Schiller (S. 162-75. Fiesko S. 167) nicht. 


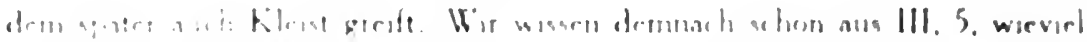

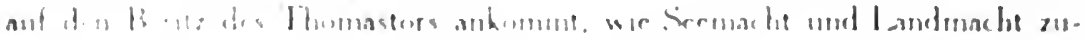

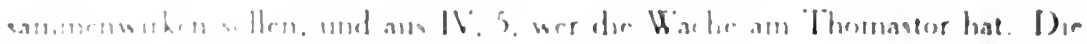

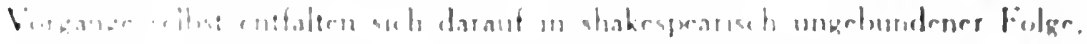

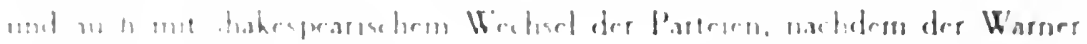

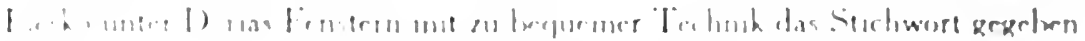

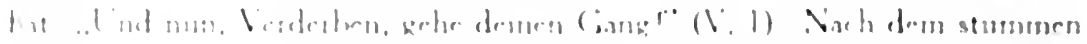

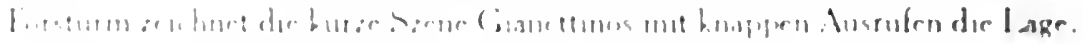

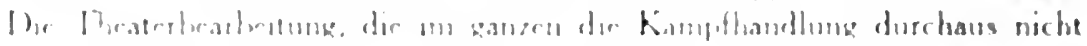

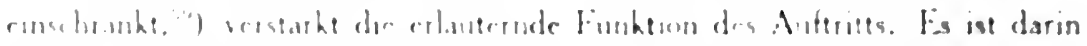

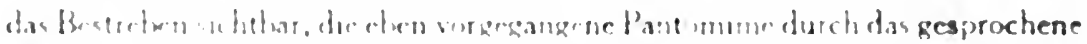

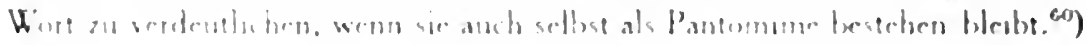

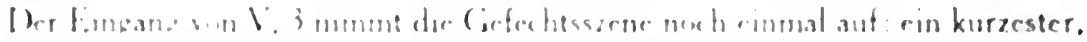

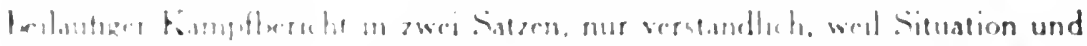

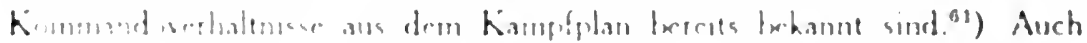

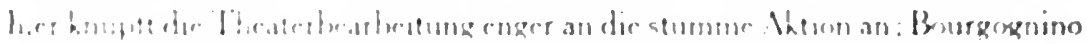

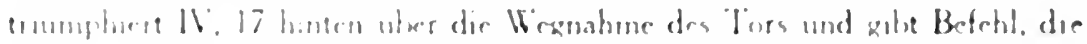

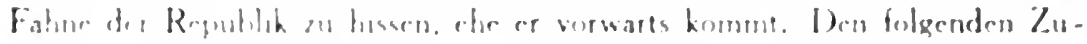

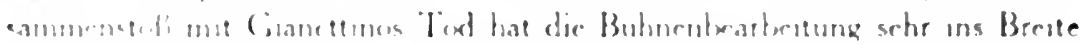

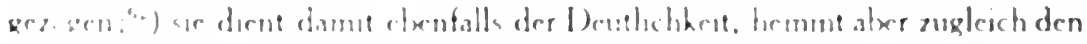

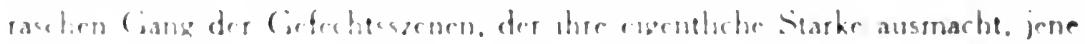

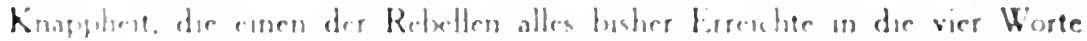

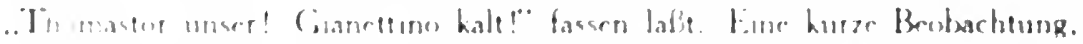

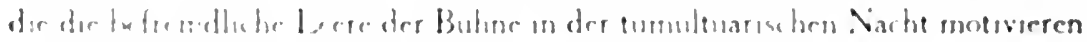

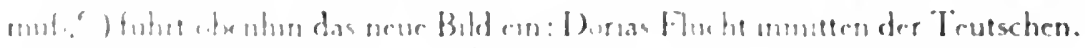

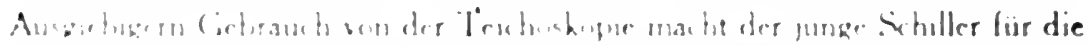

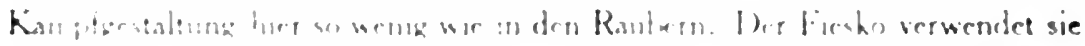

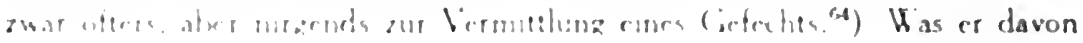

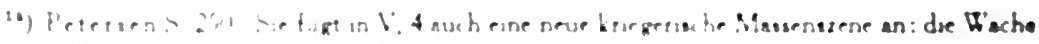

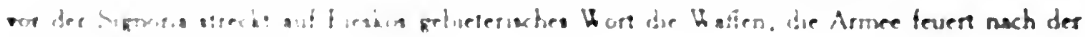
Hukbarom in ise list:

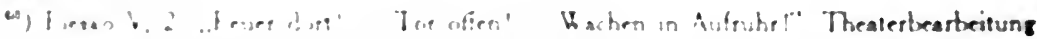

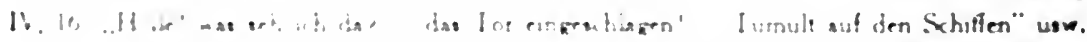

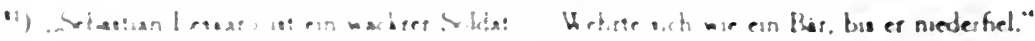

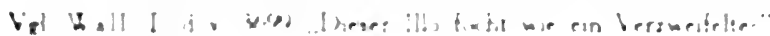

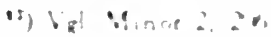

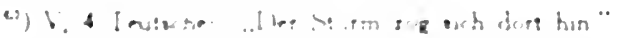

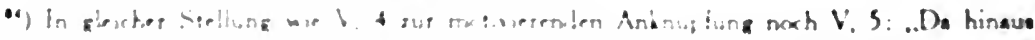

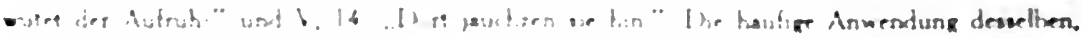

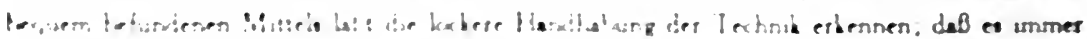


zeigen will, führt er jetzt noch wie Shakespeare unmittelbar vor; hier den kräftigsten seiner Kampfauftritte: das Einhauen der teutschen Bären mit Wort und Schlag.

Nach den drei Etappen des tatsächlichen Geschehens, die dem Plan gemäß verlaufen: Besitznahme des Tors, Abrechnung mit dem jungen und alten Tyrannen, führt Schiller eine Frauenszene in die Kampfhandlung ein. Sie ist Träger der Stimmung der wüsten Aufruhrnacht und gewährt zugleich den Kampfvorgängen hinten Zeit sich auszubreiten. Der Dichter bedarf einer solchen Füllung wie die alte Technik, weil er gegen Shakespeare am einheitlichen Schauplatz festhält; nur daß er die Frauenszene inniger mit dem Männerkampfe verknüpft. Sie steht mitten im Lokal der Kämpfe drin und Leonore greift dann selbst, wenn auch recht anfechtbar, in die Entscheidung der Waffen ein. Der Ausgestaltung der Stimmung dient die verschwenderische Fülle theatralischer Mittel, die auch die dramatisch gewichtigere Verzweiflungsszene Franz Moors aufgeboten hatte. Anschwellende Trommeln, das Wimmem der Glocke vom Turm der Dominikaner, das Sturmläuten von anderen Türmen ${ }^{65}$ ) und endlich der Zusammenklang des ganzen Tumults umschließen die steigende Erregung der Frauen; sie nährt sich aus ihnen, während sie zugleich, technisch betrachtet, allen diesen Geräuschen erst die unheimliche Deutung gibt. Franz Moor verfolgt den Hereinbruch der Katastrophe in atemlosem Horchen; hier erwächst aus derselben akustischen Beobachtung ${ }^{66}$ ) die wilde Kampfphantasie Leonorens, auf trügerisch erlauschtes Getöse gegründet. Sie führt die ihrer Sinne nicht mehr mächtige so körperhaft ins Kampfgewühl wie den Euphaes im lessingischen Kleonnis ${ }^{67}$ ) und schafft der Besorgnis um den Geliebten und damit der Spannung auf das Gefecht leidenschaftlichen Ausdruck.

Nach der gefühlsschweren Frauenszene nimmt die äußere Handlung ihren Fortgang; ein nötig gewordener Bericht über die inzwischen erfolgten Kämpfe

wieder nötig vird, ist ein Beweis für die oben dargelegten Schauplatzverhältnisse. - Unterstreichende Beobachtung von Vorgängen, die dem Zuschauer selbst sichtbar sind, V, 2 u. 4 (,,Mörder dort! "); ein Auflauf, wie häufig, vom Fenster beobachtet II, 4.

65) Vgl. Petersen S. 210.

${ }^{66)}$ Gespanntes Horchen auf Waffengeräusch auch IV, 3; Hinweis auf das kriegerische Getöse IV, 11 u. 14.

${ }^{67)}$ Gedruckt erst nach dem Fiesko, in 2. Teil des Theatralischen Nachlasses 1786. Vgl. Fiesko IV, 14 (S. $272_{3}$ ), wo Leonore schon ähnlich düster phantasiert; dort beherrscht die Kugel, hier die gähnenden Rohre ihren Wahn. In Shakespeares Coriolan I, 3 versetzt sich die Mutter des Helden im Geiste aus Rom zu Coriolan in die Schlıcht: ,Mir däucht, ich hör hier eures Catten Trommel" usw. und glaubt ihn bei der Kampfarbeit zu sehen: die angstvolle Gattin erträgt ihre gefaBte Ruhe nicht. 
wird gewandt in die Begegnung Saccos und Kalkagnos autgelöst. ${ }^{68}$ ) Dic beiden tauschen ihr Wissen über die Lage aus: Doria ist entkommen, sonst steht es gut. Motive aus dem Götz ${ }^{69}$ ) treten episodisch locker zum Abschluß der Laufbahn des Mohren ein; das lichtscheue Gesindel Genuas treibt in der Verwirrung der Mordnacht sein Wesen und legt Feuer in die Kirchen - neben dem besondern Handlungszweck eine gute Bereicherung des Bildes. Damit geht die Kampfhandlung zu Ende: ihr abschließendes Ergebnis ist die V, 12 dargebrachte Huldigung von Landmacht und Seemacht, von Stadt und Rat. Sie hebt Fiesko auf den Cipfel des Erfolgs, nachdem er schon in verhängnisvoller Verblendung den falschen Gianettino durchbohrt hat, und dient jetzt zur Folie eines tiefen Falls.

Für die nicht allzu sorgfältige technische Durchbildung der Kampfszenenreihe, die wir durchgängig beobachteten, ist noch ein Umstand beweiskräftig. Als Zcichen zum Losschlagen dient den Verschworenen ein Kanonenschuß. den Verrina im Hafen lösen soll, wenn die Schiffe crobert sind. Diesen Signalschuß gibt Schiller um des theatralischen Effekts willen sehr unbekümmert doppelt. ${ }^{70}$ ) Er ruft am Ende des vierten Aufzugs Fiesko aus den Armen Leonorens in den Kampf; der Anfang des fünften Aktes greift aber über diesen Augenblick zurück: Genua liegt noch im tiefen Frieden da, Rund und Patrouille durchschreiten wie in Zeiten guter Ordnung die wohlverwahrte Stadt, und das Getümmel bricht mit gewolltem Kontrast dazu erst nach der Warnerszene los. Der Kanonenschuß selbst ist, wie zu erwarten, nicht zum zweiten Mal ausdrücklich vorgeschrieben, aber er muß an dieser Stelle ertönen; Lomellin spricht $\mathrm{V}, 2$ von ihm.

Starker Einfluß Shakespeares ist in der Behandlung der kriegerischen Dinge im Fiesko überall zu bemerken; er tritt am unmittelbarsten in dem Halbakt im Hof (IV, 1-8) zutage, mit dem sich Schiller in die Reihe der Posten-

c) V. 6; der Ausdruck ist hier sehr gedrängt: "Auf der Burg, hör ich. fechten sic scharf" (vgl. oben Anm. "1) und bildkrätig: .Verrina - liegt zwischen Genua und dem Meer wie der böllische Keltenhund".

09) Fieskos scharte, eine wichrige Zwischenmeldung überhörende Frage V, 9 .. W'er wart das Feuer ein? - Wollen sie mich zum Mordbrenner machen?" nach Cötzens (DjG 3. 268-69) stra!endem ..die Mordbrenner!... Wer verbrannte Miltenberg?" in drängender Situation. Vgl. Minor 2, 33. - In der Szene V. 8 taucht (Bourgognino) plöłzlich Georgs blauer Busch auf (Boxberger. DNL 120, 319 Anm.). Des Mohren knappe Erzihlung vom Erlegen des Expiessen III. 4: "Baff. liegt der Marder - wir haben das Huhn" erinnert an Lerses sichern SchuB: .D. liegt der Spatz" (DjG 3. 243). - Fiesko IV, 9 nach $D_{j} C^{2} 3.252-53$.

${ }^{50}$ IV. 10, 1gl. IV. 13 Ende: IV. 14 u. 15: V. I u. 2. Pelersen S. 124 erkiart den auffallenden Umstand zurammen mil einigen anderen Stellen Iriftig als Rückfall is den Erzhhlungstil. 
szenen stellt, die insbesondere vom Hamlet herführt. $\left.{ }^{i}\right)$ Die Situation, den von Waffen und Bewaffneten erfüllten Hof, in den jedermann herein, niemand hinaus darf, gab der Kardinal Retz. ${ }^{72}$ ) Der sichtlich liebevollen, eingehenden Gestaltung kam neben dem Hamlet die eigene militärische Kenntnis des Dichters zugute. Die soldatische Knappheit, die auch vielfach in den Kampfszenen herrscht, der wortkarge Dienstton der Schildwachen greift in diesen Auftritten auf die sich versammelnden Verschworenen über. Bis zu der ausladenden Ansprache Fieskos wird der Dialog gehackt. Die drohend aufgepflanzten Hellebardiere halten auch die kurzatmigen Sätze in Zucht. Die Vorgänge vollziehen sich in der äußersten militärischen Prägnanz. Bourgognino führt eröffnend vier Doppelposten auf und erteilt ihnen die scharfgeprägte Instruktion, an der nicht eine Silbe zu viel ist. ${ }^{73}$ ) Nach kurzem stummem Patrouillieren tritt der Schildwachapparat in Tätigkeit; sechs Szenen werden durch den gellenden Anruf der Wachen symmetrisch eingefaßt. ${ }^{74}$ ) Sie tun schweigsam und unbewegt ihre Pflicht und weisen alle Fragen verschlossen und mürrisch ab. An ihrer Starrheit schärft sich die Spannung von Szene zu Szene. Eine knappe Steigerung führt von dem ersten Stutzen der betrogenen Gäste in ernste Besorgnis und über magere Trostgründe und den Galgenhumor, womit die schon in der Falle Sitzenden ahnungslose Genossen folgen sehen, in beklemmende Furcht hinein. Ein Griff zum Schwert erweist sich gegen die wohlbewehrten Kriegsleute, die diesmal ihrer Order mit Heftigkeit Geltung verschaffen, als aussichtslos.

Der straffe Aufbau gehört Schiller zu eigen; von Shakespeare befruchtet ist das Motivische, besonders die unheimliche Stimmung, die auch über dieser nächtlichen Postenszene, wie über der Terrassenszene des Hamlet liegt. In der ganzen reichen Tradition der Schildwachauftritte führt die Verbindung des soldatischen Vorgangs mit einem bedeutenden Stimmungsgehalt

71) Andere Einflüsse des Hamlet bei E. Schmidt, Säkularausg. 3, 446 u. 47; vgl. Minor 2, 47. An die Nachtwache von Helsingör erinnert später auch der Bericht vom Vorbeischreiten des Geistes Kaiser Karls an den Posten im Königl. Palast zu Madrid, mit den Fragen nach Gestalt und Gewand, Don Carlos V, 9.

72) Minor 2, 51 .

${ }^{73}$ ) Der Bemängelung Düntzers (Erläut. Nr. 7/8, 2. Aufl. S. 185), sie betreffe nur die Posten am Tor, nicht die am Schloß, ist entgegenzuhalten, daß als Ausgänge aus dem Hof sowohl das Tor ins Freie als die Pforten ins Schloß zu gelten haben. So, vom Standpunkt des Hofes aus gefaßt, gilt der Schildwachbefehl für alle.

79) „Wer da?" solange das Tor offen, „Wer draußen?" seit es geschlossen; ferner dreimal das „Zurück" der Schloßposten, einmal das der Torposten. - Anrufe auch in den Kampfszenen V,3 u. V, 5. Ein Posten in der Galerie, über den die Frauen zusammenschrecken - sein Wer da? führt den neuen Auftritt ein - IV, 11. 
immer wieder auf Shakespeare zurück. Äußere Kennzeichen seiner Einwirkung finden sich auch in Schillers, dic Mitstrebenden überragender Formung: die grimune Kältc. ${ }^{73}$ ) unmittelbar daneben wie im Hamlet die Frage nach der Uhr. dic Antworten auf den Postenanruf. ${ }^{76}$ ) Dic Bühnenbearbeitung des Fiesko mußte, um cinen schwierigen Dekorationswechsel einzusparen, ${ }^{77}$ ) mit den Szenen grausam verfahren; sic fielen dem einheitlichen Schauplatz durch den ganzen Akt fast völlig zum Opfer. Die Nobili befinden sich bei Öffnung der Szene schon im Hof. Das Tatsächliche der Auftritte, der Schildwachbefehl und anderes ist zwar in den Dialog Bourgogninos und Verrinas cingearbeitet, aber ihre dramatische Kraft und ihr Stimmungszauber ist verloren.

Der Fiesko gab Schiller ncuerdings Gelegenheit, den Mietsoldaten zu zeichnen. Er sieht ihn hier, auf historischem Boden, anders als in den Räubern, wo es um die militärische Verfassung der eigenen Zeit gegangen war; über die Forderungen seiner Handlung hinaus idealisiert er das Söldnertum einer vergangenen Epoche. Die Teutschen Dorias setzen mit ihrer ehrlichen Einfalt und handfesten Tapferkeit ihre Knochen ohne Umstände an zchn Kreuzer. Sie haben durchaus das söldnerische point d'honneur: ..Wofür mich einer kauft, das muß ich sein", und messen, dem Brotherrn mit Leib und Leben eigen, weder ihre teutschen Hiebe noch ihre Treue nach dem Sold aus würdigste Repräsentanten des Landsknechtstums des 16. Jahrhunderts. Schiller verweilt bei ihnen mit deutlicher Freude. Er macht sie zu Trägern der spezifisch soldatischen Tüchtigkeit im Stück und läßt nie cinen der Grimmbärte auftreten, ohne ihrem Charakterbild einen Zug hinzuzufügen. Die Erscheinung dieser Söldner hat an Geschlossenheit gegen diejenige der kampffrohen Räuber gewonnen, weil Schiller den realistischen Boden um keiner pathetischen Wirkung willen mehr verläßt und ihre Sonderexistenz von eigenen kriegerischen Idealen loslöst; er zeigt sie auch in ihrer Beschränkung, durch komische Züge. Die volle körperliche Rundung ihres Bildes wird erreicht, indem er die Fremdlinge nach der leiblichen und geistigen Seite wirksan vom italienischen Wesen abhebt. $\left.{ }^{i 8}\right)$ Wir sehen den einen wacker und ohne Wank seine Pflicht im Melden tun (III, II), zum Dank aber einen ..tcutschen Ochsen" einheimsen; eine

is) IV. 3 Zenturione: .P Puh! Es ist grimmkalt": IV. 4 Zibo: „Ubrige Hitze hab ich nicht”. Die Hofversammlung findet geschichlich in einer Janusmacht statt.

ie) .Freund von Lavagna" IV. 2 u. 3; .Freund von Fiesko" IV. 4: .Freunde vom Hause" IV. 5. Hamlet 1. 1: .Freund dieses Bodens". Die rasche Wechselsede und das stufenweise. Fintreten neuangerufener Personen erinnert überhaunt an den Eingang der Shakespeare-Szene (don dreimul).

$\left.{ }^{7}\right)$ Vel. Minor 2. 199 u. Pelersen S. 166-67.

75) Vyl. Minor 2.64. 
Patrouille in guter dienstlicher Haltung den schwarzen Halunken abliefern (IV, 8), aber dickfellig für das, was außerhalb des zuverlässig vollzogenen Auftrags liegt, nicht Aug' noch Ohr brauchen. Dafür bewährt sich ihre feste Art in der Gefahr, die sie in Gleichmut und starkem Vertrauen auf ihre wehrhafte Kraft findet, und sie erfüllen ihre Söldnerpflicht zum eigenen Erstaunen der genuesischen Aufrührer (V, 4 u. 6). Neben dieser würdigen Auffassung der Soldtruppen blickt eine ähnliche Vorstellung vom korrumpierten stehenden Heer, wie sie in den Räubern herrscht, nur einmal durch: die unter der Führung des Mohren wiedererstandene Kompagnie Spiegelbergs hat ihre Vögel auch unter der Garnison Genuas (III, 4), und diese Kreaturen Hassans sollen unter die Torwachen gemischt die Sinne ihrer Kameraden unter Wein setzen. Aber auch soldatische Werte klingen aus den Räubern nach. Die Gefolgstreue der Landsknechte ist derjenigen von Moors Bande verwandt. Der militärische Sinn Schillers schafft wiederum ein schroffes Disziplinverhältnis. ${ }^{79}$ ) Fiesko beugt den starren Nacken Verrinas, der mit einer soldatisch undenkbaren reservatio seinen Befehlen nur folgen will, so gewiß sie die besten sind, unter das Wörtchen unter der Fahne: Subordination (III, 5 u. 6). Die Soldatentugend heißt dem Alten zwar knechtisch, aber er will sie um eines freien Lebens willen für ein paar Stunden üben. In solcher Schärfung der Disziplinfrage verleugnet der Fiesko seinen militärischen Dichter nicht, so wenig wie in dem soldatischen Gehalt der Postenszenen und in der Darstellung des Söldnertums; er ist dadurch im ganzen bedeutender als nach der kampftechnischen Seite hin. Der Angehörige der Armee wäre übrigens allein aus dem reichen militärischen Wortschatz ${ }^{80}$ ) zu erkennen.

79) Die Parallele zieht bereits Minor 2, 32 u. 37.

80) Minor 2, 66 zum kriegerisch-nautischen Wortschatz; einiges zum militärischen, nur soweit es außerhalb der kriegerischen Handiung steht, wo die Kunstwörter sich der Sache nach einstellen müssen (z. B. Fiesko III, 5 visitieren, Rapport machen, Parole usw.) sei hier aus allen drei Jugenddramen zusammengestellt. 'Stürmen: Räuber II, 1 (Werke 2, 52 ), ,So fall ich, Streich auf Streich, Sturm auf Sturm, dieses zerbrechliche Leben an"; etwas durchgeführter III, 1 (S. $91_{20}$ ) „dein jungfräuliches Bette mit Sturm ersteigen" usw. Festungsbelagerung als erotisches Gleichnis ausgesponnen Fiesko IV, $12\left(2,268_{1}\right)$; später als galantes symbolisches Turnier geschildert Maria Stuart Il, I. Minenkrieg: Kabale u. Liebe II, 3 Ende: „Ich laß' alle Minen sprengen“; III, I $\left(2,357_{29}\right)$,die nämliche Nacht, wo die große Mine losgehen und den guten Mann in die Luft blasen sollte". Artilleristisches: K. u. L. III, 4 (S. $365_{29}$ ) „Mein Vater wird alle Geschütze gegen uns richten“. Führung: K. u. L. III, I (S. 358 $)$ : Gleichnis vom klugen General. Befehl: Fiesko III, 7 (S. 248 ${ }_{23}$ ); „Itzt, alter Doria, steht mir deine Haut zu Befehl“". Fechten: Fiesko V, 13 (S. 288 19 ): ,und ich das Stichblatt des unendlichen Bubenstücks"; IV, 12 (S. 268 8 ): "für dieses wehrlose Stichblatt fechten"; im unterdrückten 2. Bogen der Räuber (I, 2; nach Weltrich 1, 358): ,den Allmächtigen vor seine Klinge fordern". - Militärischen Ursprungs scheint 
auch Spiegelbergs Redensart (II, 3 S. $71_{3}$ ): .. Will Er itzt gleich den Zopf hinautschlagen und mit mir zum Teufel gehn?", die das DW/b nicht recht befriedigend erklär. - Knappste und kraftigate kriegerische Bildhaftigkeit an zwei Stellen in Fiesko: IV. 9 (S. 264 10 )..Der alte achwächliche Mann schlägt nit vier Zeilen dritthalbtausend Mann". - V. 14 (S. 291 4 ) auf Dorias Vervicherung. der Himmel liege in der Wagachale seiner Sache, die skeptische Antwort Lomellins: „Seitdem das Pulver erfunden ist. kampieren die Engel nicht mehr" - ein übersaschend straffes Bild. dessen Sinn aber Säkularausg. 3, 450 augenscheinlich nicht getroffen wird: vor der unerbittlichen neuen Waffentechnik bestehen die unmittelbar in den Kampl eingreifenden höhern Mächte einer früheren, gläubigen Zeit niche mehr; das moderne Schlachtfeld hat für Engel keinen Raum. Der Gegensatz ist durch die Vorstellung. daB ein Engelheer, aus dem Kindesalter der Menschheit stammend, wie ein zeitgenössisches Bataillon Biwak bexiehen soll. schlagend gegeben. 


\title{
Dritter Abschnitt.
}

\section{Die Verfestigung der Form. Stildrama, Kampftheatralik und Theatralsatire.}

\author{
Achtes Kapitel \\ Klingers Reife.
}

Indessen Schiller sich mit Kabale und Liebe dem bürgerlichen Trauerspiel zuwendet und darauf mit dem Don Carlos neue Wege einschlägt, sieht sich derjenige unter den Stürmern und Drängern, der in der freien Kampftechnik am weitesten gegangen war, Klinger in seinem Hohenstaufenstück ,Konradin ", 1) vor eine Schlachtaufgabe großen Stils gestellt. Es ist von höchstem Interesse zu verfolgen, wie er, der im „Otto“ keinerlei Schranken gekannt hatte, sich jetzt mit ihr in einer Weise abfindet, die auch dem Fiesko gegenüber als Bändigung erscheint. Die Schlacht in der palentinischen Ebene, ${ }^{2}$ ) bei Tagliacozzo, besser Alba aus dem Jahr 1268 füllt den ersten Akt des Dramas. Seine Exposition setzt im Lager des Hohenstaufen prägnant ein: „Die zwei Heere liegen einander so nahe, daß sie sich ohne Gefecht nicht mehr trennen können. Jeder Augenblíck kann entscheidend sein." ${ }^{3}$ ) In die drängende Lage tritt ähnlich den Räubern eine große Unterhandlungsszene retardierend ein. Der Legat des Papstes macht vor dem Zusammenstoß, freilich würdiger als dort der Pater, einen letzten Versuch, den „Aufrührer" Konradin zur Umkehr zu bewegen; da dies nicht gelingt, wenigstens die militärische Lage Karls von Anjou für das bevórstehende Treffen zu bessern, indem er den Deutschen den in Aussicht stehenden sarazenischen Zuzug verleidet. Die Szene leistet dramatisch viel. Die feindlichen Mächte sind damit fest umrissen und schon vor der Schlacht bedeutsam zusammengestoßen.

1) Geschrieben 1784. Kein Einzeldruck; Erstdruck im 1. Bande des „Theaters“, Riga 1786: erschienen wahrscheinlich im Herbst 1785 (Rie ger 2, 72); benutzt in Werke 1, Königsberg 1815.

3) Vgl. K. Hampe, Gesch. Konradins von Hohenst., Innsbruck 1894, S. $286 \mathrm{ff.}$

3) Dieselbe entscheidungsschwangere Situation fast wörtlich später in poetischer Sprache bei Schiller, nicht am Stück-, sondern am Aktanfang, Jungfrau v. 3063: „Die beiden Heere stehen sich so nah, / DaB nur der W'ald sie trennt, und jede Stunde / Kann es sich blutig fürchterlich entleden". 
Der Kricgsrat der Deutschen (I, 5) entschließt sich zum Schlagen. Klingers soldatischer Sinn weiß aus der Schlachtberatung einen frischen, bewegten Auftritt zu gewinnen. obwohl sie im ganzen, weil sich notwendigerweise tatsächliche Erörterungen einstellen müssen, kein günstiger Vorwurf ist. ${ }^{4}$ ) Er läßt die Meinungen aufeinandertreffen und just denjenigen unter den Führern. dessen Temperament es am wenigsten ansteht, zum Aufschub raten: der heißblütige Heinrich von Kastilien will seine sarazenischen Reitervölker abwarten, Fricdrich von Osterreich dagegen die augenblickliche starke Úberlegenheit mit raschem Griff niitzen. Konradins entscheidende Stimme stellt sich auf dessen Seite, umso eher als die deutschen Herren insgesamt der Hilfe der Ungläubigen lieber entraten woilen. Jetzt bricht sich mit trefflicher Wendung, angesichts der nahen Schlacht. Heinrichs wilde Kampflust Bahn, vorher durch seine, wie er glaubte, bessere Einsicht zurückgedämmt. Er ist der erste, der in die Fanfare stößt, und er verherrlicht mit cinem dem Soldaten Klinger aus dem Herzen strömenden Wort den Angriff als die sieghafte Kriegsform: .Greift zuerst an, es ist in der Natur des Menschen, da $B$ der Angriff unser Herz erhebt, während er dem Feinde das Gefühl unsrer Uherlegenheit auf-

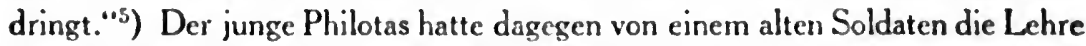
hören müssen: „Der Angriff ist kein Wettrennen; nicht der, welcher zuerst,

4) Das abschreckendste Beispiel liefen Klopstock in Hermann u. die Fürsten, worin die Beratung des Kamples allerdings an drei Viertel des Stücks einnimmt; vgl. Muncker S. 399. Das große Vorbild der Kriegsrat-Szenen ist Shakespeares nächtliche Beratung vor der philippischen Schlacht. Jul. Cäsar IV, 3, wo Brutus des Cassius Meinung, der ihm schließlich beistimmt, beiseite schiebt: Streit sozusagen als dramatische Notwendigkeit auch in der Beratung I Heinrich IV: IV.3, wogegen in II Heinrich IV: I. 3 eine Meinungsverschiedenheit nur leise angedeutet wird. Die größte dramatische Kraft wohnt dern Entschluß des Antonius zur See zu fechten inne (Ant. u. Cleop. III, 7), da sich mit ihm der Feldherrnwille gegen allen Rat der Unterführer und Soldaten durchsetzt.

$\left.{ }^{3}\right)$ Dieser Satz von dem .stolzen Vorrecht der Initiative”. der allenfalls auch in einem taktischen Lehrbuch stehen könnte, tritt hier in der Dichtung früh auf. Die ganz entsprechende moderne Auffassung s. bei v. Bernhardi, Vom heutigen Kriege, Berlin 1912, 2. 24 u. 26. - Der den Stürmern und Drängern vertraute Plutarch erzählt im Leben des Pompejus, cap. 69, wie Cäsar an ihm mißbilligte, daß er bei Pharsalus den gegnerischen Angriff stehenden Fußes abgewartet und damit sich zugleich der Stoßkraft und der moralischen C'berlegenheit des Angriffe begeben habe. Lenz äußert sich in den ..Soldatenehen“" zu der Frage mehrfach, aber kraus. Im Anschluß an seinen französischen taktischen Gewährsmann (Guibert) billigt er zwar dem Angreifer (S. 14) C'berlegenheit zu, sieht aber. indem er taktischen Angriff und strategische Offensive und zugleich noch politische Verhältnisse mitcinander vermengt. die eigentliche Aufgabe des Soldaten (S. 13-14) darin. Verteidiger (nämlich des Vaterlandes) zu sein. Er streift an das Groteske, wenn er S. 40 nicht weit davon blejbt, die gunstige Wirkung seiner Soldatenehen unmittelbar auf das feste Trithalten beim Angriff zu beziehen. 
sondern welcher zum sichersten auf den Feind trifft, hat sich dem Siege genähert" - bedächtiges Maßhalten gegen stürmerisches Sichauswirken auch hierin. Man meint fast, den Impetus der Revolutionsheere gegen streng exerzierte Kampflinien anlaufen zu hören. Nur daß Klinger selbst, bei allem ungebärdigen Toben des Kastiliers, jetzt anders als im „Otto “ die Führung in der Hand behält: Konradin fragt den Hitzigen, der nach Knappe, Pferd und Waffen schreit, mit guter Ironie „Seid ihr fertig?", um mit dem Schlachtbefehl zu beginnen.

Der taktische Verlauf der Umgehungsschlacht wird freilich trotz ordnendem Befehl, trotz einem vorhergehenden Gegenvorschlag Heinrichs und der nachfolgenden, ausführlichen Schilderung nicht greifbar. Klinger spart zwar nicht an Worten, die das Gelände und die Truppenstellung beschreiben sollen, aber er dringt zu einer klaren Anschauun davon auch jetzt nicht durch. Sein Ziel ist deutlich nicht zunächst die sachliche Deutlichkeit, die später bei der Fehrbelliner Schlacht Kleists - sie gibt zu dieser klingerischen eine Fülle von Vergleichspunkten an die Hand - die feste Grundlage für alles weitere bildet, sondern das leidenschaftliche Leben der Vorgänge. Ein Rest seiner stürmerischen Unbedachtsamkeit läßt ihn die realen Voraussetzungen geringschätzen. Er nutzt zwar die historischen Motive der Schlacht überall, aber sie ist aus ihm allein nicht aufzubauen. Wir erfahren, daß ein Fluß zwischen den Heeren liegt, daß man um eine Brücke ficht, welche die Franzosen halten, wir hören dann, daß der Kastilier das Wasser mit seinen spanischen Reitern kühn durchsetzt und von ihm abgesandte Haufen ,gegen den Ursprung des Flusses"6) Furten finden. Aber der entscheidende Charakter dieser Umgehungsaktion ist nicht herausgearbeitet, sie geht beiläufig unter anderm als das Werk des Augenblicks vor und entspricht keinem Plan, wie der Kampfbefehl Konradins die Cruppierung seiner Streitmacht überhaupt nur obenhin vornimmt; so werden auch die beiden Treffen Karls von Anjou nicht unterschieden. Die mit der größten Präzision ins Werk gesetzte Umgehung des Obristen Hennings bei Kleist sticht von solchem Verfahren scharf ab; sie ist erfunden, diejenige Klingers historisch.

Über das nötige Material an Tatsachen ohne Liebe und Eindringlichkeit wegeilend, legt der Konradindichter den Nachdruck der Szenenreihe, die zur Schlacht hinführt, auf die Stimmung. Wir erkennen den Dichter des PyrrhusFragments und den Schüler Shakespeares zugleich daran, daß er den nahenden Waffengang im Gefühlsmäßigen auffängt und die Schlachtentscheidung von der ersten Szene an auf diesem Wege vordeutet. Der Auftritt des Eingangs

6) Nach der Geschichte setzt Heinrich von Kastilien weiter unten, wo der Gießbach flachufrig ist, über. - Die Stellen bei Klinger I, 5, Werke 1, 285; 287; I, 6, S. 290. 
gehört bezeichnenderweise der königlichen Mutter, die ein Ritter Hurneis aus dem Bereich der Gefahr in Sicherheit bringen soll. Ein zufäliges Wort des Vasallen fältt schwer in ihre sorgenvolle Brust; die düstere Prophezeiung. womit der Legat scheidend die frische Zuversicht der Gegner lähmen will, schmettert sie nieder. Doch ist sie schließlich Weib, dem Bangigkeit in so schwerer Stunde zusteht. Aber Klinger wirft die Schatten auch auf den jungen Helden selbst. Der Kummer der Mutter schwindet plötzlich vor den Wolken auf sciner Stirn, die sie ihrerseits zu verscheuchen strebt; scin Abschied von ihr ist zu leidenschaftlich, um durch die äußerliche Zuversicht nicht trübes Ahnen durchscheinen zu lassen $(I, 4)$, und als sic geht, versinkt er in ein verlorenes Nachblicken. Friedrich von Osterreich, der ihn aufrichten will, ist nicht minder ergriffen. Aher mit scharfem Ruck faßt sich dieser Konradin auch wiederum soldatisch zusammen, als ihm die Führer zum Rat gemeldet werden: .Ich bin da."

Die Empfindung übermannt den unstoischen Heldenjüngling wie einen klcistischen Hermann ${ }^{7}$ ) noch einmal in der Stunde der Entscheidung. Klinger schließt die Szene, nachdem der Schlachtruf gegeben ist, nicht nach der stehenden Sitte der Kampfabgänge mit dem mutigen Trompetensignal, er bricht die Stimmung, läßt den Helden mit dem Freund verweilen und den Augenblick. da das Los geworfen ist - nur solche Tage seien des Lebens wert - in vollen Zügen auskosten. Mit der Erinnerung an die Mutter umflort sich seine Stime. ${ }^{8}$ )

Die ungebärdige, tolle Kampflust der Jugendhelden Klingers ist von diesem Konradin, unbeschadet seiner tiefen Freude am männlichen Waffenhandwerk. gewichen. Der Dichter hat sie in eine Figur zweiter Linie, den kastilischen Brausekopf gelegt: der liebt solche Stunden anhebender Schlacht ohne Gedankenschwere aus der reiterlichen Lust am Einhauen heraus. Bei allem Anteil, den ihm Klinger schenkt ${ }^{9}$ ) - Heinrich von Kastilien verkörpert als siegreicher Draufgänger die eine Seite des Soldatentums - ist doch nicht zu verkennen, da $B$ er den kriegerischen Kraftmann, der ihn in der Frühzeit ganz erfültt hätte. jetzt objektiver sieht. Das soldatische Ideal hat sich verfestigt. Es besteht nicht mehr in der ziellos ausschweifenden, sondern in der gebändigten Kraft. Klinger läßt seinen wilden Halbsarazenen zwar noch mit unverhohlener Sympathie

5) Dre Auffassung des Heldis-hen hal sich gegenüber dem frühern Klinger sehr bedeutend gewandelt, und Beziehungen zu Kleist sind offenbar. Der feinnervige Konradin dunchlebe im Kerker den animalischen Schauer vor der Vernichtung wie Homburg und meditiert darüber. warum er in der Schlache, aber nichi hier dem Tod ins Auge blicken konnte.

") 1. 5. S. 288. Vgl. des Brutus entscheidunguschweres .O wüBte jemand doch / Das Ende dieses Tagwerks -" bei Philippi. Jul. Cas. V. I.

") V'gl. Rieger 2.64. 
gewähren und die Genossen Nachsicht gegen ihn üben, aber er überschaut die Grenzen seines Wesens und ironisiert ihn gelegentlich leise.

Dieser Mäßigung in der Auffassung des Kriegerischen geht die Mäßigung der Kampftechnik parallel. Klingers ganze Schlacht beansprucht nunmehr nur noch zwei Schauplätze, die eine doppelte Szenenveränderung bedingen. Anfang und Ende des Kampfaktes spielen in Konradins Lager, das Mittelstück auf der Feindesseite. Die Partei wird dann zum zweiten Male gewechselt, ohne daß sich die Szene wandelt: der siegreiche Karl von Anjou dringt schließlich ins hohenstaufische Lager ein. Ein Zusammenstoß der Gegner unmittelbar auf der Bühne hat nicht statt; die Schlacht ist zum größten Teil in strenger Weise durch eine sorgfältig ausgebaute Beobachtungsszene bewältigt. Die historische Schlachtsituation : rückwärtige Reservestellung Karls mit 800 Rittern in waldigem Hügelgelände - wir fanden Verwandtes bei Längenfeld - bot sich dazu an; aber Teichoskopie allein war dem jungen Klinger in der verwandten Sachlage im "Otto" nicht genug gewesen, und er hatte ihr zum Trotz ins Getümmel hineingeführt. Jetzt weiß er sich zu beschränken und erreicht eine dramatisch straffe Anlage; eine erste, bühnenmäßig gespannte Gestaltung der offenen Feldschlacht, die doch dem freien kriegerischen Geist des Gegenstands keinen Zwang antut, wie sie später Schiller in der Jungfrau und Kleist im Homburg mit reiferer Formkunst gelingt. Klopstocks Vorgang in der Schlachtbeobachtung kommt damit neuerdings zu Ehren. ${ }^{10}$ ) Die Entwicklung der Kampftechnik in eine neue Strenge des dramatischen Baus hinein läßt sich am Konradin besonders gut erkennen; denn er steht an ihrem Wendepunkt einzelnes gehört noch der lockeren Kampfführung an - und der frühe Otto desselben Autors macht den unmittelbaren Vergleich möglich. Die abgerissene Guckkastenmanier dort ist einer stetigen Szenenführung gewichen, welche

10) Sein durchgehender EinfluB auf Klinger nimmt in den späten Dramen getragenen Stils noch zu. Nicht nur der Schlachthymnus des Königs Euphaes im „Aristodemos“ weist auf Klopstock (vgl. O. Erdmann, Uber Klingers Sprache u. Stil, Progr., Königsberg 1877, S. 38), auch sein Sterben auf erbeuteten Schilden ist nach Sprache und Auffassung, auch im Gespreizten, Siegmars Ende verwandt. In .Medea auf dem Kaukasos" stammen die Druiden (Rieger 2, 166), wie einzelnes ausweist, unmittelbar von Klopstocks Bardenchor ab. Klingers Oberdruide befeuert die wilden Töne (Werke 2, 287-90) wie derjenige Klopstocks usw. - Im Kampfakt des Kon radin finden sich neben allgemeinern Anklängen an klopstockische Redeweise (z. B. I, 6 , S. 289 auffällig: ,Dieser gedankenvolle Mann ... will es so“) einzelne Reminiszenzen : I, 6, S. 291 „Später Sieg ist auch Sieg“" ; Hermannsschl. 4. Sz., S. 88, Segest : „Spätes Blut ist auch Blut“ und daneben eng verwandtes: I, 6, S. 289, in der Ungeduld aufs Schlagen: , denn ich weiß nicht, was Stillstehen an einem solchen Tage ist"; Hermannsschl. I. Sz., S. 60: ,ich habe noch keine Schlacht in der Ferne gehört". - Die Beobachtungsszenen selbst formt das Temperament Klingers freilich anders, aber Klopstocks Schlachtanlage war vorangegangen und allbekannt. 
großen Steigerungen Raum gibt; dic früher abrupten Leidenschaftsausbrüche ordnen sich ihrem Gang ein. Die Schlacht nach ihrem ganzen Verlauf ist Gegenstand der fester gefügten Darstellung geworden, wenn es auch weder auf Schärfe des historischen, noch überhaupt eines taktischen Bildes ankommt. Endlich greift die dramatische Spannung auch hier, ähnlich wic in den Räubern, in die Kampfgestaltung cin. Wie genau Klinger jetzt mit der Bühne rechnet, zeigt der Umstand, daß er die Verwandlung der Szene nach Konradins Kampfbefehl durch eine „wilde Schlachtmusik" ausfüllt.

Eine buschige Anhöhe, dic Karl mit seiner Reiterreserve besetzt hält, ist das Lokal der Beobachtung. Dic Motivierung dieses entscheidenden Hinterhalts hat sich der Dichter, weil er ihn der Geschichte entnahm, allerdings zu leicht gemacht. Karls eigener Führerwille erscheint in bedenklichem Licht, wenn er dem Legaten mit lässiger Wendung erklärt, daß sein Schwager Flandern es so wolle; wenn spätcrhin dieser Graf von Flandern die jähe Wallung des Königs, der angesichts der Flucht seiner Völker die Reiter einsetzen will, mit überlegener Ruhe, wie wenn er seines gewohnten Amtes waltete, meistert. Der unbekümmerte Anschluß an den historischen Verlauf müßte sich auch vor der Bühne rächen: man würde schwer begreifen, daß die französischen Führer ihre Hauptmacht zuerst schlagen lassen, um erst dann mit einem Rest einzugreifen. Auch auf die Stärkeverhältnisse, die diesem Verfahren zugrundeliegen, legt Klinger kein Gewicht und streift sie früher im Kriegsrat der Deutschen nur beiläufig. Man blickt von hier auf Kleists fehllose Verzahnung derselben Kampfsituation aus, wie cr auf der einen Seite die taktische Lage ins hellste Licht setzt, so daß das Zuwarten von Homburgs Reiterreserve, bis die Umgehung der Schweden sich ausgewirkt hat, nach seiner entscheidenden Bedeutung für den Schlachtverlauf durchsichtig wird; wie er ferner der aufbrausenden Kampflust, die seinen Prinzen wie Klingers König Karl erfaßt, die Schranke durch den eisernen Befehl schafft, der jeden andern im Zaum hielte. Hier, im Widerstand gegenüber dem Toben des Königs, ist Klingers Motivierung am schwächsten: ganz besonders, weil der gefühlsmäßige Grund zum Eingreifen, der draufgängerische Sinn, gegen Kleist noch durch den sachlichen, die Flucht der eigenen Truppen, verstärkt wird, und ein höheres Gebot dem souvcränen Parteiherrn gegenüber nicht zur Verfügung steht. In der Tat empfängt es König Karl freilich doch, eben vom Grafen von Flandern, ${ }^{11}$ ) den der Konradin als cinzige Gegenwirkung, aber ohne rechte Vollmacht zu seiner Aufgabe, einzusetzen hat.

11) DaB Karl schon früher, als seine beiden ersten Treffen ins W'anken kamen, eingreilen wollie, ist geschichilich; der Rat des Ritters Erard von Valery hielt ihn zurück. Klinger zjeht die Figur vereinfachend (Rieger 2, 65) mis Kasls Schwager Flandern zusammen. 
Man erkennt, daß Klinger damit die dramatische Durchbildung der Schlachtaufgabe noch nicht zu Ende führt. Aber bedeutsame Anregungen gibt er für sie. Er erlöst doch schon die Teichoskopie aus der lediglich schildernden, vermittelnden Funktion, die sie im ganzen bei Klopstock und im Götz erfüllt hatte und richtet sie auf ein dramatisches Endziel, ebenso wie Shakespeare in der einen knappen Cassiusszene: das Beobachtete wirkt auf die Bühnenhandlung ein, die sich neben der Teichoskopie behauptet und sich aus ihr nährt. Wogegen die rein epische Form der Mauerschau gewissermaßen darin besteht, daß einer aus den Zuschauern die Bühne ersteigt und für alle andern um die Ecke späht. Schlacht und Flucht der Franzosen bedingen den Entschluß Karls, und daraus erst entspringt eine dramatische Spannung. Die bloß schildernde Beobachtung muß sie aus dem Gegenstand der Schilderung heraus vortäuschen: sie ist epischer Natur. Klinger besetzt die Szene mit dem ungleichen Fürstenpaar und gewinnt aus seinem Widerstreit, der sich an den beobachteten Vorgängen entzündet, die Bühnenhandlung bei währender Schlacht. Er wendet sein kriegerisches Temperament an sie und gibt dem französischen König aus dem Bedürfnis des Augenblicks selbst mehr von der eigenen Kampflust, als seinem Charakterbild ${ }^{12}$ ) entsprechen mag.

Die Aufmerksamkeit richtet sich fast über Gebühr nur auf den Reflex der Teichoskopie, nicht auf die Vorgänge selbst. Die klingerische Nichtachtung der äußeren Tatsachen tritt hier gegen Kleist wiederum scharf zutage. Was beobachtet wird, ${ }^{13}$ ) ist nur das allgemeinste: wildes Gewühl, Gewühl und Streit, schändliche Flucht. Karl antwortet auf das absichtsvoll wiederholte, steigernde „Was seht ihr nun?" Flanderns mit anschwellenden Gefühlsausbrüchen; da seine Krone in der Wagschale liegt, leuchtet der Widerschein der Schlacht von ihm am stärksten. Das wenige Sachliche, das Klinger aus dem Gefechtsverlauf heranzieht, gibt er drei Botschaften anheim, die geschickt in die Steigerung der Teichoskopie eingebaut werden: den Kampf um die Brücke samt der Umgehung durch den Kastilier, den Durchbruch der Flußschranke durch Hohenstaufen, die allgemeine Flucht. Auf ein Bild der Schlacht ist es auch damit nicht abgesehen, wohl aber auf den Eindruck des herein-

$\left.{ }^{12}\right)$ Rieger zeichnet es 2, 68-70.

13) Beobachtung außerdem noch I, 1, S. 266: Bewegung im feindlichen Lager; der ritterliche Konradin an der Spitze seiner Reiterscharen; I, 5, S. 285 kurz zur Zeichnung des Geländes. Natur: II, 4 Ausblick auf Neapel aus dem Gefängnis; IV, 4 Sonnenaufgang am Todesmorgen. Die Naturbeobachtung, die für den jungen Klinger oben S. 97 Anm. ${ }^{33}$ ) verzeichnet ist, erscheint dann am feierlichsten in den beiden Medeen: Sonnenaufgang zu Anfang der ,Medea auf dem Kaukasos" (Werke 2, 248); letzte Ánnufung des reinigenden Urvaters Helios vor dem Sterben das. 2, 313-14; Mond das. 2, 283 u. 285; Sonnenuntergang in ",Medea in Korinth", das. 2, 213, 215; beschwörender Anruf 218; 220. 
brechenden Verhängnisses. ${ }^{10}$ ) Die drängende Eile der Szene erzeugt beim Empfang des einen Boten, wie er bei Shakespeare üblich ist, einen starken Einzelzug $:^{15}$ ) weniger glücklich schleicht sich in ihren AbschluB eine augenscheinliche Reminiszenz an die Räuber ein, die hier nicht wohl passen will. Flandern bezcichnet die Situation, die nunmehr auch er zum Eingreifen reif hält - die Deutschen zerstreuen sich gemäß der Geschichte plündernd mit den Worten, es bleibe ihnen jetzt keine andere Wahl, als zu schlagen; die Flucht böte keine Rettung mehr; dies habe er gewollt ${ }^{16}$ ) - obwohl man nicht einsieht, warum die intakte Reserve nicht so gut Fersengeld geben könnte wic das geschlagene Heer. Daran ist freilich nicht zu denken. Nach einem Schlachtgebet und dem Aufruf an seine Soldaten, den die tapfern Picarder freudig erwidern, zieht Karl in den Kampf.

Das folgende Endstück des Kriegsaktes in Konradins Lager (I, 7-II) nähert sich der Technik des jungen Klinger am meisten. Die Ereignisse entladen sich in kurzen Szenen in gedrängter Fülle und der Dichter hat Mühe. mit dem einen Schauplatz auszukommen. Trotz aller Vordeutung hat Konradin gesiegt. Aber sie behält doch recht. Der Glückwechsel, den die Geschichte bot, wird scharf herausgearbeitet: der Freudenjubel im deutschen Lager endet

${ }^{14)}$ Die Meldungen unterscheiden nicht einmal nach der Seitengliederung, die Konradins Schlachtbefehl vornimmt. Danach liegt die Brücke, die Marschall Cousance deckt und der Kastilier wegnimmt, auf dem rechten französischen Flügel: der Durchbruch Konradins im Zentrum. Wie wenig sich Klinger diese Verhältnisse klarmacht, zeigt der Umstand, daß derselbe Bote, der den letztern berichtet, zugleich auch den Tod Cousances zu schildem weiB als ob er dabei gewesen wäre. - Die geschichelich häufige Verwechslung des Führers im Kampf - hier wird Cousance als vermeinslicher König Karl mit Wut erschlagen - findet sich ötter bei Shakespeare. I Heinrich IV: V, 3 glaube Douglas den König schon zum zweitenmal zu fallen, trift aber erst IY. 5 auf den wirklichen: Richard III. $(V, 4)$ hat schon fünf Richmonds getötet, ehe er den sechsten, echten besteht. Aus dieser Szene tönt übrigens das ..Mein Pferd! Es gilt urn ein Königreich" Karls von Anjou (I, 6, S. 291) herüber; Shakespeare: „Mein Königreich für ein Pfend".

15) 1, 6. S. 292 ..Hast du Zeit zu keuchen, da ein Königreich an deinen Lippen hängt?" Botenemptang bei Shakespeare: I Heinrich IV: III, 2 ,Nun guter Blunt? Dein Blick ist voller Eil." Ant. u. Cleop. V. I .Aus diesem Mann schaut seine Dringlichkeit": II Heinrich IV: I, I .Ja, dieses Manns Stim, wie ein Titelblatt. / Verkündigt eines tragischen Buches Art". Macbeth 1, 2 . Welch dringende Hast ihm aus den Augen schaut" usw. u. V, 5 .Du kommst den Mund zu rühren: "raus damil!" - Parodiert ist die Atemlosigkeit des Boten von Tieck in der Verkehrten Welt (Schriften 5. 4151.), wo Grünhelm die Rebellion zu melden kommt, aber nichts herausbringt: „Mein König, mir fehlt es an Atem”. und Skaramuz ihn zitternd auttordert: .Nun so sprich nur endlich; ich vergeh in der Angat und weiB noch gar nicht, was mir fehlt".

16) 1, 6, S. 293-94. V'gl. Moor 11. 3 ..Ich habe sie vollends einschließen lassen" usw. 
jäh, als die Hiobsposten vom Hereinbrechen des totgeglaubten feindlichen Königs mit frischen Truppen bekannt werden. ${ }^{1 i}$ ) Die damit anhebende Krise der Schlacht ist zugleich diejenige der Kampfgestaltung. Daß man im folgenden, während die Bühne leer bleibt, König Karl und Flandern von innen unter den Deutschen wüten und kein Quartier geben hört, ist schließlich nichts als ein schlecht verhehltes Bühnengefecht; es darf bemerkenswerterweise nicht mehr an die Rampe gelangen, die technische Bewältigung versagt aber darum nicht minder. ${ }^{18}$ ) Das lebendige Theater kann mit einer solchen Szene, worin aus dem Kampfgetümmel heraustönende Befehle und Ratschläge den Verlauf klarmachen sollen, nichts anfangen. Sie steht hier als ein Rest der frühern, ausschweifenden Technik und könnte in der spätern, endgültig verfestigten Form keinen Platz mehr finden; auch nicht bei Klinger selbst, denn er macht die Entwicklung ins strenge Stildrama trotz seiner räumlichen Isolierung in Rußland mit, nur behält er bis zuletzt die Prosa bei.

Nach dem kurzen Zusammenstoß der Gegner außer der Bühne geht der Schlachtakt rasch zu Ende. Klinger hütet sich, seinen prägnanten Umschwung durch genauere Anlehnung an die Geschichte zu stören, wonach Karl nach der Uberwindung des zerstreuten Hohenstaufenheeres erst noch den härtesten Kampf mit dem von der Verfolgung zurückkehrenden Heinrich von Kastilien zu bestehen hatte. Eine kurze Dankesszene, parallel der voreiligen Konradins, und Anordnungen des Siegers, dessen Freude nur durch die Meldung gehemmt wird, daß Hohenstaufen entronnen sei, ${ }^{19}$ ) schließen ab.

Auf die Zwischenstellung des Konradin fällt noch einiges Licht, wenn man ihn neben ein nahezu gleichzeitiges historisches Schauspiel hält, das ebenfalls Kampfaufgaben zu bewältigen hat, des Grafen von Soden „Leben

17) Wie Prinz Heinrich in dieser Lage zum Boten werden und seinen mutigen Kampf gegen die Andringenden berichten kann, statt ihn fortzusetzen, ist eine der Unstimmigkeiten, die sonst in der älteren Kampftechnik zu Hause sind.

${ }^{18}$ ) Lohmeyer S. 83 greift gerade diese Szene des Konradin als Beispiel wenig glücklich heraus. - Die zunehmende Strenge Klingers gegenüber dem, was auf der Bühne gezeigt werden soll, läßt sich auch außerhalb des Kriegerischen verfolgen: In Elfriede V, 2 treibt der König den Ethelwold mit dem Schwert ins Gebüsch und bringt ihn dort um. Dabei wird aber fast durchweg das Bestreben sichtbar, aus dem Verhüllen der Vorgänge eine gesteigerte Wirkung durch die Spannung auf das Ungewisse zu ziehen; so beim Kindermord in der "Medea in Korinth" (Akt IV, Werke 2, 231 f.); beim Mord der Antiope durch ihren Geliebten Kallias im ,Damokles“” (Akt V, das. 2, 443 f); die Kunst der Anordnung solcher Dinge zeigt sich auch bei der Hinrichtung Konradins V, I, wo Vorführung nicht in Frage kommen konnte. Vgl. Petersen S. $358-59$.

19) Flucht und Gefangennahme Konradins und seiner Nächsten erfährt man II, 5 aus ihren wechselseitigen Erzählungen im Gefängnis. 
und Tod Kaiser Heinrichs IV."20) Das Stück mit dem shakespearischen Historientitel gehört dem burschikosen Ton nach in die Reihe der stürmerischen Ritterdramen. Man ist voller Kriegsdurst, ${ }^{21}$ ) spricht dem teutschen Gewächs wacker zu (I, 6; III, I) und schilt sich schon einen Weibermann, wenn man nicht in die Fehde zichen kann, ohne seiner Frau Lebewohl zu sagen (I, 9): kommt es aber nicht zum Dreinschlagen, und ist's bloß cin ränkevoller Pfaffenkrieg. dann kehrt man unwillig wieder heim, die Nachbarn zu klopfen (IV, 2). Der Einklang dieser frisch und liebenswürdig vorgetragenen Auffassung mit derjenigen der führenden Bayern. Törring und Babo, ist offenbar, und ihre Einwirkung deutlich. ${ }^{22}$ ) Daneben scheinen sich Einfliisse, die unmittelbar aus Shakespeare stammen, mit solchen, die durch den Otto Klingers verrmittelt werden, zu kreuzen. Jedenfalls ist der bewaffnete Konflikt des alten und jungen Fürsten mit der Flucht des greisen Vaters vor dem undankbaren Sohn demjenigen Klingers eng verwandt, wenn auch beiden das Lear-Motiv ${ }^{23}$ ) zugrunde liegt.

Die Kampthandlung Sodens besteht in zwei Feldizügen, die Heinrich IV. gegen den aufrührerischen Sohn und Gegenkönig Heinrich V. unternimmt, daneben in einigen kleineren Scharmützeln. ${ }^{24}$ ) Den zweiten Waffengang gewinnt der junge Heinrich fast ohne Schwertstreich mit List, indem er den kaiserlichen Vater - die Durchführung ist plump - durch heuchlerische

30) Dessau 1784. Benutzt nach der Neuen durchaus verbess. [2.1 Auflage, Berlin 1790. Fehlt bei Brahm. Ritt. Vgl. O. Hachtmann. Graf Jul. Heinr. v. Soden als Dramatiker, Göttinger Diss. 1902.

21) Ritter Otto I, 6: „Was soll der Edle, was der Kriegsmann? In vorigen Zeiten hat er seine Knochen gestählt; soll er träge hinterm Ofen liegen und Litancien plerren? Krieg. Krieg. Herr! will der Teutsche."

$\left.{ }^{22}\right)$ Hachtmann geht daraut nicht ein. Soden wird den .Kaspar" vor dem Druck gekannt haben: scine Eingangsszene. Friedrichs von Hohenstaufen Schelten über das Stilliegen zu seiner Frau entspricht derjenigen Törrings vollkommen. Auch andere Motive, wie Kaspars Zom über das Antichambrieten (II, 2) kehren wieder (Soden II, 6). Aus Babos .Ot10" erscheint eine unmittelbare Rerniniszenz: die Worte der Gemahlin Friedrichs I, I: ,ihr kämpft und mordet rastlos, bis euch der Tod den Harnisch abschüttelt" - geben aus Frauenmund das Bekenntnis Ottos: „Ich reite spornstreichs durch mein Leben, bis mich der Tod aus dem Sattel hebt" wieder. Unmittelbar aus Götz scheint die Rüstungs-Mumnerei des jungen Hermann, dem kein Panzer zu schwer ist (1, 4 u. 8) zu fließen (vgl. Hachtmann S. 42), obwohl hier schon vor Soden eine Tradition vorliegt.

23) Nur dieses verfolgt Hachtmann S. $41-42$.

21) II, 7 soll Kaiser Heinrich im W'ald aufgehohen werden: V. 7, bei der Erreltung des Kaisers aus dem Geiängnisturm zu Ingelheim. fallt cin Haufe von König Heinrichs FuBknechten die Fuchtlinge an. 
Reue zur voreiligen Entlassung des Heers bewegt. ${ }^{25}$ ) Damit der Anschlag gelingt, muß freilich dieses Heer (IV, $9 \mathrm{u} .11$ ) nach erhaltener Order in wenigen Minuten völlig zerstoben und unauffindbar vom Erdboden verschwunden sein. Mit dem Abschluß des Treubruchs nähert sich Soden dem Ritterstück besonders deutlich: der Kaiser wird beim Einzug in die Burg Böckelheim, die ihm der Sohn tückisch angewiesen hat, überfallen, vom Gefolge getrennt und gefangen (IV, 12). Soden gewinnt aus dem Kampf am Tor ganz in der Weise der Burgstürme des Ritterdramas eine Pantomime und folgt der Beschränkung Babos, der sich beim Auszug Ottos aus Wittelsbach (Ende IV) mit der Spannung des beinahe ausbrechenden Kampfes begnügt, nicht.

Die gleiche freie Entfaltung der Gefechte zeigt der erste Kriegszug, worin es vor Regensburg zu einer offenen Feldschlacht kommt (III, 1-4). Für sie ist völlig die shakespearische Technik beibehalten. Soden findet sich mit ihr so unbekümmert $\mathrm{ab}$ wie nur immer der junge Klinger im Otto. In die einleitende Rastszene, während man das Lager schlägt, ißt und trinkt, tönt der Alarm; recht ritterlich steht man vom Humpen zum Kampr auf. Im Parteiwechsel bringt ein kurzer Auftritt die feindlichen Führer auf die Bühne, die ihre weichenden Haufen umsonst anfeuern. Schon erscheinen triumphierend die Kaiserlichen wieder und machen der Freude über den Sieg Luft; wiederum nach wenigen Worten kehrt Ulrich von Cosheim, der den Gegnern besonders hartnäckig zusetzte, von der Verfolgung zurück. Das ist die rasche Art des Schlachtabschlusses im „Konradin“, die mit keiner realen Kampfzeit rechnet, nur räumt Soden noch dem Getümmel selbst die Bühne ein. Dagegen nicht mehr die Art des dramatisch streng gebauten Hauptteils der Schlacht bei Tagliacozzo Klingers, die sich von diesem Verfahren scharf abhebt. Zwar kennt Soden die Beobachtung auch, ${ }^{26}$ ) aber er nützt sie für den Kampf selbst in keiner Weise. Es liegt ihm nichts daran, ihn nach seinen Umständen irgendwie deutlich zu machen, obwohl er allem Anschein nach eine größere Gefechtsaktion im Auge hat. Es ist bei ihm vor allem noch nichts von einem Bestreben zu spüren, der Schlacht einen eigentlich dramatischen Zug zu leihen, trotzdem er keineswegs der schlechthin getümmelfrohen Richtung beizählt. Er gibt seine Kriegsbilder noch immer in der abgerissenen Guckkastenmanier, ohne Verknüpfung und ohne Motivierung. Darin kann das Sodensche Stück ${ }^{27}$ )

25) Auf eine tückische Zusage hin entlassen auch die Rebellen bei Shakespeare, II Heinrich IV: IV, 2, ihre Truppen und werden sofort als Hochverräter gefangen gesetzt.

20) Anrücken der Feinde III, 1; das Überlaufen des kaiserlichen Heers zu König Heinrich von einer Anhöhe verfolgt III, 10; kurz II, 7; Natur (Donau): III, 1.

${ }^{27}$ ) In der weitern, umfangreichen Produktion Sodens weist außer dem spätern „Franz von Sickingen“ (1808) einzig die „Kleopatra“" (Erstdruck im 1. Band der Schauspiele, Berlin 1788) eine bedeutendere Kampfhandlung auf, die aber lediglich das shakespearische Vorbild stark ins 
lehren. wie bedeutende Schritte der Konradin zur Verfestigung der Schlachttechnik tut.

Von den späten Dramen Klingers ist der "Aristodemos" ${ }^{\text {"28) }}$ ) ein eigentliches Kampfstück, und darum besonders interessant, weil eine zweite Fassung dic Kampthandlung umformt. Das Trauerspiel verherrlicht in einem antiken, aus Pausanias geschöpften Stoff den Opfersinn und den Tod fürs Vaterland. Dic spartanische Belagerung gibt die Messener in ihrer Bergfeste Ithome dem Hunger und der Entkräftung preis; wie einem Orakel, das zu ihrer Errettung das Blut einer Jungfrau fordert, Genüge geschicht, bildet den Inhalt der Handlung. Der vierte Akt der ursprünglichen Fassung endet nach vollzogenem Opfer mit dem Aufbruch in den Kampf, der fünfte ist der Befreiungsschlacht gewidmet.

Es ist merkwürdig zu sehen, wie derselbe Klinger, der der ungebärdigste unter den Stürmern gewesen war, hier zu einer überstrengen Form des Schlachtaktes zurückkehrt. Der Aristcdemos gibt, anders als die Klassik Schillers, die zu ciner Synthese gelangt, die Ergebnisse der Entwicklung seit Klopstock geradezu preis und bewältigt die Schlacht nach $\mathrm{dem}$ fast unveränderten alten Schema. Eine Frauenszene, worin dic Matronen der unglückscligen Mutter der geopferten Jungfrau Trost spenden, füllt die Zeit bis zur Rückkehr der Kämpfer. Auch die Greise haben an ihr Teil: ihr Sprecher vermittelt das wenige, was vom Kampf hereinragt. ${ }^{29}$ ) Die Beziehung zur Schlacht ist nur locker, und berührt den eigentlichen Gehalt des Auftritts nicht; er kann daher in der zweiten Fassung ohne große Eingriffe aus der Verbindung mit ihr herausgenommen und an eine andere Stelle des Stücks verpflanzt werden. ${ }^{30}$ ) Auf

kurze zieht und den Vergleich mit ihm nicht ertrăgt (vgl. Hachtmann S. 45). Der kriegerische Teil des ..Heinrich" ist unter dem Einfluß des Ritterdramas entschieden frischer geraten. Die Schlacht läuft III, 9 in den AktschluB aus und bricht IV, 6, wo sie sich erneuert, nachdem Anton im Eingang des Akts sich atemholend des Siegs effreut hat, an beliebiger Stelle ab (Szenenwechsel: Kleopatras Palast). Shakespearische Motive regieren bis ins Einzelste, z. B. kehrt der körperliche Augenschmerz, den Enobarbus (III, 8) angesichts der Niederlage zur See empfindet, in Sodens Seeschlacht-Bericht (III, I) als Blindheit wieder, die sich Canidius bei Antons Flucht wünschte.

25) Geschrieben 1787; Erstdruck .Aristodymos" im 1. Teil des „Neuen Theaters", St. Petersburg u. Leipzig 1790; umgearbeitet für die ..Auswahl aus F. M. Klingers Dramat. Werken" Bd. 2, Leiprig 1794: dansch mit geringfügigen Nachbessenungen (vgl. Rieger 2, 511) in den Werken Bd. 2, Königsberg 1815. Vgl. Riegers Analyse 2, 112-18.

m) Er spricht von dem Gewühl der Schlacht, das die im Schmerz stumpfe Mutter nicht zu wecken vermag (Neues Theater 1790.1, 83); horcht auf ihren Larm und deutet eine gute Wendung an S. 86 u. 89, wo er das nahende Siegesgeschrei verkündet.

${ }^{20)}$ In den III. Akt, als Trostszene vor dem unseligen Opfer (Werke 2, 131 f.: vgl. Rieger 2, 190). Auber den Reden des Greises (siehe die vorige Anm.) mubte dabei, als einzig wirksamer 
dramatische Widerspiegelung der Kampfvorgänge auf der Bühne, wie in der Hügelszene des Konradin, geht Klinger nicht mehr aus; selbst ihre unmittelbare Beobachtung bleibt weg. ${ }^{31}$ ) Der Dichter sieht sich infolgedessen genötigt, den gesamten Verlauf des Treffens in der zweiten Hälfte des Aktes, die zugleich mit der Siegeskunde den todwunden König auf die Szene führt, zu erzählen; der Schluß zerfließt ihm damit in epische Breite. Das Motiv, das zu der Schilderung der Ereignisse Anlaß gibt, nachdem der Herold die Taten des Königs ohne weiteres preisend verkündet hat, ist ein Wettstreit um den Lohn der Tapferkeit, den Lorbeer. ${ }^{32}$ ) Auch Klopstock hatte in seinen schleppenden Schlachtausgang einen Zank um die höchste Kampftrophäe, den Legionsadler, eingeflochten (Sz. 13), um dem sinkenden Interesse aufzuhelfen. Ähnlich bewegungslos verläuft jetzt der siegreiche Abschluß Klingers.

Der Dichter selbst hat das sehr wohl gesehen und wirft bei der Umarbeitung die Schlacht im ganzen über Bord. Er verfährt damit, nachdem er sich einmal der alten Form wieder zugewendet, nur folgerecht. Die Schlacht war kein Gegenstand für sie; schon Elias Schlegels Versuch, und alle späteren Bemühungen noch mehr, konnte es erweisen. Die Entwicklung vollendet hier just in Klinger einen Kreislauf. Freilich, das Höhere, das aus ihr hervorgehen soll, wozu der Konradin das Seine beigesteuert hatte, ist damit nicht gefunden; aber immerhin, durch die entschicdene Umkehr zu alten Göttern, auf Grund eines neuen Zurückgreifens auf die Antike, eine geschlossenere Erscheinung gewonnen als sie Klopstocks Übergangswerk aufweist. Der Aristodemos von 1794 begnügt sich mit der Erfassung der Schlacht nach ihrem geistigen Gehalt. Er schließt mit dem getragenen Aufruf des Königs zum Kampf, der in der ersten Fassung den vierten Akt endet. Kein Zweifel, daß in dieser Anordnung die kriegerische Idee, die hier in Frage stand, der Kampf fürs Vaterland, zu stärkerm Ausdruck gelangt, als wenn ihr die sachliche Durchführung in ohnmächtiger Technik nachhinkt. Die Opfertragödie entläßt uns jetzt auf der Höhe des Gefühls, das ihren Verlauf beherrscht: „Herrlich ist's für das Vaterland zu streiten! Herrlich und groß für das Vaterland zu sterben!"

Reflex der Schlacht, der Ausbruch der Mutter (Neues Theater 1, 86): „Ich hasse den Sieg" - den alle wünschen - getilgt werden. Die besorgte Antwort der Matronen auf ihren Einwurf, sie hätten noch Kinder (S. 85): „Vielleicht nicht mehr, vielleicht sind sie für uns in der Schlacht gefallen " wurde durch leichte Wendung aus dem Zusammenhang mit dem Kampf gelöst (Werke 2 . 132): „Das Schwert der Spartaner kann sie noch heute wegmähen."

${ }^{31}$ ) „Wir sahen es von der Höhe“" erklärt der Sprecher, und die Frage, warum die Greise nicht jetzt noch Ausschau halten, statt hier müßig zu stehen, drängt sich nach der streng stilisierten, schlachtfernen Anlage der Szene kaum auf. Ebenso meldet in Akt I (Werke 2, 99) der Bote einen vom Turm wahrgenommenen Vorgang, statt ihn von der Szene aus zu beobachten.

32) Vgl. Rieger 2, 114. 
Der Einwurf, damit sei die Befreiungsschlacht noch nicht gewonnen und es fehle durch die Ungewißheit über ihren Ausgang ein wesentliches Stück der Tragödic. ${ }^{33}$ ) führt uns neuerdings auf die Frage der dramatischen Motivierung der Kampfentscheidung. Das Recht des Dramatikers, Gewinn oder Verlust seiner Schlachten aus geistigen Gründen abzuleiten, wird - sofern die dichterische Begabung nur irgend ausreicht - selbst derjenige gelten lassen müssen, der die moralischen Kräfte für die Realität des Krieges geringer anschlagen wollte. Die im Schlachtausgang wirksamen sittlichen Werte sind eine der wenigen Handhaben, die sich der dramatischen Verzahnung überhaupt bieten; seine sachlich-militärische Herbeiführung kann den Taktiker befriedigen, bleibt aber außerhalb der Wirkungen der Kunst. Niemand wird durch die taktische Motivierung des Teutoburger Siegs durch eingreifende Reserven bei Elias Schlegel mehr überzeugt werden, als durch dic rein geistige der philippischen Niederlage bei Shakespeare; wenn auch die Verbindung beider Elemente in der kleistischen Varusschlacht, wo die entscheidende Macht der sittlichen Urkräfte mit der schärfsten Präzision des äußern militärischen Apparates zusammentritt, den sichersten Eindruck hervorbringt. Aus dem Umstand, daß das moralische Elcment für sich allein genügend Gewicht hat, folgt aber, daß dem Dramatiker schlieflich der Weg offen steht, seine Schlachten nur im Geist zu schlagen. Diesen beschreitet Klinger mit dem zweiten Aristodemos und liefert damit in einer ganz anderen Formenwelt cin Gegenstück zu dem Verfahren Schillers bei der Räuberschlacht. Hier kommt es wesentlich auf die poetische Kraft an. Der Dichter muß uns an seinen Helden und seine auserlesene Schar glauben machen. ${ }^{34}$ ) Das gelingt bei den Räubern - wir könnten uns nicht denken, daß sie unterliegen, auch wenn das Treffen am Schluß des Stückes stünde - und cbenso bei den Messenern. Die gewaltige Erhebung, die Hermionens Opfer in ihnen wirkt, verbiirgt den Sieg in voraus: „Furchtbar ist das Volk, dessen Töchter fürs Vaterland sterben". Wir zweifeln nicht, der ,ungerechte Spartaner" wird in scinem Eroberungsfeldzug vor dem sittlichen Impetus des in seinen Tiefen ergriffenen Heldenhaufens weichen müssen. Darin, daß er diesen Eindruck erreicht, verleugnet der "Aristodemos" trotz seiner Formverwandtschaft mit dem vorgoethischen Kampldrama die neue Kriegserfassung nicht, die mit dem Sturm und Drang angebrochen

23) Rieger 2, 190 .

34) Für den Einzelfall von Kleists Guiskard handelt darüber trefflich Sp. Wukadinowič. Kleist-Studien. Stullgart u. Berlin 1904. S. 113: .Eine bloBe logische Iman würde vielleicht besser sagen: kunstlogischel Erwägung sagt uns. daB ein Mann wie Guiskard, wenn er stürmt. auch siegen muß... Eine solche Heldengestalt kann und wird zwar einem übermenschlichen Gegner, der Seuche erliegen, aber nie wird ein entscheidender Angriff, den er unternimmt, zurückgeschlagen werden." 
war. Der alten Zeit hätte die Überzeugungskraft nicht zu Gebote gestanden, weil ihr die Leidenschaft für den Krieg fehlte; jetzt wird diese auch der äußern Beschränkung Herr, und Klingers streitbarer Sinn macht sich in der wuchtigen Kampfrede des Königs, ${ }^{35}$ ) worin die Stellen aus Tyrtäus zu entbehren wären, nicht minder geltend als in der Frühzeit. Die wilde Jugendlust an Kampf und Schlacht ist einer ethisch gegründeten Kriegsbegeisterung gewichen: der heilige Kampf für Herd, Weib und Kind entflammt die Gemüter, Töne des reifen Schiller klingen vor. Das vaterländische Pathos Klopstocks wird von dem leidenschaftlichen Feuer des Stürmergeschlechtes durchglüht. Trotz der Wandlung nach innen und außen, die den ,Aristcdemos" von den Jugenddramen des Dichters trennt, bleibt das Gemeinsame der Kampferfassung deutlich; die das Erhabenste anstrebende Gestaltung des Kriegerischen nimmt Absichten der Pyrrhus-Fragmente, ohne deren überschäumende Maßlosigkeiten, wieder auf. Das stürmerische Temperament ist zwar gebändigt, aber nicht erloschen. Auch ein Aristodemos will in der Schlacht um die Freiheit die kühne Begeisterung ausrasen. ${ }^{36}$ ) Neben die soldatische Tapferkeit, die früher allein gegolten hatte, tritt freilich, als nicht minder des Preises würdig, die soldatische Klugheit. ${ }^{37}$ )

Die übrigen Dramen der Spätzeit nehmen eigentlich kriegerische Themen nicht mehr auf. Der Kriegsmann Klinger manifestiert sich in einigen von ihnen dennoch, besonders nach zwei Richtungen hin. Im „Pyrrhus“ hatte er den allgemeinen Gegensatz, den der Sturm und Drang zwischen dem tatfrohen und dem tatlosen Menschen aufrichtete, prägnant auf kriegerischem Feld gestaltet, und seinen Feldherrn Pyrrhus von dem Lüstiing Demetrius abgehoben. Diese Kontrastierung des Kriegers als des Tatmenschen im höchsten Sinn zu Charakteren anderer Art greift er noch mehrfach auf. Daneben ist es das kriegerische Mannesideal überhaupt, das in seinem Schaffen bis zuletzt festgehalten wird.

Die Eingangssituation des "Günstling" ${ }^{38}$ ) setzt Charaktergegensätze, die dem Pyrrhusfragment nahestehen, in den schärfsten Konflikt: Aus ruhmreichem Feldzug gegen die Mauren wiederkehrend, findet der treue Feldherr Brankas die zurückgelassene Braut durch den schwachen, mißleiteten König, für den er sein Blut versp ritzt hat, geschändet. Die Erwartung seines sieg-

35) Rieger druckt 2, 117-18 einen Teil daraus ab, rhythmisch abgesetzt, als Beispiel des Stils, der nach dem Vers hindrängt.

${ }^{36)}$ 2. Fassung Akt V, Werke 2, 157.

${ }^{37}$ ) In der 1. Fassung erwehrt sich Aristodemos des Vorwurfes von seiten Kleonnys', er sei ohne Wunde aus der Schlacht gekómmen: ,des Ruhmes würd̈ig ist der Krieger, der den Mut mit Gegenwart des Geistes verbindet" (Neues Theater 1, 98-99) - ein lessingisches Ideal.

$\left.{ }^{39}\right)$ Erster Druck im „Theater” Bd. 4, Riga 1787. Werke Bd. 2; vgl. Rieger 2, 85-96. 
reichen Einzuges schreckt im Beginn des Stücks den Fürsten auf (I, 4), der Krieger tritt, noch unwissend, offen und frei mit dem Bericht seiner Erfolge vor ihn hin und muß kurz darau! die ganze Wahrheit erfahren. In etwas anderer Wendung regiert derselbe Kontrast die frühere "Elfriede" ${ }^{30}$ ) Hier ist es der siarke, ritterliche König, ein kecker Reiter und frischer Jäger, der in des Dichters und Elfriedens Herz über ihren Gatten, den weichlichen, gelehrten Ethelwold triumphiert, der an der Jagd keinen Geschmack findet und nicht mit den anderen in den Krieg $200 .{ }^{40}$ ) Klinger legt sein soldatisches Mannesideal auf charakteristische Weise in seine Frauen: den Starken, den Krieger bewundern alle und fallen ihm kraft sciner sieghaften Natur, am unbefangensten im ..Grisaldo", ohne weiteres zu. ${ }^{41}$ ) Es ist sehr bezeichnend. daß dicse Hingabe des Wcibes an. kriegerische Männlichkeit bis in die späten Werke bestehen bleibt. In der Elfriede macht sic das psychologische Problem aus, und noch im "Damocles"42) ist sie so ausgeprägt wie nur irgend sonst. Klinger läßt Antiope, die Tochter des Tyrannen, um deretwillen der ritterliche Kallias seinen Vater Damocles verrät, das Gefühl ganz auskosten, sich in ihrem schwachen Weibtum dem heldenstarken Manne anzuschmiegen; und zugleich mit feiner Wendung des Genusses inne werden, daß sie über diese robuste Männlichkeit durch weiblichen Reiz herrscht. Dabei besitzt sic recht klingerisch eine streitbare Scele, die es gelüstet, mit in die Männerschlacht zu ziehen, und sie weiB, daß der Funke ihrer Liebe aus der Bewunderung des Kühnen entsprang und mit ihr erlöschen müßte. ${ }^{43}$ ) Das Jugendideal des Dichters, kriegerische Kraft und Kühnheit hat hicr, nahe am Ausgang seines dramatischen Schaffens, noch einmal seine Verklärung gefunden.

39) Basel 1783. Später im V. Akt etwas erweitert (Rieger 2, 189); so in den Werken Bd. I.

so) 1. 2; Werke 1. 201-02; vgl. Rieger 2. 37.

"1) Vgl. Rieger 1. 141: 249; 2, 38. Die Stürmerparole Klingers .Dem Starken die Schönheit" ist auch diejenige von Leisewitzens Guido (Julius von Tarent 1. 3, DLD 32, 17): ,Mainnliche "Tapferkeit verdient allein die weibliche Schönheit" usw.

42) Zuerst im Neuen Theater Bd. 2. 1790: wenig verändert (Rieger 2. 191 u. 511 ) in der Auswahl Bd. 2. 1794; danach in den Werken Bd. 2. 1815.

43) Riegers knappe Charakteristik .ganz weiblich" $(2,128)$ läBt nicht erkennen. daB Antiope eine ausgesprochen klingerische W'eiblichkeit besizt; die Hauptstellen (W'erke 2) Akt II. S. 354:" ..in dem Beben vor dem Starken liegt eine Wollust" usw.; S. 356; Akt III. S. 389. 
Neuntes Kapitel.

\section{Goethe in den achtziger Jahren.}

Goethe, dessen Götz von Berlichingen dem Kampfdrama den mächtigsten Antrieb gegeben hatte, war seither auf diesem Feld nicht mehr aufgetreten. Antike Pläne, vor allem ein Cäsar, der ihn dahin hätte führen müssen, blieben liegen; Klinger stand hier mit dem immerhin weit geförderten Pyrrhus allein. Erst spät wurde der „Egmont“ abgeschlossen, der zwar nicht durch eine kampftechnische, ${ }^{1}$ ) aber durch seine geistige Bedeutung der Kriegsdramatik angehört. Er wurzelt in kriegerischen Verwicklungen, ohne eine eigentliche Kampfhandlung zu bieten. Er erfaßt dafür, als Charakterdrama, das soldatische Ideal des Sturm und Drangs, dem er durchaus entstammt, ${ }^{2}$ ) in der größten Weite und Tiefe. Über den klingerischen Kultus der wehrhaften Kraft hinaus wird Goethe im Egmont das Kriegertum zum Gefäß des freiesten Menschentums überhaupt, der kriegerische Held in seiner besonderen Veranlagung zum geborenen Träger des am höchsten geachteten Lebensgehaltes, eines frei sich auswirkenden, aller Dumpfheit enthobenen Daseins. Goethe dringt damit zu den Wurzeln der Auffassung im Götz vor und legt den dort mehr nach außen wirkenden Kampfgeist in seinem Kern bloß. Er begründet das Kriegerische tief als das Urbedürfnis der Mannesnatur, die ihr Leben erst genießt, wenn sie es einsetzt.

Egmont ist trotz des patriotisch gehobenen Schlusses nicht zuerst Soldat für sein Land, wie Tellheim verlangt, obwohl die stoffliche Aufforderung dazu in dem Befreiungskampf eines Volkes stark genug war; er ist es ohne jede Zwecksetzung aus der vom Dichter stark betonten Dämonie seines Wesens. Zugleich gewinnt aber die soldatische Grundanschauung vom frischen Spiel um das Leben, über den soldatischen Umkreis ausgreifend, eine umfassende Weite. Sie beherrscht Egmonts ganzes Sein, ob er auf dem Sande von Gravelingen das blutige Los wirft, die vorausschauende Mahnung Oraniens, sich zu schonen, abschüttelt, oder endlich mit nachtwandlerischer Kühnheit in das

1) Uber die Technik der Massenbehandlung darin vgl. Lohmeyer S. 69--74.

2) Ein bedeutender Teil im Herbst 1775 entstandien; 1778-82 vorläufig abgeschlossen; im zweiten römischen Aufenthalt 1787 überarbeitet und vollendet. Erschienen Leipzig 1788 (Muncker, Cottasche Jubil.-Ausg, von Coethes Werken 11, XXXIII-XXXIV. 
Haus des furchtharen Gegners geht. Daß3 sie scin Tun bis in die kleinsten Züge durchdringt, schafft den sieghaften Eindruck seiner Persönlichkeit, der sich behauptet, trotzdem der Graf für sich und sein Land gleich unklug handelt. Das kriegerische Draufgängertum ist hier auf die breiteste Grundlage gestellt; die ganze strahlende Charakteranlage, der es in seiner höchsten Ausprägung entstammit, wird entfaltet. Der soldatische Ursprung bleibt dabei offenbar. Goethe selbst hebt die persönliche Tapferkeit als den Grund und Boden von Egmonts Wesen hervor. $\left.{ }^{3}\right) \mathrm{Da} B$ er als Schütze nicht seinesgleichen hat, ist das erste, was wir von ihm hören, und taucht noch spät im Kerker neben seinem Glück im Spiel als früher Keim von Albas $\mathrm{HaB}$ auf: er hat ihn einst vor versammelter Nation überschossen. Nach außen beherrscht die ritterliche $\mathrm{Er}$ scheinung des Helden von St. Quentin und Gravelingen das Stück und reißt die für das Sinnenfällige empfängliche Menge mit. Dahinter steht Egmonts kriegerisches Hochgefühl, die Sicherheit eines Mannes, der mit dem Einsatz seines Blutes nie gegeizt hat. Das Kriegerische bedeutet ihm höchstes Leben, Freiheit und Natur.')

Der Dichter hat ihm den freien Soldatentod im Getümmel, den er sich wünscht, ${ }^{5}$ ) trotz dem Kerker wenigstens im Geiste auf oft angefochtene Weise verliehen. Berauscht durch die Vision, fühlt er sich den Schergen gegenüber als Führer seines Volkes in der Schlacht, der gewohnt ist, zwischen Feindes und Freundes Speermauer mitten inne zu stehen, und steigert sich selbst, gefühlsmächtiger als Philotas, in die Situation des wogenden Treffens ${ }^{6}$ ) hinein. Mit anfeuerndem Ruf schreitet er auf die Wache los, wie wenn es nicht zum Blutgerüst, sondern zum sieghaften Angriff ginge. Coethe bedient sich für diesen nicht notwendigen Schluß eines Kriegspathos wie es dem Götz fehlt, und zugleich aller theatralischen Mittel. Anschwellende Trommeln, eine drohende Spießreihe müssen die Illusion stützen, eine Siegessymphonie sie aufnehmen; er erreicht damit auf gefährlichem Boden immerhin eine starke Wirkung. bleibt aber die innere Begründung des nur scheinbaren Märtyrertodes um nichts weniger schuldig.

J) Dichtung u. Wahrheit 20. Buch; H. G. Gräf. Goethe über seine Dichtungen II. Abt. I, 254. Vgl. Munckers Einl., Jubil.-Ausg. II, XXXVII.

๑) II, S. 221: V. S. 281-82: .. Und frisch hinaus, da wo wir hingehören, ins Feld, wo ... der Soldat sein angeboren Recht aut alle Welt mit raschem Schrill sich anmaßt und in fürchterlicher Freiheit wie ein Hagelwetter durch Wiese. Feld und Wald verderbend streicht, und keine Grenzen kennt, die Menschenhand gezogen".

¿) Zu V.S. 299 . Niche im "Tumulte der Schlacht" usw. vgl. Faust I v. 1573: ..O selig der, dem er im Siegesglanze / Die blut gen Lorbeern um die Schläfe windet".

-) V. S. 305. Ein verwandtes Motiv dient schon zum gehobenen AbschluB der ersten Kerkerszene: Egmont versetzt sich setierartig in den Hergang sciner Befreiung. V, S. 283. 
Die größte Lebenàigkeit gewinnt das Heldenbild Egmonts in dem hingebenden Emporschauen Klärchens, worin sich die direkte Charakterisierung durch das Volk wie in einem Brennpunkt vereinigt. Wie bei Klinger wird das Kriegerische am höchsten aus Frauenmund erhoben. ${ }^{7}$ ) Klärchens lauter Schrei vor dem braven Holzschnitt der Schlacht spricht noch beredter für den ritterlichen Grafen als die Schilderung der Gravelinger Affäre durch den wackern Buyck, und in ihrer bewundernden Liebe, die es kaum fassen kann den großen Egmont vor sich in der Stube zu haben, sammelt sich die Verehrung des ganzen Volkes. Sie besitzt den des Geliebten würdigen kriegerischen Sinn - ein Soldatenlied ist ihr Leibstück, sie möchte ihm als Bube die Fahne in der Schlacht nachtragen - und bewährt ihn als einzige vor der in der Gefahr scheu zurückweichenden Menge. ${ }^{8}$ )

Neben Egmonts Charakter ist die kulturgeschichtlich reiche Umwelt, worin er steht, durch soldatischen Gehalt bedeutend. Die Exposition setzt ihre Verhältnisse auseinander: Der Kriegsmann hat es in unruhigen Zeitläuften über den Bürger davongetragen, allerdings bei weitem nicht in dem Grade, wie später die aller Fessel entbundenen Wallensteiner. Der Schneider Jetter darf gegen das Kriegshoch des Invaliden, wobei es ihm lumpig zumut wird, mit einem Lamento über das ewige Getrommel, die häufigen Greuel und die unleidliche Renommage der Eisenfresser von ihren Kriegstaten protestieren. ${ }^{9}$ ) Ein Unterschied zwischen Soldat und Soldat wird aufgerichtet: der Niederländer stimmt als Bürger des Bodens in das Hoch auf Ordnung und Freiheit ein, der landsfremde Spanier erscheint, zunächst unter dem Gelächter über den Betroffenen, als ihr Verächter; er macht bei der Einquartierung nicht viel Federlesens und vertreibt den Bürger aus Keller, Stube und - dem Bette. ${ }^{10}$ )

7) Das Bürgermädchen in Fau st I, v. 881 sieht den ersehnten Geliebten im Kristall ,soldatenhaft mit mehreren Verwegnen“. Die im folgenden angezogenen Stellen I, S. 198-99; I, S. 197 und III, S. 243; I, S. 193; I, S. 198.

$\left.{ }^{8}\right)$ Úber den Bruch in deren Auffassung vgl. Lohmeyer S. 70; Bielschowsky, Goethe ${ }^{13}$ I, 333 hätte für Klärchen einen kriegerischen Tod an der Spitze eines Volkshaufens gewünscht sprechendes Zeugnis für den Eindruck ihrer kriegerischen Seele.

$\left.{ }^{9}\right)$ Der Gegensatz des bürgerlichen und des soldatischen Lebenskreises auch in Faust I, v. $860 \mathrm{ff}$., Bürger: „Nichts Bessers weiß ich mir an Sonn- und Feiertagen, / Als ein Gespräch von Krieg und Kriegsgeschrei" usw.

$\left.{ }^{10}\right)$ Denselben Ruf bewähren die spanischen Besatzungen in den Niederlanden in Kleists Zerbrochenem Krug, wo Frau Brigitte (v. 1673) zu der nächtlich erlauschten Nötigungsszene meint: „Als ob die Spanier im Lande wären“. Mit landsknechtischer Unbefangenheit macht ein Soldat in Tiecks Octavian (II. Teil, Schriften 1, 190 f.) ein Einquartierungsrecht, das sich auf die Ehehälfte des Kostgebers erstreckt, geltend und erhält es zugebilligt, weil seine Hellpart als Argument stichhaltig befunden wird. 
Der Gegensatz zweier soldatischen Welten wird spăterhin ausgebaut und vertieft; er gibt dern Gegensatz ihrer Führer. Egmonts und Albas, den breiten Rückhalt. Unablässig charakterisierend, hat Goethe seinen Helden auch in Kommandogeschäften gezeigt. Der Einblick, den wir hier in die Verfassung seiner Kompagnien tun, entspricht dem Bild, das Jetter von dem lustigen Volk der niiederländischen Milizen zeichnet. Ein Egmont kann seinen Truppen kein schroffer Herr sein, und es fehlt in seinem Verhältnis zu ihnen durchaus die militärische Schärfe, womit der Räuber Moor seine Bande in Zucht hält und Fiesko die Verschworenen leitet, trotzdem in beiden Fällen für die Freiheit gefochten wird. Goethe steht dem Disziplinproblem hier wie im Götz konzilianter gegenüber und denkt weniger militärisch als der junge Schiller. Der Grundsatz vom leben und leben lassen, der an den Milizen sichtbar wird, ist auch der egmontische; die Niederländer wollen ihn an ihren Fürsten erkennen. Der Graf sieht seinen Leuten manches durch die Finger; er hat ein Herz für sie, will seine leeren Kassen nicht aus zurückgehaltenen Pensionsgeldern alter Soldaten füllen und mag einem schönen Kerl den Heiratskonsens nicht versagen, obwohl sein Hauptmann über den übermäßigen Weibertroß bei der Kompagnic klagt. Lenzens Bemühungen um die Soldatenehen blicken flüchtig herein; der gegenwärtige Gesuchsteller soll zwar der letzte sein, dem's durchgeht, aber es steht zu erwarten, daß der gütige Chef einem späteren, dringend Bittenden nicht taub sein wird. ${ }^{11}$ )

Von diesen leichtlebigen Leuten, die so, als cinzelne, das Ohr ihres Führers zu finden wissen - der frische Buyck, freimütig und splendid wie sein Herr, vertritt sie auf der Bühne - heben sich auf der Gegenseite Albas Spanier als wahre Teufelskerle ab. Kerzengerad wo die Niederländer breitgrätschig dastunden, mürrisch und unheimlich, maschinenmäfig einer wie der andere, ein scharf excrziertes, unpersönliches Kriegsinstrument. Ihr „Halt" auf Posten Inacht erstarren, ihr Blick dringt durch und durch, und selbst ein unverfrorener Vansen findet, daß sie ungemistliche Brüder sind. Sie treten nirgends einzeln oder überhaupt sprechend hervor. Sie halten als Patrouillen, scheu beobachtet. die Stadt in Respekt und erscheinen in den entscheidenden Augenblicken, bei Egmonts Gefangennahme - hier bildmäßig unbeweglich -, bei seinem Tod als geschlossene Masse; ;") die Stärke der Charakteristik gibt ihrer stummen Rolle Gewicht. Der Dichter hat ihr sanzes Wesen glücklich schon in ihren straffen Gleichtritt ${ }^{2 \cdot 3}$ ) gelegt : die Niederländer lernen diese soldatische Präzision

i1) Die Fundstellen II. S. 215: IV. S. 245-46 แ. I. S. 176.

12) IV. S. 245: 252: V', S. 279.

13) IV. S. 245: .Fin Trin soviel ihrer sind". VKl. die thythmische Fassung des wuchtigen whriltes marsechicrender Bataillon in Faust 11. v. 9450: . In Stahl gehüllt, vom Strahl um- 
erst an ihnen kennen. Nach ihr arbeitet der ganze militärische Apparat Albas, der sich zwar nur bei dem Anschlag auf die Fürsten, aber hier bezeichnend zeigen darf: schweigendes Erfüllen des Befehls, ohne seinen Sinn zu kennen noch vom Nebenmann zu wissen. Ein Schlaglicht fällt auf die Führerkunst des Toledaners, der des Königs Heer durch alle Fährnisse mit überlegenem Blick nach den Niederlanden brachte ${ }^{14}$ ) und den die Subalternen darob lernend bewundern. In den knappen Zügen tut sich das Berufsmäßige dieser Armee kund, wie es sich bereits in der eisernen Schulung der Gemeinen offenbarte.

Der Kontrast gipfelt in den Führern. Schon gerichtet, legt Egmont mit dem scharfen Auge des Gegners die Wurzeln von Albas Soldatentum, das dem seinigen grundfremd ist, bloß; er ist Krieger kraft der Bestallung seiner streitbaren Natur, aus dem Lebensgefühl, und es verträgt sich damit die Scheu vor dem greuelvollen Krieg, der die Provinzen verheeren wird, wie ihn Oranien festen Sinnes erwartet. Ein Alba dagegen hat eben dieses Morden kaltherzig angezettelt, ,damit der Krieger im Kriege gelte, damit man seiner bedürfe,"15) fühllos seinem Handwerk ergeben, ruhmsüchtig die Gelegenheit zu einer glanzvollen Karriere wahrnehmend, ein entsittlichter Berufssoldat, seinem Wesen nach, mit Lenzens Ausdruck, ein ausgelernter Mörder. Nur daß alle Schärfe einer Tendenz fortbleibt. Die kriegerische Herrlichkeit des Herzogs wird nicht angetastet. Goethes Gestaltung stellt die Gegensätze mit der leidenschaftslosen Bildnerfreude nebeneinander. Der fremde Eroberer, der einfache Kriegsknecht sowohl wie der Feldherr, erscheint als furchtbar, aber nicht als niedrig, sondern in seiner Art groß.

In das Feld der Kampftechnik führt die „Iphigenie“" (Leipzig 1787) zurück, die für die Bewältigung des Gruppengefechts einen wichtigen Wendepunkt bedeutet, während der "Tasso" sich nach denselben Formprinzipien mit dem Zweikampf auseinandersetzt. Wir haben die Entwicklung der Technik vom Otto Klingers bis zu seinem Aristodemos verfolgt; sie läuft ohne engere Berührung dem Weg vom Götz zur Iphigenie parallel. ${ }^{16}$ ) Goethe vollzieht mit dem neuen Stildrama strenger Observanz die Abkehr von der Kampfgestaltung der Geniezeit und die Hinwendung zu der Kampfform der französischen Klassik noch entschiedener als Klinger. Der Stoff bot keine umfangreiche Kriegshandlung; das Treffen, das Orests Genossen den Tauriern im V. Akt

wittert, / Die Schar, die Reich um Reich zerbrach, / Sic treten auf, die Erde schüttert, / Sie schreiten fort, es donnert nach".

14) Vgl. dazu Schillers Darstellung von „Albas Rüstung und Zug nach den Niederlanden“ im 4. Buch der Gesch. des Abfalls der Niederlande.

15) V, S. 293 Egmont zu Ferdinand; das vorige IV, S. 253 u. II, S. 227.

$\left.{ }^{16}\right)$ Uber die gleichzeitige, voneinander unabhängige Hinwendung Goethes und Klingers zur Antike vgl. Rieger 2, 107-i08. 
liefern, wähiend or den Raub des Cötterbildes unternimint, ist aber Au!gabe genug um den gewandelten Formwillen, der jetzt am Werk ist, sichtbar zu machen. Schon äußerlich ergibt sich das von den Franzosen und ihren Nachahınern her vertraute Bild. Der bewaftnete Zusammenstoß der Scharen darf auf der Bühne nicht erscheinen. Mit strenger Linienfuihrung werden einzig die feindlichen Häupter einander zur Unterhandlung entgegengestellt. Nebst dem frühem Kampfbefehl des Königs machen nur die symmetrisch angeordneten Mcldungen der beiden Confidents das Treffen kund. ${ }^{17}$ ) Es findet sich zwar eine lebendige Bezichung zu ihm, die der klassisch-französischen Kunstübung widerspricht: Orest feuert, indem er aus dem Getümmel die Szene betritt, rückrufend die Genossen an. Der Dichter verzichtet nicht mehr wie die ältere Zeit auf unmittelbare Gegenwart des Kampfgeschehens, aber er dämmt es durchwegs sorgfältig ein. Wie er die Masse und jedes kriegerische Gefolge seiner Führer beiscite läßt, so bietet er auch keinerlei illusionistische Mittel, Lärm. Streitrufe, Hörner und dergleichen auf, um das Gefecht wahrheitsgetreu vorzutäuschen. Die Realität soll in dieser gehaltenen Welt nicht zu stark werden, und der Regisseur darf nach den Intentionen des Dichters nicht über ein bloß andeutendes Kampfgetöse, das den Dialog nicht stört. hinausgehen.

Ein Blick auf den Götz zurück setzt die innere Wandlung ins Lichi, die dem Wandel der Form entspricht: die Abwendung vom Gegenständlichen. Es ruht kein Interesse mehr auf dem Gefecht der Griechen und Taurier für sich, auf seinen Verhältnissen und seinem Verlauf; es verlautet nichts darüber, wer die wackern Freunde Orests sind, was für Taten sie verrichten, noch wie sich ihre Zahl zu Thoas' Macht verhält - alles Fragen, auf dic der gegenständliche Götz die Antwort nicht schuldig geblieben wäre. Seine Bedeutung hatte nicht zum geringsten in der Entdeckung des Dinghaften und seiner liebevollen Erfassung bestanden, und die Freude am Gegenständlichen war eins der wichtigen Merkmale des Sturm und Drangs geblicben; in unserer Provinz der kriegerischen Dinge haben wir sie noch eben in reicher Entfaltung am Egmont beobachtet. Der neue Kunstwille opfert sie anderen Zwecken auf. Der Dramatiker Coethe kehrt später zu der Andacht zum Sachlichen gerade auf kriegerischem Gebiet zurück: hicr hat sie jedoch keinen Raun. Alles Kämpferische ragt nur so weit in das Stück herein, als zur Unterlage der seelischen Vorgänge. die allein die Aufmerksamkeit fesseln, notwendig ist. Damit stellt sich ,.Iphigenie" auch nach dem Geist, wie nach der Form, neben die französische Klassik.

17) Kampfbefehl V. I: Meldungen nacheinander V. 5: Pylades drangend, weil die Fcinde überhand nehmen; Arhas gemessen und zuversichilich - wie Thoas in würdiger Rute dem eiligen Orest gegenübersteht. 
Goethe gelangt so von innen heraus zu der Beschränkung, die der nachahmenden Gottschedschule nur äußerliches Gebot und daher hemmende Fessel gewesen war. Während sie in ihrer oberflächlichen Adaptierung des französischen Vorbilds eifrig darauf Bedacht nimmt, die Kampfgeschehnisse zu Bühneneffekten auszubilden - wie bei den Franzosen selbst Voltaire das reine klassische Prinzip zugunsten der Theaterwirkung durchbricht - , ist die Kampfgestaltung der Iphigenie durchaus effektfeindlich. Das sachliche Geschehen des Gefechts wird um der Innenhandlung willen zurückgedrängt und erhält keinerlei theatralischen Nachdruck. Ein blankes Schwert genügt dem Dichter, die Situation zu Beginn der Auseinandersetzung der Gegner zu kennzeichnen, ohne daß die Klingen überhaupt gekreuzt würden.

Mit dieser äußersten Zurückhaltung im Aktionellen ist der Gegenpol der lärmvollen Kampfpantomime, die vom Götz ihren Ursprung nimmt, erreicht, eine strengste Fassung kriegerischer Vorgänge, denen keine Freiheit zur Entfaltung mehr gegönnt wird. Dabei ist bemerkenswert, daß die oft angetroffenen Unwahrscheinlichkeiten der geschlossenen Technik sich nicht einstellen. Freilich fällt ihr eine kurze Gefechtshandlung, wie sie hier vorliegt, von Haus aus leichter als die ausgedehnte Schlacht, aber daneben hat gerade die Strenge der Form daran Anteil; sie greift das Gefecht im ganzen so entschieden unrealistisch an, daß wir keine Maßstäbe aus der Wirklichkeit anlegen. Der kunstgemäße Bau der Szenen ist zu deutlich, um etwa die Frage zu erlauben, wieso Pylades und Arkas nicht auf dem Weg zum Hain mit Wehr und Waffen aufeinandertreffen, anstatt daß sie einer nach dem andern in wohlgesetzter Rede berichten, und was dergleichen rationalistische Einwürfe mehr wären.

Der formverwandte "Tasso“ (Leipzig 1790) vervollständigt das Bild dieser Gefechtsstilisierung für den Zweikampf (II, 3). Aufkeimender Männerstreit mit bewaffnetem Austrag, dem im Augenblick der Krise durch das Dazwischentreten eines Dritten Einhalt geschieht, ist ein häufiges Kampfmotiv der engen Technik. Die Gottschedschule hatte sich seine theatralische Spannung nie entgehen lassen. Eine unmittelbare Vergleichsmöglichkeit für das Verfahren Goethes bietet Schillers "Don Carlos" in dem Duell des Infanten mit Alba II, 5, das die Königin durch erschreckten Ausruf trennt. Leidenschaftliche theatralische Bewegung, hitziges Draufgängertum des Prinzen, der den abwehrenden Herzog ungestüm vor die Klinge fordert, ähnlich wie Tasso den besonnenen Antonio, dann eine schlagartige, wie überirdische Wirkung der königlichen Frauenerscheinung, die den übereilten Fechter außer Fassung setzt und taumelnd abgehen macht, kennzeichnet den Vorgang; er entlädt sich rasch, heftig und höchst eindruckskräftig. Goethes Formung zeigt sich in scharfem Gegensatz dazu aller lauten Theatralik abhold. Wiedeı wird die äußere 
Aktion auf die bloße: Andeutung beschränkt Der Zankdialog steigert sich zwar zur Stichomythic, aber dic Verse halten den gemessenen Gang ein. während sie Schiller rïcksichtslos zerhackt. Wo dieser die Gegner fechtend aufcinanderprallen läßt - der Don Carlos fügt sich darin der Zurückhaltung der französischen Klassik nicht, obwohl er sich in ihrer Formenwelt bewegt spricht in der still-innerlichen Welt des Tasso schon das Entblößen einer Waffe laut genug: damit ist der Fehltritt getan. Goethe läßt den Fürsten, den Effekt offensichtlich meidend, jetzt ruhig eintreten, wo Antonio noch gelassen steht. und einzig der blanke Degen 'assos, ähnlich wie Orestes' Schwert, die Krise kundtut. Die Außendinge geben auch hier nur die Untermalung zu den seelischen Vorgängen ab, und das für sich geringfügige Kampfereignis verschafft darin Einblick in dic Cesamtstruktur des Werkes.

Es ist lehrreich, hicr auf zwei anders geartete Fassungen des Zweikampfes bei Gocthe ${ }^{18}$ ) auszublicken, cine frühe in .Clavigo", wo er rein sachlich als Pantomime gegeben wird: Beaunarchais stößt im fünften Akt den Verführer an Mariens Leiche nach kurzem Gefecht nieder, und die ungleich bedeutendere im „Faust", Valentins nächtliches Renkontre mit dem leichtfertigen Sänger und seinem Genossen unter dem Fenster Gretchens. Die Chronologie bercitct bei diesem Auftritt cine Uberraschung; er ist spät, nach 1800 , in der klassizistischen Zeit entstanden und gehört damit erst dem vollcndeten Ersten Teil ron 1808, noch nicht dem Fragment des Jahres 1790 an. obwohl der Fall des Bruders von der Hand des Geliebten schon im Urfaust geplant war $;^{19}$ ) zur Ausfülirung kam aber dort nur der Monolog Valentins. Dic nachgedichtete Kampfszene trifft jedoch durchaus den Ton der alten Partien und fügt sich ihnen ebenso nach der Auffassung ein. Von einem Zurückdrängen des Gegenständlichen, von der klassizistischen Scheu vor dem derben Tritt der Realität ist nicht die Spur darin. Goethe wendet sich hier über das Formideal, das in Iphigenic und Tasso regiert, zu der lebenssatten Welt Götzens und Egments zurück und verleiht dem reckenhaften Landsknecht und seinem Gefecht mit dem höllischen Widerpart jene schwerlötige Wucht, womit der Sturm und Drang alles Kriegertum ausgestattet hatte. Die Freude der Frühzeit am kriegerischen Gegenstand, aus der die episodische Figur erwachsen ist, erwacht bei der Ausarbeitung der Auftritte aufs neue; sie werden zugleich durch den vordeutenden Aufzug der Soldaten im Osterspaziergang mit ihrem frischen

18) Der Autsatz K. Ohlerts ..Der Zweikampf bei Goethe" in den Grenzboten 1905. 3. Vierteljahr S. $139-46$ u. 192-98, beschäftigt sich nur mil der Duellfrage.

19) Den Beweis liefert die Stelle Cretchens im Kerker ..Deine Hand, Heinrichl" usw. (Faust I, v. 4512 ff.), die der Urfaust bereits enthält. Vgl. E. Schmidt, Jubil.-Ausg. 13. XXII u. S. 324 . 
Lied vom Burgen- und Mädchenerobern enger an das gesamte Bild der Umwelt angeschlossen.

Die späte Entstehung wird immerhin an der besonnenen Meisterschaft der Technik sichtbar, die dem gereiften Dichter für den Kampf zu Gebote steht. Er begnügt sich nicht mehr mit der kunstlosen Pantomime des Clavigo, sondern ordnet den Waffengang genau. Dem bloßen Dreinschlagen als Augenschmaus für die schaulustige Menge bleibt nichts überlassen, Hieb und Parade werden ebenso durch das Wort wie mit der Klinge geführt. Es ist nicht zufällig, daß die gesamte, ins einzelste bestimmte Aktion des Vehikels für das Pantomimische, der szenischen Anweisung, nicht bedarf; so vollständig durchdringt der Dialog die Gebärden der Fechter. Goethe erreicht damit eine höchste dramatische Gestaltung des Einzelkampfes. Die Wucht der Schwertschläge wird der Muskelkraft der Schauspieler, auf die die Kampfpantomime angewiesen ist, abgenommen und ins Dichterwort gelegt; sie ist daher im Buch gleich mächtig wie auf der Bühne, wogegen jene nur durch den Aufwand der Darstellung wirksam wird.

Die Szene verlangt übrigens durch ihre präzise Durchbildung ein kunstgerechtes Fechten, wie es Goethe im Wilhelm Meister für den Zweikampf zwischen Hamlet und Laertes fordert, wo augenscheinlich auch für Shakespeare und sein Publikum ein sportliches Interesse mitgesprochen hat. ${ }^{20}$ ) Jede eingehendere dramatische Darstellung des Duells wird auf die Regeln der Kunst Bedacht nehmen müssen. Am weitesten ist darin, und zugleich in der kunstvollen Verschlingung von Wort und Aktion, in neuerer Zeit Rostand gegangen; sein Cyrano de Bergerac formt $(I, 4)$ den überlegen geführten Zweikampf im Fechten aus dem Stegreif zur Ballade, deren Pointe den Gegner gleichzeitig mit der Spitze seines Degens trifft.

Goethe bietet bei der knappsten Fassung des Vorgangs einen erstaunlichen Reichtum der Charakteristik auf, der sich über den ganzen Valentin-Komplex erstreckt. Nirgends um ihrer selbst willen ausgebreitet wie öfter im Egmont, sondern dramatisch straff gehalten, schafft sie zwischen den Partnern eine starke Gegensätzlichkeit. Der tückisch-geschmeidige Junker Satanas steht dem urkräftig einhauenden Landsknecht ähnlich gegenüber wie die gewandten Italiener den teutschen Bären Dorias. Schon der Auftakt, wie der in seiner Schwester beschimpfte Kriegsmann mit geradem Schlag das lockere Buhlliedchen Mephistos entzweischneidet, kennzeichnet seine ganze Art: soldatisch derbes Zupacken. Der grimmen Lust des Raufers am Schädelspalten gesellt sich die

$\left.{ }^{20}\right)$ Lehrjahre IV, 5; vgl. K. Ohlert S. 141 ; C. Freytag ${ }^{3}$ S. 210; für die goethische Theaterpraxis bei Fechtszenen Petersen S. 251. Ein kennermäßiges Publikum, die Studentenschaft, pfff in Lauchstädt den Zweikampf zwischen Macbeth und Macduff aus (Petersen S. 252). 
Freude, die Schänder seiner Ehre vor der Klinge zu haben. An ihm ist es, mit Wort und Arm zu wackern Streichen auszuholen, während Mephisto, das Dreigefecht schnell ordnend, mit gewandter Zunge und gewandter Wafte pariert. Den entscheidenden Stoß3, der den durch höllisches Zauberwerk crmatteten Lümmel zähmt, muß dann der Blutschuld halber Faust führen, von dessen Flederwisch der Kamerad, in den Kavalierkünsten erfahrener, nicht eben hoch zu denken scheint: er redet ihn just hier zugespitzt mit einem .Herr Doktor" an und erteilt ihm als tüclitiger Sekundant eine gehörige Aufmunterung.

Die charakteristische Ausprägung jedes Einzelzugs hindert nicht, daß sich die Entscheidung echt dramatisch blitzschnell und in gesammelter Spannung vollzicht. Einzig die Einleitung des Auftrittes verstößt dagegen, und eine Naht ist bei seiner nachträglichen Einfügung sichtbar geblieben. Das uns aus den Postenszenen geläufige Wächtermotiv, Valentin als horchende Schildwache vor Gretchens Tür aufgepflanzt. muß zur Anknüpfung des Renkontres an seinen Monolog dienen. Das Zwiegespräch Faustens und Mephistos, das schon im Urfaust auf jenen folgt, wird in seiner ersten Hälfte übernommen, dann jedoch etwas gewaltsam abgebrochen: cin neuer Dialog von einem zu hebenden Schatz und Geschmeide führt nur stockend zum Ständchen weiter, init dem erst, nach dem kurzatmigen Füllsel, der dramatische Zug einsetzt, der Gefecht. Auflauf und Ende Valentins zur einheitlichen, gedrängten Steigerung zusammenordnet.

Die Charakterisierung des Soldaten gipfelt in seiner Sterberede, einem Motiv, das von Shakespeare bis auf Kleist eine reiche Tradition hat. Mit diesem Schlußstück des kleinen Valentin-Dramas tritt die Episode in den Gesamtorganismus der Tragödic ein: der Eigenwert der Szene ist von ihrer dramatischen Funktion nicht mehr zu trennen. Entscheidende Züge runden das Bild des hämisch um Leben und Ehre betrogenen Kriegers und dienen zugleich der grellen Zeichnung von Gretchens Schicksal. Die Härte seiner Rechtschaffenheit und seines soldatischen Ehrbegriffes kennt kein Verzeihen und geht mit der armen Schwester erbarmungslos ins Gericht. Kein Wort der Klage über das frühe, von ihr verschuldete Ende kommt über seine Lippe; er weiß dem Tod als mannhafter Kriegsgesell ohne Zagen zu stehen. Umso wilder tönen die Verwünschungen über die Schande, die sie über sich und ihn gebracht, wie sie schon im Monolog an xinem Herzen frißt. Scine Frömmigkeit ist von jener kräftigen, landsknechtischen Art, die sich mit cinem derben Fluch vorm gottergebenen Sterben verträgt und auch im Himmel, nach der Weise der Kriegsleute Hans Sachsens, nicht leise tun wird. Scin Rechtsgefühl bäumt sich noch, als or auf den Tod darniedergestreckt liegt. gegen die Kupplerin auf, die jetzt in geistlichem Trost geschäftig ist, und mit einer im streitbaren 
Sinn werktätigen Auffassung des Bußetuns hoffte er bei gesunden Gliedern an ihrem Leib Vergebung seiner Sünden zu finden. So verdient sich der christliche Streiter durch wackeres Dreinschlagen, ohne daß er es allzu genau nimmt, den Himmel. Der sprachliche Ausdruck der Szene ist am Anfang und Schluß durch höchste soldatische Prägnanz stark gehoben; sie setzt mit dem knappen „Ich sterbe, das ist bald gesagt" - die stumpfen Versausgänge häufen sich an beiden Stellen - ebenso kraftvoll ein, wie das letzte Wort des Verscheidenden sie in erschöpfender Kürze endet: "Ich gehe durch den Todesschlaf / $\mathrm{Zu}$ Cott ein als Soldat und brav". 


\section{Zehntes Kapitel.}

\section{Die theatralische Ausmünzung der Kampfmotive.}

\section{Das spätere Ritterstück und das Kampfspektakel.}

Wir haben das Ritterstück bis zu dem Punkt verfolgt, wo auf der einen Seite eine geschlossenere, dramatisch wirksame Behandlung des Kämpferischen eintritt, während auf der andern seine theatralisch effektvolle Ausbreitung als Pantomime angebahnt wird.") Man kann nicht sagen, daß der Gattung seither nennenswerte Einflüsse von der anderweitigen dramatischen Entwicklung zugekommen wären. Brahrn durfte sie daher am ehesten für die spätere Zeit mit innerer Berechtigung als eine Provinz für sich betrachten. Goethes neues, formstrenges Drama war ihr viel zu wesensfremd, um irgend einzuwirken. Klinger stand mit seiner reichen Produktion abseits, und selbst Spuren von Schillers Räubern sind nicht so sichthar, wie nach ihrem durchgreifenden Erfolg zu erwarten stïnde. Ihr berühmtester Nachfahr im Banditenstück. Zschokkes "Abällino", hat die kriegerische Welt des Vorbilds nicht übernommen. ${ }^{2}$ )

Entscheidend für das spätere Ritterdrama ist die Theaterwirkung der Kämpfe; das bestimmt noch nicht ihre Darstellungsform, wohl aber das Verhältnis, worin die Autoren zu ihnen stehen. Die Zuneigung. die der Sturm und Drang für das Kriegerische absichtslos hegte, nimmt ab. Bislang hatte sie

1) Für das eine sind Törring und Babo, die zugleich den Höhepunkt des Dramenkreises bezeichnen, Beispiele; für das andere etwa Hübners Hainz von Stain und, besonders deutlich, weil es sich um ein: Umarbeitung handelt, die zweite Fassung des Sturms von Boxberg Maiers.

2) Leipzig und Frankfurt a. d. O. 1795: Abüllino steht nicht wic Moor als Anführee an der Spitze einer streitbaren Macht. Die Handlung bleibt größtenteils im Zimmer. Kriegerisches nur in der Figur des Dandoli, der in den (wie im Fiesko) vorgesetzten Anweisungen für die Schauspieler .eein ehrwürdiger Alter, dem mans ansieht, daB er einst, und gern Soldat war" heiBt. Er schili I, 5 in dem Gespräch mit dem Dogen, worin sie gemeinsame Kriegserinnerungen an den Türkenfeldzug auffrischen, als alier Soldat auf die entnervie Jugend, die keinen Heldennachwuchs abgeben wird: sie , lassen keiner Flasche den Hals, keinem Weibe die Ruhe". - Der frühere .Craf Monaldeschi" Zschokkes (Küstrin 1790), cine wüste Hofkabale, weist an Kampfororgàngen nur einen nächtlichen Cberfall dreier Banditen auf Monaldeschi (1, 2) auf; der Graf ficht, ein Pistolenschuß auf ihn geht fehl, ein wacker zu Hilfe kommender Kamerad verscheucht die Kerle. 
sich auch in bescheideneren Produkten in verhältnismäßig reicher Charakteristik und üppigem Episodenwerk geltend gemacht. Verwandte Tendenzen, eine unbühnenmäßig sich ausbreitende Freude an Farbe und Stimmung der Kriegswelt, brechen wieder im romantischen Drama durch. Jetzt haben die Theatraliker das Wort, die lediglich auf eine effektvolle Führung der Kämpfe ausgehen. Sie handhaben die Mittel dazu nicht ohne Geschick, aber die Auffassung wird immer äußerlicher. Der reinste Ausdruck der Zeitrichtung ist eine neue Sondergattung des Kampfstücks: das zirkusmäßige Kampfspektakel. Es gehört mehr der Theatergeschichte als derjenigen des Dramas an, darf aber in unserem Cesamtbild nicht fehlen. Das Wollen vieler Ritterstücke wird damit konsequent durchgeführt und der Kampf als solcher zum Gegenstand bloB mimischer, nicht mehr dramatischer Darstellung gemacht. Es tritt das ein, was Wilhelm Schlegel sicher nicht ohne Beziehung zu zeitgenössischen Erscheinungen über das Überwuchern des Theatralischen sagt: „Es ist wahr, die dramatische Wirksamkeit des Sichtbaren kann sehr mißbraucht werden, und das Theater kann in einen lärmenden Tummelplatz bloß körperlicher Ereignisse ausarten, wo alsdann Wort und Gebärdenspièl eine fast überflüssige Zugabe sind." Jene Neigung zum lärmvollen Schwelgen im kriegerischen Wesen, die sein Spott und Tiecks bekannter Tadel trifft - auch ein kräftiges Wort Mephistos mag auf sie gehen ${ }^{3}$ ) - kommt zum Siege.

In der Form der Kampfbewältigung wirken die früheren Gegensätze nach, nur da $B$ jetzt der Theatraleffekt als gemeinsames Ziel angestrebt wird. In der geschlossenen Technik ist er seit Gottsched immer wieder anzutreffen. Dagegen war er der offenen Behandlungsweise von Hause aus fremd; sie hatte ihn in der ersten Zeit, im Zeichen Shakespeares, nicht gesucht. Noch die frühen Kampfpantomimen eines Längenfeld und Törring sind Verlegen-

3) Tieck, Einl, zu Lenz' Schriften, 1828, 1, LXXIV: ,Auf der Bühne rasselten Panzer und Helm des Götz, ohne dessen Verstand und Gemüt". Schlegel, Ehrenpforte (Werke 2, 277) im "Catalogue raisonné von Kotzebues Schauspielen": "Mit Harsthörnern und Burgen und Harnischen pranget Johanna; / Traun! mir gefiele das Stück, wären nicht Worte dabei." Dazu Dramat. Kunst und Litt. 2 3, 415-16; das zitierte das. ${ }^{2} 2,124$ f. Goethe, Faust II v. 10768 über das spukhafte Ritterheer: "Ganz' recht! Sie sind nicht mehr zu zügeln; / Schon schallts von ritterlichen Prügeln, / Wie in der holden alten Zeit" - was gewollt oder ungewollt ebenso auf die theatralische gute alte Zeit wie die historische paßt. Sichern Bezug auf die zeitgenössische literarische Rittermode haben in der Nachbarschaft der Stelle die Verse $10327 \mathrm{f}$. - Klagen der Dramaturgen über überhandnehmende Kämpfe haben wir seit den Zeiten des Spectators angetroffen. Im Jahr 1790 zieht Joh. Friedr. Schink (Dramaturg. Monate, Schwerin 1790, 3, 751 f.) gegen sie zu Felde; das Publikum vérlange jetzt ,,bald einen Turnierplatz, bald ein Feldlager“", und wolle stetsfort „Kampf- oder Ritterspiele, in denen die Helden sich die Köpfe blutig schlagen, sehen". Devrient ${ }^{1}$ 3, 35; Petersen S. 163. 
heitsauskünfte, die nicht das Theaterinteresse diktiert. Wir haben die Wendung ins Bühnengemäße verfolgt. Nunmehr zieht das Theater aus der offenen Form die lautesten Wirkungen. Die Entwicklung zweier Jahrzehnte, die den untheatralisch gemeinten Götz in ein bühnenfestes Kampfstück überführt, ist damit abgeschlossen, und sie macht auch vor der letzten Veräußerlichung, dem Kricgsspektakel, nicht Halt.

Es genügt für uns, aus der großen Zahl der späteren Ritterstücke, ${ }^{4}$ ) soweit untergeordnete Autoren in Frage stelien, einige wenige symptomatische Fälle auszusondern, die Einblick in den gesamten Troß der Gattung gewähren. Mehr und mehr erstarrend, hat sie jetzt bei weitcm nicht mehr die formgeschichtliche Bedcutung wie in den Anfängen, wo jeder noch so bescheidene Versuch sich aufs neue mit auseinanderstrebenden Richtungen der Formgebung abfinden mußte. Allerdings wird dann die Höhe theatralischer Kampferfassung vom Ritterdrama aus crreicht, aber sie gehört nicht ausschließlich seinem Bezirk an. Es ist Kotzebue, der als die bedeutendste Theaterbegabung der Zeit die Kampfmotive am wirksamsten ausmünzt. Er nimmt mit eincm sciner ersten Stücke an der ritterlichen Gattung teil und kchrt auch späterhin zu ihr zurück; aber er beschränkt sich als vielgewandtes, in allen Sätteln gerechtes Talent natürlich nicht auf ihren Stoffkreis, und erheischt daher eine Betrachtung für sich.

Die thcatralisch straffe Fassung der Kämpfe im Ritterdrama der neunziger Jahre ist an Chr. Heinr. Spieß zu beobachten. Noch geschlossener hält sich ein historisches Schauspiel Ifflands, der sich sonst auf dicsem Felde nicht versucht. Eine freiere Ausbreitung der Technik, der bühnenmäßigen Wirkung unbeschadet, zeigt ein Stück Friedr. Chr. Schlenkerts, ihre völlige Zerfahrenheit, an derselben Kampfaufgabe, ein dramatischer Halbroman Carl Cottlob Cramers; das ausschweifende Kampfspektakel endlich knüpft an den Namen Schikaneder an.

Spießens „Klara von Hoheneichen ${ }^{* 5}$ ) hat zwei Erstürmungen von Burgen zu bewältigen; eine dritte, vorausliegende, welche die Verwicklung schafft, wird I, 6 erzählt. Diejenige des ersten Aktes, worin der landgräfliche Frauenräuber in der Feste, deren Wegnahme ihm die Heldin in die Hand geliefert hat, scinerseits überfallen wird, behält Spieß im Zimmer. Eine knappe

4) $V_{B}$ I. Brahm, Ritt. S. 69-70 u. 72; einige ron ihm nicht behandelse Stücke tragen Werners und Koch, Rezensionen nach, verschiedene Kampfszenen bringt Lohmeyer S. 84 ff. bei. Die beste Ubersicht gibt Hauffen DNL 138, IX ff.

5) Prag und Leipzig 1790: benutzt in Deutsche Schaubühne Bd. 24. Augsburg 1790. Brahm. Ritt. S. 134-35. Spieß nimmt ebenso erfolgreich am Ritterroman wie am Ritterdrama teil. Vgl. Hauffen, DNL 138, XVI. 
Szenenreihe (I, 8-13) gibt das Ereignis in wohlberechneter Steigerung. Die erste. Meldung von der aufziehenden Gefahr trennt einen bewegten Liebeskonflikt: Klara hat sich des Verführers mit gezücktem Dolch zu erwehren. Die Freude der bedrängten Frau über die nahende Rettung schwillt auf Grund rasch sich folgender Berichte vertrauter Dienstleute bis zum Frohlocken. Sie horcht gespannt auf das Andringen der Erlöser und fleht auf den Knien leidenschaftlich um ihren Sieg. Als sie sich dem hereinbrechenden Freund an die Brust zu werfen wähnt, trifft sie jedoch auf den verhaßten Feind, der die umsonst sich Sträubende auf eiliger Flucht mit sich fortreißt. Das Getöse, Geschrei und Schwertergeklirr erreicht seine Höhe, die Eroberer dringen ein und finden enttäuscht das Nest leer. Der Akt schließt mit ihrem wütenden Abgang zur Verfolgung. Die Effekte sind gehäuft und dick aufgetragen, der überraschende Theatercoup regiert. Spieß versteht sich schlecht auf poetische, aber vortrefflich auf derbe Bühnenwirkung. Wie viele seiner Kollegen im späteren Ritterstück selbst ausübender Schauspieler, ${ }^{6}$ ) kennt er das Handwerk. Eine szenische Anweisung innerhalb dieses Kampfaktes, die er trotz seiner ohnehin raschen Abwicklung für notwendig hält, wäre dafür Beweises genug und verrät den Theatermann unverkennbar: „Alles wird bis zum Ende dieses Aktes sehr eilig, sehr schnell gesprochen“", schreibt er, um die effektvollste Darstellung besorgt, ${ }^{7}$ ) vor.

Den zweiten Burgsturm bewerkstelligt Spieß durch den im Ritterstück häufigen unterirdischen Gang, den er durch einen diesmal allzu plumpen Bühnenstreich in die Handlung einführt. ${ }^{8}$ ) Die Rskognoszierung hat ergeben, daß die Felsenfeste für die schwachen Kräfte der Angreifer unbezwinglich ist; eine List erwägend, machen sie sich mit ihrem Bau vertraut, von einem alten Gemäuer aus beobachtend; das stürzt zusammen und läßt den Eingang zu dem vergessenen Schacht zum Vorschein kommen. Ein Blick auf Ramond und selbst auf Hübner zurück lehrt, wie alles eingehendere Interesse für das Burglokal geschwunden ist. Einzelne Floskeln von dreifachen Gräben, glatten Felsen, Schwibbogen und Zugbrücke, dazu ein bewundernder Aufblick zu dem kühnen Bauwerk sind geblieben, aber es handelt sich nicht mehr um die lebendige, sondern die Kulissenwelt, und lediglich um eine theaterwirksame Staffage.

6) So auch Hagemann, Komareck, Ziegle $r$ usw.; daß sich die schriftstellernden Mimen der verheißungsvollen Gattung bemächtigen, ist für ihre Veräußerlichung charakteristisch.

7) I, 11; starke Theatralik schlieBt auch den II. Akt Klaras Entschluß, den Geliebten durch ihre eigene Schande zu retten, wird ihr erst dadurch abgezwungen, daß der geöffnete Hintergrund ihn unter den Schwertern der Schergen zeigt.

8) IV. 4 u. 5; Zusammenstellung des Motivs bei Brahm, Ritt. S. 158 u. 151; Kotzebue macht von ihm außer in .Johanna" noch in den ,Kreuzfahrern" und "Gustav Wasa" Gebrauch. 
Dic Vorgänge des Eirdringens in den Schlupfwinkel des Feindes vollziehen sich wicderum in kontrastreicher, angestraffter Folge. Nachdem der unterirdische Gang mit Fackeln urd Pechkränzen in aller Heimlichkeit betreten ist, führt die Szene ins Burgverließ3, worin der Freund schmachetet. Just hier mündet der Stollen, aber der Gefangene hält. ungekehrt wie Klara in der früheren, verwandten Situation, die mit wachsendem Geräusch herandringenden Retter, die endlich im Glanz der Fackeln durch die Mauer brechen, für seine Henker. Dic Erkennung geschicht mit grobern Effekt. Es gelingt nicht, die Tür des Kerkers zu sprengen; dafür naht auf den Lärm hin von außen der Erzfeind mit geringem Gefolge, um den vermeintlich tobenden Gefangenen nicderzuhauen. Die Befreier stellen sich in der Dunkelheit mit aufgehobenen Schwertern und angehaltenem Atem bercit und überwältigen ihn, den schon der Schreck lähnit, im Hereintreten samt seinen Knechten: handfeste Kampftheatralik, die in ihrer Wirkung sichergeht. Die Szene wechselt noch einmal; in die Stille des Zimmers, wo Klara sich anschickt, dem Frauenräuber vor den Altar zu folgen, dringt schnell der Tumult, der neucrdings, nun schon zum drittenmal, um des effektvollen Umschwungs willen falsch gedeutet wird. Zu ernstlichem Widerstand kommt es nicht mehr, der Augenblick der Abrechnung nach gut und böse ist errcicht. Eine kurze Meldung teilt mit, daß sich dic ganze Burg wic ihr Herr kampflos ergeben hat.

Bezeichnend für den Wandel in der Behandlung des Kriegerischen, das jetzt nach stehenden technischen Prozeduren zum Bühnendienst gepreßt wird. ist das Fehlen des Episodischen in Spießens Kampfhandlung. Knechtszenen und dergleichen, die das frühere Ritterdrama zur Abrundung des Bildes reichlich aufbietet, finden in dem enggefaßten Theaterstück keinen Platz mehr. Die spannende Verknüpfung der Aktion steht im Mittelpunkt, die Charakterisierung, wozu die Episcde beiträgt. fährt im ganzen schlecht. Auch wenn Spieß charakterisierende Züge aus der ältern Zeit übernimmt, unterstellt er sie einem bestimmten, äußern Zweck der Szenenführung. ${ }^{9}$ )

Vor einer Gefechtsautgabe großen Umfangs steht Iffland im ..Friedrich von Osterreich" ${ }^{10}$ ) worin der Zug der Ungarn gegen Erzherzog Friedrich IV. (als Kaiser Friedrich 11I.) mit Schlacht. Unterhandlung und Friedensschluß

7) Ein frisches, feldmäßiges Motiv, das Horchen mit dem Ohr an der Erde - es stammt aus Klopstocks Hermannaschlacht und detn Götz und wird auch in den Räubern II, 3 gestreift - haben wir in Maiers Fust liebevoll ausgestaliet gefunden: $S$ pie $B$ nutzt es zur Eröffnung eines Aktabschnittes (IV. 4), aber nur urn das Auftreten eines Neuankommenden einzuleiten.

19) Cotha 1791: benutzt in Deutsche Schaubühne Bd. 26. Augsburg 1791. Von Brahm nicht einberogen; Hauffen. DNL 138, IX: 139/1, 208; Lohmeyer S. 92-93. Iffland hat mit seinem Erstling .Albert von Thurneisen" (1781) auch am Soldatenstück teilgenommen: vil. Hauffen, DNL 139/1. 197 u. Stockmayer S. 36-38. 
dramatisiert wird. Von einem lockern Ausbreiten kriegerischer Szenen ist aber noch weniger als bei Spieß die Rede. Iffland behält für die ganze Dauer der Kämpfe ${ }^{11}$ ) den geschlossenen Ort, ein Vorgemach des Erzherzogs im Neustädter Schloß bei; er geht erst nach ihrer Beendigung, für die Versöhnungsszenen der gegnerischen Führer und Völker ins'Schlachtfeld, vor das Tor hinaus. Sein Schauplatz gewährt keine unmittelbare Möglichkeit zur Schlachtbeobachtung, wenn auch der Ausblick aus den Fenstern mehrfach der Handlung dient. ${ }^{12}$ ) Der Autor sieht sich damit wiederum wesentlich auf die Berichttechnik der alten Zeit angewiesen und sie genügt seiner Richtung, die in der Schlacht nur ein paar spannende Wirkungen sucht, vollkommen. Er verwendet eine große Zahl von Boten, von denen einige dazu mehrfach melden; das setzt ihn in den Stand, alle Berichte kurz zu halten - es sind meistens nur einzelne Sätze - und sie einander rasch nachzuschicken. Die pressierte Szenenfolge, ein unablässiges Hin- und Hereilen gehetzter Personen schafft äußerlich, aber wirksam den Eindruck drängender Ereignisse. Der Theaterpraktiker Iffland legt wie Spieß den größten Wert auf das Tempo, wogegen ihn das Gesamtbild der Schlacht und die Verknüpfung der einzeln mitgeteilten Vorgänge wenig kümmert. ${ }^{13}$ ) Er ist es zufrieden, wenn sie den Zuschauer für den Augen blick überzeugen und vor allem mitreißen; Zeit um ihnen allzu genau nachzurechnen, läßt er ihm ohnedies nicht.

Der Schlachtverlauf wird durch doppelten Glückwechsel reich aufgestutzt. Nach anfänglich siegreichem Vordringen der Österreicher und verfrühtem Jubel darüber wendet sich das Blatt, die Meldungen lauten schlechter und schlechter, die Niederlage scheint gewiß. Unter großem Aufgebot von Bühnenmitteln, einer gellenden Notglocke, Trommeln und Trompeten und dem Siegesgeschrei der Feinde tritt die Krise ein, zu der eine Falschmeldung von der Gefangennahme des Erzherzogs entscheidend beiträgt. Der neue $\mathrm{Akt}^{14}$ ) hat noch einen weitern Trumpf in Bereitschaft: die geängstigte Gattin liest aus den

ii) IV, $9-$ V, 12; Szenenwechsel V, 13.

12) $\mathrm{Daß}$ man nur vom Turm aus der Schlacht folgen könnte, wird IV, 16 ausdrücklich erwähnt; IV, 8 rufen aufsteigende Brandsäulen den Erzherzog zur Schlacht; IV, 9 verfolgt man sein Abreiten vom Fenster aus. Volksaufläufe, aus denen die Ereignisse erschlossen werden, IV, 16 und V, 5.

${ }^{13}$ ) So scheint der gegnerische Angriff um der momentanen Steigerung willen IV, $19 \mathrm{ff}$. bis unmittelbar an das Schloß zu dringen (IV, 27: ,Sie stürmen das SchloB, rettet euch!") - wogegen später, V, 9 u. 13, klar wird, daß die Ungarn nicht einmal das Stadttor zu gewinnen vermochten.

14) DaB eine Aktpause (IV/V) den raschen Ablauf der Kampthandlung unterbricht, ist eine Schwäche der Anlage. Iffland sieht sich doch genötigt, auf die reale Kampfzeit, die sonst gar zu kurz käme, einige Rücksicht zu nehmen und ihr noch den Zwischerakt einzuräumen; der im übrigen unbedenklich angestrebten Bühnenwirkung tut dies freilich Eintrag. 
Gebärden des unten zusammenlaufenden Volkes die Gewißheit seines Todes. jäh platzt in die allgemeine Verzweiflung die Meldung, daß er lebt, und im gleichen Augenblick steht der Fürst schon wohlbehalten im Kreise seiner Getreuen. Man braucht nicht auf Kleist, der seinen Großen Kurfürsten ebenfalls fälschlich totsagen läßt, auszublicken, urn die sträflich äußerliche Verwendung dieses Spannungsmittels bei Iffland zu erkennen.

Eine besser gegründete Wirkung erreicht er bei der Anbahnung der Schlacht. Ahnlich wie in den Räubern tritt knapp vor der Waffenentscheidung, ja sogar reichlich spät, nachdem der Erzherzog bereits seinen Abgang zum Kampf genornmen hat, ein Unterhändler der Ungarn auf (IV, II), und fordert unter mehrfachem Hinweis auf ihre feuerbereiten Kartaunen zum letzten Mal die Auslieferung des jungen Königs. Es ist bemerkenswert, wie Iffland hier die Parteien, die sich draußen an der Stadtmauer gegenüberstehen, vertretungsweise im Zimmer aufeinanderprallen läßt. In knappem Dialog scheitert die Unterhandlung; die Bedeutung der Stunde, die über Krieg und Frieden entscheidet, kommt bühnenmäßig trefflich zum Ausdruck. Der Theatermann zeigt sich auch in diesem Auftritt: er steigert den Gegensatz der Geister bis zu gezückten Klingen. Aber die Situation gibt den Effekt ohne Zwang her. Ein österreichisch gesinnter Ungar fordert den Landsmann, Räte und Wachen haben Mühe die Losbrechenden voneinander zu halten, als die Meldung vom Beginn der Schlacht den Unterhändler abruft.

Die Schlußszenen des "Friedrich" mit ihrer breiten Massenentfaltung ${ }^{15}$ ) lehren, daß weder ein bestimmter Formwille noch Rücksichten auf beschränkte Darstellungsmittel, die bei dem als Festspiel geschriebenen Stück zum vorneherein unwahrscheinlich sind, die Einengung der Kampftechnik veranlaßt haben. Augenscheinlich erhofft Iffland von ihr wie Spieß die straffste theatralische Wirkung. Sie macht es ihm zudem möglich, das Gewicht der Masse für den letzten Halbakt aufzusparen. Jetzt bringt er auch noch, ein rechter Eklcktiker, die Lokalität zur Geltung ${ }^{16}$ ) und gewinnt erst aus dem Abschluß des Friedens ein bewegtes kriegerisches Bühnenbild. Die Anlehnung an das Ritterstück, die hierin sichtbar wird, ist am deutlichsten in Ifflands Exposition. die sich der Tradition der Postenszenen einordnet. Ein Reisiger hält auf einer ungarischen Burg vor dem Gemach der fluchtbereiten Königin unheimliche

15) Für die Unterhandlung zwischen den Heeren werden V, 15, 17 und 18 genaue Vorschriften an die Komparserie - beidseitiges Kampfgefolge. Volk im Tor, bemannte Mauern - erteilt. die effektvoll mitagiert. Massenszenen vorher nur im Zimmer: Hofversammlung II, 16, Ständeversammlung III, 5. Lohmeyer S. 93.

18) Die Szene (V, 13 ff.) zeipt Tor. Turm und Mauer, mil Wiachen besetzt. Die Ungarn mustern das Tor, das ihren Siegeslauf gehemmt hat. Ihr Feldherr empfindet die Öde der Stäte nach geendetern Getümmel (V, 14). 
Nachtwache. Eulen fliegen gegen die Fenster, die Wetterhähne drehen sich knarrend im Winde, der Sturm hat dem Wächter eine Scheibe gegen den Harnisch geworfen und zerschellt. Die Parole wird soldatisch genau wie nach dem Reglement gefordert, die Bewegungen der Hellebarde dazu vorgeschrieben. Beim ungewissen Licht einer Fackel entwickelt sich das exponierende Gespräch.

Auf weniger gebundene Weise als Spieß und Iffland sucht Schlenkert in „Graf Wiprecht von Groitzsch"17) die Theaterwirkung der Kämpfe; er räumt ihnen die Bühne ein, ohne wie Frühere der Pantomime zu verfallen. Die Routine hat sich der Kampfanordnung bemächtigt und weiß auch das vorgeführte Gefecht spannend zu gestalten; sie duldet in ihm keine toten Stellen mehr und belebt seinen ganzen Verlauf durch raschen Dialog. Wiprecht legt sich $(I, 9)$ gegen die anziehenden Feinde nachts im Wald unter seiner Burg in den Hinterhalt. Herangekommen, beraten diese den Überfall. Die hell erleuchtete Feste, woraus schallende Trompeten und Pauken in die Nacht dringen - der Effekt des Dekorativen wird geschickt in die Handlung verzahnt - läßt ein schwelgerisches Zechgelage vermuten, dessen Rückwirkung auf die Wehrhaftigkeit der Burg man abzuwarten beschließt. Die Ritter haben sich gelagert, der Befehl zum Absitzen der Mannen und zum Grasenlassen der Pferde ist ins Gebüsch hinein erteilt, als drei Trompetenstöße, jeder lauter als der andere, steigenden Verdacht erwecken. ${ }^{18}$ ) Während man gespannt lauscht, schmettern mit theatralisch starkem Einsatz plötzlich die Hörner von allen Seiten, aus den Gebüschen brechen die Wiprechtischen und hauen mit Ruf und Schlag ein. Das straff am Zügel gehaltene Gefecht endet mit der Flucht der Überfallenen.

Das Bühnengeschick Schlenkerts, das sich an dieser Kampfaufgabe bewährt, wird weiterhin an seiner großen Turnierszene sichtbar. Er scheint der einzige

$\left.{ }^{17}\right)$ Augsburger Schaubühne Bd. 66, 1794; Die Autorschaft Fr. Chr. Schlenkerts für das Drama, welche die Schaubühne umschreibend angibt, ist unsicher. $\mathrm{GGr}^{2} 5,495$ u. Franz Brümme r in ADB 31, 464 kennen nur seinen gleichnamigen Roman in 3 Teilen, Zürich 1789-95, der auf den Münchener Bibliotheken fehlt. Da Schlenkert sonst Ritterdramen geschrieben hat und der Wiprecht eine kundige Hand verrät, liegt die Vermutung einer eigenen Bühnenbearbeitung am nächsten; doch weiß auch die Hauptquelle über Schlenkert, W. Lindners wohlinformierter Artikel in „Neuer Nekrolog der Deutschen “ 4. Jahrg. 1826, 2, 1101 nichts von ihr; ebensowenig ist den Arbeiten J. W. Appells, Die R tter-, Räuber- und Schauerromantik, Leipzig 1859 (über Schlenkert S. 53-55) und Karl Müller-Fraureuths, Die Ritter- und Räuberromane, Halle 1894 (S. 6) etwas darüber zu entnehmen. Kays er verzeichnet ein anonymes Schauspiel "Wiprecht“ usw., Meißen 1789. - Brahm übergeht das Stück; vgl. Lohme yer S. 85 u. 87, der irrig Schenckert schreibt.

18) Ganz ähnlich findet sich das Motiv schon in Klingers Grisaldo III, 4: drei verräterische Hornstöße beim Anschlag auf den Helden machen ihn immer mißtrauischer. 
unter den Ritterdramatikern zu scin, der die historisch gegebene Situation für die Biihnendarstellung nutzbar macht. Der Turnierhof mit seinen von $\mathrm{Zu}$ schauern besetzten Galerien bot die Möglichkeit, das Lanzenbrechen von oben beobachten zu lassen, ohne es selbst vorzuführen. Schlenkert legt die Stechbahn vor der Prager Burg (II, 4) derart, daß die Tribüne der Kampfrichter und der Balkon der Fürstlichkeiten die Szcne innehalten, während sie mit dem Eingang zum Turnierplan abschließt. Das Anrennen der Berittenen hört man nur; erst abgesessen, nach vollzogenem Lanzenbrechen und zum Fußkampf, werden die Ritter gesehen; die Pferde sind auf diese Weise vermieden, ohne daß der sachlichen Treue Gewalt geschieht. Schlenkcrts Anordnung gibt mit ihren Aufbauten dem Theatermeister viel zu schaffen; die Anforderungen an die Inszenierung sind stark gestiegen, aber sie werden sachkundig gestellt.

Als die ausschließlichste, wenn auch nur halbdramatische Behandlung der Turnieraufgabe ist Cramers "Turnier zu Nordhausen" ${ }^{19}$ ) bemerkenswert. Der Mischgattung angehörig, die zwischem dem Ritterdrama und dem dialogisierten Ritterroman die Mitte hält - auch diese Zwitterbildung schreibt sich aus dem Götz her - weif das Stück nichts von der strengen Theaterrücksicht Schlenkerts und zerläuft in ein breites Schwelgen in ritterlichen Motiven ${ }^{20}$ ) Die ganze Welt des mittelalterlichen Turniers soll in einer Form dargestellt werden, die eine lebendigere Wirkung verspricht als dic einfache Erzählung. Das Zeremoniell des feudalen Kampispiels, worauf es vor allem abgesehen ist. wird mit der umständlichsten Feierlichkeit ausgebreitet. Nach vollendeter Aufstellung erfolgen unter Trompeten und Pauken die drei Fragen an die Grießswärtel. Turniervögte und Wappenkönige, die Herolde walten ihres

19) Görlitz 1795. Brahm übergehe Cramer völlig, was schon Werners Rez. AfdA 7, 431 tadelt; sje datiert das ..Turnier" wie Haulfen. DNL 138, XI aul 1799; dieser Druck liegt auch mir vor: die Angabe GGr25,510: 1795 wird aber durch die spottende Rezension der Neven Allg. deutschen Bibl. 27. 49 (1796) bestätigt; die Vorrede der Ausgabe von 1799 ist vom 9. Febr. 1796 datiert. Fr. Horn, Poesie u. Beredsamkeit der Deutschen, Berlin 1822 f. 3. 427-30. J. Franck. $\mathrm{ADB} 4$ 4, 558. Appell S. 13-34, ebenso Müller-Fraureuth haben es nur mit dem Romanschreiber zu tun; ein Zitat aus dem. .Turnier" bei diesem S. 51 . Ein Ausfall aul das neuerschienene Stück findet sich bei Tieck, in der Erählung .Fermer der Geniale" (1796). Schriften 15. 186 u. 188, zugleich ein Zeugnis für die Datienung. Vgl. H. Günther, Romant. Kritik u. Satire bei L. Tieck. Heidelherger Diss. 1907, S. 94.

s0) In 3 Bücher abretcilt, enthält es 12 Akte oder Szenen, die meistens mehrere Schauplätze beanspruchen. Eine unüberschhare Personenfulle vird aufgeboien: $\mathrm{Zu}$ über 40 Fürsten, Rittem und Turnierteamten, die anscheinend aus Turnierakien entnommen sind, treten an 10 benamste Knechie und ebensoviele Frauenrollen, ohne das zahlreich vorgeschricbene Gefolge und Volk. Eine längere Vorrede führt in die historischen Verhälınisse ein: es handelt sich um ein geschichtliches Turnier aus dern Jahr 1263. - Die Hauptszenen sind IX. S. 161 A. und XII, S. 212 f. 
Amtes, die „Danke“ und „besondem Danke“, ins einzelne beschriebene Rüstungen, locken die Kämpfer. Nach der letzten allgemeinen Frage über die Unbescholtenheit der Kampfrichter beginnt das Anreiten der Paare. An kein Bedenken der Bühne gebunden, läßt Cramer die Streitrosse über den Grund fegen ${ }^{21}$ ) er kompliziert sogar die Zusammenstöße nach dem Auftreten des geheimnisvollen Unbekannten, der alle Gegner in den Sand streckt: der Fremde fängt einmal einen Stoß mit voller Brust ohne Lanze auf. Belangreicher als solche Kunstreiterstücke sind jedoch die Stellen, wo in die zuchtlose Dialogisierung epischer Kampfschilderung unvermerkt eine Bühnenvorstellung eintritt, von der sich keine noch so ausschweifende Kampftechnik vom Götz bis auf Grabbe ganz frei macht. Hier regiert sie die ersten Waffengänge. Während sie ausgetragen werden, bestreiten ganz ähnlich wie bei Schlenkert die $\mathrm{Zu}$ schauer auf dem Balkon den Dialog und schildern den Verlauf. Später versinken die Bühnenwände, die Ritter selbst nehmen vor dem Losrennen das Wort.

Als schlecht faßbares, zerfahrenes Halbdrama scheint dieses Turnier der lebendigen Darstellung durchaus zu widerstreben. Es steht aber in Wahrheit der gröbsten Theatralgattung, dem Kriegsspektakel, näher als man vermuten möchte und könnte ganz wohl zur Unterlage einer zirkusmäßigen Turniervorführung dienen; Effekte dafür hält es schon in Bereitschaft. Entscheidend ist, daß im Buchdrama dasselbe rohe Gegenstandsinteresse herrscht, wie es der Ausbreitung von Kämpfen zu Fuß und Pferd auf Bühne und Wiese zugrunde liegt. Dieses Kampfspektakel in seiner Vollendung bildet Emanuel Schikaneder aus. Als Verehrer des Theatergefechts ist er uns bei der Räuberschlacht Schillers begegnet; mit der Veranstaltung großer Freilicht-Aufführungen führt er die beiden kriegerischen Zweige der Dramatik seiner Zeit, das Ritterdrama und das Soldatenstück, in die pomphafte Schaustellung über. Für sie schnitt er seinen „Hanns Dollinger, oder das heimliche Blutgericht" ${ }^{22}$ ) zu, den er mit bezeichnender Titelverschiebung als „Kampf Hanns Dollingers mit dem Heiden Krako" auf einer der Donauinseln bei Regensburg zur Darstellung brachte. ${ }^{23}$ ) Schon eine Reihe von Jahren vor Cramers Stück wird damit das Turnier mit allem Gepränge der Ritterwelt leibhaftig vor Augen geführt. Eine dramatische Wirkung steht nicht mehr in Frage. Dafür bekam man nun das

21) Dementsprechend wird auch zu Pferde exerziert: als III, S. 63 eine Ritterpatrouille Roßgetrappel hört, rangiert sie sich und streckt die Lanzen vor - es sind aber Freunde, die nahen.

${ }^{22}$ ) Unter diesem Titel gedruckt in E. Schikaneders Sämtl. theatral. Werken, Wien u. Leipzig 1792, Bd. 1. Die Druckfassung ist auf Wiedergabe im geschlossenen Haus berechnet und vermeidet III, 20 durch Beobachtung vom kurzen Vorhof aus die Pferde; nach der Verwandlung wird das Gefecht zu $F u B$ geführt.

${ }^{23}$ ) Am 20. Juli 1788. Vgl.v. Komorzynski, E. Schikaneder, Berlin 1901, S. 17 u. 98-100. 
Aufcinandertreffen der Kämpen auf geharnischten Rossen wirklich zu sehen ${ }^{24}$ ) und konnte sich in der Weite der Natur an dem kriegerischen Treiben ersättigen. Der Zulauf, den Schikaneder erhielt, bestätigt die immer wache Lust daran.

Den lautesten Erfolg auf diesem Felde errang er mit cinem zeitgenössischen Militärspektakel, dessen Gerippe ihm der ".Graf Walltron” Möllers liefern mußte. Zum mindesten wo er ihn im Freien, in einem Lager von 200 Zelten gab, ${ }^{25}$ ) kann von einer Aufführung des Möllerschen Soldatenstücks kaum mehr die Rede sein, so sehr tritt das Interesse an der Welt der Uniform in den Vordergrund. Das Gegenständliche hat völlig gesiegt; die Handlung dient nur noch zum Vorwand, um das Leben des Feldlagers von der Tagreveille an in einer bunten Folge von Vorfällen der Schaulust zu unterbreiten. Schon Möller dringt dem militärischen Milieu mit förmlichem Standrecht und Exekution starke Effekte ab. ${ }^{26}$ ) Schikaneder vervielfacht den Apparat, verwendet RoB und Wagen, läßt sogar das Exekutionskommando zu Pferde ausrücken und den fürstlichen deus ex machina an der Spitze eines Reiterschwarms ventre à terre zur Hinrichtung daherfegen. Zum wirksamsten Abschluß setzt er endlich eine richtige Bataille an und verspricht, daß .,der anrückende Feind, das BataillonQuarré-Feuer, das Granatenwerfen der Grenadiers, das Kanonieren inzwischen gewiß die größte Täuschung erregen und mit Macht an das Herz jedes empfindsamen Zuschauers rühren" werden. Der Cothaer Theaterkalender, der die Anzeige des Regensburger Naturspektakels wiedergibt, ${ }^{27}$ ) sieht sich genötigt. die Schauspielkunst gegen das Donnern der Kanonen und das Geprassel der Granaten in Schutz zu nehmen und findet zu verwandten Bestrebungen des rührigen Direktors, ..Herr Schikaneder müsse überhaupt von der Allgewalt des Pulvers sehr hohe Begriffe haben". Das beste Bild einer solchen Aufführung. wenn auch von einer bescheidener zu Werke gehenden Truppe, die sich dafür mit Erlaubnis des Generals im wirklichen Lager der Reichsarmee selbst pro-

a) Für die Tradition der Reiterspiele, die an dieser Stelle theatergeschichtliche Bedeutung gewinnt, vgl. den Anhang Pferde. Von fürstlicher Seite wurde ein Turnier am 26. Aug. 1793 in Rudolstadt veranstaltet (Jähns, RR 2, 290). Die jüngste Darstellung in groBem MaBstab wird diejenige sein. welche die chernalige Reichsstadt Ravensburg zur Tausendjahrfeier ihrer Cründung am 3. u. 4. Aug. 1902 ins Werk setzte.

25) In Graz 1782, in Regensburg 1787: Komorzynski S. 7-8 u. 15-16.

se) Vgl. M. v. Schröter. Heinr. Ferd. Möller, Rostocker Diss. 1890 S. 22 ff.; über den militarischen Aufwand die Rezension aut S. 26; dazu Schütze S. 461, der dem „prunkreichen" Walliron nachträgt. $\mathrm{daB}$ er ..such in Hamburg den Geschmack an lärm- und geräuschvollen Stücken sehr befestigen" half. Hauffen DNL 138, XXXII: Stockmayer S. 38, 31 u. 51.

${ }^{27)}$ Theaterkal. aut d. Jahr 1788 S. 89 , in ."Miscellaneen zu des Lesers Kurzweil": abgodr. bei Komorzynski S. 15-16. 
duzieren darf, liefert Tieck $;{ }^{28}$ ) da sie schnell ein böses Ende nimmt, sind wir um ihren Verlauf im einzelnen gekommen, aber die ironisierende Schilderung der Vorbereitungen setzt immerhin den rein gegenständlichen Reiz ins Licht, der in diesem Spielen zwischen Kanonen und Pulverwagen gesucht wurde.

Wenn Schikaneder sich mit seinem Walltron auf das geschlossene Haus beschränkt sieht - Nicolai überliefert die Ankündigung einer Augsburger Aufführung ${ }^{29}$ ) - so beeilt er sich zu versichern, daß er das Stück ebenso gebe, wie wenn es unter freiem Himmel geschähe. Zwar auf die Pferde muß er stillschweigend Verzicht leisten, dafür bietet er umsomehr Musikanten auf und rüstet die Akte abwechselnd mit Trommeln und Pfeifen, Feldmusik und türkischer Musik aus. Nebst dem Wecken wird der Morgensegen geblasen, die Runde ums Lager gerufen; praktikable Zelte müssen noch im tiefen Hintergrund stehen, für jeden Akteur eine Uniform neu verfertigt sein - kurz, es ist nicht minder auf das militärische Panorama abgesehen.

Neben den zurechtgestutzten Walltron treten eigene kriegerische Schaustücke Schikaneders, wiederum für die Vorstellung im Freien eingerichtet. Der "Grandprofos" ${ }^{30}$ ) bringt Angriffe der Husarenposten, abwechselndes Kanonen- und Musketenfeuer. Das Kampfspektakel gipfelt in der Spätzeit des rastlosen Unternehmers, der in den "Schweden vor Brünn" mit Truppen, Kanonen und Pferden eine unsinnige Verschwendung treibt. ${ }^{31}$ )

Von verwandten Bestrebungen weiß die Theatergeschichte der Zeit mehrfach zu berichten. Auf der Hamburger Bühne ${ }^{32}$ ) führte im Frühjahr 1789 ein reisender Fechtmeister Miré mit hamburgischen Stadtsoldaten ein FechtSpektakel unter großem Andrang auf. Geringeren Zulauf hatte eine Festungsbestürmung, die er das Jahr darauf ,mit viel Waffengetöse, Geschrei und Getrommel“" inszenierte, und zwar, weil ihm der aktuellere Titel „Die Zerstörung der Bastille" verboten wurde, als "Schlacht zu Pursa“. Der Lust am kriegerischen Getümmel und Pomp, der solche Darstellungen einzig dienen, war die Oper von jeher mit reichen Mitteln entgegengekommen. An sie schließen sich diese Bataillen-Pantomimen an. Am weitesten trieb den militärischen Aufwand der Herzog von Württemberg, dessen Ludwigsburger Haus bei geöffneter Rückwand kriegerische Evolutionen der gesamten Garnison im freien Gelände

28) Phantasus, Schriften 5, 441-46; dazu Köpke, L. Tieck, 1855, 1, 164-66; Petersen S. 249 u. 257.

29) Reise durch Deutschland usw. 8 (1787), S. 151-52.

30) Regensburg 1787; vgl. Komorzynski S. 16 u. 92-94; Theaterkalender 1788 S. 90 ; A. Sauer in ADB 31, 198.

31) Vgl. Komorzynski S. 72. Massenkämpfe auch in "Graf Schembera“, vgl. dac. S. 73 u. 181 .

32) Schütze S. 623-25. 
verstattete. ${ }^{33}$ ) Fürstliche Soldatenpassion tut sich hier an denselben Schauwirkungen gütlich, die Schikaneder der Menge bot; zur Aufführung von Sacchinis Calliroë wurde beispielsweise eine Truppenmacht von 16 Unteroffizieren und 470 Gemeinen, worunter 30 Husaren zu Pferde, als Skythen, Assyrer und Meder eingekleidet. ${ }^{34}$ ) Effektvolle kriegerische Aufzüge gehören zum festen Bestand der großen Oper; in späterer Zeit war aus Spontinis „Ferdinand Cortez" der Zug des Heeres, FußBvolk, Reiterci. Artillerie, bei Nacht über das Gebirge berühmt, den ein Berichterstatter der Aufführung in Berlin dem alten Coethe ${ }^{35}$ ) schildert.

\section{Die Höhe der Theaterwirkung: Kotzebue.}

Während auf der einen Seite die Vorführung von Gefecht und Schlacht in die bloße Schaustellung ausläuft, die zur Entfaltung des größten Apparates folgerichtig das Freie sucht, tritt in Kotzebue der Mann auf den Plan, der den

33) Devrient' 2, 301. Petersen S. 195.

s) 10. Jan. 1779: J. Sittard. Zur Gesch. der Musik u. des Theaters am württemberg. Hofe, Stuttgart 1890-91, 2, 153. Weltrich. Schiller 1, 687. - Die Sitte, Soldaten als Komparserie zu verwenden (Petersen S. 252, Lohmeyer S. 114) grift von den Hoftheatern, wo sie allgemein ist, auch auf die Unternehmer über. Schikaneder (Komorzynski S. 7) verschaffe sich zur Aufführung von Törrings Agnes in Salzburg 1780-81 60 Soldaten. Fast unentbehrlich war ihre Mitwirkung beim Soldatenstück, wo sie dem Direktor zugleich die Anschaffung von Uniformen in größerer Zahl ersparen konnten. Nach Karl Lessings Zeugnis (Lessings Leben 1. Berlin 1793. S. 240, vgl. Koherstein ${ }^{5} 5.395$ und Stockmayer S. 95) war manche Truppe nicht imstande, in einer Stadt, die keine Besatzung hatte, ihre gangbarsten Stücke zu geben. Schütze klagt S. 516 über den Manzel geübter Schauspie'er in dea figurenreichen Stücken: .Wer kaum zum Stuhlsetzen taugte, mußte, in eine Uniform geknöpft, den Kricgshelden hinstellen." Natürlich sah man es von militärischer Seite nicht gern, daß des Königs Rock zum Komödienspiel gebraucht wurde und drang daher zum mindesten auf Veränderung der Abzeichen. Eine lustige Verhandlung darüber mit dem bärbeiBigen General von Spörken überliefert Fr. L. Schmidt, Denkwürdigkeiten. Hamburg 1875, I, 208-11 aus Schröders Mund; vgl. F. L. W. Meyer. Schröder, 1819. 1, 251. Schrö̀der verlangt für Stephanies .Deserteur aus Kindesliebe" (nach Meyer: für Monsignys. .Deserteur") Statisten, der alte würdige Herr will aber nichts davon wissen, $\mathrm{daB} s \mathrm{~s}$ in ihrer eigenen Uniform auftreten, und der Direktor muß ihm cin Stück der Montur nach dem andern abmarkten. - Ergötzlich spielt die Zwischenstellung solcher theatralisch verwendeten Soldaten in den oben angezogenen Walltron-Bericht Tiecks (Schriften 5, 445-46) herein. Des als Schildwechen an der Lager-Aufführung mitwirkenden Reichstruppen hat man zur Schonung kaiserlicher Majestät papierene Klappen und Aufschlige in anderer Farbe übergeheftet. In der entstehenden Unordnung läßt sich Lothar hinreißen, sich an einem dieser Posten. der die Ruhe herstellen will, zu vergreifen. Nur daß nichs klar ist, ob die angefallene Wache mehs theatralischen oder kaiscrlichen Charakter hatte, rettet ith vor schwerer Strafe.

$\left.{ }^{35}\right)$ J. Ch. Lobe: Coethes Gespräche : 2, 473. 
Kampf innerhalb der Bühnengrenzen am reichsten ausbildet. Er ist der eigentliche Theatraliker des Kriegerischen und in diesem Sinne der Vollender des im späteren Ritterstück Angestrebten; ohne ursprüngliches Verhältnis zur Kriegswelt, aber mit sicherem Blick für ihre Bühnenmöglichkeiten. Von Schikaneder trennt ihn ein scharfer Unterschied. Kotzebue ist sicherlich keinem Aufwand, und am wenigsten dem militärischen abhold; aber er läßt ihm nirgends so weit die Zügel schießen, daß die feste Handlungsführung darüber verloren ginge; er denkt viel zu bühnenmäßig, um dem lockeren Spektakel zu verfallen, und hält auch seine Kampfpantomimen straff.

In Kotzebues schier unerschöpflicher Produktion, die keine dramatische Gattung von der klassizistischen Tragödie bis zur Burleske unversucht läßt, beansprucht die kriegerische Sphäre einen breiten Platz. Eine scherzhafte Prophezeihung Brentanos, worin er die beiden Bühnenfürsten der Zeit kontrastiert, kann darauf anspielend sagen, daß „die Kotzebue teils im Krieg, die Ifflande aber im Bette aussterben " werden, ${ }^{36}$ ) und die Satire der Romantiker nimmt die Kriegstheatralik des Gegners mit besonderem Eifer aufs Korn. In der Reihe seiner ernsten Schauspiele, die hier in Frage steht, sind nalezu ein Dutzend Stücke kriegerischen Inhaltes, etwa die Hälfte enthalten Schlachten. Eine einheitliche, für den Autor charakteristische Form der Kampfgestaltung ist von Kotzebues Eklektizismus nicht zu erwarten. Er handhabt ohne feste Richtung nach Bedarf die eine und andere und schließt sich hier und dort an. Dafür zeigt er sich im Erreichen der besten Wirkung jeder Anlage als Meister, der das Handwerkliche wie wenig andere versteht. Er bingt für die Kampfdarstellung, wie für alles Technische, eine in diesem Grad noch nicht gekannte Bühnengewandtheit mit. Das Theaterverdienst der ernsten Dramatik Kotzebues ist sehr groß, und kaum genügend gewürdigt, obwohl schon Goethes gewichtige Stimme nicht einzig dem Komödienschreiber Gerechtigkeit widerfahren ließ3. ${ }^{37}$ ) Dem technischen Verdienst im besonderen werden wir auf Schritt

36) Aus dem „Dramaturgischen Beobachter" Wien 1814; abgedruckt bei Jacobs, Deutsche Schauspielkunst S. 191.

37) Die Literaturgeschichte hat sich von der Verurteilung Kotzebues in Bausch und Bogen, die sich besonders auf seine übeln Pamphlete gründete, langsam erheben müssen. Die Rolle, die W. v. Kotzebues Buch, Dresden 1881, dabei spielte, ist bekannt. Für die Zwecke neuerer Forschung wäre höchst dienlich gewesen, wenn es das reiche Material an Rezensionen und Urteilen, das Familiennachlaß und eigene Sammeltätigkeit bot, tabellarisch verzeichnet hätte, statt nur die eine und andere Probe daraus zu geben - was seinen Absichten freilich fernlag. Max Kochs reiche Darstellung des Biographischen und der Streitfälle in Ersch u. Grubers Enzyklopädie, Sektion II, Bd. 39 (1886) S. 180-189 behandelt die Werke nur kurz; trotz einem Aufschwung zu gerechterer Würdigung (S. 188) fährt Kotzebue im ganzen wohl noch zu schlecht. Eine Lanze für seine ernsten Stücke, besonders die Kreuzfahrer, bricht L. Geiger, ADB 16 (1882) 
und Tritt begegnen und seine Bedeutung auch dort anerkennen müssen, wo es in allzu leichter Anwendung zum äußerlichen Griff erstarrt.

Die Chronologie der Stücke fällt für die technische Betrachtung nur wenig ins Gewicht, weil Kotzebue, von keiner inneren Notwendigkeit bestimmt, mit den vorhandenen Formen nach Belichen schaltet ${ }^{38}$ ) Der größere Teil der kriegerischen Dramen ist in enger Nachbarschaft um die Wende des Jahrhunderts entstanden. Dennoch weist diese Gruppe eher stärkere Unterschiede auf als sie zwischen ein paar andern Stücken bestehen, die der frühern und der Spätzeit angehören. Im ganzen verändert Kotzebue als reiner Theaterschriftsteller sein Zicl nicht. Er greift zwar bereitwillig auf, was die Entwicklung bringt, wenn es neue Wirkungsmöglichkeiten verspricht, aber er ist daneben durchaus nicht gesonnen, die erprobten Wege aufzugeben. Seine Vielseitigkeit hat noch eine besondere Folge: er nimmt nicht nur an allen Gattungen, am Ritterschauspiel sowohl wie am bürgerlichen Soldatenstück und am historischen Drama teil, sondern vermittelt auch vielfach zwischen den sonst getrennten Gebieten, indem er Motive von da und dort zu neuer Verbindung zusammenfügt. So ragt in den „Hugo Crotius” aus den Offziersstücken der Konflikt

S. 778-79. Die knappste Charakteristik der gesamten Produktion gibt A. Hauffen, DNL 139;1I. scharf und treffend, aber im Uneil vielfach zu streng. Den zweifellosen Qualitäten Kotzebues (S. 14) wird im einzelnen wenig Rechnung getragen, die ernste Dramatik (S. 18-19) durch den Vergleich mit Schiller, den sie nicht aushält, vällig gerichtet. Sehr bezeichnender Weise hat gerade Kotzebue einen französischen Bearbeiter gefunden: Ch. Rabany. Kotzebue, sa vie et son temps, ses aruvres dramatiques, Paris-Nancy 1893. der seine dem romanischen Wesen naheliegende Begabung, das Theatergeschick, die straffe Zusammenfassung der Wirkung, den schlagenden Dialog usw. bedeutend höher einschätzt. als die deutsche Forschung. Minors Rezension. Cött. Cel. Anzeigen 1894, 1, 34-62, die dem Buch nach Lob und Tadel durchaus gerecht wird. betont einleitend stark die umfassende literarhistorische Bedeutung der kotzebueschen Produktion und mustert ausführlich seine dramatischen Motive, ohne auf die theatralische Seite wenigstens der ernsten Stücke einzugehen. Für die neuerliche Wertschätzung von Kotzebues Technik vgl. z. B. Petersen S. 467. - Die Urteile Coethes über ihn sind nach einem ersten Aufsatz W. v. Biedermanns in W. v. Kotzebues Buch vollständig gesammelt in C. Stengers abschlieBender Arbeit: Goethe u. Aug. v. Kotzebue, Breslau 1910 (Breslauer Beiträge Heft 22). die in der Anerkennung des Theaterbeherrschers Kotzebue im Anschluß an Goethe weiter fortschreitet; vgi. besonders S. 57 \&. u. S. 174.

as) Vgl. Hauffen DNL 139 II. S. 15. Dagegen tadelt Minors Rez. S. 40 an Rabany im allgemeinen. daB die Zeitfolge xu wenig berücksichtigt sei. Für manche Fragen in den Beziehungen zu andern, z. B. im Verhältnis zu Schiller, wäre ein genaues Verzeichnis der Erstauffühnungen wünschenswert. Die Datierung der Drucke hielet keine genügende Handhabe, da die Stücke nach der Ubung der Zeit aus Rücksicht auf die Bühnen meistens erst spät, nach 1-2 Jahren veröffentlicht werden. Leider folgt Rabanys Bibliographie der alten guten Gewohnheit der französischen Bibliographen, die Premièren zu vermerken, nicht. 
zwischen Herz und Dienstpflicht herein; in der ritterlichen Welt des „Grafen von Burgund" tummelt sich der Invalide des Soldatenlustspiels.

Dem Ritterstück wendet sich Kotzebue gleich im Beginn seiner theatralischen Laufbahn mit dem ersten Trauerspiel, ,Adelheid von Wulfingen “" ${ }^{39}$ ) zu, freilich noch nicht dem ritterlichen Kampfstück. Die Blutschande-Tragödie nutzt ein Kampfmotiv nur zum effektvollen Einsatz: sie hebt nach soeben beendigtem Gefecht auf den rauchenden Trümmern eines Wendendorfes an. Theobald der Wulfinger, ein sentimentaler, von Mitleid für die Heiden bewegter Gottesstreiter, gebietet als Führer dem Sengen, Brennen und Morden Einhalt. Es ist für Kotzebues Richtung charakteristisch, wie bereits hier ein kriegerischer Auftakt, ohne Belang für die Handlung, lediglich zur reichen Bühnenerscheinung beitragen muß. Die Aufmerksamkeit auf das Dekorative ist von Anfang an wach. Der dankbarste szenische Vorwurf, den das Ritterdrama bot, die Burg, ${ }^{40}$ ) wird zur Geltung gebracht, ohne daß die Entfaltung im Raum für das Ehekonfliktsstück notwendig wäre. Kotzebue zeigt für den Burgschauplatz in der Folge so große Neigung, daß W. Schlegels parodistische Mischdekoration zum Schauspiel der „Ehrenpforte“ mit Fug und Recht auch eine alte Burg als unentbehrliches Requisit seines theatralischen orbis pictus aufstellen konnte. ${ }^{41}$ ) Wir haben früher ein besonderes Burgenstück unterschieden, dem der junge Tieck im „Karl von Berneck“ und auch in Szenen der "Genoveva" nahetritt. Der Theatraliker Kotzebue ist daran erkennbar, daß er seine Motive zu straffer Wirkung braucht, sich aber weder aus sachlichem noch aus poetischem Interesse in die Burgenwelt verliert. ${ }^{42}$ )

Ihre effektvollste Darstellung erreicht er in "Johanna von Montfaucon “" ${ }^{43}$ ) die für eine reiche Kriegshandlung geschlossene und offene Kampftechnik nebeneinander anwendet und ein gutes Beispiel dafür liefert, wie das Theater nunmehr alle Formen zu seinen Zwecken handhabt. Der erste Akt

30) Reval u. Leipzig 1789; Werke Bd. 3. Brahm, Ritt. S. 139 u. 152; Rabany S. 148-51.

40) II, I Graben und Zugbrücke, Platz vor der Burg. II, 4 begrüßt der alte Wulfinger als heimkehrender Kreuzfahrer seine liebe Burg, ein Motiv, das in Tiecks Karl von Berneck II (Schriften 11, 47 f.) wiederkehrt; bei Kotzebue selbst findet es sich neuerdings in Johanna von Montfaucon V, 7; das Ansprechen der Burg ist seit Babos Otto häufiger und hat meistens stimmungsmäBigen Einschlag.

41) W. Schlegel, Werke 2, 79. Das allmähliche Erwachen einer Burg im ersten Tagesgrauen ausführlich im „Gustav Wasa“, Eingang zu III. Romantische Burgdekoration ferner im „Hu go Grotius" II, I ff. und im ,Schutzgeist" II, 2, hier wie dort bei Nacht (wellenbespültes Kastell an der Maas - WasserschloB am Comersee).

12) Die Liebe zum alten Gemäuer, auf die er als Theaterdichter rechnet, ironisiert er selbst in Tardieus Erzählung von seinem wackligen StammschloB, im „Bayard" III, 6.

43) Leipzig 1800. Werke Bd. 10. Brahm, Ritt. S. 138.

Scberrer, Kampf im deutschen Drama. 
schlieft damit. daß Lasarra seine Söldner aus dem Hinterhalt zum nächtlichen Uberfall aut das verratene Grandson hervorruft. Das Ereignis selbst erfaßt Kotzebue in seinem Reflex, wie es das frühe Ritterstück aus Befangenheit, aber schon ein Spieß aus richtigem Kalkül gegeben hatte. Die Theatralik ist jetzt in voller Blüte: Kotzebue greift zu ciner pantomimischen Einzelszene im spärlich erleuchteten Waffensaal der Burg, worein aus der Ferne verwirrtes Getöse und Schwertergeklirre dringt. In der Mitternacht aufgeschreckt, eilt Johanna cinsam und angstvoll durch dic Gemächer. Alieht, steht und horcht auf das draußen um sie gefochtene Treffen, das sich in ihren Gebärden malt eine dankbare Aufgabe für schauspiclerisches Können. Kein Mann erscheint. weder Gemahl noch Knappe, keine Meldung gibt Kunde vom Verlauf, bis die eindringenden Sieger hier, "wo Weiber hausen", die Klingen einstecken dürfen.44) Dafür hebt musikalischer Aufwand die Wirkung des stummen Auftritts. Von der beiläufigen Unterstuitzung der Illusion durch Hörner und Trompeten geht Kotzebue zur eigentlichen Orchesterbegleitung der Gefechtsvorgänge über. Eine so opernhafte Anwendung der Kampfmusik ist neu, entspricht aber seinem allgemeinen Streben, aus dem musikalischen Element für die Bühne allen erreichbaren Vorteil zu ziehen.

Nachdem die Zwischenaktsmusik gelernt hatte, sich dem dramatischen Cang einzuordnen, ${ }^{45}$ ) konnte sie auch der Kriegshandlung zu Hilfe kommen. Dyks "Coriolan" läßt in einer Aktpause eine Sinfonia di guerra aufführen. ${ }^{46}$ ) schon vor ihm deckt Klinger im „Konradin“" durch eine .wilde Schlachtmusik” den Szenenwechsel, der innerhalb des Aktes $(1,5)$ zur Gegenpartei führt. Schiller ersetzt später in der Jungfrau von Orleans durch das Kriegsgetümmel einer Verwandlungsmusik (III. 5) geradezu eine Bühnenschlacht. In lockerer Verbindung mit der Handlung stützt die abschließende Siegesmusik den scheinbaren Soldatentod Egmonts, am großartigsten endet der .,Kriegstumult im Orchester, zuletzt übergehend in militärisch heitre Weisen" die Schlacht der Elemente im zweiten Teil des Faust. Dic kriegerischen Symphonien Kotzebues sind zahlreich. Beim vierten Aktschluß seiner ..Octavia” nimmt ,eine wilde Symphonie" das Schlachtgetöse hinter der Szene auf, cine "abenteuerliche" Eröftnungssymphonie führt das Lagerbild der "Kreuzfahrer" ein, im ersten Zwischenakt des ..Heinrich Reuß" soll eine Zwischenmusik, die oft durch

(1) Il. I: der Hergang in einzelnen wird gelegentlich nachgetragen: Versuchte Rettung und Cefangennahme des Sohns 11. 3: ebendort Flucht des Gallen: die Kammerfrau hat ihn auf der Brücke wacker fechlen sehen 11, 6: der Flüchtige selbst crzahlt Ubestall und Uberwäligung Lirn II. 9.

4) V'gl. uher ihre Entwicklung Waniek S. 206 ff. u. Pelersen S. $148 \mathrm{ff}$.

"e) 1786; da mir das Stück selber nichi zu Gehole stand, folge ich der Angabe Petersens S. 141 . 
Kanonendonner unterbrochen wird, die Belagerung Marienburgs andeuten. ${ }^{47}$ ) Über diese musikalische Beihilfe im Z Zwischenakt hinausgehend, läßt die

47) Was auf musikalischem Gebiet in der Zeit möglich war, dafür liefert das Programm eines "Instrumental-Tonstücks, eine Bataille vorstellend“", im Zettelband $4^{0}$ Hist. 2605 (II) der Univ.-Bibl. München, das hier als Kuriosum wiedergegeben sei, einen sprechenden Beweis. Der Kapelldirektor Klöffler aus Bentheim-Steinfurth - der Schikaneder des Konzertsaals führte am 3. Jan. 1787 im Münchener Komödienhause mit „2 Orchestres, die aus 50 der geschiktesten Tonkünstler bestehen", eine Instrumentalbataille auf, die auf ihrem Feld das WalltronSpektakel noch überbietet. Es war ,ein von $\mathrm{ihm}$ komponirtes, ganz besonderes Tonstück... welches in London, Berlin, Koppenhagen, Königsberg. St. Petersburg und Mosko allen Beifall erhalten" hatte. Die „Beschreibung der Musikbataille“, zu der "das Orgester in zwey Chöre getheilet" wird, lautet:

„1. Eine zweychörichte Overture, bestehend aus einem Allegro, Andante und Presto, macht den Prolog zur Bataille; dann folgt:

2. Der Eingang, oder die ernsthafte und schreckbare Musik vor dem Marsch beyder Armeen.

3. Die Avantgarde rückt vor, und die Husaren flankiren, man hört auch einige Musketenund Kanonenschüsse.

4. Verschiedene Märsche der beiden Armeen, zwischen welchen einige Musketen- und Kanonenschüsse abwechseln.

5. A. Die Bewegung der beyden Armeen zum Anmarschiren, begleitet von der Kanonade auf beyden Seiten.

B. Das Pelotonfeuer der Infanterie von beyden Seiten.

C. Der Sturm und Vernichtung der feindlichen Armee.

D. Der lezte Angriff mit Musketenfeuer auf die erste feindliche Linie.

E. Die Eroberung der Redoute.

6. Ein Ungewitter, welches zwischen beyden Armeen ein Stillstand macht.

7. Der Kriegsrath der einen Armee. Ein begleitetes Recitativ, Violino solo.

8. Zeichen zum Angriff für die Kavallerie.

9. Der Angrift selbst.

A. Der Trapp der Pferde. B. Der Galopp. C. Geschrey der Kavallerie. D. Das Ceräusch der Waffen.

10. Die Flucht der Feinde.

11. Die überwundene Armee bläßt zum Rückzuge und setzt sich wieder.

12. Zeichen zum abermaligen Angriff für die Kavallerie der siegenden Armee.

13. A. Der Trapp der Pferde. B. Der Galopp. C. Geschrey der Kavallerie. D. Unordentlicher Lärm beyder Armeen.

14. Die siegende Armee bläßt zum Rückzuge, nachdem das feindliche Bataillon sich wohl vertheidigt hat.

15. Die Husaren flankiren noch, und man hört einige Nachschüsse.

16. Der Vorgang und die Einleitung zum Verbinden der Verwundeten.

17. Die Empfindung vor der Verbindung.

18. Noch größere Empfindung und Schmerzen.

19. Das Klagen und Seufzen der Verwundeten bey der Verbindung. 
..Johanna" das Orchester ganz im Sinne der Oper neben die Bühnendarstellung treten und verflicht Musik und Pantomime zu einer theatralisch fesselnden Wechselwirkung. ${ }^{48}$ )

Musikalische Unterstützung bescheidenerer Art ordnct Kotzebue als geschickter Arrangeur überall zu seinen Kämpfen an, gleichgültig ob sie vorgeführt oder hinten behalten werden, und die Romantiker lassen ihn darob nicht ungezaust. Die Harsthörner der "Johanna" streift Schlegels Distichon, die kricgerische Musik wird in der "Ehrenpforte" auf Maultrommeln erzeugt. ${ }^{49}$ ) Am lustigsten trifft eine Kapriole in der Gustav Wasa-Parodie Brentanos die äußerliche Verwendung der Musik zu Bühnenzwecken: Der Schauspieler, der den Fischer darstellt, bittet dic Baßgeige um Mithilfe beim Seesturm, sie schämt sich jedoch. „so ganz nackicht auf dem Theater zu stehen". ${ }^{00}$ ) Kotzebue schreibt zwar gerade an dieser Stelle des .Wasa", wenigstens im Buch, keine Musik vor; wenn dic Aufführung, die Brentano im Auge hat, sie dennoch einsetzte, und den Sturm nach der einleitenden Zwischenakts-Symphonie noch

20. Viktoria, ein dreymal wiederholtes lelshaftes Allegro, zwischen welchen ein Siegesfeuer von Musketten und Artillerie gemacht wird.

21. Verschiedene Märsche machen den Beschluß der Bataille."

Die Programmusik wird kaum höher getricben werden können. Von dem Kriegsrat, der als Violino solo offenbar sehr sanft erscheint. über die Attacke - sie muB das Clanzstück gewesen sein und erscheint daher zweimal - bis zu den ausgedehnten Empfindungen der Blessierten bei der Tätigkeit der Sanität ist nichts, was in dieser Musikbataille nicht in Tönen spräche. Allerdings doch nur so bestimmt deutbar, daß kein Hörer des gedruckten Inhalts entraten konnte, den er daher bei der Entree umsonst erhielt. Es kann kein abschreckenderes Exempel zu Nietzsches bekannten Sätzen über den neueren attischen Dithyrambus (Die Geburt der Tragödie. Werke, 1. Abt. 1, 121), daB die Musik in frevelhafter Weise zum ,imitatorischen Konterfei der Erscheinung z. B. einer Schlacht, eines Seesturmes gemachi" sei, geben als dieses Programm. Aber sicher wäre hier der Akustiker gewesen, dessen Unterstützung Kotzebues Kampfdramatik überall anstrebt. Ein reiches Material solcher Musikbataillen verarbeitet der Aufsatz E. Bienenfelds, Cber ein bestimmtes Problem der Programmusik, Zeitschr. der internat. Musikges. 1906,07 S. $170 \mathrm{ft}$.

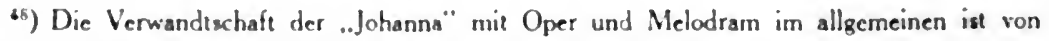
Rabany S. $154-55$ stark betont.

") Ehrenplorte und Triumphbogen für den Thenterpräsidenten v. Kotzebue usw. [Ende 1800]. VRl. Haym 325 f.; E. Schmidt, Caroline 2,600. A. W'. Schlegels Werhe 2, 277 u. 303.

so) Gustar Wasa, Leipzig 18C0. Hrsq. von J. Minor. DLD 15. 1883. Die Stelle S. 97 f.; vgl. S. III, wo aus Rücksicht auf das überlastete Instrument keine Symphonie mehr möglich ist; es muB ohnedies im letzten Akt noch..das Murren des schwedischen Volks uber den schreckliehen Tyrannen Christiern grundiren". Das musikalische Ungewitter darf neben der starken Kanonade in der oben abgedruckten Musikbataille nicht fehien: auf den Babeigen-Secsturm zuele such Nietzsche. 
bei offener Szene orchestral begleiten ließ, so mag es im Anschluß an den effektvollen "Schiffbruch" von Brandes ${ }^{51}$ ) geschehen sein, dem Kotzebue und andere die Seemotive verdanken. Brandes macht vom Orchester den ausgiebigsten Gebrauch und erkennt ihm selbst einen wesentlichen Anteil an dem großen Bühnenerfolg zu. ${ }^{52}$ ) Er zieht die Musik am wirksamsten zum Sturm heran, daneben aber auch zu kriegerischen Vorfällen, deren guten Bühneneindruck er ebenfalls rühmt. ${ }^{53}$ ) $\mathrm{Er}$ ist darin ein Vorläufer Kotzebues, und man möchte fast vermuten, dieser sei ihm auch für die Nachtszene der Johanna verpflichtet, so eng berührt sich ein Auftritt der Fanny im "Schiffbruch“" mit ihr. Brandes gibt während des Aufstandes der Insulaner, der seine Kriegshandlung ausmacht (IV, 9-12), eine monologische Besorgnisszene der Heldin, die in Todesängsten auf das Getöse lauscht und durch das Fenster in die undurchdringliche Dunkelheit auszuschauen versucht.

Nach dem stimmungsmäßig erfaßten Schloßsturm befriedigt noch der gleiche zweite Akt der ".Johanna" das sachliche Interesse am Kampf durch eine ausgedehnte Fechterszene, die von den Schauspielern und Komparsen kunstgerechte Durchführung verlangt. Von einer Knechteschar angefallen, nehmen Johannas Gemahl Adalbert und ein Begleiter (II, 10) Rücken an Rücken Position und halten sich brav, bis ganz im Sinne des Combattements ein Effekt dem Widerstand ein Ende macht: als der eigene Vater wütend auf den Cenossen Adalberts eindringt, entsinkt ihm das Schwert, und sie werden gefangen.

Eine ganze, breit entfaltete Theaterschlacht bringt der fünfte Akt und liefert mit ihr ein Spezimen für alle Stärke und Schwäche der Kampftheatralik. Der totgeglaubte Gatte Johannas setzt die Wiedereroberung seiner Burg im Augenblick ins Werk, da der Usurpator Lasarra sich anschickt, die endlich Gefügige zum Altar zu führen. Die üblichen Meldùngen ${ }^{54}$ ) rufen den Frauenräuber von der Seite der Geliebten zur Abwehr. Ein reicher Verlauf ist erfunden: während Lasarra gegen Adalberts Scharen ficht, formiert Johanna selbst in der Burg aus gefangenen Knappen eine dritte Streitmacht und führt an ihrer Spitze den Sieg herbei. Den Sturm auf Wall und Schanze vermeidet Kotzebue wie alles zu Gegenständliche, das nur die Ohnmacht der Bühnenwiedergabe verrät. Er verlegt seine Kämpfe insgesamt ins Freie, wo ein rasches

${ }^{51)}$ Zuerst als ,.Miß Fanny oder der Schiffbruch“ 1765 in München aufgeführt; eine zweite Fassung 1766; die dritte 1781; vgl. Jörde ns 1, 190; J. Klopfleisch. Joh. Chr. Brandes, Heidelberger Diss. 1906, S. 93. Benutzt in Augsburger Schaubühne Bd. 33 (I791).

58) Meine Lebensgeschichte, Berlin 1799 f. 2, 275; 327; Schütze S. 509.

$\left.{ }^{53}\right)$ Lebensgeschichte 2, 328. "Schiffbruch" V, 1-5 Marsch der Insulaner unter kriegerischer Musik über das Gebirge; Verfolgung Fannys mit Musikbegleitung.

54) V, 5 drei Boten: Hirten, Bauern und Ritter ziehen gegen die Burg und machen mit WurfgeschoB, Sturmbock und Mauerbrecher Anstalt. 
Hin- und Herwogen von Kulisse zu Kulisse stattfinden kann. Lasarra muB einen Ausfall machen. Johsnnas Trupp ihm folgen. Vom ersten Teil der Schlacht wird nur dieses schnelle Vorbeiziehen der Haufen sichtbar. Die Dekoration zeigt die Gegend am Fuß der Burg, oben ihr Tor und die Zugbrücke, das unentbehrliche Requisit, das hier die größte Bedeutung für die Führung des Theaterkriegs erhält. Kotzebue läßt sie geschickt nicht auf die Bühne, sondern in die Kulisse münden, denn es liegt ihm viel am anfänglichen Verdecken des Getümmels. Zuerst halten zwei Nichtkombattanten, der Eremit und Hildegará, die Szene besetzt; der Sturm soll rückwärts geschehen. Sie unterstreichen die Vorgänge, den Auszug der Verteidiger über die Brücke, das Nachfolgen der glänzend gewappncten Johanna mit ihrer Schar, und nehmen eine Meldung vom Verlauf des Kampfes entgegen. Dann hebt die Bühnenschlacht selhst an, und hier führt Kotzebue die kunstgemäße Kampfpantomime auf die Höhe. Nicht allein, daß er den hinteren Teil der Bühne mit Felsen verbaut, ${ }^{55}$ ) macht das Theaterverdienst dieser Gefechtsszenen aus, obwohl dadurch viel gewonnen wird. Nur fragmentarisch aufblitzend, erscheinen die Kämpfe bewegter und interessanter; die zu genauc Einsicht in sie ist benommen und zugleich das Statistenvolk der Kontrolle seiner Stärke entzogen. Mit vollendeter Theaterkenntnis wird das Schlachtgeschehen gegliedert; drei getrennte Ereignisreihen fügen sich zum einheitlichen, überreichen Bühnenbild zusammen, ohne doch die entscheidende Einzelszene zu verdunkeln. Während die Hauptkräfte in den Felsen aufeinandertreffen, wird im Hintergrund die erhöhte Zugbrücke ${ }^{56}$ ) zum Schauplatz wechselvoller Teilkämpfe zwischen den Knappen und einem lasarrischen Trupp. der die Rückenbedrohung abwehren will. Gleichzeitig stellt Kotzcbue den Führerzweikampf, aus der allgemeinen Schlacht losgelöst, in den Vordergrund der Bühne. Er behält da mit trotz dem lautesten Getümmel das Heft fest in den Händen und schließt hier seine Gefechtshandlung mit dem krönenden Theatereffekt. Im Augenblick, da Adalbert

s) Die Vorschrift dazu V. 9; den Einfall rühmt bereits Petersen S. 250 und Lohmeyer S. 83. Petersen bringt auch schon die verwandie Einrichtung der Mannheimer Bühne für den Julius Cäsar bei, die Iffland (Theatralische Laufhahn, DLD 24.59) überliefert. Nur fiel bei dieser die éelserfüllte Bühne nach hinten zu (ins Theatermagazin) ab, und die ..zerstreuten Heerhaufen, die Flüchtenden, der sterbende Cassius, Brutus auf seiner Flucht, und endlich im Siegesgeachrei das römische Heer" kamen von dort herauf. Diese Schlachtfeldanlage täuscht eine große Raumweite vor und gibt im allmählichen Auftauchen der Kämpfer gegen den Horizont spannende und hörhst malerische Motive. Die moderne Regie hat sie mit Erfolg z. B. in Berliner Aufführungen der Penthesilea Kleists angewendet.

si) Petersen S. 199 nennt Kotzchue als den ersten Dramaliker, der auf das stufenweise Ansteigen der Bühne nach der Tiefe zu bewuBt Bedacht nimmt, und vermutet, daB dieser szenische Aufbau der .Johanna" auf Schillers Jungfrau II, 4 eingewirkt habe. 
durch ein zufälliges Straucheln dem Schwert Lasarras verfällt, eilt die streitbare Gattin herzu und holt mit letzter Kraft zum Meisterstreiche auf des Feindes Haupt aus.

Es ist nicht zu leugnen, daß diese Schlachtanlage ihren augenblicklichen Theaterzweck ausgezeichnet erfüllt und den Kampf spannend und reich zur Anschauung bringt, ohne der Bühne Unmögliches zuzumuten. Weiter geht ihr Ehrgeiz nicht, und einer Nachprüfung der Motivierung hält sie natürlich nicht stand. Aber gegen alle Einwürfe - ob sie dem unwahrscheinlichen Refugium des Eremiten so nahe der Burg gelten, oder dem überschnellen Ausrücken Johannas hinter Lasarra, oder endlich dem schließenden Theatercoup, wo die Heldin über das ganze Kampffeld weg auf die Sekunde genau zur Stelle sein muß - behauptet Kotzebue das Feld durch die zwingende Wirkung auf das Auge und die Überrumpelung des Zuschauers durch die unaufhaltsam sich entladende Ereignisfülle. Statt den taktischen Verlauf mühsam dem Verstand zu explizieren, faßt er seine Hauptmomente auf Grund der Beherrschung des Dekorativen unbekümmert in ein paar effektvolle Bilder.

Der Parodie steht dieses Verfahren allerdings bloß. Kaum ein Stück Kotzebues fährt in Schlegels Pandämonium seiner Dramatik so schlecht wie die "Johanna". Die „Ehren pforte" versetzt der derben Kampftheatralik Hieb auf Hieb und verspottet die Heldin witzig als harnischrasselndes Mannweib im Bühnenkrieg, das seines Eindrucks beim Publikum sicher ist, den männlichen Gegner aber nur von hinten erlegt. Schlegels Johanne will ihren berühmten Schwertstreich aus gutschweizerischem Tyrannenhaß dem Monarchen angedeihen lassen, der den Autor bedrängt, und herrscht im übrigen durch ihre waffenstrahlende Erscheinung. ${ }^{57}$ ) Nicht weniger bekommt die Technik ab. Die kotzebuesche Kampfführung von Kulisse zu Kulisse ironisiert der Souffleur, dem dieses „Moyen“ zur Mobilisierung aller Geschöpfe des Meisters gute Dienste leistet. ${ }^{58}$ ) Der hohle Theaterkrieg ist nie blutiger verhöhnt worden als durch das schlichte Männchen, das im Herumlaufen mit Souffierbuch und Lichtputze den nötigen Kampflärm und das Waffengeklirr produziert. So scharf die Satire die bare Mache trifft, behält doch auch Kotzebue recht; Begabungen wie die seine sind zur Ausbildung der Herrschaft über den

${ }^{57)}$ W. Schlegel, Werke 2, 302: „Ha .... Ich werde den Monarchen wenigstens von hinten durch den Helm hauen ... Ich will sogleich meine Rüstung anlegen, mit meinen Knappen über die Zugbrücke ziehn, und aussehn wie Friederike Unzelmann, dann widersteht mir niemand." In dem folgenden großen Aufzug kotzebuescher Gestalten: „Johanne in glänzender Rüstung mit ihren Gewappneten über die Brücke."

56) 2, 303: „(er steigt aus seinem Loche und macht den Kreis des ganzen Theaters, indem er zu einer Kulisse hinein und zur nächsten herausgeht).“ 
äufern Bühnenapparat wichtig, und auch nie hohe Kunst lernt von berufenen Handwerksleuten des Theaters.

In cine spätere ritterliche Welt führt die dramatisierte Geschichte des Chevalier sans peur et sans reproche, „Bayard“" ${ }^{39}$ ) Auf ein Kriegerstück war es abgesehen, einem General, .dem biedern Feldherrn ... Grafen Kutusow" wurde es als ,.historisch-dramatisches Gemälde eines biedern Feldherm der Vorzeit" zugceignet. Feldzugserinnerungen, die der Held, durch eine Wunde ans Zimmer gefesselt, unınutig an Hand einer "Charte von Welschland" auffrischt, eröffnen. Die nahe Bezichung zum soldatischen Lebenskreis hindert nicht, daß jene Sentimentalisierung des Krieges in das Stück Eingang findet, die der Tränenseligkeit Kotzebues im ganzen entspricht und in den „Hussiten“" ihren Gipfel erreicht. Der alte Feldhauptmann Ligny hat IV, 6 mit nassen Augen eine scheußliche Untat der Marodeure zu erzählen, in Waffen ergraut jammert er doch über den blutig zerstörenden Krieg und ruft nach Frieden. Auf der andern Seite überrascht es inmerhin, wie frische Töne Kotzebue für den reisigen Bczirk zu treffen versteht, kaum aus Eigenem, aber in gewandtem Anschmiegen an dic ausgebildete Uberlieferung. Bayards Waffenträger Basco, eine gute Bühnenfigur aus der Familie der treuen Knappen, liefert dafür ein hübsches Beispiel im Ausdruck seiner Freude, endlich wieder reiten zu dürfen. ${ }^{60}$ )

Als dramatisierte Lebensbeschreibung folgt der .Bayard” dem Cötz. wenn auch die Fülle halb fabelhafter Abenteuer und bunter Geschehnisse, wie sic dem Heldenroman eigen sind und Kotzebues Ausstattungsneigungen entgegenkommen, von der schlichten Umwelt des Ritters mit der eisernen Hand stark absticht. Es ist eine geschickte Ökonomie von Kotzebues biographischem Stück, daß die in Bayards kriegerischem Dasein zahlreichen Kämpfe und Scharmützel durchweg gewandt erzählt werden ${ }^{61}$ ) und erst das

89) Leipzig 1801. Werke Bd. 16. Ein gleichnamiges Schauspiel desselben Stofies, ,Bayard, oder der Ritter ohne Furcht und ohne Tadel" von Fr. A. Cl. Werthes, in München am 13. Okt. 1786 zum erstenmal aufgeführt (Theaterzeitel im Zettelband $4^{\circ}$ Hist. 2605. Bd. 10 der Univ. Bibl. Müncheri: Legband S. 453). fehit bei allen Bibliographen und ist erst von Th. Herold (Werthes. Münster 1898, S. 177. vgl. S. 66) im Druck nachgewiesen: Wien 1786.

$\left.{ }^{60}\right) 11.3$ beim Einpacken: .Hinaus ins Feld! mit jedern Aiemzug / Verschling ich einen Strom von Lebenswürze! / Hinaus ins Feld! Das trockne Brot schmeckt besser / In freier Luft; es liebt sich herzlicher / In freier Lutt: und lieber Cott / ich meine / Es stirbt in freier Luft sich such wohl leichter". Die Stelle scheint an Egmonts Wort anzuklingen (s. o. S. 184 Anm. "), auch Schillers.. Wohlaul Kameraden" mag vorschweben, und der Tod des alten Cötz in Licht und Luft den letzten Zug geliehen halen.

1) Am ausführlichsten der Bericht Bascos über den Tod von Bayards Knappen V. I, dessen wackere thaltung in einem scharlen ZusammenstoB Bayard schon IV. I rühmt. Er wird im Sterben als Weib erkannt. das dem Celiebten in der Verkeppung gefolgt und für ihn gefallen ist (vgl. 
letzte, für Bayard tödliche Treffen zu lebendiger Darstellung gelangt. Der Autor spart so die theatralische Bewegung des Kampfes für einen wirksamen Abschluß der locker gefügten Lebensgeschichte auf.

Im Gegensatz zu "Johanna“ erläutert Kotzebue hier die Gefechtslage genau, denn eine Art von taktischer Intrige führt das Ende des Helden herbei. Der rachsüchtige Admiral, in dessen Händen der Oberbefehl liegt, beauftragt Bayard für den bevorstehenden Abzug des Heers nach Novarra mit einer gefährlichen Flankendeckung und verstattet ihm dazu absichtlich nur eine lächerlich geringe Mannschaft und kein Geschütz. Der todgeweihte Posten kommt dem Ritter gelegen, nachdem er der Geliebten auf ewig hat entsagen müssen; er stürzt sich mit ungebrochenem Mute ins Getümmel. Nach Schillers Art ist sein Kampfabgang durch gereimte Jamben gehoben. Das Gefecht selbst erfaßt der "Bayard", wiederum gegensätzlich zu „Johanna“, geschlossen durch Teichoskopie von Feindesseite. Für das begleitende Kampfgetöse gibt der Regisseur Kotzebue ausdrücklich einschränkende Vorschriften, weil er die crux aller akustischen Hilfsmittel der Schlachtdarstellung kennt: je realistischer sie angewendet werden, um so mehr gefährden sie den Dialog. ${ }^{62}$ ) Die Beobachtungsszene ist ausgesprochen bildmäßig angelegt. Auf erhöhtem Platz unter einer alten Eiche steht der Prinz von Bourbon, auf das entblößte

C. F. Meyers Novelle "Gustav Adolfs Page“). Der Bericht gemahnt an denjenigen des schwedischen Hauptmanns, Wallensteins Tod IV, 10, wie dort entflammt der Tod des jungen Führers die Seinen zu Rache; die stimmende Einleitung bei Kotzebue ( - „die Galgenhühner flattern / Um den bemoosten Turm, und oben kreischt / Die Wetterfahne wie Gefängnisriegel") lehnt sich eng an Tod V. 3 v. 3407 ,Des Turmes Fahne jagt der Wind“" usw. an. - Wall. Tod war in Weimar am 20. April 1799 aufgeführt worden, Schiller verlangt den Bayard am 24. März 1800 von Goethe zu lesen, am 5 . April wurde er dort zum erstenmal gespielt; Schiller an Goethe unter diesem Datum; Goethe an Schiller 3. Okt. 1800. - Weitere Kampfberichte im französischen Lager III, 9, wo die Führer abwechselnd die ruhmvollen Taten des Königs in der Schlacht von Marignano erzählen und Franz I. Bayards kriegerische Verdienste preist.

62) Bayard V, 6: „Man hört in der Ferne Schießen, Schreien, Trommeln und Trompetenstöße. Alles dies muß dem $\mathrm{Ohr}$ des Zuschauers nur eben hörbar sein und auf keine W'eise die Handlung auf der Bühne stören.“ Ebenso IV, 8: „Man hört die Trommel, doch nur ein wenig näher und nie so nah, daß ihr Schall die Sprechenden stören könnte.“ In den Regie-Anmerkungen der „Kreuzfahrer" heißt es zum Klostersturm V, 6: „Auch muß das Geschrei der Türken ja nicht zu nahe scheinen. Man macht dergleichen gewöhnlich hinter den Kulissen, es sollte aber weit mehr entfernt sein." Gleich sorglich schreibt Brandes im "Schiffbruch" am Schluß von I, I vor: "Die Ouverture beginnt von neuem und begleitet den Text des zweiten Auftritts. Stimmen vom notleidenden Schiffe ... .; [das Rufen] fällt von Zeit zu Zeit bei dem Piano der Musikbegleitung

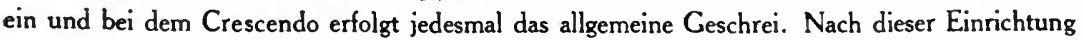
geht der Text nicht verloren und das ganze bewirkt Erschütterung und einen hohen Grad von Illusion." 
Schwert gelehnt, und schaut in die Ferne. Die Anordnung wird der bildenaien Kunst entstammen, wo Feldherrnporträts in ähnlicher Auffassung häufig sind. Fine lange Pause nach Eröffnung der Szene soll das Tableau eindrücklich machen. Den ungeduldigen Beohachtungsmonolog des Fürsten - jenseits zieht das ganze Heer des Feindes ab, indessen er hier ohnmächtig vor dem Hohlweg liegt, den Bayard uneinnehmbar verteidigt - endet die Meldung eines Ritters. Die weitere Entwicklung des Gefechtes verfolgen beide gemeinsam in steigender Belebung. Bayard bricht mit seiner Handvoll Leute sogar aus dem Hohlweg hervor. Als Bourbon, wütend über die Flucht seiner Truppen, selbst in den Kampf eingreifen will, hält ihn der Begleiter zurück; denn eben sieht man den Gegner schwer getroffen herauftragen. Immer noch ist, durch eine lange Tradition hindurchwirkend, die Selbitz-Szene lebendig. Verwundete auf aussichtsreiche Höhen zu schleppen, entspricht keiner Wirklichkeit des Kampfes, aber so sehr den Bedürfnissen seiner bühnengemäßen Darstellung, daß es längst zur unangefochtenen theatralischen Konvention werden konnte. Kotzebue legt hier wie später im "Rudolf von Habsburg" die zwei Elemente, die der Auftritt Gocthes ineinander verflicht, das Beobachtungs- und das Verwundetenmotiv auseinander und schließt beide Dramen nach der Teichoskopie mit der Sterbeszene des Führers. Nach dem Vorbild der grolidenkenden Sieger Shakespeares läßt er seinen Bourbon achtungsvoll an das Lager des frommen Ritters treten, der gottergeben auf das Ende wartet, und ihm kriegerische Ehren erweisen. ${ }^{63}$ ) Bayard spendet dafür noch cine Ermahnung. Kotzebue versteht sich auf die starke Wirkung des Todes unbezwungene: Helden, die den Feind in Bewunderung wie geschlagen an ihrer Bahre zurücklassen. Er kanı es sich auch nicht versagen, den Eindruck gehörig zu unterstrcichen: .,Wer blicb hier der Sieger?" hat Bourbon im Anblick des Toten gedankenvoll zu fragen.

Obwohl sichtharen Kämpfen verschlossen, entfaltet der Bayard kriegerischen Pomp so gut wie Johanna von Montfaucon, dic ihn in der Schlacht selbst ausbreitet. Das reichste militärische Bild gibt die große Lagerszene III, 9. wo ein Teil des französischen Heeres in Parade steht und König Franz inmitten seiner Feldobristen von Bayard den feicrlichen Ritterschlag empfängt. Kotzebue schreitet auf dem Wege dieser Ausstattungstendenzen weiter und erreicht in den .Kreuzfahrern" den Cipfel des kriegerischen Kostümstücks. Die

${ }^{63}$ ) Die Fahnen sollen, in des Baumes Zweige gesteckt. .den edeln Feind im Tode sanft beschalten". Auf die entscelie Jungfrau von Orleans werden. .slle Fahnen sanft niedergelassen. daB sie ganz davon bedeckt wird". Der geschickte Kotzebue konnte für solche Einzelzüge des theatralischen Arrangements anregen, wenn auch der kriegerische Brauch dieser Ehrenbeze: gung allgemein ist. 
ritterlichen Elemente empfangen durch ihre Überführung in die farbenprächtige morgenländische Welt neuen Glanz, eine außergewöhnlich reiche, wechselvolle Handlung schafft auf Schritt und Tritt Gelegenheit für den szenischen Effekt von Kampf und Krieg; breiter Aufwand, wie ihn das Spektakel einseitig aufbietet, und spannende Verknüpfung der Ereignisse stehen im Cleichgewicht und vereinigen sich zu einem Höchstmaß theatralischer Wirkung. ${ }^{64}$ ) Die Belagerung Nicäas durch das Christenheer hat den Rahmen für die bunte Liebesgeschichte eines Kreuzritters zu liefern, Zweikampf um eine schöne Sarazenin, schnöder Bruch ritterlichen Geleites, meuchlerischer Überfall und Rettung, gewaltsame Entführung aus dem Kloster und dessen Erstürmung sind die kriegerischen Vorgänge.

Ein voller szenischer Akkord eröffnet. Das Heerlager der Kreuzfahrer vor der eingeschlossenen Stadt wird mit toter und lebender Staffage zu einem üppigen Kriegsbild ausgestattet. Zwischen Zelten und Waffenhaufen steht die Fülle der Belagerungswerkzeuge, Ballisten, Katapulten, Sturmböcke; Gruppen Zechender, Würfler und Schachspieler halten die Runde. Allerhand intimes Detail ist verlangt, ein Müder schlummert auf einem Wurfgeschütz, ein anderer sitzt auf einem Mauerbrecher, ein dritter hat sich an ein aufgepflanztes Kreuzpanier gelehnt. Schildwachen patrouillieren im Hintergrund.

Ein vergleichender Blick auf die Bühnenerscheinung von Wallensteins Lager, das zu dieser Zurüstung Kotzebues zweifellos Pate gestanden hat, zeigt wie grundverschieden die Ziele sind. Obwohl Schillers Lagerbild sich innerhalb der klassischen Kunst buntbewegt genug ausnimmt, ist es durchaus ihrer Formstrenge untertan. Das gesprochene Wort behauptet seine Herrschaft, die Inszenierung wäre in dem Augenblick verfehlt, wo es im Massengewoge unterginge. Das leer Dekorative wird zurückgedrängt, kein Aufwand um seiner selbst willen geduldet, alles einzelne dient an seiner Stelle, wie das "Lager" im ganzen, einem bestimmten Handlungszweck. Auch wo es sich nur um den Eindruck des belebten Lagertreibens handelt, wird er in klarer Scheidung der Teile aus einem Nacheinander von Einzelszenen typischer Natur aufgebaut.

Demgegenüber stellt Kotzebue sein Ritterlager als reine Schau-Fassade

64) Den „Kreuzfahrern“ (Leipzig 1803, Werke Bd. 17) billigt bereits M. Koch (Ersch u. Gruber II. Sekt., Bd. 39, 188) ein Lob zu, während Hauffen, DNL 139 II, S. 19 nur die Abhängigkeit der ldeenwelt von Lessings Nathan festnagelt; gegen diese "leichte Abfertigung" tritt schon früher L. Geiger, ADB 16, 778-79 auf, manches Tragische des Stücks betonend. Wirkliche Bedeutung hat es aber doch vor allem als vortreffliches Theaterstück, was auch Rabany S. 153-54 hervorhebt (,un chef-d'cuvre d'entente de la scène“). Damit ist zugleich die Grenze bezeichnet, die es rom Nathan trennt. 
vor das Stiick. Das pantomimische Element regiert, der Augenlust soll gedient werden. Wie cin Jakob Maier von einer noch schüchternen Bühne herab dem Publikum von allerhand sonderbaren Belagerungsinstrumenten erzählt hatte. so befriedigt Kotzebue jetzt das gegenständliche Interesse, indem er alle die fremdartigen Kriegsmaschinen und den ganzen Apparat einer mittelalterlichen Städtebelagerung plastisch aufstellt; ohne Folge für das Stück, lediglich als kriegerisches Kostüın. Ausschließlich dekorative Wirkung steht in Frage. und darum ordnet Kotzebue das gesamte Aufgebot äußerer Mittel zum lebenden Bild zusammen, das den Zuschauer bein Aufrollen des Vorhangs auf einen Schlag ïherwältigt. Dann erhält er Muße, das Tableau im einzelnen zu betrachten: die einleitende Musik dauert bei eröffneter Szene noch eine Weile fort.

Im Verlauf der Handlung bringt der Aufzug des sarazenischen Emirs das Zeremoniell freien Geleites umständlich zur Anschauung. Am reichsten entfaltet sich der ritterliche Brauch an dem feierlich geregelten Zweikampf der beiden Kreuzritter (II, 7). Kotzebue trifft dafür eine Anordnung, die das Heikle des Vorgangs glücklich umgeht. Wie in "Johanna" die Felsen, sclaließ3t hier ein dichter Kreis von Rittern die Fechtenden so ein, daß man wohl ihre Stimmen hört, von ihnen aber ..wenig mehr als die blinkenden Schwerter gewahr wird." Zwei Vordergrundsgruppen, die des Emirs auf der einen, die Fatimes auf der andern Seite drängen das Gefecht zurück und ziehen das Interesse von ihm ab. So deckt Schiller später den SchuB Tells durch den Zank Geßlers mit Rudenz. Die Not wird bei Kotzebue sogar zur Tugend, denn das Spiel vorn nützt den Umstand, daß die Aufmerksamkeit der ganzen Bühne auf das Duell gerichtet ist: der Emir kann der Tochter auf den äußJersten Fall einen Dolch zuwerfen. Sein Ritter siegt, sein Kind ist frei, aber sein Leidensweg noch nicht zu Ende. Ritterliches Geleit bringt ihn im dritten Akt über den Fluß, wo er mit der Geretteten erschöpft rastet. indes das Gefolge abseits lagert. Wortbrüchig schleicht sich der bedeckende Christentrupp über die Brücke zurück, um den jetzt vogelfreien Heiden zu töten und zu berauben. Der tückische Uberfall wird zum Theaterstreich auszebildet. Der Meuchelmörder naht sich seinen Opfern auf den Zehen, plötzlich zerreißt der Schrei des Emirs die Stille, jetzt springt der allgegenwärtige Retter Balduin aus dem Gebüsch herab und verjagt die räuberischen Gesellen.

Die effektvollsten Kampfereignisse des Stücks gehören der Klosterhandlung an. An der Vorsicht der Äbtissin, die alle Ausgänge von Reisigen des Schirmvogts hat besetzen lassen, scheitert (IV. 10 f.) die Entführung der Geliebten durch einen unterirdischen Gang. Vom Klostergemach aus, wo er mündet, vernirumt man Balduins Zusammenstoß mit den Wächtern, indessen die Äbtissin schreckensvoll den Fluchtanschlag entdeckt. Die Nonnen schleppen die abtrünnige Genossin aus dem Gang hervor, zurückgeschlagen trift der 
Ritter auf ihre zürnende Oberin und verlangt stürmisch die Braut heraus. Über ihre Weigerung ergeht er sich in rasenden Blasphemien und vergißt sich so weit, auf die geistliche Frau mit erhobenem Schwert einzudringen. Jetzt spielt Kotzebue zum Abschluß des Aktes den stärksten Trumpf aus: auf den Druck einer Feder fällt ein eisernes Gitter vor die Nische, worin sie steht, vor seinem Hieb gefeit spottet sie der Gewalt; ohnmächtiges Rütteln an den Stäben ist das einzige, was dem schäumenden Bedränger übrigbleibt. Es entspricht der antikirchlichen Tendenz des Stücks, daß Kotzebue das Wunderbare meidet; so wird auch dieses Theatralwunder, das er hingegen nicht entbehren will, auf natürlichem Wege herbeigeführt. Glaubhafter als die so präzis arbeitende Bühnenmechanik wäre wohl das Eingreifen einer höheren Macht gewesen, wie es Schiller für einen ähnlichen, aber zurückhaltender angewendeten Effekt ${ }^{65}$ ) voraussetzt.

Für den das Stück endigenden Klostersturm des fünften Aktes zieht Kotzebue alle Register theatermächtiger Stimmung. Balduins Geliebte ist der Strafe des Einmauerns verfallen, alle Freunde versagen dem verzweifelten Liebhaber die Gefolgschaft gegen die geistliche Macht, ja derjenige, dem er das Leben gerettet, schützt selbst als Schirmherr des Klosters mit gewaffneter Hand die grausige Tat gläubigen Wahnsinns. In letzter Stunde, als dumpfe Glockenschläge und der Nonnenchor aus hellerleuchteten Kirchenfenstern schon den Beginn der nächtlichen Zeremonie anzeigen, wird ihm Hilfe von den Ungläubigen. Der Emir ist mit einer Türkenschar zur Stelle, mitgeführte Christensklaven werden bewaffnet, unter großem Getümmel wirft sich der Greis für seinen Retter begeistert auf den wohlbewehrten heiligen Bezirk. Mit diesem Kampfabgang wechselt die Szene nach dem bewährten Schema und führt, zeitlich zurückgreifend, in die Klosterkirche, wo die barbarische Prozedur mit feierlichem Aufzug der Nonnen, Einsegnung des Opfers, Glockenklang und Orgel theatralisch ausgeweidet wird. Als die aufgeführten Quadern die Unglückliche schon fast verdecken, dringt in das Gebetsgemurmel der Kriegsruf der Ungläubigen, aufgeschreckt horchen die Nonnen auf das nahende Gefecht und füchten zum Hochaltar, die Äbtissin lauscht in starrem Entsetzen.

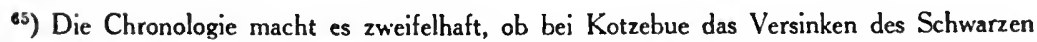
Ritters vor dem Streich Johannas vorschwebt. Die "Kreuzfahrer" sind in Berlin (Düntzer. Erläut. zu Schillers Jungfrau ${ }^{6}$ S. 4I) am 1. Jan. 1802 aufgeführt worden, die Jungfrau v. O. zuerst im Sept. 1801 in Leipzig; ihr Druck im Kalender auf 1802 erschien Okt. 1801. Eine Reminiszenz an sie, nicht bloß gemeinsamer biblischer Ursprung, scheint auch Kreuzfahrer V, 5 vorzuliegen, wo der Emir seine Schar mit einem „Und wären ihrer wie Sand am Meer“ anfeuert, wie die Jungfrau nach Raouls Bericht I, 9 die Franken: „Und wären sein mehr denn des Sands im Meere.“ Vgl. Hussiten II, 4: ,.Der Feind wie Sand am Meer." 
Den letzten Widerstand einiger Reisigen niederwerfend, brechen die Türken ein, in cinem Zug eilt die Handlung über die Befreiung der Eingemauerten, die Vereinigung des Paares und den allerdings sträflich äußerlichen Losspruch cines in Eile herbemühten päpstlichen Legaten dem Ende zu. Die erstrebte Theatralwirkung erreicht diese Erstürmung im höchsten Maß, und schließt zugleich die Kriegshandlung des Stückes, die für jeden Akt ein neues Kampfereignis in Bereitschaft hat, mit dem bewegtesten und spannendsten ab.

Schwächer als die Kreuzfahrer bringt der ihnen vielfach motivverwandte "Heinrich Reuß von Plauen" das Kriegerische zur Geltung, das er wiederum als faltenreiches Kostüm um einen höchst abentcuerlichen Liebesroman legt. ${ }^{66}$ ) Diesmal ist es eine getaufte Litauerin im Lager der Christen, die in den Kriegswirren ihren noch heidnischen Geliebten wiederfindet und zu sich herïberzieht, an die Stelle des Kreuzzuges sind die Kämpfe der Deutschherren in Ostpreußen getreten. Große Verhältnisse der Kriegführung stehen in Frage. Aber die Technik hält sich ihnen gegenüber lässig und erwirbt sich wenig Verdienst. Man sieht hier besonders deutlich, dał vor allem eine farbige Umwelt geschaffen werden soll. Zwar verrät eine Beobachtungsszene, worin Jawinne vom Fenster der Marienburg ähnlich Antigone in den Phönissen nach dem Heer ihres Volkes Ausschau hält, gerührt die Fahnen mustert und unter ihnen diejenige des Oheims erkennt, bei der sie den einstigen Geliebten vermutet. die kundige Hand. Zwei Schlachten jedoch werden durch lange, spannungslose Berichte allzu einfach abgetan. ${ }^{67}$ ) Bequemer liegen Kotzebue einige Einzelheiten der Kampthandlung, für die er alterprobte Effekte des Combattements nicht verschmäht. Verkleidet eingedrungen, zwingt der junge Litauerfürst in der feindlichen Burg den Ordenskomtur Heinrich zum Zweikampf, um die vermeintlich erschlagene Braut zu rächen. Sie tritt in diesem Augenblick zwischen die blanken Schwerter (II, 6-7). Ebenso theatralisch erwirbt sie sich dann $(I V, 6)$ dic Märtyrerkrone: mit ihrem Leib fängt sie den Streich des heidnischen Vaters auf den bekehrten Sohn auf. Zum Theatercoup, der selbst das fallende Gitter der Kreuzfahrer an eklatanter Wirkung übertrifft, bietet sich eine Anckdote von höchster soldatischer Kaltblütigkeit dar, wovon die Kriegsseschiclate eine ganze Reihe ähnlich lautender zu erzählen weiß. Kotzebue

60) H. R. v.P. nder die Belagerung von Marienburg. Leipzig 1805: Werke Bd. 22. Beiläufiger dienen die Schweizer Freiheiskriege und der Schweizer Freiheitsdurst der Liebesgeschichte des .Crafen von Burgund" (1798) zum Hintergrund, obwohl andere historische Bestimmungen des Stëcks in ganz andese Zeiten futiren: vgl. Rabany S. 243.

ei) 1.5 die eröftnende. deren unglïcklicher Verlaut die Belagerung zur Folge hat: V. 2 die abschlickende: ihr Kanenendonner dringt in die feserliche Reisetzung Jawinnens in der SchloBkirche. Der zweite Eericht zashls 40 Verse allein wher den Aufbruch, und an 90 über die Schlacht. 
steht nicht an, einen Geschütz-Volltreffer auf die Bühne zu bringen und bereitet diesen wahrsten Knalleffekt sorgfältig vor. Die Belagerer haben eine Kanone auf den einzigen Pfeiler im Versammlungssaal der Ritter gerichtet, ${ }^{68}$ ) der Schuß soll das Gewölbe über ihnen zum Einsturz bringen, ein Knecht verrät durch Zeichen die Stunde, in der sie zur Beratung zusammentreten. Die Kugel trifft durch das offene Fenster den Pfeiler zum allgemeinen Entsetzen just dann, als Heinrich Reuß am Schwören ist. „Mit der Ruhe eines Helden" fährt er jedoch, ohne durch Geschoßeinschlag und herabprasselnde Steine beirrt zu werden, gelassen fort: „Red' ich doch nicht von der Kugel. Ich ... schwöre -".

Das gefährlichste Spiel mit dem Pulver unter allen kotzebueschen Stücken treibt "Gustav Wasa". ${ }^{69}$ ) Dem Helden, dem im Schlosse zu Kalmar eine Gruppe von Offizieren Schwert gegen Schwert gegenübersteht, verschafft die Schwester knappe Frist zur Rettung. Ein unterirdischer Gang ist auch hier zur Stelle, ein verliebter Hauptmann gibt den Schlüssel her. Gustav Wasa verschwindet im Stollen, in dessen Eingang offene Pulvertonnen stehen, aber die betrogenen Offiziere dringen zu gleicher Zeit ein und wollen ihm nachsetzen. Da stellt sich die Schwester kurz gefaßt mit brennender Fackel unter die Öffnung und droht, den Funken ins Pulverfaß zu werfen und das ganze Schloß in die Luft zu sprengen, wenn sich einer nahe. Alle stehen versteinert, der Bruder ist entronnen. Die gruselige Situation, so geschickt sie erfunden ist, überschreitet das erlaubte Maß theatralischer Spannung und arbeitet auf den Nervenkitzel aufregender Zirkustricks hin. ${ }^{70}$ ) Hier wurde denn auch Brentano der Spott leicht. Seine Knittelverse genügen, den Vorgang ins Lächerliche zu ziehen. Wortwitze werden als Lichter aufgesetzt, drohend die Fackel schwenkend versichert seine Margarethe, daß sie nicht fackle. Ausdrücklich vergewissert sich Kotzebue in der Loge über die Wirkung des starken Auftritts. Der Hofrat findet, daß der Gedanke mit der Fackel unstreitig viel

68) II, 9 u. III, 2. Die artilleristische Leistung des Büchsenmeisters von Orleans bei Shakespeare, I Heinrich VI: 1, 4, dessen Stückkugel den Lord Salisbury im Belagerungsturm ereilt (vgl. Schillers Jungfrau I, 11) wird hier noch überboten.

${ }^{69)}$ Leipzig 1801. Werke Bd. 15. Die angezogene Szene II, 13.

70) Ein verwandtes Motiv hat sich immerhin Schiller für sein Seeräuberstück „Die Flibustiers"“ vorgemerkt: Bei einer Schiffsverschwörung gegen den Befehlshaber (Dramat. Nachlaß, hrsg. v. Kettner, 2, 250) sollte der „Befehl des Anführers, mit brennender Lunte an der Pulverkammer zu warten " erfolgen - also die Drohung, das Schiff mit allem was es birgt in die Luft zu sprengen und die Aufrührer mit dem Opfer der eigenen Person insgesamt zu verderben. Das Motiv der Sprengung, ohne die Zuspitzung, auch in dem Entwurf „Das Seestück“ (Dramat. NachlaB 2, 253): „Ein Schiffer sprengt sich in die Luft", augenscheinlich weil er einem Korsaren nicht mehr anders entrinnen kann. 
Fffekt mache, ein Student gewinnt aus ihm ein Sujet für einen Pfeifenkopf, der Chor der Schnupftücher endet die beispiellos rührende Szene. ${ }^{71}$ )

Dic reiche Handlung des biographischen Stückes schließt mit der Belagerung und Einnahme Stockholms durch Wasas Bauernheer. Kotzebue versteht es, die Lage des in seinem Schlof bedrängten Usurpators zu Beginn des vierten Aktes init ein paar Worten bildkräftig wiederzugeben. Ein Kämmerling überblickt im Morgengrauen aus dem Fenster den flammenden Kreis der zahllosen feindlichen Wachtfeuer ringsum. Gewandteste Beobachtungstechnik zeichnet den Wasa überhaupt aus. $\left.{ }^{i 2}\right)$ Hiobsposten treffen den König, in einer Lagerszene erhält Gustav durch einen der vielen überraschenden Wechselfälle des Dramas unverhofften Zuzug und gibt seinen schon gefaßten Entschluß zu stürmen auf. ${ }^{{ }^{\prime 3}}$ ) Demgemäß kommt es zu keiner Schlacht : nachdem die Intrige des Tyrannen. den Frieden mit dem Sohn durch das Leben der Mutter zu

i) Brentano, Gustav Wasa, DLD 15, 109-110; vgl. M. Koch, DNL 146 I, S. XXXVIII f. Das in A. Kempners [Kerrs] Teildruck: Clemens Brentanos Jugenddichtung. Diss. Halle 1894 angekündigte Kapitel ïber Gustav Wasa ist nicht erschienen. - Die vorhergehende, krause Schlachtphantasie des von Sinnen gekommenen Offiziers in hochpathetischen Ottaverimen (S. 93-95) scheint ebensosehr auf Schiller, dessen ."Glocke" früher (S. 23 ff.) übel genug fährt. als auf Kotzebue gemünzt; den Wasa soll wohl das satirisch übertriebene Mißverhältnis zwischen inhaltlicher Banalität und gehobener Form verspotten, das seinen dem Wallenstein nachgeahmten Jamben in der Tat innewohnt. Der Wallenstein selbst klingt bei Brentano öfters durch, gelegentlich wird sogar ein Vers aus der künftigen Jungtrau halbwegs voraus genommen: S. 94 ..Es ruht der Feind, und seine Donner schweigen": Jungfrau IV, I „Die Waffen ruhn, des Krieges Stürme schweigen." - Über die Parodie erhebt sich ein treffich musikalisches Verspaar über das Schlachtgetöse S. 95: „Dumpf durch des Handgemenges helles Klingen / Hört man die Mörser requiescant singen" - eine packende Vorstellung von der Totenmesse für die Gefallenen in der Schlacht selbst.

92) Die spannendste Wirkung erreicht der Auftritt der Mutter (IV, 15), die im Kloster W'asa zur Besprechung erwartet, sein fernes Zeltlager sehnsüchtig mustert und an der Spitze der heranreitenden Schar endlich jubelnd den Sohn erkennt. Die genaue Kontrafaktur dieser Szene liefert Kotzebue in den Kreuzfahrern I, 10, wo Emma an der Lebensscheide der Klosterplorte das Entschwinden des treuen Begleiters in atemloser Erregung mit großer Gebärdensprache verfolgt beides, ähnlich der Pantomime der .Johanna". glänzende darstellerische Aufgaben. Schwermütiges Nachblicken auch Wasa IV. 17. - Den drohenden Auflauf der Bürger, der das SchloB umbrandet, überblickt der König V. 3. Ausführliche Beobachtung eines Schiffes im Sturn, die der vorbildliche ..Schifthruch" von Brandes nur sehr beschränkt verwendet, II, 1-3. Eine technische Anregung kann von hier auf Tell IV. I übergegangen sein (Schiller über den Wasa an Coethe 3. u. 5. Jan. 1800 u. Coethes Antwort vom 3. Jan.): Schiffsbeobachtung auch im Hugo Grotius III. 8 น. I. 5.

73) IV, 10-14. Als AbschluB das Kommando zu einer taktischen Evolution: „Der linke Flügel rücke schnell ans Kloster! (Die Trommel wird gerührt. Getümmel)." 
erkaufen, an ihrer effektvollen Standhaftigkeit gescheitert ist, bricht das Verhängnis über ihm zusammen; die Stadt öffnet sich dem Befreier kampflos.

Das Belagerungsmotiv ist bei Kotzebue häufig und tritt uns nach Heinrich Reuß und den Kreuzfahrern in Gustav Wasa schon zum drittenmal entgegen. Ein ausschliefiliches Städtebelagerungsstück, und zugleich das erfolgreichste der Tradition, liefert er mit den "Hussiten vor Naumburg", ${ }^{74}$ ) worin das Kriegsdrama die engste Verbindung mit dem Rührstück eingeht. Der spannende Effekt der Kampftheatralik wird durch den tränenseligen abgelöst, die rauhe Kriegsweit des Hussitenlogers in Kontrast zu der sanften Schar der unschuldigen Kindlein gesetzt. Die Mischung von Grausamkeit und Rührsamkeit hatte schon Schummels Magdeburger Belagerung erprobt, herzerweichend genug war Blumhofers Landshuter Stück ausgefallen. Kotzebue trägt die Farben nach beiden Seiten hin noch stärker auf; mit dem Prunk seines kriegerischen und friedlichen Aufwandes und mit seiner technischen Virtuosität, die er hier freilich recht äußerlich handhabt, können sich die bescheidenen Vorgänger natürlich nicht messen.

Eine beherrschende Zentralszene faßt alle Absichten des Stückes in ein großes Bühnenbild zusammen. Es ist die Massenpantomime des vierten Aktes, wo die Naumburger Kinder furchtlos mit gefalteten Händen gegen die gefällten Speere der Hussiten schreiten und ihre Schlachtreihe Schritt vor Schritt über die ganze Breite der Bühne zurückdrängen, da die rauhbeinigen Gesellen doch zum Zustoßen das Herz nicht finden. Nach ihrem Bramarbasieren von haarsträubenden Untaten und dem blutrünstigen Singsang in der vorhergehenden üppigen Lagerszene ${ }^{75}$ ) müßte es ihnen zwar eine Lust sein, aber die allgemeine Rührung greift selbst auf diese Theaterwüteriche über, und auch sie bringen im Schlußchor des Aktes noch ein weiches Herz zum Vorschein. Kotzebue treibt damit die Sentimentalisierung des Kriegsvolkes, das er zuerst dem krassen Umschlag zuliebe ins Übertierische verzeichnet, bis aufs äußerste; ebenso

74) Leipzig 1803. Werke Bd. 19. Als sprechendstes Zeugnis für die Wertschätzung des Stückes gibt W. v. Kotzebue S. 86 einen überschwänglichen Brief Wielands wieder, der selbst angesichts der Toleranz seines Urteils überrascht. Noch beweiskräftiger ist die Verbreitung von Mahlmanns wohlgelungener Parodie „Herodes vor Bethlehem“ usw. in vielen Auflagen, zuerst Leipzig 1803.

75) IV, 1. Zechende und andere Gruppen, eine Wache. Jörd en s 3, 95 charakterisiert treffend: „Einige Anführer geben in ihrem Cespräch, sowie die Soldaten in ihrem Chor, Proben kannibalischer Gesinnungen." Auch das am Eckstein der Mauer zerschmetterte Kind aus Schummels Kriegsgreueln fehlt nicht. - Mahlmann geißelt das kriegerische Aufgebot durch eine groBe moderne Exerzierszene III, 2, worin ein Adjutant die Front richtet, präsentieren läßt usw.; an Stelle der Speerpantomime laufen die Kinder III, 4 den Soldaten zwischen den Beinen durch u. dgl. $m$.

S c berrer, Karmpf im deutschen Drama. 
verfährt er mit dem Hussitenfeldherrn Procopius, der anfänglich als Cottesgeifel, dann aber im Kreise der Kleinen als gutmütiger Kindervater erscheint.

Zwci nicht minder bühnenfeste Massen-Rührszenen flankieren. Voran geht der Auszug der Kinder aus der Stadt unter gedämpftem Trommelwirbel und dem Wehklagen der Mütter, eine nach Umfang und Tränenaufwand gleich ausschweifende Pantomime. ${ }^{7 \text { }}$ ) Kunstvoller fügt Kotzcbuc die Rückkehr der Geretteten zu einer seiner besten Beobachtungsszenen (V, 2). Zahlreiche Gruppen von klagenden Miittern sind vor dem Tor höher und tiefer angeordnet, das Auftauchen und Nahen des schon verloren gewähnten Zuges wird in Wechsel von erregten Einzelstimmen und Chor spannend vergegenwärtigt, wie schon IV, I der Heranzug der Kinderschar durch eine Kriegergruppe im Lager. Es scheint fast, als ob damit Aeschylus für die Hussiten bemüht würde. Aus dem effektvollen Stinmungsumschlag, wie er hier erreicht ist, zieht auch die eigentliche Kriegshandlung mehrfach Gewinn. Mit guter Wirkung gellt die Sturmglocke, die dic Kriegsnot anzeigt, am Anfang des Stückes in ein Friedensidyll ausziehender Schnitter und stillen Bürgerglückes, wogegen allerdings die momentane Peripetie, die im vierten Akt vermittelst einer höchst anfechtbaren Meldung den sonst gegebenen Handlungsablauf noch einmal unterbricht, ${ }^{77}$ ) zu den gröbsten Bühnenkniffen gehört.

Unweit einem Stück von so verschwenderischem Massenaufgebot wie diese Hussiten, und dicht neben der Theaterschlacht der Johanna von Montfaucon steht in Kotzebues Produktion die klassizistische ..Octavia“", $\left.{ }^{78}\right)$ die den Entscheidungskampf zu Wasser und Land zwischen Antonius und Octavius Cäsar entgegen Shakespeare in der gebundensten Weise erfaßt. Die Vielgewandtheit Kotzebues zeigt sich innerhalb seiner Kampftechnik nirgends deutlicher als hier, wo er sich in einem Einzelfall der strengen Form bedient, die durch die Entwicklung neuerdings nahegelegt war. Er stellt damit selbst das strikte Gegenbild zu seinen Gefechtspantomimen auf. Es erweist sich, daß scine Bühnenbegabung der Aufgabe gleich gerecht wird, ob sie danach lautet. Kämpfe in freien Dramen effektvoll vor Augen zu bringen, oder eine Schlacht in den

${ }^{26)}$ III. 5; vgl. Pelersen S. 232; Lohmeyer S. 94. Mahlmann Ende II.

77) IV, 4-5: durch eine Botschaft vom Nahen eines fremden Haufens überrascht, hält der hereits versöhnte Procopius einen Augenblick lang den ganzen Kinderzug für die schnödeste Kriegslist und will schon mit dem Schwerte unter sie fahren, als die sonderbare Aufklärung erfolgt: es sind die heranziehenden Miitter, deren ..weiße Regentücher" die Feldwachen für ..weiße Schilder und fremde Waftenristung" angeschaul haben!

"7) Leipzig 1801. Werke Bd. 14. Hauffen, DNL 139 II, S. 18. W. v. Biedermann bei Wi. v. Kazebue S. 32: ausfuhrlich Rabany S. 214-27. 
engen Rahmen der Tragödie hohen Stils einzufügen. Die Handlungselemente der "Octavia“" sind die altvertrauten, Kampfabgang, Besorgnisszene, Bericht, aber kaum eine andere geschlossene Anlage gewinnt aus ihnen theatralisch so vorzügliche Situationen wie diejenige Kotzebues. Cäsars Abgang zur Schlacht wird zu einem leidenschaftlich angespannten Auftritt, weil die Schwester allen Gründen zum Trotz nicht abläßt, um Aufschub der Waffenentscheidung zu flehen. Als die auffordernde Tuba den Stand der Dinge verrät und der Bruder fest bleibt, wirft sich ihm Octavia samt den Kindern zu Füßen $;{ }^{79}$ ) nur über sie hinweg soll er zum Kampf schreiten. Cäsar muß sich gewaltsam losmachen. Jetzt hat die Lage der Frau alles Zeug zu einer bühnengewaltigen Besorgnisszene. Zwischen Bruder und Gemahl, die an der Spitze ihrer Heere aufeinandertreffen, mitteninne stehend, reißt sie die Kinder in Todesängsten zum Beten nieder, aber sie weiß nicht anzugeben für wen und ermißt daran, daß ihr selbst das Gebet versagt ist, die Größe ihres Elends. Das anhebende kriegerische Getöse leitet zu einer antikisierenden Schlachtschilderung Octavias über, die, schon durch hexametrische Form hervorgehoben, überhaupt zum deklamatorischen Prunkstück ausgebildet wird. ${ }^{80}$ ) Die Höhe der Spannung auf den rückwärtigen Kampf erreicht Kotzebue durch das wirksamste Mittel, das die Entwicklung für diesen Szenentypus darbietet. Aus der Furcht geborene, überhitzte Phantasiebilder gaukeln Octavia das Dahinsinken des Gatten und des Bruders im blutigen Getümmel vor. ${ }^{81}$ ) In heroischer Theatralik eilt sie schließlich selbst in die Schlacht. Den Kampfbericht trennt eine musikerfüllte Aktpause $a b$, die den Vorgängen genügend Raum gibt. Dann erzählt Cleopatra selbst der Gespielin, was sie vom Dach des Palastes mitangesehen hat, den Verrat der Schiffe, das Übergehen der Reiterei; ihre starke Anteilnahme und der Triumph über ihre gelungene Intrige belebt die Ereignisse mehr als ein gewöhnlicher Botenbericht, und damit kommt auch dieses letzte Ingrediens der klassizistischen Technik zu beweglicher Wirkung. Im weiteren Verlauf tritt die Schlacht hinter dem Ende des Helden völlig zurück. Eine späterhin unerwartet auftauchende Meldung, daß das Fußvolk noch immer kampfbereit und uner-

79) IV, 7; die bekannteste antike Szene dieser Art ist Hektors Kampfabschied entgegen dem Flehen Andromaches, Ilias VI; in Shakespeares Troilus u. Cressida V, 3; Schillers Jugendgedicht „Hektors Abschied".

80) Melodramatische Absichten sind auch hier im Spiel, das Orchester schlieBt ab; der Auftritt im ganzen ist ein rhetorisches Gegenstück zu der musikalischen Besorgnispantomime der „Johanna".

81) Die Berührung mit Fiesko V, 5 scheint mehr als zufällig, weil sie bis ins Wörtliche geht. Leonore: "Haltet! Haltet! Es ist mein Gemahl!" - Octavia: "halt. Unmensch! es ist mein Gemahl!" Die Kampfphantasie erwächst hier wie dort aus gespanntem Lauschen. Die scharfe Pointieruns Bruter-Gernahl bleibt aber Kotzebue. 
schüttert stehe, hat nur die allzu rasche Tat Antons zu beleuchten und zeigt, wie gewandt Kotzebue über Motivierungsnöte wegleitet, wo ihm solche Wendungen des Augenblicks ${ }^{82}$ ) wünschbar erscheinen.

Eine Mittelstellung nimmt die Schlachttechnik der ..Spanier in Peru“83) ein, dadurch merkwürdig, daß sie aus Liebe zum Effekt das Treffen zwischen Peruanern und Spaniern für dic Handlung doppelt ausbeutet, zuerst unmittelbar durch Teichoskopic, im folgenden Akt neuerdings von entfernterem Standort aus durch Berichte. Nach den Vorbereitungen zum Gefecht auf peruanischer Seite, dem Fortschaffen der Weiber, dem ausgedehnten Abschied der Führer vor dem Kampf. bleibt ein Greis mit seinem Knaben zurück, der von einem Baum aus die entbrennende Schlacht beobachten muß (II, 5 u. 7). Hier motiviert Kotzebuc gründlich. Shakespeares Cassius und Klopstocks Siegmar sind durch kurzes Gesicht an eigener Ausschau verhindert, sein Creis ist blind. An Klopstock erinnert das Opfer der Priester vor dem Kampf, Altar und Gesang. In dem raschen Wechsel von Frage und Antwort spielen Staub und Rauch eine Rolle, am deutlichsten ist der Stand des Gefechtes an der Fahne der Inkas abzulesen, deren Flattern, Verschwinden und neues Auftauchen seine Phasen kurz bezeichnet. So schildert schon Selbitzs Knecht den Sieg Götzens in dem spannenden Vorgang, wie er die Fahne der Reichsvölker erobert. Der eindrucksvolle Umschwung darf natürlich nicht f́chlen. Die Krise hebt damit an. daß der Peruanerkönig verwundet hereingetragen wird, und gipfelt in einer Fluchtszene verzweifelter Indianer. Jetzt schwillt der Kampf bis hart an die Bühnenwände heran, man hört Rollas anfeuernde Stimme und ihren freudigen Widerhall, dann seizt die Beobachtung neu cin und schildert die gute Wendung. Trefflich reißt die Begeisterung über den nahen Sieg den blinden Alten so tin. daß er sich selbst im Getümmel wähnt und die Krieger anspornt - im Technischen ein Gegenstück zu der angstvollen Kampfphantasie Octavias. Nachdem ein atemloser Berichterstatter geineldet hat, und die Sieger aufgezogen sind, könnte die Schlachthandlung zu Ende sein, wenn sie nicht Kotzebue ein zweitesmal, wic resümierend, in gedrängtem Bericht zur Geltung bringen

82) V. 7: Ventidius' Bericht mache erst nachträglich klar, daß die Landschlacht überhaupt noch nicht geschlagen ist. Wieso Anton V. 4 von seiner Hauptmacht weg mit der Frage nach der Königin in den Palast tritt, wird wohlweislich ganz übergangen, während minder erfahrene Autoren heikle Punkte durch ungenügende Motivierung erst recht herausstellen. - Shakespeares Antonius ordnet IV. 12 nach dem Verrat der Flotte ausdrücklich die allgemeine Flucht an; die Kriegshandlung ist damit zu Ende und hat bei seinem Tod nichts mehr zu tun.

na) Leipzig 1796. Werke Bd. 5. Der kurz zuvor entstandene, am andern Ende der kotzebueschen Theaterwelt, auf Kamischatka spielende .Craf Benjowski“ erledigt cinen Kampf zw ischen verschworenen Deportierten und dem Militär im V. Akt durch Meldungen und starkes Sch iefen. 
wollte. Er trägt dafür kein Bedenken, mit der Besorgnisszene der Frauen am Anfang des dritten Aktes zeitlich über den Schluß des vorhergehenden zurückzugreifen. Die harrenden peruanischen Weiber haben im schützenden Wald wohl die Geräusche des Treffens, das Schildergetöse und den Knall der fremden Feuerrohre vernommen, aber sie sind noch ohne Nachricht über den Ausgang. Eine Beobachterin außerhalb der Szene kann endlich die nahenden Boten ankündigen, die einander in der alten Weise auf den Fersen folgen, wie es der Theatralzweck ohne Rücksicht auf Wahrscheinlichkeit fordert. Noch einmal wird vermittelst des Teilberichts der Cottschedianer der Clückwechsel zum Bühneneffekt gebraucht, obwohl der Zuschauer das Ergebnis der Schlacht bereits kennt. Der erste Bote stiftet durch die Meldung der (anfänglichen) Niederlage Verwirrung, der zweite gibt in Rollas wackerer Haltung neue Hoffnung, der dritte verkündet den betenden Frauen den Sieg und zugleich die Ankunft der Helden. Dasselbe Gefecht ist damit hintereinander in neue und alte technische Formen gefaßt, die schon dem frühen Kotzebue nach Belieben zu Gebote stehen.

Die Teichoskopie, die neben den „Spaniern“ besonders der „Bayard“ sich dienstbar macht, handhabt am geschlossensten eine späte Arbeit Kotzebues, der "Schutzgeist". ${ }^{84}$ ) Von dem verzweifelten Ausfall des Markgrafen Azzo aus Canossa, wo er die Königin Adelheid vor dem Usurpator Berengar birgt, erscheint nichts auf der Bühne. Ein alter Knappe hält vom Söller Ausschau $(V, 8)$ und berichtet der bangen Fürstin den Kampf in einer langen Versreihe. Klassische Formgebung wirkt nach, doch hat gerade die im Motiv vorbildliche Szene Schillers (Jungfrau V, 11) auf die Dialogführung keinen Einfluß. Kotzebue sucht hier die Spannung nicht im erregten Hin und Her von Rede und Gegenrede, sondern läßt die Schilderung wie einen Botenbericht in kaum unterbrochener Folge ablaufen. Für den Effekt sorgt die inhaltliche Anlage mit glücklicher Wendung nach bösem Stand des Gefechts und besonders mit der Schlußpointe: der Markgraf selbst ist den Augen des Beobachters entschwunden, mitten im Triumph über den Erfolg muß er ihn zu Tode getroffen herauftragen sehen. Mit dieser Überraschung hatte schon die Teichoskopie im "Bayard" geendet, wie Kotzebue taugliche Motive überhaupt häufig wiederholt. Beobachtung kriegerischer Dinge greift kurz darauf noch einmal halb zauberhaft in die Handlung ein. Als Adelheid verzweifelt ihrem Leben ein Ende machen will, tritt der allgegenwärtige Schutzgeist an ihre Seite und läßt sie den Heranzug

84) Leipzig 1815. Werke Bd. 32: Die Monographie über das Stück von G. Glück, K.s Schutzgeist u. seine Bearbeitung durch Goethe, Progr., Lundenburg 1907, läßt die Kampftechnik unbeachtet. S. 23 ist das Verlangen des Knappen, mit in die Schlacht zu gehen, mit demjenigen des Greises in den "Spaniern“ in Parallele gesetzt. 
des glänzenden kaiserlichen Entsatzheeres, die schnelle Niederlage der Feinde und Otto den Großen selbst auf sich bäumendem Roß sehen. ${ }^{85}$ )

Die letzte große Kampfaufgabe der kotzebueschen Dramatik ist die Schlacht am Marchfeld des "Rudolf von Habsburg" ${ }^{86}$ ) Die Lösung steht dem .Bayard" am nächsten, nur regiert die Teichoskopic minder ausschließlich als dort. Dic äußeren Bedingungen für sie schafft eine in jedem Betracht geschickt gewählte Lokalität, cin Kloster auf der Anhöhe, an deren Fuß gefochten wird. Hier sendet am Morgen der Schlacht, noch ehe die "Mordlust" im Tal sich zu regen beginnt, der empfindsame Kaiser Rudol ${ }^{87}$ ) den eröffnenden Stoßseufzer zum Himmel und hört die Todesengel über den Zelten; hierher kehrt er leicht verwundet zu kurzer Rast aus dem Getümmel zurück und gibt damit Anlaß zu gesprächsweisem Kampfbericht (VI, 5). Hier herauf wird später sein Gegner Ottokar mit tödlicher Verletzung gleich Bayard gebracht, vor allem aber kann Kotzebue in dem klösterlichen Bezirk zwanglos die Frauen ansiedeln. die auf diese Weise sowohl für dic Besetzung der Bühne während der Männerschlacht als für den Abschluß des Stückes zur Stelle sind. Beobachtungs- und Frauenbesorgnisszene gehen in eins auf. Die Äbtissin des Klosters, der Ottokars verstoßene Tochter Agnes als Novize unerkannt zur Seite steht, verfolgt vom Kirchhof aus das Treffen (VI, 3) und heißt die Begleiterin für des Kaisers Sieg beten. Die starke Situation der Octavia kehrt in dieser freiern Schlachtanlage wieder. Agnes' Vater steht in blutiger Entscheidung gegen ihren Celiebten, den Kaisersohn, und ihre Angst ist zwischen den Parteien geteilt. So straff hält sich die Technik freilich nicht durch den ganzen Kampfakt. Äußerst sorglos wird eine letzte, haibhistorische Intrige über Ottokars Nachfolge eingefügt, um deretwillen der klösterliche Schauplatz als eine Art neutralen Ortes zu gelten hat, wo Freund und Feind abwechselnd Platz finden können, ohne aufeinander zu stoßen. Abschließend gewinnt Kotzebue aus Ottokars Ende eine sichere Theaterwirkung. Die Verwundetenszene crhält Rührung reichlich zugemessen, das verstoßene Kind labt den verscheidenden Vater mit Wein. An sein Sterbelager tritt wie im "Bayard" der verzeihende Gegner, dessen Großmut freilich übel genug in eine platte Eheschließung ausmündet. Im Nachruf auf den Toten fehlt die nachdenkliche Betrachtung nach dem Vorgang Shakespeares und Schillers nicht: .,Ihn deckt ein kleiner Hügel, / Zur Spanne Landes wird sein Eigentum".

2) V. 13; Massenbeobachiung VI, I, wo die Bürgerschaft, auf Ottos Einzug harrend, die Mauern besetzl hält.

8s) Leipzig 1816. Werke Bd. 34. Akt VI.

87) Vgl. Hauffen. DNL 139 II, S. 19: C. Glück. K.s Rud. von Habsburg-Drama, Progr.. Lundenburg 1910. S. 11; über den Schauplaiz S. 18; zum folgenden S. 7 u. 19. 
Eine besondere Szenengruppe innerhalb der kriegerischen Dramatik Kotzebues bilden die zahlreichen Schildwachauftritte. Kotzebue macht sich das dankbare Motiv in rein technischer Funktion, wie auch für reich ausgestaltete Episoden zunutze, worin der schlichte Kriegsmann als wirksame Bühnenfigur sein Wesen treibt. Die Charakteristik zeigt sich in der Sphäre des einfachen Soldaten von ihrer, besten Seite und derjenigen in der hohen Kriegswelt weit überlegen. Die derben Züge, die der Erscheinung des Waffenknechts schon im frühen Ritterstück ein halb komisches Ansehen geben, werden vollends ins Lustspielmäßige gewendet.

Die exponierende Postenszene, die wir zuletzt bei lffland antrafen, eröffnet die „Octavia“. Zwei Wachen vor Octavius' Zelt ermuntern sich im Morgengrauen und stellen in belebtem Disput die Lage klar. Der Anschluß an Shakespeare ist hier unmittelbar, und auch ein schwacher Nachklang seiner Stimmungskunst ist geblieben. ${ }^{8}$ ) Nach derselben Technik führt Kotzebue den "Hugo Crotius" ${ }^{89}$ ) mit dem knappen Vorgang der Schildwachablösung ein. Ein brummiger Sergeant versieht geräuschvoll seinen Dienst vor Grotius' Gefängnis und bleibt den Bitten der Tochter um Schonung seines Schlafes taub. Die Situation des duldenden Ketzers könnte einleitend kaum gedrängter und anschaulicher für die Bühne gewonnen werden. Während die Kriegsleute hier unzugänglich ihrer Pflicht genügen, weisen zwei beiläufige Postenauftritte der "Spanier in Peru“, ein vorgeführter (IV, 6) und ein erzählter (III, 6), unwahr sentimentalisierte Wachen auf, die den Kameraden im Hussitenlager ähnlich sehen. Der Wachhabende vor dem Zelt des gefangenen Alonzo ist weder durch Bitten noch Kostbarkeiten zu bestechen, wohl aber, so barsch er zuerst auf seine Order pocht, durch die rührsame Erinnerung an Weib und Kind. Noch sträflicher zeigt sich der Posten Pizarros weiblichem Reiz untertan; seine Hellebarde senkt sich trotz gemessenem Befehl vor dem Blick der schönen Elvira, der ihm sanft ,,vom borstigen Haar zum straubigten Bart herunter" gleitet.

Die beiden großen Schildwach-Episoden Kotzebues, eine zweite nächtliche Postenszene im „Hugo Grotius" und eine engverwandte im „Schutzgeist“, halten sich von so unsoldatischer Süßlichkeit fern. Der kräftige Landsknechtston ist gut getroffen, die Charakterisierung der Kriegsgesellen einheitlich im Derben gehalten. Hier wie dort soll ein wohlbehüteter Gefangener befreit und darum die Aufmerksamkeit handfester Wächter getäuscht werden; das eine Mal tut starkes Getränk, das andere ein romantischer Spuk den Dienst.

88) Vgl. Rabany S. 217; den entsprechenden Auftritten in Ant. u. Cleop. IV, 3 u. 9 fehlt gemäß ihrer Stellung der exponierende Charakter.

89) Leipzig 1803; Werke Bd. 19. 
Die Szenen haben den reichen dekorativen Rahmen gemeinsam, beide Gefängnistiirme: stechen ain mondbeglänzten Wasser. An die Schildwachen des Grotius vor Schloß Löwenstein an der Maas (II, 1-6) macht sich sein Sohn als scheinbar angetrunkener Fischer heran und setzt ihre Sinne unter Wein. bis sie unter krausen Reden an ihre Hellebarden gelehnt einschlummern ein hübscher Zug altgedienter Kricgsleute, dic auch unter so bedenklichen Unständen buchstäblich ihren Mann noch stellen und den Posten nicht verlassen. Kotzebues schlagfertiger Dialog formt sie in knappen Strichen zu theaterfesten Typen: stolz auf ihr Handwerk, sind sic mit aller Protzigkeit würdiger Veteranen als Schildwach aufgepflanzt, mehr körperlich als geistig respektabel, nicht subtil in Definieren und leicht an ihren Schwächen zu packen. Außer dem Wein benimmt ihnen vorgemachter Dunst von Kampftaten rasch die Urtcilskraft, ein für brav gehaltener junger Kamerad hat im Augenblick ihr ganzes Vertrauen und holt sie aus; aus seinem Mund darf selbst ein loses Wort über den Kriegsherrn passieren, wenn sie es ihm auch pflichtgemäß bärbeißig verweisen. Neben den wackern Teutschen Dorias. denen sie in manchen Zügen gleichen, erscheinen diese Gesellen als lockere Vögel. Die Auffassung ist die des Lustspiels, aus dem ihre weinseligen Mißverständnisse stammen, und ebenso der glückliche Griff, wie sie dann halbwach der Unterredung von Scliwester und Bruder sekundieren..$^{90}$ )

Die Posten, welche die Königin Adelheid in ..Schutzgeist" an einer Wasserburg des Comersees bewachen, hält Kotzebue ernster. Der eine schilt auf sein beschwerliches Los, und man möchte fast vermuten, das Klima der Hamlettcrrasse habe wic bei Früheren auch für diese südliche Gegend Geltung, wenn man ihn über kalte nasse Steine. rauhen Nordost und Mark und Bein durchschüttelnden Fieberfrost klagen hört. ${ }^{91}$ ) Die Atmosphäre für den Spuk ist damit bereitet, gleich Grotius' Sohn als Fischer verkappt, beginnt der Schutzgeist die Soldaten zu äffen. Nebel jagen sich, die wallenden Dünste trügen Auge und Ohr, Gestalten zerfließen vor dem wachen Wer-da-Anruf zu nichts; es hilft wenig, daß der wackere christliche Kriegsmann, nachdem er das Kreuz geschlagen hat, auch Gespenstern zu Leibe geht, der Zauber

$\left.{ }^{\circ}\right)$ Eine reine Komödienszene folgt II, 5, wo der verdächtige Fischer dem Sergeanten das aufgefangene Brieflein Satz für Satz aus dem Stegreif ins Harmlose deulet. - Ähnliche Meinungsverschiedenheiten betrunkner Soldaten über Sonne und Mond usw. in den "Spaniern" V. 2. wo Kotzebue durch ein in Wald und Gewitter henumirrendes Pas den Kindsraub bewerksteiligt.

") Schutzgeist II. 2. Oher die parallele Kontraslierung der beiden Wächter und der beiden Reiter vgl. Glück, K.s Schutzgeist S. 23. Am beweglichsten räsonniert die Schildwache Shakespeares. I Heinrich VI: II, I, über das nächeliche Pustenstehen: .So mussen arme Diener / Wenn andre schlafen auf bequemem Bett / In Finsternis, in Kält und Regen wachen" - wie es noch leute im Solda'enlied heibr. Wenn ander leut schlafen. so müssen wir wachen". 
narrt die beiden und führt sie von ihrem Posten weg in die Irre. Der Auftritt gehört zu den trefflichsten Schildwachszenen. Die breitgrätschige Wirklichkeit der Kriegsgesellen tritt zu dem schwanken Spuk, der sie neckend umgaukelt, ohne daß sie ihm mit Wehr und Waffen beikommen können, in reizvollen Gegensatz. Das Motiv steht wie manches andere im "Schutzgeist“ dem Zauberstück nahe $;{ }^{92}$ ) es wird uns sehr ähnlich im zweiten Teil des Faust wieder begegnen.

Wo Kotzebue den Soldatenstand eingehender charakterisiert, ist der Einfluß Schillers unverkennbar. Ein alter Reiter im "Schutzgeist" tritt der Klage des Wächters über das mühselige Gewerbe bei, und seine Tirade von dem ruhelosen Beruf, worin man um kargen Sold täglich die Haut zu Markte trägt und auf Heimat, Weib und Kind verzichten muß, schließt sich unmittelbar an die Schilderung des Ersten Kürassiers an. ${ }^{93}$ ) Das Disziplinproblem aus dem Soldatenstück greift Kotzebue im „Hugo Grotius“" auf; der simple Pflichtbegriff seiner einfachen Söldner ${ }^{94}$ ) kehrt hier in höherer Sphäre wieder, wo (II, 8) im Offizierskreis der Grundsatz aus dem Soldatenkatechismus des Oktavio Piccolomini: „Ich klügle nicht, ich tue meine Pflichť", so formuliert wird: "Doch räsonnieren darf ich einmal nicht, Gehorchen nur - das will ich." Mit der Sentimentalisierung der Offiziersfiguren steht der Autor auf diesem Felde nicht allein; schon die frühesten Dramen der Gattung weisen sie auf. Bei Kotzebue siegt in einem ersten starken Konflikt die Kameradentreue als höchste soldatische Forderung über die Liebe, um deretwillen die bloße Dienstpflicht verletzt werden sollte; ein zweiter stellt in einer häufigeren Situation diese Dienstpflicht in aller Härte gegen die Rechte des Herzens. Hier, wo Hauptmann Gaßweiler in eigener Person die Exekution des liebsten

92) Verwandtes bei Shakespeare findet sich neben dem Hexenspuk im Macbeth, der I, 3 vor den Feldherren in Luft zerrinnt, im Sommernachtstraum II, 2, wo Puck Lysander und Demetrius, die sich zum Zweikampf suchen, nasführt. Klingers Medea in Korinth. Akt IV (Werke 2, 223), zerstreut die Korinther, die auf Befehl des Führers ihre Kinder greifen wollen, durch Zauberbann in die Finsternis: „Fliehet! irrt in dem Walde! . . Tappt und tappt in dicker Finsternis, verschwindet!" Glück S. 26 weist auf Vorgänger der Schutzgeist-Schildwachen innerhalb des kotzebueschen Zauberlustspiels im ,Sultan Wa mpum“ (1794, Werke Bd. 1) hin; dort (III, 7 u. 10) werden die Posten, die nach einem Reskript des Herrschers ihren Dienst unablässig singend verrichten, durch Vertauschen der Leibesgestalt kraft eines Zauberringes wie jedermann irregeführt; das eigentliche Spukmotiv fehlt aber der Verwandlungskomödie.

${ }^{3}$ ) Schutzgeist III, 7 - Wallensteins Lager v. 917 ff.; vgl. Piccol. 1141 ff., Tod 1921 ff. - Die Schilderung eines Lageraufbruches in Hein rich ReuB V, 2 berührt sich mit Piccol. v. $490 \mathrm{ff}$.

$\left.{ }^{94}\right)$ Schutzgeist II, 2: „Was kümmerts uns? wir haben Brot und Sold“ - und III, 6: „Der König befiehlt, ich muß gehorchen; / Soldat und grübeln, das steht nicht fein"; vgl. Wall. Tod v. 3235 ,wir denken nicht nach" usw. 


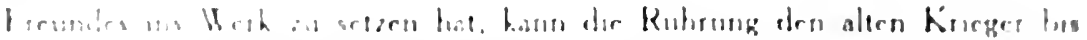

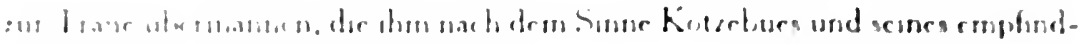

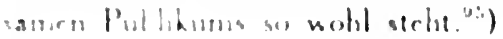

\section{; Orer Thestergots}

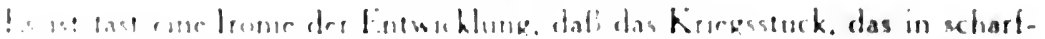

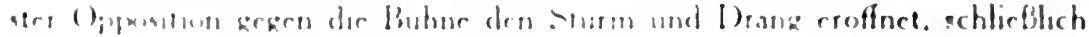

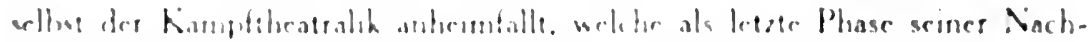

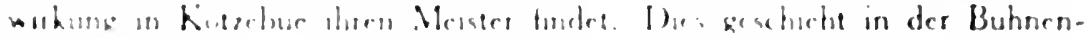

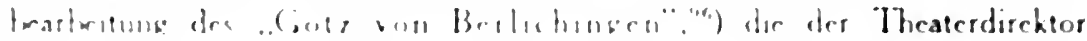

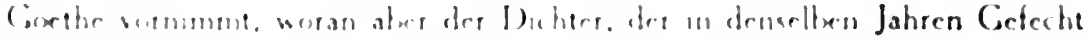

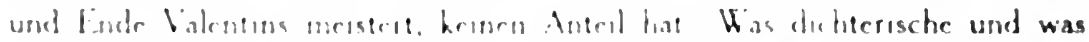

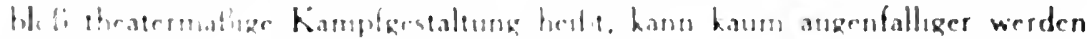

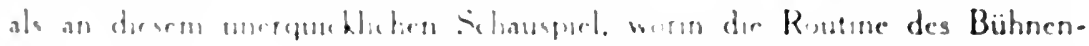

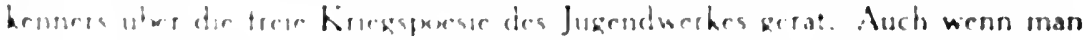

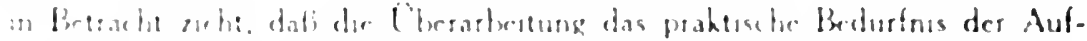

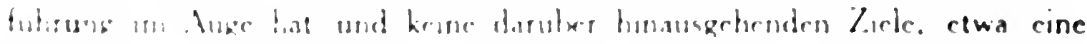

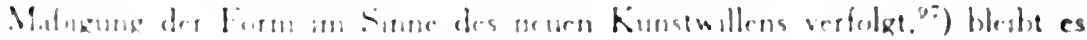

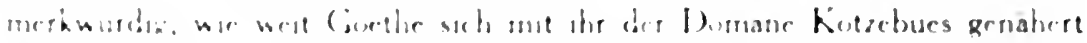

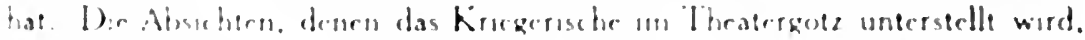

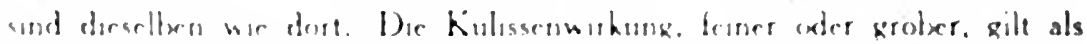

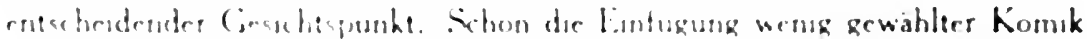

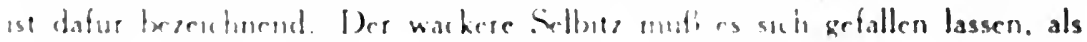
lexkerer Kumpan zu gellen. des de Kurfel meble lassen kann: dic Reichs-

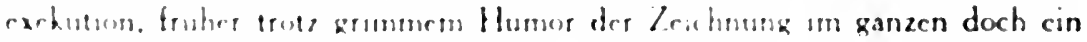

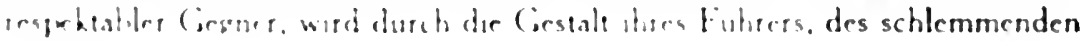

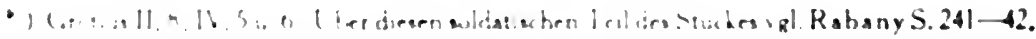

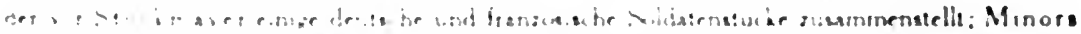

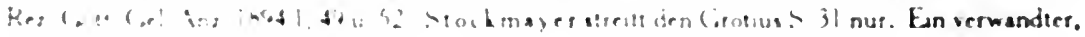

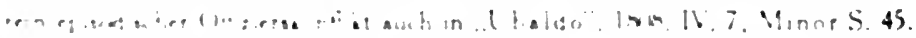

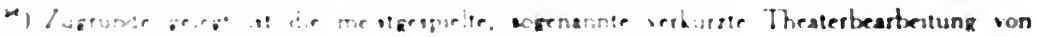

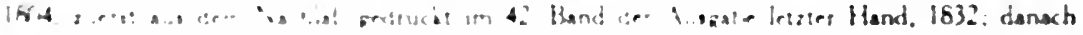

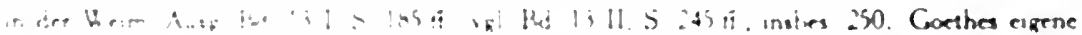

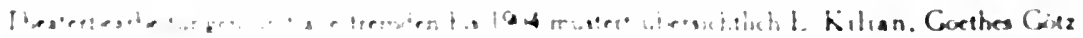

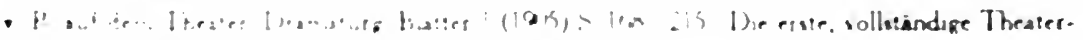

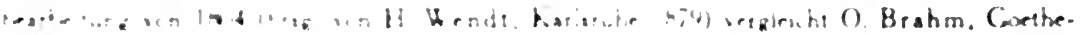

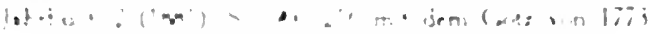

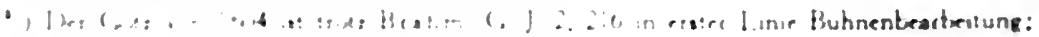

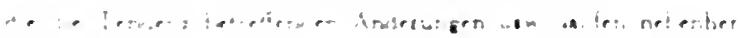


Hauptmanns von Wanzenau, zur halben Posse herabgedrückt. ${ }^{98}$ ) Es entspricht den Forderungen der Bühne, daß die kurzatmigen Kampfauftritte zu längerer Folge verbunden sind. Die Beobachtung leistet dafür in äußerlich routinierter Anwendung gute Dienste und wird nunmehr schon auf der Feindesseite, beim Lustgezelt des Hauptmanns eingesetzt. ${ }^{99}$ ) Die Selbitzszene, die nach der Flucht der Reichsvölker und der Plünderung des Platzes durch Georgs Trupp an eben der Stelle vor sich geht, verliert damit freilich ihre beherrschende Bedeutung innerhalb der Schlacht. Schlimmeres fügt ihr Goethe durch den neuen Abschluß zu, den keine Rücksicht auf den Fluß der Handlung, sondern allein das Streben nach theatralischer Kampfvorführung diktiert. Der Zuschauer bekommt ein Combattement zu sehen, nicht anders als es ihm Kotzebue in Johanna von Montfaucon liefert, noch dazu mit einem besonderen Effekt. Mehr als streitbar, weiß sich der verwundete Selbitz selbst im Liegen und Sitzen einer Schar von Reichsknechten zu erwehren, die ihn auf ihrer Flucht mitnehmen wollen, bis Lerse im letzten Augenblick allein unter sie fährt und als wahrer Eisenfresser gegen ein halbes Dutzend erlegt. ${ }^{100}$ )

Mit kotzebueschen Tendenzen berührt sich der Bühnengötz außerdem im Anordnen kriegerischer Gruppen. Zwei theatralische Massenbilder bezeichnen Anfang und Ausgang von Götzens Beteiligung am Bauernkrieg. Als er sich weigert, die Führerschaft zu übernehmen, senken sich die Spieße des Haufens in der Runde gegen ihn; in berechneter Stellung inmitten starrender Spitzen spricht er nur freier von der Leber weg gegen ihre Greuel. Eine ähnliche Theatersituation gab Kotzebue in der Speerpantomime der Hussiten. ${ }^{101}$ ) Eine echte Theatergruppe endet die Bauernschlacht: Götz sitzt erschöpft inmitten

98) Theaterbearbeitung II, 8 u. III, II; vgl. Brahm, G.-J. 2, 203, der S. 204 über den Hauptmann wohl zu milde urteilt; scharf Kilian 1, $184-85$.

99) III, 11; die neuen Partien halten sich im Gegensatz zu der plastischen Schärfe der Ausschau von der "Höhe mit einem Wartturm" des alten Götz in ihren Motiven im allgemeinsten, Staub usw. An Beobachtungsszenen ist weiter dazugekommen II, 11, Götzens Überfall auf den Nürnberger Warenzug; szenenverbindende Kampfbeobachtung durch Zigeuner III, 12 u. V, 10. Allzu leichthin wird V, I der Bauernkrieg durch Ausschau auf einen nahenden Haufen in die Handlung eingeführt.

100) III, 14-15; vgl. Kilian 1, 209. Billigen Heldenruhm erwirbt sich Georg 1I, 12, indem er als einzelner die Kaufleute stellt; vgl. Brahm G.-J. 2, 207.

102) Sie wurden während der Beschäftigung Goethes mit der Götz-Bearbeitung am 2. April 1804 in Weimar aufgeführt. Coethe an Schiller unter diesem Datum u. am 12. März 1804. Innerlich ruht die Neigung zur Gruppe auf der Tendenz des klassischen Goethe zur BildmäBigkeit, die den gehobenen Augenblick absondert und festhält, und in seiner Regieführung schlieblich zur Steifheit führte; vgl. Petersen S. 237 ff. In der äußeren Durchführung des Prinzips im Theatergötz. überwiegen jedoch die kotzebueschen Theatralabsichten. 
von Weibern und Kindern, von beiden Seiten her brechen die Bündischen im Bühnenkainpf den letzten Widerstand der Bauern und Zigeuner und heben endlich, sich Bahn schaf!end, zum Schlußbild die Partisanen auf Berlichingen. ${ }^{102}$ ) Ebenso mündet die packendste Szene der Bearbeitung. Adelheids grausenvolle Todesangst, in ein Tableau. Die Reisigen umschließen die von allen Schrecken der Vernichtung heimgesuchte Herrin mit gezückten Schwertern und kampfbereiten Hellebarden, inmitten des waffenstarrenden Haufens will sie den vollen Tag erwarten. In diesem Auftritt, worin sich höchstes Raffinement mit dichterischer Kraft paart, wird Kotzebue an Bühnengewalt allerdings übertroffen. So aufregende Wirkung, wie sie der nächtlichen Ausschau Adelheids innewohnt, die den Boten ihres Verbrechens mit Wort und Blick den mondbeglänzten Schloßberg hinabgeleitet, bis sie der Schauder über die ihn kreuzende schwarze Unheilsgestalt packt, hat er in technisch eng verwandten Szenen kaum erreicht. ${ }^{103}$ ) Auf den starken Effekt hin, womit Goethe den wirklichen Vermummten in das weichende Wahnbild treten läßt, wird in der Mitternacht die Besatzung alarmiert. ${ }^{1(n)}$ ) Während man Sturm läuten hört, ordnet sich in verschwenderischem Fackelschein die kriegerische Gruppe. Dann schlicßt die verkürzte Bearbeitung dic Adelheid-Handlung mit der den Postenszenen verwandten Begegnung zweier Reisigentrupps auf erfolgloser Streife durch Hallen und Gänge der Burg. Das Ende. Adelheids Er-

${ }^{102)}$ V., 2 u. 12: auch Ende III eine kriegerische ..Cruppe in Bewegung "; eine theatralische Schlachtordnung läßt Cocthe V. 4 in bezeichnender Abänderung der Szene .Berg und Tal" im V. Akt des Cötz von 1773 über die Bühne schreiten; W'eislingen rückt mit einer Ritterreihe, die sich an den Händen gefaBt hat um enge Fühlung zu halten. langsam vor, dahinter folgt wohlgeordnetes Kriegsvolk. Der ursprüngliche Auftritt wußte von so korrektem Exerzieren des Staistenheeres nichts.

${ }^{103}$ ) V, 14 vgl. V, 13; von den hier zusammengearbeitcten Aultritten "Adelheidens SchloB" und "Adelheidens Schlafzimmer" der Geschichte Cottfriedens weist nur der letztere schwache Ansitze zur Naturbeobachtung auf, alles ührige ist neu. Kotzebue. Kreuzfahrer I, 10; W'asa IV, I5: vgl, o. S. 224 Anm. 72.

10s) Die Szene berührt sich hierin eng mit derjenigen Franz Moors. Räuber V. I, der die Situation im ganzen, die bange Erwartung des nahenden Verhängnisses, welche im Fieberwahn Truggestalien erzeugt, verwande ist. Adelheid weckt wie Moor die Schläfer: „Läutet Sturm! daB alle sich bewafinen." - Moor: .AAlles soll auf sein - in Waffen" - usw. Die Geschichte Cottfriedens laBt Adelheid nur des einsamen Wachens innewerden und vergeblich klingeln, dano aber selbst einschlafen. - Zweilellos aus den Räubern (Schweizer IV, 5 u. V. I) stammt der neue Zug. CAB Ceorg V. 6 mit der Versicherung nach Miltenberg eilt: .Ich will es retten, oder ihr seht mich nicht wieder" - . eine Vordeutung auf den Ausgang, die auf sein Ende im scharfen Gefecht (V. 19 u. 20) viel weniger als auf Schweizers Selbstmord paßt. Andern Einfluß der Räuber s. bei Brahm. C.-J. 2. 207-08. - Schiller hat an der Bühnenbearbeitung des Cötz Anteil. vgl. Goethe an ihn 12. Marz 1804 u. Tagebücher 23. Juli 1803 (3. 74). 
mordung, wird bloß vorgedeutet und wirksam die Wehrlosigkeit der bewaffneten Macht gegen die schleichende Vergeltung gezeichnet: die Patrouillen können nichts Verdächtiges finden, fühlen sich aber dennoch dem Arm der Vehme untertan.

Wie die Selbitzszene das Combattement zugeteilt erhält, so finden sich innerhalb des alten Bestandes der Kriegshandlung allenthalben Änderungen im Sinne der Kampftheatralik. Die wachsende Bedrängnis der Belagerten wird durch anschwellenden Trommelklang verdeutlicht, der nach dem Kirchgang zuerst entfernt den feindlichen Anmarsch bezeichnet und dann in berechneten Rapport zur Handlung tritt. Er wird drohender, als Marie sich der Trennung widersetzt, und bleibt selbst nach Götzens Wort „Wen Gott lieb hat, dem geb er so eine Frau", nicht erspart. Demgemäß ist auch Lerses Meisterschuß nicht mehr der einzig vorgeschriebene; von draußen wird öfters geschossen, Götz befiehlt einmal das Feuer einzustellen, weiterhin fallen auch bei seiner Überwältigung Schüsse. Gleich Kotzebue schreibt der Regisseur Goethe jetzt sowohl für die Trommeln als die Detonationen vor, daß sie nicht zu nahe sein dürfen. ${ }^{105}$ ) Eine bezeichnende Retusche empfängt der Brand Miltenbergs, der nunmehr bei Nacht stattfindet und im Anwachsen und Übergreifen auf das Schloß die Szene des unbekannten Warners begleitet. An die Seite der Kampfgruppen treten kriegerische Aufzüge, breit beim Kirchgang angeordnet, wo die erbeuteten Fahnen zupaß kommen, um das Brautpaar zu salutieren, und die Wache dem Trauungszug kriegerische Ehren erweist. Bei der Rückkehr aus der Kirche ergibt sich ein neues reiches Bild daraus, daß die Hochzeitsgesellschaft durch die Gruppen sich rüstender Knechte schreitet. Ein starkes Beispiel, wie poetische Züge des klassischen Götz zu sträflichen Theatralszenen ausgeschlachtet werden, liefert endlich das Jagdmotiv. An die Stelle weidfroher Heimkehr Georgs und Lerses, die aus braven Reitern brave Jäger geworden sind, und an den Platz jenes frischen Wortes von Jagd und Krieg ist ein Georg getreten, der mit vorgehaltener Büchse über das Theater weg einen Hirsch beschleicht und den Zuschauer in die aufregende Erwartung des Schusses versetzt. Mag auch dieser des Brigantenstücks würdige Vorgang zu den äußerlichsten Einschiebseln der Bearbeitung gehören, ${ }^{106}$ ) er zeigt immerhin, wie weit Coethe sich auf bloße Kulissenwirkungen einläßt.

105) Trommeln IV, 6-7; ähnlich bereits im Egmont, zu dessen opernhaftem Schluß der Theatergötz mehr Beziehungen hat. Schießen IV, 10-13 u. 16; die Regie-Anweisung IV, 7 u. 10.

106) V, 1; außerhalb der kriegerischen Motive ist das theatralische Arrangement am auffälligsten in der Szene der vier Vehmboten V, 9, rgl. Kilian 1, 187. 


\section{Kapitel}

\section{Romantische Theatralsatire und neue Einkehr bei Shake- speare: Ludwig Tieck.}

Die schmelzende Harmonica ist nicht dazu gemacht, den Tritl eines Heeres zu ordnen und anzufeuern.

W. Schlegel.

Ausfälle auf die Kampftheatralik aus dem romantischen Lager, unmittelbar gegen Kotzebue als den erfolgreichsten Führer der Theaterheere gerichtet. waren in Brentanos Gustav Wasa und Wilhelm Schlegels Ehrenpforte aufzuweisen. Mit einer allgemeiner gedachten, umfassenderen Ironisierung des Bühnenkampfes geht Tieck voran, von dem insbesondere Brentanos Parodie durchaus abhängt. Ohne daß einzelne Stücke erkennbar aufs Korn genommen wären, und in den Jahren, als die Reihe der kotzebueschen Kampfdramen erst anfing. die Bretter zu betreten, ersteht in der ..Verkehrten Welt" die beißendste Verspottung der Kulissenschlachten insgesamt. ${ }^{1}$ ) Mit schneidenderen Waffen als sie der nie ganz verstummenden Kritik zu Gebote stehen, macht hier die Komödiensatire allem Theaterkrieg den Krieg. Zu der Zeit,. wo unter Cottscheds Führung die Literatur die Vorherrschaft über die Bühne an sich rib. hatte das lebendige Theater in einer Parodie wie der Kurzschen Pumphia die strenge Kampftechnik verhöhnt. Jetzt, in der Blüte der theatralischen Kampfausbreitung, nachdem eine ganze Sippe von Schauspielerauteren sich des Ritterstücks bemächtigt hat und Kotzebue sich anschickt. die höchste Theaterwirkung zu erreichen, geht umgekehrt die Literatur dem Treiben der Bühne zu Leibe.

Tieck schwingt die Geifel über dem Kulissenkampf als Kundiger: er hat sich selbst in seinem frühen Ritterstück in ihm versucht. Es entspricht seinen

') Ersidruck in 2. Teil von Bernhardis Bambocciaden. Berlin 1799: zugrunde gelegt ist der Druck des Phantasus in Schriften Bd. 5; vgl. Haym² S. 102 f. Das Entstehungsjahr 1798. das Tieck selbst (Sthriften 1, XXI) angibt, stimmt nicht zu dem Datum des von ihm angezogenen Briefes von Nicolai (Holiei, Briefe an L. Tieck 3. 58), wonach die Komödie schon Ende 1797 fertig gewesen sein muB: sie liegt vor Kolzebues Johanna von Montfaucon. - Die Sammlung der Tieekschen Ausfalle auf Kolzebue bei Hans Günther, Romant. Kritik u. Satire bei L. Tieck. Heidelberger Diss. 1907, S. 122-28, ergibe lur uns nichts. 
Anfängen als Erzähler in Rambachs Diensten, daß er in Teilen des „Karl von Berneck" 2 ) wüste Theatralik gibt und in ihrem Bann zwei vorfallende Zweikämpfe zu stärkstem Effekt aufstutzt. Ein Motiv zu dem ersten mag ihm aus Shakespeare, der schon hier allgegenwärtig ist, zugekommen sein; jedenfalls empfängt die Art, wie er es ausbeutet, durch den Vergleich mit der verwandten Szene in Romeo und Julia Licht. ${ }^{3}$ ) Der alte Bemecker, der als heimkehrender Kreuzfahrer auf seiner Burg ein rauschendes Fest vorfindet, fordert den Galan seines ungetreuen Weibes vor sein Schwert; widerwillig zieht dieser, durch die Dazwischenkunft der Frau erhält der Gatte den Todesstoß. Ebenso verschuldet Romeo den Tod seines Freundes Mercutio, als er dessen Zweikampf mit Tybalt trennen will. Aber Shakespeare läßt davon erst in Mercutios Klage, nachdem alles vorbei und der Gegner abgegangen ist, die Rede sein. Tieck stellt den Vorgang selbst als straffes Combattement heraus. Aufschreiend stürzt sich Mathilde zwischen die Klingen, mit einem Fluch auf sie sinkt der getroffene Berneck seinen Leuten in die Arme. Es ist auf dieselbe Wirkung abgesehen, die Kotzebue späterhin in ähnlichen Bühnenduellen des „Heinrich Reuß" erreicht.

Mit allem theatralischen Aufwand, in Nacht, Donner und Blitz geht der andere Kampf vor sich. Postenmotive leiten ein, ein verzerrter Hamlet, bewacht Karl von Berneck die Ehre seiner Mutter an der Schwelle ihres Schlafgemaches mit scharfem Schwert. Der nahende Buhler stößt in der Finsternis auf sein heftiges: Zurück!, in dem ungleichen Gefecht zwischen Jüngling und Mann ruft Karl pathetisch den Geist seines Vaters an und fällt den Feind mit zweihändig geführtem Meisterstreich. Auf seinen Schrei tritt für einen Augenblick die Mutter mit einer Leuchte hervor, dann sprengt der Sohn wahnwitzig ihre Türe ein und schreitet drinnen zum Mord. Zurückkommend zerschmettert er verzweiflungsvoll das Schwert - es ist die Schicksalswaffe - an der Erde. Neuerdings spricht der Donner, dann schleicht auf die leergewordene Bühne der Burggeist herein und sammelt still die Stücke auf. Der junge Tieck erweist sich in dieser grellen Effektfolge, die dem Theatergewitter eine so entscheidende Rolle einräumt, ${ }^{4}$ ) als gelehriger Schüler des späten

2) Entstanden seit 1793; zuerst gedruckt im 3. Bd. der „Volksmärchen“, Berlin 1797. Schriften Bd. 11. Vgl. Haym 3 37-38; Brahm, Ritt. S. 141-42; Hauffen, DNL 138, XII; Koch, Shakespeare-Jahrbuch 32 (1896), S. 335-36. Uber Tiecks Verhältnis zum Ritterdrama siehe den Abschnitt „Ritterdrama u. Ritterroman“ bei H. Günther, S. 86 f.

3) Berneck Ende II, Schriften 11, 63; Romeo u. Julia III, 1; der Hinweis darauf bei Brahm, Ritt. S. 141, der auch eine Reihe von Vorgängern im Motiv der Nötigung zum Kampf namhaft macht.

4) Die Vorgänge schließen den III. Akt, S. 89 ff. Das Gewitter spielt fast leitmotivisch auch vorher und nachher mit; es begleitet im Aufziehen den Racheentschluß in der Rüstkammer, 
Ritterstücks, dem dergestalt handfeste Bühnenwirkung als höchstes Zicl vorschwebt.

Die Kamptszenen der Verkehrten Welt nun führen die allgemeine Ironisierung der theatralischen Illusion, worau! es wie im vorangehenden Cestiefelten Kater abgeschen ist, trefflich innerhalb der kricgerischen Domäne durch. Tieck wählt für dic Satire, welche an dic Wurzeln der Theaterwirkung des Krieges greifen soll, mit gutem Blick dessen kräftigste Vorwürfe. Neben ciner Bataille zu Lande erscheint als kühnstes Wagnis, das selbst die Ausschreitungen des Kamplspektakels karikierend überbietet, eine wahrhaftige Seeschlacht auf seiner imaginären Bühne. $\left.{ }^{5}\right)$ Es ist an sich ein undankbares Geschäft, den luftigen Spaß zu zergliedern, worin die Komödie die Flotten der skurrilen Admirale Pantalon und Harlekin mit vielem Knall und Rauch aufeinandertreffen. Schiffe entern und umfallen und ihre Besatzungen im Wasser herumschwimmen läßt, bis schlicßlich der Theaterdirektor in eigener Person die Verwirrung endet. Der satirische Ertrag entschädigt immerhin dafür. Schon der Einfall dieses Gefechts zur See trift neben dem Kulissenkrieg zugleich das theatralische Wasserwesen, wie es sich seit Brandes' "Schiffbruch" breit macht, und in kurzem von Brentano an Kotzebues "Wasa" gegeißelt wird. Die Beziehung in den abschließenden Reden der Zuschauer ist unverkennbar: Pierrot setzt ihrer primitiven Gegenstandsfreude das boshaft doppelsinnige Bedenken entgegen, .,da $\$$ in solchen Szenen immer viel Wasser sein muf": torium cinräurnt, noch von keinem überwunden ist. ${ }^{6}$ ) Auf die militärischen

Akt III S. 83 f. u. 89; nach vollzogener Tat tritt es als Gewissensmahner auf, IV S. 99 u. 102 !., val. S. 95. Abzichendes Genitter eröftnet das Stück, I. 2. Für das Unwettermotiv im Ritterdrama vgl. Brahm, Ritt. S. 154.

5) IV. 4: Schriften 5. 389-98. Unmittelbar wird Schikaneder im Gestiefelten Kater II, 4 u. III. 7 an den Pranger gestellt, aber niche in seinen kriegerischen Schaustellungen, sondern mit seinem Aufwand an exotischen VierfüBlern und dern Dekorationsprunk der Zauberflöte. H. Günthers Musterung der gesamten Personalsatire Tiecks berücksichtigt im Abschnitt über Schauspielkunst und Bühne S. 75 ff. seine dramentechnische niche.

6) Schriften 5. 397: Tieck selbst hatte den Berneck mit einem abflauenden Seesturm. dem seine Personen eben entronnen sind, eröfnet. Wie er hier eine Richtung satirisiert, an der er früher teilnimmt, so fähnt jetzt unter der Maschinerie des Theaters besonders das ihm im Berneck so unentbehrliche Cewitter schlecht. S. 313 ff.: der Maschinist will es S. 419 zur Schlacht einrichten, wie es dort beim Zweikampt dient. - An der See-Dramatik nehmen auch drei Entwürfe Schillers. Das Schiff. Die Flibustiers und Das Seestück teil. Der erste verzeichnet unter den Motiven (Dramat. Nactilaß hrsg. von Kettner 2. 244) ..Sturm. Seetreffen, Meuterei auf dem Sxhiff. Sxheiterndes Schiff" usw.; der zweite ..Die Anstalten zu einem Seetreffen und das Entern" (2. 250): der dritte, der alle Hauptmotive, die in dem Stofie liegen, herbeibringen will, ebenfalls eine ...Meuterei. Brand in Wiasser, Seegefecht und Seeraub" $(2,251)$; ausdrücklich wird hier - 
Spöttereien wird zurückzukommen sein. Die technische Pointe der Seebataille liegt darin, daß an ihrem Ende die Schlachtillusion urplötzlich an der bretternen Realität zerschellt. Der als seltsames Zwitterwesen aus Meerestiefen auftauchende Direktor, halb Neptun, halb Theatergewaltiger, heißt die herumschwimmenden Soldaten auf den Bühnenboden abstehen, sie gehorchen und waten aus diesem Theatermeer ungestraft ans Ufer. Gemäß dem geistreichen Hin und Her des ganzen Komödienscherzes spielt Tieck daraufhin mit der Täuschung der Bühne Fangball. Als Wassergott holt Wagemann eine verlorene Admiralskappe vom Grund, als Theaterunternehmer schilt er auf das liederliche Gesindel seiner Schauspieler, das ihm in der Hitze des Gefechtes die Requisiten verschleudert hat. Derselbe Zwiespalt setzt sich in seine nachfolgende Begegnung mit König Skaramuz fort.

In der Seeschlacht wird der Schein der Kunst auf komische Weise vernichtet, in der späteren Landschlacht ebenso komisch für bare Realität genommen; die Illusionsstörung als Hauptwaffe der Parodie ist damit nach beiden Möglichkeiten hin genutzt. Die Bataille zwischen Skaramuzens Philisterund Apolls parnassischem Heer im fünften Akt, worin etwas zu handgreiflich der Poet im Zweikampf mit dem Maschinisten auftritt, ,,der nur immer für den elendesten Effekt arbeitet", endet mit der verzweifelten Apostrophierung der Zuschauer durch den geschlagenen Skaramuz. Diese rührt das Leiden des großen Mannes so sehr, daß sie, das Spiel völlig vergessend, kurz entschlossen zum Theater hinaufklettern, um - natürlich auf der Philisterseite den Kampf gegen den schon triumphierenden Apoll selbst aufzunehmen. Sein und seiner ganzen Armee Gelächter weckt sie aus ihrer Täuschung. Der Einfall ist glücklich genug, weiter kann keine Theaterschlacht die $\mathrm{Zu}$ schauer hinreißen, als daß sie ihre eigenen Fäuste in ihr brauchen wollen. Lustig bestätigt hier die Satire die Beobachtung, daß verlorene Schlachten für das Drama besser taugen als gewonnene; es ist der Unterliegende, dessen fadenscheinige Tragik die tätliche Äußerung der Sympathie für sich gewinnt. Ähnliche Verwechslungen zwischen dem theatralischen Schein und dem realen Sein sind keinem naiven Publikum fremd. Man darf daran erinnern, daß das empfindsame Zeitalter eine ungleich stärkere Neigung zu überschwenglichen Gefühlsausbrüchen gerade in der Öffentlichkeit besaß, als wir sie heute

die Tiecksche Parodie zum Ernst machend - vermerkt: „Der Korsar entert ein andres Schiff, und macht sich davon Meister. Dieses geht auf der Szene vor" $(2,253)$. Ausgeführt wurden nur die beiden Sturmfahrten im Tell, die - die technische Lösung kann von Kotzebues Schiffsbeobachtung im Wasa II, 1 angeregt sein - charakteristisch zeigen, wie die klassische Kunst die Mittel der Bühne nur sekundär heranzieht; wo die Theatraliker, die Brandes und Kotzebue den Wogendrang aus Gaze und Pappe reden lassen und den Effekt allenfalls noch durch eine Sturmsymphonie stützen, tobt er bei Schiller in der Gewalt des Fortes aus. 
zugeben mögen. Einen tatsächlichen Vorfall, der von Tiecks Komödienscherz nicht allzuweit absteht, überliefert Iffland von einer Mannheiner Aufführung der Oper .,Richard Löwenherz". Die zahlreich anwesenden Emigranten wären nach ihen von Tagesereignissen, zu denen sie in der Vorstellung Beziehungen fanden, so erregt gewesen, daß sie beim Sturm auf die Burg am Schlusse von ihren Plätzen fuhren, auf die Bänke stiegen und das Geschrei der Stürmenden auf der Bühne mit Angstrufen begleiteten. )

Es liegt im Wesen der Sache, daß Tieck seine Satire nicht allein auf die Kampftechnik, sondern ebenso auf die Charakterisierung des fragwürdigen Kriegsvolks erstreckt, das er zu Wasser und zu Lande gegeneinander führt. Zum Stichblatt des Witzes dient ihm dabei, wie aller Soldatenverspottung seit dem plautinischen Gloriosus, zuvörderst der Mut. Die Truppen Pantalons legen vor dem Sectreffen eine höchst jämmerliche Gesinnung an den Tag, der ihr Führer nicht steuern kann. In der Seeschlacht protestiert er selbst wie ein verprügeter Bubengeneral gegen das Entern seines Schiffes, das aller Kriegsmanier und Abrede zuwiderlaufe und daher nicht gelte. Triftig tritt der Soldatenstandpunkt dem des Admirals entgegen: er betrachtot die Verluste als unvermeidliche Zugabe, die Gemeinen finden, wen es treffe, der habe doch den Schaden. Zugänglicher zeigen sich Harlekins Soldaten seinen $\mathrm{Er}_{\mathrm{r}}$ munterungen, in der Art. man müsse doch einmal sterben und brauche hier fürs Grab nichts zu bezahlen. Noch toller geht es zu Lande zu, wo König Skaramuzens Parteigänger von nichts anderem als dem Davonlaufen reden und er, obwohl huldvoll nach ihrer Courage fragend, selbst kaum etwas davon verspürt. Am beweglichsten beklagt die Übel des verwünschten Feldzugs der Bäcker, dem am Krieg, vom Schießen bis zu der Aussicht, daß sein Geselle seine Frau heiraten könnte, wenn er fällt, alles zuwider ist. $\left.{ }^{8}\right)$ Belangreicher als diese zu Tode gehetzten Späße aus der Sphäre Falstaffs sind ein paar Stellen, an denen Tieck auf das Wehrwesen seiner Zeit anspielt. Ein beiläufiges Witzwort. daß die Soldaten nur im uneigentlichen Sinne Verteidiger

7) Theatralische Laufbahn. DLD 24, 87; vgl. Devrient'3, 49. In Frage stand das Schicksal Ludwigs XVI. Es soll niche verschwiegen sein, dab Iffland für Szenen so emphatischer Art kein ganz unverdächtiger Zeuge ist.

9) 5. 416-20 u. weiterhin. Verwandt die Tirade des Narren Claus. Blaubart I. I (SchrifIen 5. 16). der keine Trommel hören kann ohne Kolik zu bekommen, usw. - Mit der Gesinnung Sharamuz's berührt sich cin verenzzelter satirischer Ausiall Klingers im .Orpheus" (zit. nach Rieger 1. 251), wo der Grobe Köniz. den es beim Gedanken an Krieg friert, reflektiert: ,Ist der König da, sich für seine Untertanen totschlagen zu lassen. oder sind seine Untertanen da, sich fur ith tolschlagen zu lassen?" und dannit schlieBt, die auszulachen. ..die sich für uns totschlagen lassen, weil wir ihnen Brot getorn." - In Kotze bues Burkske .Pandorens Büchse" (Werke 21.294) wird der Soldat definient als ..ein Held, der sich für mich totschlagen läBt, wenn ichs befehle." 
des Vaterlandes heißen, gleich wie die Studenten Musensöhne und die Advokaten Diener der Gerechtigkeit, wiegt zwar nicht schwer, ebensowenig ein und die andere Bemerkung, die auf die Desertierplage jener Periode geht. ${ }^{9}$ ) Dagegen fallen in dem knappen Schlachtgesang der Musen scharfe Hiebe auf das Prügelsystem der Armee. Der Stock des Korporals flößt hier, im Kehrreim aufschlagend, die Kampfbegeisterung fürs Vaterland ein und wird diesem schließlich boshaft gleichgesetzt: „O Vaterland! O Vaterland!... Du bist der Stock!"

Mit der ,erstaunlichen Lust zum Desertieren“" beschäftigt sich eingehender eine Szene des „Gestiefelten Katers" ${ }^{10}{ }^{0}$ ) worin ein Wirt an der Grenze eines Duodezländchens nur von den regelmäßig entlaufenden Soldaten lebt. Auch die Husarenpatrouille, die dem Ausreißer pflichtgemäß nachsetzt, spricht bei ihm vor und trinkt dem Entronnenen unter peinlicher Achtung der Gebietshoheit jenseits des Grenzbaumes, wo er in Sicherheit ist, gemütlich zu. Er hält den Verfolgern dafür dankbar die Pferde, während der Wirt sich ihm für sein nächstes Ausreißen aus dem Dienst des neuen Herrn geschäftsgewandt empfiehlt. Neben der militärischen läuft literarische Satire mit unter. Der Schwarm der Deserteurstücke wird in Stephanie des Jüngeren „Deserteur aus Kindesliebe "11) rasch gestreift, dazu die übermäßige Freude des Publikums an der Montur verspottet, worauf der Erfolg der soldatischen Gattung beruht; lustig verwerten die über den Auftritt räsonnierenden Zuschauer die Husaren als eine „neuere Erfindung“ zur Datierung der Handlung des Stückes, aus dem sie nicht klug werden können.

Die Wachtparadeszene des „Zerbino"12) ist demnach nicht die einzige, worin Tieck zeitgenössische Heereszustände skeptisch beleuchtet, wenn sie auch als die bedeutendste schon durch den Umstand erhärtet wird, daß sie

9) 5, 341, 389 u. 420. Aus der Kriegserfahrung der Zeit fliebt späterhin sichtlich die Klage des Bauern im .Däumchen“" I, 1 (1811; Schriften 5, 491) über die GefräBigkeit der fremden soldatischen Gäste: die Last der napoleonischen Einquartierungen wird fühlbar. Eine Zeitanspielung wird auch in dem Spott auf fragwürdige Kriegsberichterstattung in der etwas zu gedehnten Szene Blaubart IV, I (Schriften 5, $92 \mathrm{ff}$.) stecken, wo der "Ratgeber", ebenso wie schon I. I (5, 12 ff.), für den bevorstehenden Feldzug angezapft wird.

$\left.{ }^{10}\right)$ Zuerst in den „Volksmärchen“ Bd. 2, Berlin 1799; Akt I, 3. Schriften 5, 197-201. Uber die Desertion als Geißel der ständischen Heere vgl. Jähns, KW 3, 2220 f.; 2241 f.; Heeresverfassungen 274 f.; G. Freytag, Bilder ${ }^{20}$ 4, 189-91; Biedermann 1, 194.

11) Wien 1773. Stockmayer S. 25. Zur ganzen Sippe im Anschluß an Merciers „Deserteur" vgl. die Übersicht bei Hauffen, DNL 138, S. XXXI u. Stockmayer S. 32 ff.

12) Zuerst in den Romantischen Dichtungen 1. Jena 1799. Schriften Bd. 10, 24-28; $\mathrm{Ha} \mathrm{y} \mathrm{m}^{3}$ S. 102 u. 104 f. Akt I, Marktplatz. 


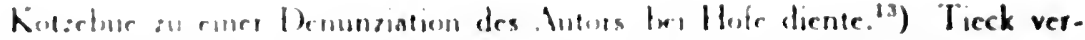

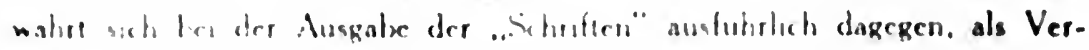

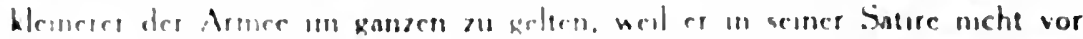

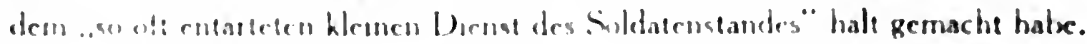
Ber aller Anerhennung semer lesstungen unter dern gerofien Köng habe er

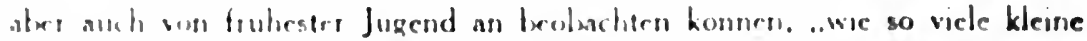
Corister das, was beim Sidelaten freilich cternse notwendig wie Tapterkeit ist. zur emposen Beschaftegung des I rbess und zur hexhsten Aufgabe deaselben machen wollern." i) Auferrung woft auch Lohte aut die geringfügigeren lusfalle in den Komolemeatirn. Sie leestatigt vor allem, was sich schon aus der Verberitung der Anspuclungen uter verschiedene. Werke ergibe. daB die

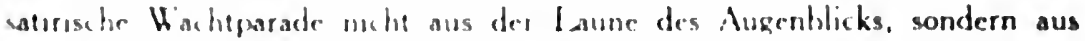
ecgrundeter. hrutuscher Anschanung des Soliateriwesens erwachsen ist. Tieck stelle sich dame in de Reshe der I rme und Sehiller, nur handhabe er spiclerusch die Waffen des Sivottes, wo jene nit schwerem Ermst zu Felde ziehen.

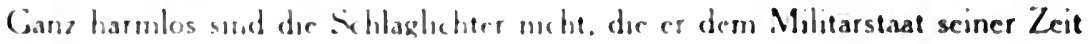
autsezz. In der Oberschuthe reprasentiert ihn Konp Cotelieb. dessen Regecrungssorges in des verwichenen . Vache in der Frage bestanden haben, ob nuch en Puschel an die Mutzen serner Regirnenter anzuturingen sei: in der Lintersebuche der Soldat. dem ob emes schuet sitzenden Hutes der Stock des Kaputans - er findet sich als militarisches Kernmosiv aus dem Schlachekesang der Verketirten Vielt neuerdings cin - zwischen den Rippen praludiert. Mitten unne stehen die Burger, die son der Helsankent dieser Prügel für die staseliche Ordnung in ihrer Mehrheit ticfinnerlich uberzeugt sind. Der Vorbeimarseh der Trupenen ${ }^{14}$ ) fordert den Entschlub des Herrschers zutage. dab die Carde andere Stiefeletten kriegen soll. dann tritt unter lautloser Stille und behuset von eigens ausgestelleen Wachen der feieshebe Augenblick der Paroleausgater esn. den Tieck zur eigentluchen Pointe der Szene mache. Erstarrte mulitarisetie Formen, die en nethessagendes Ceschaft decken, werden witzig getroffen. wenn die Burger sich wor dem malitaruschen Mysterium dieser Parole chrfurcheg beugen. cinem harmlesen Bauem ater neche Rede stehen können. was es dame fur ene Bewanderus hat: nur das wissen sie, deb der Soldatenstard ..daurn fact gamz allom lebte".

Dis furstluche Sildatengassion faint nom echlimmer in der Figur von

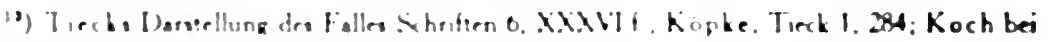

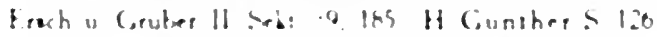

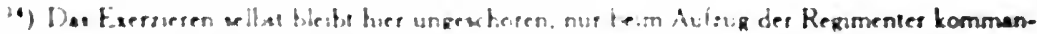

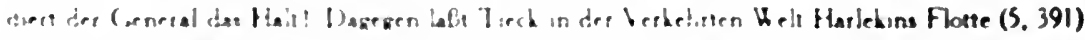

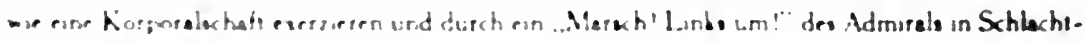
restrute verlien. 
Gottliebs Vorgänger, dem abgedankten alten König, der sein Dasein halb kindisch unter bleigegossenen Regimentern zubringt und erst bei ihnen das ruhige Altersglück gefunden hat (Akt II). Er sorgt für diesen stillen Soldatenstaat, den seine Kavaliere in Reih und Glied halten müssen, noch peinlicher als Gottlieb für den wirklichen, hält auf richtiges Avancement, hat seine bleiernen Favoriten und auch in Ungnade Gefallene, und freut sich als unbestrittener Souverän, unter ihnen das Schicksal zu spielen. In die Satire mischen sich halb wehmütige Züge. Die Bleisoldaten werden zu Trägem jener Gleichnisse des Treibens in der großen Welt, die in der Romantik - Tieck selbst, Kleists Schroffensteiner, Bonaventuras Nachtwachen geben Beispiele häufiger auf die ebenso fügsamen Marionetten gegründet sind. Nebenbei blickt eine Bubenliebe des Dichters zu den bleiernen Gesellen unverkennbar durch. In denselben Jahren weist ihnen die Exposition zur „Familie Schroffenstein" einen dramatisch gewichtigeren Anteil zu.

Die ernste Kriegsdramatik Tiecks, die sich am reichsten in der „Genoveva" ${ }^{15}$ ) entfaltet, ist charakterisiert durch ein neues, enges Eingehen auf Shakespeare, durch eine so unbedingte Gefolgstreue, wie sie seit dem frühen Sturm und Drang nicht mehr erhört war. ${ }^{16}$ ) Tieck gleicht den ersten Jüngern des Briten darin, das auch ihn das Nachbilden seiner Form mit der lebendigen Bühne entzweit. Sein geistiges Verhältnis zur Kriegswelt Shakespeares und zum Krieg überhaupt ist allerdings ganz anderer Natur. Während zumal der Götz, im Sinne des großen Vorgängers, in der Kampfdarstellung vor allem die kräftige Aktion sucht, erfaßt der Gefühlsdichter Tieck das Kriegerische als Farbe und Stimmung. Er schwelgt in seiner Atmosphäre, ohne auf den bestimmten Umriß des Geschehens viel zu achten, wie die Genoveva im ganzen sich am Duft und Glanz der frommen ritterlichen Welt, an ihrem "Klima" ${ }^{17}$ ) und schließlich auch am bloßen musikalischen Klang der Worte genugtut. Einen Stimmungs-, nicht einen Handlungsgehalt setzt der Autor selbst ausdrücklich seinen Mohrenschlachten zum Ziel. Die „Begeisterung des Kriegers" soll in ihnen ihren gemäßen Ausdruck finden, „Krieg und Getümmel, mosaische und christliche Helden im Streit, Schlacht und Aus-

\footnotetext{
${ }^{15}$ ) Erstdruck in den Romant. Dichtungen 2, Jena 1800. Schriften Bd. 2.
}

18) An Iffland schreibt Tieck (16. Dez. 1799, Ifflands Briefwechsel, Reclam Nr. 5163-65 S. 154), er habe in Genoveva den Versuch gemacht, die shakespearische Form mit der spanischen zu verbinden; daB das letztere auf die metrische Vielfältigkeit und die Lyrismen zu beziehen ist, bezeugt der Dichter selbst (Schriften I, XXVIII); J. Ranftls Untersuchung des Calderonschen Einflusses (L. Tiecks Genoveva als romant. Dichtung betrachtet, Graz 1899; Schönbachs u. Seufferts Grazer Studien Bd. 6 S. 107 ff.) bestätigt es. Die Kampftechnik ruht auf Shalespeare.

$\left.{ }^{17}\right) \mathrm{Haym}^{3}$ S. 534; vigl. S. 531. 
fälle" dienen zum .,Vorgrund des Gemäldes". ${ }^{18}$ ) Es ist bemerkenswert, wie üppig sich dieser Vorgrund ausbreitet. An die Stelle der knappen Erzählung im Volksbuch - auch Maler Müller hat vom Feldzug nur zwei Szenen im Christenlager am Anfang des vierten Aktes, mit Botschaft aus der Heimat tritt eine ganze umfängliche Kriegshandlung. ${ }^{19}$ ) Karl Martells Schlacht zwischen Tours und Poiticrs, darauf cin Uberfall im Frankenlager vor Avignon crhalten reichlichen Raum zugemessen.

Tiecks Richtung zeigt sich am reinsten in der zweiten, der Nachtschlacht, worin die Mauren mit anfänglichem Erfolg überraschend aus der Stadt ausbrechen, dann aber endgültig überwunden werden (Schriften 2, $122 \mathrm{ff}$.). Nächtige Stimmungsszenen im kricgerischen Feld sind bei Shakespeare häufig, noch näher steht der Untergang Götzens im Dunkel der Zigeunerwelt, stehen Nachtkämpfe eines Ramond. Auch mit Tendenzen Klingers berührt sich Tieck: er macht den stimmungsschweren Gedanken vom herrlichen und fürchterlichen Schlagen bei Nacht in dessen Pyrrhus zur Tat. Es liegt aber Shakespeare und dem Sturm und Drang gleich fern, eine Schlacht so ganz in weiche Lyrik aufzulösen, wie es hier, nicht zum Gewinn des Dramas, geschicht. Das eigentliche poetische Absehen der Szenenfolge geht dahin, dem wackeren Gottesstreiter Otho ein Ende in kriegerischem Glanz und zugleich in frommer Innigkeit zu bereiten. Sein ausladender Monolog, danach sein Abschied von dem leichter verwundeten Pfalzgrafen Siegfried drängt die Gefechtsaktion in den Hintergrund. Auf das Geschehen kommt sehr wenig. alles auf seinen Stimmungsertrag an. So verweilt Tieck schon bei der stimmenden Einleitung des Treffens: in vorahnender Unbehaglichkeit deuten Siegfried und Otho den Lärm des feindlichen Einbruchs und das Aufflammen einiger Zelte zuerst irrig als Postenruf und Wachtfeuer. Aber er geht rasch über ein paar Kampfauftritte weg. um die Verwundeten- und Sterbeszene zu entfalten. Die Sonderart des Stimmungsdichters prägt sich um so deutlicher aus, als die Einflüsse von Shakespeare und Gocthe her im Sachlichen zutage liegen. Das Selbitz-Motiv erscheint sogar doppelt, die Verwundeten werden wie zum Verbandplatz zusammengetragen. ${ }^{20}$ ) Doch folgt in bezeichnender Umbildung der goethischen Teichoskopie statt der knappen, sachlichen Wechselrede Selhitzens und des Knechtes das lyrische Prachtstück eines Monologs, statt

18) Schriften I. XXIX in Iffland 16. Dez. 1799 (Ifflands Briefw. S. 153).

iv) Vgl. dariber die eingehende Monographie J. Ranftls S. 32 ff., bes. S. 35.

20) Selbitz: „Legt mich hieher und kehrt zu Götzen. - LaBt uns bleiben Herr": Siegfried: .Legt mich hieher und helft den Sieg erfechten” “(2.129); Otho: „Hier laBt mich liegen, und geht ihr zurück. - Ihr seid nicht sicher" (S. 127). - Selbitz: ..Schwimm braver Schwimmer, ich liege hier." - Siegfried: ..(. . . Ceendigt ist der Krieg) - Ich liege hier" (S. 132) usw. - Eine andere Beruhinung mit dem Cöız: Minor. DNL 144 I, S. 17I. Tieck über Cö̌z: Schritten 6. VI. 
höchster Gegenständlichkeit verschwimmende Bilder, an Stelle atemloser Aktion sinniges Sichversenken. Tieck läßt hier alle Vermittlung greifbarer Kampfvorgänge dahinten. Auf den verwirrenden Zusammenklang starker Sinneswahmehmungen kommt es ihm an, sein musikalisches Ohr horcht auf das Getümmel in der Finsternis, Schreien, Panzergedröhn, Glockenläuten; für seine Stimmungskunst gewinnt die in die Nacht aufsteigende Lohe mehr Bedeutung als die ganze Schlacht. Mit seinem Otho, dem das Brennen der Wunden mit dem verzehrenden Brand von Stadt und Gezelt in eins verschmilzt, berauscht sich der Dichter selbst an dem gleißenden Feuerwerk der Kriegsnacht und faßt es in ein weitgespanntes Gleichnis des Kriegerdaseins. Dessen voll ausklingende Lyrik ist das Ziel des ganzen Aufwandes, im Buch erreicht, nicht aber für die Bühne, der die untheatralisch zerfließende Gefühlspoesie nicht gerecht wird.

Shakespeares Einwirkung ${ }^{21}$ ) kreuzt sich mit der goethischen schon in der Einzelszene Othos und regiert völlig seinen Abschied vom Leben. Charakteristisch wendet Tieck im Monolog des sterbenden Kriegers die viel konkretere shakespearische Betrachtung ins lyrisch Vage. ${ }^{22}$ ) Für den abschließenden Auftritt mit Siegfried gilt, was für das Verhältnis zum britischen Meister überhaupt. Die Shakespeare-Frömmigkeit, die Goethe aus dem Straßburger Kreis der siebziger Jahre im 11. Buch von Dichtung und Wahrheit überliefert, herrscht neuerdings im Kreis der romantischen Übersetzer. Tieck ist in Shakespeare so fest, daß sich ihm seine technischen Formen, seine Motive und Worte in aller Kriegshandlung unablässig aufdrängen. Er dichtet in seinem "Ton", und shakespearisches Gepräge tragen auch die Stellen, wozu sich scharf Entsprechendes in seinen Werken nicht nachweisen läßt. Hier steht das Scheiden vom Freund, der knappe Nachruf in der Nachfolge des Briten. ${ }^{23}$ )

${ }^{21)}$ Vgl. Ranftl S. 81 u. 84 ff.; über das Durcheinanderspielen der Einflüsse S. 80 u. 104. Ein Beispiel ist gleich die Brandbeobachtung der Nachtszene, die sich ebenso bei Shakespeare (Cassius' Zelte) als im Götz (Miltenberg) findet; s. o. S. 119 Anm. ${ }^{54}$ ). Ranftls Nachweise S. 92 ff. und 101 f., die erste Bemerkungen Minors in dessen Ausgabe (DNL 144) ausführlich belegen, lassen für das kriegerische Gebiet noch einige Nachträge zu; Klees Parallelen (Einl. zur Genoveva, Ausg. des Bibliogr. Instituts 1, 175) berühren dieses nicht.

22) Ranft] bringt S. 101-02 die Sterberede Warwicks, Ill Heinrich VI: V, 2 bei. Ein Einzelzug entstammt der parallelen Cliffords, ebenda 1I, 6: „Die Luft drang in die schweren Wunden mir" usw. Tieck S. 127 : „Ihr seid nicht sicher, euch taugt nicht die Luft. - W'as kümmern sich die Wunden um die Luft" usw.

${ }^{23}$ ) Warwick: „Nimm meine Hand, bist du da, lieber Bruder ..."; Otho (S. 131): ,drum gib / Mir deine Hand, daß ich sie fühle jetzt - “. Satirisch gewendet ist Shakespeares Sterberede und Abschiednehmen vorher im Blaubart III, 1 (Schriften 5, 77 f.) wo Winfred sich mit lächerlicher Wunde in tragischem Ton zum Sterben anschickt. - Zum Nachruf S. 131: „Fahr woohl, redlich 
Dagegen sind ein paar huibsche Züge an dem gottseligen Ende des christlichen Streiters, wie er nach dem jenscitigen Krieg fragt und vom Schlachtfeld als dem schönsten Sterbebette dic Seligkeit ohn' Sakrament und Ollung erhofft. wohl der Wclt der Genoveva eigentümlich. ${ }^{24}$ )

Die Anklänge stellen sich nicht minder reich in der Tagschlacht ein, die schon mit dem shakespearischen Motiv kampffroher Morgenstimmung anhebt. ${ }^{25}$ ) An der Durchführung dieser mehr aktionellen Aufgabe scheitert Ticcks dramatische Kraft allerdings vollends. Es gelingt ihm nicht, die wirre Folge von einem Dutzend rasch wechselnder Einzelbilder, in deren Verlauf die Mohren sich von frühem Mißgeschick bis fast zum Siege erheben, um schließlich im Tod des Führers den vernichtenden Schlag zu empfangen, zu einer durchsichtigen Schlachthandhung zusammenzufassen. Das Beste liegt

gesinnter Degen du! / Ich finde nicht mehr deinesgleichen wieder" vgl. etwa Brutus (Jul. Cäsar V. 3): „Du letzter aller Römer, lebe wohl. / Unmöglich ists, daß Rom je deinesgleichen..." Bittere Vergänglichkeits-Betrachtung in Zulınas Nachrul S. 61 f.: ..O Abdorrhaman!... Ist dies de in Ruhm? Sind dies die Plane?" usw.: vgl. neben Warwicks Monolog Antonius in Jul. Cas. III, 1: .O großer Cäsar" usw:- Shakespearische Anschauungsweise z. B. Siegfried S. 130: . An dir hat einen Mann der Krieg verloren".

2) Für den letzteren zieht Ranftl S. 114 eine unsichere Parallele zu Calderon. Skeptischer äuBert sich über Krieg und Christentum im Rückblick auf eine sündige Jugend der Pilger Clemens im Octavian (Schriften I. 104f.): ..Und das versteht sich, manche Tat / Verübt im Mute der Soldat. / Daß sich auch selbst die allerbest / Vor Gott nicht verantworten läßt."

25) ..Schlachtfeld”" Schriften 2.52-65. Ranfll verweist S. 102 lür Karl Martell $(2,50$ f.) auf I Heinrich IV: V. I : die frische Meldung Aquitaniens: ..Seht, fröhlich hat der Tag sich angetan" und die freudige Zuversicht der andern auf den Kampftag rückt die Szene jedoch näher an Ant. u. Cleop. IV. 4. Reminiszenzen an dieses Stück sind häufiger: Karl Martells Ruf S. 57 .Es gilt nichts inindres als die halbe Welt" gernahnt an den in Ant. u. Cleop. öftet gebrauchten Ausdruck (III, 11: .da halb die Welt der andern Hälfte trotzte“" 111 . 8 .das gröBre Eckstück dieser Welt verloren ..."); durch Abdorrhamans W'ort S. 59 ..Sollt ich nein großes, tatenreiches Leben... einem Jüngling oplern" hört man Antonius' Bitterkeit (III, 9) durch, daB ex ..dem jungen Mann demüt "gen Vorschlag senden" muß; im Kampf möchte der Mohrenfïrst S. 52 unter der feigen Herde brüllen, wie Anton (in anderer Situation. III, II) auf Basans Hügel die gehörnte Herde überbrüllen will. Im Motiv ist diese Fluchtszene I Heinrich VI: I. 5 verwand, wo Talbot die Fliehenden mit ganz ähnlichen W'orten stellt (.Sonst reißt die Löwen weg aus Englands Wappen" : Abdorrhaman: .seid ihr jene Sarazenen, vor deren Tritt ....) und insbesondere das Herdengleichnis übereinstimmt, das sich bei Tieck mit der Reminiszenz aus Antonius assoziiert - ein gutes Beispiel für sein Dichten in Shakesperare. - Zu Otho S. 53 .Der Abdorrhaman wütet wie ein Teufel / Nicht Menschenkraft vermag zu widerstehn" vgl. Richard III: V.4 ..Der König tut mehr Wunder als ein Mensch / Thm fiel sein Plerd" - dieselbe Stelle, die in der Verkehrten Welt (Schriften 5. 429) parodiert ist: .Skaramuz tut wahre Wunder der Tapferkeit; den Esel haben sie ihm unterm Leibe umgebracht" usw.. ebenso wie darauf 5,430 das berihmte ..Mein Königreich für "n Pferd" Richards. 
wiederum in der Stimmung des heißen Tages und der blutigen Stunde. Einen besonderen lyrischen Part flicht Tieck in der Rolle der schönen Mohrin Zulma ein, die schmerzlich das anfängliche Weichen ihres Volkes besingt, dann ihrem Herm in der Not beispringt und endilich an seiner Leiche die verweilende, gefühlsgesättigte Liebesklage hält. Der Ausgang des Kampfes wird nach der vordeutenden Aufbruchsszene am Morgen auch weiterhin stimmungsmäßig, im Religiösen, motiviert; das christliche Gottvertrauen behält recht, Mahoms Heidenmacht zerschellt an ihm.

Am durchgreifendsten zeigt sich Shakespeares Einfluß an der technischen Seite der Schlachten. Vor der Genoveva schaltet der Blaubart mit seiner charakteristischen Form, selbst die Verkehrte Welt bedient sich ihrer und stellt spielerisch neben die ernste Nachbildung auch die satirische. An Shakespeare angelehnt ist der rasche Wechsel der Parteien zu Beginn und innerhalb des Treffens, besonders ihr Aufzug mit kriegerischem Pomp kurz nacheinander..$^{26}$ ) Seinem Verfahren folgt Tieck mit dem Herauslösen von Einzelkämpfen der Führer aus dem allgemeinen Getümmel, das davor in den Hintergrund tritt ; ${ }^{27}$ ) ferner mit einer Reihe schlachttechnischer Einzelzüge: der Art, wie der Kampf eröffnet und der Schlachtbefehl erteilt, wie ein Führerauftritt angeknüpft, eine Fluchtszene eingestreut wird. Beim einen und andern ist die Reminiszenz greifbar, häufiger halten sie sich allgemeiner innerhalb seiner Formenwelt. ${ }^{28}$ ) Unverkennbar weist endlich die Mischung ernster und komischer Kampf-

26) Im Nachtüberfall der Genoveva $(2,126 \mathrm{f}$.) doppelter, in der Schlacht $(2,53 \mathrm{ff}$.) fünfmaliger Wechsel. Den Ort bezeichnet Tieck allgemein als "Schlachtfeld" und gibt über eine Veränderung nichts an; Shakespeare schreibt öfter verschiedene Teile des Feldes vor (z. B. Macbeth V, 7 ,Ein anderer Teil der Ebene"). - Wechselweises Aufziehen Blaubart I, 3 (5. 23 f.); - Verkehrte Welt IV, 4 (5,389 f.); komisch die Flotten, offen parodistisch „Pantalon tritt mit seiner Flotte auf"; V (5, 427 f.) die Landheere. Vgl. bei Shakespeare z. B. Ant. u. Cleop. IIl, 8. Tiecks szenische Vorschriften („Fahnen, Kriegsmusik" - „Sie ziehn vorüber", Blaubart) entsprechen denen Shakespeares wörtlich, ebenso das szenenverbindende .Getümmel, Feldgeschrei“" (Genoveva). Zu Tiecks Schlachttechnik vgl. auch Lohmeyer S. 164.

i5) Genoveva (2, 55 ff.): Abdorrhaman-Franken-Zulma, ein Vierkampf; Otho-Derar; Abdorrhaman-Aquitanien. Im Komischen in der Verkehrten Welt (5, 392 u. 429): Harlekin-Pantalon; Maschinist-Poet.

28) Frohgemuter Kampfruf des Führers: Genoveva $(2,51)$ : „In Gottes Namen dann! Rückt aus! Trompeten blast!" - Blaubart $(5,26)$ : „Nun laßt die Trompeten schmettern und ihnen rasch entgegen!" Vgl. z. B. Richard 11I: V, 3: ,Schallt Trommeln und Trompeten froh zum Krieg" usw.; ähnlich Macbeth V, 6. - Karl Martells kurze taktische Anordnung (2, 125), in Tiecks verschwommenen Schlachtbildern vereinzelt, beruht auf shakespearischern Führerbefehl (am ausführlichsten Richard III : V, 3; knapper Ant. u. Cleop. III, 8; IV, 6, 10 u. II). - Verschnaufen in der Schlacht motiviert $(2,54)$ Karl Martells Auftreten ebenso wie dasjenige Warwicks, III Heinrich VI: II, 3. Zur Fluchtszene Genoveva 2, 52 vgl. o. Anm. ${ }^{25}$ ); eine zweite 2, $125 \mathrm{f}$. 
szenen auf den Briten. Im Blaubart steht ein Narrenmonolog während des Treffens, worin Claus Falstaffs besseres Teil der Tapferkeit zum Vorschein bringt, allerdings im Einklang mit dem halb ironischen Ton der ganzen Kampfhandlung. der zwischen der Schlachtposse der Verkehrten Welt und dem stimmungsschweren Ernst der Genoveva die Mitte hält. ${ }^{29}$ ) Dagegen nimmt sich in der Nachtschlacht vor Avignon ein derbes Einschiebsel fremd aus. Es paßt nicht wohl zum übrigen, daß Otho die fliehenden Hauptleute plötzlich in der shakespearischen Prosa der niederen Stände als "Gesindel" anredet und die Trommeln zu rühren befiehlt, damit man das feige Winseln dieser fragwürdigen christlichen Ritter - er erinnert sie im selben Atemzug an ihre Edelmannspflicht - nicht höre. Eine Vorstellung falstaffischer Gesellen, die Verachtung geworbener Truppen, die bei Shakespeare öfter zutage tritt, scheint sich einzumengen. ${ }^{30}$ ) Der folgende Zug grimmigen Kriegshumors, wie Otho einen Dahingestreckten zu neuem Kampf aufrütteln will, aber seinen Tod als triftige Entschuldigung gelten läßt, gehört ebenfalls mehr in diess Welt als neben den überzarten Sterbemonolog, der kurz darauf einsetzt. ${ }^{31}$ ) Die Umbildung ins Sentimentale. Gefühlsschwelgerische, die der männlichkräftige Ernst Shakespeares bei Tieck erfährt, kann nicht deutlicher als an diesen Unstimmigkeiten offenbar werden. Die unverändert übernommene Komik verträgt sich mit der neuen Gesamtstimmung nicht mehr.

Für die eigentliche Schlachthandlung Tiecks kommt sein Vorgänger und erster Anreger in der Behandlung des Stoffes, der Maler Müller, der die Kämpfe mit den Mohren beiseite läßt, nicht in Betracht. ${ }^{32}$ ) Die Berührungen

29) I, $3(5,26)$; frei angelehnt an Falstafis Monolog. I Heinrich IV: V, 3 u. 4; der Feldzug wird bei Tieck 1,1 (5, 12 ff.) durch eine komische Beratung eingeleitet.

30) Cenoveva 2. 125 f., die einzige Prosastelle innerhalb der Schlachten: über die Prosa in der Genoveva im ganzen vgl. Ranftl S. 223 1.; vgl. etwa, noch um einige Noten tiefer gegriffen, wie Fluellen. Heinrich V: III. 2, sein Soldatengesindel in die Bresche treibt. Das Motiv der ubertäubenden Trommeln erinnert an Richard III: IV, 4, vgl. o. S. 146 Anm. ${ }^{26}$ ).

3) Die Episode rechnet zu den ganz und gar shakespearisch gebildeten, ohne soviel ich sehe eine Reminiszenz zu sein. Nur verwandt Falstafts Mißtrauen vor dem gefallenen Percy. I Heinrich IV: V. 4: Aufrütteln eines Toten: die Plantagenets an Cliffords Leiche III Heinnich VI: II, 6; danach wohl Schweizer u. Franz Moor, Räuber V, I. In dem burlesken Zweikampt Blaubart III. I $(5,78)$..fäll" Winfred, erholt sich dann aber trotz scinen am Leben verzweifelnden Reden schnell wieder. In Lenz's Entwurf Der tugendhafte Taugenichts III, 3 mustert der vom Gefecht ausgerissene Johann mit falstaffischen Betrachtungen und shakespearischem Totengräberhumor die Gefallenen, während Bauern um ihre Plünderung zanken.

a2) Die Stücke sind verglichen von B. Colz. Pfalzgräfn Genovefa in der deutschen Dichtung. Leipzig 1897 S. $74-82$. Ranftl S. 67 f., vgl. S. 82 u. R. Meszlény. Fr. Hebbels Cenoveva. Berlin 1910. Abschnitt 5 u. 6 des I. Teils. - Die Aufbruchszenen zum Feldzug behandeln beide Dramen, aber, soweit das Kriegerische in Frage steht, völlig verschieden; vgl. Golz S. 74. 
der romantischen Genoveva mit derjenigen des Sturm und Drangs liegen allgemeiner in der Atmosphäre der kriegerischen Umwelt, in der farbigen Ausgestaltung der ritterlich-soldatischen Dinge, worein sich Tieck mit eben der Freude versenkt wie der pfälzische Dichter-Maler. Unter den klaren Erinnerungen von einzelnen Stellen, die der Romantiker (Schriften 1, XXVII) aus der ersten Lektüre von Müllers handschriftlichem Stück davontrug, muß offenkundig das Bild des alten Schloßhauptmanns Adolf gewesen sein, wie er sich an einer Damaszenerklinge als köstlichem Beutestück ergötzt. Es kehrt bei Tieck in dem Entzücken des greisen Ritters Wolf über einen herrlichen Mohrensäbel wieder, den der Pfalzgraf heimgeschickt hat. Jenem Veteran Müllers nötigt die türkische Arbeit höchstes Lob ab, dieser wackere Herr und gute Christ - der fromme Konflikt ist neu - kann den Heiden schon um ihrer schönen Waffen willen nicht völlig gram sein, wenn sie nur dazu noch nach dem Clauben trachten möchten. ${ }^{33}$ ) Wichtiger als die Einzelparallele ist die Übereinstimmung der ganzen Richtung. Der Maler Müller rührte mit Zügen dieser Art an gleichgestimmte Saiten in der Brust des Nachfolgers, der schon im "Berneck", noch bevor er ihn kannte, reiche Proben liebevoller Erfassung von Waffe und Rüstung gegeben hatte, und später im „Octavian“ die Wappnungsmotive in Ernst und Scherz abwandelt. Ebenso zeichnet bereits das Jugendstück, wenn auch roher und theatralischer, die Welt der mittelalterlichen Burg bei Tag und Nacht, das ritterliche Treiben, Herren, Knechte und Pferde, kurz den ganzen Umkreis des reisigen Daseins, ${ }^{34}$ ) Dinge, die jetzt der pfälzischen Genoveva so ähnlich sehen, daß man sie allein darauf zurückführen möchte. Ein innerer Unterschied besteht immerhin, derselbe der Tiecks Kampfgestaltung vom Sturm und Drang trennt. Der Sinn für die Wirklichkeit, die satte Lust am Gegenständlichen, die dieser vor allem andern in Shakespeare fand, macht der Tendenz zur Stimmung Platz. Sie ist das entscheidende Shakespeare-Erlebnis des Romantikers. Gleich wie Nacht, Fels und Wald in seinem Gedicht zum musikalischen Akkord zusammenklingen, so dient das ganze Rüstzeug des Krieges letzten Endes lyrischer Absicht. ${ }^{35}$ )

${ }^{23}$ ) Tieck, Genoveva 2, 79; Maler Müller III, 3; bereits verzeichnet von Golz S. 77 vgl. S. 76 und Ranftl S. 77; beide betonen die Verwandtschaft der Kriegergestalten überhaupt.

34) Für den Burgschauplatz im Karl von Berneck s. o. S. 128. Gruß an die Burg bei der Heimkehr Akt Il (Schriften 11, 47); Ausritt zum Turnier und Bericht darüber Akt I u. II (S. 11-13 u. 33); das entsprechende Motiv in der Sphäre der Diener, Lanzenstechen um Preise, findet sich im Fortunat, 1. Teil I, 4 u. 6 (Schriften 3, 45 f.); Cespräch der Knappen über den Dienst, Berneck I, S. 9 f.; hier wird nur über die Pünktlichkeit, in Genoveva (2, 25 f.) eingehender über die soldatische Unterordnung und den schweigenden Kriegergehorsam verhandelt. Cber Waffen u. Pferde s. die Anhänge.

25) Dieser Richtung folgt auch Fr. Schlegels "Alarcos“", Berlin 1802 (vgl. Haym S.734 f.), 
Die naturhafte Körperlichkeit, die der Götzdichter und Müller ihm geben. müßte hier stören. Tieck drängt das Sachliche zurück und achtet mehr auf seine schimmernde, unablässig wechselnde Erscheinung, auf Licht- und Farbwerte seiner Oberfläche.

Die Betrachtung führt im großen und kleinen zu den gleichen Ergebnissen: 'Tieck ist überall in seinem Element, wo es um das Stimmungsmäßige des Krieges geht. In Gefühlsergüssen, in Othos Sterberede, in Zulmas Klage gipfeln seine Schlachten. Schon bevor der Kampt anhebt, macht der sehnsüchtige Monolog der Mohrin an die mondbeglänzten Sarazenenzelte, die den Geliebten bergen, das maurische Kriegslager (2, 46 f.) zum Schauplatz weicher Nachtpoesie: erbleichender Mond, verlöschende Feuer, ernster Tritt der Wachen sind die Träger dieses gefühlvollen Kriegsbildes. Reine Zustandschilderung, die besondere Luft des Belagerungskriegs, gibt eine kräftigere Tagszene, worin die christlichen Helden auf Turm und Mauer der Feinde grollen, vor denen sie mit ihren Waffen machtlos stehen (2, 99f.). Tieck hat gute Worte für diese Stimmung, für den gerechten Zorn robuster Tapferkeit auf überlegene Klugheit, der nicht beizukommen ist, und für den Spott des Mohrengenerals über die einfältigen Franken, die sich nicht zu gebärden wissen außer wenn es gilt, gerade dreinzuschlagen. Ungemein bezeichnend schließlich, daß der höchste Ausdruck, den die "Begeisterung des Kriegers" in der Genoveva gefunden hat, aus keiner Schwungkraft der Schlachtaktion hervorgeht. In der stillen, vorbereitenden Nachtszene vor Avignon findet er sich, worin Otho den verdrießlichen Siegfried und sich selbst über das Verliegen im Lager tröstet. Hier $(2,123)$, außerhalb der Gefechtshandlung, in einem bloßen Bild der Schlacht, nicht in ihrer dramatischen Wirklichkeit, schöpft Tieck im trefflichen Kontrast zu dumpfigem Stillsitzen die selige Trunkenheit des „Krieger-Festes", des freien männlichen Tuns voll aus: .Doch tummelten wir uns im freien Felde. / Die Fahnen hoch im Fluge uns voran -." Nah verwandte Alexandriner in zweiten Teil des .Octavian" (1, 377), die das darin nur anklingende Zecherbild ausführen: .Der höchste Wein des Lebens fließt in dem Schlachtgefild -" finden sich zwar in den Kampfszenen selbst, aber ebenso handlungsfern in gefühlsschwer ausladenden Partien.

der den romantischen Apparat von Jagd und Burg von Tieck übernimmt. Seine jagende Infantin Solis (1. 1) kommt sich wie Golo (Tieck. Schrifien 2. 242) schwermülig selbst als das gehetzte Wild vor. Alarcos wendel sich I. 5 (Sämtl. Werke. Wien 1822 f., 8. 247) mit einer lyrischen Anrede an seine unheildräuende Burg und spricht im folgenden sogar ein Sonett an sie. Gefolgstreue (8. 252): . Du bist des Dagobertes Hierz und er dein Arm" usw. nach Cenoveva (2, 26): .Ex [der Kricgsonany ist der Arm, sein Feldherr das Haupl". 
Die ausgedehnte Schlachthandlung des „Kaiser Octavianus“"36) zeigt das völlige Zerflattern der Tieckschen Kriegsgestaltung in ein lyrisches Formenspiel. Die Genoveva-Szenen erscheinen dagegen trotz ihrer im Kern untheatralischen Haltung bühnengerecht. Shakespeare hatte seinen Jünger immerhin einigermaßen im Zaum gehalten. Die Spanier, deren Einfluß jetzt überwiegt, lassen seinem Hang zu reiner Gefühlspoesie die Zügel schießen. Unbekümmert um die Schranken der Gattung - Handlung sollte nach dem Bekenntnis der „Schriften“ (I, XL) nur ein Teil des Cedichtes sein -, um Folge und Verknüpfung der Ereignisse, um irgendwelche Realität der behandelten Dinge, schaltet die romantische Willkür mit Vorgang, Bild und Wort und musiziert in einem unerhörten Reichtum metrischer Gebilde mehr über die Schlacht, als daß sie sie darstellt. Die Kampftechnik hat mit der fessellosen Lizenz dieser Behandlungsweise wenig zu schaffen. Als Träger der Wortmusik kommen nur die Führer in Betracht, der Zusammenstoß der Massen ist in der kriegerischen Märchenwelt neben ihnen kaum vorhanden und findet höchstens in ihre Schilderungen Eingang. Sorglos reiht Tieck abrupte Monologe der christlichen Heeresfürsten aneinander, Octavians, König Edwards, Rodrichs, Graf Armands, poetische Einzelleistungen, worin er der schwankenden Stimmung des Kampfes in gereimten Alexandrinern, kunstvollen Strophen, einem Sonett Ausdruck verleiht. Von den sachlichen Vorgängen geben diese Ergüsse nur nebenbei und sehr verschwommen Kunde. Als einziges Gefechtsmotiv bestreitet der Führerzweikampf die Handlung. In symmetrischer Wiederkehr begegnen den fränkischen tobende heidnische Helden, ${ }^{37}$ ) zweimal haut der wackere Florens bedrängte Christenhäupter

36) Jena 1804; Schriften Bd. 1. Großer Kriegszug des mächtigen Sultans gegen die Christen im II. Teil. Sein Aufbruch Akt 1, Ende (1, 215 ff.); Erwartung des Feindes, Meldungen über den christlichen Zuzug an den Frankenkönig Dagobert, II (225 ff.); Aufziehen der Christenkontingente im Lager zu Saint Germain, II (239 ff.); skurrile Heroldbotschaft 245 ff.; im folgenden zahlreiche gedehnte Lagerstimmungsszenen des Sultans und seiner Tochter Marcebille; Schlachtlyrik besonders beim Aufbruch des Christenheers zum Schlagen, IV (363 ff.); vgl. dazu den kampffrohen Kriegerchor in Walde, der den Prolog des Octavian (S. 5) eröffnet. Die Schlacht selbst in V. Akt, $374 \mathrm{ff}$.

37) Zweikampf Dagobert-Arlanges 375; Octavian-Sultan 378; Rodrich-Lidamas 381; die mimische Aktion ist dabei nach dem romanischen Prinzip (vgl. M. Zickel, Die szenar. Bemerkungen im Zeitalter Gottscheds u. Lessings, Berliner Diss. 1900, S. 6-9; Petersen S. 339) nach Kräften in Worte gefaßt: ,Sieh, wie meinem grimmen Schwerte / Von dem Haupte dein Helm flog“ 378; ,denn er ist schon / Ohne Schild und ohne Helm / Und ein großer Blutesstrom“ usw. 376; ebenso Ge noveva $(2,59)$ „Gedoppelt fühlst du aile deine Schläge, / Es träuft dein Blut zu deinen Füßen nieder" - so daß die szenische Anwcisung knapp auf "Gefecht" lauten (375), oder ganz fehlen kann (378). 
heraus. Außer den Einzelkämpfen wird vom ganzen Verlauf der Schlacht sie bricht mit dem dritten unvermutet ab - nur das Wunder, das den Sieg der Christen entscheidet, ausführlicher behandelt: die Erscheinung der Jungfrau in einem Purpurmeer, das Herabsteigen der weißen Ritterschar, die das Heidenheer in kopflose Flucht jagt, vom Montmartre. Auf dem bildhaften, stimmenden Vorgang verweilt Tieck wiederum. Umkleidet mit aller Farbenpracht, deren seine Diktion, wenn auch auf Kosten begriflicher Klarheit, fähig ist, läßt er ihn in zwei Berichten dem verwundeten Sultan vortragen. Es ist ein grelles Aufblitzen romantischer Ironie, die sonst aus der Claubensschlacht wegbleibt. $\mathrm{da} B$ hart neben das fromme Siegeswunder eine an Shakespeares Zynismen geschulte Prosa-Tirade des mißgestalteten Hornvilla zu stehen kommt, worin er in seiner Weise die widersprechenden, vom Kampf eintreffenden Berichte glossiert (1.386); schärfste Selbstironie insofern, als das unappetitliche Gleichnis des Rüpels die Kehrseite des voraufgehenden, hochpoetischen Zecherbildes zeigt: die selige Trunkenheit der Schlacht wird körperlich verstanden, sie taumelt als besoffenes Weib über das Gefilde.

Derselbe „Octavian", der sich von der realen Bühne weg so weit in eine phantastische hinein verliert, weist daneben eine durchaus theatermäBige Kampfszene auf - ähnlich wie in den Libertinismus der Gefechte Götzens plötzlich eine straffe Bühnenvorstellung eintritt. Es ist der Zweikampf zu RoB und Fuß, worin der junge Florens, ein zweiter David, den heidnischen Riesen vor den Mauern der Stadt fällt, von Tieck durch Teichoskopie im strengen Bühnensinne gemeistert. ${ }^{38}$ ) Antike Motive, homerische Ausschau von den Mauern Ilions scheinen Anteil zu haben. Unter den deutschen Vorgängern in dramatischer Cefechtsbeobachtung steht der Maler Müller mit dem Gotteskampf zwischen Golo und Carl - die romantische Genoveva kennt diese wichtige Episode Müllers nicht - am nächsten. Schillers Jungfrau, wenn sie zur Zeit der Ausarbeitung des Auftrittes überhaupt schon vorlag, hat kaum eingewirkt. Müllers Stück hatte Tieck in demselben Hamburg, wo er das Volksbuch vom Kaiser Octavian fand, und während er mit dessen Dramatisierung beschäftigt war, zu neuer, eingehender Lektüre in die Hand bekommen. ${ }^{39}$ ) Man wird annehmen dürfen, daß Anregungen zu seiner realistischen

23) Akt Il, ..Oben auf den Wallen der Stadi", 1، 264-70. Durch lyrische Partien überwuchert wird ein vereinzelter Ansalz zu bühnenmäigem Kampf in einem Appendix zur Heidenschlacht. beim Gefecht um die Gefangenen (Akt V. 1, 401), wo Florens lauschend das Getümsnel sehildert: akustische Beobachtung. Ausschau aut Marcebillens nahenden Kriegszug das. S. 408. - Ein in der Art der Ritterdramen vorgelührtes Gefecht mit Räubern im I. Teil (1, 121 f.); im theatesfremden Stil des Marchens wird darin einem der Gesellen der Kopf abgehuuen.

29) Schriften 1. XXXVII f. u. XXXII. - Die Jungfrall v. O. erschien im Herbst 1801: der Octavian ist ( $\left.\mathrm{Haym}^{2} \mathrm{~S} .918\right)$ in Fruhjahr 1801 begonnen und in 18 Monaten vollendet. 
Gruppenbeobachtung aus bewegter Volksmasse heraus, welche wie Müllers Tumierpublikum in gespannter Erwartung die Mauern besetzt hält, daher geflossen sind. ${ }^{40}$ ) Im einzelnen gehen die Szenen sowohl sachlich als der Auffassung nach auseinander. Tieck schildert ungleich breiter, behaglicher, wo Müller in gepreßtem Geniestil die aktionsschweren Worte ausspart; von einem Vorführen der letzten Phase des Kampfes kann im Octavian nach der Anlage der Szene nicht die Rede sein.

Tiecks Teichoskopie gewinnt schon aus der trefflichen Zusammensetzung der Beobachtergruppe große Beweglichkeit. In der typisierenden Weise der Klassik werden Soldaten, die für den ungescheuerten Harnisch des absonderlich gerüsteten Streiters nur Spott haben, neben philiströse Bürger gesetzt, denen das Außerordentliche, Überkühne seines Unterfangens wider den Strich geht, während ein Ritter in ihm umgekehrt einen Kämpen aus fabelhafter Heldenzeit vermutet. Ein fechtverständiger $\mathrm{Graf}$ richtet sein Augenmerk auf die sportliche Seite des Zweikampfs und beschreibt die kunstgerechte Führung von Roß und Schwert, ein Mönch schickt in der Krise des Gefechts einen Stoßseufzer für den jungen Helden zum Himmel. Die erste Stimme im Chor gehört dem nächstbeteiligten Zuschauer, Florens' Pflegevater Clemens, der vor Aufregung ganz aus dem Häuschen gerät und mit der unermüdlichen Geschwätzigkeit des Alters, gleich närrisch in Angst und Freude, sich bald im Stolz über diesen seinen Sohn bläht, bald vor Zittern und Zagen vergehen will. Der Tiecksche Humor spielt glücklich herein, ob der Alte den Heidenkerl, der über den ersten mächtigen Stoß des zwerghaften Gegners verdutzt steht, gönnerhaft als ,,mein Riesechen" anspricht, oder schließlich sein abgetrenntes Haupt ein "großes Vieh von Kopf" nennt. Die gesammelte Spannung auf die Gefechtsvorgänge, die in Clemens' Vermittlung ein liebenswürdig heiteres Gesicht annehmen, würde jedem Bühnenstück zur Ehre gereichen. In geschmeidiger Technik zeichnet der ruhelose Nährvater, dem keine Wendung des fechtenden Lieblings entgeht, angstvoll jede seiner Blößen nach und schwelgt tief aufatmend in seinen wackeren Streichen; er lebt sich - wie es auf jedem Sportplatz zu sehen ist so sehr in den Zweikampf ein, daß er den Sohn durch Zuruf lenkt und antreibt, dem scheinbar Saumseligen auch einmal eine väterliche Rüge an den Kopf wirft ${ }^{41}$ ) und in dieser Weise die zu schildernde Aktion zum Teil vorweg nimmt.

40) Die Beobachtungsstellen der Tieckschen Genoveva (Lagerbrand bei Nacht 2, 123 f. u. 127. Kampf am feuerglänzenden Strom und in der Stadt S. 126) tragen ganz anderen, stimmenden Charakter und haben mit Müller nichts zu tun. Sie gehören eng neben die in der Genoveva und bereits im Berneck häufige Naturbeobachtung.

41) 1. 269 „Du schläfst Florens! du schläfst!" Ebenso feuert bei Shakespeare (Troilus u. Cressida IV , 5) Troilus den fechtenden Bruder beim (vorgeführten) Zweikampf mit Ajax an: „Hektor, du schläfst, erwache!" 
Plastischeres ist dem Dramatiker Tieck kaum je gelungen, ebenso schwerlich kräftigeres als ein paar fast überraschend starke Ziige, die die Wucht des feindlichen Zusammenpralls und das Ausmaß des heidnischen Kolosses vergegenwärtigen. Der Riese holt mit seinem Schild zum zerschmetternden Schlag so gewaltig aus, daß3 sich selbst die Zuschauer auf den Wällen unwillkürlich ducken: die mächtige Erschüttcrung seines Falles - hier regiert der Schalk spürt der feinnervige Clemens "wie ein partiell Erdbeben" bis unter seinen Sitz. Die Szene wäre nicht echt romantisch, wenn Tieck es an der komischen Würze im allgemeinen genug sein ließe. und nicht noch die kunstvoll geschaffene Spannung selbst ironisierte. Das geschieht in einem spaßhaften Intermezzo, worin der alte Hampelmann, der rittlings auf der Mauer Posto gefaßt hat, vor zappelnder Begier des Hinsehens sich zu weit vorwagt und von hilfreichen Händen noch eben vor dem Sturz in die ungastliche Arena bewahrt wird. Eindringlicher als in dem satirischen Unfall kann sich die Anteilnahme des Beobachters nicht äußern.

Eine im Ernsten festgehaltene Ausschauszenc, die an spezifisch dramatischer Wirkung die des ..Octavian" übertrift, hatte Tieck bereits am Schlusse des .Blaubart" ${ }^{42}$ ) geliefert, wo die Schwestern in Todesnot auf die nahenden Retter harren. Der Auftritt - im Dramatischen wohl der straffste bei Tieck überhaupt - gehört zu jener seltenen Art der Teichoskopie, die sich nicht bei der Aufgabe bescheidet, Außerszenisches greifbarer zu geben als der epische Botenbericht, sondern darüber hinaus als treibendes Moment der Handlung dient. Die Spannung quillt hier aus der Situation und muß nicht erst, wie überall in der schildernden Gattung seit Klopstock und Goethes Selbitz-Szene, durch technischen Aufwand geschaffen werden: das Leben der Heldin hängt an dem Ergebnis des atemlosen Spähens. Tieck fand das vortreffliche Motiv allerdings in seiner Quelle vor, zur szenischen Darstellung wic zugerichtet, mehr als nur dialogisch gefaßt. Schon Perrault gibt Frage und Antwort der todgeweihten und der beobachtenden Schwester, den Kontrast der Ruhe in der Natur mit dem menschlichen Tumult, den trügerischen Hoffnungsstrahl und die erst im Augenblick, wo es zu spät scheint, auftauchende Hilfe. Ein beigehefteter Stich soll zudem Tiecks dekorativem Aufbau zugrunde liegen. ${ }^{43}$ ) Danach würde

"2) Im 1. Bd. der ..Volksmärchen" und gleichzeilig einzeln. Berlin u. Leipzig 1797. Benutzt in Schriften 5. 7 ft. die die fünfaktige Umarbeitung des Phantasus fast unverändert übernehmen. Die Fassungen sind verglichen von K. Brodnitz. Die vier Märchenkomödien von L. Tieck. Münchener Diss. 1912, S. 65 ff.

4) Vgl. Brodnitz S. 49.55 u. 59. Die Teichoskopie findet sich im Märchen nicht allein hier; die ..Volksmärchen" brachien neben dem Blaubart Tiecks Bearbeitung der .Geachichte von den Heymonskindern", wo im 14. Bild (..Die Belagerung auf dem Berge". Schriften 13, 50 f.) Reinold mit seinen verwundeten Brüdern vom Felsen das als Retter unler seinem Vetter Malegs heran- 
ihm einzig das Verdienst gehören, den innerlich schon dramatisch geformten Vorgang in die reale Bühnengestalt übersetzt zu haben. Sein eigener Anteil ist aber doch größer. Er vertieft die Wirkung der übernommenen Szene durch den dramatischen Zusammenhang, worein erst er sie stellt. Die Art, wie er im Sinne dichter Handlungsführung die bei Perrault auseinanderliegenden Ereignisse, Blaubarts Heimkunft und die Katastrophe, eng zusammenrückt und über vorangeschobene Motive in schrittweiser Steigerung auf die entscheidungsschwere Ausschau hinführt, kann als Beispiel wohlgelungener Dramatisierung gelten. Technisch ungemein glücklich wird die Teichoskopie, die Perrault nur für die Rettung bot, in zwiefacher Wiederkehr schon zur Vorbereitung dieser Hauptszene eingesetzt, die damit formal ebenso wie nach ihrem Spannungsgehalt als Krönung einer wohlgegliederten Anlage erscheint.

Den stimmenden Eingang liefert die bewundernde Naturbeobachtung der Schwester vom Altan, dessen freie Aussicht die alte Mechtilde der neuen Herrin gleich nach ihrer Ankunft (IV, I) rühmt. Agnesens Bangigkeit, die für den schönen Sonnenaufgang kein Auge mehr hat, hebt sich davon wirksam ab. Darauf angstvolles Lauschen und der treffliche $Z u g$, daß die feinhörige Erregung der Schuldigen den fernen Hörnerklang eher vernimmt als die ruhigeren Blutes horchende Gefährtin. Mit wachsender Beklemmung erkennt jene im Heranreiten Blaubarts Kriegstroß, das nahende Verhängnis - wie späterhin die nahende Erlösung beobachtet wird. Jetzt erst betritt Tieck Perraultschen Boden und läßt die Spannung in der kunstvoll retardierten Schlüsselübergabe bis zu Blaubarts Wutausbruch und dem vergeblichen Flehen der Schwestem ansteigen, und schließlich, so ausgezeichnet emporgeführt, in der Ausschauszene des Franzosen gipfeln. In ihrer fein empfundenen räumlichen Anordnung sind Motive der Quelle trefflich zur szenischen Erscheinung verdichtet. Mit schlichter, dem Märchen angemessener Symbolik werden die Figuren in drei Stufen angeordnet. Unten, in der Burg verborgen, das dräuende Unheil, Blaubarts mahnende Stimme aus der Schreckenskammer; mitteninne, auf dem flachen Dach, zwischen Furcht und Hoffnung schwankend, Agnes; oben, auf dem Turm, die ausschauende lichte Hoffnung, die Schwester, die dann dem heransprengenden Bruder zum Zeichen ihr Tuch von der Zinne wehen läßt. ${ }^{44}$ )

sprengende Roß Bayart gewahr wird - ein der Erlösung im Blaubart verwandter Vorgang; als Lieblingsstelle Tiecks dadurch bezeugt, daß er sie in extenso in den Karl von Berneck (I, Schriften 11,14 f.) aufnimmt.

4) Perrault stellt die Lokalität nicht ganz klar. Blaubart ruft zwar ebenso von unten und droht heraufzukommen. Anne steht auf dem Turm, von Agnesens Standort jedoch wird nur deutlich, daB sie zur Vollstreckung der Strafe hinuntersteigen muß. - Eine Lässigkeit der Motivierung, die der Erzählung hingeht, ist im Drama anstöBig : Perrault kann, nachdem Blaubart der flehenden Gattin die Galgenfrist gewährt hat, mit einem einfachen "Lorsqu elle fut seule" fortfahren, Tieck 
Tiecks anspruchsvoll vorgeschriebene Dekoration entfaltet hier ihre beste Wirkung, geht aber kaum auf den Stich bei Perrault zurück, der gerade die entscheidende Situation anders darstellt. ${ }^{45}$ ) Viel eher haben - der Blaubart war (Schriften I, VI) auf den Theatereffekt berechnet - die Burgschauplätze des Ritterstücks mit ihren Aufbauten Anteil, nur daß Tieck den äußern Aufwand geistig durchdringt. Ohne verjüngte Ausmaße, wie sie die theatralischen Ritterburgen allgemein aufwiesen, wäre die zeitgenössische Bühne auch mit seinen Forderungen kaum zurecht gekommen, denn er verlangt den Platz vor der Burg, ein 'Tor, das Berners Zug zu fassen vermag, hohes Söller und Turm zugleich ${ }^{46}$ ) und bestreitet mit der cinen umfassenden Szenerie geschickt den ganzen schließenden Halbakt.

Der Kampf selbst und das Ende Blaubarts wird ent sprechend der drängenden Vorbereitung rasch abgetan. Bruder Simon crreicht in atemlosem Lauf die Burg allein, stürzt schreiend ins Tor, stellt den Bösewicht auf dem Altan und stößt ihn in stummem Gefecht nieder; Bruder Anton - bei Perrault erlegen sie den Gegner, der zu fliehen versucht, vereint - langt erst nach vollzogenem Gericht an.

Das Märchen vom Blaubart lieferte Tieck eine dramatisch vorzügliche Beobachtungsszene; das spät behandelte vom .Däumchen ${ }^{017}$ ) gab ihm Anlaß zu halb scherzhafter, jedenfalls unübertrefflich knapper Berichttechnik. Aus schwachen Ansätzen der Quelle ${ }^{48}$ ) entwickelt er eine größere Kriegshandlung, den Feldzug des Königs Artus gegen die Sachsen, und gewinnt damit außer einem farbigen Hintergrund für die Geschichte von den Siebenmeilenstiefeln den Boden, worauf diese sich ihr bestes Verdienst um König

muB ihn von der Szene schaffen und bleibt dabei cine Begründung schuldig, warum der Wüterich jetzt sein Opfer verläßt und zur Karnmer vorangeht.

45) Er findet sich - die Angabe fehlt bei Brodnilz - im 1. Bde. des .Cabinet des fées" 1785. der Perraulis Contes des fies enthält, und zwar übereinstimmend sowohl in der Oktav- (Amsterdam u. Paris) als der bescheidencren Kleinoktav-Ausgabe (Genêve u. Paris), die Lanson, Manuel bibliographique (unter Nr. 394) niche unterscheidet. Der Zeichner verlegt den spannenden Moment - Blaubart bedroht mil crhobenem Säbel die ari den Haaren niedergerissene Gattin entgegen der Erzählung in den SchloBgarten, an den FuB einer Freitreppe, darmit er im Hintergrund den Turm mil der winkenden Schwester anbringen kann. Tieck steht demnach hier dern Text Perraulis näher als der Illustration.

46) Eine Mauerzinne neben dem Turm zeigt auch der Stich; doch sind die zahlreichen Söller nebst Türmen des Rillerstucks, die ihm im Thealer eindrücklicher entgegentraten. Vorbilds genug. abgesehen davon, ob er das Kupfer überhaupt kannle. Nach Koberstein ${ }^{3} 4,560$ Anm. hätte er Perrault übersetzt im 1. Bd. von Bertuchs .Blauer Bibliathek aller Nationen“"Weimar 1790 (fehlt aut den Münchener Bibliorheken) benutzt.

47) Zuerst im 2. Bd. des Phantasus. Berlin 1812. Schriften 5. $497 \mathrm{ff}$.

19) $\mathrm{V} g$. Brodnitz S. 82 u 93. 
und Land erwerben. Der kleine Thoms stellt mit seinem zauberhaften Gehwerk die stark verfahrene Kriegslage - Artus' eines Heer unter Kay ist geschlagen, das Schicksal des andern unter Gawein unbekannt, es gebricht an aller Verbindung - im Handumdrehen her. ${ }^{49}$ ) Boten wie er, der keine Distanz kennt, kaum abgeschickt, schon mit dem gewünschten Bericht wieder eintrifft und stets zu neuer Verwendung zur Hand ist, bis ihm vor Müdigkeit die Knie brechen, hätten dem gottschedischen Kampfstück alle Meldeschwierigkeiten erspart. Die dramatische Feldhermkunst beschränkt sich, gestützt auf einen solchen Helfer, auf das Erteilen von Befehlen; in fünf geflügelten Gängen bringt er die Vereinigung der gesamten Heeresmacht zustande und sichert damit den Sieg.

Das Gesamtbild der Tieckschen Kriegsdramatik ändern die wenigen technisch straff gehaltenen Szenen, die Teichoskopie im Octavian und Blaubart, die Berichterstattung im Däumchen nicht. Tieck bleibt im ganzen der untheatralischen Richtung getreu, die in der Verkehrten Welt zur Satire auf die Bühnenschlacht wird. Die großen Schlachtaufgaben in Genoveva und Octavian zeigen überall den lyrisch gearteten Dichter am Werk, dem Stimmung vor Handlung geht. Für seine gefühlsmäßige Auffassung des Kriegerischen weitet er die shakespearische Form aus und verliert sich im Octavian, an der Hand der Spanier. vollends in eine Wirmis bloßer Stimmungseindrücke des Schlachtgeschehens. Als Gegenpol dieser Gefühlspoesie und als ihr Korrektiv regiert dazwischen vielfach die Ironie; sie bemächtigt sich des Kriegerischen nach seinem Gehalt wie nach seiner dramatischen Technik und richtet ihre Spitzen auch gegen die zeitgenössischen Heereszustände. In strenger Selbstzucht das eigentliche, dramatische Ziel zu erreichen, ist Tieck nicht gegeben. Bei großem Reichtum im Poetischen, der das kriegerische Gebiet freigebig bedenkt, und scharfer, früh durch die Satire, später in der Kritik bewiesener Einsicht in das Technische gelangt er über geschlossene Einzelszenen nicht wesentlich hinaus. Er ist daher auch mit den Stücken, die er ausdrücklich für die Bühne geschrieben glaubte, zu keiner breiteren Wirkung gelangt.

49) Kriegsrat bei König Artus II, 1 ; Zeltszene, worin Kays Niederlage besprochen wird und ein shakespearisch geschwätziger Bader im Verbinden über dessen gewaltigen Sturz vom RoB peroriert. III. 1: Thoms' Botenszene III, 4; Berichte über den Erfolg III. 6. 


\title{
Vierter Abschnitt. \\ Das deutsche Kriegsdrama in seiner Blüte.
}

\author{
Zwölftes Kapitel. \\ Die Klassik Schillers.
}

\section{Wallenstein.}

Nach mehr als zehnjährigem Schweigen tritt der Dramatiker Schiller gegen Ende des Jahrhunderts mit der neugeschaffenen, der klassischen Form des Dramas hervor. Er gibt im ,W allenst $\operatorname{cin}^{\text {"1) }}$ ) zugleich, dem soldatischen Gehalt nach, der deutschen Literatur das erste Kriegsdrama, das sich im universalen Umfassen der kriegerischen Welt neben Shakespeare stellen kann. Nic ist das Feldherrntum eingehender gestaltet, nirgends so wie hier das gesamte Heer in allen seinen Schichten vom Gemeinen bis zum General erfaßt, und der ganze militärische Apparat eines gewaltigen Kriegsunternehmens zum Gegenstand dramatischer Darstellung gemacht worden. Tieck stellt unter den drei Inhalten, die er als das Herrlichste in dem unverbrüchlich bewunderten Werk bezeichnet, das Kriegerische (dem Politischen und Historischen) voran, eine andere Stimme ${ }^{2}$ ) konnte unter Preisgabe der Liebeshandlung von dem Stück behaupten, es rieche ganz nach Pulver.

Es liegt nahe, in diesem hervorstechenden militärischen Charakter des Wallenstein das Soldatenkind Schiller wiederzuerkennen und ihn als eine Frucht der Abstammung und Jugend des Dichters anzusprechen. Im einzelnen hat schon Charlotte von Schiller das farbige Gewoge des Vorspiels mit Eindrücken des Knaben im Lustlager in Verbindung gebracht. ${ }^{3}$ ) Eigene Zeugnisse Schillers aus der Zeit des Ringens mit dem Stofflichen der Tragödie lauten aber anders und zeigen jedenfalls, daß der Dichter selbst sich der soldatischen

1) Die Uraufiührungen, sämtlich in W'eimar: Lager 12. Okt. 1798; Piccolomini 30. Jan. 1799; Tad 20. April 1799. Der Druck: Tübingen 1800.

7) Gervinus" 5. 533. - Tieck, Krit. Schriften, Leipzig 1852. 3. 47.

$\left.{ }^{2}\right)$ Ch. v. Schiller u. ihre Freunde, hrsg. von L. Urlichs. Stuttgart 1860 l. 1, 78 f.: vgl. Weltrich 1. 15: Berger ${ }^{3} 1.24$; vor der C'berschatzung dieser frühen Erlebnisse warnt Minor. Ejni. zu Säkularausg. 5, XLIII. 
gleichwie der politischen Sphäre fremd und schlecht gewachsen fühlte. Er entbehrt bei der Arbeit schmerzlich die „eigene Erfahrung mit Menschen und Untemehmungen aus diesen Klassen“" sucht eifrig"nach Quellen, die ihm ,jene Art von Welt, militärische und politische, in einer anschaulicheren Form näherbringen könnten", und kommt sich gegenüber der Weite des kriegerischen Welttheaters als ein ,armer Schelm von Poet" vor, dem es in abgeschiedener, von allem Weltlauf getrennter Lage unsäglich viel kostet, ,eine solche fremdartige und wilde Masse zu bewegen"..4) Der Gedanke an die eigene Jugend bleibt fern. Es hat den Anschein, als ob die breite Spanne Zeit, die seit den Jahren verstrichen ist, wo Schiller in den Räubern aus persönlicher Not zum zeitgenössischen Soldatentum Stellung nahm, und der lange, inzwischen durchmessene Weg, der ihn aus dem militärischen Milieu femab führte, die $\mathrm{Er}_{\text {- }}$ innerung daran ausgelöscht hätte. Allerdings konnte auch die reichste, in der Gegenwart erworbene Anschauung militärischer Zustände für die historische Soldatenwelt, die es zu erwecken galt, nicht unmittelbar dienen. Der mühselige Prozeß, sie aus der fremdartigen gedruckten Überlieferung in ihrer Zeitwahrheit aufzubauen, war nicht zu umgehen. In diesem Sinne tritt Schiller als Neuling an eine neue Aufgabe, anscheinend ohne sich bewußt zu sein, welche Stärke er nach ihrer stofflichen Seite an ihr entfalten konnte. Ein Probestück in der Zeichnung historischer Kriegsleute hatte er immerhin an den Teutschen Dorias abgelegt; jetzt mußte die ganze wallensteinische Kriegsepoche in weitestem Rahmen heraufbeschworen werden. Weil in allem historischen Gewand des Kriegerwesens derselbe unverlierbare soldatische Kem steckt, fand nun freilich das angeborene kriegerische Teil Schillers, das militärische Erbe vom Vater her, das in der harten Schule der Jugend gefestigt worden war, unvermerkt - die Zeugnisse sprechen höchstens in der frühesten Phase einmal von der Lust am Stoff, sonst nur von seiner Last - überall Anlaß, sich zu dokumentieren. Von dem Soldatendichter Schiller, der früh mit dem Gedicht „In einer Bataille“ auftritt und später die schlachterfüllte „Jungfrau von Orleans" folgen läßt, stammt der Reichtum der kriegerischen Umwelt, die erschöpfende Abwandlung der soldatischen Charaktere, stammen die militärischen Probleme, die Fragen der Disziplin und des Söldnertums, die jetzt, aus den Jugendstücken wieder aufgenommen, in der Weite der Geschichte behandelt werden.

Kriegshistorische Vorarbeit im präzisen und allgemeineren Sinn liefern die geschichtlichen Schriften Schillers. Mit Heeresorganisation hat sich der Historiker bei „Albas Rüstung und Zug“" im 4. Buch des Abfalls der Nieder-

1) An Körner 28. Nov. 1796; 10. Juli 1797 (Jonas 5, 123 f. u. 219); vgl. An Coethe 18. Nov. 1796 (Jonas 5, 113). 
lande zu befassen. Die Charakteristik der Armee des Toledaners, "fürchterlich durch Ungebundenheit, fürchterlicher noch durch Ordnung ". ${ }^{3}$ ) könnte auch für die wallensteinischen Scharen geschrieben sein. Stadtbelagerung. Bombardement und Erstürmung gab der „Bürgerliche Krieg” desselben Abschnittes auf. Aus der Geschichte des DreiBigjährigen Krieges ragt besonders die $\mathrm{Be}$ schreibung der Schlacht bei Luitzen gegen Ende des 3. Buches durch straffe dramatische Anlage hervor.

\section{Das Formproblem.}

Aber freilich, der soldatische Gichalt, wie reich er sein mag. Wallenstein als Dichtung des Kricges, ist nicht zunächst das Vordringliche. Man müßte den eigenen Äußerungen Schillers während der Arbeit und ebenso dem fertigen Werk Gewalt antun, wenn man nicht sehen wollte, daß sich das Formproblem alle stofflichen Interessen unterwirft; im Sinne des Dichters sogar vollkommener, als nach der verschwenderisch bedachten Außenseite der vollendeten Tragödie zu schließen stünde. Schiller freut sich im Bewußtscin ciner neu errungenen, objektiven Dichtweise der Kälte, worin ihn sein Gegenstand zum erstenmal läßt. Er meint geradezu, er habe von dem Inhalte fast nichts, alles von einer glücklichen Form zu erwarten. ${ }^{6}$ ) Es ist aber offenbar, daß seine innerste Dichternatur die kühle Objektivität nicht einzig in der Liebeshandlung durchbricht, wo er sich keinen Zügel anlegen wollte. Entgegen der prätendierten Trockenheit entfaltet das Kriegerisch-Stoffliche eine Wirkung, wic sic reicher kaum zu denken ist. Dennoch herrscht die Form in der Tat so streng, daß man den kriegsgesättigten Wallenstein auch gegen den Vorwurf hat sichern müssen, ${ }^{\text {? }}$ ) das Militärische komme in dem eigentlichen Stück zu kurz.

Schiller hat seine ganze technische Kunst aufgeboten, um das Unerhörte zu leisten und das Feldherrndrama, dessen Basis und entscheidende Macht die unübersehbare Armee bildet, gemäß dem klassischen Ideal in den engsten Bezirk einzuschließen. Mit strenger Architektonik wird die kriegerische Masse es zeigte sich während der Arbeit, daß sie nicht zu entbehren war - in den Unterbau des Lagers verwiesen. Das Führerstück ist davon abgetrennt und in seinem ganzen Verlauf in den vier Wänden gehalten, obwohl seine Krise auf der Meuterci der Truppen beruht. Ein einziges Mal - die wohlgegliederte Kürassierdeputation an den Feldherrn abgerechnet - betritt das Heer, an dessen Verhalten Gelingen oder Fehlschlag der friedländischen Unternehmung hängt, als Masse den Boden der Tragödie. Ein Blick auf Shakespeares Antonius, auf

s) Werke 6, 500 .

') An Goethe 28. Nov, 1796: An Körner vom selben Tug: Jones 3, 119 u. 122.

7) Mirce. Einleipure zu Sikularansp. 5, XU. 
Klingers Pyrrhus lehrt, wie nahe eine andere Behandlungsweise lag, die zwischen der Schicht der Gemeinen und der Welt der Führer hin- und hergeht. Zum mindesten hätte weder Shakespeare noch der Sturm und Drang sich die Brandung einer wilden Empörerszene entgehen lassen, worin die Soldateska in ihrer Entfesselung gegen den eigenen Abgott sichtbar werden konnte. Für Schillers Absichten, die jetzt auf geschlossene Führung des dramatischen Prozesses, auf Mäßigung und Dämpfung, auf ein Zurückdrängen der lauten Aktion hinter die Kulissen gerichtet sind, kommt sie so wenig in Betracht wie etwa die Vorführung des Gefechtes bei Neustadt, worin der junge Piccolomini fällt. Wie die ästhetischen Ziele, so nähern sich die technischen Mittel der französischen Klassik. Für das Treffen tritt der Botenbericht der Franzosen, ${ }^{8}$ ) beim Aufruhr der Regimenter, in der bewegtesten Szenenfolge der Tragödie, ihre Reflextechnik ein. Die Auftritte des Abfalls der Armee zeigen aber zugleich, wie wenig sich die neue klassische Formgebung bei einer Nachbildung der alten bescheidet. Der Zuwachs an Kunstmitteln aus der jüngeren Entwicklung ist so groß, daß von keinem Zurückkehren zu Früherem, sordern einzig von einer Formsynthese die Rede sein kann. Dem alten Kunstwillen, der auf Verflüchtigung des Sachlichen ausging, widerspricht schon die Gegenständlichkeit, womit der Tumult der Massen ergriffen wird, trotzdem er hinter die Szene zurückgedämmt ist. Der Realismus der Geniezeit liegt dazwischen. Sollte die Eindruckskraft, die diese aus der körperlichen Wiedergabe der Vorgänge schöpfte, in der neuen strengen Form nicht verloren gehen, so mußte allerdings die Technik so weit ausgebildet sein, daß sie das Höchste an intensiver Erfassung des Außerszenischen leisten konnte. Dieser Punkt in der Entwicklung ist erreicht. Schiller beherrscht die Mittel so souverän, daß ihm die Beschränkung, statt zum Hemmnis, zum Rahmen straffster Wirkung wird.

Er bewährt die Meisterschaft des dramatischen Architekten zunächst an den Szenen, wo der treulos mürbe Bau des friedländischen Heeres im Zusammenbruch offenbar wird, Ereignissen von großer räumlicher Ausdehnung, die er in knappe Berichte zusammendrängt. Anwachsende Hiobsposten sind in der strengen Technik häufig. Die reife Besonnenheit, womit Schiller die Meldungen vom Abfall der Regimenter zu einer ins einzelste durchgebildeten Steigerung anordnet, hat aber schwerlich ihresgleichen. Der ersten, unerklärlichen Botschaft Terzkys (III, 5), daß Kroaten und Jäger in der Nacht verschwunden sind, folgt Illos schlimmere Kunde vom Fehlen fünf weiterer Regimenter auf dem Fuße. Die ratlose Unruhe darüber, deren Äußerung dem

$\left.{ }^{8}\right)$ Schiller selbst bezeugt gegenüber L. v. Wolzogen (Gespräche, hrsg. von Petersen, Leipzig 1911, S. 282), daß ihm Theramènes Bericht vom Tode Hippolytes in Racines Phèdre vorschwebte; vgl. Minor, Säkularausg. 5, 419; allgemein über das Technische das. S. XL. 
Feldherrn selbst schlecht anstünde, malt sich in der vagen Angst der Frauen. vor denen die Männer, begütigend, nur mühsam die Fassung bewahren. Retardierend schildert Terzky den Zusammenlauf im Lager, tröstet sich Wallenstein über den Verlust eines Isolani. Dann erfolgt mit Illos neuer, gepreßter Meldung der Hauptschlag, der den Friedländer niederwirft: die Tiefenbacher meutern, Oktavio ist ein Verräter, der größere Teil der Armee ist verloren. Dieses Ergebnis wird unterstreichend noch einmal der Gräfin gegenüber, die eigens dazu auftreten muß, in zwei Verse gefaßt (III, 9). Darauf bemächtigt sich die Reflexion und das Gefühl seiner und ergießt sich in Wallensteins Klage über den Betrug. Mit dem lyrischen Ruhepunkt scheinen die Steigerungsmittel erschöpft. Aber noch ist die letzte Unglückspost, der Verlust Prags, der Abfall der in Böhmen verstreut kantonierenden Regimenter, die kaiserliche Acht zurück. die Buttler jetzt im Gegensatz. zu den vorhergehenden, blitzartig einschlagenden Botschaften in schleichender Langsamkeit enthüllt. Maßvoller als früher, wo Schiller in König Philipps W'orten: ,Muß ich so lang um einen Tropfen Gift euch bitten ?"9) seine Karten zu aufdringlich aufdeckt, übt er hier die Kunst spannender Retardierung, das stärkste Mittel durchdachter Berichttechnik.

Nach dem Monolog Wallensteins, worin er sich nach den ersten Schlägen innerlich festigt, setzt mit dem Ende der Kürassierszene, die äußeren Machtzuwachs verspricht, die zweite schärfere Krise ein, die statt heimlichen Abzugs der Truppen ihre offene Empörung bringt. Die ältere seschlossene Technik hätte sich auch diesen Gegenwartsereignissen gegenüber allein auf Botschaften angewiesen gesehen, die neue legt an der Erfassung des Massenaufrubrs ihr eigentliches Probestück ab. Dic Steigerung im Sachlichen drückt sich formal darin aus, daß einleitender Bericht und Meldung ${ }^{10}$ ) in die unmittelbare Beobachtung der Vorgänge übergeführt werden. Man sieht die rasenden Aufständischen durch das Fenster das Rathausdach abdecken. Geschütz aufs Haus richten und Anstalt zur BeschieBung machen, sieht den Adjutanten, der ihnen den Befehl des Feldherm überbringen soll, von ihren Kugeln durchbohrt

") Don Carlos 111, 4: ăhnlich relardierte Mitteilungen W'all. Tod III, 2 u. III. 12.

$\left.{ }^{10}\right)$ Buttles: Abreißen der kaiserlichen Feldzeichen bei Terzkys Regimentern. III, 16 - zugleich ein Beispiel, wie der Reflex, die Wirkung des Mitgeteilien auf die Kürassiere, wichtiger als das Ereignis selbst ist; Illo: Anrücken der Pappenheimer, mil leisem Ubergang zur Beobachtung. 111. 17: Neumann: Sturmdrohung des abgesessenen Regiments III. 19: Terky: Bitte der treuen Truppen um die Erlaubni anzugreifen. 111.20. - Anschwellende Volkstumule in Don Carlos V, $4-5$, wo die Menge, ahnlich wie die Pappenheimer inren Oberst, den Prinzen herausverlangt. ferner in Maria Stuart IV, 6-9 vgl. Il, wo sie den Tod der scholtischen Königin fordert, endlich in Junglrau V. 9, wo die englischen Truppen das Haupt Johannas begehren; sie werden ausschlieBlich durch Meldung und Gelöse ins Zammer hereingetragen. 
fallen. ${ }^{11}$ ) Mit diesen zwei Hauptmomenten ist aber das Hereindringen des Außerszenischen schon erschöpft. Nur das Notwendigste, dafür in packender Eindringlichkeit, wird gegeben. Für die behaglich schildemde Teichoskopie, welche die Vorgänge um ihrer selbst willen ausbreitet, ist kein Raum, ebensowenig für einen größeren Aufwand akustischer Mittel. In starkem Gegensatz zu den häufigen Detonationen der Räuber bleiben die beiden Schüsse, die Neumann niederstrecken, die einzigen des ganzen Tumults und des kriegerischen Stücks überhaupt. Sie sprechen in seiner gebändigten Welt für die Entfesselung der Scharen laut genug. Die neugewonnene Bewegungsfreiheit der strengen Form tut dem Streben, die Außenaktion einzudämmen, dem Rechnen mit der geschlossenen Wirkung keinen Abbruch. Es lag diesem Verfahren fern, den Feldherm in einer breiten Massenszene den Aufrührern entgegenzustellen. Aber selbst den andern Ausweg, daß er sich der unsichtbaren Menge von der Szene aus am Fenster zeigte, vermeidet Schiller. Die Klassik gewinnt den stärkeren Eindruck aus dem reinen Reflex, der Besorgnis der Frauen und Wallensteins zerschmetterter Erscheinung, nachdem der Einsatz der eigenen sieghaften Persönlichkeit fehlgeschlagen hat. Der Sturm und Drang hätte die Wirkung im Ereignis selbst gesucht.

Sachlich wird die Úberwindung der lärmvollen Aktion durch den Meistergriff der Doppelhandlung möglich. Zwei Themen, der Heeresaufruhr und der Abschied Piccolominis, sind kunstvoll ineinandergeschlungen, in rhythmischem Wechsel abgewandelt ${ }^{12}$ ) und endlich im großen Finale vereinigt. Die straffe Kausalverknüpfung zwischen ihnen, die im Verlauf mehr und mehr hervortritt, könnte sie für eines gelten lassen: die Pappenheimer stürmen das Haus, um ihren Oberst zu befreien. Unter der persönlichen Tat dieses Regiments wird aber zugleich der bewaffnete Aufstand der Truppen im ganzen dargestellt. Die Tiefenbacher, die als einzige neben den Kürassieren hervortreten, meutern lange ehe von einem Festhalten Piccolominis im Schlosse die Rede ist. ${ }^{13}$ ) Wallenstein sieht sich auf dem Altan nicht einer einzelnen Ein-

11) III, 19 u. 20, Illo und Terzky in abgerissenen, durch Fragen und Reflexrufe gehetzten Sătzen. - Etwas locker muß III, 6 (Terzky: „Bleib hier“ usw.) die Möglichkeit, vom Fenster zu beobachten, eine sonst nötige Szenenveränderung verhindern. Akustische Beobachtung dann III, 22: das von der Gräfin falsch gedeutete Kaiserhoch; ebenso V, 7 „Schwedische Trompeten l“ und öfter. Stimmende Naturbeobachtung V, 3: Wallenstein nachts am Fenster.

$\left.{ }^{13}\right)$ Der Meldung des Auflaufs 11I, 17 folgt die große Szene Wallensteins und Maxens, auf die Sturmdrohung, den Verteidigungsbefehl Wallensteins und die Aufruhrereignisse III, $19 \mathrm{f}$. dicjenige Maxens und Theklas, die Wallenstein Zeit gibt, sich den Rebellen zu zeigen.

13) Die Situation auf der Höhe der Empörung III, 20 (.O komm! LaB ihren Eifer nicht erkalten... - Soll diese Stadt zum Schlachtgefilde werden ...") klingt bereits bei ihrem Aufruhr III, 8 (,.So laß sie niederschießen! O, gib Ordre!") vor. 
heit, sondern dem rebellischen Heer gegenüber. ${ }^{4}$ ) Ebenso geht die Bedeutung der Piccolomini-Szenen über das Persönliche hinaus. Schiller stellt in Max mit ciness symbolisierenden Verfahren, das dann in der ,Jungfrau" die klassische Schlachtdarstellung krönt, den außerszenischen Massenabfall, in eine Gestalt sublimiert, auf die Bühne. Cber sie ergießt sich der ganze Zorn des befehlsgewohnten Feldherrn, wie er unsichthar vom Altan aus die Rebellen treften soll, sie umwirbt im Wechsel des Tones der Halbverlassene mit allen den Sophismen des Verstandes und des Gefühls, die er vorher, dem gemeinen Manne gegenüber herrschermäßiger gefaßt, an die Kürassiere verschwendet. Die körperliche Erscheinung der Męnge kann kraft dieser vertretungsweisen Behandlung - schon die zehn Pappenheimischen sind eine Deputation ebenso im dramentechnischen, als in militärischen Sinne - für die letzte Steigerung aufgespart blciben.

Nichts macht die strenge Ókonomie der äußeren Mittel sichtbarer als die gemessene Weise, wie die Masse schließlich eingesetzt wird. Schillers Vorschrift ist deutlich. Keine entfesselte Aufrührerhorde dringt durch brechende Türen mit stürmender Hand ins Schloß, .,Kürassiere mit gezogenem Gewehr treten in den Saal". Ihre blanke Waffe - im Tasso ersetzt sie den Zweikampfwird für ausreichend befunden, die Situation zu kennzeichnen. Das Gewaltsame des Vorgangs ist, soweit es überhaupt angeht, gedämpft. Der Rationalist müßte fragen, wo die friedländischen, im Aufruhr sicher verdoppelten Schildwachen bleiben, die den Weg zum Feldherm nicht leichthin preisgeben würden. Aber man steht jener combattementfrohen Drainatik fern, die sich ihren letzten Widerstand an der Türe nicht hätte entgehen lassen, und kann sich dergleichen in dieser Welt kaum denken. Es ist merkwürdig, wie Schiller der Masse nicht nur die grelle bewaftnete, sondern überhaupt jede Altion

10) Entsprechend dem Zurückdrängen des Außerlichen wird die Masse beim Aufstand wenig gegliedert: die Vorstellung, daß sie bedeutend ist (besonders aus v. 2213), genügt. Die Friedland treuen Truppen, fünt Terakysche Regimenter (v. 1820). denen die buttlerischen Dragoner zugerechnet werden, sind wohl die ..prößre Zahl". scheinen aber mit den Abtrünnigen immerhin nicht leichten Kaufes fertig zu werden. Unter diesen haben die Pappenheimer die Fühnung, die schließlich allein eindringen. An die Arkebusiere Tiefenbachs, die schon im Lager (v. 838 ff., vgl. 657 ff.) als kaisertreu cingefühn, im Tod (v. 962) als besonders zuverlässig gebraucht werden, die den W'achdienst an den Toren (1577 f.) im Sinne Oktavios versehen, dann als erste (1598) .bö̈se Mienen" machen und (1644 ff.) offen meutern, ist beim Besteigen des Rathausdaches usw. (2207 ff.) zu denhen, nichı, mil Minors Anmerk., Säkularausg. 5. 412, an die Kürassiere; sie tun (2250) den SchuB. Der Rest hat nur als Masse Geltung; es sind nach v. 1267 die Regimenter Lothringen und Toskana, im folgenden (15\%6 f. 2243) außer 1862, wo neben Tiefenbach noch Toskana genannt wird, cinzeln nicht mehr unterschieden; demnach drei Regimenter Fußvolk, die vor Neustadt (303I) zurückbleiben, neben dem einen zu Pferd. 
benimmt und sie allein durch ihr Gewicht, ihre kubische Qualität wirken läßt. Einzig am Schluß, und hier ausdrücklich, „entsteht eine rasche Bewegung unter den Kürassieren", zum tumultuösen Abgang. Vorher ${ }^{15}$ ) sind sie geschlossen als lastende Körperlichkeit empfunden, die wie ein steigendes Wasser ruhig, aber unentrinnbar den Raum mehr und mehr, bis zur Beklemmung füllt, indessen unten in korrespondierendem Anschwellen die Hörner lauter und lauter rufen. Der Eindruck verdichtet sich schließlich in Max Piccolominis Worte: Gewicht hängt sich an Gewicht, die Masse zieht ihn schwer hinab. Nur die Richtung kann er ihrer unwiderstehlichen Wucht noch geben. Die moderne Bühne pflegt sich bei dieser gebändigten Steigerung nicht zu bescheiden. $\mathrm{DaB}$ aber dem klassischen Formprinzip durch tumultuarische Inszenierung ${ }^{16}$ ) Gewalt geschieht, bezeugen die entstehenden Unstimmigkeiten. Wer tobende Scharen auf die Szene führt, stößt daran an, daß der Dichter ihnen keinerlei Anteil am Dialog, keinen einzigen Chorruf verstattet und sie stumm bleiben läßt, obwohl Max sie anredet. Die Fanfaren sprechen für sie. Eine wirklichkeitstreue, lärmende Masse könnte nur kurz den Führer herausholen, aber nicht den Hintergrund zu seinen ausgedehnten Abschiedsreden abgeben. Die Szene im ganzen ist darauthin konzipiert, daß Bewegung und Äußerung der Komparserie auf das theatralisch Notwendigste beschränkt bleiben, und bis in das scheinbar Zufällige dem herrschenden Kunstwillen untertan, der auf Begrenzung und Verinnerlichung ausgeht.

Die Heeresmasse, die an der einzigen Stelle, wo sie in das Feldherrnstück tritt, dergestalt eingedämmt wird, war in ihrer ganzen Breite in Wallensteins Lager darzustellen. Die Aufgabe heischte den freiesten Spielraum. Coethe kündigt das Lagergemälde "unter der Rubrik eines Lust- und Lärmspieles“ an. ${ }^{17}$ ) Es ist früher darauf hingewiesen worden, wie sehr die Formgebung dennoch von klassischen Tendenzen zeugt. ${ }^{18}$ ) Das Lärmvolle des Treibens wird zurückgeschoben, die eigentliche, ungegliederte Masse, ganz anders als in den Räubern, stumm in den Hintergrund gedrängt und erst zur Schlußwirkung, als disziplinierter Chor, eingesetzt. Scharf sind die Gruppen der Sprecher abgesondert, viel mehr als die militärische hält die künstlerische Organisation des Heerlagers auf Maß, Ordnung, Trennung der Teile. Fast überraschend ausschließlich ersetzt das Wort alles wilde Tun. Seine Macht

${ }^{15}$ ) Alle Anweisungen lauten passiv: „Der Saal füllt sich mehr und mehr mit Bewaffneten an" usw.

$\left.{ }^{16}\right)$ Vgl. Lohmeyer S. 124, dessen Polemik dagegen aber auf eine Verwechslung der Deputation mit der schließenden, wirklichen Massenszene gegründet ist.

${ }^{17}$ ) In der ,Allgemeinen Zeitung“", Werke 40, 5.

18) Vgl. oben S. 219; über die Gruppentechnik Lohmeyer S. $117 \mathrm{ff}$. 
in Schillers Hand ist freilich so groß, daß man kaum gewahr wird, wic wenig von dem Rohen und Barbarischen der Soldateska wirklich vor Augen kommt. Die Geniezeit hätte die Gelegenheit zu maßlosen Kraftszenen wahrgenommen. Der Klassiker schildert das Creucl- und Heidenleben durch den maulenden Kapuziner viel krasser, als er es leibhaftig vorführt. Ein Tänzchen und ein $\mathrm{KuB}$ könnte etwa auch in einem gottesfürchtigeren Lager riskiert, ein illuminierter Rekrut außerhalb friedländischer Saufgelage angetroffen werden. Schon der Auflauf um den Bauern bleibt im wesentlichen im Zelt, der um den Pfaffen kann nach dem begütigenden Zuspruch der Kroaten nicht gefährlich gemeint sein. Zu laute Inszenierung wird an allen diesen Stellen, wie bei der Kürassierszene im ."Tod", mit dem Dichter in Konflikt kommen und seinen beherrschenden Dialog übertönen. Ohne Ängstlichkeit - eine Derbheit wie das gemütlich-rohe .,da trink', du Hund!" des Ulanen findet Eingang - ist der Ton der Wallensteiner doch bedeutend gehoben und gehört, trotz aller realistischen Abstufung, viel enger zu dem der Tragödie, als etwa zu der Ausdrucksweise der Räuberschar. Es ist nicht bloß ein Zeichen der späten Einfügung der Kapuzinerpredigt, daß von dem dort gerügten Blasphemieren, von kolossalischen Flüchen in den friedländischen Kriegsquartieren im wirklichen Dialog kaum etwas verlautet; die Schilderung malt auch hier greller, als der Augenschein lehren darf. Ähnlich steht es um das Benehmen der Kriegsgesellen. Sie haben wohl eine kecke, freie Art sich zu geben, aber nichts von kraftgenialischem Aufdonnern, wenig Ungebärdiges, keine abstoßenden Züge, die man von den verwilderten Horden erwarten müßte, von denen der Prolog spricht. Im ganzen kann die Zeichnung realistisch nur mit der Einschränkung heißen, daß Realismus der Klassik nicht dasselbe bedeutet wie Realismus des Sturm und Drangs. Der derben Wirklichkeit am nächsten stehen einige niedrige Soldatentypen des Eingangs und, dieser im engsten Anschluß an die Quelle, der Kapuziner. Geläutert im Dichterfeuer, geadelt durch den Schwung der Sprache ist dagegen schon dic Schilderung der holkischen wilden Jagd im Munde des zweiten Jägers, eines wilden Gesellen, der ein schlimmes Reitervolk vertritt. Die greuelvolle Realität, Gewalttat und Schändung, blickt nur gedämpft durch, die Grenze des Schönen wird nirgends überschritten. Wie wäre hier Raum für die krassen Zynismen, womit ein Spiegelberg ähnliche Zuchtlosigkeiten im Nonnenkloster preisgibt! Die Idealisierung greift mit dem Auftreten des Kürassiers weiter um sich und erfaßt schlicßlich das friedländische Soldatentum in seinem ganzen Umfang. Mit dem Schluß, der das Ethos des Standes in den triumphalen Chor ausklingen läBt, $\left.{ }^{19}\right)$ ist der hohe Stil der Tragödie erreicht.

19) Vgl. Berger 2, 407 u. 409. 


\section{Der Kriegerstand.}

Nach des Dichters Intention sollte das Lager als „ein lebhaftes Gemälde einer gewissen soldatischen Existenz" ${ }^{20}$ ) auf sich selber stehen können. Geleistet ist mehr als das, gegeben geradezu die Totalität soldatischer Existenz, jene vielbewunderte, erschöpfende Typisierung des Söldnerwesens, das sich von der Dumpfheit kroatischen Raubgesindels stufenweise bis zu dem Hochsinn des Kürassiers erhebt, der den Krieg egmontisch als das wahre Tun des freien Mannes anschaut. ${ }^{21}$ ) In ihrer alle Schichten des Heeres umfassenden Weite, die Niedriges und Erhabenes einschließt, könnte die Gestaltung objektiv heißen. Aber die lichten Töne, das Bejahende, Große und Edle auch in der Verwilderung herrschen so stark vor, daß die Prologworte vom finsteren Zeitgrund, die dem geschichtlichen Bild gelten, ${ }^{22}$ ) seine dichterische Spiegelung nicht mehr ganz treffen. Die Gründe für diese Auffassung der wallensteinischen Soldateska ${ }^{23}$ ) liegen tiefer als in dem idealisierenden Prinzip der Klassik schlechthin, das das Rohe und Gewaltsame nur in der Veredelung duldet. Wohl war die Begeisterung der Massen für ihren Abgott, Sinn und Ziel des Vorspiels, das Wallensteins Verbrechen durch seine Macht erklären sollte, nicht zu entbehren. Es ließe sich aber auch eine mehr düstere, minder strahlende Zeichnung des Soldatenstaats denken. Daß Schiller ihn mit allem kriegerischen Clanz umhüllt, daß er in ihm insbesondere, die historische Bedingtheit verlassend, die Cröße des Kriegertums überhaupt gestaltet und den friedländischen finsteren Krieg zum gültigen Bild des hohen Krieges erhebt, ist sein eigenstes $\left(\mathbb{V e r k},{ }^{24}\right)$ persönliche Prägung seiner besonderen Konzeption, die später, am Bild des Helden, aufzuweisen sein wird.

20) An Goethe 21. Sept. 1798.

${ }^{21)}$ Vgl. darüber W.Scherer ${ }^{12}$ S. 594; E. Kühnemann, Schiller ${ }^{3}$ S. 448; Berger 2, 404 ff.; Minor, Säkularausg. 5, XLII.

$\left.{ }^{22}\right)$ Vgl. dafür die Kapitel „Das Heer“ u. „Soldatenleben und Sitten im 30 jähr. Krieg” bei G. Freytag, Bilder ${ }^{20}$ 3, 13-99; besonders S. 42, 45 u. 87. Jähns KW 2, 1030 ff. Die einschlägigen Stellen des Schillerschen Geschichtswerkes bringen Minors Anmerkungen bei.

$\left.{ }^{23}\right)$ K. Werder, Vorlesungen über Schillers Wallenstein, Berlin 1889, kann die Armee S. 8 , 40, 42 u. 45 ff. zugunsten seiner Anschauung von der Tragik nicht dunkel genug, als eine bestialische. blutlüsterne Räuberhorde malen und tut damit der Gestaltung Schillers trotz seiner Verwahrung (S. 47) offenkundig Gewalt an. Skeptisch betrachtet auch H. v. Tr e it sch k e, Histor. u. polit. Aufsätze ${ }^{5}$. Leipzig 1886, 1, 107 die Wallensteiner. Die unbestreitbare, kriegerisch erheberde Wirkung des Vorsp̧iels möchie er darats erklären, daß al's M:iıerstand dem nur dramatisch Gültigen ein absoluter Wert beişemessen verde.

24) Über die Idee des Krieges als Zentralpunkt des "Lagers" vgl. Kühnemann ${ }^{3}$ S. 448. .Wallensteins Lager [als] eine Symphonie über den Krieg " betrachtet Adolf Thimme, ZfdU 16 (1902), S. 492-98, wesentlich in der Kontrastienung des Kürassiers und Zweiten Jägers. 


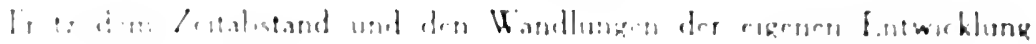

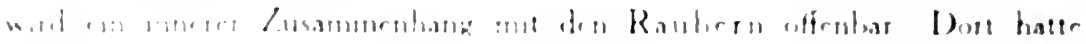

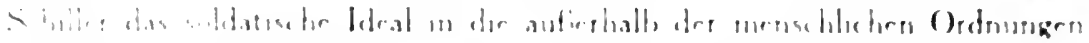

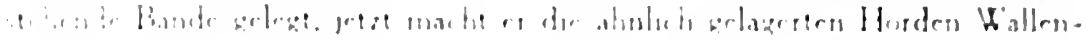

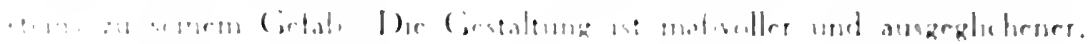

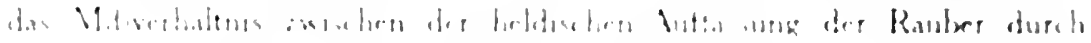

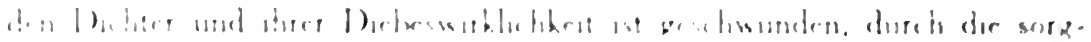

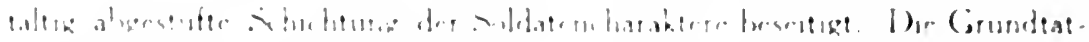

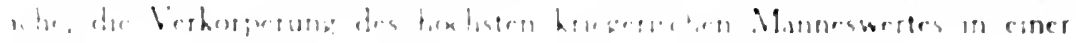

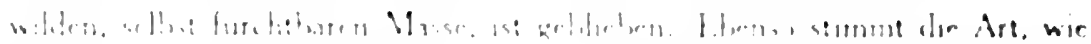

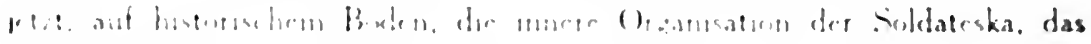

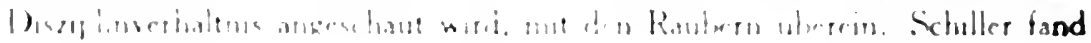

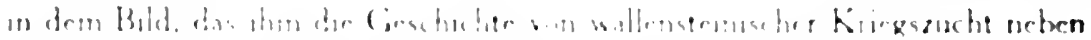

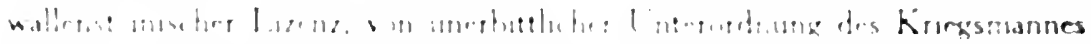

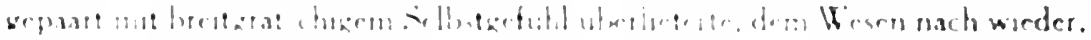

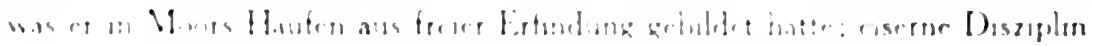

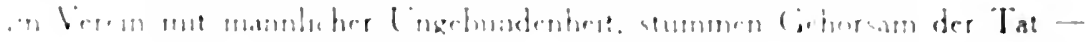

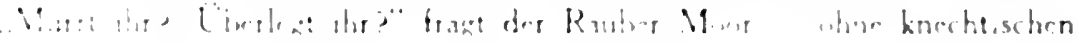

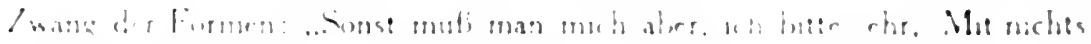

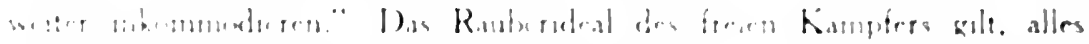

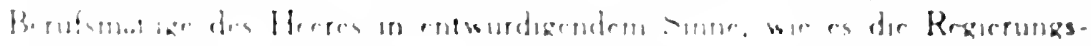

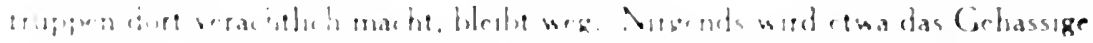

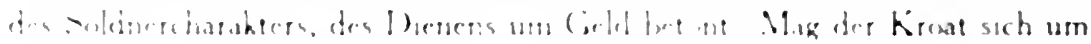

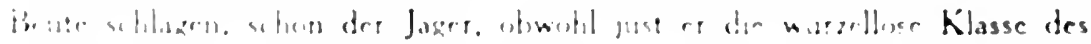

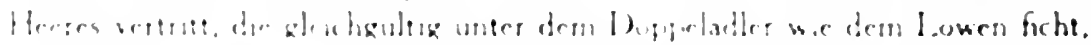

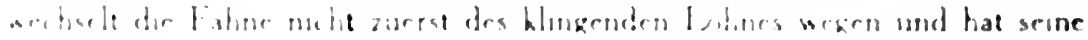

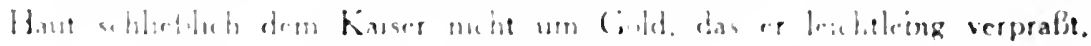

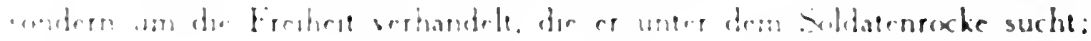

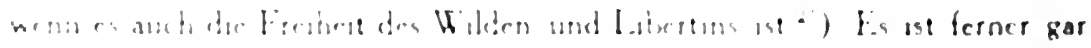

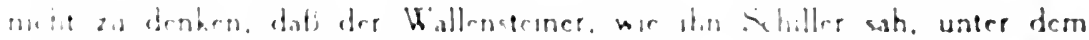

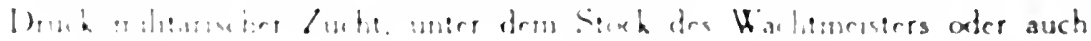

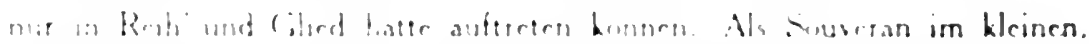

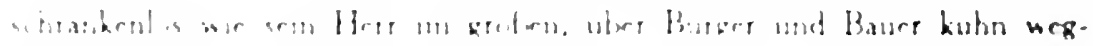

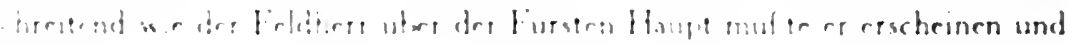

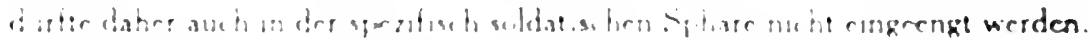

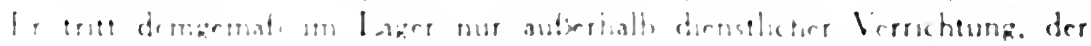

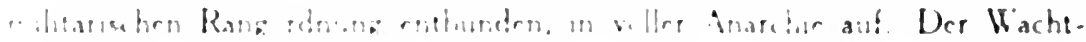

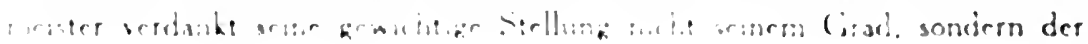

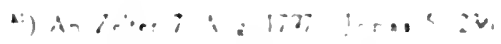


Gravität seiner Reflexion; als Chargierter kann er sich nur vor dem einen Novizen in die Brust werfen, während ihn die gedienten Leute mit aller Respektlosigkeit behandeln.

Die Verwandtschaft der Wallensteiner mit der idealisierten Räuberschar kann lehren, daß ihnen einigermaßen Gewalt geschieht, wenn man dem Parallelismus mit der Welt der Führer zuliebe den Kürassier als den soldatischen Idealisten seinen Kameraden schroff entgegenstellt. ${ }^{26}$ ) Das Lager kennt weniger den Kontrast als das mähliche Aufsteigen der Kriegertypen. Die freie Mannesgesinnung, die der Wallone geläutert in sich trägt, herrscht roher gefaßt auch im Jäger und in zunehmender Verdumpfung bis gegen die Niederungen des Heeres. Seine Gesamtheit fühlt sich, klarer oder dunkler, von dem Windesweben des Geistes ergriffen, und es ist nicht bloß eine effektvolle Schlußsteigerung, sondern der gesammelte Ausdruck der Auffassung Schillers von diesem Soldatenreich, daß die Masse im ganzen zu dem Gipfel kriegerischen Hochgefühls im Reiterlied emporgerissen wird.

$\mathrm{Die}_{\mathrm{i}}$ Theatergeschichte liefert dafür einen sprechenden Beleg. Die verklärende Zeichnung, die über der hohen Idee des freien, wehrhaften Lebens das kühle Abwägen von Licht und Schatten vergißt, der optimistische Grundton, der über Rohes und Verruchtes des historischen Standes hinwegträgt, machte es möglich, das Lagerstück in patriotisch gehobener Stunde der Armee zur Befeuerung, als eine Verherrlichung des Kriegertums, vorzuführen. Iffland gab es am Vorabend des Auszugs der Berliner Garnison im Oktober 1805 vor soldatischem Publikum - jede Kompagnie durfte 24 Mann stellen und erntete einen Sturm der Begeisterung. ${ }^{27}$ ) Der Gedanke Klopstocks, der seine Hermannsschlacht vor einigen preußischen Bataillons dargestellt wissen wollte, war damit in die Tat umgesetzt, die Kriegsdramatik unmittelbar dem lebendigen Heer fruchtbar gemacht. Der Verlauf dieser Aufführung stützt Caroline v. Wolzogens Urteil ${ }^{28}$ ) über die Zeitwirkung des Wallenstein: die Militärverhältnisse hätten durch ihn eine neue Seele gewonnen, der begeisterte Jüngling sich nach Kriegstat und Ruhm gedrängt. Ein knappes Jahrzehnt später konnte Goethe das Vorspiel mit eigener Schlußmahnung zum Auszug freiwilliger Jäger in Weimar spielen lassen.

Es ist interessant, denselben Iffland ein paar Jahre früher über die Gegen-

25) So bei W. Scherer ${ }^{12}$ S. 594-96; dagegen betont Berger 2, 409 treffend, daB der Dichter auch bei den barbarischen Horden den trotzigen Schwung noch mitfühle und die Soldateska im ganzen gegen die Kleinheit des Alltagsdaseins ins Heldenhafte emporhebe. Ähnlich Minor. Einl. 5, XLII und Anmerk. S. 384.

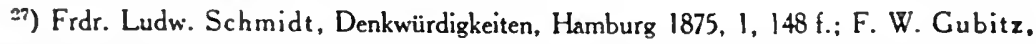
Erlebnisse, Berlin 1868, 1, 110; H. Holst ein, Einl. zu Ifflands Theatral. Laufbahn, DLD 24, LVI.

${ }^{28)}$ Schillers Leben usw.. Stuttgart u. Tübingen $1830,2,180$. 
wartsnähe des Soldatischen im .Lager" zu hören. Er sah zuerst in dem Vorspiel nur das Gefährliche der Diskussion über die soldatischen Grundfragen für einen Militärstaat wie Preußen und setzte dem Dichter im strengsten Vertrauen die Gründe auseinander, weshalb dic Aufführung in Berlin nicht stattfinden könne. ${ }^{29}$ ) Es war ein starkes Zeugnis für die Treffsicherheit, womit Schiller die militärischen Probleme dargestellt hatte, daß der Berliner Intendant "die ganze militärische Debatte bedenklich" fand und ein Stück nicht verantworten wollte, ,wo über dic Art und Folgen eines großen stchenden Hecres ${ }^{30}$ ) so treffende Dinge in so hinreißender Sprache gesagt werden "; ein weniger gutes allerdings für den Staat, für den aus den Erörterungen der Friedländer über . Zivil und Militär" Erschütterungen befürchtet wurden, für den ,.militärischen König", dem man des Wachtmeisters Worte über Stock und Zepter nicht zumuten wollte; ein ganz schlechtes endlich für die Armee, der , die Möglichkeit, in Masse darïber zu deliberieren, ob sie sich da oder dorthin schicken lassen soll und will" - also der Gedanke an Meuterei -. nicht ,anschaulich dargestellt" werden durfte. Man fand demnach - Iffland beruft sich auf das Urteil mehrerer bedeutenden Männer - in dem Geschichtsdrama viel engere Beziehungen zu den Heereszuständen der Gegenwart, als sich der Autor bewußt war. Iffland weist ihn darauf hin, daß die Personen des Lagers „oft dic jetzige Empfindung vieler ausdrücken“, obwohl er sieht, daß sie "nach des Verfassers Willen nur die Charakteristik des Standes und jener Zeiten geben sollten". Schillers Antwort ${ }^{31}$ ) gesteht, es sei ihm bei der Arbeit keine solche Bedenklichkeit gekommen, und bestätigt damit erneut, wie er selbst sich der tendenziösen Schärfe, womit die Jugendstücke die zeitgenössischen Militärverhältnisse auffassen, entrückt fühlte.

Die lichte Zeichnung der Soldateska im Vorspiel wird besonders fühlbar neben den zwei Auftritten der Tragödie, die das Bild nach den dunklen Partien hin ergänzen: demjenigen Wrangels und der Mörderszene. In der Unterhandlung mit dem Schweden ${ }^{32}$ ) steigt neben dem wallensteinischen Kriegsstaat ein ganz anderes soldatisches Ideal auf, wird das Triumphale, kriegerisch

29) An Schiller 10. Febr. 1799; in Teichmanns Literar. Nachlaß hrsg. v. Dingelstedt, Stuttgart 1863. S. 206; in lfflands Briefwechsel (Reclam Nr. 5163-65) S. 26 ff.

${ }^{30}$ ) Ein Aperçu von Len z (Ủber die Soldatenehen. S. 21) darüber hatte gelautet: „Es ging den Königen mil den stehenden Truppen anfangs wie mit den Nesseln, sie faßten sie an, wenn sie mußten, und ließen sie sogleich wieder fahren."

81) An Iffland 18. Fehr. 1799; ich kann daraus weder mit Jonas $(6,439)$ und Berger $\left({ }^{3} 2.400\right)-$ beide zitieren unvollständig - cine feine Zurechtweisung. noch mit C. Müller (Reclam Nr. 5163 bis 65 S. 26 Anm.) verhalienen. Arger und Mitleid zugleich" herauslesen; aus dem Brief allein wird man nur entnehmen können. daB sich Schiller ehrlich bei lfflands Gründen bescheidet.

ax) Tod 1. 5: vgl. Kühnemann S. 480 und Werder S. 39 f., vgl. 173. 
Große des Lagers entscheidend gedämpft. Der geschichtliche Gegensatz schließt die große Frage des modernen Soldatentums in sich. Neben das geworbene, gekaufte, entsittlichte Soldheer in seiner schärfsten Ausprägung, neben den Auswurf fremder Länder und den aufgegebenen Teil des Volks tritt das schwedische Volksheer, das für die nationale Sache, für Herd und Glauben ficht. Die unmittelbare drainatische Situation forderte nur den $\mathrm{Er}$ weis, daß die unerhörte Felonie der Kaiserlichen möglich sei; der Schwede hätte mit dem Revers allein befriedigt werden können. Was darüber hinausgeht, sein maßloses Erstaunen, das die Kluft zwischen zwei Welten auftut, die Erläuterung Wallensteins, der seine eigenen Truppen so skeptisch ansieht, ist Teil der umfassenden historischen Gestaltung und der erschöpfenden soldatischen Charakteristik und insbesondere wichtigstes Glied in der zunehmenden Verdüsterung, welche die Armee in dem Maße umfängt, wie der Feldherr Stufe um Stufe von der Höhe seiner Herrschgewalt herabsinkt. Es gilt, auf seine bisher glanzvoll gezeichnete Welt tiefe Schatten zu werfen.

Am Eingang der Tragödie steht als Paladin friedländischen Soldatentums der Kürassier, an ihrem Ausgang der Mörder. Nachdem die Soldateska ihrem Herrn und Meister bereits im Aufruhr ihr furchtbares Gesicht gezeigt hat, ${ }^{33}$ )

${ }^{\text {as) }}$ Drohend ragt die Söldnermasse auch in die Exposition der "Jungfrau" herein, als unentbehrliches Kriegswerkzeug, das die Not des Königs, der es nicht zahlen kann, durch seine Dienstverweigerung steigert, v. 494 f., 587 ff., 606; zum Sold vgl. Wall. Lager 879 ff.; Piccol. 1150 ff. Als einzelner tritt der gemeine Soldat in der Jungfrau - Montgomery ist der Masse völlig enthoben - nicht hervor; Schiller führt zwar die Fliehenden II, 5 redend ein (vgl. Lohmeyer S. 85 f. u. 128 f.), hat aber die englischen Söldner, die Johanna gefangen nehmen (V, 6), stumm gelassen, obwohl die Jungfrau sich lebhaft an sie wendet. - Im Tell erscheinen die landenbergischen Reiter, die auf der Verfolgung Baumgartens wütend in Herde und Hütte fallen, als unmenschliche Wüteriche und Geißel des Landes (Kotzebuesche Reiter in nahverwandter Verfolgungsszene in G. Wasa III, 11 halten sich manierlicher und begnügen sich schließlich mit einem Häring und ein wenig Salz). Eingehende Söldnercharakteristik gibt Schiller in dem Schildwachauftritt unter dem Hut, Tell III, 3, der klassischen Postenszene, worin er den verschlossenen Grimmbart Frießhardt, den dienstfertigen Schurken, durchgängig mit dem lichter gezeichneten Leuthold kontrastiert, der sich als wackerer Reitersmann des Postens schämt. Frießhardt wacht mit gehässigem Eifer über dem Befehl, ohne ihn zu besehen, und weist den Einwand des Kameraden mit bärbeißigem Humor ab; er verscheucht zornig die Weiber, er stellt Tell und ist bei seiner Verhaftung als ein Kerl, der keinen Spaß versteht, der Handelnde, der Geßler unter den Knechten. Sein Geschrei ruft den Vogt herbei, er meldet. Leuthold gleicht dem menschlicheren Rudolf dem Harras, er kritisiert den Befehl, will beide Augen zudrücken, nimmt an Tells Gefangennahme eher begütigend teil, verkündet staunend den Ruhm des Schützen und findet am Ende als Scherge des grausamen Vogts ein Wort mitleidiger Teilnahme. Die Zeichnung FrieBhardts als Vorläufer Geßlers in der hohlen Gasse IV, 3, freundlicher, aber ohne besondere Farbe, nimmt auf das frühere kaum mehr Bezug. - Mit goethischem Realismus wird der Söldner in 
wird sie in Deveroux und Macdonald zum Werkzeug seines Untergangs. Jetzt erst tritt die roheste und gewissenloseste Klasse des Hecres hervor, der gedungene Söldling, den der hat, der am meisten hietet, anstatt des ehrlich geworbenen Soldaten. Es ist, trotz dem Vorspiel, die einzige Szene, worin die Wirklichkeit der Soldateska des Dreißigjährigen Krieges sichtbar wird, und damit, nach der Echtheit und shakespearischen Naturnähe ihrer Gestalten, allerdings ein Ausbiegen von sonst festgehaltenen Grenzlinien des hohen Stils. ${ }^{34}$ ) Nur noch Rudimente aus dem friedländischen Soldatenkodex, der im Lager hochgehalten wird, wirken in dieser untersten Kreatur von Wallensteins Welt nach. Die paar soldatischen Grundhegriffe sind das einzige, was aus dem tiefsten sittlichen Verderb hervorleuchtet. Disziplin in ihrer rohesten Form, ein Rest von Scheu gegen des Feldherm geheiligte Person, die das geleistete Jurament schützt, unterscheidet die wüsten Gesellen immerhin vom Mörder gewöhnlichen Schlages. Aus dem ,Lager” kehrt der Truppenaberglaube vom Festsein des Chefs wieder, womit sich der gemeine Mann das Unerklärliche und Geheimnisvolle der überragenden Führergestalt auf seine Weise zurechtlegt. Das soldatische Point d'honneur macht sich schließlich in der grimmigen Ironie Luft, daß die Kerle dem Feldherrn die Wohltat zuerkennen, statt durch Henkers Beil ehrlich von ihren Soldatenhänden zu fallen.

Der Wallenstein wäre nicht das alles soldatische Fühlen umspannende Heerstück, wenn neben diesen schrillen Tönen nicht auch das Hohelied der Soldatentreue bis in den Tod, wie früher in den Räubern, in ihm erklänge. Es ist das Sterben der Kürassiere Piccolominis, das sieghaft von ihr zeugt, die einzige freie Mannestat inmitten des düsteren Armeehildes der Tragödie. Schiller hat für die Art, wie er das Regiment dem Verzweiflungsritt seines Führers zum Opfer bringt, leidenschaftlichen Tadel erfahren. ${ }^{35}$ ) Man kornmt seinen Absichten wohl am nächsten, wenn man den soldatischen Gehalt des Vorgangs in den Mittelpunkt rückt. Das praktisch allerdings zwecklose Opfer ist ethisch befriedigend durch die persönliche Treue zum Obersten, die die Schwadronen in ihrem Ende bewähren, durch das eingelöste Gelübde von

Demetrius v. 736 凡. gesehen: . Wer sind denn die? Es ist genein Gesindel. - Nimm sie in Sold, gib ihuen Pferd und Stiefel / Sie schlagen drein gleich wie der beste Mann."

34) VBl.Scherer ${ }^{12}$ S. 597-98: W' erder, der die Szene verwirh, muB hier entgegen Früherem, wo er schon die Cestalten des Lagers im Lichte dieser Mörder sicht. cen grellen Unterschied des Tones von jenen einräusnen. S. 173, Minnr. Einl. 5. XLI betont nur die Cbereinstimmung. keinen Abstand vom Lager.

${ }^{25}$ ) Den Ausfälen O. Ludwigs. Schriften, hrsg. v. E. Schmidt u. A. Stern. 5, 301 schließt sich K. Werder, S. 200 ff., vgl. 195. an. Bellesmann ${ }^{2} 2.111$ ff. unternimmt ausfithrlich den fruchtbsen Versuch, ihnen gegenüber die taktische ZweckmäBigkeit von Piccolominis Angriff zu erweisen. 
ihrer Reiterpflicht, lieber umzukommen als den Führer sinken zu lassen. Die Gesinnung der erlesensten wallensteinischen Schar, langhin vorbereitet, mußte die Weihe der Tat empfangen. Den Einwand des nutzlosen Menscheneinsatzes erhebt Schiller bei einem parallelen, bloß gedachten Fall aus Buttlers Mund selbst und schlägt ihn durch ein einfaches Wort Gordons nieder: der Tod in der Pflicht ist der soldatisch ehrenvolle und befriedigende, gleichviel was er nach außen wirkt, selbst wenn er umsonst gestorben wäre. Nur ein Schritt trennt diese Denkart von der Anschauung, die mit einem: ja gerade dann, in die Poesie des verlorenen Postens ${ }^{36}$ ) führt. Die weite Auffassung der Tragödie knüpft das Geschick der Kleinen überall an das der Großen an. Die Truppen gehen mit den Führern. So hält es auch Shakespeare, bei dem die Heeresmasse fast durchweg als stummes Werkzeug das Schicksal der hervorragenden Heeresfürsten teilt. Scharf drückt Schillers Bastard von Orleans diese aristokratische Gliederung aus, die in der historischen Tragödie mehr auf künstlerischer Notwendigkeit als politischer Überzeugung beruht, monarchisch gefaßt, aber soldatisch gemeint, unmittelbar auf den Krieg bezogen: „Für seinen König muß das Volk sich opfern, / Das ist das Schicksal und Gesetz der Welt. ${ }^{\text {"37) }}$ Diesem Gesetz unterwirft Schiller auch das Tausend tapfrer Heldenherzen, die dem kühnen Führer kühn in den Tod folgen.

Es gehört zu der restlosen architektonischen Organisation des Stoffes, daß die drei militärischen Welten der Gemeinen, der Führer und endlich des Feldherm in ein aufsteigendes Nacheinander gegliedert sind. Nach der Exposition der niederen Sphäre im "Lager" erfolgt diejenige der höheren innerhalb der Generalität, wesentlich der Inhalt der Piccolomini-Akte, mit dem Mittelpunkt in der Bankettszene. Darauf setzt, mit dem dritten Akt der Gesamttragödie, der Gefangennahme Sesins und der Unterhandilung mit Wrangel, das eigentliche Feldherrndrama ein.

Der Kreis der Generale wird allgemein mit dem Kreis der Soldatentypen des Lagers in Rapport gesetzt. ${ }^{38}$ ) Aber die Entsprechung ist nicht scharf und

s8) Tod 2723 ff.; Bellermanns Beweisführung ${ }^{12}$, $111-13$ vermengt in diesem Vers Cordons die einfache, um den Ausgang unbekümmerte Soldatenpflicht mit dem Nutzen des Sichopferns. den er S. 111 als entscheidendes Kriterium hinstellt; vgl. etwa die Schlußrede von Rostands Cyrano de Bergerac V, 6: ,Mais on ne se bat pas dans l'espoir du succès! / Non! non! cest bien plus beau lorsque ceat inutilel"

$\left.{ }^{87}\right)$ Jungfrau v. 844 f.; vgl. Braut v. M. v. 181 f., wo der Chor die Gleichgültigkeit der Gründe des Kampfs für den schlichten Gefolgsmann ausspricht: , Aber wir fechten ihre Schlachten" usw.

${ }^{38}$ ) Zuerst von K. Hoffmeister, Schillers Leben, Geistesentwicklung und Werke, Stuttgart 1838 f., 3, 376 f. Scherer ${ }^{12}$ S. 595; Minor, Einl. 5, XLII, vgl. Anmerk. S. 384; Berger 2. 405 f. Bellermann 2,119 wendet ein, daB Detailzüge nicht stimmen. Am besten charakterisiert die Generale Kühnemann ${ }^{3}$ S. 452 ff, besonders glücklich den Kontrast Isolani-Buttler, S. 453. 
kann es nicht sein. Ein irgendwie rechnerisches Verfahren, das die Personen des "Lagers" in den "Piccolomini" gewissermaßen avancieren ließe und dieselbe Charakterfolge im höheren Stand wiederholt hätte, lag Schiller natürlich fern. Uber den Parallelen dürfen wichtige Unterschiede der Gesamtauffassung nicht vergessen werden. Mit dem Eintritt in den höheren Lebenskreis muß viel mehr Explikation realer Verhältnisse geleistet, das militärisch-politische Getriebe einer kompliziert verzahnten Welt geschildert, gehaltene Staatsaktion gegeben werden, wo das unbeschwerte Lager, ein freies Dichterkind Schillers, es mit dem menschlichen, das ist hier soldatischen Kern, allein zu tun hat. Für die eigentliche Soldatenbegeisterung, für den Adel des Handwerks war dadurch weniger Raum, und nach der Art, wie Schiller die Generalität gebildet hat, kann man vollends sagen, daß der friedländische Staat nach oben viel schlimmer aussicht als unten. Auch darin tritt der optimistische Ton des Lagers und die Verdüsterung in der Tragödie wieder zutage. Aus der Charakterisierung der Führer allein wüßten wir von dem Ethos der wallensteinischen Schöpfung viel weniger, denn sie sind in der Tat, außer Max, Realisten, minder hochgenommen in ihrer Berufsauffassung als etwa der holkische Jäger. Vom freien Sicheinsetzen, von Genuß des Lebens im Wagen ist kaum die Rede, wenn auch Buttler im Eingang eine Brücke zu Gesinnungen des Lagers hinüberschlägt. Von eigensüchtigen Zwecken, vom kleinlichen Nutzen wird diese Welt regiert, und niemals könnte der Chor der Generale in das Reiterlied der Gemeinen einstimmen, das dem Hohen und Erhabenen des Kriegsstandes gilt. $\mathrm{Zu}$ der geistigen Verfassung treten die äußeren leiblichen $U_{m}$ stände. die Schiller unterstreichend genutzt hat. Es sind die Chefs der Natur der Sache nach ältere, zumeist gesetzte Herren, deren Sinn wohl noch etwa nach dem friedländischen Saus und Braus steht, aber mehr im bequemen Lehnstuhl beim Gastmahl, als im Sattel. Jedenfalls fehlt ihnen insgesamt - denn neben der Behäbigkeit eines Tiefenbach soll die stahlharte Erscheinung Buttlers, soll das rohe Draufgängertum lllos nicht vergessen sein - das Jugendliche, das den Soldaten macht, das frisch kreisende Blut, woraus die Begeisterung quillt, die Fülle der Kraft, die sich unbedachtsam wegwirft, kurz gerade das kriegerisch Gloriose der jungen Gesellen. Eingedämmt in Zweck und Ziel haben sie, zwiefach gealtert, mit der körperlichen auch die geistige Haltung verändert. Diener ihrer Gurgel und Tasche in der unteren, ihres Ehrgeizes in der mittleren, ihres Kaisers in der obersten Schicht, wo der kühl rechnende Politiker und Hüter alter Ordnungen den Soldaten völlig verdrängt; nicht Kriegsleute, die als höchstes Gut, roher oder edler, im Soldatentum die Freiheit des Mannes suchen.

Als einziger Führer gehört Max Piccolomini, nach außen im Alter, nach innen der Auffassung nach, dem begeisterten Kriegerstand zu. Die Beziehung 
zwischen dem Kürassier und ihm ist die durchgreifendste. Er aber, zwischen Mars und Venus geteilt, führt zum Ärger aller gutgläubigen Martismänner neben andern auch recht unkriegerische Reden und würde sich allein, ohne den festen Untergrund seiner Kürassiere, ins Schwärmerische verlieren. Selbst bei ihm erweist sich, wie wenig kongruent die Charakteristik der Führer mit derjenigen des Lagers ist. Viel zu beschäftigt mit seiner Liebe und durch sie völlig gewandelt, könnte er am allerwenigsten für die männische Selbstherrlichkeit des freien Soldaten in Anspruch genommen werden, die der Kürassier, ledig der Würde und Bürde, unbekümmert um zarte Bande und jedes bürgerliche Glück, an den Tag legt. Der Glanz kriegerischer Größe, der auf der Gestalt des jungen Obersten liegt, quillt mehr aus seinem Reitertod als seinem Leben.

Für die Auffassung der Generalität spricht am deutlichsten die Hauptszene, worin Schiller sie - in der großen Audienz hat der Feldherr fast allein das Wort - versammelt vor Augen führt, das Bankett. Hier steht die Soldateska in ihren höchsten Würdenträgern bloß, ohne daß bejahende Züge das Gegengewicht hielten. Der Dichter spart die Realismen bis auf Tiefenbachs Rheumatismus aus dem pommerschen Winterfeldzug und das Kreuz des Analphabeten, und selbst das in der Tragödie seltene komische Element nicht, ${ }^{39}$ ) um eine reiche Anschauung ihrer inneren Verfassung zu geben. Viel schlimmer als unter dem Marketenderzelt des Lagers haust in den Prachtsälen das Laster des Weins, dem die halbe Generalität untertan ist; die Tragödie stellt Gruppen von Betrunkenen dar, während das Vorspiel diese minder lichte Seite des Soldatenlebens an einem Rekruten nur andeutet. Bedenklich behauptet sich deutsche Trinkfestigkeit gegen die Welschen, grell endet ein blitzender Degen, Völlerei und Rauferei im Verein, das wüste Gelage. Das Geschlecht, das sich nicht anders freuen kann als bei Tisch, die Gesinnung, die ein Illo später (Tod IV, 7) in der Trunkenheit trügerischen Erfolgs barbarisch äußert, in Ansehung der Rangdifferenz etwa derjenigen der Mörder gleich, wird scharf gezeichnet.

Das Führerstück gibt den Blick auf das Heeresbild, das im Lager von unten her gewonnen ist, von oben herab frei. Einzelne Hauptpunkte kehren von der höheren Sphäre aus betrachtet wieder. So nimmt die gehobene Schilderung des vom Belt bis zur Etsch gewaltig geeinten friedländischen Heeres aus dem Munde Buttlers das auf, was der Wachtmeister, volkstümlich exemplifizierend, dem gemeinen Manne vordemonstriert. ${ }^{40}$ ) Anderes wird

$\left.{ }^{39}\right)$ Vgl. Minor, Säkularausg. 5. XLI.

40) Lager Sz. 11 v. $724-808$; Piccol. I, 2. Lessing an Gleim 12. Mai 1759: ..Und war Keith kein Preuße, weil er ein Schotte von Geburt war? Einerlci Kriegszucht, nicht einerlei Himmelsstrich macht im Soldatenstande den Landsmann." 
verschärft und erst jetzt in seiner vollen Bedeutung ermessen. Die Härte des Disziplingesetzes, das gegen den Obersten Suys in höchster Zuspitzung, weil er einen kaiserlichen Befehl befolgt, auf Tod erkennt (Piccol. II. 7), klingt in den Worten des Jägers von dem einzigen Soldatenvergehen, fürwitzigem Widerspruch gegen die Order, bloß vor.

Erstaunlich wird immer, besonders nach Schillers eigenen Äußerungen über das ihm Fremde dieser Welt, die erschöpfende Erfassung der soldatischen Dinge bleiben, die Art wie der gesamte Heeresmechanismus, nach außen und innen, nach seinen Formen und seinem Geist, lebendig gemacht wird. Man würde erwarten, daß dem Poeten, der sich dem militärischen Wesen entwachsen fühlt, den in Karlsbad österreichische Militärs interessieren, weil sie ihm neue Ansichten des Standes für das geplante Stück geben, dem Dichter, der während der Arbeit auf das Urteil eines einfachen Husaren über sein Reiterlicd und sein "Feldstück" gespannt ist, ${ }^{41}$ ) mehr der intuitiv gewonnene Gehalt des Lebenshrcises, als seine nur dem Eingeweihten zugängliche, spezifische Atmosphäre zu Gebote stünde. Schillers Gestaltung dringt aber auch dazu vor und beherrscht als echteste Soldatendichtung das militärische Dasein in scinem ganzen Umfang. An poetischer Bedeutung stehen natürlich die Partien obenan, die den Kern des Kriegsstandes treffen, dichterische Formungen wie das großartige Feldherrnwort "Ein ruheloser Marsch war unser Leben", das unter dem militärischen Bild alle Mühsal des Standes begreift, oder das schlichtere vom Sold, der dem Soldaten werden muß, weil er danach heißt. Konziser ist die staunenswerte Heeresorganisation, die vollkommenste menschliche, kaum je gefaßt worden als in Questenbergs Antithese vom hohen Geist der Ordnung, durch die der Krieg, weltzerstörend, selbst besteht. ${ }^{42}$ )

Für die Dichtung ist das kavalleristisch wilde Tempo in der brausenden Rede des zweiten Jägers wichtiger als die öfter wiederkehrende Schilderung von Attacken. Die Kraft ihrer Vergegenwärtigung und die Echtheit der Farben sei darob nicht vergessen, und nicht übersehen, wie Schiller dieses Gefechtsmotiv abwandelt. ${ }^{43}$ ) Mit derselben poetischen Kraft sind andere Schlachtereignisse geformt, ctwa das Ringen bei Nürnberg, wo sich der nie gehemmte Angriff Gustav Adolfs an der eisernen Festigkeit des Fricdländers bricht, oder

4) Gervinus ${ }^{5}$ 5.532: [Carolinev. Wolsogen], Schillers Leben 2, 85 f.: An Kömer 18. Juni 1797: Jonas 5, 200 u. 528.

42) Tod 1928: Piccol. 1151 f.: Piccol. 86 \&.

4) BildmàBig für das hemmungslose Dahinstürmen des Kriegers über den Bürger und Bauern. von der sieghaften Empfindung des einhauenden Reiters aus: Lager 978 ff.; als Alperaum Wallensteins, mit der Erstickungsvorstellung des Cherriltenen: Tod 926 ff.; als realer Cefechisvorgang beim Ende Piccolominis (Tod 3025 f.), den der Dichter nicht anders als unter den Hufen seiner eigenen Rosse umkommen lassen wollie (Gespräche. Leiprig 1911, S. 282 u. Minor. 
das Furchtbare des Ortskampfes, der nur Raum zum führerlosen Würgen läßt. Ebenbürtig werden die Lagerbilder gegeben, jene meisterliche Schilderung Oktavios vom Emporwachsen der leichten Zeltstadt zu ihrem Eintagsdasein, abschließend mit der Stimmung verödeter Biwakplätze, und die gefühlsschwere Zeichnung des nächtlichen Heerlagers mit düster brennenden Feuem und einförmigem Rundenruf durch Wallenstein. ${ }^{44}$ ) Scharf erfaßt Schiller das Unpersönliche, Maschinenmäßige des Dienstes, nicht bloß in seiner Wirkung auf das empfindsame Gemüt, auch in der Empfindung des wackeren Subalternen, der in seiner Enge gelernt hat dem ,schönen menschlichen Gefühl“ zu entsagen; weiter in dem Fernblick des Feldherm, der in der Heereswoge nur die Fahnen, nicht das einzelne Haupt unterscheidet und durch blinden, eisernen Befehl regiert. ${ }^{45}$ ) Im intimen soldatischen Bezirk fällt ein so glückliches Wort wie das des Lagers vom Korporal, der auf der Leiter zur höchsten Macht steht, wird der spezifisch militärische Korpsgeist hervorgehoben, und in der obersten Sphäre, gesättigt mit tragischer Ironie, die Waffenkameradschaft angerufen. ${ }^{46}$ ) Erschöpfend gibt Wallensteins Klage über den Verrat seines nächsten Waffengenossen jenes Verhältnis wieder, das nur die innige Lebensgemeinschaft im Feld, in Gefahr und Tod und den Kleinigkeiten des Daseins schafft; ergreifend, weil sich der doppelt Betrogene damit arglos dem alten „Kriegsgefährten "47) Buttler ans Herz wirft.

Säkularausg. 5, 419), um diese Todesart dann leitmotivisch zu verwerten: 3109 f. u. 3179 f., die vielumstrittenen Verse Theklas vom Los des Schönen auf der Erde; vgl. darüber Berger ${ }^{5}$ 2, $428 \mathrm{f}$. u. 788.

44) Piccol. $1040 \mathrm{ff}$;; Tod $2225 \mathrm{ff}$. - Piccol. $490 \mathrm{ff}$.; Tod $900 \mathrm{ff}$.

45) Piccol. 526 ff.; Tod $2507 \mathrm{ff}$; $1895 \mathrm{ff}$.

40) Lager $434 \mathrm{f}$. Der verwandte, Napoleon zugeschriebene Ausspruch vom Marschal'ssiab im Tornister (eigentlich: in der Patrontasche), den Bellermann dazu beibringt, ist erst aus dem Jahr 1819, aus dem Munde Ludwigs XVIII. bezeugt (Büchmann, Geflügelte Worte ${ }^{25}$, Berlin 1912, S. 469). Korpsgeist im ganzen, als friedländisches Heer: Lager $308 \mathrm{ff}$., $795 \mathrm{ff} ., 1027 \mathrm{ff}$.; Piccol. 231 ff. und häufig; innerhalb der Regimenter: Lager $194 \mathrm{ff} ., 211 \mathrm{ff.} 672$ ff.; Tod 1836 f. Kameradschaft: Tod 1689 ff., vgl. Piccol. 887 f.; Jungfrau 1812 ff.

4i) Das DW'b belegt den Ausdruck, den Campes Wörterbuch als Neuschöpfung (Schillers) kennzeichnet, außer der Wallensteinstelle nur aus Vossens llias (1793). Er scheint von Klopstock gebildet, als terminus technicus für die unmittelbare Gefolgschaft des germanischen Fürsten,

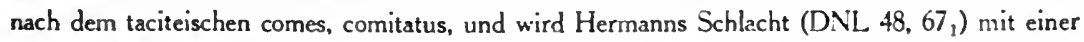
erläuternden Anmerkung eingeführt: „Spielen denn die schnellen Jünglinge, meine Kriegsgefährten, mit ihren Lanzen?”; vgl. S. 114 $4_{22}$ : „Wo sind meine Kriegsgefährten?" Schönaichs Neologisches Wörterbuch kennt das Wort noch nicht. Klopstock übersetzt die Tacitus-Stelle (Germania, cap. 13 u. 14) mit: „Das Ansehen eines Fürsten, sogar sein Ruhm bei den benachbarten Völkern wird dadurch sehr vermehrt, wenn er viel und tapfre Kriegsgefährten hat" "; Tacitus : „,si numero ac virtute comitatus emineat" usw. - Zschokkes Abällino, 1795, I, 5: „Nun, lieber, 
Für die Crenzen der Sachkunde Schillers wird angeführt, daß er im Lager kaum cine sichere Vorstellung vom Unterschied der Waffengattungen an den Tag lege. $\left.{ }^{18}\right)$ Aber auch in diesen Dingen trifft er durchaus den Kern, wenn er auch mit oder ohne Willen am Äußerlichen vorbeigeht. Bei den flüchtig gezeichneten Typen, dem Ulanen, den Dragonern, lag keine Veranlassung vor. auf ihre waffentechnische Eigenart Bezug zu nehmen. Der Einwand zwar, daß die Wege noch nicht praktikabel sind, wïrde dem Konstabler, der mit scinem Geschütz auf die Straßen angewiesen ist, besser anstehen als dern Wachtmeister, einem Anzehörigen der berittenen Waffe, und diesen Wachtmeister selbst möchte man nach seiner gemessenen Gravität, die dem holkischen Saus und Braus entgegentritt, cher als Infanteristen ansprechen. ${ }^{49}$ ) Dagegen ist das Reiterliche, das im Schlußchor zum Symbol des Soldatischen überhaupt wird, in der Stufenfolge der holkischen Jäger und des Kürassiers in seiner Wurzel erfaßt und die kavalleristische Losung: „Und auf das Gehudel unter mir/Leicht wegschauen von meinem Tier". so fachmännisch wie möglich mit dem Stoßscufzer geplagter, schwer bepackter Infanteric kont rastiert: "Lustiger frcilich mag sich's haben, / Uber anderer Köpf" wegtraben".

\section{Das Kriegsbild.}

Wie in der Zeichnung der Waffengattungen nach ihrem inneren Gehalt. weniger nach Nummer und Abzeichen des Regiments, so verhält sich Schiller zu dem toten Ballast und Notizenkram der Überlieferung überhaupt. Wir besitzen über sein Verhältnis zur kriegshistorischen Gelehrsamkeit das wichtige Zeugnis Ludwig v. Wolzogens, ${ }^{50}$ ) das den Tatbestand des fertigen Wallenstein durch einen Blick in die Werkstatt des Dichters ergänzt. Schiller geht mit einem Offizier zu Rate, um für die Schilderung von Max Piccolominis Tod cin lebhaftes Bild einer Schlacht des Dreißigjährigen Krieges zu gewinnen. Aber er schlägt die Hände über dem Kopf zusammen, als ihm der kundige Thebaner in guten Treuen mit der ganzen artilleristischen Rüstung des 17. Jahr-

alter Kriegsgefahrte, lustigl" Tieck, Genoveva, Schriften 2. 122: "W'as ist dir, lieber Kriegsgejährte Siegfried?" u. 2. 129: .. H'ie, sehn wir uns denn wieder. Kriegsgefährte?" Bei Schiller selbst weist Köster. Sch. als Dramalurq. Berlin 1891. S. 90 das ..kernige und zugleich vertrauliche Wort" mchriach im Macbeth nach. Goethe. Pandora v. 617: . Wie Kriegsgefährte den Schüzen docks / Mit dem Schild."

4) Minor. Säkularausg. 5. XLLIII.

4) Seine und des Trompeters Zugehörigkeit zu eisuem der Regimenter Terzkys zu RoB (v.1017) wird beiläufig im Text (v. 113) gestreift, geht a!so nich: cinzig aus dem l'ersonenverzeichnis, vgl. v. 37 - Karabiniere sind reitende Schützen - hervor.

we) Memoiren des Generals L. Freih. v. Wolzozen. Leipzig 1851. S. 14; abgedruckt Gespräche S. 282; vgl. Minor. Säkularausz. 5, 419. 
hunderts, großkalibrigen Kartaunen, langrohrigen Kolubrinen (Feldschlangen) und kurzen, schweren Bombarden (mörserartigem Wurfgeschütz) aufwartet und ist über die Zumutung entsetzt, daß er eine Szene, die den höchsten tragischen Eindruck zu machen habe, mit soviel Knall und Dampf anfüilen soll. Der Kriegsdichter verwahrte sich hier gegen den Archivstaub, den der Kriegshistoriker aufwirbelte, und verwarf auch, so berichtet Wolzogen, alle seine Projekte, wie Max aus der Welt zu schaffen sei, ausdrücklich ,,als viel zu kriegswissenschaftlich"; während ein Jakob Maier sich nicht genug tun konnte, sein mühsam zusammengelesenes Wissen vom mittelalterlichen Kriege in seinen Stücken an den Mann zu bringen. Man wird angesichts dieses Gegensatzes kaum mit Otto Ludwig annehmen, daß Schiller für die Kunst, die Vorgänge aus der Ceschichte zu beglaubigen, beim „Fust von Stromberg“ in die Schule gegangen sei. ${ }^{51}$ ) In Maier ist es der Geschichtsfreund, der gegenstandsfreudig den Kriegsapparat der Vergangenheit in Bewegung setzt, im Wallensteindichter der Künstler, der den historischen Krimskrams zugunsten des menschlichen Gehalts zurückdrängt.

Im Botenbericht des schwedischen Hauptmanns, so wie ihn Schiller mehr entgegen als nach den Angaben seines militärischen Beirates gebildet hat, ist das Meisterstück poetischer Bewältigung des Kriegshistorischen und zugleich des Taktischen geleistet. ${ }^{52}$ ) Sorgfältig wird alles Steife der Kostümechtheit,

51) O. Ludwig, Schriften 5, 316. anläßlich Maria Stuart; vgl.Petersen S. 105 f., wo Schillers Urteile über den Fust zusammengestellt sind; über das Historische im Wallenstein das. $107 \mathrm{f.,}$ über das Kostüm 271 f. - Auf eine Berührung des ,Lagers“ (Schilderung des Ersten Jägers von seinen Erlebnissen) mit Maiers Sturm von Boxberg, Mannheim 1778, II, 5 (Tirade des Reisizen Blink über das Treiben im pfalzgräflichen Lager) vurde oben S. 105 hingewicsen. Vgl. zu Lager 270 f.: ,Alles da lustiger, loser ging, / Soff und Spiel und Mädels die Menge“" Sturm S. 40: „Da ging's zu... Die [Lieder] sangen wir, wie geschmiert; die eherne Helme voll des köstlichen Weines gingen im Kreise um, wir soffen weidlich, der Pfalzgraf soff uns vor ... da war euch alle Tag volle Metten, da hieß es, wann der Abt die Würfel auflegt, dann rasselt der Mönch" usw. - Für die Zwischenrede des Wachtmeisters v. 262: .JJa, es war ein gottesfürchtiger Herr" vgl. diejenige Breidmanns: „Er ist ein hochweiser Poeta“ usw., für seine Frage v. 302: „Und wie lang denkt Ihr's hier auszuhalten?" dessen ....,Warum bliebt ihr dann nicht bei den Pfalzgräflichen?" Zu v. 267 „So ritt ich hinüber zu den Ligisten“ Blinks ,,ich mußte also umsatteln und weiter reuten". - Uber Goethes erfolglose Aufführung des Sturms vgl. Werke 35, 50; Petersen S. 105 Anm. 6.

i2) Tod IV, 10; der Tatsachengehalt wird in dem trockenen Bericht Terzkys IV, 4 und den Ergänzungen Illos IV, 5 vorweggenommen, ferner IV, 5 u. 9 die heftige Gefühlswirkung gezeigt. so daß die Erzählung selbst, befreit von der groben sachlichen Spannung und lauter Reflexwirkung, sich in gehaltener Ruhe ausbreiten kann. Auch Racine (Phèdre V,6) läßt die Nachricht vorangehen und schließt zuerst eine kurze Klage Thésées an; Schillers Anlage ist ungleich reicher. Demselben Verfahren folgt der Gefechtsbericht Raouls, Jungfrau I, 9 mit Vorausnahme der 
alles was der Erklärung bedürfte und damit an kulturgeschichtliche Lektion erinnerte. vermieden. ${ }^{53}$ ) An technischen Ausdrücken bleiben die Piken des Fußvolks und die früher (v. 1922) schon genannte Partisane, die Piccolominis Pferd durchstößt, vereinzelt. Wir wissen durch Wolzogen, daß der Dichter dem Geschütz. und der Handfeuerwaffe den Anteil am Gefecht aus bewußter Absicht verwehrt, weil er dem heroischeren Nahkampf ohne Pulver und Blei den poetischen Vorzug gibt. ${ }^{51}$ ) Nur mit ein paar Strichen, frei von gelehrter Pedanterie, wird die Beschaffenheit der schdedischen Feldbefestigung gezeichnet: Verhack und Graben können jedes Lager umsäumen, auch der Vortrab gehört zu den allgemeinsten Begriffen der Kriegführung. Schiller hält demnach mit Rücksicht auf das Poetische peinlich Distanz von der historischen Realität. Er erreicht die starke Anschaulichkeit des Gefechts nicht auf dem Wege der geschichtlichen Beglaubigung, sondern durch straffe, bildmäßige Organisation. Er drängt den taktischen Verlaúf, entbehrliche Zwischenstücke vernachlässigend, in ein paar Hauptmomente zusammen und setzt diese auch in der äußeren Berichtform durch Pausen, die der inneren Cliederung entsprechen, voneinander ab. Die erste Versreihe gilt dem unversehenen und ungehemmten Ansturm der Pappenheimer, ihr bestimmender Eindruck ist der .volle Rosseslauf", der den fliehenden Vortrab vor sich hertreibt und die einbrechenden Schwadronen widerstandslos über Verhack und Graben weg ins Feindeslager trägt. Die zweite Situation, durch den knappsten Übergang gewonnen, zeigt die ('berkühnen mit schroffem Umschlag in gesammelter Bildkraft ,.gekeilt in drangvoll fürchterliche Enge“, dann erfolgt der befreiende verderbliche Sprung mit der neuen zügellosen "Cewalt der Rosse“ und schließlich der grimmig wütende Endkampf. Für das bildhafte Zusammenfassen in die entscheidenden Phasen, für die poetische Abbreviatur der Gefechtsereignisse ist besonders charakteristisch, wie die ganze schwedische Gegenaktion

Siegespost, noch enger Mörners Erzählung in Kleists Hornburg II. 4 mit vorangesteller Todesbotschatt.

3) Interessant ist in diesem Zusammenhang der von A. Kö̈ster. Sch. als Dramaturg S. 88 f. vgl. 104 geführte Nachweis, daß die Vorstellung des 30 jähr. Krieges die Phantasie Schillers so stark beherrscht, daß sie unwillkürlich auch in die bald nach dern Wallenstein untemommene Macbeth-Bearbeitung eintritt (Bericht des Treffens im Eingang).

5) Dieser Sachverhalt ist im Stück noch daran erkennbar, daßs Schiller das Schießen als bequemes Motiv einleitend - an Stellen, wo die Rücksicht auf den gehobenen Ton des Todesberichts noch nicht gegeben war - dennoch einsctzt: das Cefecht ist gehört worden: v. 2619 "Ein starkes Schießen war ja diesen Abend": 2652 gar ..Zwei Stunden hat das Schießen angehalten" - während nach denn Bericht des Hauptmanns im ganzen Verlauf auch nicht ein SchuB fallt: es hälte 2. B. nahegelegen, den Vortrab (3021) alarmierende Schüsse abgeben zu Lassen. Uber Keliner Annahme zweier Schlachten bei Neustadi vgl. Bellermanns Anm., Werke 4, 358. 
in einem einzigen Satz erschöpft wird. Man hat gehört, daß die Schweden eben noch Zeit fanden, sich aufs Pferd zu werfen, dann treibt ihre gesamte Reiterei, das vereinzelte Regiment beidseitig umfassend, den Feind zum Graben zurück, über dem der Pikenrechen des Fußvolks starrt. "Schnell geordnet" ist das einzige, was wir von diesem erfahren. Der Dichter braucht es hier für das Bild der beklemmenden Enge und für Maxens Todessprung, nimmt sich aber keine Zeit mehr auszuführen, wie es hingekommen sein mag. Vom Augenblick an, wo der Führer hervortritt, verengt sich der Gesichtskreis ganz auf ihn, soll die taktische Bestimmtheit die dichterische Wirkung nicht mehr durchkreuzen und jener poetische Femblick herrschen, der es auch nicht verstattete, daß die Partisane des Schweden den jungen Piccolomini selbst statt des Pferdes traf, oder daß die Art seiner Verwundung irgend näher beschrieben wurde. Weder bei seinem Tod noch im abschließenden Gemetzel darf die Vermittlung des Sachlichen über Andeutungen hinausgehen..$^{55}$ )

Trotz aller formalen Einschränkung und der Sorglichkeit des Dichters gewährt der Wallenstein das reichste Kriegsbild der ganzen Entwicklung. Es erwächst aus jener Eigenart des dramatischen Dialogs bei Schiller, die als Rhetorik viel angefeindet ist. Der Dichter geht über das, was Situation und Charaktere unmittelbar erfordern, immer wieder hinaus und erschöpft im Wort die einmal ergriffenen Dinge. So wird die Welt des Krieges allseitig bis zu Widersprüchen im einzelnen ausgeführt und selbst ein und der andere Verstoß gegen die dramatische Charakteristik in den Kauf genommen. Die ungezügelte Pathetik, die in den Räubern solche Unstimmigkeiten im Gefolge hatte, ist zwar gebändigt, aber die Kunstart im Grunde sich treu geblieben. Auch der reife Schiller überschreitet im Schwung seiner Diktion die Grenze, die strenge Ökonomie der dramatischen Rede zieht. Das auffallendste Beispiel ist jene gehobene Schilderung von der Heimkehr des Heers in den Frieden, die nur im Munde eines jungen Reiterobersten zu weich klingt $;{ }^{56}$ ) ebenso wie die durch

$\left.{ }^{35}\right)$ Der Gefechtsverlauf würde sich so darstellen, daß die schwedische Infanterie, während der Reiterkampt innerhalb des Lagerumkreises tobt - die Vorstellung von Zelten u. dgl. ist nicht gegeben, vielmehr ein freier Raum für die Reiteraktion angenommen - den Graben, der das Lager (v. 3027) einfriedigt, umzieht und von außen den Ring um die Pappenheimer schließt. Zurückgedrängt, wirft sich Max umwendend im Sprung über den Graben auf sie, und hier würde den überlebenden Pappenheimern, deren wuchtige Attacke hoch über ihn und also auch das schwedische Fußvolk hinweggeht, wohl Rettung im Durchbruch winken, wenn sie sie nicht (v. 3056) verschmähten; in der folgenden Ausdrucksweise, wonach ihre Vernichtung bis auf den letzten Mann sich aus ihrem ,starren Widerstand“" erklärt, scheint dem Dichter allerdings ein neues Eingeschlossensein und wieder die Möglichkeit der schon angebotenen Übergabe vorzuschweben.

s6) Piccol. 534 ff.; .,O schöner Tag“"; vgl. Tieck, Kritische Schriften 3. 55, wogegen Hoffmeister 4, 54 die Stelle zu verteidigen sucht; Werder S. 191 f.; allgemein und einseitig über das Rhetorische O. Ludwig. Schriften 5, 298 ff.; vgl. Berger 2, 445 u. 788. 
sie erweckte Rührung dem kaiserlichen Kriegsrat, der in kühler diplomatischer Mission begriffen ist, nicht wohl ansteht. Die Ausbiegung von der Wahrscheinlichkeit, nicht die einzige in der Figur des Max, wird dadurch ersichtlicher, da $B$ dicht daneben die vortrefflich in die Charakteristik verfugten Kriegsgleichnisse Oktavios stehen, das Bild vorn fürchterlich geraden Pfad des Kanonballs, der den Weg der Ordnung und noch inehr den eigenen krummen Weg Oktavios durchschneidet, das Bild der Zeltstadt als des Augenblicks erstaunenswertes $\mathbb{W}$ under, symbolisch für die großen schnellen Taten der Gewalt, die wiederum dem Wesen des alten Piccolomini so fremd sind. ${ }^{57}$ ) Aber der Dichter brauchte in der kriegserfüllten Exposition, aus der Gruppe der Generale und Politiker, den Ausblick in die gegensätzliche, in verklärender Ferne erschaute Friedenswelt. Es ließen sich eine Reihe von Fällen ähnlicher Art aufzählen. Derselbe Illo, der im ganzen zu der niedrigsten Klasse der Generalität gehört und wenn einer, als Clücksritter seine ,eigenen kleinen Interessen “ verfolgt, findet plötzlich - hier weil es die Situation verlangt - die höchsten Worte für die ideelle Einheit des friedländischen Heers. Derselbe Wallenstein, von dem bckannt ist, daß er sechzig- statt zwölftausend Mann warb, um ihren Unterhalt durch das Gewicht der Masse zu erpressen, kann das Unschöne gewaltsamer Requisitionen beklagen. ${ }^{58}$ )

Schiller selbst war sich wohlbewußt, daß seine Personen ungleich mehr ausdrücken, als für die dramatische Handlung schlechthin vonnöten wäre. Nachdem er in ersten Niederschriften von Szenen eine gewisse Trockenheit zu spüren glaubte, überließ er sich, seit der jambische Wallenstein beschlossen war, dem Zug der Verse. Er fand schlieBlich die Rechtfertigung der Breite, womit sich seine Figuren herauslassen, im Beispiel der Alten und dem symbolischen Charakter der poetischen Gestalten, die zugleich ,immer das allgemeine der Menschheit darzustellen und auszusprechen haben ". ${ }^{59}$ ) Hier liegt der Schlüssel für die umfassende Gestaltung der kriegerischen Welt und auch für ihre gelegentlichen Unstimmigkeiten. Es entspricht dem schillerischen Kunstwillen, da $B$ der Dialog jede Möglichkeit nutzt, ihr poetisches Gesamtbild zu erweitern, und so im Verlauf der Tragödie ihren ganzen Gefühlsgehalt ausmißt. Das rednerische Element, das die breit einherflutenden Versreihen eines Max, Buttlers und des Feldherm selbst über Heer und Krieg trägt, dient überall neben dem nächsten Handlungszweck diesem Ziel. Das Allgemeingültige. Uberindividuelle soll zugleich mit dem dramatisch Bedingten zur Aussprache

97) Zu Piccol. 468 ff. vgl. Tod 1192: zu Piccol. 486 f. vgl. Tod 675, wozu Bellermann die Devise Oktavios ..Gradatim” beibringt.

s") Piccol. 929 ff.: Lager 750 fl. u. Piccol. 1145 f.

:9) An Cocthe 2. Okl. 1797. I. Dcz. 1797. 24. Alug. 1798; Jonas 5. 270: 292: 418. 
kommen. Ein Organ, es ohne die dramatische Fessel auszubreiten, schafft sich Schiller später im Chor der „Braut von Messina“, der diese Tendenz seiner Kunst am deutlichsten, weil in der einseitigsten Ausprägung zeigt. Dort wird die Kontrastierung von Krieg und Frieden in das Zeitlose gehoben und die historische Zeichnung im Wallenstein bis zur Allegorie verflüchtigt. ${ }^{60}$ ) Maxens Bild vom Frieden erscheint dagegen konkret, mit Zeitfarbe gesättigt. Im Grunde herrscht aber auch in ihm, ähnlich wie wir es im Kampfbericht des Schweden gefunden haben, der überzeitliche, von geschichtlichen Zügen losgelöste Gehalt vor. Nur etwa die angeführte Petarde legt als waffentechnischer Ausdruck das Jahrhundert fest, die Vorstellung von Tor und Wall und frohem Heimzug mit klingendem Spiel und wehenden Fahnen hat für viele Jahrhunderte Geltung, die Szene des Empfangs für alle Zeiten.

Den realistischen Anspruch, der Stellen wie diese, die fast ausschließlich dem Gesamtbild dienen, verbieten und von Heerführern vor allem eine knappe Militärsprache fordern müßte, weist Schiller ausdrücklich zurück. ${ }^{61}$ ) Nicht die Wirklichkeitsnähe, sondern die Wirklichkeitsferne hat die klassische Kunst ehrlich zu betonen, und man erkennt ihr Prinzip besonders deutlich darin, daß der Dichter der breiten und vollen Behandlungsweise nachrühmt, sie dämpfe zugleich das Gewaltsame heftiger Situationen. Die besten Vergleichspunkte zu den großen Sprechstellen der Generale bieten die soldatischen Diskussionen in Kleists Offiziersstück. Auch in ihnen ist zündende Beredsamkeit, aber, dem gemeinsamen Blankvers zum Trotz, in eine ganz andere Redeform gefaßt. Das Prachtgewand der Diktion im Wallenstein weicht einer dichten, gehackten, charakteristischen Sprache, die neben das poetische Bild den Ausdruck des militärischen Alltags setzt und an der realen soldatischen Straffheit festhält : ein vielfach gebrochener Wassersturz neben dem majestätisch fließenden Strom.

Die Liberalität, womit in der Soldatenwelt des Wallenstein das Wort gehandhabt wird, trennt seine Kriegserfassung scharf von derjenigen Shakespeares. Ein ähnliches Ergebnis, die erschöpfende Gestaltung des militärischen Bezirks, wird von beiden Dichtern auf sehr verschiedenen Wegen gewonnen. Das schildernde, beschreibende Element mußte in der Tragödie

$\left.{ }^{60}\right)$ Braut v. M. 872 ff.: „Schön ist der Friede. Ein lieblicher Knabe“ usw. Die Chorrede über den Krieg 880 ff.: „Aber der Krieg auch hat seine Ehre“ usw. gibt im ganzen und einzelnen genau den Geist von Wallensteins Lager, in den Formen der Klassizität, wieder. Vgl. zu „Mir gefällt ein lebendiges Leben" usw. Worte (v. 241 f.; 951 f.) und Auffassung des Ersten Jägers und Kürassiers; zu „Denn der Mensch verkümmert im Frieden“" v. 424 f.: ,.Es treibt sich der Bürgersmann, träg und dumm" usw., und besonders das Reiterlied.

61) An Goethe 24. August 1798; Jonas 5, 418; O. Ludwig, Schriften 5, 317 : „In der Regel sind Soldaten keine Kunstredner"; vgl. Scherer ${ }^{12}$ 597; Kühnemann ${ }^{3} 454$; Berger 2, 444 f. 
Schillers durch die Strenge der Form mächtig gefördert werden. Heer und Krieg waren fast ohne Eigenhandlung durch die Macht der Rede zu bewältigen. Darin lag ein starker Anreiz für rhetorische Behandlung, für die Shakespeares aktionsgesättigte, sachlichere Kriegsdramatik, die mehr die Vorgänge als die Personen sprechen läßt, keinen Raum hat. Schiller steht ihr im Wallenstein im ganzen fern ${ }^{62}$ ) und nähert sich ihr erst wieder in der Jungfrau, wo ihn die Fülle der Kriegsereignisse zu einer Lockerung der Technik führt.

\section{Der Feldherr.}

Alle soldatische Gestaltung der Tragödie, der Unterbau des Lagers, der Umkreis der Führer, ist schließlich Folie der zentralen Person des Foldherrn, ${ }^{63}$ ) Grundlegung seiner Macht, Material seiner Untemehmung. Auf das Bild des gewaltigen Heeresfürsten, der seine Grenze, nach außen schrankenlos, nur in sich selber findet, kam es für den tragischen Knoten vor allem an. Nun trägt aber Wallenstein als Charakter nach der Auffassung Schillers nicht die Züge, die am Feldherrn zunächst zu erwarten sind. Es fehlt ihm gerade die entscheidende Eigenschaft des Führers, der soldatische Entschluß. Er ist ein großer Cunctator, der sich ewig treiben und drängen läßt. Er tritt im Stück kaum als Handelnder, fast nur als Leidender auf, den der Notzwang der Begebenheiten mit sich führt. Dadurch wuchs die Gefahr, die angesichts der Macht des schillerischen Wortes bestand, daß die tatsächliche Erscheinung Wallensteins dem Bild nicht entsprach, das der Dichter aus seinem eigenen und dem Mund anderer von ihm entwarf. Schiller war ihr schon einmal, im Don Carlos, verfallen. Kriegspathetik ohne den dahinterstehenden Charakter und die

ez) Eng ist der Anschluß an Shakespeare nur in cles Mörderszene, außerhalb des Soldatischen. Die Massentechnik des Lagers scheidet sich in ihres strengen Ordnung und dem breit gefabten Dialog charakleristisch von der shakespearischen, tumultuarischen Massenbewegung. Im Motiv berïha sich der Abschied der beiden Piccolomini vor dem .blut gen Krieg, in den wir gehn" (Tod 1276 f.) mit dem Abschied des Brutus u. Cassius vor des Schlacht: ..Ob wir uns wieder treffen, weiß ich niche" (Jul. Cäs. V. 1). - Für die Simplizität der Vorgänge bei Shakespeare gegen die getragene Wortkunst Schilless kann man etwa vergleichen, wie des Antonius Feldherrnautoritäl durch ein schlichles .Cuten Tag. General" der Truppen (Ant. u. Cleop. IV. 4) spricht, diejenige W'allensteins (Tod v. 2264t) in das grandiose ..LaB sehn, ob sie das Antlitz nicht mehr kennen. Das ihre Sonne war in dunkler Schlacht" gefa3t wird. .Des blut gen Tages trohe Vesper" (Piccol. 545) kündigt Antonius mit einern trivial-kräftigen..Wir schlugen sie zu Bett" (IV, 8) an.

6) Eine ähnlich beherrschende Gestalt plante Schiller noch einmal in den Maltesern (An Ifland 19. Nov. 1800. Jonas 6. 215), wo der GroBınesster in seinem Orden, den eine furchtbare Eelagenung von außen und eine Empörung von innen an den Rand des Abgrunds geführt hat. dastehen sollte .,wie ein Hausvaler in seiner Familie, zugleich aber auch wie cin König in seinem Stast, und wie ein Feldherrunter seinen Rittern." 
folgende Tat hatte den Herzog Alba zu einem Großsprecher gemacht, dessen schwerlötige eigene und fremde Charakteristik hohl klingt. Die großen, an sich prachtvollen Worte von dem Feldherrn, der in zwanzig Schlachten dem Tod entgegenging, der auf Erden richtete wie Gott im Himmel, passen schlecht auf den Höfling, der sich an der Seite des tückischen Priesters in Boudoir-Intrigen erschöpft. Für den Mann, der geschaffen war am Ende aller Tage zu kommen, war auf dem glatten Parkett des Hofstückes kein Platz. ${ }^{64}$ ) Von diesem Mißverhältnis kann bei Wallenstein nicht die Rede sein. Selbst der schärfste Tadler seines dramatischen Charakters, Otto Ludwig, ${ }^{65}$ ) muß zugeben, daß der Heeresfürst, der Befehle gewohnte, zur größten Bewunderung hinreiße. Schiller gründet seine königliche Gestalt so fest auf das breite Fundament des Lagers und verleiht ihm ein so hohes Maß gebändigter Kraft und feldherrlicher Haltung, daß sein tatenloses Verharren dem Eindruck nicht schadet. Entscheidend stützt ihn der Zug des Geheimnisvollen, der den Kriegsfürsten im Aberglauben der Armee und auf Grund seines Sternglaubens in den Augen der Zuschauer umwittert.

Es sind zwei Hauptmomente der Tragödie, die es fast allein mit dem Feldherrn Friedland zu tun haben, die Audienzszene der Piccolomini, die ihn auf der Höhe seiner Herrschgewalt, und die Auftritte des Truppenabfalls, die ihn im Augenblick der Krise zeigen. Getragen von der Gunst des Heers, umgeben von einer glänzenden Generalität, als Souverän der größten Kriegsmacht Europas steht Wallenstein in der Audienz den Forderungen des Hofs gegenüber und tritt, auch gestützt auf das verbriefte Recht des Paktes, zum Waffengang mit seinem Kaiser an. Der ganze erste Piccolomini-Akt, alles was in aufsteigender Folge Isolani, Illo, Buttler, der verzweifelnde Questenberg und endlich Max zum Bild des Chefs beibringen, dient in gerader Fortsetzung des Lagers der Vorbereitung dieses Zusammenpralls kaiserlicher Ohnmacht mit friedländischer Macht. In der schärfsten Form schützt der allvermögende Generalissimus seine unbedingte Kommandogewalt im Falle des Obersten Suys gegen jeden Anspruch der Krone, demonstriert er den notwendig souveränen Charakter seines Amtes an dem Beispiel des schwedischen Gegners, des unbesiegten Königs in seinem Heer, und gibt dem Namen des Feld-Herrn die schroffste Ausdeutung: ,Wenn für den Ausgang ich mit meiner Ehre/Und meinem Kopf soll haften, muß ich Herr / Darüber sein." Der Ausgang ist so,

84) Don Carlos v. 3820, vgl. 2798; 1440 f.; Selbstcharakteristik besonders II, 5; dazu v. 858, 878 ff.; 4880. Vgl. Minor, Schiller 2, 585. Albas Kriegsheldentum trägt noch starke Züge vom Titanismus der Geniezeit, von der überschüssigen Kraft eines klingerischen Alcim usw. an sich. Zugrunde liegt die Vorstellung eines Giganten, der das Eherne, schicksalsmäßig Unentrinnbare des Krieges verkörpern soll.

8.5) Schriften 5, 305. 
wie ihn Questenberg voraussieht, zwar nicht offener Trotz, aber für den Kaiser unerträgliches Entgegenkommen, das einen Suys aus „schuld'ger Achtung" begnadigt, und stille Verhöhnung sciner Order durch die Farce der Abdankung.

Schiller läßt den Mann, der hier gegründeter als der Räuber Moor cine Armee in seiner Faust fühlt, noch höher emporwachsen in der Stunde der Entscheidung, als das langbeherrschte Heer seiner Hand entgleitet. Es ist die einzige, die den Feldherrn Wallenstein wirklich handelnd zeigt. Seiner Führerkunst inne, zu stolz sich ihrer über unterlegene Gegner zu bedienen, oder wie ein junger General die Schlacht zu suchen nur um sich zu bewähren, hat ihn der Dichter bereits gegenüber Questenberg gezeichnet. Jetzt muß sich sein Heerfürstentum im Unglück erweisen, bei der Trennung von Haupt und Gliedern des Kriegskolosses offenbar werden, wo die Seele wohnt. ${ }^{66}$ ) Ein ganzes großes Selbstgespräch, der eigentliche Feldherrnmonolog Wallensteins wird aufgeboten, um an dieser Stelle, nach den ersten katastrophalen Schlägen, im Selbstgefühl des Helden seine kriegerische Vergangenheit heraufzurufen, das Bild des Mannes, der schon einmal als Einzelner statt eines Heeres galt, dessen Schöpfungswort sechzigtausend Krieger aus dem Nichts ins Feld stellte. Ebenso geschieht alles, um nach außen das Königliche seiner Führererscheinung bis zuletzt zu wahren. Er allein steht den einbrechenden Hiobsposten und erhebt sich gefaßt über den Verlust der Truppen. Er fordert stolz auf seine Schule den jugendlichen Gegner, der bei ihm den Krieg gelernt hat, zum Probegang mit seinem Meister heraus. Er zieht zum Erstaunen Gordons mit den paar Regimentern, die er aus dem Zusammenbruch gerettet hat, nicht als Gefallener, sondern mit dem alten sieghaften Ansehen des Feldherrn in Eger ein und nimmt dem Subalternen mit gehaltener Würde den Rapport über den festen Platz ab. Er erscheint als die überragende Führerbegabung seiner Zeit schließlich noch in den Worten Illos, der die Diener des Kaisers der Reihe nach verächtlich an ihm miltt. ${ }^{67}$ ) In der Katastrophe selbst, wo mehr das Menschliche als das Kriegerische am Helden zu Worte kommt, leuchtet sein Feldherrntum noch einmal aus der Mörderszene auf.

Als cinziger Auftritt,worin Wallenstein sichtbar seinen Truppen gegenübersteht, hatte die Verhandlung mit der Kürassierdeputation die Macht zu beweisen, die er bis dahin auf die Soldatengemuiter ausübt. Die Aufgabe war umso schwerer, als der Feldherr den Sprechern seines besten Regiments gegenüber eine verlorene Sache führt. Die Lösung mußte aber gerade dadurch, wenn

86) Piccol. 1103 fl.: Ted 111. 13. Für die Charakteristik des Feldhern ist femes wichlig die Szene mit Wrangel Tod 1. 5, wo Wallenstein gegen Gustav Adolf ähnlich aheesetzl wird, wie seine Soldateska gegen dessen Heer: vel. Werder S. 39 f.

6i) Tod 1740 ff.: 2235 ff.: 2456 ff.: 2619 ff: 2791 ff. 
sie gelang, die Kunst seiner Mannschaftsbehandlung ins hellste Licht rücken. Schiller verdeckt das Odiose für den Führer, daß ihn die Truppen über sein Tun zur Rede stellen, mit der größten Sorgfalt und nutzt dazu auch die äußeren militärischen Formen. Es wird nach dem Kommando exerziert, ${ }^{68}$ ) der reglementarische Gruß erwiesen und schließlich, besonders fein, der Stimmungsumschlag nur durch das korrekte „Rechts um“ ausgedrückt. Die Treuherzigkeit, womit die guten Truppen das Ohr des guten Feldherrn suchen, das persönliche Verhältnis, das sie den andern voraus zum Herrn haben und das ihre Kühnheit rechtfertigt, macht seine schwierige Lage vergessen. Der Auftritt hebt sein Führeransehen beim Zuschauer, statt es zu schwächen. Wallenstein seinerseits setzt sich zuerst in seiner Autorität den Leuten gegenüber fest, er mustert sie anfänglich stumm, greift dann nach Kommandeursweise den einzelnen heraus und bewährt das unfehlbare Personalgedächtnis des Generals, das keinen vergißt, der sich ihm durch eine wackere Tat empfohlen.$^{69}$ ) Erst darauf gibt er ihnen zögernd das Wort für ihr Begehren frei. In seiner Antwort nun, die das einzige, was die Reitersleute verlangen, die schlichte Erklärung über den Punkt des Verrats, nicht geben darf, war Raum für Schillers Kunst der Überredung, für ein mitreißendes Stück kriegerischer Rhetorik. Hier konnte der Feldherr selbst, gerechtfertigt durch die dramatische Situation, sich über seine Stellung zum Heer in hohen Worten aussprechen, indem er das Regiment an seinen Vorzugsplatz gemahnte, und den gemeinen Mann durch jene Schilderung des fluchbeladenen Soldatenloses, am Band gemeinsam überstandener Not, vollends zu sich herüberziehen. Die Kürassiere sind mehr als halb gewonnen, als Buttler tückisch den Erfolg zerstört.

Auf die Höhe dramatischer Wirkung führt Schiller seinen Kriegsherrn durch den jähen Umschlag, den der ausbrechende Aufruhr der Truppen in seiner Haltung zeitigt. Die vertrauliche Güte wandelt sich in furchtbaren Zorn, das wortreiche Werben weicht dem eisernen Befehl - dem einzigen gewichtig militärischen, den der Heerführer erteilt. Die Szenen des zürnenden, befehlenden und dann zusammenbrechenden Friedland sind ohne Zweifel seine stärksten überhaupt, Gipfelpunkte für den Wallensteindarsteller. ${ }^{70}$ ) Scharf und schneidend ertönt auf die Sturmdrohung der Pappenheimer das Kom-

${ }^{88)}$ Vgl. dazu Minor, Säkularausg. 5, 411-12.

69) Die Parallele zu Egmont Akt II ist bemerkt von Minor 5, 41]; von Lohmeyer S. 125 f.

70) III, 19-23; Flecks Spiel erreichte hier nach dem Zeugnis Z. Funks seine Höhe (Jacobs, Deutsche Schauspielkunst S. 217); enthusiastisch preist auch Tieck, Krit. Schriften 3, $60 \mathrm{f}$. (abgedruckt das. S. 209) die Art, wie Fleck gebrochen vom Altan zurückkam. Immermann (das. S. 223) fand diese Auftritte unübertrefflich in EBlairs Darstellung. Zum unverbrüchlich festgehaltenen Grundzug der Auffassung im ganzen wurde das Soldatische, der Feldherr Wallenstein, nach L. Speidel (das. S. 232 f.) bei Sonnenthal.

Scberrer, Kampf im deutschen Drama. 
mandowort des Chefs, der sich jetzt, bewaffncter Cewalt gegenüber, zum rücksichtslosen Handeln mit Geschütz und Kugel zusammenfaßt. Jede Silbe ist akzentuiert, gesättigt mit schroftster Autorität: „In der Ordnung schwcigend warten / Was mir gefallen wird zu tun." ist die herrische Order. Der Befehlsträger fällt durch den frevlen Schuß, und nun reckt sich der Feldherr Friedland aus der Wirrnis des Aufruhrs gewaltig auf, der Heerfürst und gefürchtete Gebieter, der erst zu lemen hat der dämonischen Macht über die Masse zu entraten, und noch immer wähnen kann, sie durch den bloßen Blick zu zähmen. Gegen den Widerstand seiner Getreuen setzt er sich selber ein, und kehrt von dem fehlgeschlagenen Versuch zerschmettert wieder, niedergeworfen durch den Abfall der Völker, deren Abgott er war, gebrochen durch den Hohn, den sie ihm entgegenschleudern. Schiller läßt an dieser entscheidenden Stelle seinen Helden wortlos auftreten, hier karger als Shakespeare, dessen Feldherr Antonius in ähnlichem Zusammenbruch - nach schimpflich verlorener Schlacht eine monologische Klage hält. ${ }^{11}$ ) Wallenstein erteilt nur, anhebend mit einem inhaltsschweren "Tcrzky!", die sachlichen Anordnungen zum Abzug von Pilsen, der durch die Meuterei nötig geworden ist; das Ereignis selbst zittert einzig im Ton nach, und nachdem er noch Max den eindringenden Kürassieren hat freigeben müssen, schweigt er ganz. Der Bann sciner Unbesiegbarkeit ist gebrochen und sein Untergang besiegelt.

Gegen das Charakterbild des Kriegshelden Friedland richtet Otto Ludwig einen Einwand, der an die Wurzeln der Kunst Schillers greift. Es seien der historische, eiserne Wallenstein des DreiBigjährigen Krieges und der poetische, gemäßigte, verklärte des Dichters eine unleidliche Doppelheit in der Tragödie. Schiller habe dic Züge des einen unbekümmert in diejenigen des andern hineingezeichnet. ${ }^{72}$ ) In der Tat tritt der zweite Attila und Pyrrhus, der mit Feuer und Schwert durch Deutschlands Kreise zog, der Mann, der den Fluch der ganzen Welt auf sich lud, um seinen Sultan groß zu machen, der Scherge des Kaisers, der seinen Fürstenmantel Diensten dankt, die Verbrechen sind, kaum vor uns hin, ${ }^{73}$ ) und darin besteht allerdings eine Inkongruenz. Was Schiller gibt, ist wohl der mächtige, in seiner Güte königliche, in seinem Zorn furchtgebietende Feldherr, aber nicht, nach den Worten des Prologs, der Länder Geißel, der stahlharte Chef wilder Horden, der kalten Blutes das Reich verheert. ${ }^{74}$ ) Ein

7) Ant. u. Cleop. III, 9 ..Horcht! Mir verwehrt der Corund auf ihn zu treten. / Es schämt sich mich zu tragen" "1sw.

72) Schrifien 5. 298 f., 302 f., 306. 310 \%.

i3) Tod 285 f.: 558 ff; 592 f.; 619 凡t.

i4) Zu einem Condotiere dieser Art konnte Max - um nur das Militärische zu berühren nicht (Tod 1727 ff.) vom ..guten Krieg" sprechen, den er mit der Auflehnung gegen den Kaiser verläBt; er hätte nie cinen solchen geführt und dürfte nicht von sich sagen, er könne auch Unmenach 
Shakespeare hătte, nach Ludwigs treffender Beobachtung, die Größe des Charakters in seiner Furchtbarkeit gesucht. Für den Klassiker Schiller war dieser Weg nicht gangbar. Man steht hier vor einer Kernfrage der Tragödie, die auch die lichte Zeichnung des Lagers in sich begreift, welche schließlich nur Abspaltung aus der Konzeption des Feldherm ist. Wir sind über den Prozeß der Formung des Friedländers durch Selbstzeugnisse ungleich besser unterrichtet als über die Auffassung der Soldateska. Den Hauptpunkt, daß der Dichter es der begrenzenden und bindenden - klassischen - Kunst anheimgibt, den Helden menschlich näher zu bringen, hat er selbst im Prolog niedergelegt. Schiller machte sich die Schwierigkeit klar, den Realisten Wallenstein, der das einzige Kriterium seiner Bedeutung, den Erfolg, gegen sich hat, der praktisch scheitert und daher auch ästhetisch zu scheitern droht, ,,auf der gehörigen Höhe" zu erhalten. Aber er traute dem neuerworbenen Zuwachs an Kunstmitteln zu viel, wenn er dachte, dies unter Verleugnung seiner ursprünglichen Dichternatur „auf rein realistischem Wege“ zu bewerkstelligen. ${ }^{75}$ ) Da die Möglichkeit, den Helden durch Steigerung der Kraft im Bösen dramatisch groß, zu einem shakespearischen Richard zu machen, durch die klassische Forderung der Vermenschlichung abgeschnitten war, sah er sich doppelt auf den ihm völlig gemäßen Weg seiner Idealisierung verwiesen. Schiller zeichnet demnach wohl einen Realisten, aber er zeichnet ihn nicht mit realistischen Mitteln. Er gibt dem Friedländer die Fülle jener hohen, absolut wertvollen Eigenschaften, ${ }^{76}$ ) worunter sein Feldherrntum die strahlendste ist. Äußerungen wie die an Körner, Wallenstein sei niemals edel und dürfe es nie sein, er könne durchaus nur furchtbar, nie eigentlich groß erscheinen, ${ }^{77}$ ) wollen auf das vollendete Werk nicht mehr passen. Man braucht nicht an die letzte Verklärung des Helden vor der Katastrophe, an seinen Schmerz um Max zu denken, sondern nur den Heeresfürsten im Auge zu behalten, um zu erkennen, daß Schiller ihm auch das Große und Edle nicht versagt hat. Friedland steht als Feldherr trotz seinen kühl verfolgten $Z$ wecken nicht viel tiefer, als die Kürassiere auf dem bedenklichen Grund des Lagers als Soldaten. Daher rührt auch der Vorwurf

sein wie ein anderer (207l ff.); Friedland müßte schon längst die Losung jeder Aluchenswerten Tat (536f.) sein.

75) An W. v. Humboldt 21. März 1796, Jonas 4, 436; die ,sentimentalische Idealität“, die Schiller nach diesem großen Rechenschaftsbericht im Wallenstein abzulegen sich anschickt, ist gerade der Hauptangriffspunkt Ludwigs.

io) Vgl. dazu W. Scherer ${ }^{12} 591$.

77) 28. Nov. 1796, Jonas 5, $121 \mathrm{f}$; d die frühere, ähnliche an Humboldt (das, 4, 436) betrifft noch die historische, nicht die poetische Cestalt; die spätere an Böttiger (1. März 1799, das. 6, 14), die rückblickend beide vergleicht, drückt sich bezeichnenderweise minder apodiktisch aus: „Der historische Wallenstein war nicht groB, der poetische sollte es nie sein." 


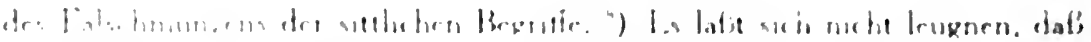

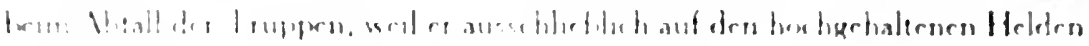

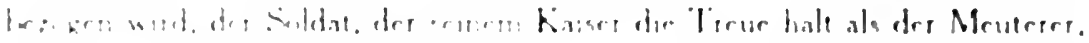

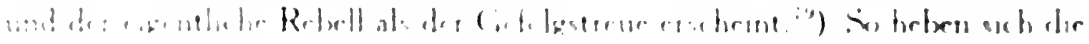

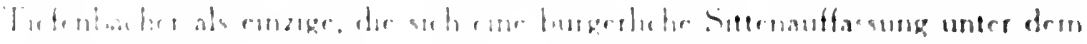

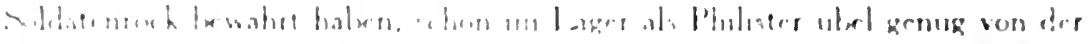

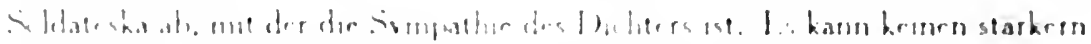

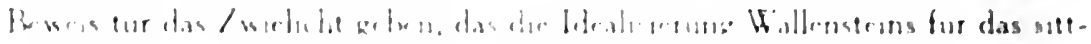

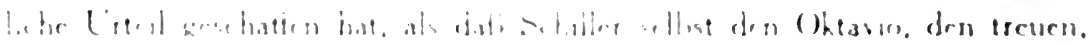

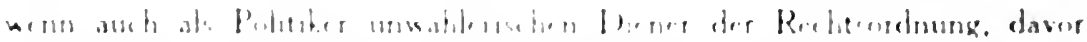

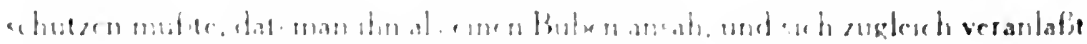

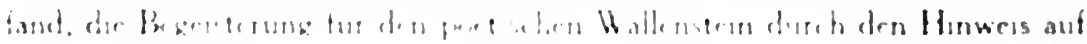

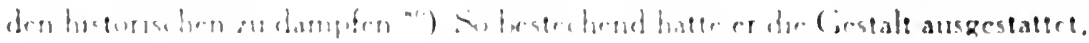

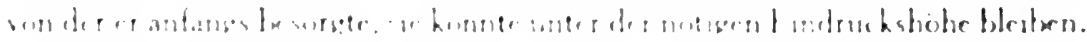

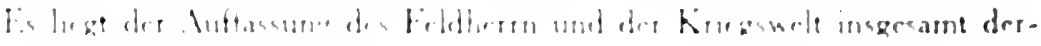

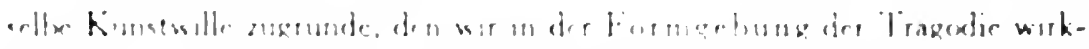

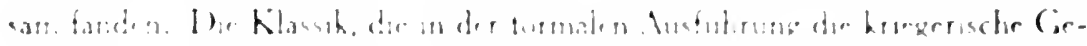

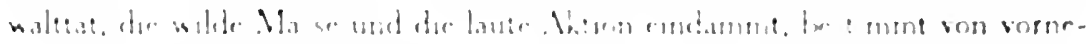

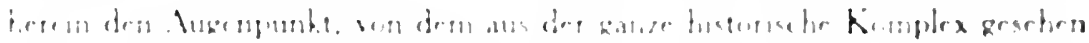

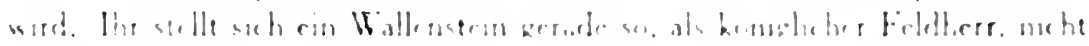

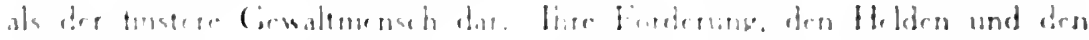

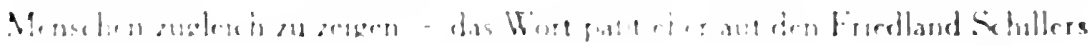

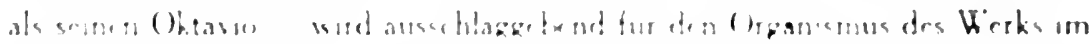

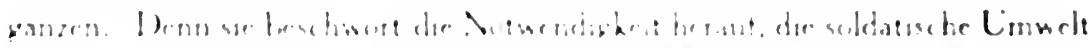

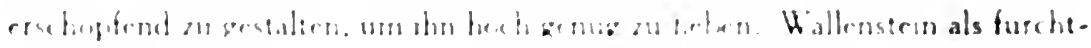

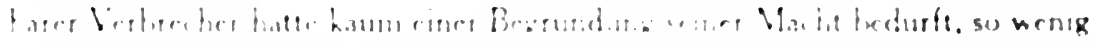

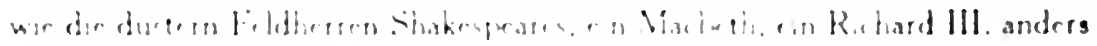

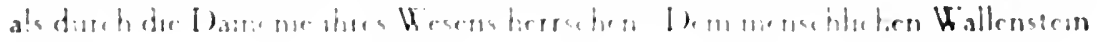

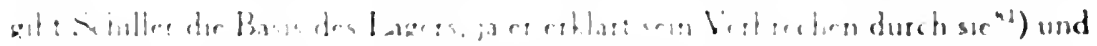

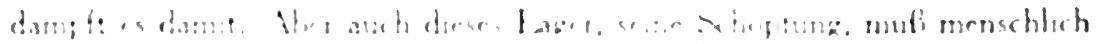

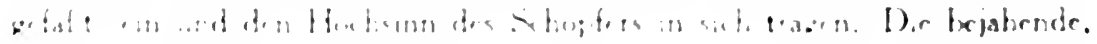

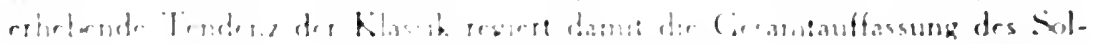

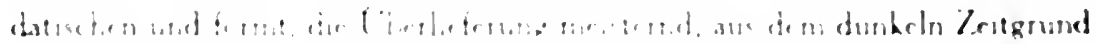

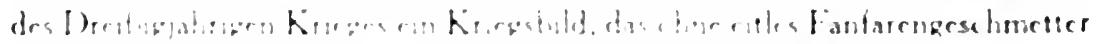

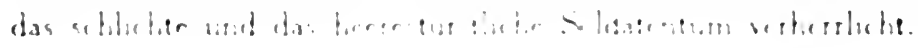

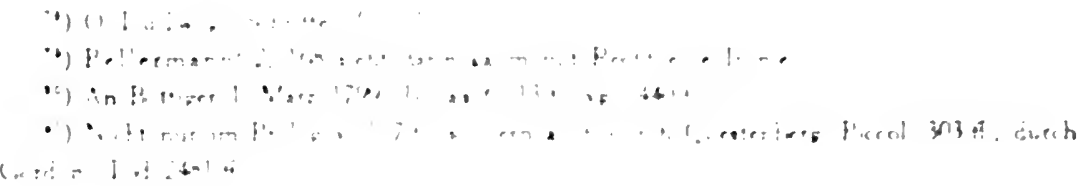




\section{Die Jungfrau von Orleans.}

Neben dem Kanon der Heeresdarstellung steht in der Reife Schillers das beherrschende Schlachtstück der ganzen Epoche, neben Wallenstein die ,Jung frau von Orlean s". ${ }^{1}$ ) Gegenüber der Charaktertragödie des Feldherrn könnte sie im Reichtum ihrer Kriegsaktion fast als kriegerisches Handlungsdrama erscheinen. Die Kampftechnik jedenfalls fand in diesem Vorwurf eine Aufgabe der schwierigsten Art, und Schiller löste sie, die gesamte Entwicklung vielfach zusammenfassend, mit einem höchsten Aufwand an Mitteln. Die triumphale Gestaltung von Schlacht und Sieg, die er dem kriegerischen Stoffe angedeihen ließ, trug entscheidend dazu bei, die Jungfrau zu seinem glänzendsten Bühnenstück zu machen, dem an Schwung der Handlung und Pracht der Erscheinung keins seiner andern Werke gleichkommt.

Die Zahl der Gefechte und Schlachten im Stück ist allerdings so groß, daß Immermann im respektlosen Bühnenrotwelsch von dem ,alten Bataillenpferd dieser Jungfrau " reden konnte. ${ }^{2}$ ) Die kriegerische Vorgeschichte nicht gerechnet, die mit der Exposition der augenblicklichen Kriegslage, insbesondere der Schilderung der Belagerung von Orleans, in ein eigenes Vorspiel verwiesen wurde, fallen in den Bereich der Handlung das Treffen bei Vermanton, der Entsatz von Orleans mit der englischen Niederlage, der nächtliche Überfall auf das englische Lager, die Schlacht vor Reims und endlich die abschließende, ungeschichtliche und daher unbenannte Entscheidungsschlacht.. ${ }^{3}$ ) Mit der Formstrenge des Wallenstein war dieser Fülle nicht gerecht zu werden. Schiller empfand die Notwendigkeit, zu dem neuen Stoff die Form neu zu erfinden und mit größerer Kühnheit und Freiheit zu verfahren besonders deutlich, weil er von der engbegrenzten Maria Stuart her an ihn herantrat. ${ }^{4}$ ) Durch eine Vielheit von technischen Motiven mußte vor allem jeder Eintönigkeit in der Wiederkehr der Schlachten vorgebeugt werden. Schiller nähert sich daher auf der einen Seite der Ungebundenheit Shakespeares. Er führt in die Kämpfe hinein, wechselt auf dem Schlachtfeld den Ort, er macht Gebrauch von Theatralmitteln, die in der Richtung Kotzebues liegen. Aber er erweitert durch diesen Zuwachs, wenn auch die Rechnung nicht völlig rein aufgeht, doch nur die klassische Form und stößt sie nicht um. Er hält ihr Prinzip der Beschränkung hoch, er setzt das Wort über das laute Geschehen, drängt die kriegerische Massenaktion zurück,

1) Uraufführung in Leipzig am 11. Sept. 1801. Erstdruck im Kalender auf das Jahr 1802, Berlin 1801.

3) Jacobs, Deutsche Schauspielkunst S. 183 (aus Immermanns Theaterdiarium).

${ }^{3}$ ) Den historischen Verlauf des Krieges und die Taten der Jungfrau stellen Düntzers Erläut. Heft $50 / 51^{6}$ Leipzig [1906] S. 74 u. 84 ff. dar.

7) An Goethe 26. Juli 1800. An Körner 28. Juli 1800; Jonas 6, 176 f. u. 182. 
meidet das Getüinmel und den sichtbaren Zusammenprall. Er gibt dem Botenbericht strenger Observanz Raurn und führt - dies ist das Entscheidende in seiner Hauptschlacht die im Wallenstein angebahnte Synthese der klassizistischen und der freien Kampfform zu ihrer Vollendung. ${ }^{5}$ ) In der Anordnung der Darstellungsmittel bewährt sich der dramatische Baumeister. Der geschlossene Kriegsbericht, der große Stoffmassen schnell bewältigt, hat seine Stelle in der Exposition. Er gibt die Bahn frei für die Steigerung in die vorgeführte Gefechtshandlung, die in schrittweisem Anheben das Mittelstück der Tragödic einnimmt. Die dramatisch straffste, wirksamste Erfassung der Schlacht, die Schiller durch die besondere Durchbildung der Kampfbeobachtung erreicht, schließt ab.

\section{Die Berichte.}

Wie im Wallenstein entlastet ein Vorspiel die überreiche kriegerische Welt des Stückes. Schiller hat darin das Thema des Krieges durch einen Meistergriff mit dem Thema der Heldin verflochten, deren Vorgeschichte es in erster Linie zu geben hatte. An die Stelle überwiegender Zustandsschilderung in Wallensteins Lager tritt eigentliche Exposition, der dramatisch eingegliederte Rechenschaftsbericht eines Prologus, der den Verlauf und Stand des Krieges zusammenhängend darstellt. Zugleich hebt aber auch schon die Handlung selbst an, im Augenblick, wo Bertrands Erzählung die Jungfrau zu ihrer Mission aufruft. ${ }^{6}$ ) Thibauts einleitende Rede schließt die verzweifelte Lage Frankreichs und den verheerenden Brand des Krieges in ein paar umfassende Bilder. Mit dem Auftreten Bertrands geht das Vorspiel zur konkreten Kriegshandlung über.

Was der Bericht des schwedischen Hauptmanns über Schillers Stellung zur Kriegsgelehrsamkeit ergab, bestätigt sich an der Schilderung der Belagerung von Orleans. Das Technische des Krieges war dabei weniger zu umgehen als im Wallenstein. Die Zurüstungen der Briten zur Bezwingung der Stadt verlangten mehr kriegswissenschaftlichen Aufwand als die Attacke der Pappenheimer. Das Bild ist von der Errichtung der Belagerungstürme über das Bombardement bis zum Minenangriff in der $T_{a t}$ vollständig. ${ }^{7}$ ) Aber schon die

$\left.{ }^{5}\right)$ Lohmeyer S. 128 f. vgl. S. 83 f. schließt die Kampftechnik der Jungfrau zu eng an diejenige des Ritterdramas: vgl, zu ihr auch Petersen. S. 251 u. Säkularausg. 6. XXVI.

-) Die Kriegsexposition geben vorwiegend die 1. und die ersie Halfte der 3. Szene, dazwischen der 2. Auftritt Johannas Charakter; der Rest der 3. u. die \&. Szene rechnen zur Handlung. Im Wallenstein entspricht dem Bericht Bertrands das nachgeholte Resumé Questenbergs in der Audienzszene. Den Prolog der ..Jungfrau" vergleicht schon Hoffmeister 4, 346 f. mit dem wallensteinischen. Obes den Crund seiner Abtrennung Bellermann'2. 227: Petersen S. 33 6.

i) Da besonders die letzte Vorstellung für das Belagerungsjahr 1429 etwas modern anmutet (Pulverminen im allg. erst gegen Ende des 15. Jahrh.), möchie man dafür auf Shakespeare blicken. 
Wortwahl, die keinem dieser Dinge seinen technischen Namen gibt, zeigt wie Schiller dem archivalischen Ton ausweicht. Vollends aufgesaugt wird das Kriegshistorische durch die dichterische Bildkraft, welche die verwirrende Fülle des Mechanischen in einen großen Eindruck sammelt. Statt äußerer Beschreibung der Belagerungsmaschinerie wird ihr poetischer Gehalt gegeben. $\mathrm{DaB}$ selbst der königliche Turm von Notre-Dame sein erhabenes Haupt beugt, ist das entscheidende bei der Beschießung, nicht die artilleristische Ausrüstung der Belagerer, ihre Geschützzahl und ihre Kaliber. Nur gestreift wird das Graben der Minengänge, aber ausgeführt die ungeheure Spannung, worin die unterminierte Stadt über der Hölle steht. Fast gleichzeitig bringen dagegen Kotzebues „Kreuzfahrer“ die Kriegsmaschinen zur Berennung Nicäas als willkommene Staffage auf die Bühne.

Auf diese Weise wurde das Wagnis möglich, den Bericht über eine Stadtbelagerung mit Kanonen und Pulverminen in ein homerisierendes, antik-zeitloses Kriegsbild hineinzustellen, wo im Heerbann des gewaltig herrschenden Burgund auch die herdenmelkenden Holländer Platz finden und neben dem Maurenzertrümmerer Salisbury Talbot als der himmelstürmend Hunderthändige erscheint. ${ }^{8}$ ) Die Töne der Montgomery-Szene klingen vor. Im Anschluß an den Schiffskatalog der Ilias hat sich Schiller in der wortgewaltigen Schilderung des orleanischen Kriegsgewimmels selbst kühner über die dramatische Wahrscheinlichkeit der Rede hinweggesetzt als dort. Hier spricht nicht der einfache Landmann, der das Schwert nicht zu führen und den Helm nicht zu brauchen weiß, auch nicht der wohlberedte Bauer der Klassik Schillers, sondern der Prologus des Dichters, der außerhalb des Dramas steht und an seine Welt nicht gebunden ist. Im Stück selbst lautet der Bericht des Ratsherrn von derselben Belagerung viel schlichter, obwohl im königlichen Palast statt vor der ländlichen Hütte erstattet. Man ist aus der dichterisch freien Grundlegung des Krieges in die Bedingtheit der Handlung versetzt. Aber auch jetzt darf der

dessen Kriegsgestaltung in Heinrich VI. wie allenthalben von zeitgenössischen Vorstellungen durchtränkt ist. Möglich allerdings, daß Schiller diese moderne Färbung aus älteren Berichten, denen sie häufig eigen ist, etwa der „Histoire du siège" (vgl. Dü ntzer ${ }^{6}$ S. 156) herübernahm. Die Geschützsalven im Hamlet hatte schon Voltaire triumphierend der Académie signalisiert (Lettre à l'Académie française 25. VIII. 1776), die anachronistischen Kanonen im Macbeth Schiller selbst in seiner Bearbeitung getilgt (Köster, Sch. als Dramaturg S. 88 f.). Außerhalb der Schilderung Bertrands, in den Schlachten des Stücks, hat Knall und Dampf der Artillerie außer im Eingang zu $V$ so wenig wie im Treffen bei Neustadt Raum. Vgl. etwa die heroische Vorstellung im Monolog der Jungfrau v. 2555: „Daß der Sturm der Schlacht mich faßte, / Speere sausend mich umtönten."

8) Vgl. R. Peppmüller, Biblisches und Homerisches in Schiller Jungfr. v. O., Schnorrs

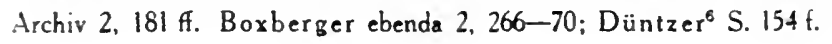


kriegstechnische Apparat sich nirgends vordrängen. Die Genauigkeit, womit eine cinzige Episode der Belagerung erzählt wird, ${ }^{9}$ ) hat die hellseherische Gabe Johannas zu beglaubigen.

Der überreiche, cröffnende Halbakt des Stücks dient geschlossen der einen Absicht, den ersten Sieg der Jungfrau zum überwältigenden Wunder zu machen. Schiller übt neuerdings das im Wallenstein erprobte Können, eine Steigerung von Hiobsposten retardierend zu verstärken und durch lyrische Ruhepunkte zu heben. Erlösend tritt endlich, als das volle Maß des Unglücks ausgeschöpft ist, die triumphale Sicgesnachricht ein. Die himmlische Musik des Zauberwortes Sieg erklingt kaum irgendwo so festlich, wic hier. Raouls Bericht hat mit demjenigen des schwedischen Hauptmanns die knapp geschaffene Situation der Umzingelung mit dem Gedanken an Úbergabe gemein. ${ }^{10}$ ) Die Lösung. dic dort durch die Verzweiflungstat Piccolominis erfolgt, wird hier durch das Wunder bewirkt, zu dessen überzeugender Gestaltung alle Kraft der Schilderung aufgeboten werden mußte. Der Ton, von vorneherein hochgegriffen, erhebt sich mit der rätselvollen Erscheinung der behelmten Kriegesgöttin zum feierlichsten Gang. Biblische Wendungen, archaisierende Formen treten ein. ${ }^{11}$ ) Es ist

$\left.{ }^{9}\right)$ I. 11, der bei Shakespeare, 1 Heinrich VI: 1, 4 vorgeführte Tod Salisburys; Todesart und Lokal sind bezeichnet; Düntzer ${ }^{\circ}$ S. 74, 156 u. 193; man vergleiche, wie dagegen v. 583 bei Saintrailles' Ende die poetische Dignität nur ein allgerneines ..An unsern Mauern sank/ Der edle Held" erlaubt. - Einen nur scheinbaren Widerspruch in der Belagerungsgeschichte löst schon Holfmeister 4. 352 auf. Die Kapitulation auf den zwölften Tag (v. 571) ist dem Herzog von Burgund angetragen (v. 744), dem sich auch Johannas Heimat (v. 297) übergeben will. Der Ratsherr selbst identifiziert in dringendem Flehen (v. 749) dessen Herrschaft allerdings mit der ., harten Herrschaft" Englands. Burgunds Absicht durchkreuzend, fertigt Salisbury den Herold aut eigene Faust (v. 1277 ff.) an den König ab, um die Stade für England zu gewinnen und droht (v. 1184) mit Sturm. Schiller hat sich bei dem etwas verwicke!ten Sachverhalt wie billig nicht weiter aufgehalten.

$\left.{ }^{10}\right)$ Vgl. o. S. 281 Am. 52 . Tod 3038 „Nicht vorwärts konnten sie, auch nicht zurück”" Jungfrau 945 1. .Da stand in weiter Ebene vor uns der Feind. / Und Waften blitzten, da wir riukckwärts sahn." - Fernet verwandte Einleitung: Jungfrau 939 ..Wir hatten sechzehn Fähnlein aufgebracht. .. Als wir nun" usw. - Tod 3018 .. Wir standen, keines C'berfalls gewärtig. ... Als gegen Abend" usw. Charakieristisch sind die gehobenen Endzeilen als kräftiger Schlußstrich des Berichtes: Tod 3059 .. Und eher nicht ... Als bis der letzte Mann gefallen ist" : Jungfrau 984 .Und von den Unsern ward kein Mann vermiBe"; die berihmteste Tod 942 .Und RoB und Reiter sah ich niemals wieder." - Kleist bildet diese Technik nach: Penthes. 350 .Und was aus ihm geworden, weiß ich nichi": Homburg 677 . Und keinen Laut vernahm man mehr von ihm."

11) 962 ..Und wären sein mehr denn des Sands im Meere"; 960 „erhub und also sprach": 947 .umrungen sahn wir uns"; 975 .Wehr und Waffen son sich werfend": 976 ..entschart das anze Heer sich": entscharen, weder von Campe noch im DW'b aufgeführt, ist eine kraftvolle 
interessant, aus dem Vergleich mit dem Gefechtsbild von Neustadt zu ersehen, was für eine Steigerung ins Großdichterische und völlige Loslösung vom Historisch-Technischen über die dort geleistete Poetisierung hinaus noch möglich war. Das Wunder vollzieht sich in einer zeitlosen Allgemeingültigkeit und soll nirgends an sachliche Bestimmungen anstoßen. Die Fahne in der Hand der Jungfrau, der die Franken wie gebannt zum Sturm folgen, ist gültiges Kriegssymbol für alle Jahrhunderte. Hochpoetisch, fern aller taktischen Realität wird das folgende Bild der sinnverwirrten Panik gefaßt, ,der Feind" mit kühnem kollektivem Singular ${ }^{12}$ ) als Person in seinem Staunen, mit weitgeöffnet starrem Blick und dem jähen Ausdruck des Entsetzens gezeichnet. Kein Wort verlautet von Aufstellung und Zusammensetzung der Truppen, ja das zweite Heer im Rücken der Franzosen wird ganz beiseite gelassen, weil dafür in dem hemmungslosen Zug der Flucht kein Raum mehr ist. $\left.{ }^{13}\right)$ Die verderbliche, gottgewollte Panik darf weder durch irgendwelche Explikation, noch durch realistische Einzelzüge beeinträchtigt werden. Ein einziger ausdrucksmächtiger Vers umspannt den ganzen Verlauf des Würgens: .Ein Schlachten war's, nicht eine Schlacht zu nennen" ${ }^{14}$ )

Wiederbelebung des alten Kriegswortes „scharen“ (das Heer scharen), das die eindringende französische Militärsprache durch den terminus ranger (rangiert = geschart, im DWb reich belegt) in Vergessenheit brachte.

12) 970 „Der, hochbetroffen“ usw.; vgl. 979 „Mann und Roß“; andere Fälle aus Jungfrau u. Ritter Toggenburg bei Bellermann 2, $297 \mathrm{f}$.

13) Das Heer, das sich sinnlos in den Fluß stürt, kann nur das den Franzosen frontal entgegentretende sein, das (944 f.) in der Ebene der Yonne vor dern Flusse steht; das Verfolgungsheer wäre an den Höhen zu denken. Düntzer ${ }^{6} \mathrm{~S}$. $183 \mathrm{f}$. faßt die Situation unrichtig, augenscheinlich durch einen zu genauen Blick auf die Landkarte verführt, die nur ganz allgemein zugrunde liegt.

14) Das Wort weist Bellermann aus Curtius, Alexander Magnus IV. 15: ,Jarnque non pugna, sed caedes erat“, Boxberger aus Anquetil, Esprit de la Ligue 1, 273: „,ce ne fut plus un combat, mais un massacre", nach; Düntzer 184 Anm. bringt auch Livius XXVIII. 16 u. seine mehrfache Gegenüberstellung von pugna (proelium) und caedes, Büchmann ${ }^{25}$ S. 188 Tacitus, Hist. III. 77 und IV. 33 bei. - Das Stück ist reich an Formungen dieser Art. Eine Neubildung aus Plutarch ist das verzweiflungsvolle „Kann ich Armeen aus der Erde stampfen?" Karls v. 596 (Düntzer S. 172, Büchmann ${ }^{25}$ 188); Leben des Pompejus cap. 57, vgl. cap. 60 u. Leben Cäsars cap. 33; „wo ich nur in Italien mit meinem Fuße auf die Erde stampfe, da müssen sogleich Heere zu FuB und zu Pferde hervorspringen" (nach Kaltwasser); als Feldherrnwort schon vor Schiller von dem ebenso plutarchfesten Klinger im „Günstling“" gebraucht: ,ich [befehle] durch meinen Namen; wo der erschallt, springen Männer aus der Erde“ (III, 2, Werke 2, 46). Zu crinnern ist an die aus Jasons und Kadmos' Saat von Drachenzähnen der Erde entspringenden riesenhaften Gewappneten, von denen Klingers Medea in Korinth im 3. Akt erzählt (Werke 2, 194); Wall. Tod 649. - Dem Manneswert im Kriege, den bereits der Wallenstein preist, gilt das prachtvolle 
Das Wunderbare, das Schiller in Johannas Sendung beibehielt, konnte ihm die Motivierung von Sieg und Niederlage für die ganze Reihe der Kämpfe ersparen. Das Glück der Schlachten ist in ihnen in der Tat das Urteil Gottes. Der Erfolg bleibt den französischen Waffen treu, solange die Jungfrau dem Heere voranschreitet, und verläßt sie mit der Verbannung der Cottgesandten. ${ }^{15}$ ) Das eigentliche Mirakel wird für die Entscheidung abet doch nur in den beiden unsichtbaren Schlachten, der ersten und der letzten, gebraucht. Beim Sieg des lothringischen Häufleins gegen vielfache Übermacht ist es durch die Verlustziffer, zweitausend gegen keinen - in den Räubern fallen auf natürlichem Wege dreihundert gegen den einen Roller - absichtlich außer Zweifel gesetzt. Noch stärker spricht das Siegeswunder des Schlusses, wo die Jungfrau die schon verlorene Schlacht blitzschnell in vollendeten Triumph wendet. Die übrigen Kämpfe führt Schiller auf realem Boden durch. Das dramatische Interesse würde bei öfterer Wiederkehr der göttlichen Entscheidung erkalten. Er motiviert den Wechsel des Kriegsglücks beim zweiten Sieg durch das neue Vertrauen, das die Franzosen über sich selbst hinaushebt. Die Engländer haben zu lernen, daß sie nicht mehr gegen die fränkischen Weichlinge stehen. die sie in zwanzig Schlachten überwunden. ${ }^{16}$ ) Der dritte Erfolg ist vollends das natürliche Ergebnis geschickter Führung der Jungfrau, die in verschwiegenem Nachtmarsch den Weg ins feindliche Lager zu finden weiß. Johanna selbst tritt zwar in die Montgomeryszene nach antiker Vorstellung als die unentrinnbar ihres Rächeramtes waltende Vollstreckerin des Schicksals, die schließlich selbst, nach vorbedachtem Plane, aber nicht jetzt und heute des Todes Opfer werden wird. ${ }^{17}$ ) Aber der Walliser seinerseits hält davon nur

Königswort Karls v. 585 ..O in dem einz gen Mann / Sinkt mir ein Heer!": vgl. Tod 1795 ..Schon einmal galt ich euch statt eines Heers. / Ich einzelner": dazu Jungfrau 459 "Ein Mann ist viel wert in so teurer Zeit" und Tod 1790 ..Doch was / Ein Mann kann wert sein. habt ihr schon erfahren": Jungtrau 33 ..Die treue Brust des braven Manns allein" usw.

15) Eine Schwicrigkeit lag darin, daß ihre Verschuldung in der siegreichen Reimser Schlacht. die ihre Kriegstaten krönt, zu geschehen hatte: das entscheidende Ende Talbots muBte daher vorausgenommen und der Sieg vor der Lionelszene, die ihn nicht mehr rechifertigt, bereits proklamiert werden (v. 2357). In diesem Zusammenhang erscheint dic Szene des Schwarzen Ritters. die Johanna auf der Höhe des kriegerischen Erfolgs zeigt und zugleich den Fall einleitet, als besonders glücklicher Grift. Dagegen will die Siegesbotschaft nicht mehr recht in die abschließende Szene III, II passen (2510. ein Verlegenheilsvers); der Aktschluß ist trolz dem treflichen Motiv der Verwundung. als Symbol der gebrochenen inneren Kraft, der schwächste des Stücks.

16) v. 992 f.. 1128 \&., 1235 f., 1544 .

17) Zu 1660 ff. vgl. 1520 u. 2229 l. Zu der christlich gewendeten, fatalistischen Vorstellung 'gl. Rauber I. 2 .Fürchtel euch nicht vor Tod und Gelahr, denn über uns waltet ein unbeugsame Fatum! Jeden ereilet endlich sein Tag" usw. 
das eine fest, daß sie seinen Waffen verwundbar ist, und schreitet mit dieser tröstenden Gewißheit zum Kampf. Außerhalb dieses cinen Auftritts ist die Absicht deutlich, der Heldin jeden frostigen Charakter gefeiter Sicherheit zu nehmen. Sie erscheint in der Besorgnis der Freunde, die sie vor dem falschen Gott der Schlachten warnen, von der blutigen Entscheidung fernhalten wollen und während des Kampfes um sie zagen, als zarte Jungfrau, nicht als robuste Amazone. ${ }^{18}$ ) Der Kampf mit Lionel gibt dann bei äußerem Sieg ihre innere Niederlage. Aller übernatürlichen Kraft entkleidet zeigt sie endlich die Auffassung der Feinde, der Rationalisten im englischen Lager, Talbots, Isabeaus, die ihre Siegerkraft nur in die Pöbelfurcht der Truppen legen und für die natürliche Erklärung der mittleren Schlachten jedenfalls starke Handhaben geben. Ihr Gegengewicht allein ${ }^{19}$ ) wäre genug, den wunderbaren Einschlag der Kriegshandlung nicht über das dramatisch Wirksame hinauswachsen zu lassen.

\section{Die Bühnenkämpfe.}

Die mittleren Akte des Stückes zeigen technisch die freieste Haltung. Es ist die Forderung des Stoffes, die Schiller zu shakespearischen Formen greifen läßt. Es ist der klassische Formwille, der sich ihrer Lizenz entgegenstemmt. Aus dem Ringen beider Tendenzen geht auf mittlerer Linie die Lösung hervor, hier ein Kompromiß, noch nicht die Synthese, die der letzte Akt findet. ${ }^{20}$ ) Mit weisem Maßhalten, die künftigen Gefechtsaufgaben vor sich, verweist

18) 1506 ff.; akzentuiert besonders 1707 „Mit Männern kämpfe, nicht mit Jungfrauen!“" III, 8 u. II. Allgemein über das Wunderbare im Stück handelt Bellermann ${ }^{12}$ 2, 240 ff.; H. Baumgart, Euphorion 1 (1894) S. 110-24; ferner ein Aufsatz Munckers, Sitzungsber. der K. Bayr. Akad. der Wiss. 1906, S. 267-78.

19) 1247 ff.; 1542 f.; $2320 \mathrm{ff.;} 3203 \mathrm{ff}$. Mit den Einwänden Fr. Th. Vischers und Bult haupts. Talbots machtvoller Materialismus vernichte die Wunderwelt überhaupt, setzt sich Bellermann ${ }^{1}$ 2. 292 f. auseinander. Vgl. H. Hadlich. Die Jungfrau und Talbot, Euphorion 16 (1909) S. $379-411$, bes. $406 \mathrm{ff}$.

20) Die stoffliche Veranlassung zur freien Behandlung wird noch stärker im Demetrius, bei dem schon die räumliche Weitschichtigkeit (vgl. Petersen S. 101 f.) eine geschlossene Anlage verbot. Der Heereszug nach RuBland wird II, 2 in eine Marschszenc gefaßt, die den bedeutsamen Augenblick der Grenzüberschreitung wiedergibt; die Ausschau von der Höhe in das weite russische Land hinein steht dem Blick Karl Moors über die Landschaft an der Donau (III, 2) parallel, auch im Gegensatz des menschlichen Tuns zur Natur: „und ich ein Ungeheuer auf dieser herrlichen Erde“ (Moor); „Auf diesen schönen Au'n wohnt noch der Friede, / Und mit des Krieges furchtbarem Gerät / Erschein' ich jetzt, sie feindlich zu verheeren!" (Demetrius, v. 1231 f.). Nach der Weise Shakespeares wird die bloß gedachte Marschsäule illusionistisch durch Trommeln und Kriegsmusik vorgetäuscht und eingangs durch einen Befehl (1209 „Laßt die Armee am Wald hinunterziehn, / Injes wir uns hier umschau'n auf der Höhe") von der Bühne abgelcitet. Der Plan läßt weiterhin shakespearisch die Parteien (Lager des Demetrius - Loger des Boris) wechseln. 
Schiller dic erste Schlacht um Orleans und den Entsatz der Stadt in den Zwischenakt (I/II) und hebt erst nach geschlagenem Treffen an. Das getüinmelfrohe Jugendstück Shakespeares dagegen breitet die Unternehmungen der Pucelle gegen Orleans und Rouen, vor Bordeaux und Angers in ermüdender, kunstloser Gleichförmigkeit aus. ${ }^{21}$ ) Ein Einzelmotiv aus der Fülle des Briten genügt Schiller, die Schlacht in wenigen Strichen greifbar zu machen. Der Zank der geschlagenen Führer über die Schuld an der Niederlage ersetzt technisch vortrefflich den Bericht durch hitzigen Dialog. Bei Shakespeare sind es die französischen Feldherren, die sich gegenseitig für den Verlust der Stadt verantwortlich machen, ${ }^{22}$ ) ohne daß die Szene, weil der Sturm selbst dargestellt wird, die berichtende Funktion zu crfüllen hat. Die bühnenmäßige Deutlichkeit verlangt, daß der Ausgang der übergangenen Schlacht scharf und wiederholt betont wird. Schiller stellt die theatralische Notwendigkeit zugleich in den Dienst der Charakteristik. Der starkgeistige Talbot, der den Tatsachen ins Auge sieht und zu stolz ist, das Widrige vor sich selbst zu bemänteln, spricht das verhaßte Wort „.geschlagen" klar und fest aus. Lionel, leidenschaftlich, empfindlich für die Schändung des englischen Namens, nimmt es auf und gibt in seiner ausbrechenden Klage das StimmungsmäBige der Niederlage. Burgund, schwankend, zum Parlamentieren geneigt, sucht seinen eigenen und der andern Unmut durch den bequemen Glauben an feindlichen Höllentrug zu beschwichtigen. Isabeau schließlich faßt die Situation noch einmal knapp zusammen: „Wir haben eine Schlacht verloren, Feldherrn." ${ }^{23}$ ) Dic Beratung der Führer, die den Entschluß zutage fördert, morgen erneut

2) I Heinrich VI: I, 2 u. 4-6; II, 1: III, 2; IV, 2-7: V, 3. Orleans wird von der Pucelle nach einem ersten fehlgeschlagenen Versuch der Franzosen enlsetzt, in der Nacht aber von den Engländern genommen: Rouen wechselt sogar in derselben Szene zweimal den Besitzer. Uber die historischen. auseinanderliegenden Kämpfe vgl. Düntzer ${ }^{6}$ S. 107 f.

23) I Heinrich VI: II, I. Die aus den Vorwürfen Talbots und Lionels an Burgund (v. 1250 ff.) erhellende - erfundene - Gefechtssituation bei Schiller, die später (1471 f.) beiläufig noch weiter geklärt wird, stellt sich in den allgemeinsten Zügen so dar, daß die Jungfrau an der Spitze des Entsatzheeres auf den burgundischen Flügel des britischen Lagers eindringt, und die dort entstandene Panik, auch durch persönliche Schuld Burgunds, auf die Engländer übergreift. Fliehend hat Talbot mit dem Heer das Südufer der Loire gewonnen. - Zu v. 1244 „Die Sieger bei ... Axincourt gejagt von einern Weibe" vgl. Talbot bei Shakespeare 1.5 ..Sie jagt ein Weib, mit Rüstung angetan."

23) v. 1369; gegenüber übernatürlicher Einwirkung halien sich die englischen Führer scharf ausgedrückt von Talbot $1247 \mathrm{ff}$. - im Gegensatz zu ihren Truppen (Montgomery) durchaus skeptisch und werden von ihr auch nirgends berihhrt. Burgund glaubt an Höllenkraft und wird später vom Himmel gewonnen. Mitten inne steht lsabeau, die hier zwar (I321 f., 1372 f.) von Satanskünsten spricht, sie aber, wie sich auch späler (3203 ff.) zeigt, so wenig hoch anschligt wie die Mission der Prophetin - tür die sie sich selbst anbictet. 
zu schlagen, trägt Züge aus Shakespeares Kriegsrat in Brutus' Zelt bei Philippi. ${ }^{24}$ ) Des Briten Formungen der Hauptmomente kriegerischer Handlung erweisen sich immer wieder als so mächtig, daß sich Anklänge, sobald die freiere Technik Geltung hat, fast unvermeidlich einstellen.

Mit dem Nachtüberfall auf das englische Lager geht Schiller zur Vorführung über. Hier und in der folgenden Reimser Schlacht ist das klassische Prinzip am meisten gelockert und der Anschluß an Shakespeare am engsten. Dennoch werden gerade in der Nachtschlacht, in dem nicht völlig gelösten Widerstreit zweier Stile, die klassischen Grundabsichten besonders deutlich. Schiller kann sichtbare Kampfvorgänge nicht länger entbehren und braucht zum Rahmen seiner Einzelszenen auch die kriegerische Massenaktion. Der lautlose Zug der Jungfrau ins Feindeslager, die Panik bei den Briten, Lagerbrand und Flucht wird dargestellt. Aber diese auf den engsten Raum zusammengedrängten Ereignisse sind nur Einleitung zu den weitgespannten Führerauftritten, worin die allgemeine Schlacht untergeht. Auch Shakespeare schließt den Kampf der Massen in die Einzelgefechte der Feldherren ein. Aber die zentral gestellte Montgomeryszene weist ganz andere, ihm völlig fremde Tendenzen auf, und in der Hinwendung zu antiken Vorbildern zeigt sich ein stilisierender Kunstwille. Fast zu plötzlich ist der Übergang in diese Welt, und der Einfluß des epischen Urbilds bei Homer stärker, als sich mit

24) Jul. Cäsar IV, 3; Jungfrau II, 3; beide Beratungen bei Nacht, nach vorausgegangenem Zank und Versöhnung, mit dem Ergebnis, daß das entschlossene Zupacken gegen abwartendes Zögern durchdringt. Meinungsverschiedenheiten ähnlicher Natur sind für Ratszenen eine dramatische Forderung, daher überall zu treffen; dagegen gemahnt die Art, wie Lionel v. 1473 das sich eindrängende „Oberlegt - “ Burgunds beiseite schiebt: „Mit eurer Erlaubnis. Hier ist nichts zu überlegen“" deutlich an das "Erlaubt mir gütig" des Brutus, der damit einem Einwand des Cassius: „Hört mich, lieber Bruder" das Wort abschneidet. - Ferner abschließend Brutus: „Und die Natur muß fröhnen dem Bedürfnis / Das mit ein wenig Ruh wir täuschen wollen. Früh stehn wir also morgen auf, und fort"; Talbot 1494 f. „Kommt jetzo, die ermüdete Natur / Durch einen leichten Schlummer zu erquicken, / Und dann zum Aufbruch mit der Morgenröte !" Lionels zu erfolgssicheres Versprechen, die Jungfrau im leichten Kampfspiel lebend zu fangen, und das bedenkliche „Versprechet nicht zu viel“ Burgunds (1486 ff.) erinnert an die Prahlerei des zweiten Offiziers der Reichsexekution im Götz (Akt III), gegen die der erste einschreitet. Die Stelle ihrerseits ist wiederum nachgebildet von Collin im Coriolan (Berlin 1804) II, I; „O führte Mars / Mir diesen Halbgott [Coriolan] Einmal nur und bald / Entgegen — färben sollte sich mein Schwert / Sogleich mit seinem Blut, auf daß ihr sähet, / Wie gar nicht furchtbar dieses Schreckbild sei / Vor dem ihr feig erstarret." (Vgl. Talbot 1478 ff. „Und dies Phantom des Schrekkens zu zerstören“" usw.). Die Anlehnung wird dadurch sicher, daß Collin im folgenden auch den Zank der Feldherrn bei Schiller nachbildet : „Es wägt der Zorn die schnellen Worte nicht... Und so vergibt sie gern ein edler Mann“; vgl. Talbot 1358 f. „Ein edles Herz / Bekennt sich gern ron der Vernunft besiegt" usw. 
der dramatischen Forderung verträgt. Der Auftritt scheidet sich von den anstoßenden Szenen, wie nach seiner äußeren metrischen, so auch nach seiner inneren Form. ${ }^{25}$ ) Die Aktion, bis dahin knapp und dicht geführt, erhält mit eineınmal einen breiten, gemessenen Gang; die Schilderung nimmt überhand. Der Stilwechsel wird dadurch fühlbarer, daß Schiller einleitend starke Theatralmittel braucht. Das Feldgeschrei der eingedrungenen Franken, das „unter wildem Waftengetös“ plötzlich die nächtliche Stille zerreißt, ist ein eigentlicher Bühneneffekt. Sogar eine rasche Pantomime wird zu knapper Zusammenfassung nicht verschmäht: der sich öffnende Prospekt soll das brennende englische Lager freigeben, die stehende shakespearische Vorschrift verlangt .Trommeln, Flucht und Verfolgung". Es war nicht unbedenklich, den äußeren Apparat der Kampftheatralik dergestalt in Bewcgung zu setzen, wenn der Dichter sich unmittelbar darauf einzig der seelischen Handlung zuwenden wollte. Je voller das Massengefecht in der Pantomime erscheint, um so dünner muß die folgende Einzelbegegnung wirken. Je deutlicher das realistische Bild der Verfolgung wird, desto eher drängt sich vor der Stilisierung der Einwand auf. daß die Jungfrau bei so reicher Ernte im Britenheer bei dem einzelnen Feind nicht so lange verweilen könnte.

Zur Einheitlichkeit hat demnach die Vereinigung freier und gebundener Formen in der Nachtschlacht nicht geführt. Erreicht ist weniger eine Durchdringung, als ein Nebeneinander von klassizistischer Strenge und shakespearischer Technik, der die Mittel der Kulissenbühne zu Hilfe kommen. Im klassischen Geiste, wenn auch im Motiv an Shakespeare angeknüpft, folgt dann die große Sprechszene der Gewinnung Burgunds, worüber das Treffen vollends vergessen geht. Nur einen Augenblick lang wird sein Ergebnis, als gewichtiges Argument, noch einmal aufgerufen. ${ }^{26}$ ) Warum Schiller die dra-

2i) Als cpische Einmischung aus der llias (21. Buch), die aus dem Tone falle, bezeichnet ihn bereits W. S chlegel, Dramat. Kunst u. Litt. ${ }^{3}$ 3. 41 ;: vgl, auch Petersen, Säkularausg. 6. XXVI. Ober die Nachbildunz Homers im einzelnen igl. R. Peppmisller. Schnorrs Archiv 2. 185 f. u. Düntzer 205 f.

26) 11. 10: v. 1775 8f.; für die Stilis ¿erung ist charakteristisch, da B Schiller während der Einzelszenen keinerlei Bühnenmittel aufbietet, um die lllusion der hinten vorgehenden Schlacht aufrecht zu erhalten. Bei Shakespenre. I Heinrich VI: III, 3, wird Burkund von der Pucelle niche im Kampf, sondern bei einer Unterhandlung auf dern Marsch gewonnen. Schiller gibt auch diesem FührerEespräch, wie dem Gefecht, ein pasar theaterwirksame Momente: crüffnend das Dazwischentreten der Jungtrau unter die kampfbereiten Großen (effektvoll schon Don Carlos II. 5. wo die Königin zwischen Don Carlos und Alba tritt: gemessener Braut v. M. 1749 ff., wo Don Manuel mit gezogenem Schwert die Chöre trennt); die Jungfrau stehs ähnlich zwischen Burgund und Dunois 1. Hire wie Cocthes Ifhigenie V. 4 zwischen Thous und Orest: abschließend die Versöhnungssruppe mit dem emphatischen Fallenlassen der W'affen. 
matischen Nachteile der antikisierenden Gestaltung unbedenklich in Kauf nahm, ist offenbar. Die Episode Montgomerys war in planvollem Parallelismus zur Lionelszene erfunden worden, um die Jungfrau in der Unerbittlichkeit ihrer Sendung zu zeigen. Je härter und exemplarischer der Einzelfall ausgebildet werden mußte, um so schwieriger wurde die Aufgabe des Dichters, das Tun der Heldin vor dem Eindruck des Gräßlichen zu bewahren. Hier waren unerschütterliche Vorstellungen der Antike und ihre ehernen Klänge willkommen, und die besondere, nur dieser Szene zugebilligte Erhabenheit hatte für die besonderen, nur ihr eigenen Schwierigkeiten einzutreten. Aus gleichen Gründen durfte Montgomery nicht wehrlos als Flehender, sondern nur in Waffen als Streiter gefällt werden. Dazu gab ihm Schiller vor Antritt des Kampfes noch ausdrücklich eine Hoffnung auf Erfolg. Die homerische Einkleidung verhinderte weiter, daß die beiden parallelen Gefechte Johannas gefährlich gleichförmig verliefen. Der Dichter hat die zwei Vorgänge so weit als nur möglich geschieden. Nichts macht die epische Ruhe der Begegnung mit Montgomery eindrücklicher als die gedrängte Hast, womit Lionel der Jungfrau in den Weg tritt, seinen Entschluß kundtut, sich zu erkennen gibt und ihr erliegt. Dort überall breites Ausholen, verweilende Reflexion, hier der rascheste Gang und die straffste Konzentration.

Als einzig zugelassene Form des feindlichen Zusammenstoßes waren die wiederholten Führerzweikämpfe ${ }^{27}$ ) auf mannigfaltige Gestaltung angewiesen. Ähnlichkeiten blieben ohnehin unvermeidlich. So gleichen sich die Begegnungen der Jungfrau mit Burgund und dem Schwarzen Ritter in manchen äußern Zügen, und bei Burgund und Lionel führt dieselbe Art des herausfordernden Zusammentreffens zu fast gleichen Ausdrücken. ${ }^{28}$ ) Ganz war eine gewisse Ermüdung in dieser Reimser Schlacht nicht zu überwinden, denn es gesellten sich noch Schwierigkeiten des Schauplatzes dazu. Schiller kam hier nicht ohne die shakespearische, für die Kulissenbühne aber umständlichere Veränderung in „eine andere Gegend des Schlachtfelds“ aus. Das nächtliche Treffen hatte sich noch in die einheitliche Szene gefügt und bloß eine Teilverwandlung im Hintergrund erfordert. Aber vor der Einförmigkeit der Führer gefechte in Tiecks Genoveva und im Octavian schützte ihn schon die Mäßigung, womit er es nur in den beiden unentbehrlichen Fällen wirklich zum Schlagen

9) II, 7 Jungfrau-Montgomery; II, 9 Jungfrau-Burgund; II, 10 Dreigefecht: BurgundLa Hire-Dunois; III, 9 Jungfrau-Schwarzer Ritter; III, 10 Jungfrau-Lionel.

23) Burgund tritt Johanna als unbekannter Ritter mit geschlossenem Visier wie Talbots Geist gegenüber, nur erscheint dieser als Verfolgter, jener als der Verfolger; ganz ähnlich Johannas Frage "Wer bist du" usw. und der Versuch, aus der Rüstung auf den Träger zu schließen, v. 1691 ff. u. 2414 ff.; die Vorstellung vom höllenentstiegenen Blendwerk, das die Jungfrau (2445 ff.) täuscht, keherrscht 1689 f. Burgund ihr gegenüber. - Lionel und Burgund: 1687 f. u. 2454 f. 
kommen ließ. Die Zusammenstöße mit Burgund werden durch Dunois und La Hire, dann durch die Jungfrau ihrerseits getrennt.

Die sichtbaren Zwcikämpfe mit Montgomery und Lionel sind beide stumm durchgeführt und ein bloß „kurzes Gefecht" ausdrücklich gefordert. Montgomery fällt lautlos, die Gewißheit seines Todes gibt ein Vers der Jungfrau. In dem Gefecht mit Lionel stützt Schiller die mimische Aktion durch einen einzigen Ausruf des Briten: „Treuloses Glück!", obwohl die Einzelheiten des Verlaufs wichtig sind und durch genaue Vorschrift geregelt werden. Johanna durfte erst mit dem Ausholen zum Tedesstreich ihre Stimme erheben und verstummt in den folgenden, für die Tragödie entscheidenden Augenblicken ihrer Liebesergriffenheit aufs neue. Die effektvolle Pantomime - das erhobene Schwert der Jungfrau sinkt vor dem Blick des todbereiten Gegners langsam nieder - gemahnt an Kotzebucs Art, der so wirksames stummes Spiel liebt. ${ }^{29}$ ) Man darf daran erinnern, daß kurz vor Schillers Jungfrau die ,Johanna von Montfaucon" das gehamischte Frauenw'esen auf den Bühnen heimisch gemacht hatte. Einige technische Prozeduren mögen daher stammen, und fast scheint es, daß romantische Kreise in dem Heldenmädchen von Orleans - die Sticheleien in den Briefen Carolinens sprechen dafür ${ }^{30}$ ) - etwas Verwandtes zu der handfesten Streiterin Kotzebues wittern wollten. Beim Sieg der Jungfrau über Lionel wird die Aktion durch dichterische Läuterung allerdings weit über die derbtheatralische Heldentat des kotzebueschen Mannweibes emporgehoben. Aber anderwärts stellt sich Schiller unbedenklich in die Sphäre der Kulissenwirkung: das Versinken des Schwarzen Ritters vor dem Streich Johannas unter Nacht, Blitz und Donnerschlag ist ein echtes Theaterrequisit. ${ }^{31}$ ) Wie Kotzebue zieht Schiller ferner das Orchester heran und führt beim pantomimischen Zweikampf mit Montgomery durch .,kriegerische Musik in der Ferne" über die Leerheit des Aufeinanderschlagens der Klingen hinweg. So fältt der Musik auch eine wichtige Rolle in der Schlacht vor Reims zu, die Schiller in ihrem Hauptteil illusionistisch, durch das Kriegsgetümmel hinter der Szene und im Orchester wiedergibt. An die Stelle des dekorativen Auf-

39) Cerad: er hälte deshalb am allerwenigsten über die zu schwach belestigte Helrrschnalle Lionels, woran das Schicksal Johannas allein hänge. spotten dürfen; vgl. darüber Hoffmeister 4. 365: W. Ficlitz. Studien zu Schillers Dramen, Leipzig 1876, S. 91: F. Weineck, Herrigs Archiv 58, 171 17.: Düntzer" 188: Bellermann ${ }^{1}$ 2. 270.

30) Caroline, hrsg. v. E. Schmidt, Leipzig 1913. 2. 219: 224; 122.

11) Uber den verwandien Effekt in Kotzebues Kreuztahrern s. o. S. 221 Anm. 65; für das folg. 0. S. 210 f. Zum Versinken des Sehwarzen Ritters Petersen S. 214 f. Die gerüstete Jungfrau - sie erscheint hier zum erstenmal im Kriegsgewand - zicht an der Spitze der Franzosen ahnlich über den hohen Felsenweg. wie die waffenstrahlende Johanna Kotzebues mit den Knoppen über die Zugbrücke: Petersen S. 199. 
wandes beim Nachtüberfall tritt hier der musikalische. Ohne sich zu wiederholen, erreicht der Dichter durch beide Mittel dasselbe Ziel, die allgemeine Schlacht kurz abzutun. Da die Trompeten, die nach den letzten vertrauensvollen Abschiedsworten der Sorel an den König ${ }^{32}$ ) einfallen und in die Kampfsymphonie übergehen, zugleich die szenische Verwandlung decken, ist die knappe Zeitspanne doppelt genützt. Die für den Theatermeister unentbehrlichen Minuten fassen gleichzeitig die Schlacht in sich; allerdings nach der irrealen Zeitbehandlung Shakespeares, der gegenüber die gottschedische Ästhetik fragen würde, wieso die Entscheidung mit Talbots Auftreten schon gefallen sein kann, da doch die Jungfrau wenige Augenblicke vorher erst zum Ordnen der Scharen abgeeilt ist. Innerhalb des Aktes steht dieses kühne Schalten mit kontrollierbaren Zeitabschnitten auch in Schillers Klassik allein und gehört zu den shakespearischen Freiheiten der Schlachtgestaltung. ${ }^{33}$ ) Die musikalische Kampfvermittlung stützt der Dichter noch durch ein rasches szenisches Bild: Soldaten ziehen schnell über den neueröffneten Hintergrund weg. Darauf heben die Führerszenen an, und die Masse betritt die Bühne nur noch als stummes Kampfgefolge der siegreichen französischen Großen. Als bewaffnete Zusammenstöße bleiben die Einzelszenen der Jungfrau allein.

Schiller hat der Reimser Schlacht ein starkes, an die Johanna-Handlung bloß mittelbar gebundenes Sondergewicht in dem machtvollen Ende Talbots verliehen, mit der scheinbaren Digression aber nur einer inneren dramatischen Forderung genügt. Wenn der Sieg der Gottgesandten schon unzweifelhaft war, mußte er sich wenigstens gegen einen bedeutenden Widerstand durchsetzen. Der Platz für den Heeresfürsten, den einzigen wirklichen Feldherrn der kriegerischen Tragödie, konnte nicht neben der Jungfrau, sondern allein im Feindeslager sein, und die Gestalt dieses ebenbürtigen Widerparts hätte sich nicht höher recken können, als in der herben Cröße seines Todes. Im Leben durfte er der Heldin nicht begegnen. Es ist kein Zufall, daß sein Wunsch, sich mit dem jungfräulichen Teufel in persönlichem Gefecht zu messen - so geschieht es bei Shakespeare -, nicht in Erfüllung geht. ${ }^{34}$ ) Auf sein Sterben

32) IIl, 5; sie deuten den Schlachtausgang aus der sicheren göttlichen Hilfe besonders eindringlich vor. Die Uberleitung in die neue Schlachthandlung, die nach der kriegsfernen Werbeszene durch die Meldung des eilfertigen Ritters allein zu plötzlich erfolgen würde, ist durch das beängstigende Gefühl der Waffenstille, worunter Johanna leidet, vortrefflich vorbereitet.

33) Im 5. Akt sind verwandte Sprünge bei den Verwandlungen (der von Raimond zurückzulegende Weg, das Anrücken der Franzosen zum Treffen) durch die Zwischenszenen V, 7 u. 9 gedeckt. Petersen übergeht bei der Behandlung ähnlicher Fälle S. 122 f., vgl. $100-01$ u. 125. die Schlacht des 3. Aktes. Zur Verwandlungsmusik vgl. Petersen S. 151; Düntzer ${ }^{6} 134$.

34) Vers $1492 \mathrm{f}$; $2415 \mathrm{f}$. wird angenommen, daß die Jungfrau Talbot in der Schlacht habe fallen sehen; dagegen wissen nach $2358 \mathrm{ff}$. die französischen Großen nichts von seinem Aus- 
häuft Schiller allen Glanz eines unbeugsamen, bis zum letzten Atemzug sich selbst getreuen Charakters und straft Talbots eigene skeptische Worte über die menschliche Größe Lügen durch die kriegerische Herrlichkeit seines Falles. vor dem auch der Feind bewundernd steht. Der unbezwingliche Tote, den der Dichter mit einem grandiosen Bild antiken Kriegerbrauchs auf Frankreichs Erde bettet wie den Helden auf seinen Schild, den er nicht lassen will, hat sein Dasein, trotzdem er unterliegt, nicht umsonst an das Würdige gewendet. Man kann in dieser dem Gegenspieler eingeräumten Größe eine Untreue Schillers an der göttlichen Mission der Jungfrau und einen Wechsel der Beleuchtung, der im Wallenstein Analogien fände, erblicken. ${ }^{35}$ ) Sicherlich war der Talbot der Sterbeszene trotz Böttigers „Bemerkungen” zum schlechthin höllischen Geist zu gut, und schon darum durfte der Schwarze Ritter nur ungewiß mit dem Feldherm zusammenhängen. ${ }^{36}$ ) Aber jedenfalls entspringt seine Zeichnung ins Erhabene dem bedachten Kunstverfahren des Klassikers, der im dramatischen Gefüge Gewicht und Gegengewicht planvoll verteilt. Es bestätigt sich dabei die Erfahrung, daß der untergehende Kriegsheld dem siegreichen dramatisch überlegen ist.

In der Sterbeszene Talbots erreicht der Einfluß Shakespeares seine Höhe. ${ }^{37}$ ) Auf seinem Vorgang beruht die großartige Weise, wie der sterbende Held in den letzten Augenblicken das Fazit des Lebens zieht, der Gegner zu dem Verscheidenden tritt und der neidlose Nachruf aus Feindes Mund seine Größe abschließend feststellt. Vorbildlich ist weniger das Ende des shakespearischen Talbot, der mit dem toten Sohn im Arm den Geist aufgibt und der Verunglimpfung durch die Franzosen nicht entgeht, als die Gestaltung

scheiden aus dem Kampl, und Johanna wird im Gefeche bloB 2317 von Lionel, ohne persönliche Berührung mit den englischen Führern, erwähnt. Wie Talbot die Todeswunde empfängt, beibt mit d m ganzen genaueren Verlauf des Treffens (daraus einzig 2357 mit einleitender Funktion: .Die Schanze ist erstürmt") absichilich im Dunkeln: die poefische Würde fordert wiederum den allgemeinsten, gehobensten Ausduck: 2306 .. Vom Strahl dahingeschmeltert, lieg ich hier."

35) Vgl. die bereits angezogene Po ermik Bellermann.'2, 292 f. gegen Fr. Th. Vischer und Bulthaupt: dazu Düntzer 128 f.; 241 f.

38) Den ausgebreiteten Streit um den Schwarzen Ritter faBt R. M. Werner. Euphorion 12, 579 ff. zusammen. Vgl. Diintzer 244 ff.: Minor. Grillparzer-Jahrb. 9, 75 u. bes. W. Fielitz, Studien S. 83 ff.; S. 90. Uber scinen homerischen Ursprung: Boxberger in Schnorrs Archiv 2. 266 ff.

${ }^{37}$ ) Bereits W. Schlegel. Dramal. Kunst und Lit. ${ }^{2} 3.411$, betont, daß Schiller im Charakter des Talbot - seiner Meinung nach nicht gliicklich - mit Shakespeare gewetteifert habe. Eine Reihe shakespearischer Reminiszenzen in der Junglrau verzeichnen Bellermann u. Petersen in ihren Ausgaten, die im folg.. wo sie angezogen werden. kennllich gemacht sind. Das Verhältnis der Jungfrau v. O. zu I Heinrich VI im ganeen untersucht ausführlich A. Bäthlingk. Shakespeare 1. unsere Klassiker 3. Leipzig 1910, S. 237 f. und 324 ff. 
des Führertodes von Clifford und Warwick im dritten Teil Heinrichs VI., die wir schon bei Tieck wirksam fanden. In Schillers Neuformung fließen Motive aus den beiden Szenen ${ }^{38}$ ) ineinander.

38) III Heinrich VI: V, 2 Warwicks skeptische Betrachtung: „Von allen Länderein / Bleibt nichts mir übrig, als des Leibes Länge. / Was ist Pomp, Hoheit, Macht, als Erd' und Staub?"* usw.: Schillers Talbot 2349 ff. „Und von dem mächt' gen Talbot ... bleibt nichts übrig / Als eine Handvoll leichten Staubs" usw. Die Stelle Shakespeares liegt viel näher als die weithergeholten antiken Parallelen des Gedankens bei Düntzer ${ }^{6}$ S. 241. Für die vorhergehenden Verse (,der Erde geb" ich, / Der ew'gen Sonne die Atome wieder" usw.) hat G. Kettner, ZfdPh 20, 344 f. die Eingangsworte zum Testament Friedrichs des Gr. nachgewiesen. - Das Hinzutreten der Franzosen zu Talbot wie bei Clifford, III Heinrich VI: II, 6 .,Weß Seele nimmt da ihren schweren Abschied? Seht, wer es ist: nun, da die Schlacht zu Ende, / Freund oder Feind, behandelt schonend ihn.“ Jungfrau $2358 \mathrm{ff}$. „Seht, wer es ist, der dort vom Licht der Sonne / Den unfreiwillig schweren Abschied nimmt! / ... Geht, springt ihm bei, wenn ihm noch Hülfe frommt." - Talbot stirbt ebenso wie Clifford wortlos im Anblick der Nahenden; ähnlich auch Geßler, dessen Ende demjenigen Salisburys u. Gargraves, I Heinrich VI: I, 4, gleicht; er versucht nach dem Versagen der Rede ebenfalls, sich mit Gebärden der Hand verständlich zu machen; Harras ist um ihn beschäftigt wie Talbot um seine Freunde. Die alte Erfahrung, daß das Gehör bei Sterbenden am spätesten erlischt, welche die Kirche beim Sterbesakrament berücksichtigt, verwendet Schiller beim Tod Franz Moors (vgl. Petersen S. 363 f.), wohl eher im Anschluß an Leisewitz als an Cliffords Ende, den die Prinzen schreiend höhnen. Die Aufforderung des Harras v. 2808 „Laßt das Ir i ische” entspricht derjenigen Lionels 2331 „,denkt an Euren Schöpfer!"; Shakespeares Talbot zu Sa.i i ibury: „Du hast ein Aug', um Cnad emporzublicken." - Für den Nachruf bei Shakespeare s. o. S. 9] f.; seinem Talbot, dem der Feind die Ehre versagt, hält ein englischer Parlamentär den Nekrolog. I Heinrich IV: V, 4, Prinz Heinrich über Percy: „Als dieser Körper einen Geist enthielt, / War ihm ein Königreich zu enge Schranke; / Nun sind zwei Schritte der gemeinsten Erde/Ihm Raum genug“; Dunois $2367 \mathrm{ff}$. „Furchtbarer Talbot! Unbezwinglicher! / Nimmst du vorlieb mit so geringem Raum, / Und Frankreichs weite Erde konnte nicht / Dem Streben deines Riesengeistes g nügen?" Vgl. auch Antonius in Jul. Cäsar III, I „O großer Cäsar! liegst du so im Staube?/ Sind alle deine Siege, Herrlichkeiten, / Triumphe, Beuten, eingesunken nun / In diesen kleinen Raum?" (Bei Kotzebue, Rud. v. Habsburg VI, 8, s. o. S. 230: „Ihn deckt ein kleiner Hügel. / Zur Spanne Landes wird sein Eigentum"). Auch hier stehen die antiken Fassunzen des Gedankens, die Düntzer ${ }^{6}$ S. 242 beibringt (Juvenal über Alexander), ferner. - Zu Lione's Versicherung 2339 f. „Der Tränen schuld'gen Zoll / Will ich Euch redlich nach der Schlacht entrichten, / Wenn ich alsdann noch übrig bin" vgl. Jul. Cäsar V, 3, Brutus: „Diesem Toten, Freunde, / Bin ich mehr Tränen schuldig, als ihr hier / Mich werdet zahlen sehn: aber, Cassius, / Ich finde Zeit dazu, ich finde Zeit.“ - Aus der Kriegshandlung vgl. noch zu Junz̧ fr. 691 „Nimmer tät's ihm [Burgund] not, / Um das zu fechten, was er schon besitze", die Antwort der Pucelle auf Talbots Ausforderung vor Orleans, I Heinrich VI: III, 2 „Es scheint, der gnäd'ge Lcr 1 hält uns für Narrn, / Daß wir uns noch bequemten auszumachen, / Ob unser eignes unser $i{ }^{*}$, ob nicht." Sachlich steht der verzweifelten Herausforderung Karls an Burgund und ihrem Abschlag (vgl. 817 ff.) diejenige Antons an Cäsar Ocłavian (Ant. u. Cleop. III, II u. IV, 2) nahe. - Zu Jungfrau 1738 „Unser Schwcrt / Hat keine Spitze gegen dich“, Jul. Cäs. III, 1 „Für Euch sind 
Es konnte nicht ausbleiben, daß das gemeinsame britische Vorbild zu Ähnlichkeiten zwischen den Führer- und Gefechtsszenen in der Jungfrau und der ihr kurz vorangegangenen Genoveva führte. Wo sic sich, ohnehin durch gemeinsame Kampfsituationen nahegelegt, aus Shakespeare ableiten lassen, bleibt eine Einwirkung Tiecks aut Schiller problematisch. Allerdings können die Übereinstimmungen dieser Art den Eindruck Tiecks verstärkt haben, daß sein Trauerspiel für die romantische Tragödie Schillers, aus der er so manches seinem Werk Verwandte heraushörtc, mannigfach anregend gewesen sei. ${ }^{30}$ ) Nun finden sich aber neben diesen eine Reihe von Berührungen engerer Natur, die in ihrer Gesamtheit den Charakter des Zufälligen ausschlicßen. Schiller hat in der Zeit des Entstehens der Jungfrau über die Genoveva korrespondiert. Weder die ablehnende Schärfe seines Gesamturteils, ${ }^{40}$ ) noch tiefgreifende Unterschiede der Wesensart, noch endlich Schillers Úberlegenheit als Dramatiker ist ein Hindernis, daß nicht einzelne glückliche Formungen des Vorgängers bei ihm gehaftet haben sollten. Ähnlichen Schwierigkeiten der Gefechtsgestaltung gegenüber mochten brauchbare technische Motive ganz wohl übernommen werden. Ein Beispiel, wie die Einflüsse durcheinandergehen, oder besser, wie eine feste technische Tradition vorhanden ist, woraus sich der Anteil des einzelnen nur unsicher herauslösen läßt, liefert freilich schon der Eingang der Sterbeszene Talbots. Der Typus des verwundet gebrachten Führers, der die Begleiter ins Treffen zurückschickt, geht auf Coethes Selbitz zurück. Tiecks Otho und Siegfried fußen auf ihm, Schillers Gestaltung faßt die Motive von beiden Seiten zusammen und erschöpft die vorliegenden Möglichkeiten. ${ }^{4}$ ) Der Verwundete im Götz dient der Motivierung einer

unsre Schwerter stumpf. Anton” (Boxberger): zu 1750 .Erst Worte und dann Streiche”, Jul. Cäs. V. I „Erst Wort, dann Schlag!” (Düntzer): vgl. auch noch die Unterhandlungsszene Ant. u. Cleop. II, 6 ..Reden wir, eh wir fechten." - Die Voraussage der Jungfrau 1222 ff. .. Jetzt, Herold. geh und mach dich eilends fort. / Denn eh du noch das Lager magst erreichen / Und Botschaft bringen, ist die Jungfrau dort / Und planzt in Orleans das Siegeszeichen" klingt stark an König Johann I. I an: ..Sei du in Frankreichs Augen wie der Blitz: / Denn eh du melden kannst. ich komme hin. / Soll man schon donnern hören mein Geschüız." Collin im Coriolan I11, 2 „Drum eilt, damit nicht schneller als der Bote / Der Schrecken meiner Gegenwart sie noch / Befalle" fuBt wiederum auf Schiller.

39) Tieck, Schriften I, XXXII. Die Geistigkeit beider Dichtungen grenzt R. Petsch. Freiheit u. Notwendigkeit in Schillers Dramen, München 1905. S. $218 \mathrm{ff}$. gegeneinander ab: Tiecks Auberungen dort S. 227: Berger' S. 527 u. 791: E. Schmidt, Caroline 2. 122 u. 612: B. Colz, Pfalzgräfin Genoveva S. 97; Klees Einl. zur Genoveva, Tiecks Werke (Bibliogr. Institut) I. 178.

40) Nach einer ersten, wohlwollenden Erwähnung an Körner 3. Juli 1800 mit steigender Strenge in den beiden Briefen an Körner 5. Jan. u. 27. April 1801: Jon as 6, 167: 235; 270. Haym ${ }^{3}$ S. 531 .

') V. 2292 ..Hier unter diesen Bäumen setzt mich nieder. / Und ihr begebt euch in die 
Teichoskopie, die in die Cenoveva-Szene übergeht, aber monologisch gefaßt und mit der shakespearischen Sterberede gepaart wird. Schiller hat einzig diese, ohne Beobachtung, stellt sich aber mit der berichtenden Funktion des Auftritts eng neben Tieck. Sein Talbot nimmt wie Otho sterbend entscheidende Meldungen entgegen, und es ist interessant zu verfolgen, wie in der sachlichen Gegensätzlichkeit der Situation - Sieg und Niederlage - das technische Verfahren übereinstimmt. ${ }^{42}$ ) Die parallelen Szenen geben eine gute Vergleichs-

Schlacht zurück“; Selbitz: „Legt mich hieher und kehrt zu Götzen." Dem Einwand des goethischen Knechtes "Laßt uns bleiben Herr, ihr braucht unser" entspricht Talbots "Ich brauche keines Beistands, um zu sterben." Der Gedanke an den Tod liegt aber dem leichter verwundeten Selbitz hier fern (wohl aber später, auf ungünstige Meldung: „So stirb Selbitz“, wie Talbot auf die Hiobspost, in der Sprache Schillers, ,,So strömet hin, ihr Bäche meines Bluts"); dagegen bereitet sich Tiecks Otho (s. o. S. 246 Anm. ${ }^{20}$ ) wie Talbot zum Sterben und erwidert auf den Einspruch des Dieners "Ihr seid nicht sicher": „Zum Sterben ist jedweder Ort noch sicher" (Vgl. dazu wiederum Schillers: „Fastolf, bringt den Feldherrn / An einen sichern Ort“). - Bei Shakespeare, wo der Vorgang selbst sich in König Johann V, 4 (,.Graf Melun verwundet und von Soldaten geführt") und I Heinrich VI: IV, 7 (,.Talbot verwundet von einem Diener geführt") findet, fehlen diese Einleitungen. - Weiteren EinfluB des Cötz auf die Jungfrau s. o. S. 301 Anm. ${ }^{24}$ ); die Jungfrau bei den Köhlern wie Götz bei den Zigeunern: Hoffmeister 4, 368; Düntzer ${ }^{6}$ S. 287; Brahm, Ritt. S. 143. Dieser Szene des in den Unwettern der Natur gehetzten Cötz steht eben so nahe die Flucht Baumgartens vor den landenbergischen Reitern im Tell I, I. Die wichtigste Einwirkung ist diejenige der Selbitzszene auf die Teichoskopie des 5. Aktes der Jungfrau.

42) Hauptmann (Tieck, Schriften 2, 128) „Sterbt nicht, der Feind ist schon zurückgeschlagen.“ Jungfrau 2298 „Edler Lord, steht auf! / Jetzt ists nicht Zeit, ermattet hinzusinken.“ Parallel ist auch die Einleitung dazu; Tiecks Hauptmann auftretend: „Wo seid ihr denn, Herr Otho? Hier, in meines Gottes Namen. - Doch nicht verwundet?" Schillers Fastolf zum auftretenden Lionel: „Hier liegt der Feldherr auf den Tod verwundet. - Das wolle Cott nicht!" Darauf folgen in beiden Szenen die genaueren Schilderungen des Verlaufs. Othos "So sterb ich gerne“ (weil der Sieg gewiB ist) dreht das "So stirb Selbitz" bei Coethe (dort, weil die Niederlage gewiß scheint) sachlich um; Talbots ,,So strömet hin" steht darin dem Götz näher. - Zu den allgemeinern, auch aus Shakespeare oder der Situation zu erklärenden Übereinstimmungen gehört das religiöse Motiv; Tieck 2, 129 „Geht nur in die Schlacht, / DaB ich vor Cott zu stehn mich möge sammeln“; Lionel 2330 (s. o. Anm. ${ }^{\text {38) }}$ ) auf S. 307 ,Mylord! Ihr habt nur noch / Für wenig Augenblicke Leben" usw.) - Ebenso der Abschied vor dem Sterben, Tieck 2, 131 „So laß uns also, Bruder, Abschied nehmen“; Lionel 2345 „Kurz ist der Abschied für die lange Freundschaft” — der für Tieck oben (S. 247 Anm. ${ }^{23}$ )) bereits aus der Warwick-Szene nachgewiesen wurde. Zu Lionels ,Auf Wiedersehn in einer andern Welt!" vgl. Warwicks „Denn Warwick sagt euch Lebewohl bis auf den Himmel.“ - Talbots Worte „Verflucht sei, wer sein Leben an das Große / Und Würd'ge wendet und bedachte Plane / Mit weisem Geist entwirt ... War unser ernstes, arbeitsvolles Leben / Keines ernsthaftern Ausgangs wert?" klingen an diejenigen Abdorrhamans an (Tieck 2, 59) "Sollt" ich mein großes, tatenreiches Leben, / Den Ruhm der Welt und meine groBen Plane, / Die schöne Zukunft einem Jüngling opfern?" 
möglichkeit. Aus der motivischen Verwandtschaft treten die Unterschiede zwischen der Dramatik Tiecks und Schillers scharf hervor, im Geistigen - Otho stirbt als frommer Gottesstreiter in wehmütiger Ergebung. Talbot als ungebeugter Cottesleugner in gewaltiger Auflehnung gegen das $\mathrm{Ge}$ schick - und ebenso im Dichterischen: in Tiecks Sterbemonolog schwelgt das Gefühl, bei Schiller herrscht der machtvoll gefaßte Gedanke.

$\mathrm{Ob}$ die Führerzweikämpfe Schillers von Tieck mitbestimmt sind, läßt sich nicht ausmachen, da sie schon bei Shakespeare im Vordergrund stehen. Anklänge an die Genoveva scheinen in der Art zu liegen, wie die Kämpfer sich stellen. ${ }^{43}$ ) Sicherer ist eine Einwirkung auf die Fluchtszenc, obwohl auch der shakespearische Talbot die Weichenden umsonst anfeuert. Auf Tieck weist hier entschieden die Übereinstimmung der Situation, kopflose Verwirrung beim nächtlichen Úberfall, und die gleiche technische Anordnung, die eine Folge rascher Schreckensrufe auf mehrere Flüchtlinge verteilt. ${ }^{44}$ ) Bei Shakespeare, wo die Szene zur Tagschlacht vor Orleans gehört, bleiben die Soldate stumm, ${ }^{45}$ ) und Talbot willigt selbst in den Rückzug.

Neben der Summe von Einzelheiten ist augenscheinlich das Motiv der Nachtschlacht selbst aus der Genoveva geflossen. Die Geschichte kennt keine nächtliche Unternehmung Johannas gegen das englische Lager. ${ }^{46}$ ) Dafür ent-

43) V. 1678 ..Verfluchte! Deine Stunde ist gekommen“" 2454 ..Verfiuchte, rüste dich zum Kampf" (s. o. Anm. ${ }^{28}$ )): Tieck 2, 55 ..Die Stunde deines Todes ist gekommen." Zu 2455 .Nicht beide / Verlassen wir lebendig diesen Platz" vgl. aber auch Shakespeare. I Heinrich IV: V. 4: „Denn die Stunde kam. / Wo einer von uns endet”, ein beim Antreten zum entscheidenden Zweikampf naheliegender Cedanke; zu 2463 .. Und unbezwungen noch ist dieser Arm" vgl. Tieck 2. 55 „Prahl nicht zu früh, dies ist ein fränksches Schwert”. - Weitere, schwankende Ähnlichkeiten entziehen sich der Gegenüberstellung in einzelnen Versen.

4) Tieck 2, 125: Erster bis Dritter Hauptmann: Schiller 11. 5: Erster bis fünfter Soldat. Auch die metrische Ungebundenheit der Zeilen bei Schiller, wenn auch durch den Charakter solcher Rufe nahegelegt, crinnert an Tieck, bei dem sie vom Vers zur Prosa überführen.

4) I Heinrich VI: I, 5 (Petersen). Daran klingt die Einleitung des Talbotschen Monologs bei Schiller an: .,Sie hören nicht, sie wollen mir niche stehn“" (Shakespeare: „Hört, Landesleut ! Erneuert das Gefechi"): ferner 1540 ..Vor diesen fränk'schen W'eichlingen zu Alehn. / Die wir in zwanzig Schlachten überwunden" - verwandt zu Shakespeare .. Nicht halb so bang fliehn Schafe vor dem Wolf /... Als ihr vor euren of bezwungnen Knechen." - Die Tiergleichnisse des shakespearischen Talbot haben wir oben S. $248 \mathrm{Anm} .{ }^{26}$ ) in der andern Fluchtszene der Genoveva (2. 52) nachgebildet gefunden; bei Schiller anklingend v. 1545; an diesen Auftritt bei Tieck (Abdorrhaman 2, 52 ..Ich könnt" euch all" mit diesem Arm vernichten") möchte man bei Wort und Tun des schillerischen Feldherm 1550 .Flich zur Hölle / Du selbst! Den soll dies Schwert durchbohren - - denken. Tiecks Oiho 2, 125 treibt die fiehenden Hauptleute ebenfalls gewaltsam zurück, aber in komischer Form.

(n) VRl. Düntzer" S. 107 f. 
spricht der überraschende Einbruch der Feinde, der Brand der Zelte und die entstehende Panik bei Schiller völlig dem Ausfall, den Tiecks Mohren in das fränkische Lager vor Avignon machen. Nur zeigt Schiller auch die ersten, bei Tieck beobachteten Vorgänge auf der Bühne. Der sachlich entgegengesetzte Handstreich Talbots gegen Orleans bei Shakespeare steht hier ferner, trotz ein paar verwandten Zügen. ${ }^{47}$ ) Beweiskräftig ist vor allem die Verwendung der nächtlichen Feuersbrunst für die der Massenaktion folgenden Auftritte. Schiller gewinnt aus ihr eine düstere, nicht mehr wegzudenkende Folie für die Montgomery-Szene, zu der die Jungfrau aus Brandes Flammen schrecklich heranschreitet, ganz ähnlich wie Tieck sie leitmotivisch seiner anschließenden Sterbeszene zugrunde legt. Damit ist freilich schon wieder die trennende Grenze berührt: für Schiller bedeutet Nacht und Brand stimmende Umhüllung eines im Grunde - trotz der Sonderart der Montgomery-Szene doch aktionellen Auftritts. Tieck verliert sich in Bild und Stimmung der auflodernden und in der Finsternis ersterbenden Flamme. Die Betrachtung von Anlehnungen sachlicher und technischer Art führt damit immer wieder zur Erkenntnis der grundsätzlichen Unterschiede im dramatischen Verfahren.

Eine besondere Stellung innerhalb der Kriegshandlung der Jungfrau nimmt die Schlachtbereitschaft ein, die den fünften Akt eröffnet. Schiller faßt darin so unbestimmt wie nirgends sonst die kriegerische Entwicklung seit Johannas Verbannung (Ende IV) in eine szenisch wirksame Einzelsituation; er gibt sich damit zufrieden, daß sie, ohne weiter in den Verlauf der Kriegsaktion eingegliedert zu sein, den augenblicklichen Zweck erfüllt. Die wiedererstandene Macht der Engländer dokumentiert sich in dem Artillerieduell, das hinter der Szene zwischen ihnen und einem französischen Heer tobt und den tosenden Gewittersturm übertönt. Die Köhlersleute erhalten daraus Veranlassung, die neue Lage in gedrängten Versen zu exponieren. ${ }^{48}$ ) Woher die französischen Truppen kommen, brauchte nicht deutlich zu werden, und das folgende lehrt,

47) Die Wachen, für die Schillers Talbot v. 1230, den Überfall vordeutend, Befehl erteilt, werden bei Shakespeare, I Heinrich VI : II, I sichtbar aufgeführt; daB sie darauf ihre Pflicht nicht tun - sie alarmieren wie diejenigen Schillers (v. 1502) u. die Hauptleute Tiecks $(2,124)$ zu spät wird schon dabei durch ihre Mißstimmung begründet. Bei Schiller hätte eine solche Motivierung der Überlegenheit der Jungfrau geschadet. Sie fehlt auch bei Tieck, der den Otho 2, 124 zornig ausbrechen läßt, daß den Mohren die Überraschung gelungen ist. Ein ähnlicher Überfall, ebenfalls mit einer einleitenden Wachszene, III Heinrich VI : IV, 3. - Shakespearisch ist die Art, wie die Jungfrau zum Losschlagen den Feldruf gibt, und wohl auch die Form: v. 1501 „Gott und die Jungfrau“; I Heinrich VI: IV, 2 „,Gott und Sankt George!", I Heinrich IV: V, 2 „Esperance! Percy!" und oft; vgl. auch I Heinrich VI: II, I.

48) V. 3061 ff. Zu 3063 „Die beiden Heere stehen sich so nah" vgl. aus dem Gedicht "Die Schlacht" v. 34 „Nah umarmen die Heere sich“; dieselbe Eröffnungssituation in Klingers Konradin, s. o. S. $167 \mathrm{Anm}^{3}$ ). Das Gewittergleichnis für die Schlacht ebenfalls in dem Gedicht. 
daB dieses Heer des Königs, das sich hier fechtbereit im Angesicht der Engländer befindet, außerhalb der greifbaren Handlung steht. Einzig Raimond gedenkt seiner noch einmal, dann entschwindet es dem Blick völlig und ist in der weiteren Entwicklung der Ereignisse nicht unterzubringen, wenn auch der Zuschauer nicht dazu kommt, die Rechnung anzustellen. ${ }^{49}$ ) Dafür konnte Schiller durch das Motiv die neue Lage mit einem Schlag ins klare setzen. Er gewann zudem in dem eröffnenden Schlachtgewitter - Kampf in der Natur umtobt das Ringen der Heere auch im Eingang des Macbeth - einen kraftvoll stimmenden Auftakt zu seinem letzten, entscheidenden Kriegsakt.

\section{Die symbolische Parteiung.}

Nachdem im vorangegangenen Reigen der Schlachten alle Mittel dramatischer Wiedergabe, der geschlossene und der dialogisch aufgelöste Bericht,

wenige Verse vorher. $Z_{41}$ dern entscheidungsschwangeren .Und jede Stunde / Kann es sich blutig fürchterlich entladen" vgl. .Die Schlacht" v. 33 .Eisern fallen die W'ürfel”.

49) Das .Französische Lager" V, 7 f., wohin Raimond nit der Kunde von der Gefangennahme Johannas gelangt, kann nach dem Klang seiner Worte vom Ardennerwald 3303 u. 3313. die eine größere Distanz voraussetzen, nicht das von den Engländern nur durch den Wald getrennte (3364) sein; dem widerspricht auch entschieden die Szene Dunois' mit den Abgesandten des Königs, worin wohl von neuer Bedrängnis durch den Feind, aber nicht von so unmittelbarer Gefahr und nach weniger von bereits erfolgter Gefechtsberühnung die Rede ist. Es sind demnach zwei französische Heere zu unterschciden. Die Worte Raimonds 3119, die dem nähern gelten: .Dort stehn die Unsern, die cuch ausgestoßen". bezeichnen nur die Partei. nich die Führer persönlich: von deren Lager - dem französischen Hauptquartier - ınuß sich Johanna in den drei Tagen ihres Herumirrens (3075) weiter entfernt haben; auch die Worte des Köhlers 3094 ff. möchte man cher auf den ferneren Standort des Hauptheers beziehen. Die nahe Streitmacht berücksichtigt der Dichter weiterhin weder bei Raimonds Meldung - er müßte doch sie zuerst aufsuchen nach den Aufbruch Dunois' (3318 ff.), noch beim Anrücken zur Schlacht (3369 ff.). Den Platz der königlichen Macht hat Schiller nicht näher bestimmt und sich damit eine elastische Raumvorstellung gewahrt. So fern den Engländern man im Eingang von V. 7 zu stehen wähnt, so nah rückt man ihnen mil Dunois' abschließendern Aufruf zum Gefecht. Hier legt der Dichter auch Wert darauf, die Fiktion ausdrücklich zu stützen, als ob der ganze, überreiche Akt an einem Tage vor sich gehe: 3323 .Frei muß sie sein, noch eh der Tag sich endet". Realiter können die Distanzen. die doppelt, zuerst von Raimond. dann nach erfolgtem Aufbruch vorn Heer zurückzulegen sind. zusammen mit der Schlacht selbst nicht wohl an einem Tag bewältigt werden, noch weniger, weil schon zu Beginn des Aktes der Köhlerbub aus der Stadt zurückerwartet wird, also nicht früher Morgen ist; auf der andern Seite wäre angesichts der drängenden Entwicklung die Annahme, $\mathrm{da} B$ die Jungfrau im Turm ütsernachten müßte, natürlich absurd. Der Akt ist in der Freizügigkeit seiner poctischen Zeitrecthnung ein gutes Beispiel für den von Petersen S. 122 (vgl. 126 u. 130) aufgewiesenen, einzigen Cinundsatz der stetigen Folge der Handlung. - $\mathrm{Zu}$ der ausdrücklichen Festsetzung des Zwischenraums von IV zu V auf drei Tage (3075) ist zu sagen, daB in 3066 \&. ebenso wie in 3249 A. U. $3262 \mathrm{ft}$. die Vorstellung cines längeren Zeitraums herrucht. 
die szenische Vorführung, die stilisierende Erfassung und die musikalische Andeutung erschöpft sind, greift der Dichter für das Schlußtreffen zur Teichoskopie. Der Soldat der Königin schildert die Feldschlacht vom Ausguck seiner Warte aus. Schiller steht mit diesem Auftritt in einer ganzen Tradition und lehnt sich an ihr Urbild, Goethes Selbitz-Szene, auch unmittelbar an. ${ }^{50}$ ) Aber die Bedeutung seiner Lösung liegt gerade in den Abweichungen von jener Gestaltung. Mit einer neugeschaffenen, krönenden Formung schließt er die gesamte Ausbildung der Schlachtbeobachtung seit Klopstock ab.

Der Dichter schreibt an Goethe am 28. November 1797 über Shakespeares Richard III.: „Zu bewundern ist's, ... wie geschickt er das repräsentiert, was sich nicht präsentieren läßt, ich meine die Kunst, Symbole zu gebrauchen, wo die Natur nicht kann dargestellt werden." Die allgemeiner gemeinte Äußerung bezeichnet scharf das, was er selbst im fünften Akt der Jungfrau für die Gefechtsdarstellung leistet. Die gesamte Entwicklung der dramatischen Schlachttechnik ist nichts anderes, als ein Ringen der beschränkten, allseitig eingeengten Darstellungsmittel der Bühne mit dem unbegrenzten Vorwurf, tiefer gefaßt ein Bemühen, den auseinanderstrebenden, uferlosen Schlachtstoff in einen dramatischen Brennpunkt zu sammeln, ihn künstlerisch zu organisieren; denn der entscheidende Umstand, daß die Natur nicht kann dargestellt werden, beruht beim Schlachtproblem nicht so sehr auf dem äußeren Unvermögen der Bühne, als dem Kunstgesetz. Ein Schikaneder, und von der entgegengesetzten Seite auch Crabbe, stellt sich mit seinen naturwahren Schlachten außerhalb seines Bereichs.

Die Geschichte der Auseinandersetzung zwischen Kampfstoff und dramatischer Form hat uns im wesentlichen drei Typen gezeigt. Ein kühn abbreviierendes Verfahren, worin das Wirklichkeitsbild grundsätzlich beibehalten ist, befolgt Shakespeare. Es setzt ein unverwöhntes Publikum voraus, das

50) Brahm, Ritt. S. 152 f.; Düntzer ${ }^{6}$ S. 301 ; Bellermann in Werke 5. 511; Petersen, Säkularausg. 6, 401 f. - Die allgemeine Verwendung der Beobachtung gehört zum wichtigsten formalen Zuwachs der neuen gegenüber der alten Klassik. In der Jungfrau zwei hervorstechende Fälle, zur Unterstützung des Dekorativen: 1755 „Blick um dich her!/In Asche liegt das engelländ'sche Lager" usw.; 2434 „Schau hin! Dort hebt sich Reims mit seinen Türmen“ usw. Fensterbeobachtung v. 671 u. 1919 ff.; Sonnenuntergang 3093 u. 3193 (ähnlich bedeutungsvoll schon Räuber III, 2). Die Naturbeobachtung leistet die größten Dienste im Tell, wo die Umwelt am reichsten in die Handlung einbezogen ist: Berg und See, Gewitter und Sturm werden durch sie gegeben, und die szenische Darstellung mannigfach unterstützt. Hauptbeispiele im Eingang (I. I) und auf dem Rütli (II, 2; Mondregenbogen 972 ff.; Morgenröte 1441 ff.). Beobachtung von Undarstellbarem: Viehherde $49 \mathrm{ff}$.; Schiffsbeobachtung: Baumgartens Rettung $165 \mathrm{ff}$.; GeBlers Fahrt 2163 fr. Die Braut v. M. dagegen zeigt nur die auch der alten Klassik eigene Beobachtung von Auftretenden; $2151 \mathrm{ff}$; $2259 \mathrm{ff}$. usw. Erlauschen $125 \mathrm{ff}$.; $982 \mathrm{ff}$. 
keinen Anstob nummt, wenn die Realitat auf der Bïhne nur mangelhaft zur Anschauung kommt, also etwa cine Volkerschlacht, durch ein Dutzend Statisten dargestelle, sich gefallen läle. Durch williges Mitgehen in den Aubendingen eroffnet es dem Dicher den writesten Spielraum in der poetischen Erfassung des Kricges. War die Anspruchslesigke't verloren, wie schon im Sturm und Drang. so mulite diese kriegsedichterisch reichste. Darstellungsweise die Stücke dem Theater entfremden. In strikten (iekensatz dazu steht die stilisierende Schlachterfassung. die in der deutschen Entwicklung ain reinsten in dem Gefecht der Iphigenie"1) gegeben ist. Sie ruckt von der Realität bewußt und ausdruicklich ab, und enthindet sich dadurch von ihren Ansprüchen. Je entschiedener sie den Standpunkt der Kunst betont, um so unanfechebarer wird sie. Dagegen hatte freilich schon die franzosische Klassik mit Versuchen, die strenge Form rationalistisch 31 begrunden, verstolien. Die gottschedische Theorie und Tragodienpraxis kam mit hrem Citundsatz, sie vor der platten Vernunft zu rechtfertigen. aus dem Dilrmma vollends niche mehr heraus. Als Resultat der Fintwicklung von Cottsched uler den Sturm und Drang erstehe an dessen Ausgang der dritte. der theatralische. Siblachentyp. von da ab der häufugse und zumal auf den Bühnen herrschende. In seiner Art und Unart prägt er sich am scharfsten bei Kotzebue aus, alxer auch in der hohen Kampfdramatik Schillers - aus der Jungfrau getören die mittleren Schlachien hierher - und Kleists ist er unenthehelich. Er beruht aut einem Kompromiß zwischen dem unbeschränkten Stoff und den breschrankten Möglichkeiten der Darstellung. Fir wird dic Realitat der Schlacheen niche erreichen können. aber er kann sie vortäuschen: nicht im aussichtstosen Welteifer mit der Natur. sondern durch Frsetzen der Erscheinung durch ihren bloken Eindruck. Er steht darin Shakespeare nahe, daß er dic Wirklichkeit zugrunde legt. und weil die Theaterschlachten viele Kunstmittel dem Brnten entlehnen, sehen sie vielfach aus wie shakespearische. fur die moderne Kulissenbiahne zugestutzte Gefechtsbildungen. Aber das Wollen ist ein anderes und die Grenze nur dadurch verwischt, daß3 auch Shakespeare heute auf dieser Bühne autgeführe wird. Her ist das Fold der geschickten Regesenurauskunfte. der unentbehrlichen Theaterkennenis der Dicher. der Tummelplatz der szenischen und musikalischen, insgesamt der lllusionistischen Hiffumatel. Elenso wicheig wie die dramatische Organisation der Schlache wird das gewander. Verdecken ihrer theatralischen Sihwachen, die Beherrschung des Szenenwechsels, der Auflau

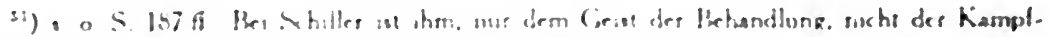

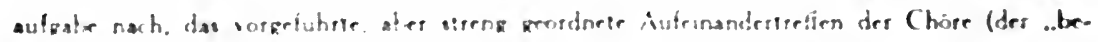

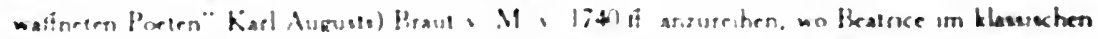

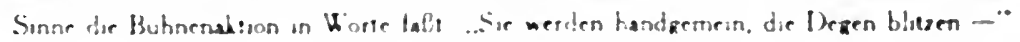


der Dekoration. Es gilt, die leidigen Störungen zu meiden, die beim Bühnengefecht mit stumpfen Klingen immer zu fürchten sind. Ein gewisses Entgegenkommen des Publikums muß auch hier vorausgesetzt werden, aber es fällt demjenigen am sichersten $z u$, der es versteht, die Illusion, wenn auch mit taschenspielerischen Kniffen, am vollkommensten' zu schaffen.

Der Schlußakt der Jungfrau reiht diesen Hauptformen ein neues Schlachtgebilde an. Vermöge einer eigenartigen Fundamentierung der Teichoskopie erreicht er den ohne Frage vollendetsten Typus der dramatischen Kriegsaktion. Schiller hält an der Realität des Schlachtbildes fest, aber er behält den Kampf selbst hinten und repräsentiert auf der geschlossenen Szene das, was sich auf ihr nicht präsentieren läßt. Seine Lösung besteht darin, daß die unsichtbar fechtenden Parteien nicht nur durch Teichoskopie erfaßt, sondern zugleich, zu Symbolen verdichtet, auf die Bühne gestellt werden. Die Königin Isabeau und die Jungfrau stehen sich greifbar anstatt der draußen ringenden Heere auf Leben und Tod gegenüber. Durch diese symbolische Parteiung wird die feindliche Spannung der uferlosen Schlacht auf ihren gesammeltesten Ausdruck gebracht. Ihr dramatischer Kern ist für die Szene ohne alle Bühnenbalgerei gewonnen. Es liegt diesem Verfahren ein klassisches Prinzip zugrunde, das mit dem System der vertretungsweisen Führerkämpfe bei Shakespeare, der nur das Massengefecht durch das Einzelgefecht ersetzt, nicht zu verwechseln ist. Eine technische Vorstufe haben wir in der Stellung Max Piccolominis beim Truppenaufstand im Wallenstein gefunden. Indem aber Schiller in die geschlossene Szene zugleich die gegenständliche Vermittlung des Treffens aufnimmt, wie sie der Götz geübt hatte, gelangt er zu einer Synthese der strengen und der freien Schlachtform. Sie vermeidet das shakespearisierende Getümmel auf der einen, die klassizistische Verflüchtigung der Vorgänge auf der andern Seite. ${ }^{52}$ ) Aber sie bewahrt sich aus der losgebundenen Technik den Impetus der Kriegsbewegung und paart ihn mit den dramatischen Vorteilen der angestraften Formgebung.

52) Was immerhin auch die klassizistische Tragödie strenger Observanz in der Epoche Schillers, obwohl sie sich nach wie vor dem Kampfgeschehen verschließt, an Wirklichkeitsnähe gewonnen hat, lehrt am besten der Vergleich der beiden österreichischen Dramatiker und Soldaten, C. v. Ayrenhoffs und Heinr. Jos. v. Collins. In dessen "Coriolan“ (Berlin 1804) wird in starkem Gegensatz zu der frostigen alten Schule alles getan, um die Kriegshandlung durch eine Fülle lebendiger Züge innerhalb der Schranken der Form sinnfällig zu machen: Feldherrnautorität II, 5 u. IV, 2; Führerbegabung II, 7 u. IV, 2; Soldatenbehandlung III, 1; Waffnung II, 7; Kriegsplan II, 7; Beobachtung IV, 6; strenger Disziplinbegriff (aus Collins strengem Staatsbegriff erwachsend) II, I u. II, 5. - Im „Regulus“ (Berlin u. Frankfurt 1802), der sonst wenig Kriegerisches enthält, wird der Wert und die Unersetzlichkeit altgedienter Truppen (II, 2, DNL 139 II, S.312) verständig ins Licht gesetzt. 
Rückblickend sind schüchterne Ansätze zur symbolischen Parteiung in der Entwicklung mehrfach zu erkennen. Für die Hermannsschlachten bot die Uberlieferung in Segest eine Gestalt, die zwar nicht dem Feindeslager, aber auch nicht dem eigenen angehört. Elias Schlegel wie Klopstock machen sich die Möglichkeit zunutze, ihn während der Schlacht als dramatischen Vertreter des Feindes auf die Szene zu führen, und deuten damit einen spannenden Zwiespalt wenigstens an. Entfernter verwandt ist eine Situation in dem sonst kümmerlichen Ritterstiick von Hahn (I, 5). Robert weilt scheinbar als Freund auf Adelberts Burg, als diesem tückische Angriffe von Roberts Leuten gemeldet werden. Der hinterhältige Feind gibt sie Schritt um Schritt kalt zu. Etwas vom dramatischen Wert der Parteiung wird auch in dieser, im einzelnen anders gelagerten Szene sichtbar. Viel näher steht die Unterhandlung in Ifflands Friedrich von Österreich (oben S. 200), die Freund und Feind vor dem Schlachthintergrund im Zimmer zusammenführt. Sie scheint auf dem Auftritt des Paters in den Räubern zu beruhen und weist damit in Schillers eigenes Schaffen. Schon der junge Dichter faßt den Gehalt des Massenzusammenpralls in eine Auseinandersetzung der Führer, Moors und des Unterhändlers, die an die Stelle des kriegerischen Sachgeschehens tritt. Aber ein weiter Weg trennt diese Szene von den streng gebundenen Formungen des Wallenstein und der Jungfrau. Die wirklichkeitsferne Gefechtsgestaltung der Iphigenie liegt dazwischen. Das Kennzeichnende des klassischen Typus ist die parallele Führung der sichtbaren und der unsichtbaren Handlung, wie sic auch nicht zufällig in den Ansätzen bei Klopstock und Elias Schlegel vorliegt. Die Räuberszene fällt wie diejenige Ifflands noch vor die Schlacht und läßt den Bühnen Raum für ihre pantomimische Durchführung. Es ist immerhin bemerkenswert, daß schon sic einen knappen, aber wichtigen Gebrauch von der Teichoskopie macht, nach der Situation zwar nicht für den Kampf, aber für die drohende Bereitschaft der gegnerischen Scharen.

Eine genaue Parallele zu der Anlage der Jungfrau, mit der korrespondierenden Partciung der Fechtenden und der Zuschauer, findet sich in der Geschichtschreibung Schillers. Die Bürger von Antwerpen sind auf ihren Wällen Zeugen der nahe vor der Stadt ausgefochtenen Schlacht von Osterweel (Austruweel). Jedes von den schlagenden Heeren hat nach Schillers Worten ${ }^{53}$ ) seinen Anhang und seinen Feind auf den Mauern, und die Spannung des Treffens wird wie später im Drama in das gegensätzliche Frohlocken und Entsetzen der beiden Zuschauerparteien gefaßt. Die Schlachtbeschrcibung formiert sich so unter Schillers Hand zur dramatischen Szene. Fast scheint es, da $B$ die Vorstellung einer Bühne zugrunde liege. Die Zuschauer des Schlachtschauspiels ver-

23) Ceschichie des Abfalls der ver. Niederl. 4. Buch. Werke 6, 463. 
drängen das Treffen selbst aus dem Gesichtskreis. Die Reflextechnik tritt ein, jede Bewegung auf dem Gefechtsfeld malt sich in den Gesichtern der Antwerpener. Fast kühner als es dem Epiker zusteht, verdichtet Schiller den Widerschein der Vorgänge in knappe Aktionen der Beobachter: Sie wollen, von den geschauten Ereignissen mitgerissen, den Sinkenden halten, den Fliehenden zum Stehen bringen, die Gegnerischen ihn einholen, aufreiben, vertilgen so wie der Beobachter auf der Szene dem Erspähten mit der Gebärde folgt. Die sachliche Beschreibung des Treffens geht im Geschichtswerk, das ein episches Nacheinander des Gleichzeitigen verstattet, der Mauerschau voran. Aber sein Handlungsgehalt erschließt sich dem Dramatiker sehr bezeichnend erst in der Zuschauerpaniomime, die er in einer antithetischen Satzfolge scharf durchführt; historisches Präsens hat ihren dramatischen Gegenwartscharakter zu stützen.

Minder nahe steht, als dramatische Vorstufe, die Teichoskopie in Klingers Konradin. (Diejenige im Octavian Tiecks fällt zeitlich später und liegt sachlich ferm.) Klinger bereitet die Lösung der Jungfrau immerhin darin vor, daß er schon die bloße Schilderung der Schlacht dramatisch eingliedert und in dem Widerstreit der Führer eine wirksame Gegensätzlichkeit gibt; sie hat allerdings noch nichts für den Zwiespalt des unsichtbaren Kampfes Symbolisches. Im Konradin hängt an dem beobachteten Verlauf des Treffens die Entscheidung über das Eingreifen; in der Jungfrau, mit höchster Anstraffung der Spannung, das Leben der Heldin. ${ }^{54}$ ) Tieck konnte im Blaubart dieselbe dramatisch unübertreffliche Verzahnung der Teichoskopie - außerhalb kriegerischen Zusammenstoßes - seiner Quelle entnehmen. Bei Schiller, der sich schwerlich dieser abliegenden Szene erinnerte, ist sie als technischer Meistergriff frei erfunden. ${ }^{55}$ ) Aber auch dieses Kernmotiv der Anlage tritt bereits in der Schilderung der Antwerpener Schlacht auf. „Der Ausgang des Treffens schien das Schicksal jedes Zuschauers zu entscheiden“", heißt es dort zur stärksten Begründung ihrer Anteilnahme. Abschließend wird das Resultat des Kampfes in emphatischer Gegenüberstellung auf die Bürgerschaft bezogen. ${ }^{56}$ )

54) Vgl. Petersen, Säkularausg. 6, 401-02; für Klinger s. o. S. 173; die Situation ist bei Schiller mehrfach eindringlich klargestellt, am prägnantesten in Johannas ahnender Voraussicht 3376 ,Mein Volk wird siegen, und ich werde sterben“, und in Fastolfs höhnender Aufforderung 3405 f. „Du weißt, was dich erwartet. Jetzt erflehe / Glück für die Waffen deines Volks!“

$\left.{ }^{55}\right)$ Nur eine schüchterne Andeutung liegt in dem ,So stirb Selbitz!" des Götz, das bereits oben S. 309 Anm. ${ }^{42}$ ) zu Talbots Ende heranzuziehen war, und seinerseits auf des Cassius Tod, Jul. Cäsar V, 3 zunückgeht, den die schlechte Meldung verschuldet.

36) „Jetzt fiehen die Geusen, und zehntausend glückliche Menschen sind gemacht; Thoulouses letzter Zufluchtsort steht in Flammen, und zwanzigtausend Bürger von Antwerpen sterben den Feuertod mit ihm." Werke 6, 463. 
Dic Erzählung rückt damit noch enger an den Schlußakt der Jungfrau heran, und man wird einen inneren Zusammenhang zwischen den beiden Schlachtformungen nicht verkennen können.

Weil die'symbolische Parteiung eine besondere Disposition des Stoffes verlangt - Vertreter der kricgerischen Gegenmächte müssen nebencinander ohne den Appell an die Waffen auf der Bühne Platz finden -, wird sie ein seltener Typus sein. Der shakespearische, die Massenschlacht vertretende Führerzweikampf und die klassizistische, stilisierte Führerbegegnung beherrschen das Feld. Aber den Erweis, daß ncben derjenigen Schillers weitere Lösungen möglich sind, liefert eine stofflich und formal ganz anders gelagerte Szene Kleists in den Schroffensteinern. Einmalig ist allerdings die besondere, nach allen Seiten vollendete Durchbildung dieses schlachttechnischen Meisterstücks. Dic Geschichte bot einzig die Tatsache der Gefangenschaft der Jungfrau. Alles weitere, der Gedanke, sie an den Block zu ketten, während draußen die Entscheidungsschlacht ihres Landes geschlagen wird, die Wendung, sie in der höchsten Not kraft ihres Glaubens das letzte und größte Wunder tun und dann auf dem Bette der Ehren fallen zu lassen, gehört dem Dichter. Gegen die Abkehr vorn geschichtlichen, düsteren Ende sind zuerst dic Romantiker aufgetreten. Dieser Tadel berührt aber nicht die dramatische Vollkommenheit des unhistorischen Ausgangs.

Es war einer der sicheren Griffe Schillers, der gefangenen Johanna die weibliche Gegenspielerin, das Mannweib Isabeau, zur Hüterin zu setzen. Die Kontrastfigur, der schon der Triumph ihrer Gefangennahme zufällt, müßte allein um der strengen Symmetrie der entscheidenden Szene willen erfunden sein. Für die Reflextechnik bietet das leidenschaftlichere Gefühlsleben der Frauen die größten Vorteile. Zugleich wird damit die Unwahrscheinlichkeit aus dem Wege geräumt, daß wichtige Führer dem Kampf entzogen bleiben. Die Motivierung der Teichoskopie ist so unanfechtbar wie nirgends sonst. Die gefangene Jungfrau darf nicht mitstreiten und darf nicht sehen. Ein übermächtiger Zwang tritt an die Stelle mehr oder minder lockerer Begründungen, warum die Zuschauer untätig stehen und dazu einen Berichterstatter zwischen sich und den Ereignissen dulden. Aus der Schwäche wird so eine Stärkc, denn aus Johannas Auflehnung gegen das äußere Machtgebot quillt gerade dic dramatische Kraft der Situation. Dic Jungfrau strebt mit heißen Wünschen aus den beengenden Mauern in dic Schlacht, aber sie ist gefesselt. Sie glüht, den wogenden Kampf wenigstens mit Augen zu sehen, aber es ist ihr verwehrt. Sic darf sich ihres unfehlbaren Gesichtes rühmen und prägt das Feldherrnwort vom Blick, der die Schlacht regiert, aber der Feind vergönnt ihr auch nicht eine Ritze in der Maucr. Isabeau ihrerseits hat für das Leben der Gefangenen gebürgt und läßt sie nicht aus den Augen. Sic ist damit 
ebenso an eigener Ausschau gehindert, und die Parallelität in der Stellung der beiden Frauen auch darin durchgeführt. Die äußere szenische Anordnung hilft mit: es geziemte der Königin nicht, die hohe Warte zu ersteigen. Der Soldat muß somit als notwendiger Vermittler der Ereignisse eintreten. Innerlich aber schreibt sich seine Bestallung von der klassischen Forderung des klar geschiedenen Aufbaus und reinlicher Trennung der Aufgaben her. Die sachliche Motivierung deckt nur restlos die aus tieferen Notwendigkeiten erwachsende formale Anlage.

Ein besonderes technisches Interesse hat die Überleitung, die Schiller zwischen dem Abgang der englischen Feldherren und dem Anheben der Teichoskopie einlegt. Genau gerechnet muß Lionel noch erst die Scharen zum Kampf stellen und eilt daher vor Fastolf ab; jedenfalls muß so viel Raum geschaffen werden, daß die Führer das Schlachtfeld erreichen können. Dazu dient akustische Beobachtung ${ }^{57}$ ) durch die Jungfrau, die sich aus den Klängen des fränkischen Kriegsmarsches das Bild des Heranzugs ihres Heeres aufbaut. Es ist der seltene technische Typus der hypothetischen Schilderung, den Schiller zuerst im Fiesko braucht. ${ }^{58}$ ) In engverwandter Bildung, aber visionär gewendet, kehrt dasselbe Mittel noch einmal im „Demetrius" wieder. Dort erschließt sich Marfa aus der Kraft der Phantasie das Nahen des befreienden Heerzuges, sie hört die Trommeln und Kriegstrompeten des Sohnes über die Weite der russischen Steppen weg im Geist, wie Johanna durch die Mauern des Kerkers körperlich, und sie ruft daraufhin die Völker Rußlands von allen Enden des Reichs begeistert zum Krieg auf, gleich wie die Jungfrau die draußen anrückenden Franken zu Kampf und Sieg. Zugleich mit der technischen Prozedur geht, lehrreich, der ganze Komplex der dichterischen Vorstellungen auf die neue Gestaltung über. Auch Marfa gibt in der Szene mit Hiob als gefangenes, geknechtetes Weib dem Mächtigen, trotzdem er ihr Leben in der Hand hat, in Banden Gesetze - vor dem Werbeaufruf, in derselben Anordnung wie in der Jungfrau. Wie auf Johannas Hochsinn beim Anzug der

${ }^{57}$ ) Sie ist in der Jungfrau auch sonst häufig (v. 994, 1909, 2551, 2763); ebenso in der Braut v. M. (Lauschszene Beatricens 982 ff.) und im Tell (Läuten 967, 2151, 2841 ; Hörner 1728 usw.). Technisch am nächsten steht der Horchmonolog Leicesters Maria Stuart V, 10.

${ }^{58}$ ) Er konnte von ersten Ansätzen bei El. Schlegel über Lessing zu Fiesko, Egmont und endlich Kotzebue verfolgt werden. Es scheiden sich voneinander der visionäre Typus, ohne oder wenigstens ohne nähere Beziehung zu außerszenischen Vorgängen (Lessing. Egmont). wozu auch eine Kampfprophezeihung wie diejenige Attinghausens Tell IV, 2 zu rechnen ist, und der konkrete, der wirkliche Kampfgeschehnisse vermutungsweise erschließt. Dieser kann sich, wie hier in der Jungfrau, der sicheren optischen Beobachtung sehr nähern, wenn ihm Gehörseindrücke zugrunde liegen. Der Fiesko gewinnt allerdings gerade aus ihnen, aus Leonorens fiebrig gespanntem Horchen, umgekehrt eine Kampfvision, die mit der Realität nichts zu tun hat. 
Hhren die schueren Kelten doppelt lasten, ist Marka ..peengt, geturnden., Beschrankt unit dem unendlichen Ciefithl". ahgeschnitten von der befreienden Tat. Aler we der Jungfran Secte sich aut den Flugeln des fränkischen Kriegsgesangers frei aus dem Kerker schwengt, so schöppt dic Mutter ihr Gebet und Hehen flanmend aus der urfuten Serele und sondet es dern Sohne beflugete.

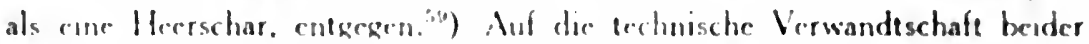
Auftritte netere der poetischen falle noxh ein Lirht aus den Skizzen zum De.

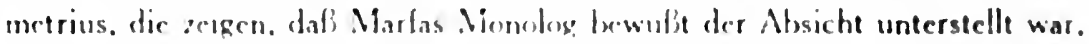
rinen weiten. Sprung im Ortawerhsel innerhalth des Aktes zu überbrucken. ${ }^{60}$ ) Dir hrpothetisctio Sthilderung Joharmas dient drmsellen Zweek der Szenenverhindung in der Yeit.

Der Gang der darauf anhebenden Tricheskenpie erhalt dadurch. daß Freund und Feind zugleich den Kampt werfolgen und im erregten Wechsel seinen Verlauf ahfragen, cine ganz newe Stobkraft. Der Jubel des einen ist der Schmerz des andern. Die. Spannung auf dic Entscherdung kann niche höher anwachsen als in dem Tumult von Angse und Hoftnung. den jede Wendung des Gefeches zeitigt. Fur seine sachliche Durchfuhrung war die Rucksicht auf einen geschichelichen Tatbestand nicht gegetren. Auch das Schlachereschehen konnte daher durchaus dem klassischen Cesetz unterworfen werden. Der unerlälliche Gluckwerisel ist doppelt. streng symmetrisch sind die dramatischen Akzente gesetzt. zwei Handlungen. in die sich der gesteigerte Affekt entlädt. Bei der ersten Krise, der scheinharen Niederlage der Englander, zückt Isabeau den Dolch aut die Jungfrau, und nur die augenthlickliche fiendung hemme den Todesstreich: lxi der zweiten, dem gewissen Linterliegen der Franzosen, zerreibt Johanna die Ketten. Diese innere dramat ische Organisation des Gefechts iblerragt scine auleere Buedeutung weit. Darum ist das taktische Bild, trotz Schillers oft bewährter Kunst, es prägnant zu formen. hier vernachlässigt. Nur cinzelne Fetzen aus einem im Zusammenhang nicht vorgestellen Verlauf werden nach Bedurfnis in die Szene geworfen. Der französische Angriff entwickeft sich, man hört von einer Brücke, die der Burgunder bedrängt. Fastolf im erbitterten Fufkampt verteridigt, von cinem Graben, wo im dichtesten Gewühl die Cirofien brider Heere aufeinandertereffen: dann wird Lionel umzingelt und befreit und durch denselben Fastolf. der den Feind im Rücken faft wieso er, selbut sctiarf im Cefecht, dazu gelangt, blethe unterïcksichtigt - die Entscheidung herbeigefuhrt. Aus der allgemeinen Fucht der Fränkischen

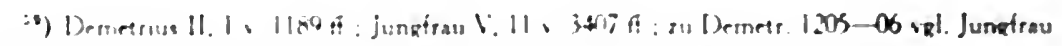

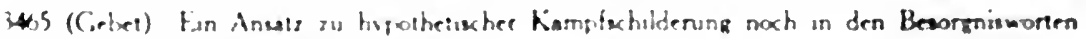
[Duno: um Johenns. 2300!

๑) VRl daruter Peteroen $\leqslant 102$ 
blitzen wichtige Einzelbilder auf: der Zusammenlauf um den schwerverwundeten Dunois und, den Ausschlag gebend, die Gefangennahme des Königs, auf deren Stichwort das Wunder erfolgt.

Vom Eingreifen der Jungfrau ab erfüllt sich das Geschick der Engländer augenblicks. Kaum daß sie dem Turm entwichen ist, muß Isabeau mit ihren Rittern vor den eindringenden Franken schon die Waffen strecken. Die überstürzte Schnelligkeit des Geschehens war hier durch das Wunderbare gerechtfertigt, und Schiller unterstreicht sie noch ausdrücklich in der Unfähigkeit des Soldaten, den Vorgängen auch nur mit dem Auge zu folgen. Dasselbe sieghafte Tempo gibt er aber unbedenklich schon der ersten Schlachthälfte, deren umfängliche Aktionen in der knappen Bühnenzeit real niemals Platz fänden. Klopstock hatte mit einer der Wirklichkeit nahekommenden Schlachtdúuer alle dramatische Spannung seiner Kampfhandlung verscherzt. Schiller setzt die dramatische Forderung ohne Rücksicht über die rationalistische, und der Erfolg gibt ihm Recht. Den Hauptanstoß hat er sorgfältig dadurch umgangen, daß eine neu auftauchende, im Gefecht unten nicht gesehene Gestalt, La Hire, in den Turm eindringt. Die Zeit, die die entwichene Johanna braucht um ins Schlachtfeld zu gelangen, wird durch die stockende Pause nach dem unfaßbaren Ereignis ihrer Befreiung gewonnen, deren Dauer sich im Bühneneindruck stets vervielfacht.

In den sachlichen Motiven der Ausschau faßt Schiller das ganze Gut, das die Entwicklung bot, zu einer kraftvollen Einheit zusammen. Die wesentlichen Möglichkeiten enthält schon die Selbitz-Szene, und es sind im Grunde immer dieselben durch den Gegenstand bestimmten Züge, die in den Teichoskopien wiederkehren. Als Rahmenmotive die eröffnende Aufforderung an den $\mathrm{Be}-$ obachter, den Auslug zu erklimmen, und die zum Schluß drängende Mahnung herabzukommen, die schon bei Shakespeare durch trübe Ergebnisse veranlaßt wird; dann die treibenden Fragen der Untenstehenden, die Hindernisse, die sich der klaren Auffassung des Bildes entgegenstellen, im Gätz das Drunter und Drüber des Kampfgewühls, seit Ramond und Längenfeld stereotyp die aufsteigende Staubwolke. Doch zeigt auch bei Motiven von allgemeinerer Verbreitung die enge Übereinstimmung im einzelnen, daß sie Schiller vor allem aus dem Götz geläufig waren. Ein paar feinere Wendungen finden sich nur bei Goethe und ihm, und auch wörtliche Anklänge fehlen nicht. ${ }^{61}$ ) Aber wie in

61) Die Wegnahme der Reichsfahne durch Götz scheint ebenso wie bei Isabeaus Frage danach (3439) bei der atemlosen Schilderung der Gefangennahme des Königs vorzuschweben; die unterstreichende Frage, die deutlich zwischen den Parteien scheidet, im Götz: , Er stürz!. - Der Hauptmann? - Ja Herr - “ kehrt bei Schiller scharf entsprechend wieder: 3446 ,Sie entfiehen! - Wer fiieht? - Die Franken, die Burgunder fliehn." - Das Feststellen der Kämpfer nach ihrem Äußem, das Petersen S. 279 als geschickten Criff der Kostümbeschreibung aufführt, findet sich eben- 
der Gesamtanlage der Teichoskopic, so sind bis in die letzten Verästelungen der Formgebung hincin die Unterschiede von Gocthes Gestaltung, nicht das Gemeinsame der Sachmotive das Entscheidende. Der Vergleich mit der SelbitzSzene ist fruchtbar, weil er an besten die klassische Verfestigung ermessen läßt, die Schillers Auftritt von dem vorbildlichen der Geniezeit trennt. Charakteristisch scheidet sich schon der Duktus der Reden und Zwischenreden, die in der Jungfrau bei gleichem Schlachttempo ungleich gemessener schreiten als im Götz, und sich wohl zur höchsten Eile, aber nicht zu der abgerissenen Hast der Realistik Goethes erheben. Daß der Vers an sich dafür kein Hindernis wäre, sondern nur der klassisch maßhaltende Vers, wird Kleists ebenfalls jambische Beobachtungsszene in den Schroffensteinern crweisen.

Scheinbar äußerliche Abweichungen der Szenenanlagen führen in die Tiefe. Schillers ,.Wartturm“ ist kein beliebiger Punkt des Schlachtfeldes wie die „Höhe mit cinem Wartturm" des Cötz, der Auftritt in ihm kein lockerer Ausschnitt aus der Kampfhandlung, worin eine beliebige Figur, Selbitz, zur Motivierung der Teichoskopie dienen muB. Der Kerker der Jungfrau birgt das Handlungszentrum, und die symbolische Parteiung besteht eben darin, da $\beta$ das dramatische Gewicht aus der außerszenischen Schlacht in das Bühnengeschehen herein verlegt wird. Der Kampf draußen ist nicht mehr Zweck eines über die Bühne hinausweisenden, sondern Material eines in sich selbst geschlossenen Auftritts. Das Prinzip der Verinnerlichung, das der französischen Klassik Schlacht und Kampf verbot, kehrt in der deutschen wieder. Aber als Ergebnis der gesamten Entwicklung seit Cottscheds Reform hat sie die Mittel in der Hand, die größte Kampfaufgabe, die Feldschlacht, in voller Gegenständlichkeit in den strengen

falls übercinstimmend im Gölz: ..Ein weiBer Federbusch, wer ist das? - Der Hauptmann": Jungfrau 3455 . Wer trägt den himmelblauen Mantel ...? - Das ist mein Herr, der König". Beide Male fragt der Beobachter, der Empfänger antwortet. Ähnlich Jungfrau 3421 „Ein W'ütender aut einem BarberroB...- Das ist Graf Dunois !’" umgekehrt v. 3430 f. Im Gözz antwortet der Knecht auf Selbitzens Frage nach der Person einmal mit ihrem Abzeichen: ..Siehest du Cötzen? Die drei schwarzen Federn seh ich mitten im Getümmel”: vgl. „Georgs blauer Bussh verschwindt auch". - Auch dic antike Teichoskopie pflegt die Helden aus Rüstung. Waffen und besonders dem Schildzeichen zu erkennen. Schiller halte 1788 die Eingangsszene aus Euripides' Phönizierinnen übersetzt, worin der Erzieher die parallelen Fragen Antigones nach der Person der erspähien Führer befriedigt: die Verse der Jungfrau sind aber der Selbitzszene ähnlicher. - Für wörtlichen Anklang ist das fast unvermeidliche ..Sieg! Sieg! Sie entflichen!" (3446). Götz: ..Sieg! Siegl Sie flichn" (Brahm) allerdings nichı beweiskräflig; viel eher 3437 . Am Craben ist ein furchterlich Gedräng": Cotz: ..ein fürchterlich Cedräng wo or stund”" - gemeinsame Wortvahl, gemeinsarne Apokopen. - Düntzer" S. 302 nimmt Arsto3 an Dunois ..Cendarmen", dem einzigen kriegshistorischen terminus der ganzen Teichoskopic (schwergerüstete, aus Rittern formierte Kavallerie Karls VII.). Die allerding unpathelische, moderne Bedeutung ist aber erst nachschillerisch. Preußen hatte bis 1806 ein Kürassierregimest Gens d'armes. 
Bau einzufügen. Die alte Klassik hatte auf sie verzichtet, die Übergangszeit war an ihr gescheitert. Jetzt überwindet die neue nicht bloß die Schwierigkeiten des Vorwurfs, sondern erreicht eine Lösung, die aus dem Treffen die dramatische Grundlage für die entscheidende Szene des Stücks gewinnt. Was Klopstock anstrebte, ist geleistet, die blutige, schöne Todesschlacht in geschlossener Form zu triumphaler Geltung gebracht; allerdings als Schlußstein eines reichen Dramas, nicht - dies war der unheilbare Irrtum des Bardiets - als sein alleiniger Inhalt. So wie W. Schlegel das dramatische Gesetz der Darstellung des Krieges aus Shakespeare abstrahierte $:^{62}$ ) er muß, ,wenn dramatisches Interesse da sein soll, nur Mittel zu etwas anderm und nicht letzter Zweck und Inhalt des Ganzen sein".

In der Schlachtform bestehen zwischen Klopstock und Schiller engere Beziehungen, als die unüberbrückbare Kluft im Dramatischen vermuten liesse. Die angekettete Jungfrau hält die Szene bis zu der wunderbaren Wendung gleich unverrückbar als festes Widerlager der Ausschau besetzt, wie der Bardenchor in Hermanns Schlacht. Dessen schlachtregierende Funktion ist in Aufruf, Wunsch und Gebet Johannas enthalten, die dem Geiste nach das Treffen leitet; sein überquellender lyrischer Part, dramatisch angestrafft, in den Gefühlsausbrüchen beider Frauen bei den Wendungen des Kampfes; im Auftreten Segests liegt ein erster Keim zur symbolischen Parteiung. Die Gestaltung Schillers darf demnach nicht nur im allgemeinsten als die Erfüllung dessen gelten, was der erste große Versuch im deutschen Schlachtdrama wollte, aber nicht erreichte.

Wie sehr die klassizistische Engherzigkeit der Form Schiller fern lag, erwiesen die mittleren Schlachten. Auch das letzte, formal verfestigteste Treffen endet mit einer shakespearischen Verwandlung in das Kampffeld, die das Schlachtstück durch eine große kriegerische Apotheose abschließt. Der Dichter will beim Tod der Jungfrau nicht auf einen vollen Ausklang mit allem Glanz der Bühnenerscheinung verzichten. Es wird darin dieselbe Freizügigkeit in der Formenwahl sichtbar, die viel unvermittelter den Auftritt Montgomerys aus dem szenischen Schaustück des Lagerbrandes hervorgehen ließ. Schiller wahrt sich jetzt alle Beweglichkeit und kennt von der Jungfrau ab, den einen unmittelbar darauf mit der Braut von Messina betretenen Seitenpfad abgerechnet, keinen unverbrüchlichen Regelkanon mehr. Die Lockerung der Technik gegenüber dem Wallenstein ist in der Kriegshandlung besonders auffällig, aber sie umfaßt das ganze Gebiet der Formfragen und hält im Tell und Demetrius an. Auf der andern Seite tritt aber das klassische Grundprinzip aus der letzten und wichtigsten der Jungfrau-Schlachten so deutlich hervor, daß von ihr ein starkes Schlaglicht auf die innere Notwendigkeit der Form in der Montgomery-Szene

69) Dramat. Kunst und $\mathrm{Lit}^{2}$ 3, 202. 
zurückfällt. Auf klassischem Boden wird die Synthese der freien, vorgeführten und der gebundenen, berichteten Schlacht gefunden und in der Beschränkung und Verinnerlichung der Schlachtaktion leistet Schiller sein kampftechnisches Meisterstück. Die Szene ist darin der gesammelteste Ausdruck der Formgebung in der Jungfrau und der letzten Periode Schillers überhaupt. Nach anfänglich größerer Strenge ist der klassische Kunstwille weitherzig genug geworden, um auch shakespearischen Bildungen Platzrecht zu gewähren und sich damit eine shakespearische Fülle der Erscheinung zu gewinnen. Aber er behält die Zügel in der Hand und er ist es, der nach allen Seiten die Grenzen absteckt, die durch stoffliche Forderungen gelegentlich hinausgeschoben, aber nie ernstlich überschritten werden. Der ganze Reigen der Schlachten der Jungfrau führt, trotz unablässiger sachlicher Aufforderung dazu, nirgends zu dem im Ritterstück gepflegten Kampfspektakel, weil es dem klassischen Ideal zuwiderläuft. Dieses steht letzten Endes über allem Stofflichen. und Schillers eigene Worte vom Neuerfinden der Form zum neuen Stoff erfahren durch das Werk selbst die Einschränkung, daß dieses Neucrfinden nur innerhalb des geschichtlich bedingten, hier des klassischen Stilgesetzes statthaben kann. 


\title{
Dreizehntes Kapitel. \\ Die Kriegsdramatik Heinrich von Kleists.
}

\author{
Horcht aut sein Kriegsgespräch, und grause Schlachten \\ Vernehmt ihr vorgetragen in Musik.
}

Shakespeare in Heinrich $V$.

Die beiden Soldatenkinder der deutschen Literatur, die zu ihren größten Soldatendichtern heranwachsen, treten ihre Dichterlaufbahn in ähnlicher Opposition zum Heer ihrer Zeit an. Schiller entflieht ihm, Kleist nimmt seinen Abschied. Aber so wenig die Auflehnung des jungen Schiller gegen bestimmte militärische Zustände für sein Verhältnis zum Krieg etwas ergibt, so wenig sagen die biographischen Daten und Zeugnisse im Leben des jungen Kleist darüber aus. Den Friedensdienst schüttelt er ab, und die Erfahrungen eines ihm gleichkommenden schleppenden Feldzuges. Die Quellen über Kleists Soldatenzeit fließen spärlich. Es sind immer wieder dieselben dürftigen Berichte, die durch die ganze Literatur wiederholt werden: zwei Mitteilungen Fouqués und einige Angaben Bülows - an dokumentarischem Wert weit überragt durch die eigene Darstellung Kleists, die er seinem Lehrer Martini am 19. März 1799 gibt, an der Lebensscheide, wo er sich von der Offizierskarriere abwendet. ${ }^{1}$ ) Ein beweiskräftiges Seitenstück zu diesem Brief ist in

1) Fouqués und Bülows Berichte jetzt in Gespräche, hrsg. von F. v. Biedermann, Leipzig [1912], Nr. 10 u. 79; 8 u. 13. Uber den Soldaten Kleist vgl. zunächst Heinr. Meyer-Benfeys umfassende Monographie, auf die im folgenden nicht überall eigens verwiesen ist: Das Drama H. v. Kleists, Göttingen 1911-13, 2 Bde. 1, 9-11; ferner aus der überreichen Kleistliteratur, die E. Kapers dänische Guiskard-Monographie, Kopenhagen u. Christiana 1908, bis 1906 in weitem Umfange verdienstvoll verzeichnet: A. Wilbrandt, Kleist, Nördlingen 1863, S. 6 u. 8; O. Brahm, Kleist ${ }^{5}$, Berlin 1911, S. 6, 9-11, 13-15, 18; Th. Zolling, DNL 149 I, S. IV, V. VII; F. Bamberg, ADB 16, 128; H. Gaudig, Wegweiser durch die klass. Schuldramen, IV. Abt., Gera u. Leipzig 1899, S. 7-9; Fr. Servaes, Kleist, Leipzig usw. 1902 (Dichter u. Darsteller Bd. 9), S. 3ff.; E. Schmidt, Einl. zu Kleists Werken 1, 6*-7*; A. Eloesser, Kleists Leben, Werke u. Briefe (SchluBbd. der Áusg. des Tempelverlags, Leipzig [1911]), S. 6-8, 30; W. Herzog. Kleist, München 1911, S. 21 f. u. 29. - Den Brief Kleists (Werke 5, 31-32) rückt schon Wilbrandt S. 17 f. und nach ihm Bamberg, ADB 16, 129, als innerlich erschöpfendes Zeugnis seiner militärischen Periode in den Mittelpunkt, nachdem E. v. Bülow. Kleists Leben u. Briefe, Berlin 1848, S. 9 versucht hatte, den darin aufgerichteten Gegensatz zwischen Dienst- 
einem Schreiben des Freundes Pfuel beigebracht, der „in anderen Diensten, wo Krieg ist, Verwendung finden" will, weil "der preußisch militärische Schneckengang" ihm alle Hoffnungen benimmt, sich emporzuschwingen.") Diesem Friedensberuf des Offiziers, dem Garnisonsdienst allein, gilt auch Kleists Rechenschaftsbericht. Gegen ihn fallen die bösen Worte, gegen ihn ist die aus dem Mund eines preußischen Offiziers allerdings befremdliche Charakterisierung des preußischen Drills gerichtet. Lessing, der Vorgänger des späteren Homburgdichters in der Verherrlichung preußischen Soldatentums, hatte darüber als Fernstehender leichthin spotten dürfen (Minna IV, 5), inmerhin hinter einem unverbindlichen, schalkhaften Frauenurteil vorsichtig Deckung suchend. In Kleists Lage war der Druck des ganzen Systems bitterernst, und die mit dem Frühjahr herannahende Exerzierzeit ist es geradezu, die den langgehegten Entschluß zur Reife bringt. Vorn Krieg im ganzen Brief auch nicht ein Wort. Was Kleist von ihm gesehen hatte, mochte nicht dazu angetan sein, ihn von der Friedensplackerei auszunehmen. Eine jugendliche Schilderung der ersten bunten Eindrücke der Kampagne, die der sechzehnjährige Feldzugsteilnchmer im März 1793 an die Tante v. Massow aufsetzt, kann nicht ins Gewicht fallen, so wenig wie die schablonenhafte, noch völlig unkleistische Polemik gegen den Kricg in seinem frühesten Gedicht. So spricht auch der oft angezogene Stoßseufzer an Ulrike (25. Febr. 1795) über das unmoralische Zeittöten im Feldzug viel mehr den Ärger über diesen lahmen Krieg, als über den Krieg überhaupt aus. Der reifende Kleist jedenfalls, der zu eigenem Denken erwacht war, ist in den Anschauungen des Zeitalters der Humanität und in seiner Friedensliebe nicht heimisch. ${ }^{3}$ ) Wie es darum in den Tiefen seines Wescns bestellt ist, zeigt vicl eher jenes aus dunkeln Gründen aufsteigende heiße Wünschen, womit er, über dem Guiskard zusammengebrochen, den „schönen Tod der Schlachten" umfängt, jenes Bild des „unendlich-prächtigen Grabes", das ihn mit der sinkenden Flotte Napoleons aufnehmen soll (an Ulrike 26. Okt. 1803), zeigen vor allem, charakteristisch, die Schroffensteiner.

Kleist wirft das Berufssoldatentum hinter sich als undisziplinierter Individualist, der in keiner militärischen Zucht, und am wenigsten in der preußischen, gedeihen kann. Er ist sich dessen sellist bewußt: es ist das ,durchaus

pflicht und Menschenpflicht als kleistische Spitzfindigkeit beiserte zu schieben; befangen genug. weil darin ein erster Keim zum „Homburg" zurage liegt. Inzwischen hat die Forschung dargetan, da B dieser Konflikt schon das Soldatenstück des 18. Jahrhunderts mannigfach beschäfrigte. - Als zwei arme adelige Offiziere und Dichter stell $O$. Fischer, Kleists Guiskardproblem. Dortmund 1912, S. 33 Cerstenterg und Kleist nebeneinander.

2) S. Rahmer, H. v. Kl. als Mensch u Dichter. Berlin 1909, S. 12 u. $6 \mathrm{ff}$.

$\left.{ }^{2}\right)$ Die gegenteilige Auffassung vertritt Mever-Bentey 1, 10 u. 2,519; vgl. W. Herzog S. 22. 
Ungleichartige“", das der Soldatenstand mit seinem eigenen Wesen in sich trägt, das ihn zu dem Schritte zwingt. Aber ähnlich Schiller verklärt der Mann, der jung sich gegen eiserne Disziplin bäumt, in seiner Reife sie als das unverbrüchliche Grundgesetz. Man wäre versucht, die Parallele durchzuführen und zwischen ersten und letzten Werken bei beiden eine ähnliche Mäßigung und Bändigung der Grundanschauungen zu erkennen. So wie bei Schiller die Strecke vom zwecklos vernichtenden Krieg des einen gegen alle bis zu dem notwendigen Krieg der geschlossenen Gesamtheit, der Weg von den Räubern zum Tell durchlaufen wird, so hier die Bahn vom Krieg als fesselloser Auswirkung der Individualität (Schroffensteiner, Penthesilea) zum Krieg als oberstem Mittel der Staatsorganisation, als eisem diszipliniertem Werkzeug in der Hand des überlegenen Staatslenkers (Homburg). Und weiter: wenn des späten Kleist Hohelied der Manneszucht nach seinen Anfängen und nach einer unbotmäßigsten Gestalt wie Achill überrascht, so könnte man auf das schroffe Disziplinverhältnis hinweisen, das er daneben schon im Guiskard bildet, ganz wie inmitten der revolutionären Auflehnung der Schillerschen Räuber ihre unerbittliche soldatische Unterordnung steht. Aber man würde mit diesen Annäherungen das wirklich Wesentliche verdecken : den entscheidenden Gegensatz zwischen Schillers und Kleists Kriegsauffassung.

Schillers ganze Gedankenwelt ist auf eine sittliche Weltordnung bezogen, und ihr fügt sich seine Anschauung vom Krieg ein; am reinsten in den späten Werken, im Prinzip aber schon in den Räubern. Das moralische Denken fordert eine Begründung des Krieges, und so wird er denn in der Jungfrau von Orleans vaterländisch, im Tell menschheitsrechtlich verankert. (Der Wallenstein ersetzt das objektive Recht zum Krieg durch persönliches Ethos.) Selbst der Räuber Moor, durch das höchste Unrecht zu bewaffnetem Aufruhr gestachelt, trägt an jedem Greuel seiner Durchführung schwer und beugt sich schließlich der Weltordnung, das erweisend, was er widersprechen will. Ganz anders Kleist. Ihm steigt der Krieg aus den Tiefen menschlicher Anlage, aus der Dämonie der Seele herauf, ist naturhaft, elementar in seinem Ursprung, und daher schrankenlos, barbarisch in seiner Äußerung, ein grausamer Vernichtungswille, der keine Zweckmäßigkeit und daher auch nicht die Zügel kennt, die menschliche Sitte dem Krieg als politischem Mittel von beschränktem Geltungsbereich angelegt hat. Die staatsmännische Weisheit des Oktavio: „Im Kriege selber ist das Letzte nicht der Krieg“, hat hier keine Geltung, er ist in der Tat das Letzte, das Furchtbare, Blindwütende, das alles und zuletzt sich selbst (Penthesilea) Vernichtende. Jene Auffassung ist entschieden falsch, die schon in Wallensteins Lager das Elementare des Krieges zu sehen vermeint. Elementar ist er erst bei Kleist, und in dieser Zeit nur bei Kleist, bei Schiller aber immer noch sozusagen gottgewollt, in seinen Greueln 
gemäßigt, ,schön", und stets doch ein 'Teil des harmonischen Weltbildes. Es trennt hier nicht ein Unterschied im Grad: ein mehr oder weniger, sondern in der Art: ein entweder oder.

Diese hemmungslose Auffassung Kleists, die alle Brücken zu der reinen Humanität hinter sich abgebrochen hat, wird nicht erst - dies ist das wichtige - in seiner politischen Zeit erzeugt. Dort tritt sic nur in den Dienst des vaterländischen Gefühls und wird durch den $\mathrm{Ha}$ a des Patrioten zur lodernden Flamme angeblasen. Enthalten ist sie schon in den Schroffensteinern, dem Erstling, der in jähem Gegensatz zu der ganzen ritterlichen Gattung, die den optimistischen Ton des Götz bewahrt, nicht die Tag-, sondern die Nachtseite des Krieges aufruft, nicht das frohe Reckentum, sondem den dämonischen Kriegszug des Hasses. Enthalten ist sie im Kohlhaas, dessen Rache in furchtbarem Ausbruch Unschuldige haufenweis opfert, um den Schuldigen zu treffen. Innerlich am verheerendsten greift diese Nachtseite in der Penthesilea um sich; nach außen allerdings am deutlichsten in der Hermannsschlacht und der politischen Schriftstellerei Kleists, im Dienste der Tendenz. ${ }^{4}$ ) Hier ist der Gegensatz zu Schiller mit Händen zu greifen. Wie sorgfältig wird in dessen gebändigtem Revolutionsstück ${ }^{5}$ ) auf feinster Wage das Recht zum Kriege gewogen: ,Wenn der Gedrückte nirgends Recht kann finden" - wie wird er als das Letzte, Äußerste angeschaut, erst erlaubt, wenn alle sanften Mittel erschöpft sind, wie fast ängstlich ist ein Recht der Stärke verneint: „Schrccklich immer, auch in gerechter Sache, ist Gewalt" -, wie maßvoll selbst der Tyrann geschont: „Doch, wenn es sein mag, ohne Blut"! Skrupellos, bestialisch erhebt dagegen Kleists Empörung ihr Haupt, und so blutig ihre kriegerische Auswirkung gegen Schillers Zucht steht, so verschieden ist ihre treibende Kraft. Bei Schiller die Freiheit ein höchstes Menschenrecht, eine sittliche Forderung, daher nur mit reinen Händen zu erwerben. Bei Kleist triebhaftes Urbedürfnis der Kreatur, ein Wollen, das mit dem Leben selbst gegeben ist, vor allem Rechisbegriff, wie das Verlangen nach Licht und Luft; daher jedes Mittel recht, dieses Lebenselement an sich zu reißen. Dieser wilde Freiheitsdrang äußert sich gleich barbarisch wie in Cheruska etwa in Penthesileas Erzählung vom Ursprung des Amazonenstaates, dem Seitenstück zu Stauffachers Bericht vom Ursprung der Schweizer: das Unterdrückervolk wird in einer Nacht tückisch mit Dolchen zu Tode gekitzelt.

-) Für diese Zeit formuliert H. Schneider. Studien zu H. v. Kleist, Berlin 1915. S. 16. 19-20 die Forderung Klcists als . .löchste Brutalitä". nachdem schon mannigfach auf seine nicht zu übersehende wilde Auffassung hingewiesen war; so von R. Petsch. Kleists Homburg. Leipzig u. Berlin 1903 (Lyons Deutsche Dichter des 19. Jahrh. 7). S. 10-11.

s) Tell und Hermannsschlacht sind von Mcyer-Bentey 2. $330 \mathrm{ff}$ - - mit seinem durchgehenden Ubelwollen gegen Schiller - kontrontiert. 
In Schillers poetische Welt hätte ein solches Motiv aus den Quellen nimmermehr eingehen dürfen. Nicht daß Kleist die Tagseite des Krieges nicht kennte. Er hat das Triumphale seiner Erscheinung in Penthesilea zu höchstem Glanz gestaltet, und das Käthchen schließt die freudig ritterliche Welt durchaus bejahend ab. Aber auch darin bleibt überall die moralische Beziehung fern. Die Frage nach Recht und Unrecht hat ebensowenig im Homburg Platz, wo der Krieg als elementares Bedürfnis des Individuums sich in den Krieg als Staatsraison umsetzt. Schiller dagegen nimmt auch beim politischen Krieg moralisch Partei, etwa gegen Alba, für die Niederländer. Bei Kleist ist der Zweck oberstes Gesetz, und sein vaterländisches Pathos schöpft weder hier noch in der Hermannsschlacht seine Kraft aus dem Recht.

\section{Die Familie Schroffenstein.}

Es ist eine geniale Ironie der Schroffensteiner, ${ }^{6}$ ) daß sie die landläufige, optimistische Kriegsauffassung des Ritterstücks in ihre düstere Welt einführen, um einen vermeintlich Wahnsinnigen zu beschwichtigen. Begütigend fällt Sylvester auf Aldöberns barbarische Kriegsansage (v. 604) ein: „Doch, Alter - Was den Krieg betrifft, das ist / Ein lustig Ding für Ritter." Aber diese letzte Ausflucht vor den schon entfesselten Dämonen gefriert ihm auf den Lippen, und er muß den Zeitvertreib für Ritter in seiner zerstörenden, zum Irrsinn treibenden Furchtbarkeit anschauen. Nicht ehrlicher Krieg wird hier geführt, nicht nach Maria Stuarts Worten, "was irgend nur in einem guten Krieg / Recht ist und ritterlich" geübt, sondern der unerbittliche Kampf bis aufs Messer, die letzte Brutalität verkündet, vor der "Sengen, Brennen, Reißen und Verheeren“ als "frostig reden“ abfällt. Hier zum erstenmal blitzt grell eine Auffassung auf, von der in Schiller gipfelnden des Zeitalters der Humanität grundverschieden: man wäre versucht zu sagen, die moderne. In Rupert ist die Dämonie des Krieges, ein aus finsteren Gründen der Seele aufsteigender Zwang zur Vernichtung mächtig, und keinerlei ratio, auch nicht die ultima irgendeiner zweckbewußten Politik, sondern verheerende Leidenschaft allein regiert sein kriegerisches Handeln. "Die Leichen liegen lassen, daß von fernher / Gestank die Gattung schreckt" (v. 71), ist die Auswirkung dieser Gesinnung, die „nach dein und deines Kindes Blute“ dürstet. Der milde Sylvester selbst wollte in dieser wilden Welt entschuldigen, daß der Feind ,im Krieg mein Haus verbrannt, mein Weib und Kind / Im Krieg

6) Die Familie Schroffenstein. Bern u. Zürich 1803. Der von E. Wolff (Hendels Bibl. Nr.1634) u. H. Conrad aufgeworfenen Streitfrage Chonorez-Schroffenstcin (vgl. E. Schmidts Einl. in Werke 1, 8 u. Meyer-Benfey 1, 63f.: 2, 529) widmet H. Schneider, Studien S. 24-80 eine exakte Untersuchung. 
erschlagen" (1. 1139) -- also gerade das als begreiflich hinnehmen, was in Stanifachers Kriegshold autierstes Schreckms ist: .Dies Haus - Der Krieg. der ungetereure, brement es nieder. . Es schont der Krieg! Auch niche das zarte Kundlem in der Wicge."

Der Antanger Kleist giht in der formal wicheigsten Szene der Schroffenstemer ein Cencentild zu jener symbolischen Parteiung in letzten Akt der Jungtrau von Orleans, die Schiller aus reffer trehnischer Meisterschaft geschaffen hat. Es ist wie wern sich netern der Kluft in der Kricgsauflassung auch die Klutt in der Form entschedend dokumentieren müßte, in enem Auftritt, der nach Mitteln und Ziel demienigen Schullers genau parallel geht. Dic Szene Ruperts und Eustaches") erfatit, wie der Jung!rau-Auftritt die Feldschlache. durch Teichoshopie den Kampt im Hot. dem Jeronimus zum Opfer falte. Sie stelle, wir Schiller in Johanna und Isabeau, in Mann und Frau dic feindlichen Partesen aut die Buhne und erschopft in ihrem Cegerisatz den auterszerischen Strut. Nach den autieren Daten") und noch mehr den inneren Corunden erseheine Kleusts Foumung ganzlich unahbangig. Der junge Dicher erweist seinen Beruf zun Dramatiker durch eincn ersten, intuitiven Criff. zwei Meister funden spleichzeitig die krönende Lösung eines alten Problems. Fs stebt hicr niche die Canzheit der Szene im Sviel, mit ihrer gewittersechweren Finleitung. ihrer Eiseskalie in Ruperts Haltung bis zu seiner furchebar ausbrechenden Frage .. Was ist ein Herold?" - die nicht hlok an einer geheiligten "liadition des Rechtes von Volk zu Volk, sonden, in letzte Tiefen bohrend. an den Cirundfesten des Dasems won Menseh neben . Vienseh ruttelt. Es sind am selleen Iechnischen Typus, fur derodie stofflichen Unterschicde niches besagen. die Gegensatze zu erweisen. die Klessts Cestaltung von Schiller trement. Schon in der Aat der Symbolisicrung der Kricgsparteicn tun sie sich kund. Dort. enghell geschieden, die Königin in Waffert. die Jungtrau in Fesseln. Hier. aus unsicherer Dammerung erst ins klare licht sich aufreckend, der Morder Rupert. netern ihen die fur Jeronumus und Reche und Menschlichkeit flehende Eustache. Si) fanden wir in der Durchfuhrung die sanze Anlage

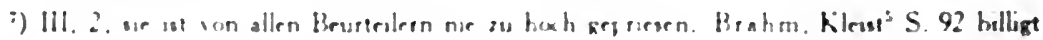

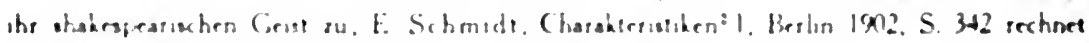

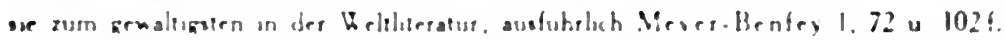

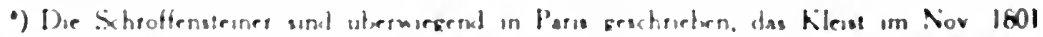

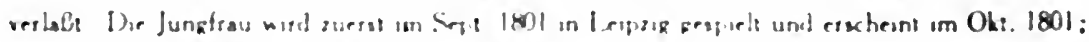

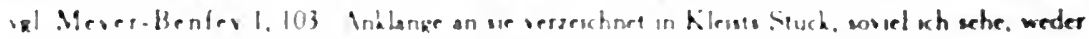

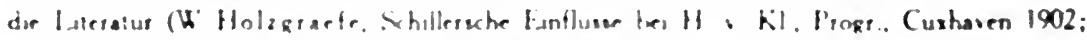

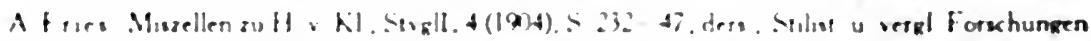

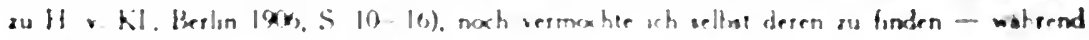

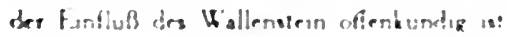


Schillers durch eine klassisch reine Scheidung der Aufgaben gekennzeichnet, den referierenden Part in den Händen des Ausspähers, dem niemand weder mit Blick noch Wort ins Handwerk pfuschen darf, den Reflex zu gleichen Teilen auf die beiden Frauen verwiesèn. Es herrscht zwischen dieser Dreiheit ein streng symmetrischer Wechsel der Rede, eine Stimmführung, die an Aeschylus' dreigeteilten Chor in den Sieben gegen Theben gemahnt. Man meint den Kapellmeisterstock zu sehen, der die durchdachten Crescendi und Decrescendi des Auftritts an- und abschwellen läßt. Bei Kleist keine gegliederte Ensembleszene, keine Verteilung der Rollen, nichts von Symmetrie. Eustache allein spricht, Rupert steht und schweigt. Sie ist Bote und bittendes Weib zugleich. Nichts kann unklassischer, aber auch nichts atemloser sein, als diese Satzfetzen der Beobachtung, dazwischen sich immer wieder ein flehendes Wort, ein Angstruf, ein Aufschrei drängt, bis die tiefe Pause nach dem dumpfen Fall des Erschlagenen im Hof die fiebernde Hast des Geschehens erst wie mit Hämmern ins Bewußtsein schlägt. Die Klassizität der Szene Schillers ist nicht besser zu erkennen als neben dieser grell realistischen Teichoskopie und zugleich auch der innerste Charakter der symbolischen Parteiung: daß sie aus außerszenischem Kampf einen stärksten dramatischen Konflikt für die sichtbare Handlung formt. Ruperts grauenvolles Schweigen, Eustaches richtender Schrei: „Du bist ein Mörder!" wuchtet schwerer als die Keulenschläge im Burghof.

\section{Robert Guiskard.}

Der gewaltige kriegerische Torso Guiskards des Normannen hat die Forschung immer wieder aufgefordert, sich an den fehlenden Gliedern zu versuchen. Soweit das Unterfangen aber über inhaltliche Anweisungen hinaus selbst auf die Form der folgenden Kriegsakte übergreift, bleibt es schlechterdings fruchtlos. Hier soll der Gesichtskreis streng auf die vorhandenen Szenen beschränkt, und vor allem das kriegerische Motiv, das sich darin schon rein ausspricht, ins Auge gefaßt werden. Es ist ein überraschender Sachverhalt, $\mathrm{da} B$ jede Lektüre dieser bloßen Tragödienexposition und noch mehr jede Aufführung den Eindruck des im Wesen Fertigen, Abgeschlossenen, nicht mehr höher zu Führenden bestätigt. ${ }^{9}$ ) Dies sollte die Verfechter des reinen Formproblems, dem Kleists Ringen allein gegolten habe, doch stutzig machen und deutet auf ein schweres Hindernis zur Vollendung wenn nicht schon im

9) Trefflich betont von Eloesser, S. 218f.; früher von W. Waetzoldt, Grenzboten 61 (1902) 3, 470-72. Die Fortsetzungsversuche mustert Kaper S. 141-42; mit den bedeutendsten setzt sich Meyer-Benfey 2,539f. auseinander; auf ihn ist auch für die gesamte, stark angeschwollene Literatur zu verweisen. Die vorgebrachten Meinungen über die Gründe, warum Guiskard Fragment blieb, bei Kaper S. $148 \mathrm{f}$. 
Stoff, so ganz gewiß in seiner besonderen, kleistischen Erfassung. ${ }^{10}$ ) Die Untersuchung der kriegerischen Kernfrage des Fragments will damit immerhin ein Beitrag zu dem so komplexen Guiskardproblem sein. Erweist sich Klcists Imperatorenmotiv als neu gefunden, als ein schöpferisch ergriffenes, bisher unerbörtes Thema dramatischer Dichtung, und liegt einer jener ganz seltenen Fälle vor, wo nicht ein neues stoffliches Gewand um altes Motivgut geworfen, sondern ein dichterisches Problem selbst - und dazu dieses - entdeckt wird, so könnte der berauschte Finder dafür wohl jene starken Worte der Briefe gebraucht haben. ${ }^{1}$ ) Schon in ihnen, nicht erst in Penthesilea, wird ihm das Ringen mit dem Guiskard selbst wieder zum Gedicht. Aber allerdings mochte diese Erfindung $2 u$ groß gedacht sein, eine gewaltige Vision mehr als ein Dramenstoff, eine titanische Situation statt einer dramatisch cinträglichen Verwicklung. Diese ist im Torso zwar angelegt, und sicher nicht an ihrer Durchführung, aber vielleicht an der Erkenntnis ihrer Minderwertigkeit gegenüber dem geschauten grandiosen Bild ist Kleist gescheitert. Auf nichts mehr und nichts weniger war es abgesehen als auf die größte Feldherrntragödie der Weltliteratur, und die Szenen des Fragments bleiben hinter diesem Ziel nicht zurück. Was aus ihnen mit jener einzigen, kleistischen Elementargewalt spricht, ist der Kampf Cuiskards mit der Pest. Darin liegt doch wohl, trotz dem methodischen Bedenken, das diesem Rückschluß aus dem Eindruck des Empfangenden entgegensteht, das Urerlebnis der Dichtung, das als das Primäre, vor allen Formabsichten Gegebene nicht scharf genug erfaßt werden kann. ${ }^{12}$ )

10) Das Formproblem vertritt am eingehendsten Meyer-Benfey 1, 210ff. u. 586ff.; das Stoffproblem, geistvoll und fördernd, O. Fischer, Guiskardproblem, bes. S. 13 u. 44f. u. Rez. za Meyer-Benfey, Euphorion 18 (1911). S. 522f,; dazu dessen Replik 2. 533 u. Fischers Duplik Euph. 22 (1918), S. 182 f. Vgl. ferner Frieda Teller, Euph. 20 (1913), S. 537 ff. u. K. Günther, Lit. Zentralblatt 1913 S. 85 (gegen). R. Schacht, Jahresber, f. n. d. Litgesch. 1911/12 S. 882 (für Fischer). - Der seltsame Umstand, daB Kleist in der Zeit der Wiederherstellung des Fragments (erschienen im Maiheft des Phöbus 1808) zwar in den Briefen das fertige Werk in Aussicht zu stellen scheint, in einer FuBnote zurn Torso ( $v$. 372) aber darauf resigniert, ist trotz E. Schmide in Werke 1. 162. Kaper S. 149f., Meyer-Benfey 1. 193: 590f.; 600f. u. O. Fischer S. 13 ( $\mathrm{vg}_{\mathrm{g}}$ Brahm S. 124) nicht abgeklär. Es ist innerlich kaum denkbar, da B er. wenn wirklich das ganze Werk so seformt vor seiner Seele stand wie das Fragment, nur eben dieses von sich abgestoben hätic.

11) An Ulrike Dez. 1802 his Okt, 1803. Die neue Deutung dieser Zeugnisse versucht $\mathbf{O}$. Fischer. Cuisk. S. 16-18, 32. 43: vgl. Sp. Wukadinowir., Kleist-Studien, Stuttgart u. Berlin 1904. S. 104t. Es ist zudern nicht zu übersehen. daB Kleist selbst stoffliche und formale Probleme viel enger zusammengeschaut haben kann als die scheidende Forschung.

J) Zuletzt ist dies beredt von O. Fischer, S. 5-11, 41-43, geschehen, der den Guiskard in den Zusammenhang des Philoktetesmotivs (kërperliches Leiden) rückt. S. 21 fi. Zur Methodik sal Pelersen. Literaturgesch. als Wissenschaft. Heidelberg 1914. S. 30 f. 
Ganz ohne Zweifel ist hier die Stofflichkeit, die Problemstellung an sich so stark wie kaum irgendwo sonst. In gesegneter Stunde gingen Kleist für eine dichterische Inkarnation titanischen Wollens gegen titanisches Schicksal die beiden Grundgewalten der mittelalterlichen Welt: Krieg und Pest, als dramatische Gegenmächte auf, ergab sich ihm die Konzeption, worin der Feldherr als höchstes Symbol triumphalen Willens dem furchtbar in der Seuche heranschreitenden Tod entgegentritt.

Wie einsam diese Konzeption steht, und wie schon das Motiv allein ein Einmaliges, Unvergleichliches ist, lehrt zunächst eine Überschau dessen, was in der deutschen Entwicklung vorangeht. Schloßbelagerung und Burgsturm des Ritterstückes bleibt für einen Guiskard belanglos, wenn sich auch gelegentlich ein tobender, Sturm über Sturm ansetzender Belagerer (Ramonds Waldemar im „Hugo“) vorfindet. Das Stadtbelagerungsstück ist zwar eine in den Niederungen viel angebaute Gattung, neben Kleist aber eben deshalb kaum zu nennen, und nur um der Tradition willen interessant. ${ }^{13}$ ) Etwas näher rückt Tieck, dessen Frankenheer in der Genoveva (Schriften 2, 99f.) macht-

13) Für eine kurze Zusammenstellung scheide ich drei Gruppen, ohne daß die Grenzen überall fest wären: 1. Die weitaus umfänglichste lokalhistorische, worin Zeiten der Belagerungsnot der eigenen Stadt und damit verbundene Croßtaten ihrer Bürger, öfter panegyrisch und in engem Horizont, behandelt werden. Fast jede dereinst belagerte Stadt hat dergleichen aufzuweisen. Herausgegriffen seien: als berühmteste die Türkenbelagerungen Wiens, deren erster schon eine Historia des Hans Sachs gilt (1566); vier Stücke über die zweite in Wiener Neudrucke 8. 1884; dann von P. Weidmann 1775 und J. B. Pelzel 178I bis auf R. v. Kralik 1883. Nahestehend die Belagerungen von Szigeth (Zriny): Werthes 1790, Pyrker 1810, Körner 1812 (über bemerkenswerten EinfluB des Guiskard auf ihn vgl. O. Fischer S. 39). Am erfolgreichsten Kotzebues Hussiten vor Naumburg, 1803. Aus Bayern: Blumhofers Schweden in B. (Landshut), 1783; aus dem 30jähr. Krieg noch: Hanau, von Großmann, 1812. Dann die Magdeburger Reihe von v. Rohwedel über Schummel und Reineke 1793 bis auf zwei Stücke F. L. Schmidts (1799 u. 1808); endlich Hamburg: Frambach 1810. Eine Einzelsituation aus solchen Belagerungsstücken satirisch in Tiecks Marionettentheater im Zerbino. Ein Beispiel aus Frankreich: De Belloys Siège de Calais, 1765; aus Spanien: Calderons El Sitio de Breda, 1636, zu Ehren Spinolas. 2. Das Konfliktsstück irgendwelcher Art, das die Belagenung als Hintergrund oder zur Schaffung der benötigten Situation verwendet: Törring-Seefeld, Belagerung d'Aubignys, 1778; Kotzebue, Heinr. ReuB von Plauen od. die Bel. von Marienburg, 1805; eine besondere Zuspitzung innerhalb des bürgerlichen Soldatenstücks: Kretschmanns Belagerung, 1786 (ein General muß seinen eigenen Sohn belagern, vgl. Stockmayer S. 42). - 3. Das Kostümstück, das die Belagenung als glänzende kriegerische Erscheinung ausbreitet: völlig naiv Einzings Eroberung Jerusalems. 1790. Äußerst kundig Kotzebues Kreuzfahrer, 1803. Das mit dem Guiskard gemeinsame morgenländische Kostüm ist in diesen Ausstattungsstücken nicht zufällig. Über den durch F. v. Üchtritz überlieferten Plan Kleists zu einer Belagenung und Zerstörung Jerusalems, aus seiner letzter. Zeit, vgl. Minor. AfdA 11, 202. 
los vor Turm und Mauer Avignons liegt. Man könnte daran erinnern, daß, zur Einnahme der Stadt ein ähnliches Motiv angelegt, wenn auch nicht durchgeführt wird wie bei Kleist: innere Uneinigkeit, hier die scheclen Blicke der christlichen Bürger auf die heidnische Besatzung. Aber man braucht nur einen Pfalzgrafen Siegfried sagen zu hören: ..Hier muß Geduld der beste Kriegsmann sein", um zu erkennen, daß für Guiskard, der vor Stambul wie ein gekrümmter Tiger liegt, hier im besten Fall eine stoffliche Situation vorgebildet war. die ihre letzte Wurzel in der Geschichte hat: die Ratlosigkeit der frühen deutschen Kriegsheere vor einem in der Kriegskunst durchgebildeten Gegner.

Dic Gestalt des unbeugsamen Belagerers ist aus der Weltliteratur in Tassos Gottfried von Bouillon beigebracht, der mit Guiskard den eisernen Führerwillen gemein hat, aber im Gegensatz zu ihm schließlich nur äußere Hindernisse siegreich überwindet. Das besondere kriegerische Motiv des Fragments, der sterbende oder der tote Belagerer, dessen Tod dem Heer verborgen bleiben muß, wurde kriegsgeschichtlich in Plutarchs Leben des Kimon (Kap. 19) und den allerdings abliegenden Berichten uiber Solimans Tod nachgewiesen. ${ }^{14}$ ) Wir vermögen zu der schlechterdings originalen Konzeption Kleists, worin sich alles, was Tragik des körperlichen Leidens, Philoktetes- und Oedipusreihe heißen kann, mit dem Willens-, das heißt hier dem Feldherrnmotiv durchdrang, nur mit Vorsicht einige weitere, vielleicht näherliegende Keime bloßzulegen.

Man weiß von dem mit Äußerungen über literarische Eindrücke wie niemand sonst kargen Dichter, wie er den Wallenstein in sich aufsog. Die Spuren, die der Friedländer in seinem Erstling hinterließ, sind mannigfach aufgezeigt. ${ }^{15}$ ) Hier nun las Kleist von einem Feldhauptmann - es ist mehr der historische als der Schillersche Friedland, den dieser Zug greifbar macht - : ,Rühmte sich mit seinem gottlosen Mund, / Er müsse haben die Stadt Stralsund, / Und

11) Tasso: Wukadinowic S. 69-72.59ff. 79f.; vgl. Kaper S. 107-10; Meyer-Benfey 2.534f. Kimon und Soliman: O. Fischer S. 38\%.. 41. Nur entfernt verwandt ist die Situation bei Burkersdorf am 21. Juli 1762, wo Friedrich d. Gr. dem russischen Kontingent den Tod Kaiser Peters III. verheimlichte.

15) $\mathrm{V}_{\mathrm{gl}}$ allgemein Minor. AfdA 11, 200f. Einzelnes bei Holzgraefe 12f.; E. Schmidt in Werke 1. 454: A. Fries. Miszellen. Strgll 4.432-36 u. Forschungen S. 12 u. 92: Fr. Teller, Euph 20, 548 Dazu noch Schroff. v. 935, werbende Kraft des grauen Hauptes, zu Wall. Tod v. 1918: ferner Schroff. 2068ff. Sylvester über seinen Zuzug: .sind sie wohl / Gestimmt, da $B$ man sie schleunig brauchen kann?" usw., wic Wallenstein über die Stimmung der Generale. Piccol. 882: "So, meinst du, kann ich was mit ihnen wagen?" usw. Sylvesters Haltung in dieser Szene ist überhaupt unter dem Bann Friedlands feldherrnmiBizer, als die kleinen Zshlenverhältnisse rechtfertigen. 
wär sie mit Ketten an den Himmel geschlossen." Die bildhafte Situation des verbissenen Belagerers, ${ }^{16}$ ) prägnanter als bei Tasso, kann für Cuiskard vor Byzanz immerhin gezündet haben, der sich vermißt nicht den oberen, aber den unteren Mächten seinen Willen aufzuzwingen: „In Stambul halt' ich still, und eher nicht!" Dazu das Wort des entschlossenen Verteidigers Gordon: "Verderben wird er eher / Mit seinem ganzen Volk vor diesen Wällen" wo Guiskards Belagerertrotz im Zuge ist, der Leiche seines ganzen Volks das Grab zu schaffen. Das Motiv kehrt im Wallenstein noch einmal in veränderter Gestalt wieder und zeichnet hier scharf die Guiskardsituation des Stürmens um jeden Preis, bedeutsam gepaart mit dem Eingreifen der Seuche. Es ist Gustav Adolfs grauser Angriff vor Nürnberg, in Questenbergs Schilderung: „Verzweifelnd endlich will der König stürmen, / Zur Schlachtbank reißt er seine Völker hin, / Die ihm des Hungers und der Seuchen Wut / Im leichenvollen Lager langsam tötet." Das sind festgeprägte Motivansätze, die eine Brücke von Wallenstein zu Guiskard schlagen, von dem Condottiere des Dreißigjährigen Krieges zu dem Condottiere der Normannenzeit, wie ihn Funks Horenaufsatz bot. Aus der unmittelbar vor Kleists erster Konzeption liegenden "Jungfrau"17) käme Bertrands wortmächtige Schilderung der Belagerung von Orleans in Betracht, in das der Maurenzertrümmerer Salisbury von hoher Warte gierig hineinspäht. So belauert Guiskard (mit umgekehrter Raumvorstellung) aus offnem Zelt wie ein gekrümmter Tiger die hohe Kaiserzinne. Ferner die Verse Lionels an den todwunden Talbot, fast eine Formel zum Guiskardmotiv: ,Jetzt ist's nicht Zeit, ermattet hinzusinken. / Weicht nicht dem Tod, gebietet der Natur / Mit Eurem mächt'gen Willen, daß sie lebe!" Belangreicher ist eine Spur, die aus Schillers Stück auf Shakespeare zurückführt. $\mathrm{Daß}$ Kleist in ihm fest war, belegen auch hier neben den Werken ausreichend die Briefe. Nicht die Szene, worauf die Erzählung Schillers ruht, aber zwei Gestalten aus ihrer Nähe haben starke Beziehungen zum Guiskard: Talbot der unbeugsame Städtestürmer und Bedford der kranke Belagerer, im ersten Teil Heinrichs VI. „Und hier steigt Talbot oder schafft sein Grab", führt der kriegsgewaltige Lord, als ,ein Geist der Hölle“ in den Augen der Franzosen, den Sturm auf Orleans an (II, 1), noch schärfer nimmt er vor dem eben verlorenen Rouen den Eid auf Leben und Tod ab:

${ }^{16)}$ Lager v. $603 \mathrm{ff}$. Es ist nicht ohne Bedeutung, daß das Bild noch im Homburg, v. $364 f$. nachwirkt: .Wärst du auch siebenfach, mit Eisenketten, / Am schwed'schen Siegeswagen festgebunden!" (Holzgraefe S. 21; E. Schmidt in Werke 3, 430). Das folg. Tod v. 3641; Guisk. v. 12; Piccol. $1049 \mathrm{ff}$.

17) Eine Spur von ihr in Guisk. v. 503f.: ..Und täglich, wie vor Sturmwind Tannen, sinken / Die Häupter deiner Treuen in den Staub“, nach Jungfr. 821 : „Und meine Städte sinken in den Staub" -? 


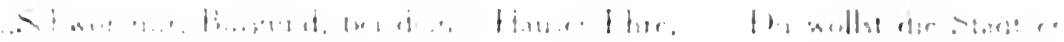

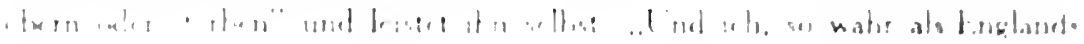

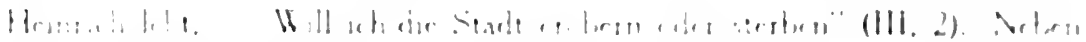

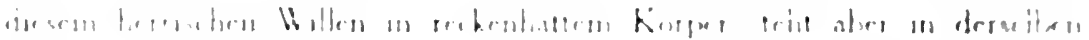

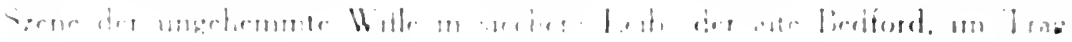

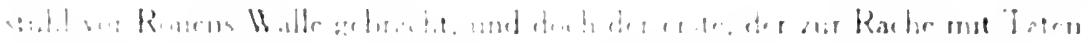

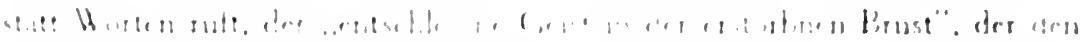

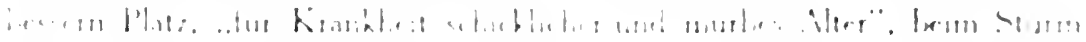

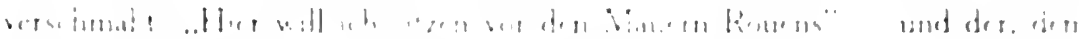

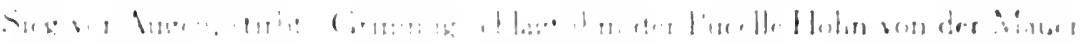

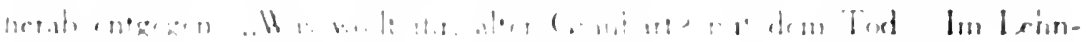

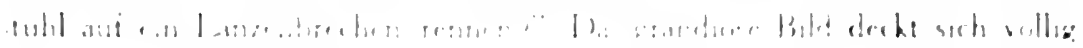

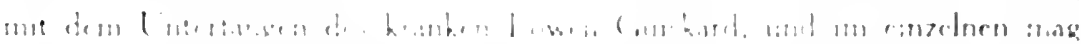

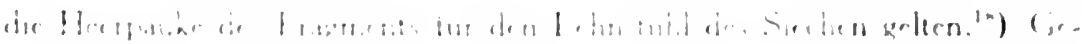

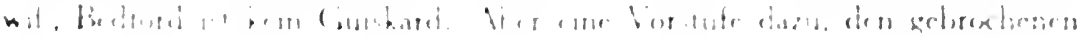

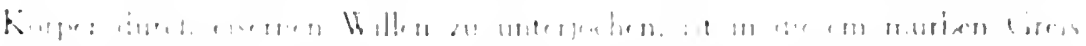

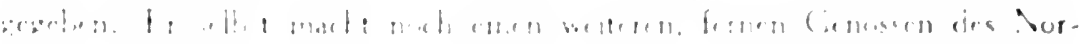

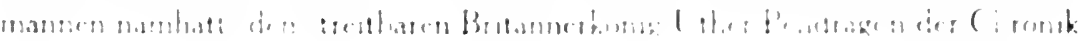

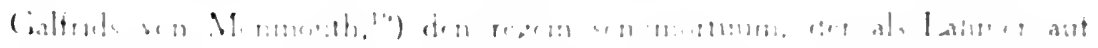

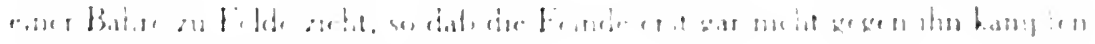

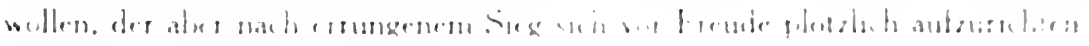

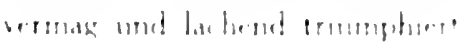

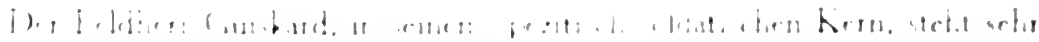

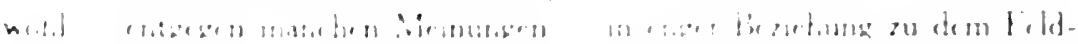

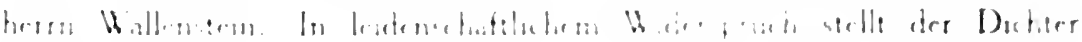

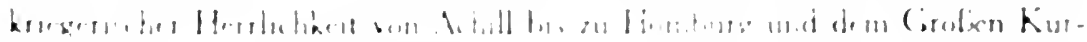

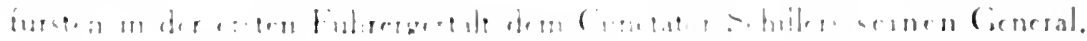

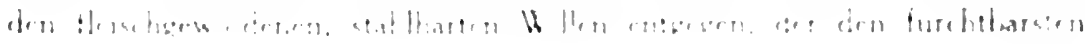

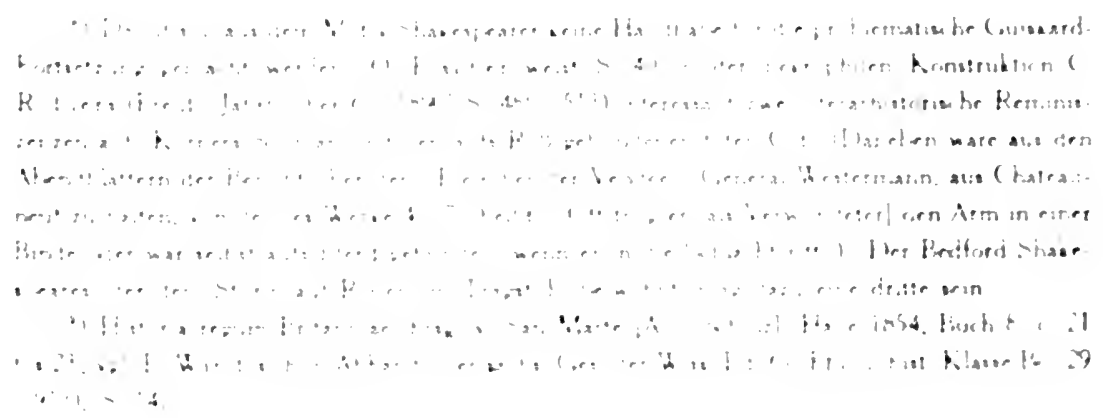


Feind ohne Besinnen besteht. Ist das Bild des Feldherrn im Dramatischen nie weitausgreifender, universeller gezeichnet als von Schiller, so nie gewaltiger, in schärfster Beschränkung auf das Kernmotiv umrissen als von Kleist. Dort der schwankende, mehr getriebene als treibende Grübler, hier der vulkanische Tatmensch.

Dieser Titane hat einen bedeutsamen Vorgänger im Sturm und Drang: Klingers Pyrrhus. Nicht im Motivischen, aber als zwei gleicherweise Torso gebliebene Versuche, das Heldentum im antiken Riesenmaß der Leiber zu bezwingen, sind die Szenen von Pyrrhus' Leben und Tod und die Guiskardszenen verwandt. In der Imperatorenreihe, die von der Antike, etwa dem geschlagenen Xerxes der aeschyleischen Perser zu Kleist führt, jener Reihe, die dann in dem Achill der Penthesilea ebenso unantik als gewaltig gipfelt, ist der Pyrrhus ein Clied; ein Vorgänger zudem, der unausweichlich auf Shakespeare hinweist. Ohne Antonius kein Pyrrhus und kein Guiskard. Auf Shakespeares Römerdrama, als der großen Neuschöpfung der heldischen Antike in modernem Geist, ruht auch Kleists Fragment, wern es auch das Gewand des normannischen Mittelalters trägt. Es ist überzeugend dargetan, wie der Guiskarddichter kraft seiner unerhörten Erfindung - nicht das Formproblem steht hier in Frage - sich vermessen konnte, der Antike den Kranz abzureißen. ${ }^{20}$ ) Wie Shakespeare, mag ein Blick auf Antonius lehren, dessen heldischer Wille dem Liebesgenuß erliegt, wo der Normanne nach titanischem Ringen mit der Pest fallen sollte. Die Krafttendenzen der Geniezeit, aus Shakespeare genährt, finden in dieser Konzeption ihre Krönung. Wie nahe Kleist damit dem Sturm und Drang steht, wie eng sich seine Auffassung des Heldischen mit dessen Titanismus berührt, ${ }^{21}$ ) macht der gemeinsame Gegensatz zum Wallenstein handgreiflich. In der friedländischen, politisch komplizierten Welt, in Schillers streng gebundener Auffassung wäre für die primitive Urkraft eines Pyrrhus so wenig wie eines Guiskard Raum. Allerdings, ein fundamentaler Unterschied besteht zwischen ihnen. In Klingers Fragment - es ist darin, gegen Kleist, im eigentlichen Sinne fragmentarisch verpufft dieser Titanismus kraftgenialisch ohne rechte Gegenwirkung. Die großartige Geste kann daher an das Muskelprotzentum streifen. Bei Kleist hat der Gewaltige den ungeheuern Gegner gefunden, den einzigen, den er nicht zu zermalmen vermag: die Pest. (Man denke an die neue Wendung

$\left.{ }^{20}\right)$ O. Fischer S. 41-43, 38; von aeschyleischem Kothurngang des Fragments spricht E. Schmidt. Charakteristiken² I, 345. Ausschließlich antiken Charakter sieht Wukadinowič S. 107f. im Guiskard; gegen ihn Meyer-Benfey 1, 243 u. 246; 2, 540.

21) Fr. Tellers Polemik (Euph. 20,548) gegen O. Fischer (S. 33, 43f.), die den Zusammenhang Kleists mit der Sturm- und Drangdichtung (Fischer stellt Gerstenberg in den Vordergrund) leugnen möchte, kann ich nicht beipflichten. 
bei Hebbel: des einsamen Titanen Holofernes Sehnsucht nach Vernichtung durch einen Mächtigeren).

Minder gewichtig sind Übereinstimmungen der beiden Fragmente in der Formgebung. Die Ähnlichkeit der Exposition überrascht zwar zuerst, ebenso in der äußeren Situation - vor dem Zelt, worin der Held bei Klinger wirklich, bei Kleist dem Vorgeben nach ruht; dort die Nachtwache vorgeführt. hier cin wichtiger Vorfall aus ihr erzählt - als in der inneren Anlage. Bei Kleist wie bei Klinger wächst der Feldherr, bevor er selbst erscheint, auf indirektem Weg ins Große. Doch war diese Expositionsweise eben erst mit höchstem Kunstverstand im Wallenstein geübt worden, wenn auch Guiskard dem Pyrrhus im einzelnen unleugbar näherkommt. Der eine Zug, den Helden unmittelbar vor seinem Auftreten aus Beobachtermund aufrecht im Zelt zu schildern, findet sich bei beiden übereinstimmend. Die besondere Mischung des höchsten Stils mit kecker, selbst krasser Realistik steht in Kleists Schaffen im Guiskard allerdings nicht allein. Aber es ist doch beachtenswert, daß sie auch in dem Torso Klingers, der das Erhabenste anstrebt, schärfer als sonst im Sturm und Drang zutage tritt. Äußere Zeugnisse für Kleists Kenntnis des Pyrrhus fehlen. Die in Frage stehende Szene war nach dem Druck im „Deutschen Museum" 1776 nur im ersten Teil des „Neuen Theaters" 1790 wieder erschienen. Sichere Einwirkung Klingers auf Kleist scheint sonst nicht nachgewiesen. ${ }^{22}$ )

Es gehört zu dem beispiellosen Reichtum des kleistischen Fragments, daß in der Fülle seiner Gesichte die kriegerischen Probleme, das Verhältnis

22) Eine Berïhrung der Penthesilea mit Klingers Medea in einer antiken Vorstellung verzeichnet Fries, Forschungen S. I Anm. 2. Eine Parallele O. Fischers S. 44 (vgl. auch S. 34) zwischen dem Jupiter des Amphitryon und demjenigen in Klingers Verbanntem Göttersohn wird von Fr. Teller, Euph. 20, 547t. bestritten. Aber es begegnen merkwürdig ähnliche Vorstellungen. Im ausgehungerten Lager des Pyrrhus (Szene V. Dramat. Jugendwerke 2, 388) rast Strabo: ..Horch. der Hunger jagt die Soldaten auf, dauerts lang, fressen sie sich auf, fressen uns auf! - Lysimach, hungern will ich nicht, meine Sätigung liegt in deinen Eingeweiden" - was ebenso an .des Sinns entsetzliche Verwirnung" der normännischen Belagerer, als an Penthesilea gemahnt. Wirks hier bei Klinger und Kleist der Ugolino nach (der für Kleist von Fischer S. 33-36 herangezogen wird), so zeigt sich doch die gemeinsame geislige Disposition, die in den Naturalismen nicht vor dem Gräblichsten zurückschreck!. Und mehr: die Szene der mit schaumbedeckter Lippe ihren Hunden beigesellien Penthesilea hat trotz Pentheus und Aktäon kaum so Verwandtes wie bei Klinzer, dessen dänonisch-bestialischer Machaon (Szene V u. VI) - ein ins Grausige gewendeter Caliban - sich mit wülender Meule herumbeißt. Er beschwört mit scheußlich ausgestoBenern Auge und vertiertem Schmerzesrasen den ganzen Horror kleistischer Körpersehändung herauf. 
von Feldherr und Heer, der Kontrast von altem und jungem Führer und besonders die soldatische Grundfrage der Disziplin so gut Platz finden, als später in den militärischen Diskussionen des Homburg. Es erweist sich, daß Kleists soldatisches Teil nicht seit der Jugend auf fast unbegreifliche Weise in ihm brachliegt, um dann in seinem letzten Werk ganz plötzlich hervorzubrechen. $\mathrm{DaB}$ es sich vielmehr in ungleicher Stärke, aber doch stetig in seinem Schaffen manifestiert. Hier endet die Parallele zu Klinger. Die eingeborene Mannszucht, eine innere Bändigung, trennt Kleists Gestalten bedeutsam von den Wildlingen des soldatischen Dichters der Geniezeit. Wie Guiskard in der Pest seinen Meister, so haben seine Krieger ihren Herrn gefunden: das Gesetz, den hier noch von aller historischen Bestimmtheit freien, aber darum nicht minder scharfen Disziplinbegriff. Man prüfe, um den Abstand zu ermessen, den alten Armin Kleists neben dem alten Alcim Klingers - zwei greise, bewährte Krieger, die sich in äußerem Betracht mannigfach gleichen - auf ihr Verhältnis zum Führer. Ein Alcim steht mit seinem König auch innerlich auf du und du, er weiß nichts von Rangordnung, er meistert eigenwillig nicht bloß den Schwelger, sondern auch den wiedererstandenen Feldherrn Demetrius; wohl daß er an seiner neuen Größe ,hinaufschwindelt", doch ohne sich ihr irgend zu unterziehen. Dagegen gibt Kleist in Armin den höchsten Typus des sturmerprobten, seines Werts bewußten, aber von Crund der Seele auf disziplinierten Kriegers. Er kann stolz von sich sagen, daß man von Guiskard lernen müsse, ,wie man mit mir spricht", als ihm der Heißsporn Robert unwürdig begegnet. Derselbe Mann aber wird, triftig ein normännischer Kottwitz genannt, nie der Empörung, nur dem Flehen seine Stimme leihen, ja er gehorcht auch dem mit Ungebuihr erteilten Befehl des Herrn, der ihn beleidigt, als unverbrüchlichem Gesetz: „Du bist der Guiskardsohn, das ist genug!" So fein er das gebietende Feldherrnwort von dem bloß erlaubenden zu. unterscheiden weiß (man denkt an die Prozeßführung um den Bruch der Ordre im Homburg), ist er als echter Soldat weit entfernt, den Zank der jungen Fürsten zu eigenem Deuteln zu nutzen. Wallensteinisch gesprochen: „Nichts, ihr Herm, gegen die Disziplin!" Neben der höchsten Achtung die höchste Liebe für den Feldherrn, den er mit zärtlicher, fast weiblicher Sorge umhüllt, seinen Schlaf behütend, seine Gesundheit ängstlich betreuend. In jedem dieser Züge, und je menschlicher sie sind um so sonorer, tönt das eine soldatische Grundmotiv: eingeborene, zur Natur gewordene Unterordnung unter den Einzigen, den Ewig-Unersetzlichen, höchste Disziplin. Von ihr gerade weiß der frühe Sturm und Drang, angeführt von dem unbotmäßigen Selbsthelfer Götz, am wenigsten. Ein Krieger, der von seinem Vorgesetzten das Wort deckt den Sachverhalt - so mit sich reden läßt wie der Abälard Kleists, wird dort schwer zu finden sein. Schweigendes Ordre parieren ist 
nicht Sache der Stürmer. Dafür steht Kleist hier eng neben Schiller, der als erster, schon in den Räubern, das Wörtlein unter der Fahne: Subordination. kennt.

So lassen sich nun freilich im einzelnen der soldatischen Charakteristik die Fäden von Schillers Imperator zum Guiskard hinüberspinnen. $\left.{ }^{23}\right) \mathrm{Ge}-$ meinsam ist die Stellung des Feldherm zum Heer, gemeinsam die virtuos geübte Kunst der Soldatenbehandlung. Das strenge Heergesetz gilt in Guiskards Lager nicht minder als in Wallenstcins, in Zeiten einer mehr differenzierten, konventionelleren Kriegsorganisation. Daneben aber steht dort wie hier der Grundsatz: „Das Wort ist frei, sagt der General”, und was Abälard im Sinne Guiskards dem kecken Normann zubilligt, ist nichts anderes als das friedländische ..Der Soldat muß sich können fühlen." Die Stilgegensätze treten scharf heraus, wenn man innerlich so nah Verwandtes in der äußerer. Formulierung nebeneinanderhält. So freier Gesprächston herrscht freilich bei Schiller nur im Lager, dessen Bezirk die Klassik von der Welt des Feldherm reinlich abgrenzt. Guiskard wohnt im Lager, aber wie weiß Kleist Distanz zu schaffen, wie entrückt er den Feldherm im leichten Gezelt auf dem Hügel der Heeresmasse so gut wie Schiller seinen Friodland - in der Etikette vorgeschrittener Zeit - hinter den Mauern des Schlosses, hinter Garden und glänzendem Stab! Den Wallenstein wissen die Kürassiere in entscheidender Stunde treuherzig zu finden, und diese Deputationsszene, eindringlich schon als einzige Auscinandersetzung von Führer und Truppen, hat auf Kleist ersichtlich stark gewirkt. ${ }^{24}$ ) Der Ton, den Cuiskard mit dem Sprecher des Volks anschlägt, die politische Art. wie er die gewichtige Abordnung zu nehmen weiß, manche Wendung in der äußeren Führung der Handlung war hier vorgebildet. Die gewaltige Körperlichkeit, bei Kleist Hauptmotiv, ist schon bei Schiller sichtbarer Ausdruck der Herrschnatur. Das Antlitz. ..das ihre Sonne war in dunkler Schlacht", und die sieghafte Stimme, die Wallenstein selbstsicher in der Brandung des Autruhrs einsetzt, sind ebenso Attribute des kleistischen Feldherm. ${ }^{25}$ ) Aus der Sphäre des Geheimnisvollen, die beide Hecrfürsten umwittert, tritt noch ein überraschend gemeinsamer Zug hinzu: Wallensteins historischer Lärmhaß, worüber man im Lager allerhand Mei-

27) Das Verhilinis beider Dichlungen am den (von Holzgrsefe S. 23f.. Fries. StrglL 4. 233 u. Fonshungen S. 14. ferner in E. Schmidıs Ausgabe) aufgewiesenen Parallelen mustert Kapee S. 1061.

20) Sie ist von Meyes-Benfey 1. $238 \mathrm{rgl} 240 \mathrm{zu}$ Untechs ubergangen. Eine deutliche Spur aus ihs schon in den Schroff.. 3. 0. S. 334 Anm. "9). Daneben sind allerdings auch die Oodipus-Anklinge (Kaper S. $\%-9$ ) bemerkenswert.

\#) Das gebietende Antliz Friedlands (Tod 2260) - Wont und Siluation - wird von Fries. Ferxchungen S. 92 schon für Sxhroff. v. 1801 herangezogen: Cuisk. 433, 420; Stimme 411. 
nungen hegt, und der noch bei seiner Ermordung motivierend eingreift, ist zu erhabener Vorstellung geläutert. ${ }^{26}$ ) Das ernste Kriegsgesetz, das die Stille des Bezirks hütet, ,wo sich der kühne Schlachtgedank ersinnt", lautet in der Sprache der Wallensteiner: „Muß alles mausstill um ihn sein. / Den Befehl haben alle Wachen, / Denn er denkt gar zu tiefe Sachen."

Lessings zugespitztes Aperçu über das Befehlen in der 5. Szene des Philatas: „Haben dir alle deine Befehlshaber Gründe gesagt? - Alle, Prinz; ausgenommen die jungen" - ist nie schlagender in die Charakteristik eingefleischt worden als in Kleists Fragment. Wie sich Robert und danach Guiskard zum Heer stellen, das ist in knappster Gegensätzlichkeit eine schlechterdings erschöpfende Gestaltung des Befehlsproblems. Es steht der anmaßende Befehlston des jungen Robert, der sein Ansehen einzig in herrischer Haltung sucht, neben der unerhört gewichtigen Autorität des alten, der sich mit einem gemütlichen Scherzwort nichts vergibt. Es steht die verletzende Schärfe, womit der Tollkopf dem Greis begegnet, neben der reifen Achtung des alten Führers vor dem Ceschlecht, „das ihm den Ruhm im Bette zeugt der Schlacht", jener Achtung, die den greisen Waffengenossen als Kameraden anredet und seinen Anspruch darauf versteht. Es steht die despotische Lust jeder Soldat hat sie einmal erfahren -, womit der Sohn das Joch der Disziplin nicht als die kriegerische Notwendigkeit auflegt, sondern frevelnd dem Nacken aufdrückt, neben der freundlichen Milde des Vaters, dem der Normann kühn und frei nahen, der Krieger in den Mähnen spielen darf. Der Gegensatz dieser Charakteristik läßt sich bis ins einzelste verfolgen. Ein Robert kennt den grauen Toren nicht, den er hochfahrend vortreten läßt, will ihn zuerst nicht kennen, nicht mit Namen und nicht als den ersichtlichen Wortführer des Heers. Ein Guiskard hebt ihn sogleich ehrenvoll aus der Menge heraus und nennt ihn traulich beim Namen. Nur in einem Punkt versteht sich dieser unähnliche Sohn mit dem Vater: das soldatische Draufgängertum hat er als Lichtseite seines kantigen Wesens vom Alten geerbt. Er berauscht sich an dem halb wahnwitzigen Unterfangen, das zermürbte Heer zum Hauptsturm anzusetzen, das jenem zugetraut wird. Es ist die Soldatenwelt des Homburg, die sich in dieser Vielfältigkeit der Züge auf so engem Raum mannigfach ankündigt.

\section{Penthesilea.}

„Pfuels kriegerisches Gemüt ist es eigentlich, auf das es durch und durch berechnet ist", äußert Kleist zu einer Freundin (Briefe Nr. 103) über sein Amazonenstück, das an triumphalem Glanz des Krieges sowohl wie an dämonischer Wildheit alles übertrifft, was die deutsche Literatur sonst aufzuweisen

26) Lager 610; 623ff. Tod 3369; Cuisk. 67ff., 87ff., 184ff. 
hat. Das "Schlachtfeld bei Troja" einziger Schauplatz, ein kriegstrunkenes Gewühl von Gefechten einziger Inhalt, so stellt sich die Außenseite von Kleists Dichtung neben jene Leinwand des Rubens, die den Amazonenkrieg in einen wirren Knäuel von Menschen- und Pferdeleibern zusammenballt. Eine Außenseite freilich nur, und dazu eine vielfach willkürliche, die nicht das feste Eigendasein hat wie etwa die bis auf Klcinigkeiten pragmatische Schlachthandlung der Jungfrau von Orleans. Kleists subjektive Tragödie, persönlichstes Bekenntnis, formt die Kriegsgeschehnisse souverän aus inneren Notwendigkeiten. Nur so weit blitzen sie aus dem dunklen Untergrund der Handlung auf, als ein Strahl der Zentralsonne Penthesilea sie trifft. Diese Sonderart stellt das Stück abseits von jedem Verband. Im Schaffen Kleists selbst bildet es, unbeschadet der starken Bande zu andern Werken hinüber. letzten Endes seine eigene Gattung.

Es scheint zwar im Amazonenfeldzug zunächst auf eine deutliche Kriegführung abgesehen. Kleists Neigung zu scharfumrissenen Schlachtanlagen, in Hermannsschlacht und Homburg dann voll entwickelt, keimt hier schon auf. In der ersten und vierten Szene wird cindringlich der besonnene Kriegsentwurf Agamemnons der sinnentblößten Leidenschaft Achills entgegengesetzt, späterhin im neunten Auftritt ein amazonischer Kriegsplan vor Penthesilea ausgebreitet. Die ausholende Exposition sucht Ordnung und Übersicht in das wilde Schlachtgetümmel vor Troja zu bringen. Sie schildert die Griechen, zu einem Kampf der Troer mit Penthesilea eintreffend, zwei fruchtlose Botschaften von beiden Seiten um ein Bündnis mit ihr, dann ein Gefecht der Amazonen gegen Griech' und Teukrer vereint, endlich den ersten Zusammenstoß Achills mit der Fürstin, aus wutvoller Schlacht der Völker aufleuchtend. Die Handlung selbst hebt an mit der Hetzjagd hinter Achill. Über den Kriegsrat der Amazonen, dagegen sich Penthesileas Kampfentschluß so flammend behauptet wie derjenige des Peliden auf der Griechenseite, führt sie zum zweiten Zusammenstoß, mit Penthesileas Niederlage. Es schließt sich an ein Sieg der Griechen, der die Gefangennahme der Königin, und, nach dem großen Mittelstück der Tragödie, ein Sieg der Amazonen, der ihre Befreiung zur Folge hat. Aus der freundlich gemeinten Herausforderung von seiten Achills erwächst dann die furchtbare Katastrophe.

Aber die so gewonnene Kampthandlung, wozu noch eine Fülle verstreuter Andeutungen rechnen würde, ist nicht das kleistische Kampfbild. Die im Eingang gebotene Sachlichkeit, schon dort durch eine Wirmis von Gefechtsbildern überwuchert, wird vollends verworfen, sobald die ersten Vorgänge sich Bahn brechen und mit Achills Meisterfahrt der leidenschaftliche Drang der Kampfszenen anhebt. Kaum taucht das Heldenpaar auf, so versinken die kriegerischen Massen. Die Heere treten zwar auf - Penthesilea 
steht immer inmitten der Amazonenschar, Achill àankt dem Griechenheer zweimal die Rettung - aber sie sind nicht einmal mehr, wie bei Shakespeare, das belanglose Material der Kriegführung. Schon die Flucht Achills vor den Amazonenscharen wird zum freien Wettstreit des kampftrunkenen Liebespaares ausgebildet. Auf ihm allein ruht der Blick, und nur zur Apotheose der glänzenden Fahrt tritt "das ganze Griechenheer, im Strahl der Sonne“ grandios ins Bild. So löscht weiterhin der Kampf der Heere und mit ihm das soziale Motiv des Amazonenkrieges, für das doch die Teilnahme stark geweckt wird, auf große Strecken völlig aus. Es ist nur folgerichtig, daß sich in dem abschließenden Zweikampf die Führerhandlung ganz vom allgemeinen Krieg lossagt und eine Rache der Griechen für Achill gar nicht mehr in den Gesichtskreis des Stückes fällt. Aus dieser ihrer Grundrichtung heraus gibt Kleists Tragödie, wo immer die Geschicke der königlichen Gestalten sich erfüllen müssen, keinerlei Motivierung des Verlaufs. Die tragische Ironie vermeintlichen Sieges in den Mittelszenen, unverkennbar Hauptbestand der Konzeption, hat Penthesileas Gefangennahme zur Voraussetzung : das Griechenheer ist in der zwölften Szene zur Stelle, um sie zu vollziehen. Die Lösung der Situation verlangt jhre Befreiung: urplötzlich wendet sich der inzwischen fast vergessene Kampf zugunsten der Frauen, obwohl sie nach früherem völlig zerstreut und dazu noch führerlos sind. Nichts ist bezeichnender als hier (Szene 16) die Motivierung. „Das Schlachtglück lockt, das wetterwendische, / Die Amazonen siegreich wieder vor" - der blinde Zufall ausdrücklich zum Herrn des Kampfgefildes erhoben. Dazu die mehr als anfechtbare Durchführung, wie die Königin den Händen Achills, der allzu leicht von ihr läßt, im Gedränge entgleitet. Neben solcher Lässigkeit der Fügung weist die Kampfhandlung schlechterdings Unstimmiges und Widersprüche in Menge auf, und nicht nur sie, die ersichtlich zurücksteht, sondern auch das Wollen und Tun der Helden selbst. Die vergessenen Wunden Penthesileas ${ }^{27}$ ) sind nur das sichtbare Zeichen dafür, daß auch die Hauptgestalt in ihrem realen Sein noch nicht den letzten Sinn der Dichtung erschöpft. Die unberechenbaren Schwankungen der Dichterseele zeichnet sie nach, Amazonenkönigin wohl, aber zugleich auch Symbol jener inneren Tragödie Kleists, die nach realen Handlungsvoraussetzungen nicht fragt. In diesem über das gegebene Werk hinausweisenden Gehalt liegt der Schlüssel für die Momen-

${ }^{27}$ ) Die Widersprüche insgesamt sind zuerst festgestellt von J. Niejahr, VjsL 6 (1893), S. 506-53; dann zu Angelpunkten seiner großen Kontroverse mit H. Roetteken geworden, die Meyer-Benfey 2, 556 bibliographisch verzeichnet; vgl. diesen 1, $549 \mathrm{ff}$. Über die Wunden bes. Roetteken, ZvglL N. F. 8 (1895) S. 25ff.; Niejahr, Euph. 3 (1896) S. 655f.; Roetteken, Euph. 4, 741-45; Meyer-Benfey 1, 540, 550; 2, 560. - Penthesilea ist Tübingen 1808 erschienen. 
taneität in der Auffassung des Äußern. Das Vorrecht des Dichters, die Dinge nach poetischen Bedürfnissen in wechselndes Licht zu tauchen, wird hier kühn ausgedehnt. Die Stetigkeit der Tatsachenwelt, vom Verstand gefordert, ist vicl schärfer verletzt als sonst in dramatischer Dichtung. ${ }^{28}$ ) Der kriegsgewaltige Pelide darf der heranschreitenden Furie gegenüber als scheues, ängstlich im Geklüft irrendes Reh erscheinen, und mehr: das ganze streitbare Amazonentum kann auf Schritt und 'Tritt seinem eigensten Wesen widersprechen, nach der Seite des Zartweiblichen sowohl wie nach der des Grausigen. Prothoe, ganz fühlende Freundin, ist nicht Prothoe die Amazone, die mit kriegsgewohnter Geste ihr Haupt für die sichere Führung der Nachhut cinsetzt, und das in der Katastrophe auftauchende furchtbare Rüstzeug der Schlacht verleugnet allen Sinn und Zweck des Amazonenkriegs.

Jener apokalyptischen Vision fesselloser Vernichtung, dem ..ganzen Schreckenspomp des Kriegs", ist allerdings nicht nachzurechnen. Mit dem Umschlag in der Secle Penthcsileas verwandelt Mars sein Angesicht, wandelt sich die .große Welt des heitern Krieges“" jäh, voraussetzungslos ${ }^{29}$ ) in die .blutumtriefte Graungestalt" letzten Entsetzens. Alles was vorher war, Glanz und Hoheit des königlichen Handwerks, ist versunken, niedergeschlazen durch das Furchtbare dieses Geschehens. Hier herrscht dieselbe Maßlosigkeit, aber auch derselbe eherne Gang wie im Heranschreiten der Pest im Guiskard. Jenes wahnwitzige Gebet zum Vernichtergott Ares, jenes grause Feldherrngebot an die Werkzeuge des Untergangs hat in moderner Poesie kaum seinesgleichen. So hatte sich der Krieg noch keinem Sohn des 18. Jahrhunderts geoffenbart, und von hier gab es einen Pfad weder zu Goethe noch zu Schiller. Wo könnten in der reinen Humanität, etwa an Johanna d'Arc, die fleischermäßigen Spuren der blutigen Hantierung so furchtlos angeschaut, mit so fanatischem Wahrheitsdrang zum Bild geformt werden: „Nun freilich Siegen geht so rein nicht ab, / Und jede Werkstatt kleidet ihren Meister"! Nur in dieser Greuelrüstung des Krieges allerdings durfte die Furie, die Hündin unter Hunden, ${ }^{30}$ ) den hehrsten Helden zerfleischen, und der asiatische Ver-

25) Kleists Verfahren geht viel weiter als Goethes wichtige Äußerung über Macbeths Kinder (Gespräche ${ }^{2}$ 3. 379f.) vertritt, die zuerst Roetteken. Euph. 4. 727 f. beibrachte und MeyerBentey, den innern Ursprung der Vorgänge scharf herausarbeitend. 2. 560 \%., vgl. 1, 555 neuerdings heranzicht.

27) Die Brïche in der Auffassung im einzelnen bei Meyer-Benfey 1, 554f: E. Schmidt in Werke 2.12.

30) Uber das Motiv der Meute. Namengebung und Herkunft, handeln Niejahr. VisL 6. 5181., 536: Roesteken. ZvglL 8, 48f.; Niejahr. Euph. 3, 667\%.: Roelteken. Euph. 4, 748f.: Meyer-Benfey 1, 555. Die bernerkenswerte Parallele aus den Räubern II. 3 (.Auch müssen alle Hunde los" usw.) bringt Fries. Forschungen S. 15 Anm. 2 bei. Nach dem Vorstellungs- 
nichtungstroß mußte die barbarische Umwelt schaffen, wenn er auch bei der Tat selbst unbrauchbar blieb. Der Dichter verzahnt in früheren Szenen den Schreckenspomp zwar äußerlich in die Handlung. Penthesilea ruft ihn ein erstes $\mathrm{Mal}$ in der Verwirrung ihrer Niederlage (9. Szene) auf. Die Amazonen verlangen in der 11. Szene nach Elefanten, Sichelwagen und Bluthunden, um das Andringen Achills zu hemmen. Das Unvereinbare der barbarischen Kriegsmittel mit der frauenhaften Sanftheit dieser Amazonen wird dadurch nicht beseitigt. Aber ein Kleist kann es wagen, den schneidenden Kontrast selbst aufzuweisen und ihn dichterisch zu nützen: „Du mit den blauen Augen bist es nicht, / Die mir die Doggen reißend schickt, noch du...", umschmeichelt Achill den schönen Feind. Der Schreckenspomp ist damit stärkster Ausdruck der Momentaneität, die in der sesamten Zeichnung des amazonischen Kriegswesens und in der Kriegshandlung überhaupt herrscht. Zugleich aber auch abgründige Formung der kleistischen, dämonischen Kriegsanschauung. Was im Ausgang der Tragödie blutig sich erfüllt, ist elementare Brutalität, triumphales Siegesfest der Vernichtung, Nachtseite des Krieges; in ihrer letzten Auswirkung als Wahnwitz zwar gezeichnet, aber doch diesen Gesiaiten eingeboren, der Amazone sowohl - halb Furie, halb Grazie - als dem Peliden. Wie die Frauen zart und furchtbar zugleich, ist Achilles in Rosenbanden gefangen zwar der sanfte Schäfer einer seligen Stunde, aber dennoch der Schreckliche, der den Größesten der Priamiden häuptlings schleifte. der Wilde, der roh den Fuß auf rosenblütne Wangen setzen und das Namenlose an der Feindin vollstrecken will. Man kommt hier mit den antiken Vorstellungen darum allein nicht aus, weil eine genaue Übereinstimmung mit den Schroffensteinern besteht. Schon ein Rupert trägt diese äußerste Brutalität in sich, die noch den Leichnam des Feindes schändet. ${ }^{31}$ ) So der Pelide, in Penthesileas Rasen gegen den eigenen Leib: „Den Hunden mag er ihn zur Morgenspeise, / Dem scheußlichen Geschlecht der Vögel, bieten." So die Furie, die den Toten tötet und den hehren Bau seiner Glieder in zuckender Wildheit zerfleischt.

Eine Handlung, die ausschließlich im Schlachtfeld angesiedelt war, mußte an die Kampftechnik die höchsten Anforderungen stellen. Kleist hat vor allem zu einer eigentümlichen Behandlung des Ortes gegriffen. Das ,Schlachtfeld bei Troja“" ist einheitliche, doch weitgefaßte Szene, die äußerlich keine

inhalt am nächsten steht der oben S. 338 Anm. ${ }^{2-2}$ ) herangezogene Machaon Klingers, die Bestie unter Bestien.

31) „Die Leichen liegen lassen“ usw., v. $71 \mathrm{ff.;}$ Stich in den schon Getöteten und Fubtritt nach der Leiche bei v. 2534; weitere Belege bei Roetteken. ZvglL 7, 41-42. 
Veränderung erleidet, in Wahrheit aber, durch ihre jeweilige Besetzung erst näher bestimmt, zu sehr verschiedenen Teilen des Kanpflokals unmerklich gewandelt wird.$^{32}$ ) Fast wichtiger als diese Sonderheit ist die andere Tatsache: wie fest Kleists Raumvorstellung dennoch an dem Geviert der Bühne haftet. Nirgends tritt ein Verschwimmen des Raums in die Weite der Kampfebenen ein wie bei Grabbe und öfter im Götz. Durchaus wird dic reale Bühne von der außerszenischen Welt scharf abgegrenzt. An diese straffe Organisation der Raumanschauung sind Begriffe wie indirekte Darstellung und dramatische Teichoskopie ja gebunden, jene Forınen, die Kleist vor andern zu Trägern seiner Kainpfgestaltung macht.

In aller Maßlosigkeit der kriegerischen Leidenschaft hält das Stück in seiner Kriegsdarstellung besonnen Maß. Nur zwei wirkliche Kampfauftritte aus dem Gewühl der Schlachten finden auf die Szene Fingang: Achills Nachdrängen hinter den Amazonen init Penthesileas Gefangennahme (Szene 10-12) und der amazonische Überfall, der sic rettet $(17 \mathrm{u}$. 18). Im Nachdrängen der Griechen allerdings wird mit Pfeilschüssen über Achilles' Haupt und unfehlbaren Speerwürfen mehr gefordert als die Bühne leisten kann, so bedeutsam die Kunst ist, womit der Dichter dic Kampfsituation in bildhafter Ruhe der Realität entrückt. Umgekehrt macht die zweite Szene von einer Auskunft der Bühnenpraktiker Gebrauch, der undurchsichtigen Schnelligkeit des Ceschehens. Das eine und das andere ist Ausnahme, Lösung des Augenblicks, nicht fester Formbestand des Werks. Dieser liegt in der Durchbildung von Bericht und Beobachtung, ihrer gegenseitigen Unterstützung und kunstvollen Verschlingung.

Drei brünstige Turniere des Heldenpaars sind mit unverkennbarer Symmetrie in verwandter Technik gegeben: Achills Wagenfahrt im Eingang, das entscheidende Aufeinandertreffen der 7. und 8. Szene, der grause Mord am Helden im Schlusse. Wie wenn die historische Entwicklung der Kampftechnik seit Gottsched in ein Symbol gefaßt werden sollte, so wächst in dem tektonischen Prachtbau der Exposition das Gegenwärtige aus dem Vergangenen, das Angeschaute aus dem nur Gehörten, die Teichoskopie aus dem Botenbericht sieghaft hervor: Achills Gespann, gleich dem des Helios am Horizonte aufsteigend. Hier ist, was schon die Szene der Schroffensteiner in reicher Entfaltung zeigt, was sich dann an der knappen Stelle des Knaben im Guiskard erweist, zum Meisterstück der Ausschau gestaltet: höchste Bildkraft, gepaart

${ }^{32)}$ Vgl. darüber Niejahr. VisL 6, 520ff., 530f.: E. Schmidt in Werke 2, 15; MeyerBenfey 1. 569-74. Vom Standpunkt des praktischen Theaters W Kühn, H. v. KI. U. das deutsche Theater. München 1912, S. 129-32 (mit Kritik der Szeneneinrichtung P. Lindaus und eigenem Vorschlag): E. Kilian. Dramatiorg Blätter 2, 236-38. 
mit atemloser Spannung. ${ }^{33}$ ) Eine starke Wandlung der Form gegen die Szene Eustaches drängt sich auf. So unklassisch auch diese Schilderung dahinjagt, so rücksichtslos der Vers zerrissen wird, man kann die strenge Stimmführung, die Stilisierung nicht übersehen. Aeschyleische Gliederung wie in Chorstellen des Guiskard oder, gleichviel, eine Annäherung an die Jungfrauszene Schillers hat statt. Eine Einzelstimme, der Myrmidonier, mit dem Hauptmann als Gegenpart hebt an. Eine zweite, der Ätolier, gesellt sich ihm an bedeutsamer Stelle zu, beim Auftauchen Penthesileas hinter Achill. Als dritter wird der Doloper durch die für den Helden wachsende Gefahr zur lauten Äußerung mitgerissen. Dreimal greift der volle Chor in das Stimmgefüge ein: zurn Abschluß der ersten Steigerung, die aufgehende Sonne Achill mit Jubel grüßend ; dem Verfolgten durch Zuruf den sichern Port weisend; endlich den Geretteten froh umjauchzend. Etwas von musikalischer Kompositionsweise liegt dieser Anlage unverkennbar zugrunde, so problematisch der Versuch bleiben mußte, Kleists dramatische Form im ganzen auf dem Generalbaß aufzubauen.

In ganz anderer Weise verfugt, jeder lähmenden Wiederholung fern, tritt die Teichoskopie für die Hauptschlacht der 7. Szene ein. Statt stufenweisem Anstieg von ruhiger Erzählung über drängende Botschaft zu sinnlicher Gegenwart, wird Bericht und Ausschau parallel geführt und absichtsvoll ineinandergeflochten. Die Möglichkeit zu symbolischer Parteiung, die durch die Gefangenenschar geboten war, hleibt zwar ungenutzt. Aber ähnlich Schiller besetzt Kleist die Szene mit einem Frauenpaar, dessen Gespräch der hinausweisenden Beobachtung das Gegengewicht hält: Oberpriesterin und Hauptmännin unten, die Mädchengruppe auf dem Hügel. Es ist ein Doppelbau durchdachtester Art, und man möchte hier wohl ein kontrapunktisches Element am Werk sehen. In das Gewirr des dräuenden Schlachtfeldes, das die Teichcskopie überblickt, wirft der Bericht das helle Motiv der kriegsjauchzenden Penthesilea. Auf die dreifach andringende Frage des Gesprächs, was der Sinnberaubten zu erringen übrigbleibe, enthüllt die Hügelschau die Funkelpracht des Einzigen, der ihr zu sinken wert. Auf die zürnende Zurechtweisung aus Priestermund wird das strahlende Bild der Kriegsfürstin geschaut, auf das Wort von ihrer Liebesverwirrung - Vordeutung der Niederlage - erfolgt der schmetternde Zusammenstoß. Jetzt allerdings bricht die Beobachtung, und mit ihr die Thematik der Szene ab. Der Übergang aus so unmittelbarer

33) Den Aufbau der Exposition und den Charakter der Beobachtungsszene legt MeyerBenfey 1, 511-17 eingehend dar; Niejahr, Euph. 3, 666; E. Schmidt in Werke 2, 15f., vgl. auch Charakteristiken ${ }^{2}$ 1, 351. Dagegen erhebt Gaudig S. 146 u. 148 gegenüber den Berichten und Teichoskopien den Vorwurf der Eintönigkeit. Zur sukzessiven Schilderung im Auftauchen Achills: Gaudig S. 157; Fries, Forschungen S. 15. 
Gegenwart in dic epische Darstellung, die hier der Teichoskopie nachfolgt, wird kaum rein aufgehen können.

Eine Lösung besonderer Art selbst dafür gelingt dem Dichter immerhin im Endkampf, der dieselbe Anordnung der Kunstmittel zeigt. In der 22. Szene zeichnet dic Ausschau in schrillem Aufschrei nur das grause Bild der Mänade, die den. Achill in Stücke reißt. Der versteinernde Bericht der Meroe, mit der entsetzensvollen Pause seines Schlusses, wird daraufhin zur Steigerung. weil nicht ein neues Aufwïhlen der dramatischen Welle, sondern ihr Gefrieren, nicht Bewegung, sondern Erstarren der letzte Gipfel dieser Szene ist.

$\mathrm{Da}$ ß sich die Botenberichte der Penthesilea klassischen Mustern nähern, wurde oft bemerkt. Kunstgriffe der Meldetechnik, die schon Gottscheds Schule den Franzosen abgelernt hatte, kommen damit neuerdings zu Ehren. Das dramatische Mittel des Teilberichts, des übertreibenden und des Falschberichts gehört zum festen Bestand der kleistischen Technik, bequem, weil es bündig die Hauptsituationen schafft, fruchtbar, weil es zu starken Umschlägen führt. Der Hauptmann der zweiten Szene meldet gleich Corneilles Julie im Horace, nachdem er nur cinem Teil von Achills Abenteuer angewohnt, und damit nicht genug, er sagt bei weitem mehr als er sagen dürfte. Im strengen Sinn gegründet ist nur sein schließendes Bekenntnis: „Und was aus ihm geworden, weiß ich nicht", nicht aber die eröffnende, apodiktische Schreckensnachricht: „Achill - ist in der Amazonen Händen." Gleich übertrcibend schlägt in die ach.te Szene die Unglückspost ein: „Dic Königin - Im Kampf gefallen, / Das ganze Amazonenheer zerstreut", und trügerisch im Glück erschallt im 22. Auftritt der Jubelschrei des Heeres: „Achillcus stürzt! Gefangen ist der Held!" - eine besonders anfechtbare Teilbotschaft, die aus der folgenden Schilderung Meroes keinerlei Berechtigung empfängt. Übereinstimmendes Verfahren zeigt der Prinz von Homburg. Auf grobem Irrtum beruht dort der Falschbericht vom Tod des Kurfürsten, obwohl Mömer so zuversichtlich wie der griechische Hauptmann zu erzählen vorgibt, .,was diese Augen, leider, selbst gesehn". Auch hier hat der nachgetragene Pferdewechsel mit Froben, scharf gerechnet, in Mörners Bericht keinen Platz. Auch hier bleibt ein ungelöster Rest, obwohl Kleist den Gefallenen sorglich durch deckende Fahnen dem Blick entzieht. ${ }^{34}$ ) In allen diesen Fällen wird krittelndes

34) Zu Kleists Berichttechnik vgl. E. Schmidt. Charakteristiken ${ }^{2}$ 1. 360; Fries, Forschungen S. 5f. Ober die antiken Elemente der Penthesilea-Berichic Nicjahr. VjsL 6, 533-37: Euph. 3. 668. Mehr das Trennende als das Cbereinstimmende betont C. Minde-Pouet. H. v. KI.. Seine Sprache u. sein Stil. W'eimar 1897. S. 24ff. - Die Cleichartigkeit der Falle ist die wichtigste Stütze der Deutung auch bei dern umstrittensten Vers Penth. 1117: .Die Königin - Im Kampf gefallen." Er wird am natürlichsten doch wohl als übertreibende Hiobspost des Augenblicks r-klärt, die der folgende Bericht zunehmend abschwächt. Die Interpreten (Roetteken, ZvglL 
Bedenken mißachtet und dafür die Wirkung mit kleistischer Schroffheit erreicht, schlagartig, überwältigend. In schärfster Prägung geht darum der Meldungsinhalt, die kurze Kunde, dem breiteren Bericht überall voran. Schiller gab für diese Technik Beispiele in Raouls Siegespost, in des schwedischen Hauptmanns Todesnachricht. Für Kleists Dramatik ist der jähe Clückwechsel solcher Augenblicke, auch auf Kosten der Motivierung, Lebenselement.

Gegenüber der Schlachttragödie, die dergestalt kaum durch Vorführung, fast allein durch Erzählung und Ausschau in unsem Gesichtskreis tritt, erhebt sich die Frage, ob diese Mittel für sich zureichen. Die Aufgabe war die schwerste. Kleists Anlage teilt eine letzte, unüberwindliche Schwäche mit Klopstock, dessen Handlungszentrum so unheilvoll außer die Szene gefallen war. Man möchte auf Hermannsschlacht zurückblicken, wenn Tadler die undramatischen Behelfe der Penthesilea in den Vordergrund rücken, das fortgesetzte Hinausweisen auf eine jenseitige, nicht sichtbare Aktion oder ihre Erfassung in epischem Bericht. Für einen Kampfakt hatte Schiller die Lösung gefunden, für eine Szene Kleist selbst in den Schroffensteinem. Für das ganze Stück - das lehrt hier gerade der sehr bedeutende Kunstaufwand - gibt es auf diesem Wege keine. Nur um ein Mehr oder Weniger an Erfolg der Formgebung, nicht um endgültigen Sieg über den unbezwinglichen Vorwurf kann es sich handeln. Was zu leisten war, hat neben der reifen technischen Gliederung die unerhörte Bildkraft kleistischer Sprache, hat ihre wilddrängende Energie geleistet. Hier trat der Dichter auf, der das Wortkunstwerk des Berichtes, die bildnerische Aufgabe der Teichoskopie mit unerreichter Vehemenz wie abschließend meisterte. Die Dichte dieser Diktion, die pralle Fülle der Anschauung, die Formgewalt so schroffen Umrisses selbst im eilendsten Lauf hatte die deutsche Kampfrede trotz Schiller noch nicht gekannt. Wie in der Kriegsauffassung Mäßigung und Gehaltenheit dort, unbändige Maßlosigkeit hier, so in der Kriegsschilderung. Bezähmter Schritt edler Verse, besonnener Gang gedämpfter Bilder bei Schiller, ein Wirbelsturm von Wort und Ton, gehetztes Jagen von Bild zu Bild, ein rücksichtsloses Greifen nach dem stärksten, sinnlichsten Ausdruck bei Kleist. So grollt sein Schlachtgewitter mit immer reger Wut über die skamandrische Ebene und schlägt mit Donnerkrachen ein, so verbeißen sich Heere und Helden hungerheiß erbosten Wölfen gleich, so bläst der Sturmwind wilden Angriffs

8, 25-27, vgl. Niejahr. VjsL 6, 545, 541; Niejahr, Euph. 3, 655-59; Roetteken, Euph. 4, 733-35, 741-48) sind über die scharfe Wortbedeutung hier und in der nachfolgenden Versreihe von Penthesileas Verwundung nicht einig geworden. Die Biegsamkeit des poetischen Ausdrucks ist aber gerade ein Erfordernis solcher Technik. 
feindliche Scharen hinweg vom Rund der Erde, braust die Attacke mit cines Waldstroms wütendem Erguß den Gegner nieder. Es begegnen in dieser Kampfsprache Bilder crhabenster Prägung, der Hieb von Pferdesrücken, .,wie aus dem Firmament geholt”, neben kecken Naturalismen: „Die Katze, die so stürzt, verreckt : nicht sie - -", vom Sturz der königlichen Jungfrau. in den hochfestlichen Versen der Wagenfahrt Achills. Wie später in Hermannsschlacht das grandios aufrichtige Bild kotigen Marsches: "Das Heer schleppt halb Cheruska an den Beinen" neben den Klängen der Alraunenszene steht. Mit derselben bildnerischen Leidenschaft ist noch der kleinste Zug angeschaut, nichts gleichgültig, unbelebt und flach geblieben. Statt nächtlich zu marschieren, verschlingt ein Griechenheer die Straße. Hinter dem Peliden schlingt die Verfolgerin Penthesilea mit jedem Hufschlag ein Stück des Wegs hinunter. In allem Drang des Fechtens sind Pferde und Waffen, Panzer und Helmbusch mit zwingender Schärfe gesehen. ${ }^{35}$ ) Inbrünstig haftet Kleists Auge auf dem berauschenden Schauspiel des Lichtes, das in die Wirrnis des Kampfgefildes fällt und Mann und RoB umgoldet. Die triumphale Vision, die des Äginers schimmernde Gestalt aus Wetterwolkenriß wie einen Cherub treten läßt, worin die ganze Erde zur Folie der Funkelpracht des Einen dient, worin dann Königin und Held, zwei blendenden Kometen gleich aufeinanderschmettern, ist nur der höchste Ausdruck einer Schaubarkeit, die dieser Kriegswelt eingeboren ist. Zugleich das Zeugnis einer souverän ordnenden Phantasie, die das chaotische Gewühl der Schlacht allein durch die Kunst der Lichtführung schlichtet. Es tritt dazu ein für die Akustik des Krieges, für jede Abstufung seines gehörten Seins empfindlichstes Ohr. In rauschender Symphonie der Worte wird die Musik der Schlachten, ,des Krieges ganze ehrne Stimme" vernommen vom Aufbruch, .,still und heimlich, wie auf wollnen Sohlen“ zum „Donnerruf der Königin, Drommeten, Tuben, Zymbeln und Posaunen" anhebenden Kampfes, vom melodischen Jubel des Sieges zu den furchtbaren Gewitterschlägen des vernichtenden Wahnsinns. Bestes Wollen des Sturm und Drangs findet in dieser sieghaften Sinnlichkeit der Kriegserscheinung seine Erfüllung. Kleist nennt das stolze shakespearische Vorrecht des unersättlichen Auges und Ohrs, um das die Geniezeit zuerst rang. sein eigen, ${ }^{36}$ ) darin dem Briten ungleich näher als der geistigere Schiller. Aber er büßt nichts von der Aktionskraft Shakespeares ein. Als Dramatiker

$\left.{ }^{35}\right)$ Die mittelalterlichen Vorstellungen im kriegerischen Kostüm, besonders Achills, bespricht Nicjahr. VisL 6. 519 u. Euph. 3. 663f.: Roetteken. Euph. 4, 745f. Wukadinowie S. 61-62 sucht sie aus Tasso abzuleiten.

36) Zum sprechendsten Zeugnis wird in diesem Zusammenhang Musik und Farbe der Verse aus Othello 111. 3, die Fries. Forschungen S. 3 zum Schreckenspomp (Penth. 2412f.) heran- 
ureigenster Bestimmung widersteht er der Gefahr, sich in verweilender Anschauung zu vertun. Diese Tendenz des frühen Geniedramas, die erst der straffe Gang der Räuber überwand, hatte von dem sinnenfrohen Stück eines Maler Müller in die farb- und tonschwelgerische Undramatik Tiecks hineingeführt. Kleist erlöst das, was der Romantiker der shakespearischen Kriegssymphonie nachmusiziert, aus seiner dramatischen Sterilität. Er ist musikalisch und plastisch zugleich, aber immer zuerst und vor allem dramatisch.

Die Gestaltung kriegerischen Heldentums in der Amazonenkönigin und Achill weist rückwärts auf den Guiskard, nach vorwärts in die vaterländischen Dramen der letzten Zeit. Gigantisch ist der Pelide gebildet. Dem Maß dieser Glieder, dem Pomp seines Leibes liegt dieselbe Anschauung des Heldischen zugrunde, die vom Normannenherzog zur Geniezeit zurückzuverfolgen war, robuste Kolossalfigur, strotzend von unbändigem Lebensdrang. Nicht zufällig wird dem gewaltigen Mann ein starker Zug des Sturm- und Dranghelden Egmont zugeeignet. Ein neues Klärchen, zweifelt die Amazone, in seinen sanften Anblick verloren, ob er auch wirklich der Schöpfer seiner Taten sei. ${ }^{3 i}$ ) Auf den Sieger von Fehrbellin deutet Achills soldatischer Subjektivismus hin, der in ungebärdiger Welt wild auflodert. Es ist besonders merkwürdig, wie darin ein späteres Hauptmotiv vorklingt, aber noch nicht als Problem erfaßt, noch ohne dramatische Folge. Denn eine tragische Belastung des Peliden durch sein Draufgängertum wird im Werk nirgends versucht und hat in die Betrachtung nur durch falsche Analogie zum Prinzen von Homburg Eingang gefunden. Das disziplinlose Tun beider allerdings stimmt überein, -gleich leidenschaftlich jagen sie der eigenen Eingebung nach, und bis in Einzelzüge geht die Entsprechung. So bäumt sich Achill gegen das Kriegführen nach Instruktion, gegen allen vorgefaßten klugen Plan, wie Homburg dem Temperament des Soldaten die Zügel schießen läßt. So überhört der Grieche teilnahmslos den Kriegsbefehl, wie der Preuße die Parole.

Allen Glanz und Schmerz des Krieges gießt Kleist über seine Amazonenfürstin aus. Eine christliche Sendung, ein hartes Gebot des Himmels zwingt die zarte Jungfrau Schillers wider die Natur in den Männerpanzer. Eine

zieht: „Fahr wohl, mein wiehernd Roß und schmetternd Erz, / Mutschwellende Trommel, muntrer Pfeifenklang, / Du königlich Panier und aller Glanz, / Pracht, Pomp und Rüstung des glorreichen Kriegs!" (Schlegel).

37) Fries, Forschungen S. 7. Uber den Kriegshelden Achill vgl. bes. Brahm ${ }^{5}, 232-35$. In anderer Wendung findet sich das Egmontmotiv bei Shakespeare, 1 Heinrich VI: II, 3, wo die Gräfin von Auvergne enttäuscht in dem „nichtigen Zwerg“" Talbot den Mann, „von dessen Herrlichkeit die Welt erschallt", nicht erkennen will, aber schnell erfahren muß. was Tąlbot sei. Hier schattenhafte, dem Gehalt nicht gemäße Körpererscheinung. 
gewaltige heidnische Kraft, die nach der Männerschlacht lechzt, waltet in Penthesilea. Ein Zwiespalt zwischen Frauentum und Kriegertum kündet sich zwar, wohl unter dem Eindruck Schillers, auch bei Kleist an. In weichen Augenblicken kann seine Amazone beklagen, daß sie den Geliebten unweiblich im Feld der Schlacht sich suchen muß. Aber diese Züge sind von der Herrlichkeit des amazonischen Kriegsstaats überschattet. Jauchzend badet die Königin die Lust des Krieges aus, taucht unter in der rauschenden Woge, tummelt sich in der Luft der Schlachten, strebt mit Inbrunst dem Kampf zu. Wo Johanna schon vor des Eisens blanker Schneide schaudert und durch Zwang zum blutigen Handwerk getrieben wird, das sie nur einmal mit Willen herbeisehnt, um die Verzweiflung des Innern zu übertäuben. ${ }^{38}$ )

38) Jungtrau v. O. v. 2555. Die Beziehungen Penthesileas zu ihr, die Brahm5 S. 240 behauptet, sind von Nicjahr, VjsL 6. 526f. bestritten. Vielfache Parallelen bei Holzgraefe, S. 24 bis 27. Aus der kriegerischen Sphäre noch: Odysseus Kampfbericht v. $30 \mathrm{ft} .{ }^{\circ}$ "Doch, bei des Morgens ersier Dämmerröte ... Da wir, in cinem weiten Tal vor urs - " sehr ähnlich Raouls Schilderung, v. 942ff.: „Als wir nun die Höhen ... Da stand in weiter Ebene vor uns der Feind.” Wie die Franken im folg. ..Rat suchten und nicht fanden”, so die Gricchen: „und wir, im kurzen Rat ..."-Das bei Kleist häufige Schnitterbild für die Schlacht (das Erntemotiv verfolgt Berthold Schulz S. 16f. durch die Penthesilea) erinnert bes. in v. 900ff. (vgl. 689, 2413; Homburg 753. verwandt 533): .W'Wn dichtgedrängt, aut allen Hügeln rings. / Die Saat der jungen Griechen steht, die Sichel / Nur einer muntern Schnitterin erwartend" an Jgfr. 305 ff.: ..Sein MaB ist voll, er ist zur Ernte reif. / Mit ihrer Sichel wird die Jungfrau kommen / Und seines Stolzes Saaten niedermähn." Vgl.Penth. 1173: ..Und mähet seine üpp gen Glieder nieder!" Dazu noch Jgfr. 251: .Die Völker niedermähet in den Schlachten.” - Zu Penth 542ff. . Bedeckt ... Sind alle Hügel von der Weiber Haufen: / Heuschrecken lassen dichigeschlossner nicht / Auf eine reife Sastenflur sich nieder" liegt Jgfr. $217 \mathrm{ff}$. .Wie aus geschwärzter Luft die Heuschreckwolke / Herunterfält und meilenlang die Felder / Bedeckt in unabsehbarem Gewimmel" näher als llias 2, $87 \mathrm{ff}$., $469 \mathrm{ff}$.: 21. 12f. ..Cewimmel" und .,umwimmeln" ist (dies als Nachtrag zu Minde-Poueis u. Fries' Sammlungen) eine Licblingsvorstellung Kleists für die quirlende Bewegung der kriegerischen Menge, Penth. 441, 480, 293. 1027. - Für die Vorstellung des Schlachigewitters Penth. 140f. vgl. Jgfr. 3050ff. - Zu Penth. 667 .Willst du das Spiel der Schlachten neu beginnen?" vgl. Jgtr. 1514 „Versuche nicht den falschen Gott der Schlachien“" u. Shakespeare, Jul. Caesar V, 3 ..Versuchen wir das Clück in zweiter Schlachi”. Zu Penth. 1015 ..Die in Gefild des Tods cinander suchen". vgl. Jgfr. 1688 ..Dich sucht" ich aut dem ganzen Feld der Schlacht"; ferner Penth. 1898 ..Im blut gen Feld der Schlacht muß ich ihn suchen" und 2316 ..Den Cegner dir im Feld der Schlacht gesucht"; Homburg 575 ..Jhn, im Gefild des Todes, aufzusuchen"; Penth. 1187 ..Ist's meine Schuld, daB ich im Feld der Schlacht" usw. Alle diese feierlichen Verbindungen (dazu .,Glück der Schlochi" Penth. 2302. ..Cliick der Schlachten“" Jgfr. 371, ..Luft der Schlachten”" Penth. 1024) sind Lieblingsformeln Kleists wie Schillers. .Feld des Todes" noch Hermannschl. 2128, wie Wall. Tod 2414; ..Feld der Schlacht" noch Homburg 362: ..Gefild der Schlacht" Hermannsschl. 1856. Homburg 75 u. 1793 (..Gefilde“" Jgfr. 221. 976, 3448). - Weiter trägt das Flehen Achills vor den Amazonen (Szene II) Züge der Úberredung Burgunds durch Johanna II, 10 
Diese jubelnd erfüllte Bestimmung zum Kriege, woraus allein der furchtbare Umschlag hervorgehen konnte, schließt Kleists Amazone an die Reihe der selbstherrlichen Imperatorengestalten an. Trotz ihrer mädchenhaften, unreflektierten Bildung hat sie männische Feldherrnzüge, den Titanenwillen Guiskards, den wallensteinischen Nachdruck des befehlenden Wortes. ${ }^{39}$ ) In solchem weiblichen Führertum ist allerdings die kühnste Verbindung eingegangen. Die Feldherrin Penthesilea, die auf Augenblicke die Stimmen ihrer Generale mit der Hoheit des Friedländers hört, kann doch gleichgültig die Führung in der Schlacht abgeben. Nichts anderes soll das Heer, als bloß den Griechentroß beschäftigen, ,daß sich des Kampfes Inbrunst mir nicht störe". Die eine Weisung macht das ganze Schattenwerk dieser Kriegsleitung offenbar. Ganz Weib, mit allzu weiblichen Waffen tritt die Heeresfürstin an derselben Stelle der Prothoe entgegen, kaum daß diese ihrer besinnungslosen Leidenschaft den Spiegel vorhält (5. Szene). Einheitlich, ehrgeizig und hart ist nur die Nebenfigur Asteria gezeichnet, das Mannweib unter den kriegerischen Frauen, die Inkarnation entschlossenen Amazonentums und darum der Königin in einer Stunde höchster Auflehnung - aber nur für diese die nächste. Sonst gilt für weibliche Führerin und weibliches Kriegsrolk am allermeisten die poetische Lizenz des ganzen Werkes, aber freilich auch die Überzeugungskraft der eigenwilligen Formung.

(Penth. 1439 „Er meint mit Schmeichelworten uns“ wie Jgfr. 1742 „Mit süßer Rede schmeichlerischem Ton“; zu Penth. 1414 „Mit euren Augen trefft ihr sicherer" vgl. Jgfr. 1746 (,deines Auges Feuerpfeile“). Hier lautet allerdings Kleists viel mehr als Schillers Rede ,wie eines Kindes“" - Endlich steht das wahnsinnige Schlachtgebet der rasenden Penthesilea (2428ff.) wie eine grause Kontrafaktur neben dem heißen Flehen der gottgesandten Jungfrau (3463ff.).

39) Die genaue Entsprechung von Penth. 740 „Kann das geschehn, Asteria?" zu Piccol. 1196 verzeichnet mit anderen Wall.-Parallelen Fries, Forschungen S. 15; vgl. zur Antwort der Generale: „Es ist nicht möglich. - Es kann nicht geschehn“, die Einwürfe der Amazonen 2407 „Unmöglich ist's! - Es kann nicht!" Penth. 713f. „Nein, eh' ich, was so herrlich mir begonnen / So groB, nicht endige“" zu Wall. Tod 532f. (E. Schmidt). Königlicher Befehl Penthesileas: $836 \mathrm{f}$., nach Wall. Tod 2411 f. (Fries); 852ff. (vgl. Homburg 715ff., wiederholt 735) und noch einmal 2881 : Achills : 1460ff. - Aus den Kampfberichten: Penth. 122f. ,Jetzt hebt / Ein Kampf an, wie er, seit die Furien walten, / Noch nicht gekämpft ward auf der Erde Rücken" verwandt mit Piccol. 1056f. „Da ward ein Angriff und ein Widerstand, / Wie ihn kein glücklich Auge noch gesehn". Ebenso Penth. 254f. ..Und eher nicht vermögen wir den Fuß, / Als fern von dem Peliden, fest zu setzen“, mit Wall. Tod 3059f. „Und eher nicht erfolgt des Kampies Ende, / Als bis der letzte Mann gefallen ist.“ Der wilde Ausbruch Achills Sz. 16 (..Mit mcinem Wagen rädern will ich sie“) gemahnt an denjenigen Wallensteins, Tod III, 19 (,Mit Kettenkugeln will ich sie empfangen"); hier wie dort erfolgt er mit jähem Umschwung nach lyrisch weichem Auftritt, auf eine fragend empfangene, vierzeilige Kampfmeldung hin. 


\section{Das Käthchen von Heilbronn.}

Die mathematische Gegensätzlichkeit, die Kleist zwischen Penthesilea und Käthchen erkannt wissen will, trifft scharf auf das Kriegsbild der beiden Stücke zu. Wohl spricht die kriegerische Herrlichkeit aus Amazonen- und Griechentum. Aber alles Freudige ihrer Erscheinung geht unter in dem Graus der Katastrophe, wo der Krieg, wie in den Schroffensteinern unter dem Giftqualm des Hasses, wie im Guiskard unter dem Anhauch der Pest. sein dämonisches Antlitz enthiillt. Úherall ruht in diesen Werken die lichte Welt der wehrhaften Kraft wie auf dünner Schicht über brodelndem Krater der Leidenschaft, dessen Ausbruch stündlich droht und schlicßlich alles verheert. Dagegen nun bedeutet das Käthchen die Umkehr, Bejahung, den positiven Pol. Es steht am Ausgang der ritterlichen Gattung ähnlich bedeutsam wie der Götz von Berlichingen an ihrem Eingang. Es ist vor allem, in schärfster Wendung gegen die Familie Schroffenstein, auf denselben weltfreudigen Ton gestimmt. Zum erstenmal bei Kleist tritt das Derbe und Komische in die Zeichnung des Kriegerischen so kräftig ein, daß es dessen Gesamtbild bestimmt. Der heitere Gottschalk, aus bestem Stoff des Ritterstückes geformt, wäre in den Schroffensteinern ganz undenkbar. Die kurze Fratze einer Frauenbesorgnisszene im Auftritt der quiekenden 'Tanten von Thurneck (III, II) zeigt eine neue Unhefangenheit den kriegerischen Dingen gegenüber. Die Wandlung wird vorbereitet durch humoristische Lichter, die im Amphitryon auf den soldatischen Lebenskreis fallen, wenn sie auch wesentlich auf Molières Rechnung gehen. Durch den Hintergrund des Zerbrochenen Kruges schreitet ein ironisch gesehener Korporal, .,der würd'ge Holzgebein“, und weiterhin tauchen in die Beleuchtung des Lustspiels Rekrutierung, Stockprügel, Desertion. Werbungsschwindel und schlimme Einquartierung ein. ${ }^{{ }^{30}}$ ) Im Käthchen wird nun Ritter und Knappe mit jenem derben Humor bedacht, der auch dem grimmen Spaß der kleistischen Kriegsanekdoten zugrunde liegt. Das so geschärfte Vermögen, unbestochen die beiden Seiten der Dinge zu sehen, schafft schließlich die Prachtfigur eines Kottwitz, dessen soldatisches Ethos aus einer wunderlichen, mit liebreich spöttischer Hand gezeichneten Körperlichkeit so sieghaft emporwächst, wie es nur je aus erhabener Heroengestalt geschehen kann.

Es herrscht in dieser neuen ritterlichen Welt Kleists, in den Fehden von Burggraf und Rheingraf gegen den Grafen vom Strahl die robuste Rauflust der gesamten, optimistischen Gattung, das Kriegführen als Sport sozusagen oder auch aus Ritterpflicht, gegen den und jenen, ohne tiefere Verfeindung.

10) Krug 471. 473f., 528ff., 1215ft., 1307ff., 1673. 1915ff.; sehr ausführlich im Variant; Vgl. H. Schneider, Studien S. 91., 85 f., 91 f. 
Eine genaue Parallele läßt den ganzen Abstand von den Schroffensteinern ermessen. Auch im Käthchen wird Krieg angesagt (II, 3), aber nicht der Krieg wahnwitzigen Hasses, sondern eine Fehde von vielen und daher ein frischfröhliches Aufgebot, warm wie es eben von des Herolds Lippen kommt. Nicht daß die Leidenschaft fehlte. Aber sie ist trotz einem starken Ausbruch wie dem des verschmähten Freiburg gegen Kunigunde (II, 6) nicht mehr maßlose Auswirkung der Verwirrung des Gefühls, sondern Temperament, streitbare Lust, am stärksten beim Helden Wetter vom Strahl selbst. Ein zweckbewußter, politischer Krieg wird hier geführt, deshalb ein konventioneller Krieg, eingefangen in die Satzungen ritterlichen Brauches, der besonderen ständischen Auffassung, der Ritterpflicht gegen Freund und Feind. Jene Objektivierung des Kriegsbildes bahnt sich an, die im Homburg zum Durchbruch kommt. Nur ist sie hier noch mehr literarisch, durch die feststehenden Züge eines überkommenen Schemas bestimmt.

An kriegerischem Gehalt war das Ritterdrama mehr und mehr in die größte Dürftigkeit geraten. Auch hier wiederum knüpft Kleist an den Sturm und Drang unmittelbar an. Das Käthchen stellt sich neben den Götz durch die überquellende Fülle der Charakteristik, neben das Ritterstück Maler Müllers durch die freudige Farbigkeit seiner Erscheinung, neben Klinger durch seinen junkerlichen Sinn für RoB und reisiges Wesen. ${ }^{41}$ ) Neuerdings, wie in der Geniezeit, tritt die Episode, der einzelne, gesättigte Lebensausschnitt in den Vordergrund der Kriegshandlung, und fast sträflich vernachlässigt Kleist darob die kriegerische Intrige, das Hauptabsehen des späten Ritterdramas. Es begegnen jene starken Ungereimtheiten der Verknüpfung, daß etwa der verräterische Brief zwar verwechselt in die Hände des Priors gelangt, aber zugleich auch den richtigen Empfänger, den Burgvogt erreicht. ${ }^{42}$ ) Oder in der technischen Anlage der Kampfszenen die Lässigkeit, daß der Graf vom Strahl auf hitzigster Verfolgung (IV, I) eine ganze Szene lang, wie wenn er angewurzelt in der Kulisse stünde, nach Gottschalk rufen kann; ferner die schlechterdings stümperhafte Motivierung, womit ihn Kleist in drängendster Situation der Burgverteidigung (III, 10) mit einem Genossen tatenlos auf der Bühne hält. So geschieht auch nach Käthchens Bericht von dem Anschlag auf die Burg, trotzdem die Minuten gezählt sind, nichts, um die Thurnecker zu den Waffen zu rufen, weil die Aufmerksamkeit auf Käthchen und Strahl allein ruht und Gottschalk, den ein Befehl des Herrn zwar fortschicken will, ebenso-

11) Für Kleists Verhältnis zum Ritterstück vgl. Brahm, Kleist ${ }^{5}$ S. 285 ff. u. Ritt. S. 143; E. Schmidt in Werke 2, 174f.; Lohmeyer S. 86; Meyer-Benfey 2, 150f. - Das Käthchen ist nach Bruchstücken im Phöbus 1808 vollständig Berlin 1810 erschienen.

17) Vgl. Meyer-Benfey 2, 88, der 2, 75-92 die ganze Reihe der Unstimmigkeiten mustert. 
wenig fehlen darf. Auch ein theatralisches Interesse mag hereinspielen, und damit begibt sich der Dichter auf den Boden der späteren Ritterdramatiker. Schlagartig und trotz der vorangehenden Meldung überraschend, bricht der nächtliche Burgsturm. Getümmel und Glockenklang in den innerlich gerichteten Auftritt. Das Kundschafterverhör, dem das kleine Käthchen hier so sachkundig Rede steht, bleibt in seiner militärischen Präzision in der Kriegshandlung vereinzelt, ein bezeichnendes Stück jener vielfach belegten inquisitorischen Dialogführung Kleists, und den taktisch klaren Situationen in Hermannsschlacht und Homburg verwandt. In den folgenden Hauptszenen schaltet Kleist dann so unbekümmert wie nur einer mit dem Theatralapparat des Ritterstücks, Schloßbrand, Sturm und Einsturz, aber nur um des einen Zieles, des holden Käthchenwunders willen. Wicderum wird der Blick unverwandt allein darauf gerichtet, und der Verlauf des feirdlichen Einbruches bleibt ebenso gleichgültig wie schließlich nur obenhin der glückliche Ausgang des Kampfes gemeldet ist. Mit der Naivität der Volksbühne wird der theatralische Formenschatz gebraucht, aber dic Führung gehört nicht ihm. Die besondere Verbindung später Theatraltendenzen mit der frühen dichterischen Richtung der Gattung, die das Käthchen eingeht, neigt sich völlig nach der dichterischen Seite. So bühnenfest die kleistischen Akte etwa gegen Tiecks zerfließendes Ritterdrama sich halten, sie überschreiten in gewichtigen Stücken dic Grenzen des Theaters. In der Kriegshandlung am sinnfälligsten in der Verfolgungsszene am Bach, durch das ganze Stück hindurch in der Naturhaftigkeit des Weltbildes. Alle Kreatur, hier Brücke und Bach, Mann und RoB in Licht und Luft zu hüllen, das ist das alte Ideal des Sturm und Drangs, das er in Shakespeare erfüllt sah: die Atmosphäre. Theaterbäche verlaufen sonst trocken, in diesem Forellenbach aber wird man naß, und Gottschalks Mordmähre scheut wirklich. Jene kecke Realistik der Geniezeit gilt, womit die theatralische Scheinwelt nie ganz fertig werden kann. So ist die Raumvorstellung, eng verwandt mit der Naturweite eines Götz und Ramonds: Bachufer, geräumig genug, daß man Pferde tummeln kann, ein Wasserlauf, hinreichend, um die Parteien zum Pfeilwechsel zu trennen. So die Gegenständlichkeit: eine Brücke, deren Balken und Bohlen lustig ins Wasser prasseln, ein Sturzbach, den nur frisches Wagen nicht als bedenkliches Hindernis respektiert. Nicht zufällig hat die reiterliche Kühnheit, womit Strahl unter den Warnungen seiner Leute durch das Bergwasser setzt, Vorläufer im Sturm und Drang: Ramonds Adelbert im „Hugo" (I, S. 10) schickt sich an, zu Pferd durch den Fluß zu schwinmen. Törrings Herzog Albrecht in der Agnes Bernauerin V, 7 wird mit Mühe zurückgehalten, in die Donau hineinzureiten. Belangloses Kleinwerk wenn man will, aber wichtig, weil es cin gemeinsames Verhältnis zur Natur und Figur erweist. Könnte diese eine Szene der Ver- 
folgung, da sie durch Raumweite ur.d theaterfremde Körperlichkeit ganz besonders auffällt, als Ausnahme gelten, ${ }^{+3}$ ) wer hatte nicht bei jeder Aufführung gefühlt, daß keine Bühne imstande ist, den Naturhauch des anschließenden Auftritts unter dem Hollunderstrauch zu bewahren! Wie Mauer, Baum und Blume hier, so ist überall Burg, Wald und Gebirge in atmosphärisches Leben getaucht, gleichsam zum Atmen gebracht, nach jener Auffassung der Geniezeit, die über die Illusionsbühne hinaus in die Wahrheit der Natur selbst führt.

Daneben allerdings stehen robuste Bühnenszenen, und der Brückenkampf selbst birgt ein theaterwirksames Element. Zusammenbrechende Stege sind im Volksdrama und besonders im Zauberstück beliebt, das Ritterstück kennt den Kampf um die Zugbrücke. Die Käthchenszene keimt aus Versen des Bürgerschen „Graf Walter": „Ho, Maid, siehst du das Wasser dort, / Dem Brück' und Steg gebricht?" - aber höchst dramatisch schafft Kleist die Steglosigkeit erst durch das Kampfmotiv. ${ }^{44}$ ) Die Brücke ist in seinem Kriegsbild nicht allein hier wichtig. Für den Schauplatz der Penthesilea, wo um sie zwar nicht gefochten wird, möchte man Rubens' Kampfgewühl über dem Fluß heranziehen. Die drei Rhynbrücken bei Fehrbellin verdanken ihre gegen die Geschichte gesteigerte Bedeutung vielleicht eigenen Kriegseindrücken Kleists, jedenfalls eher als literarischen Vorgängern. ${ }^{45}$ ) E. T. A. Hoffmann, der als Schüler des Theaterpraktikus Holbein die einstürzende Burg für das hochgepriesene Käthchen baute, nennt unter den Großtaten der Bamberger Bühnenmaschinerie im gleichen Atemzug die Brücke von Mantible für Cal derons so betiteltes Stück. Dieses beruht auf dem Motiv einer zauberhaften Brücke und schließt mit großer Schlacht auf ihr ab - damit das Hauptbeispiel bühnengemäßer Auswertung dieser Kriegsszenerie, wenn es dem Käthchendichter auch kaum schon bekannt sein konnte. ${ }^{46}$ )

Streng theatergerecht, mit glücklicher Erfindung, legt Kleist das Cottes-

43) In diesem Sinne untersucht Meyer-Benfey 2, $86 \mathrm{f}$. u. i7f. ihre Anstöße, dem Bach gegenüber allzu hydrographisch exakt gestimmt. Der Einklang der Naturanschauung mit dem Götz ist glücklich betont von Herzog S. 440 u. 445; vgl. Eloesser S. 284.

44) Zu erinnern ist an Weislingens Verfolgung hinter den Bauern (Götz V), der umziehen muB, weil die Wasser vom Regen alle ausgetreten sind (.Nach! Nach! Sie fliehen“ "usw.; Strahl: .folgt! folgt!" usw.).

45) Brückenangriff des Burgunders in der Teichoskopie von Schillers Jungfrau V, 11; des Kastiliers, samt kühnem Durchsetzen des Flusses, in der Schlacht in Klingers Konradin I, 6.

16) E. T. A. Hoffmann an Hitzig, 28. April 1812; Briefwechsel, hrsg. v. H. v. Müller, Il. 1, Berlin 1912, S. 77. Nach H. Breymann, Die Calderon-Literatur, München u. Berlin 1905. S. 91 u. 100 ist A. W. Schlegcls Übersetzung von "La puente de Mantible" im 2. Bd. des Spanischen Theaters, Berlin 1809, die erste deutsche. Brückenkampf auch in Calderons GroBer Zenobia, Akt II (Schauspiele, übers. von Gries I, Berlin 1815, S. 88ff.). 
gericht des letzten Aktes an, weniger als Kampf denn als Schwertprobe. Das Wunderbare liegt in der sieghaften Kraft des Glaubens der Anlage zugrunde, aber die Durchführung geschieht natürlich. Strahl bietet dem Feind furchtlos die freie Stirn. Theobald findet den Mut zum Zuschlagen nicht und wird entwaffnet. Der Zweikampf ist damit ohne Schwertstreich ausgetragen. Auch jedes Zeremoniell fehlt. Der Kaiser läßt nach dem Aufcinanderprallen der Kampfreden Signal blasen, und die Entscheidung fällt knapp und schlicht nach den machtvollen parallelen Gleichnisreden der Gegner von Schwert, Helm und Stim.

Neben Schloßbrand und Einsturz ${ }^{17}$ ) sind die theatralischen Requisiten des Ritterstücks, Köhlerhütte im Gebirg, Nacht, Donner, Blitz und Fackelschein am ausgiebigsten zum romantischen Frauenraub herangezogen, der Szenenfolge (II, 4-8), die den Kampf um die Thurneckerin einschlieft. Auch er nimmt nur wenige Augenblicke in Anspruch. Gebieterisch fordert Strahl den Namen Freiburgs und reißt dem Widerspenstigen, der beim Nahen des Lichtes das Visier schließt, den Helm ab. Seinem Streich ausweichend, haut er ihn seinerseits nieder. Ein zugleich entstehendes Handgemenge des $\mathrm{Ge}-$ folges wird kaum sichtbar, denn die Partei des Gezüchtigten entweicht augenblicks. Das Bedeutsamste an diesem Kampfauftritt ist die Art, wie Kleist die mimische Aktion in Worte faßt. Er gibt damit ein knappes Gegenstück zu der großen Szene ,innerer Beobachtung" bei Penthesileas Selbstbesinnung nach der Tat, wo ihr stummes Spiel in die Schilderung der Amazonen aufgefangen ist. Ein scharf abgetreppter Vers: „Entsetzen! Schaut! Er stürzt, er wankt, er fällt!" begleitet Freiburgs Sinken und gliedert es zugleich. Ủber den praktischen Zweck hinweg, auf die Aktion unterstreichend hinzuweisen, zielt diese Technik höher: sie formt den sichtbaren Vorgang gleichzeitig dichterisch und hebt ihn damit weit über den Eindruck der realen Darstellung hinaus. ${ }^{48}$ )

47) Als Lieblingsmotiv Kleists verfolgt von Minor. Euph. I, 583-84. Uber die Kampfszenen vgl. auch Meyer-Benfey 2. 104. - Es ist für die Beurteilung von Kleists Belesenheit und die Sichtung der literarischen Einflüsse im ganzen vichtig zu sehen, wie er hier mit dem Bestand einer konventionellen Gattung so durchaus vertraut ist. ohne daß seine Kenntnis von ihr äuBerlich besser belegt wäre als sonst.

4) O. Fischer. Minische Studien zu H. v. KI., Euph. 15. 489f., vgl auch 724, bespricht nur die Penthesileaszene, im Verhältnis zur Lady Macbeth. Zum Wortaut des Käthchenverses vgl. Lessing. Kleonnis v. 89 (W'erke 3, 367f): „,er wankt; / Er fält; er stirbt!” - hier aber die hoB vorgestellte Aktion malend, nicht die wirkliche begleitend. In dieser Funktion dagegen scharf entsprechend bei Schiller. Jungfrau v. 2513: .Was ist der Jungfrau? Sie erbleicht, sie sinkt!" : vorher 2. B. schon Babo, Römer in Teutschland 1780, V. 5: "Seht! Sehtl Sie wankt. rie sinkt!" Dazu die parallelen Fälle bei Kleist, Käthchen III. II: „Geachwind Um aller Hei- 
5. Die Hermannsschlacht.

Kleists Hermannsschlacht ${ }^{49}$ ) steht in aller Kriegsdramatik darin allein, daß nirgends so entschlossen wie hier das Schlachtstück selbst als kriegführende Macht eingesetzt wird. Keine stärkere Verankerung in der Zeitgeschichte läßt sich denken. Statt rückgewendeter Siegesfeier eines Klopstock, eines Aeschylus ein heiß werbendes, hetzerisches Werk, nicht Niederschlag vergangenen, sondern Aufruf künftigen Krieges, ein Sturmzeichen des aufziehenden Gewitters: agitatorische Kriegsdichtung. Zur Belohnung wackerer Truppen wollte einst Klopstock seinen Bardiet aufgeführt wissen. Die Aufgabe von Kleists Werk ist in der eng zugehörigen Ankündigung zu der geplanten Zeitschrift „Germania“" mit umschrieben. Aus klopstockischen Vorstellungen heraus, aber in ganz anderer Zeitnähe, soll Schrift wie Dichtung hoch vom Felsen ,„den Schlachtgesang herabdonnern ins Tal", sich mit glühenden Wangen unter die Streitenden mischen und ihnen Todesverachtung ins Herz gießen. Das Jahrhundert des dreißigjährigen Ringens hatte in Johann Rists Stück ein „Friedewünschendes Teutschland“" gesehen, wie die Zeit des peloponnesischen Krieges in Komödien des Aristophanes ein friedewünschendes Griechenland. Hier trat ein krieglechzendes Germanien auf, rücksichtslos auf die Forderung des Tages zugeschnitten, mit allem künstlerischen Nachteil, aber auch der ganzen Glut leidenschaftlicher Tendenz. Programmatisch, fast mit der lehrhaften Endabsicht des „Katechismus der Deutschen", ist darin die kleistische Kriegsauffassung niedergelegt und unerbittlich die äußerste Probe auf den hemmungslosen Willen zur Vernichtung angestellt. In der Ermordung des Wehrlosen, Septimius Nervas (V, 13), in der Verletzung jeglicher Siegerpflicht und heiligster Gesandtenrechte, die schon ein Rupert Schroffenstein verhöhnt, wird die Gewissensfrage ob guter, ob schlechter Feind so exemplarisch wie nur möglich gelöst. Der Gute ist der wahrhaft Schlechte, kein feindlich Haupt kann in dieser schillerfernen Welt dem abgründigen Hasse heilig sein. Jene beißende lronie in dem „Brief eines jungen märkischen Landfräuleins“, daß die Männer „unmöglich, wenn es zum Handgemenge kömmt, sich auf die Frage einlassen können, wer von

ligen! Sie wankt, sie fällt!“; Homburg v. 511: „O meine Mutter! - Cott! Sie bleicht! Sie fällt!" und besonders ausdrucksvoll vom Bogen, dem großen, goldenen des Amazonenreichs, Penth. v. 2770f.: „Seht, wie er taumelt - Klirrt, und wankt, und fält - - / Und noch einmal am Boden zuckt - Und stirbt - ." Hier ist zugleich, wie in Schillers Vers und in allen Stellen, die es mit unwillkürlichen mimischen Veränderungen wie Erbleichen und Erröten zu tun haben (vgl. darüber Petersen S. 342), Undarstellbares durch das Wort ersetzt. So auch im Käthchen, anschließend an Freiburgs Sturz: „Blut füllt, rom Scheitel quellend, ihm den Mund." Hermannsschl. v. 2514: „Blut rötet ihm den Arm."

19) Erster Druck von Tieck in Kleists Hinterlassenen Schriften, Berlin IS21. 
denen, die auf sie anrücken, schuldig ist oder nicht", steigert der blutige Emst noch. Auch kalten Sinnes, außer dem Kampfgewühl, muß der Feind mitleidlos ausgerottet werden.

!. Dem elementaren Ausbruch solcher Leidenschaft kam der Untergrund einer primitiven, barbarischen Umwelt zustatten. Zugleich forderte aber die Tagesbezichung, daß in sie das ganze Getriebe einer politisch alten Zeit gestellt wurde. Für das Kriegsbild ergab sich daraus die gleiche unbekümmerte Mischung der Züge wie für das Kulturhild im ganzen. Die historische Kostümierung deckt moderne militärische Verhältnisse vielfach nur notdürftig. Ein Ceneral des 18. Jahrhunderts, leitet Marbod inmitten seines Stabes die Schlacht vom rückwärtigen Hügel. Als Stabschef, gleich Dörfling, gibt Winfried den Kampfbefehl aus, wobei einzig das Diktat gespart wird. Die Tendenz ist es auch, die Kleists Verhältnis zum Schlachtstoff bestimmt, in einer Weise, die ihn von Klopstocks ausschließlicher Schlachtdarstellung entfernt und viel näher zu der Anlage Elias Schlegels stellt. Das agitatorische Stück legt das Hauptgewicht auf die Vorgeschichte, die Entflammung Germaniens, die Entfesselung der kriegerischen Leidenschaft. Im Augenblick, wo diese im Angesicht des Feindes zu hellen Flammen auflodert, hat es seinen Gipfel erreicht. Die Durchführung des Kampfes verliert an werbender Kraft und damit an ursprünglichem lnteresse des Dichters. Daher das unleugbar Skizzenhafte der Schlachttechrik, die dem festen Gefüge der späteren Fehrbclliner Schlacht bei wcitem unteriegen ist, das fühlbar Eilfertize und Sorglose der Komposition. ${ }^{50}$ ) Allerdings konnte weder der Dramatiker Kleist seinen fünften Akt, noch der Kriegsdichter die gewaltige Freiheitsschlacht unter der gehörigen Eindruckshöhe lassen. Er gewann sie sich vermöge einer glänzenden Erfindung, zwar durch einen Wechsel der Beleuchtung und gewissermaßen einen Verrat an seiner Sendung, im eingeschobenen Varusdrama. Hier wich der Parteimann, der glühende Propagandist dem Künstler, und hier wurde. trotz aller Schnellkraft der Tendenz, noch höheres erreicht: ein reines Stück erhabener Kriegspoesie. Aber schon dieser für sich stehende Einschub, noch mehr die Lässigkeit, womit mitten in die Schlacht die ganz abliegende Thusneldenhandlung gezwängt und damit jede Bindung und Steigerung zerrissen ist, verrät einen schwanken Bau. Die shakespearische Freiheit der Szenenführung kommt zupaß, um widerstrebende Teile bloß behelfsmäßig zusammenzuordnen. Zu der Formsicherheit ausgereifter Kunst dringt der Schlachtakt im ganzen damit nicht vor.

so) Vgl. Eloesser S. 288. In Meyer-Benfeys ausführlicher Analyse wird dies zwar einerseils 2. 249 geleugnet und 2. 2001. eine beredte Apologie der Technik gegeben (vgl. auch 2368). an anderer Stelle aber $(2,2471$.) die Zerfahrenheit des V. Aktes eingeräumt. 
Im einzelnen verwendet Kleist etwa den Botenbericht für den gesamten Inhalt der Kämpfe recht obenhin (V, 20) und fern der Tektonik der Penthesilea, die die Kunstmittel bei aller Eigenwilligkeit der Kampfführung mit Strenge gliedert. Die Stelle, wo die Schlachthandlung nach der Abschweifung nach Cheruska neuerdings aufgenommen wird, verlangte einen stärkeren Auftakt als die bloße Erzählung des Geschehenen. Mit leichter Wendung stellt sich der Dichter jedoch selbst jeden wünschbaren Freibrief für weitmaschigen Bericht aus: "Laß hören, Komar, / Und spar' die lusterfüllten Worte nicht." Über das folgende seltsame Gefecht zwischen Hermann und Fust um die Ehre, den untätig zuschauenden Varus zu fällen, sind alle Beurteiler einig. Aber auch das shakespearische Motiv des Führerzweikampfes, mit dem Tod des Römers, ist das erste sich bietende und als Vertretung der ganzen Volksschlacht dünn genug. Es entspricht dem eilfertigen Verfahren, daß beide Gefechte mit der bloßen Anweisung "Sie fechten" abgetan werden. Selbst Varus' vorangehender Monolog, zwar groß gedacht, bleibt in der Ausführung skizzenhaft, aus Reminiszenzen nach Schiller und Shakespeare gestückt, in seinem Gang stockend, keineswegs auf der Höhe kleistischer Kunst und am allerwenigsten der früheren Varusszenen. Gegen eine sorgfältig abwägende Technik sprechen ferner Ansätze, die keine Folge haben und gleich leeren Sparren in die Luft ragen, wie der merkwürdige Nachdruck, der darauf liegt, daB Marbods Heer vor Hermanns Eintreffen die Schlacht gewinnt, ersichtlich dem kunstfremden Wunsch des Diplomaten Kleist entstammend, den Anteil der Großen am Befreiungswerk auszugleichen. Beweiskräftig ist schließlich die Verschwommenheit des Schlachtbildes. Wohl tritt in der peinlich genauen Vorbereitung des Kampfgeschehens durch Plan und Abrede, in der germanischen Urwelt besonders auffällig, bereits die militärische Schärfe und Hartnäckigkeit des Homburg hervor. Doch gelten die fast pedantischen, wiederholten Bestimmungen so gut wie ausschließlich der Zeit. ${ }^{51}$ ) In der Raumvorstellung wird nur die Bedeutung der Weser und der Hauptgedanke klar, die Legionen in den Morästen des Teutoburger Waldes zwischen den beiden Heeren zu erdrosseln. Die Ausgangslage dazu schafft des Varus Irrmarsch. Seine verzweifelte Situation beim Schlachtbeginn macht Kleist noch mehr als durch die Meldungen, die er empfängt, szenisch durch die sich antwortenden Brandfanale und Hörnertusche Marbods und Hermanns deut-

31) Der Schlachtplan wird II, 10 von Hermann entwickelt, IV, I von Marbod angenommen. Die Dispositionen des Varus erhellen aus 1I, 10 u. III, 6, die Anordnungen Hermanns für das Blutbad in Teutoburg aus IV, 9 u. 10. Die Zeitrechnung ist von Meyer-Benfey 2, 223-36. vgl. 190, erschöpfend angestellt. 
lich. Alles weitere, das einzelne der Durchführung, bleibt im Dunkeln. Ein taktisches Bild ist kaum versucht, ganz anders als bei dem ausgearbeiteten Exerzitium von Fehrbellin. Winfrieds Schlachtentwurf - darin endet die Parallele zum Homburg - hält sich im allgemeinsten und verteilt die Legionen mehr als lässig wie Schulaufgaben auf beliebige germanische Führer. Eine nationale Kampfform, der Keil, wird obenhin herangezogen, aber früher angelegte Motive, ein Gegensatz zwischen römischer und germanischer Fechtart $(I V, 7)$ und insbesondere die Auscinandersetzung der primitiven Stoßkraft deutscher Haufen mit der "Cohorte, der gegliederten" und ihrer Kriegskunst, .,in den vier Himmelsstrichen ausgelernt", bleiben liegen. Klopstock. dessen exerzierende Manipeln diese Vorstellungen Kleists wohl bestimmten, war taktisch viel genauer verfahren. Sein militärisch geschulter Nachfolger geht über den Schlachtanteil der Römer völlig hinweg. Die Marschformation, worin sie den Teutoburger Wald durchirren, setzen noch des Varus Befehle an die Zenturien voraus, die den Vortrab erkundend unterstützen sollen, und ebenso an die "Cohorten, die den Schweif mir bilden". Aber von einem Aufınarsch, von der Entfaltung römischer Schlachtordnung ist in seinem knappen Entschluß zum Angriff nicht die Rede. Daher kann dann Komars Schlachtbericht den Verlauf, der in der dichterischen Phantasie kaum Gestalt gewonnen hat, nur gleichnisweise fassen: .Zerschellt ward nun das ganze Römerheer, / Gleich einem Schiff, gewiegt in Klippen." Statt sachlichen Kleinwerks der Niederlage, etwa der naheliegenden Begründung, da $B$ die überlegene Manövrierfähigkeit der Römer sich in Wald und Morast nicht geltend zu machen vermag, treten die Varusszenen ein: shakespearische Stimmungskunst größten Stiles.

Aus künstlerischer Notwendigkeit wendet sich Kleist von dem dramatisch unfruchtbaren siegreichen Feldherrn zu dem unterliegenden und gibt in diesem Augenblick alle Tendenz preis. Varus ist weder, hoch genommen, Napoleon, noch, zu subaltern gefaßt, ein pflichttreuer französischer Marschall nach der Schablone, sondern in diesen Szenen einzig der todumschattete Imperator, die Gestalt, durch die der Dichter seiner untragischen Handlung ein ergreifendes Führergeschick gewann. Es scheint, daB er von vorneherein niedriger gegriffen war, wie alle übrige Figur nur Stoff, woraus Hermann fast spiclerisch seine Gestalten formt. Er zeigt sich in den früheren Auftritten zwar immer würdig, als Repräsentant römischer Macht, im Besitz ciner erprobten Eroberertechnik, doch auch, wie alle Römer Kleists, leicht getäuscht, nicht weithlickend. zunächst wenig mehr als cin wackerer Soldat. Mit Ansehen führt er das wallensteinische Feldherrnwort vom unerbittlichen Gesetz des Kriegs im Munde, aber ebenso den für den Chef fast zu bescheidenen Grundsatz des Subalternen Gordon: „Es ist nicht meines Amtes, / Den Willen 
meines Kaisers zu erspähn. “ ${ }^{52}$ ) Als Kommandant wird er durch die dramatisch unerläßliche Disziplinlosigkeit seiner Truppen nicht eben empfohlen. Ein Schatten von Hilflosigkeit fällt auf ihn, wenn ein zehnfach ausgegangenes Heroldsgebot nicht genügte, um seine Soldateska im Zaum zu halten. So möchte man vermuten, der Römer sei dem Dichter erst in den Ungewittern der Schlacht zu seiner imperatorischen Größe aufgewachsen. Die schlimmste Lage eines Generals, die des angeführten Führers, konnte seine Unfähigkeit erweisen. Statt dessen erweist sie sein Feldherrntum. Wie Guiskard darum der größte Kriegsfürst ist, weil er gegen Pest und Tod zu Felde zieht, so reckt sich Varus erst im Untergang, am übermächtigen Feind gewaltig auf. Es ist bezeichnend, daß die Schlacht den ebenbürtigen Gegenspieler gebieterisch auf den Plan ruft. Bis an ihre Schwelle überschattet die Gestalt Hermanns, den die außerkünstlerische Absicht zu überragend bildet, alle andern. Der Zusammenprall selbst fordert eine ihm im Eindruck gewachsene Gegenmacht. Aus demselben Zwang hatte Schiller der Wunderkraft seiner Jungfrau den irdisch großen Talbot entgegensetzen müssen, der für den Varus Kleists weniger durch Einzelheiten, als durch diese übereinstimmende Funktion bedeutsam ist. Hier wie dort hält ein düsteres Feldherrnende dem Sieger die Wage, wechselt um des Gegenspielers willen die Beleuchtung, geht die Sympathie fast überstark auf den Unterliegenden über. Nur steht Schillers Imperator zentraler, in seiner Wirkung abgeglichener, während Kleists Heerfürst für eine letzte Wegstrecke plötzlich die Führung an sich reiß\}t. In diesen Szenen der Schlacht herrscht er dann unbedingt und schlägt als die soldatisch packendere Gestalt den Cheruskerfürsten poetisch aus dem Felde. Zwar ist auch Hermann Feldherr, aber trotz aller ,strategischen Genialität", die man denn doch übertrieben hat, nur in einzelnen Augenblicken wahrhaft groß. Wenn er gleich in der dritten Szene des Stückes sein alles, Haus und Hof, Fluren und Herden mit fanatischer Ausschließlichkeit für den Vernichtungskrieg einsetzt; wenn er dem Heere alle Siegeshoffnung nimmt, damit es nicht gelte, ,in dem gefährlichen Momente der Entscheidung, / Die ungeheure Wahrheit anzuschaun"; wenn er starkgläubig, nachdem die menschliche Voraussicht am Ende ist, das Gelingen in die Hand des Gottes legt. Doch wird er kaum je völlig der Tendenz ledig und vor allem fehlt seinem Führertum bis in die Schlacht hinein der ebenbürtige Widersacher. Seinen Waffen

52) Hermannsschl. 1161 zu Piccol. 1212 (Fries); Hermannsschl. 1273f, verwandt mit Wall. Tod 2507ff. Die Charakteristiken des Varus, die einseitig auf dieser Stelle fußen, wie Brahm 326f. u. Gaudig 269 (trotzdem gerade er S. 256f. u. 263 triftig das Anheben eines eigenen Varusdramas im V. Akt betont), werden seiner späteren Haltung nicht gerecht. Für das Verhältnis zum historischen Varus vgl. Niejahr. VjsL 6, 426. 
des Betruges sind die Römer von vorneherein ausgeliefert, und Tücke kann trotz staunenswertem Kunstaufwand nicht groß erscheinen. In allen diesen Stücken ist ihm der Varus des Schlachtaktes überlegen. Wer es dem Dichter zum hohen Ruhm anrechnet, daß sein $\mathrm{Haß}$ das Bild des Gegners nicht verzerrt habe, geht am Kern der Sache vorbei. Es liegt darin nicht eine Mäßigung des Politikers, die zu üben Kleist sicherlich, am wenigsten gesonnen war, sondem ein Bedürfnis des Künstlers. Der Agitator muß hinter den Poeten zurücktreten.

Die weite, schicksalsmäßige Auffassung von Varus' Untergang, der zugleich doch sehr real durch Hermanns Intrige herbeigeführt wird, knüpft an Shakespeare an. Der Talbot Schillers erliegt als Realist, in der Taghelle der Feldschlacht, einem mit Bitterkeit verhöhnten, gauklerisch gescholtenen Wechsel des Kriegsglücks. Der Varus Kleists als Schicksalsgläubiger in nächtlichem Würgen, eine vorgeahnte, dunkle Bestimmung erfüllend. Gleich Wallenstein umwittert ihn die Sphäre des Geheimnisvollen, aber noch näher steht er den Feldherren Shakespeares, die durch das Walten dämonischer Mächte in düsterer Größe untergehen. Mit Brutus, dem Führer bei Philippi, teilt Varus die schwerblütige Gemütsart, das lastende Ahnen, mit Richard III. den lähmenden Druck böser Vorzeichen, mit Cassius, dessen Siegeshoffnung ein Schwarm von Raben und Krähen über dem Heer niederschlägt, hängt er dem Bild des unheilkündenden Raben nach. Shakespearische Kunst der Schlachtvordeutung ist nie kongenialer nachgeschaffen worden als in der nächtigen Alraunenszene, die allein die Volksschlacht schon entscheidet. So wird des Antonius Erliegen in nächtlichen Entweichen des Cottes aus seinem Lager vorbestimmt, des Brutus Niederlage in Caesars Erscheinung, die Katastrophe Richards durch die Beklemmung seines Traumes. ${ }^{53}$ ) Durch den tiefen Eindruck dieser Formungen Shakespeares scheint schon ein früher Entwurf Kleists bestimmt, jene verlorene Würfelszene des "Leopold von Ósterreich", von der Pfuel berichtet. Die bloße Konzeption, ohne die dichterische Durchführung, stellt sich ebenbürtig neben den Auftritt der todverheißenden

33) Für die Gestalt der Alraune weist O. Fischer. Euph. 15.500f. auf die Hexen im Macbeth hin, den man auch für die Verbindung von Gewitter und Schlacht heranzichen könnte; vgl. auch Meyer-Benfey 2, 196. Eine Waldhexe prophezeit dem Otto Klingers (II, 3) nach furchtbarem Unwetter Blut, lähmt seinen Gaul und verschwindet ins Gebüsch. Varus fragt die Feldherren: .Saht ihr es auch, das sinnverrückte W'eib?" wic Brulus. Jul. Cacsar IV, 3 nach Caesan Verschwinden die Diener weckt, um sie über die Erscheinung zu vernehmen. DaB die Einleitung des Aktes: „Ruft: Halt! ihr Feldherrn. den Cohorten zu!" mit dem sich entfernenden Hale! der Unterführer nach Jul. Caesar IV. 2 gebildet ist, wurde schon oben zu Ramond bemerkt; ganz ähnlich Homburg v. 366f. Auf Shakespeare deutet auch die Marschszene als solche, wie III, 6 das Vorbxizichen des Römerheers. 
Alraune. Leichtfertig, lästernd würfelten hier die österreichischen Herren vor der Schlacht um Leben und Tod. In furchtbar anschwellendem Vorklang wurde der Untergang des stolzen Heeres Schritt für Schritt zur düsteren Gewißheit, wandelte sich der kecke Übermut der Siegessicheren in das Grauen vor dem hereinbrechenden Verhängnis. ${ }^{54}$ ) Zwei Schritt vom Grab, hart zwischen nichts und nichts, hätte die anhebende Schlacht auch diese vom Schicksal gezeichneten Ritter Leopolds, wie den Varus, gefunden.

Vor der zwingenden Vordeutung des Teutoburger Sieges drängt sich ein Blick rückwärts auf Elias Schlegels dürre Intrige, auf Klopstocks Zufallsentscheidung auf. So viel hatte das deutsche Kampfstück aus Shakespeare zu gewinnen. Aber neben das shakespearische tritt doch noch ein anderes Element. Viel mehr als der Brite geht der neuere Dichter, nach Wilhelm Schlegels Ausdruck, auf das einzelne der Kriegskunst ein. Wenn in Hermannsschlacht manches davon in der Andeutung stecken blieb, so lehrt die Schlacht bei Fehrbellin, wie es darum bei Kleist bestellt ist. Mit besonderer Meisterschaft und durchaus eigenrichtig verflicht er Stimmungsmotive und tatsächliches Geschehen. In der zwiefach gegründeten Sicherheit, womit die Entscheidung fältt, erhebt sich der Teutoburger Kampf über alles Skizzenhafte. Die Niederlage der Legionen wird zum notwendigen, unabänderlichen Ausgang zwar zunächst aus der Macht der Stimmung, aber doch ebenso aus der Kunst der Führung: ein Schicksal und zugleich ein strategischer Erfolg. Im Homburg, wo umgekehrt das Sachlich-Militärische vorzuherrschen scheint, liegt das eminent Schlachtmäßige eben darin, daß aller vorbedachte Plan durch ein zügelloses Temperament hinweggefegt wird. Auch hier ein Stimmungselement, auch hier die sachliche Begründung des Sieges durch die gefühlsmäßige überboten, daß solcher Impetus Sieger bleiben muß. Die Varusszenen sind für die Doppelheit der Themen charakteristisch und gemahnen in symphonischem Bau an Kampfauftritte der Penthesilea. Drängende kriegerische Handlung und verweilendes Gefühl durchschlingen sich. Entschlossen und fest stellt der Dichter den Feldherrn eingangs in die Verwirrung der Sturmnacht, in weglose Finsternis. Aber die Todesbotschaft der Hexe

54) Pfuels Schilderung der Szene jetzt in Gespräche Nr. 41. Für die Vorstellung des Würfelns um den Erfolg bei Kleist hat Fries, Forschungen S. 24 die Belege gesammelt. In Shakespeares Heinrich V. rühmen sich die französischen Führer III, 7 in einer Nachtszene vor der Schlacht großsprecherisch ihrer Pferde und Waffen und bemitleiden den verächtlichen Gegner. Ein Ubermütiger fordert zu einem Wurf um zwanzig englische Gefangene auf. Der Chorus zum IV. Akt verstärkt das Bild: ,Stolz auf die Zahl und sichern Mutes würfeln / Dic muntern selbstvertrauenden Franzosen / Um die geringgeschätzten Englischen" - und in der Schande der folgenden Niederlage (IV, 5) ruft der Dauphin verzweifelt aus: „Sind dies die Elenden, die wir verwürfelt?" Hier liegen deutliche Keime zu Kleists tragischer Vertiefung des Motivs. 
wirft schwere Schatten über ihn und jetzt, als sich die taktische Lage unheilvoll entschleiert, wechselt Fallen und Aufstehen, würdiger Entschluß mit verlorenem Sinnen. Soldatisch knapp, klar und erschöpfend, eine Fanfare, ertönt der Aufklärungsbefehl. Bang raunt darauf im Monolog - das todgeweihte Heer ist im Hintergrund gedacht - die düstere Ahnung. Dañn stachelt der offenbare Verrat den Feldherm zur Wut und groß und frei faßt er sich schließlich im Kampfruf zusammen. Doch klingt der dumpfe Unterton fort, und in Wahrheit ist die Schlacht schon entschieden.

Die Stimmungstendenzen des Lyrikers Klopstock sind es, die der Dramatiker Kleist in dieser Varusschlacht vollendet. Erst in die Dämme festen Geschehens gefaßt, entfalten sie ihre eigentliche, mitreißende Kraft. Keine matte Breite wie im Bardiet, kein vages Zerfließen wie in den Schlachten Tiecks wird dem Gefühl gegönnt, straff und in strenger Selbstzucht bleibt es der Aktion eingegliedert. Der grundlegende Unterschied in der künstlerischen Struktur der beiden Hermannsdichter könnte sich nicht schärfer aussprechen als in der Art, wie Kleist die zerdehnte lyrische Anlage der Bardengesänge in den einen Brennpunkt des Chors der süßen Alten sammelt. Selten ist ein Vorgänger genialer genützt und seine beste Absicht gegen ihn selbst so restlos erfüllt worden. Dicht und heiß schlägt hier auf germanischer Seite die Stimmungslohe im Augenblick der anhebenden Entscheidung auf, ein Fanal der sich bäumenden Empfindung, die sonst gewaltsam in dem $Z_{\text {wang }}$ zu unerbittlichem Handeln erstickt wird. Bei Klopstock war umgekehrt die ganze Schlachtaktion in dem Meer der Empfindungen untergegangen. In der einen Szene gelang es Kleist, auch den vorbestimmten Sieger in ergreifende Gefühlsschwere zu tauchen, und damit allerdings tritt Hermann menschlich so erhaben wie Varus den Kampf an. Es ist ein besonderer Triumph dieser Stimmungskunst, daß sie beide Gegner an poetischer Potenz für die Schlacht gleich auszustatten vermag.

\section{Der Prinz von Homburg.}

Literargeschichtlich gefaßt, schließt Kleists letztes Werk das Soldatenstück des 18. Jahrhunderts krönend ab und führt diesen Dramentypus zugleich aus der Enge des bürgerlichen Schauspicls in die Kriegsdramatik großen Stils über. Die Standesfrage der Subordination wird zur tiefmenschlichen Angelegenheit. Der neue Gehalt fordert die weiten Formen des historischen Dramas. Es gilt hier, allein dem militärischen Problem des Stücks, als seinem konkreten Inhalt, auf den Grund zu sehen, und diese Einstellung hat ihr gutes Recht. Der Konflikt der kriegerischen Unterordnung mag nur Gewand, nur der exemplarische soldatische Fall für den fundamentalen Konflikt zwischen Cesetz und Willkür, Staat und Individuum sein. Aber die restlose Einfleischung 
der höhern Idee, die symbolische statt allegorische Geltung des gestalteten Werks muß sich darin erweisen, daß es für sich allein, in seinem spezifisch soldatischen Klima bestehen kann. Über den Sinn der kleistischen Lösung des immanenten allgemeinen Problems sind die Meinungen geteilt. Man wird ihn sicherer treffen, wenn zunächst festgestellt ist, wie Kleist die besondere militärische Frage beantwortet. ${ }^{55}$ )

Der Dichter zieht die Fehrbelliner Schlacht, die den Knoten durch die Verfehlung des Helden schürzt, als große kampftechnische Aufgabe in den Rahmen seiner Handlung ein. Er führt das daraus hervorgehende Disziplinproblem bis in seine letzten Folgerungen durch. Er stellt dabei den Einzelfall in eine knapp gefaßte, aber unendlich reich begabte soldatische Umwelt, woraus er erst sein volles Licht empfängt. Nach drei Richtungen hat demnach die kriegsdramatische Betrachtung des Stückes Ausschau zu halten.

\section{Die Darstellung der Schlacht.}

Kleist preßt in der Hermansschlacht unbekümmert germanische Urwelt zum Dienst der Stunde. Er verfährt im Homburg mit der Überlieferung im Grunde nicht minder radikal und weit entfernt von der ängstlichen Treue des Panegyrikers vaterländischer Geschichte. Einzig auf die schärfste $\mathrm{Zu}$ spitzung des soldatischen Konflikts bedacht, pietätlos gegen allen wirklichen Gang der Ereignisse, bildet er mit souveräner Willkür um, was Historie und Legende über das Treffen von Fehrbellin boten. Das Verhältnis der poetischen zu der realen Schlacht klarzustellen, ${ }^{56}$ ) kann nur den einen Sinn haben, zu lehren, wie genial Kleists Anlage nicht durch die Geschichte, sondern gegen die Geschichte ist.

Es kümmert ihn wenig, das Gesicht des Fehrbellinschen Reitersiegs durchaus zu entstellen. Es ist dessen besonderer Glanz, daß er allein von Kavallerie,

55) Die neueste Formulierung H. Schneiders, Studien S. 5 f., ein Held dürfe nicht immer Held sein, sondern nur auf Kommando, und Disziplin sei das $\mathrm{A}$ und $\mathrm{O}$ aller Kriegführung, kann nicht befriedigen. Die vorgetragenen Auffassungen der Grundidee mustert Meyer-Benfey 2 , 587 f., wozu noch die überkühne Interpretationsgymnastik Julius Harts, Das Kleistbuch, Berlin [1912], insbes. S. 100-156 beizufügen ist, und gibt seine eigene, wohlgegründete 2, $475 \mathrm{ff}$. $-\mathrm{Der}$ Prinz von Homburg ist wie Hermannsschlacht erst 1821 von Tieck in den .Hinterlassenen Schriften" gedruckt.

${ }^{56)}$ Die ältere historische Forschung faßt C. Varrentrapp in den Preuß. Jahrbüchern 45 (1880). S. 335-58 zusammen, vgl. bes. S. 342. Ferner Joh. Jung fer. Der Prinz von H., Berlin 1890 S. 73-89. Populär Rob. Kohlrau sch, Klass. Dramen u. ihre Stätten, Stuttgart 1903, S. 283-306, der S. 294 u. 297 das histor. Schlachtfeld beschreibt; vgl. Jungfer S. 76 ff. Weitere Verweise bei Meyer-Benfey 2, 582. Über die Quellen Kleists handelt O. Pniower, Dichtungen u. Dichter, Berlin 1912, S. 251-37. 
nur gestützt auf ein Dutzend Geschütze und ein stärkeres Detachement von Dragonern (deren ehemalige Bedeutung als berittene Infanterie sich seither verloren hat) über ein wohlformiertes Schwedenheer aller Waffen erfochiten wurde. Kleist macht daraus eine rangierte Schlacht, die auch auf brandenburgischer Seite Fußvolk planvoll ins Treffen führt, und ihm sogar den Hauptanteil an der Kampfarbeit zuweist. Die Reiterei dagegen soll ihren eingeborenen Angriffsgeist zähmen und erst Nachlese halten. Der Dichter verdirbt demnach, kavalleristisch gesprochen, den Tag von Fehrbellin als Ruhmestag der reitenden Waffe. Aber er verherrlicht ihren Geist wie kein zweiter gerade durch die Widerstände, die er ihrer freien Entfaltung in den Weg legt.

Es war ein zwiefacher Meistergriff, den draufgängerischen jungen Führer an der Spitze der märkischen Dragoner in Reserve zu stellen und damit ihm und seinen Reitern die schwerste Aufgabe aufzubürden. Kleist hat die soldatisch unübertreffliche Situation frei erfunden, entgegen der Ceschichte, entgegen auch der für ihn wichtigeren legendarischen Darstellung Friedrichs des Großen. Nach beiden Überlieferungen führt Homburg den Vortrab, was auch in den Eingangsszenen des Stücks noch festgehalten, dann jedoch schnell fallen gelassen wird. Mit der Avantgarde begeht er nach der Legende seine Übereilung. ${ }^{57}$ ) Die Anlage Kleists dient zunächst, wie frühere auf diese reichste Formung vorwärtsweisende Reserveaufstellungen bei einem Längenfeld und die bedeutendere in Klingers Konradin dazu, die Bühne während der Aktion zu besetzen und den Kampf durch Teichoskopie wiederzugeben. Sie hat den technisch unschätzbaren Vorteil, daß der Held selbst im Brennpunkt der Ausschauszene steht, statt daß, etwa im Cötz, seine Handlungen von der Peripherie des Stückes aus beobachtet werden. Schon darin kündigt sich eine Beziehung zu dem Jungfrau-Auftritt Schillers an. Das ist aber nur das Äußerliche. Die innere, in eigentlichen Sinn dramatische Vollkommenheit dieser Schlacht beruht darauf, daß sic statt vorlaut zu herrschen allein dem tieferen Handlungszweck dient, die Verwicklung zu schaffen, auf den Bruch der Order hinzuführen. Noch schlagender als bei Schiller, wo das Treffen im Ausgang des Stückes steht, erweist sich hier jene feine Beobachtung Wilhelm Schlegels, daB Kriegsgeschehnisse im Drama nur Mittel zu etwas anderem und nicht letzter Zweck und Inhalt sein können. Wiederum ist damit ein Schlachtvorwurf dramatisch bezwungen, mit Handlungsenergien gesättigt, und jener aktionelle

i7) Friedrichs d. Gr. Erzählung ist aus den Mémoires de Brandebourg in der Litcralur viellach abgedruckt. zuletzt im Original bei Meyer-Benfey 2. 579 f., vgl. 2. 356 f. Ober Kleists Verhältnis zu dieser Quclle Gaudig S. 344 f., der sie in Ubersetzung bietet. - Ceschichtliche Parallelfälle zu Homburgs Vergehen sind zusammengetragen bei Brahm ${ }^{6} \mathrm{~S} .384$ f.: E. Schmidt in Werke 3. 431: Meyer-Benfey 2. 490 f. Die Nachweise zu der wichtigen Parallele aus Livius VIII. 30-35 ebendort 2, 583. 
Typus der Kampfdarstellung, der sich keimhaft in Shakespeares CassiusSzene ankündigt, gegen den episch schildernden des Götz und seiner Sippe sieghaft durchgesetzt. Dies begründet die wohlerkannte Überlegenheit der Homburg-Schlacht über andere Schlachten bei Kleist, die in der technisch vollkommenen Übermittlung des Undarstellbaren gipfeln und letzten Endes aufgelöster Botenbericht sind.

Der dramatischen Anstraffung arbeitet dabei - nach dem formalen der inhaltliche Triumph - die völlig beherrschte Stofflichkeit in die Hand. Die Elemente des Treffens sind so zueinander gestellt, daß die gewollte Entwicklung aus der inneren Logik der Dinge wie von selbst sich vollzieht. Wohl ist des Prinzen vorzeitige Attacke persönlichste Tat, die sich gegen Rat und Widerstand der Nächsten schrankenlos Bahn bricht, aber sie sollte zugleich auch der „Fehltritt, blond mit blauen Augen“" sein, das liebenswürdigste Vergehen, für Heer und Hörer gleich verzeihlich. Dafür tritt der Geist der Waffe ein, nicht eine vage Kampflust des jungen Soldaten, sondern konkret, lebensstrotzend wie stets bei Kleist, das spezifisch kavalleristische Draufgängertum, dem auch ein bewährter Krieger wie Kottwitz erliegt. Für diesen besten Besitz ihres soldatischen Temperaments kann sich dann der geschlossene Kreis der Offiziere, kann sich die ganze märkische Reiterei dem Kurfürsten gegenüber an des Schuldigen Seite einsetzen. Wir lernten unbeschwerten Angriffsgeist, der über die Bedenklichkeit früherer Generationen hinwegbraust, zuerst in der Kriegsdichtung des Sturm und Drangs kennen. In der Vertiefung der soldatischen Frage zur menschlichen trifft Kleist mit dem Charakterproblem des Egmont zusammen.

Für die technische Durchführung des Kampfes dient der exakte Plan der Paroleszene zur Grundlage. Wichtiger als die Übereinstimmung des Verfahrens mit demjenigen der Hermannsschlacht ist der völlig abweichende Charakter dieses Schlachtentwurfs: ein starkes Beispiel für die Verdichtung der historischen Anschauung seither und zugleich ein Beweisstück ausgereifter Arbeit gegenüber der hingeworfenen Skizze. Es hält unendlich schwer, von der Bühne herab den Mechanismus einer ausgedehnten Kriegsunternehmung nicht nur faßlich, sondern zugleich fesselnd zu erläutern. Kleists Vorgänger sind dem unfruchtbaren Unternehmen fast durchweg ausgewichen. Selbst Shakespeare und Schiller begnügen sich zumeist, der eine mit raschen summarischen Angaben, der andere mit impressionistisch aus dem Gang der Aktion ausgehobenen Augenblicksbildern. Man mag in mehr als einer Richtung einen preußischen Zug darin erkennen, daß Kleist entgegen der ganzen Tradition mit aller Hartnäckigkeit auf begriffliche Klarheit dringt. Gerade der innere Zusammenhang der Kampfhandlung und der in ihr niedergelegte Führerwille soll vor allem andern aufgefaßt werden, und keine Mühe wird ge- 
scheut, den geistigen Aufbau der Schlacht jedém Hörer klarzumachen. Wie vorzüglich dic Sonderheit der kriegerischen Entscheidung dann aber dadurch getroffen wird, daß die Realität nicht nach dem Uhrzeiger des Plans abläuft. wurde bereits betont. Es gibt für den Impetus der Darstellung den Ausschlag. es ist eminent dramatisch, daß die Ereignisse, cinmal entfesselt, die Menschen in ihren Strudel ziehen. Ein im Strom des Geschehens mitgerissenes maßloses Herz wirft das sorglich aufgeführte Gebäude zum Heil und Unheil über den Haufen. Es geschicht so in eigentümlichster Weise den beiden Elementen der kriegerischen Entscheidung ihr Recht: der militärischen Präzision und Beherrschung aller Mittel wie dem unausweichlichen Schicksalsrest.

Damit allein wäre die Anlage Kleists, die denn doch bei aller Genauigkeit und Sachkunde cine poetische Schlacht, kein taktisches Exempel ist, ${ }^{58}$ ) vor jeder Trockenheit bewahrt. Trotz der Schärfe in den wesentlichen Zügen. trotzdem die Rücksicht des klassischen Schiller auf poetische Dignität fernbleibt und die Wirklichkeit keck angepackt wird, ist das Kampfbild dichterisch konzipiert, nicht kriegswissenschaftlich ausgeklügelt. Dies lehrt am besten der Versuch, es graphisch aufzufangen, so wie es bei der Befehlsausgabe geplant, in der Teichoskopie gezcigt, durch die angeschlossenen Berichte weitergeführt und endlich in der großen Auseinandersetzung des Schlusses disputiert wird. Dabei zeigt sich zunächst, wie wenig es dem Dichter auf einen erschöpfenden Überblick über alle Aktionen ankommt, wie er sie über- und unterordnet, Akzente setzt, und schließlich, wie frei er mit einzelnen Umständen nach dem jeweiligen Zwecke schaltet. So unbekümmert wie möglich ist die Behandlung der geographischen Situation, die mit Fehrbellin als preußischem Hauptquartier vor der Schlacht die Dinge auf den Kopf stellt, und ein Schwanken findet sich in der Vorstellung des Geländes. Der Schlachtentwurf postiert etwa die Reiterei, wie es ihrem Charakter entspricht, in die Ebene vor dem rechten schwedischen Flügel. Die Ausschau verlangt aber einen erhöhten Platz. Demgemäß tritt in der Schlacht ein Hügelgelände mit deckendem Talweg an die Stelle des offenen Feldes. In der Aktion selbst läßt sich beim Aufmarsch zum Gefecht das Durcheinanderspielen zweier Vorstellungen nachweisen. ${ }^{59}$ ) Aller Nachdruck ruht dafür auf den Kernmotiven. DaB die Infanterie

s8) Vgl. dazu Brahms S. 393.

39) Den Tatbestand der Schlacht bei Kleist legt Meyer-Benfey 2. 385 dar: vgl. auch Gaudig S. 292 u. bes. Gilow. Die Grundgedanken in Kleists Prinz v. H., Progr., Berlin 1893. S. 4. Die Quellenauszüge zu ihr sibe Pniower S. 222-28. Uber die schwankenden Ortsbezeichnungen neben Pniower auch Kohlrausch S. 294. Auf die verschiedenen Unstimmigkeiten - bei weitem belanglosere als etwa in Penthesilea - gründet Niejahr. VjsL 6. 413-15 auch hier die Annahme zweier Fassungen. Sie endlären sich viel zwangloser aus der Nachwirkung 
den Angriff führt, die Reiterei schlagfertig des Befehls harrt, daß dann Homburg losbricht, bevor Hennings' Umgehung sich ausgewirkt hat, ist unablässig ins Bewußtsein gehämmert.

Die Teichoskopie, die Kleist einer beweglichsten Beobachtergruppe in die Hand gibt, schöpft restlose taktische Durchsichtigkeit aus dem Umstand, daß der Prinz als völlig Unwissender über jede wahrgenommene Bewegung auf dem Gefechtsfelde informiert werden muß. Er darf, anders als Schillers Johanna, selbst sehen. Aber er ist nicht imstande, das Gesehene allein zu verstehen. Wie nebenbei entfaltet hier das vor allem innerlich gemeinte Motiv seiner Zerstreutheit bei der Parole eine vortreffliche Wirkung nach außen. Es führt zu einer Ausschauszene, worin weder ein vorlauter Nothelfer sich zwischen die Ereignisse und die zentralen Personen drängt, noch die Beobachter das Erspähte zum Besten des Zuschauers in fließende Rede fassen müssen. Jede kleinste Tatsache des Verlaufs wird im Augenblick erarbeitet, allein für den beobachtenden Stab und seinen Führer festgestellt und nur mittelbar, wie absichtslos, dadurch dem Hörer kund.

Das technische Gerippe der Kriegsaktion ist dichterisch schließlich völlig überwunden durch die kleistische Kraft der Anschauung. Man sieht den Hennings furchtbar sich am Rhyn entfalten, den Wrangel aus zwölf Feuerschlünden auf ihn loswirken. Formidabler können Feldredouten dem Angreifer nicht entgegenstarren als in Kleists glänzender Hyperbel, die schlagend aus dem eigenen Augenpunkt des Anstürmenden geholt wird: daß sie sich bis zur Kirchturmspitze des (zurückliegenden) Dorfes türmen. Man blickt in die Verwirrung des Brandes, sieht die durcheinanderjagenden Meldereiter der Schweden und den Effekt, den sie in der Schlachtordnung bewirken: die vom rechten Schwedenflügel unter dem Schutz vorgestaffelter Kavallerie abbrechenden Fußregimenter. Den imaginären optischen Eindrücken treten reiche akustische Mittel zur Seite, die bis zum Zuschauer selbst vordringen und damit seine Phantasie noch stärker anregen. Die Beobachtungen knüpfen zumeist an sie an. Der neue Realismus scheut nicht wie Schiller im Treffen von Neustadt das Geprassel der Musketen, den „Knall und Dampf“ einer gewaltigen Kanonade. Aber auch die unterstützende Arbeit des Pulvers wird mehr vom Dichter als vom Theatermeister geleistet. Über das äußere Getöse triumphiert der akustisch ausdrucksmächtige Vers.

Bei aller Konzentration der Schlacht auf ihr einziges Handlungsziel im Vergehen des Prinzen bietet ihr Eingang doch für die "lieblichen Gefühle“ Raum. Kleist versagt sich nicht manche Stimmungselenente. Er gibt den

der geschichtlichen Situation auf die Szenen des Eingangs, die dann, sowie das Problem sich ankündigt, der erfundenen Lage weicht. 
Kontrast des rauhen Handwerks zu der Naturfrömmigkeit taufrischer Frühe, zu dem jungen Tag, ,gemacht zu süßerm Ding, als sich zu schlagen“, worin sein podagrischer Dragonerobrist vielleicht um ein weniges zu poetisch, aber für die morgendliche Stimmung des Blachfeldes unübertrefflich, seine Gefühle mit der Lerche emporfiattern läßt. Er gibt darin, und ebenso in Stellen des Vorabends, einzelneVorklänge des Schlachtgeschehens, entgegen der Stimmungsschwere vor dem Anheben der Hermannsschlacht durchaus freudige, feste Zuversicht. Wo Septimius beziehungsreich nach schwüler Nacht ein Gewitter fürchtet, feiert Kottwitz frohgemut den heitern Duft des Himmels, bricht der Kurfürst mit dem siegbewußten Wort auf: .,Noch vor der Sonn' im Schlachtfeld will ich sein". ${ }^{60}$ ) Der tieferen Verankerung der Entscheidung im Stimmungsmäßigen bedurfte es hier nicht. Der Sieg der Brandenburger versteht sich so gut wie von sclbst. Nicht wie in dem shakespearischen Parteiwechsel der Hermannsschlacht die Römer neben den Germanen, treten nur sie in den Gesichtskreis des Stückes, und der Kampfplan des überragend gebildeten Kurfürsten allein, ohne die schwedische Gegenaktion, ist bekannt. Auch hier zeigt sich wiederum, wie ausschließlich die Schlacht auf das Disziplinproblem hin angelegt ist. Daß die Märkischen siegen, gehört zu den Voraussetzungen, und der Disput erhebt sich erst darüber, ob es durch des Prinzen Verhalten mehr oder weniger vollständig geschah.

\section{Das Disziplinproblem.}

Der dramatische Prozeß, der vom jähen Umschlag der Verhaftung des ahnungslosen Siegers bis in die großen Sprechszenen des fünften Aktes geführt wird, stellt die spezifisch soldatische Grundfrage, das Thema von Subordination und Persönlichkeit in entscheidender Weise zur Diskussion. Dagegen bleibt

co) Hermannsschlacht v. 1648 f. Homburg v. 355: dazu 241 ff. Die Schlacht des kommenden Tages erfüllt das ganze Sinnen des Träurners Homburg. Der Kampfmorgen bedeutsam bei Shakespeare: hoffnungsfrisch in Ant. u. Cleop. IV, 4 (..Wir stehn früh auf zum Treiben das wir lieben/ Und gehn mit Wonne dran"): übermütig in Heinrich V: IV. 2, wo der glanzvolle Autstieg der Sonne zu der Uberheblichkeit gehört, womit die französischen Herren zu Pferde steigen, indessen Englands vernutzte Krieger ..passen schlecht zum Morgenfeld": schicksalsschwanger in I Heinrich IV : V. I, düster lastend in Richard III: V. 3. ınit deın grandiosen Motiv, daB die Sonne über Richards Heer nicht scheint. Die Szene des Antonius ist varijert in Sodens Kleopatra II. 7. das Morgenmotiv nachgebildet von Tieck in der Cenoveva, 8. Szene (8. o. S. 248). In sentimentalisierter Fassung lindet es sich in Kotzebues Rudolf von Habsburg VI. I (s. o. S. 230). Morgenröte und Feind begrüBt emrhatisch der erwachende Pyrthus Klingers (Sz. I. Dramat. Jugendwerke 2, 372 und 370 f.). Frühsonne und Morgennebelduft (ein wohlgerüstetes, kamptfrohes Heer ist fast unzertrennlich an die Vorstellung des Morgens gebunden) spielen um das in Schlachtordnung stehende Kaiserheer im Faust II, v. 10361 ff., vgl. auch 10459 \&. 
die soziale Seite des Soldatentums, die Lenz und der junge Schiller im Vordergrund gesehen hatten - bezeichnend für den Individualisten Kleist - im Stücke unerörtert. Es prallen aufeinander der unerhört gewichtige Sachwalter der Satzung und der mitreißend geformte Bannerträger sieghafter Willkür, Kurfürst und Prinz. Was Kleists eigene Meinung dabei denn eigentlich sei, ist in der Forschung strittig.

Um zum Kern der Auseinandersetzung vorzudringen, gilt es zwei Momente aus dem Wege zu räumen, die im Drama nur zu retardierenden Vorstufen der Lösung dienen und darum die Betrachtung nie hätten verwirren sollen. Das eine ist die taktische Beurteilung von Homburgs Eingreifen in die Schlacht, das andere das Argument des Erfolgs: daß der Bruch der Order zum Sieg führt. Beides erscheint letzten Endes nebensächlich.

Das Taktische zunächst läßt Kleist aus äußeren und inneren Gründen unentschieden. Ob es besser war, mit der Reiterei zuzupacken oder abzuwarten, ist wie in allen den Rechnungen, worin die feindliche Gegenwirkung als unbekannter Faktor steht, schwer auszumachen. Der Prinz darf weder als unfähiger General, noch als unbedingter Sieger erscheinen. ${ }^{61}$ ) Dazu schießt die ganze Erörterung an der Hauptfrage insofern vorbei, als er keineswegs aus taktischen Erwägungen heraus gehandelt hat. Homburg bricht mit seinen Regimentern los, weil er auf der Höhe der Schlacht sich nicht mehr zu zügeln vermag, und nur Leidenschaft, keine Überlegung ist hier im Spiel. Wie weit dem Ausbruch des Soldatentemperaments ein richtiger Instinkt für die Lage zugrunde liegen mochte, läßt Kleist offen, und deutet eine divinatorische Führerbegabung des Prinzen nur eben an. Was Kottwitz später an sachlichen Motiven in den Entschluß hineininterpretiert, sind wohlmeinend nachgetragene Gründe, die ihm selbst im Augenblick der Attacke nicht minder fremd waren als dem Führer.

Mehr in die Tiefe führt die Kontroverse über den Erfolg der Tat. Im strengen Sinne des Kurfürsten scheidet auch dieses Kriterium völlig aus: dem Gesetz muß Gehorsam sein, der Krieg kann ein festes Staatsgebilde nur tragen, wenn er methodisch berechnet und frei von schwankendem Zufall geführt wird. Dagegen beruft sich Homburg als Gefangener mit seinem ersten Wort auf den Erfolg, und Kottwitz vertritt dann beredt die Autorität des vollzogenen Faktums. Gleichviel auf welchem Wege, die Schlacht ist gewonnen, der Feind geschlagen; die Regel, die ihm schlägt, ist die höchste. Der Obrist wird hier, im Eingang seiner entscheidenden Rede, im Eifer der Polemik über seine eigenste Überzeugung weit hinausgeführt und bekennt sich zu einer ganz landsknechtischen Auffassung des Kriegswesens. Der Sieg schlechthin, wie

61) Ich verweise auf die erschöpfenden Ausführungen Meyer-Benfeys darüber, 2, 384-89. 
wild auch gewachsen und zufällig errungen, wäre nach ihr die letzte Instanz des Urteils. Er bahnt damit immerhin die Lösung an. Seine Úbertreibung enthält den richtigen Kern, daß der glïckliche Ausgang den Führer sachlich entlaste. Seine Lehre, daß ein Sieg, der am Wege liege, auch gegen die Order aufgenommen werden müsse, bleibt (vom Dichter) unwidersprochen. Damit ist aus den besonderen Bedingungen des militärischen Handelns heraus, das wie kein anderes zu rascher und eindeutiger Entscheidung führt, eine Teilfrage schon beantwortet. Der Erfolg entlastet sachlich. Aber er entlastet nach der strengsten Auffassung noch nicht moralisch, und hier ist der Punkt, wo Kottwitzens Beweisführung das gegebene Vergehen des Prinzen verläßt, um frei den höheren, einigenden Gesichtspunkt und damit zweifellos die Meinung des Dichters zutage zu fördern.

Die Order ist verbindlich und durch unerbittliches Kriegsgesetz verbürgt. Aber zugleich gibt es Fälle, wo sic nicht gebrochen werden kann, sondern gebrochen werden muß. Nicht aus Willkür, sondern aus einer tieferen, für den Handelnden viel gefährlicheren Pflicht als nur der des verantwortungslosen Kadavergehorsans. Diese Pflicht fordert im Dienste der Sache Entschlüsse auch gegen den ausdrücklichen Befehl. Nur verpfändet der, der nach ihr handelt - dies scheidet sein Tun von aller Eigenmächtigkeit - Leib und Leben bewußt dem Gesetz. Er scheut um des Ganzen willen nicht davor ztrück, sich selbst, wie vor dem Feind, so vor dem Kriegsrecht einzusetzen. Moderne Dienstvorschriften - die Dichtung greift hier der soldatischen Realität zukunftweisend vor - nennen diese besondere Bereitschaft des Offiziers die Verantwortungsfreudigkeit. Sie geht mit dem Disziplingebot jene dem militärischen Lebenskreis eigentümliche Verbindung von eiscrnem Gehorsam und eigenrichtigstem Schalten ein. Kottwitz attackiert wider die Satzung, um nahen Sieg zu haschen, und legt seinen Kopf dem Gesetz zu Füßen. Er wird ihn aller Voraussicht nach behalten, wenn er den Erfolg erringt, aber er wird ihn - hier greift der Ausgang, Sieg oder Fehlschlag ein verlieren, wenn er seine Schwadronen nutzlos geopfert hat: das Geschick manches unglücklichen Generals von lautersten Absichten, sozusagen die Berufsgefahr des militärischen Führers. Das war nun freilich Homburgs Tun in der Schlacht nicht, und auch nicht die bisher mit Worten vertretene Meinung des Kurfürsten, der dem Verächter des Gesetzes gegenüber auch für dessen Buchstaben Gehorsam fordert. Es tritt als ein Neues hervor, wozu sich der Prinz erst durchringen muß, dem der Kurfürst seinerseits erst beistimmen kann, nachdem dieses geschehen ist. Und zwar hat sich Homburg, dessen Eigenwillen schrankenlos jede Satzung verwarf, jetzt unter ihre äußerste Schärfe zu beugen: als Sieger soll er dennoch sterben. Der exemplarischen Durchführung des Prozesses gehört auch an, was Kottwitz schließlich als Ergebnis 
der ganzen Entwicklung vor dem Kurfürsten in ein Beispiel faßt: „,Du könntest an Verderbens Abgrund stehn, / $\mathrm{DaB}$ er, um dir zu helfen, dich zu retten, / Auch nicht das Schwert mehr zückte, ungerufen!" Das ist letzte, bloß noch gedachte Konsequenz der schroffsten Disziplin, Zeugnis radikalster Umkehr des Prinzen, und steht weit jenseits der vom Dichter selbst durch Kottwitz gegebenen Lösung.

Es geht demnach nicht tief genug, wenn gesagt wird, daß in der Schlußdebatte beide Prinzipien, Gesetz und Individualität Recht behalten, oder gar, daß Kleist die Entscheidung in der Schwebe lasse. Halbheit und Stehenbleiben vor beendetem Weg ist seine Sache nie gewesen. Er führt auch hier das Problem zu Ende. Das „Höhere, vor dem auch das Gesetz zerfällt" aus jener schönen Formulierung Wilhelm Grimms ist auf spezifisch soldatischem Boden das freie Handeln mit dem Einsatz seiner selbst, das von der äußeren Verpflichtung zu Satzung und Buchstabe entbindet, ist die Vertiefung der leichtfertig in aufbrausendem Herrenwillen empfangenen Losung „Auf deine Kappe nimm's!" zum sittlichen Imperativ. Darum kann die Brandenburger Armee, „die Schule dieser Tage durchgegangen“, es mit dem Prinzen aufs neue und ruhig wagen. Das soldatische Grundgesetz der Disziplin erfährt eine ethische Sublimierung, eine tiefste Verankerung im Gefühl frei menschlicher Verantwortung, und damit, in seiner scheinbaren Verneinung, allerdings die schönste Verherrlichung. Aus diesen konkreten Gedankengängen des Soldatenstücks führt dann der Weg in jenen höheren Geltungsbereich seiner Resultate im allgemein Staatlichen, und noch umfassender in der menschlichen Frage der Stellung des Einzelnen zum Ganzen.

\section{Die soldatische Umwelt.}

Die Heeresorganisation, worein der Disziplinkonflikt gestellt ist, gibt zu dem Bruch der Order die kontrastreichste Folie ab und schafft doch zugleich auch die Bedingungen für die Verfehlung des Prinzen. Man hat treffend bemerkt, wie fein die Wendung ist, daß Homburg im Augenblick hitzigster Mißachtung des Befehls den pflichtgemäßen Widerstand der Subalternen brutal bricht kraft desselben Soldatengesetzes, das er selbst mit Füßen tritt. Das Vergehen des Oberen ist nur möglich durch die Zucht der Nachgeordneten, und selbst bei Kottwitz, wo ein noch stärkeres Motiv geboten schien, um ihn zur Attacke mitzureißen, spielt die Gefolgspflicht durchaus ihre Rolle. Nur eine Frau, Natalie, darf ungestraft die starre Männersatzung verletzen, die für sie - mit subtiler Unterscheidung - nicht verbindlich sein kann. Nach der inneren Verfassung dieses Heers steht der Kurfürst auch dort nicht allein, wo er sich scheinbar als einzelner gegen die Meinung der versammelten Generalität setzt. Es tritt ihm unsichtbar zur Seite, was über die Erregung des 
Augenblicks hinaus den unverrückbaren Kern seines Kriegsstaates ausmacht, die Treue, die Unterordnung. der Respekt vor dem Herrn. Diesen Geist hinter sich, kann er auch vor dem Anschein offener Rebellion sich auf märkische Weise fassen, felsenfest auf einen Hans Kottwitz aus der Priegnitz bauend. auch wenn er einmal rappelköpfisch sein sollte. Ein beiläufiger Zug spricht mehr als alles andere für den Pflichtbegriff der gereiften Offiziere, den Homburg dann so gröblich verletzt. Als Vorhutführer haftet der Oberst Götz dem Kurfürsten kühn und fest zum voraus für den Besitz der Hackelberge, von denen es erst noch tausend Schweden zu vertreiben gilt. Damit ist hier im Eingang schon jene Verantwortungsfreudigkeit wirksam, die Kottwitz abschließend entwickelt.

Das Meisterstück soldatischer Charakteristik hat Kleist in diesem Dragonerobristen, dem wunderlichen alten Herrn geleistet, dessen Leiblichkeit er mit fast eifersüchtiger Zuneigung, die sich nie genugtun kann, ironisiert. Vom zerfallenen Gehwerk, das nur noch für den Sattel taugt. bis zu der unsicheren Handschrift des Haudegens und den drei einsamen Locken seines Hauptes bleibt kein Teil seiner Wesenheit unangeschaut. Bildnerische Kraft durchsetzt mit tiefem Hurnor formt einen gültigen Soldatentyp, zu dem Schillers mehr beiläufiger Tiefenbach nur noch Vorstufe ist. Kottwitz trägt verklärte Züge des Polterers und auch des Invaliden aus dem Soldatenlustspiel und tritt viel eher als der kleistische Prinz dem historischen Bild des Landgrafen Friedrich von Homburg mit dem silbernen Bein nahe. Das Behagen, womit der Dichter die Fülle kleiner Charakteristika über ihn auschüttet, ist dasselbe, das die Welt der Frau Marthe Rull in jeden Winkel und die bedenklichere des Richters Adam in alle Verschwiegenheiten hincin durchspürt. Man möchte nach dem Zeugnis der soldatischen Prosastücke Kleists, jener ungeheuerlichen TambourGeschichte und etwa der beispiellos anschaulichen Reiter-.,Anekdote aus dem letzten preußischen Kriege" sagen, daß es im inilitärischen Lebenskreis seinen eigensten Gegenstand gefunden hat. So gibt die Paroleszene echteste, wahrhaftigste Anschauung des Soldatenwesens. Wie dort der Stabschef, mit Sorgfalt und Nachdruck diktierend, inmitten der knapp sich meldenden Befehlsempfänger steht, wie der junge Reitergeneral um eines zierlichen Handschuhs willen das fromme Aufmerken auf den Schlachtbefehl so ganz vergißt, wie er in raschen Anleihen bei Kameraden dem strafenden Blick des Vorgesetzten nicht entgeht - wenn auch, als .,des Prinzen Durchlaucht", scinem offenen Verweis - das alles ist als Totalität soldatischer Existenz schon außerhalb jeder dramatischen Verknüpfung dokumentarisch.

Kleist verleiht seinem Kottwitz zugleich, nicht einzig in der Programmrede des Schlusses, cine hohe ideelle Bedeutung. Er macht ihn zum lebenden Beispiel dafür, wie das Cesetz zwar herrschen. aber das Temperament nicht 
unterdrücken soll, das freie Werk der Persönlichkeit, ohre das Siege nicht erfochten werden. Kottwitz ist in unterer Sphäre das schon, was Homburg in der Schule des Stückes erst wird. Er ist ein scharf disziplinierter Soldat, der zwar zu seinem Fürsten frei und kühn spricht wie der Normann zu Guiskard, aber gleichzeitig die feinste Bedenklichkeit trägt, das geringste zu unternehmen, „das man/Mit einem übeln Namen taufen könnte“. Er zeigt sich in seinem Treusinn gleich verwundert über die Frage des Fürsten, wer ihn hergerufen, wie er über die Möglichkeit erschrickt, es könnte mit dem Befehl dazu und also seinem Tun nicht richtig sein. Er verrät seine Erregung nach der schärfsten Probe auf seine Unterordnung nur durch die Kälte des Tons, worin er korrekt um Beurlaubung bittet. Er wird durch einen bloßen Blick des Herrn in seine Augen festgebannt. Aber das ist nur die eine Seite. Gerade diesem wackern Graukopf geht das eine Mal, zur Attacke, der Gaul durch wie dem Jüngling. Die Wendung der Schlachtszene, die ihn dazu bringt und die der Prinz dem alten Freund in der Stunde der Todesbereitschaft rührend abbittet, zeigt einen ganz anderen als den ergebenen Subalternen, eine viel eigenrichtigere Gesinnung als die des blinden Gehorsams. Kottwitz ist als gesetzter, besonnener Herr von Dörfling zum Hüter der Order ausdrücklich bestellt. Aber als er sie geltend machen will, trifft ihn, den Alten, Morschen, scharf und schneidig der Hieb des jungen gloriosen Draufgängers: „Ei, Kottwitz! Reitest du so langsam?" Darauf hat er, der in sich selbst den Reiterkitzel nur mühsam zügelt, keine Parade. Alles, was an Reitergeist, an Stolz und Liebe zur Waffe in dem Reiterobersten, was an jugendlicher Spannkraft und dem festen Willen, daB nie einer der Jungen es ihm zuvortun soll, in dem greisen Soldaten lebt, schließt in glänzender Verknüpfung dieses eine Wort von der Herzensorder auf. Hier angefaßt, wirft er in hinreißendem Ausbruch soldatischen Temperaments - wenn er auch sein Soldatengewissen dann kurz resolviert - die offenbare Pflicht, alles Bedenken und die Gewöhnung eines ganzen Lebens weg und ruft noch hitziger als der junge Heißsporn nach der jauchzenden Angriffsfanfare.

Ist dieses Durchbrennen, von der entscheidenden Entlastung des Untergebenen durch den Höheren abgesehen, dem Vergehen des Prinzen verwandt, so liegt ihm doch bestes Soldatengut zugrunde. Es schließt die Erkenntnis ein, daß Kottwitz sich in aller Subordination der eigenen Persönlichkeit nicht begibt, und führt damit zu der stolzen, männlichen Auffassung von Gehorsam und Unterordnung, die er schließlich als die kleistische Meinung vorträgt. Für den freien Lohn der eigenen Brust dient Kottwitz dem Herrn, kein resignierter Gordon, wie ihn Schiller auf ähnlicher Rangstufe zeichnet, dem Gehorsam die Tugend heißt, um die der Niedre sich bewerben darf, kein willenloser Knecht, der sich selbst den Schergen des Gesetzes nennt. Der historische 
Boden wird völlig verlassen, wenn dieser Selbstbewußte die letzten Wurzeln seines Cehorsams bloßlegt, die in keiner gottgewollten dynastischen Weltordnung, sondern im Willen seiner freien Seele liegen. Hier gibt Kleist fast ein Vermächtnis, jedenfalls cine moderne Neubegründung des Soldatentums, die ganz ihm gehört. Kottwitz schicbt dic beiden Pole der Auffassung Schillers im Wallenstein zusammen. .Wir sind Soldaten der Fortuna, wer/Das meiste bietet, hat uns", heißt es dort in der untersten Schicht, während der Kürassier es edel und nobel treibt und für dic Ehre ficht, und gleichartig steht in der Welt der Generale ein Isolani neben einern Max. Dagegen sagt nun Kleist: Sold ist es immer, sei’s Geld, sei's Ehre, und für Sold sein Blut zu verschütten, .,behüte Gott, dazu ist es zu gut!" Er bricht schroff mit der Uberlieferung und streift den letzten Rest so oder so bezahlten Söldnertums vom bunten Rock ab. Schillers Pappenheimer halten sich noch auf Grund des bloßen Werbeverhältnisses, aber aus einer geschichtlich wohlbelegten, braven Auffassung des Geldvertrags heraus wacker genug. .Wofür mich einer kauft, das muß ich sein". Lessings Tellheim begründet eine höhere Anschauung vom Berufssoldaten durch nationale Einordnung. Kleist geht eigentümlicher, individualistischer vor und verankert das Kriegertum nicht patriotisch schlechthin, überhaupt in keiner fortweisenden Bezichung auf diesen oder jenen außenliegenden Wert, sondern tiefschürfend in einem selbsteigenen ethischen Idealismus: .,Was! Meine Lust hab, meine Freude ich,/Frei und für mich, im Stillen, unabhängig" - Er löst die soldatische Frage in charakteristischer Durchdringung des souveränen Eigenwillens mit dem Staatsgedanken.

Aber er hält sich dabei - dies darf nicht übersehen werden - durchaus in den Schranken des Berufsheers, und innerhalb dieses Berufsheers noch schärfer als früher die Minna von Barnhelm an den ständisch geschlossenen Kreis der Offiziere. Die Masse der Armee bleibt entgegen dem Wallenstein bloßes Material der Kriegführung, die Gemeinen treten, keine gewichtigen Pappenheimer, nicht einmal zum Petitionieren für ihren General in den Gesichtskreis des Stücks. Kottwitz' Dragoner werden von Arnstein nur darum herbemüht, damit ihre Offiziere sich auf legalem Wege mit ihren Kameraden vereinen können, und wenn auch davon die Rede ist, daß jedwedes Heer seinen Helden liebe und die Bittschrift im Namen des gesamten Heers überreicht wird: begriffen ist darunter nur das Offizierskorps. Eine Auflehnung der Mannschaften, auch die leiseste, müßte sich in dieser Welt immer "höchstverhaßt" ausnehmen.

In einer Zeit, die in der kontinentalen Geschichte dic Umbildung der ständischen Truppen zum Volksheer vollzicht, greift das Stück auf den engsten Bezirk des berufsmäßigen Soldatentums zurück und schöpft seine eigentümliche Stärke gerade aus der Versenkung in das Altererbte, durch Tradition 
Glorreiche, geschichtlich Gewordene. Vom Volk in Waffen zeugt die Hermannsschlacht, aber der Prinz von Homburg weiß davon unmittelbar nichts. Was er mit einem neuen, modernsten Inhalt begabt, ist das Berufssoldatentum der alten Zeit, das seinen eigensten Charakter behält. Dieser Inhalt ist zwar geeignet, über die ständische Schranke hinaus auch einem breiter gegründeten Wehrverband den Sinn zu geben, oder anders gewendet: die Idee des Volksheers findet Platz in der neugefaßten Idee dieses Standesheers. Doch hat die poetische Wirklichkeit des Stückes allein mit ihm zu schaffen, und Kleist verklärt es dichterisch im Augenblick, da es geschichtlich untergeht.

Die offenbare Wandlung in der Auffassung des Wehrstands gegenüber der Jugendzeit des Dichters zu begründen wird angeführt, daß weniger die Stellung Kleists als der Gegenstand seines frühen Hasses und seiner späten Liebe sich verändert habe. Die Armee sei inzwischen eine andere geworden. ${ }^{62}$ ) Die Erklärung trifft die Sache nicht recht, denn nicht ein neuer, erst werdender Heerbegriff, sondern das altpreußische Kriegsinstrument in seiner kantigen Sonderheit wird verherrlicht, alles wertvolle preußischer Traditionen freudig erhoben, Sollten die Dinge nicht einfacher liegen und Kleist als Dichter das sublimieren. was er im Leben nicht ertrug? Daß schon dem jungen Kleist, der das Lebensjoch des militärischen Alltagsberufs unwillig abschüttelt, die innere Größe des Standes dennoch aufgegangen war, bezeugt der Guiskard deutlich genug. Für den Homburg ergibt sich dabei noch eine wichtige Einsicht, die am Schlusse seiner soldatisch eingestellten Betrachtung nicht fehlen darf. Die Apologie des märkischen Heeres ist nicht Kern des Dramas, sondern nur Nebenwirkung der Durchführung des Problems. Demgemäß tritt in diesem Kriegsstück trotz Kampf und Schlacht die Frage des Krieges an sich selbst zurück. Er wird fast unreflektiert als gegebenes Institut des Staatslebens übernommen. Wenn Treitschke den „,schönen Idealismus des Krieges“ feiern konnte, der aus jeder Zeile des Stückes spreche, so ist doch zu sagen, daß das Bild, das Kleist vom Kriege in sich trug, sich hier nicht eigentlich, zum mindesten nicht programmatisch offenbart.

62) Brahm 5 S. 372. Meyer-Benfey 2, 483-84, mit dessen Ausführungen S. 480 ff. ich sonst durchaus zusammentreffe. 
14. Kapitel.

Faust. Zweiter Teil.

Herrlichers ist niches ersonnen,

Uns ist diese Schlacht gewonnen!

Faust II.

Wie Goethe im Alter über sein Verhältnis zu den kriegerischen Dingen dachte, darüber gibt jenes Geständnis zu Eckermann am 14. März 1830 bündig Auskunft, worin er seine Haltung in den Befreiungskriegen rechtfertigt. „Bei mir aber", heißt es dort, "der ich keine kriegerische Natur bin und keinen kriegerischen Sinn habe, würden Kriegslieder eine Maske gewesen sein, die mir sehr schlecht zu Gesicht gestanden hätte." Doch ist die bedeutsame Einschränkung dazu nicht zu überhören: „Kriegslieder schreiben und im Zimmer sitzen! - Das wäre meine Art gewesen! - Aus dem Biwak heraus, wo man nachts die Pferde der feindlichen Vorposten wiehern hört: da hätte ich es mir gefallen lassen! Aber das war nicht mein Leben und nicht meine Sache, sondern die von Theodor Körner." Damit lehnt Goethe schon nicht mehr die Kriegsdichtung, sondern nur die gemachte Poesie der Stube statt der erlebten der Front als seinem Wesen fremd ab. Höchst bezeichnend entwickelt sich ihın dann gerade hier, aus dem besonderen Fall dieser zum Verdruß der Nation ungeschriebenen Kriegslieder, das allgemeine Gesetz seines Schaffens: daß es allein aus Gelebtem hervorgehen könne, daß er nur das dichte, was ihm auf die Nägel brenne. Damit ist der Kernpunkt seines Schweigens zu jener Zeit bloßgelegt. Dem Goethe der Befreiungskriege fehlte aus mehr als einem Grunde zum Kriegsdichter das Erlebnis. Der Sechziger konnte die Spannkraft des Leibes nicht mehr besitzen, die ihn in jungen Jahren hätte teilnehmen lassen. Dem Verkünder der Humanität war dic nationale Bindung des Geistes fremd geworden, die in Befreiungskampf eines Volkes ein Höchstes sieht. Der Denker, dem nur Kultur und Barbarei Dinge von Bedeutung waren, crkannte im Kriege, wie zu zeigen scin wird, ein vorwiegend destruktives Element der Geschichte. So fand er kein Verhältnis mehr zu den Vorgängen. Aber der Dichter des Götz und noch mehr der des Egmont, der den kriegerischen Mannesbegriff des Stürmergeschlechtes aus seinen Fundamenten aufzubauen wußte, hatte einst ..kriegerischen Sinn" durch seine Dichtung tief 
genug bewiesen ${ }^{1}$ ). Die eigentlichen, tagebuchartigen Kriegsschriften können dabei, als durch äußere Umstände hervorgerufen, ganz außer Betracht bleiben. Ein reicher Schatz vorlängst aufgespeicherter Feldzugserlebnisse schlummerte bloß und war nicht verloren. Noch die letzten Jahre sollten eine Kriegsdarstellung größten Ausmaßes zur Reife bringen, die denn doch lehrt, daß die napoleonischen Kriegsstürme auch an dem ihnen abholden Dichter nicht spurlos vorübergehen konnten. Man darf der Altersäußerung kriegfernen Wesens die Bemerkung entgegenhalten, daß Coethes Dramatik mit kriegerischen Dingen anhebt und ausklingt: 1771 tritt der Stürmer mit dem kampffrohen Götz auf den Plan, 1831 schließt der greise Dichter das „Hauptgeschäft“" seines Alters, den zweiten Faust, mit dem Kriegsakt ab.

\section{Die Allegorisierung des Krieges.}

Die Entfernung von der Wirklichkeit, wie sie in den Gefechtsvorgängen der Iphigenie unter strengem Kunstgesetz statthat, ist unter den möglichen Formen stilvoller Verarbeitung des Gegebenen noch nicht eine äußerste. Die Verflüchtigung des Realen, die Unterjochung der zufälligen, bedingten Stofflichkeit zugunsten der Prägung des Unbedingten, Gültigen, kann fortschreiten bis zur Allegorie. Die folgerichtige klassizistische Darstellungsweise bleibt bei der Typisierung nicht stehen, die im Aufsteigen vom Individuellen zum Allgemeinbindenden den Erdenrest ihrer Bildungen bewahrt. Sie verfährt grundsätzlich anders. Sie schlägt den kürzeren Weg ein und geht vom Abstrakten aus. Sie gelangt durch dessen Personifikation zu einem Schein wirklichen Lebens und einer freilich begrenzten Anschaulichkeit der Idee. Es tritt neben den vielfach gegliederten Chor der Friedländer, der aus einer langen Reihe ins Typische gehobener Individuen die kriegerische Summe zieht, der geschlossene Kriegerchor der „Pandora“" die Idee des Kriegerstandes in gleichheitlicher Masse verkörpert. Es steht dem typischen, aber wirklichkeitsschweren Kriegsbild von Wallensteins Lager der personifizierte Dämon des Krieges in „Epimenides' Erwachen“ gegenüber. Es verdrängt die Allegorie der Drei Gewaltigen im zweiten Teil des „Faust“ die so persönliche als gültige Gestalt des Landsknechts Valentin im ersten. Dieses Verfahren repräsentiert, um den Ausdruck Schillers zu wiederholen, auf der Bühne und in aller Kunst be-

1) Düntzer zwar möchte (Goethes Faust ${ }^{1}$ 2, Leipzig 1851 S. 317/18), indem er den Götz verleugnet und über den Egmont bemerkt, er habe die Kriegslaufbahn hinter sich und sei „mild und liebevoll" geworden, eine durchgehende Abneigung gegen kriegerisches Treiben behaupten. Eine etwas rasch gearbeitete Kriegsanthologie aus Coethes Schriften, die wesentliches vermissen läßt und auch im Abdruck nicht durchaus zuverlässig ist, gibt C. Schüddekopf im GoetheKalender auf 1917. Völlig wert- und schlimm geschmacklos E. Bertin, Krieg u. Coethes Faust, Leipzig 1917, ein Spezimen absurder „Kriegsliteratur". 


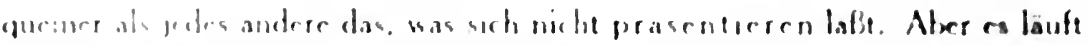

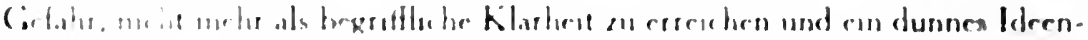

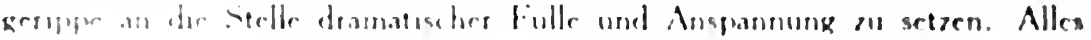

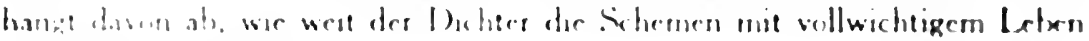
zol lendwen wimag.

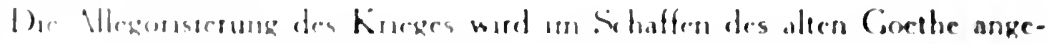

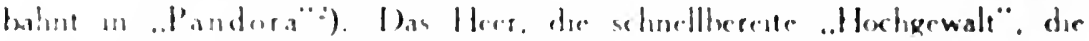

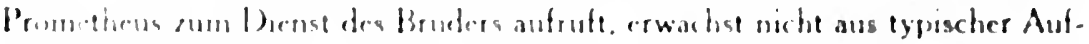

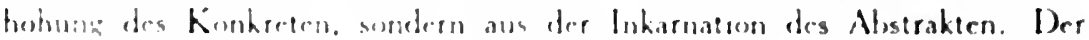

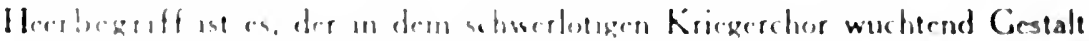

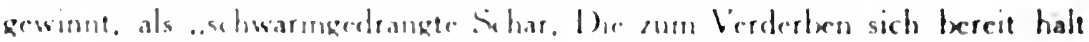

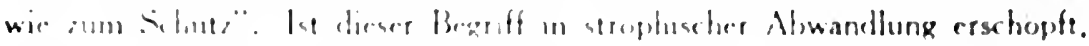

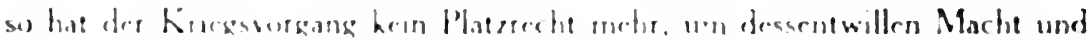

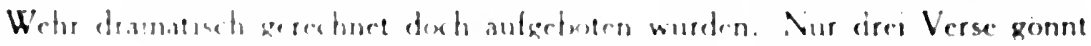

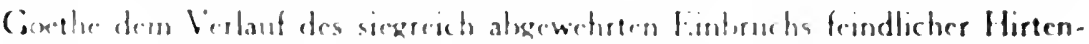

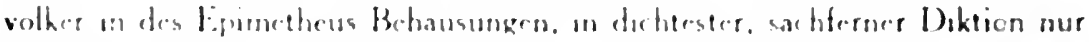

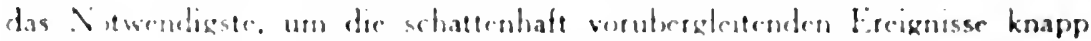

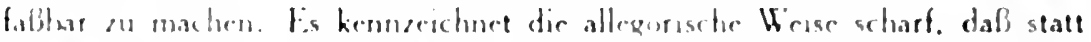

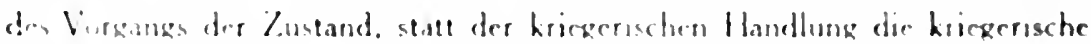
Eusteng gevelen wird. Als Ausdruckstorm dea Bleitenden hat die Allegorie

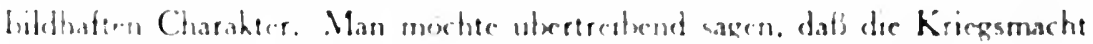

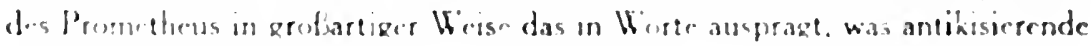
Alleg sien der hiddenden Kusse in ihen Hemblesness. was die Heiligenfiguren des Matelaters in thres Marterwerkecugen in den Handen tragen. Die Bild-

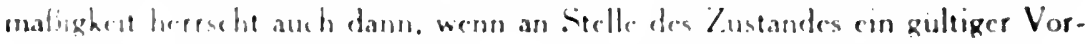
sang garn Auderuck des Cirdankens dient. Methr allegorisch als symbolisch.

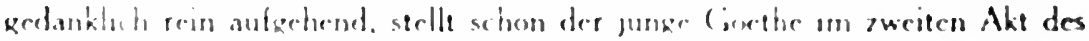

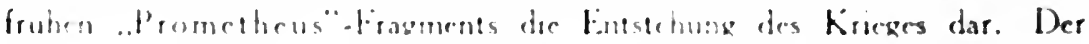

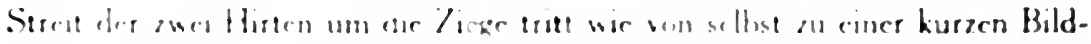

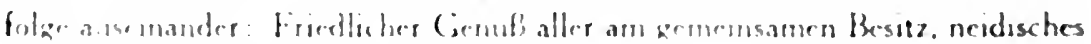

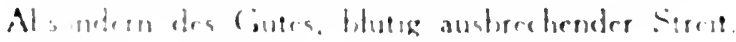

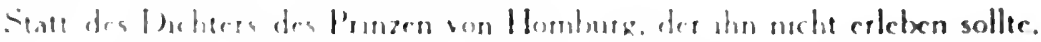

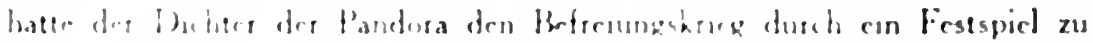

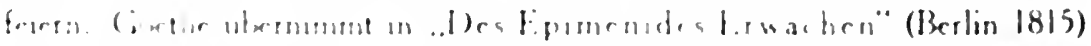

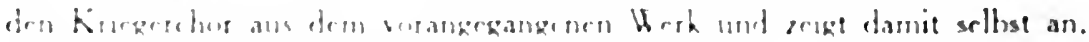

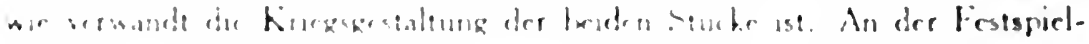

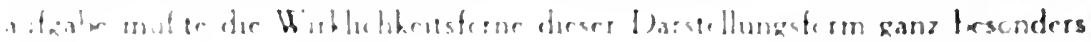

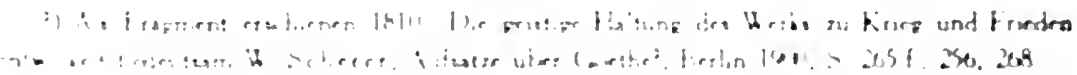


schroff hervortreten. Hier wird, in der Verflüchtigung kriegerischer Aktualität, der äußerste Gegenpol zu der satten Gegenständlichkeit des Götz erreicht. Ein allegorisches Element ist Festspielen gemäß, und zu rascher Zusammenfassung weitschichtiger Vorgänge willkommen. Aber Goethe geht darin so weit, daB das Erkennen der Zeitbezüge schon beim Erscheinen des Stücks eine Aufgabe war. Manche seiner Allegorien bedeuten nicht mehr dies und jenes, sondern deuten bloß noch darauf hin. Anspielungen statt Symbole fassen zum Teil den Zeitgehalt auf. Ist das Wirkliche aus der Vermummung dann herausgeschält, so stört es in seiner historischen Bedingtheit fast die überzeitliche Geltung des Werkes. So sieht die napoleonische Kontinentalsperre aus Versen des Kriegsdämons, so die Einnahme von Paris aus dem Schlußchor wie fremd, so die Gestalt Blüchers aus dem ,Jugendfürsten“" schlechterdings scheel hervor. Denn das Wichtige des Augenblicks, das Einmalige des historischen Moments wird sonst vernachlässigt und geflissentlich zurückgedrängt. Darüber mit dem Dichter zu rechten, hatte die Nation, hatte vor allem das lebende Geschlecht wohl guten Grund. Doch macht dieses Verfahren nicht nur die Schwäche, sondern zugleich die eigentümliche Stärke des Spieles aus. Weil Goethe sich von dem besonderen Anlaß ganz löste, konnte Gültiges, Allgemeinstes, Ewiges ausgesprochen werden. Es kennzeichnet den Altersstil, daß dies nicht aus erhöhten Gestalten der zeitlichen Wirklichkeit hervorbricht, sondern in freie Personifikationen niedergelegt wird. Der gewichtige Schatz der Altersweisheit, der ausgemünzt sein will, überwiegt noch den bedeutendsten geschichtlichen Stoff, duldet Fessel und Zwang konkreter Verhältnisse nicht mehr. Der Dämon des Krieges selbst, der Krieg an sich statt der und jener Feldzüge beschreitet die Bühne. Er ist dem Dichter wichtig, er allein bedeutend, wenn auch das Herz der Zeitgenossen an jenen hängt. (Man möchte auf den Streit um den Versuch ähnlicher Sublimierung durch einen überschauenden Dichter-Seher unserer Tage hinweisen). Goethe steigt hier selbst zu den "Müttern“" hinab und bringt das ewige Teil des Krieges, ledig aller temporären Schlacke, in gewaltige Vision gehüllt zurück. jene Beschwörung von Finsternis und Flammenmeer, den apokalyptischen Einbruch ,höchster Stunde“, worin der Kriegsdämon über allen Erdkreis das Heer aussendet. In dieser Formung mythischer Weite, die zugleich die Mittel der Bühne groß und schlicht einsetzt, ist kriegsdichterisch ein Höchstes und ungleich mehr geleistet als später, trotz dem machtvollen kriegerischen Tatchor, in dem großen Aufzug des Befreiungsheeres. Ein tiefer Blick in die Geistigkeit des alten Dichters eröffnet sich hier : der Zerstörer Krieg tritt ihn näher an als der Befreier Krieg, er sieht im Siegesfestspiel! - das Furchtbare des Schwertes stärker als sein Wohltuendes. Durch diese innere Haltung des Epimenides ist ein schwerwiegendes Zeugnis gewonnen, das weiter reicht als Eckermanns Bericht. Unbeirrt durch 
die letztlich gegensätzliche Aufgabe, führt das Spiel im innersten Kern Gedanken der Pandora zu Ende, worin des Prometheus tat- und kampffrohe Welt der Weisheit letzter Schluß noch nicht ist, und verherrlicht Werke des Friedens mehr denn des Krieges. Der Ablehnung beim Publikum seiner Zeit liegt doch wohl mit der richtige Instinkt zugrunde, daß es das, was alle dankbar bewegte, eben den Krieg, verneint. Wenn Epimenides-Goethe sich dem Geschehenen so weit beugt, daß er den errungenen Sieg nun mitfeiert - er bedeutet ihm vor der vernichtenden Wut des Kriegsorkans, vor „,dem letzten Grauen endlicher Zerstörung" für sich noch nichts. Erst der schönere Aufbau ist das wahrhaft lobenswürdige Tun. Die unerläßliche siegfrohe Beschwingung des Schlusses darf über diesen wesenhaften Gehalt, den schon die Muse einleitend ausspricht, nicht leichthin wegtragen $\left.{ }^{3}\right)$. Die Polarität zwischen Götz und Epimenides in der Darstellungsweise des Krieges wiederholt sich in der geistigen Haltung zu ihm. Der kriegjauchzende Stürmer und Dränger - um scharfer Betonung willen sei ein häßliches Schlagwort nicht gescheut - schließt ab als Pazifist. Er spricht zu Eckermann berühmte Worte gegen den Nationalhaß. Der Gedanke des Weltfriedens ist aus der Klassik, aus dem Weltreich der Humanität nicht wegzudenken. Man braucht auf Kant nur hinzuweisen ${ }^{4}$ ). Goethes Werk umspannt auch darin die ganze weitverästete Entwicklung und schöpft sie voll aus, daß es von frühem kriegerischem Drang in die leidenschaftslose Höhe befriedeter Kulturgeltung aufsteigt.

Die klassizistisch dünnwandigen Allegorien des Festspiels sind in ihrer extremen Vergeistigung nicht Goethes letzte Form der Kriegsdarstellung. Die späteste Zeit greift auf die Sachfreude der Jahre des Anfangs zurück und gelangt zu einem denkwürdigen Ausgleich. In kühner Synthese stellt der Kriegsakt des Faust II die Allegorie der „Drei Gewaltigen“" mitten in die Realität seines Kriegsbildes und faßt sie selbst neuartig. ,Allegorisch wie die Lumpe sind". Personifikationen von Haus aus, gibt ihnen Goethe doch zugleich grobschlächtige Individualgestalt und umkleidet sie mit keckster Gegenständlichkeit. Aus kostümierten Begriffen werden die drei .,Tüchtigen“ oder „Rüstigen“", wie sie in Entwürfen auch heif̧en, zu Kriegsgesellen von persönlichem Körperund Geisteshabitus. Von typischen Gestalten scheidet sie immerhin der gedankliche Ursprung, die grundsätzliche Bedeutung und ihre daraus fießende

ग) Aus patriotischem Gefuhl heraus stelle H. Morsch im Coethe-Jahrbuch 14 (1893). 243 6. u. 16 (1895). 185 den Schlußchor zu sehe in den Vordergrund. Abgewogener urteilt v. Loepers Einleitung zum Epimenides in Hempels Ausgabe Bd. II (auch separat Berlin 1871) u. O. Pniower in Jubil.-Ausg. Bd. 9.

") J. Petersen. Weltíricde. In: Abhandlungen zur deutschen Literalurgesch., Fr. Muncker zum 60 . Geburtstage dargebrachi. Müchen 1916 S. 259 ff. 
gröBere Reichweite. Der Krieger urtümlicher Art wird in ihnen in verschiedene Erscheinungsformen auseinandergelegt, aus „Urgebirgs Urmenschenkraft" soll sich die gültige Dreiheit der rohen Kriegsgewalt formieren. Der abstrakten Bildung darf man scharf nachrechnen. Sie ist erschöpfend in der Antithese von Raufebold und Haltefest. Die beiden offenbaren sich nach ihrem Part in der Schlacht, worin mehr als in den einführenden Versen der Präsentation ihr innerstes Wesen erscheint, als junge Offensiv- und alte Defensivkraft. Zwischen ihnen steht, aus einem andern Einteilungsgrund gencmmen, die nur materiell bestimmte Raub- und Beutegier, Habebald; im ganzen minder sicher verankert, ist er auch durch sein Lebensalter nicht zwingend charakterisiert. Er dient dann zu besonderer Szene, und ihm schmiegt sich eine genial konzipierte Begleiterin, die Franz Halssche Eilebeute an. Ihn fester einzugliedern, teilt Goethe auch dem Haltefest stark materielle Züge zu und stellt den kriegerischen Defensivwillen geistvoll mit zähem Bewahren des Besitzes zusammen. Restlos geht zwar die Allegorie des Urkriegertums in die Dreizahl auch damit nicht ein, aber für den begrifflichen Einwand bleibt vor der primitiven Wucht der Schlachtgewaltigen kein Raum. Der Sturm und Drang, allen voran der Götz, individualisiert, Schiller im Wallenstein typisiert, der greise Goethe allegorisiert den Krieger in gigantischen Maßen.

\section{Die technischen Formen.}

Der Epimenides schwelgt im reichsten szenischen Prunk, schließt das kriegerische Geschehen in zwei große symmetrische Heeresaufzüge der Uriterdrücker- und der Befreiervölker zusammen und stellt an Dekoration und Maschinerie die höchsten Anforderungen. Die gleiche opernhafte Weise herrscht auch in Teilen des Faust, am meisten im Helena-Akt. Hier gleitet der Feldzug Fausts gegen den rächend heranziehenden Menelaus in zauberhafter Schnelle vorbei. Auf den krächzenden Mahnruf der Phorkyas, der grell in die selige Liebesw vergessenheit des Fürstenpaares einbricht, setzt sich die Burg selbsttätig mit imposanter Machtfülle zur Wehr: ein tosender szenischer Aufwand an Detonationen und Musik entlädt sich, der Durchmarsch gewaltiger Heereskraft erfolgt. Doch muß diese Lösung nach dem Ausweis der Entwürfe als Notdach gelten. Sie dachten Faust einen würdigeren Anteil am Kriege zu, er sollte selbst fechten, statt daß er jetzt die Verpflichtung zu eigener Tat (,Nur der verdient die Gunst der Frauen,/Der kräftigst sie zu schützen weiß") mit einem leichten , laß sie ziehen!" beiseite schiebt und sich mit befremolichem Übergang aufs neue der Schäferstunde zuwendet. Zur Ausführung kam nur Fausts strophische Ansprache an das Heer, Schilderung überwältigender Macht, Aufforderung zum Streit, Verheißung des Lohns, daneben die stumme, vom Chor begleitete Befehlsausgabe, die der Abstand einer ganzen Welt andersgearteter 
Form von Kleists sachtreuer Paroleszene trennt. Helena hätte, indessen Faust kämpfte, cine "Einladung auf den Turm" erhalten sollen, zur Ausschau auf sein Tun ${ }^{5}$ ). Das Motiv des Ritterstücks also wäre zusammen mit der gigantisch gesteigerien Burgenwelt in ihren Akt eingetreten.

Es blieb hier liegen, aber Teichoskopie im größten Maßstab ist ein Hauptmittel und geradezu die Grundform von Cocthes dramatischem Altersstil. Dic Tendenz des Götz, den Bülınenraum zum Naturganzen auszuweiten, erfährt nach der strengklassischen Verengung der Szene auf der Formstufe von Iphigenie und Tasso ihre reifste Ausbildung in den späten Werken. Die eigentümliche und einzigartige Größe der szenischen Welt im zweiten Teil des Faust beruht vor allem darauf, daß Coethe nicht melır Bühne und Nichtbülnne als Gegensätzlich!eciten, sondern das All des Raumes als Einheit empfindet. Er geht aus dem bretternen Geviert in die großdichterisch geschaute unbegrenzte Natur, nach durchaus romantischem Prinzip, das jetzt so gut wie im Sturm und Drang die Bindung und Begrenzung formstrenger Jahre ablöst. Das technische Mittel dazu - denn der Darsteller wird immer auf einer Art von Bühne, oder weiter gefaßt: der handelnde Mensch unweigerlich in der zunächst ihn umhüllenden Raumsphäre begriffen, von der aus es weiterzuschreiten gilt - ist Teichoskopie. Nicht mehr scheidende Teichoskopie der Klassik, die Grenzen betont und aus reinlich umfriedctem Bezirk in die Fcrne blickt (so etwa Schillers Soldat aus ummauertem Wartturm auf das Cefilde), sondern romantisches Allumfassen. Weiten ins Grenzenlose. Als Zcugen klassischer Ausschau möchte man noch Lynceus den Türmer ansprechen: „Zum Schen geboren,/Zum Schauen bestcllt,/Dem Turme geschworen./Gefällt mir die Welt" - romantisch empfangen ist schon die bis zu Meer und Firmament ausgebuchtete Szene der Pandora, sind die ins Unendliche sich dehnenden, lebenden Räume der antiken Walpurgisnacht. Diese Kunstweise darf nichts Undarstellbares kennen, und auch das leistet die Teichoskopie. Gibt sie sonst schwer zu bewäligende Menschenschlacht, so hier die sagenhafte Schlacht der Kraniche und Pygmäen. Weben und Wirken der lieblichen und der drohenden Natur, Wunderỏing und Zauberei $\left.{ }^{6}\right)$. Aus

5) Paralipomenon 165. Werke 15 II. 229; vgl. Max Morris. Gocthe-Studien2 1. Berlin 1902. S. 208. Einen andern Weg zur Ausfüllung der Kamplzeit deutet das von Morris S. 204, vgl. 207 neu mitgeteilic Paralipornenon 164 a an: Helenas ..Einführung ins Gynäceurn”. Die für Dichtung u. Wahrheit aufgesetzte Skizze des II. 'Teils (Paralipomenon 63. Werke 15 II. 177) plant femere Kiriegstaten Fausts nach Helenas Entschwinden. Er .führt Krieg mit den Mönchen, räche den Tod seines Sohnes und gewinnt große Güter". Für diesen Krieg solle ihen Mephisto nach der damaligen Absicht die drei Gewaltizen stellen. die dann in die Kaiserschlacht übertreten.

6) Pygmäenschlacht v. 7644 fl.; 7884 ff. Adler und Creif 10621 ff. Danebea sei nur weniges Wesentliche auszchoben: der Sonnensufgang. von Faust v. 4686 fi. in berühmte Wiorte aufgefangen, 
blutgetränktem Crund zieht sie gespenstische Cestalten herauf, aus den Dünsten weltgeschichtlichen Bodens ballt sich ihr die Vision Erichthos zusammen, die mit magischem Akkord griechische Fabelnacht eröffnet.

Lukan und Plutarch bestimmen zunächst das „Nachgesicht der sorg- und grauenvollsten Nacht" auf den pharsalischen Feldern'). Aber es gab auch in moderner, dramatischer Poesie schon eine Tradition der schicksalsdüsteren Vornacht über Heerlagern, die dem entscheidenden Kampftag entgegenwachen. Goethes Gestaltung, deren Beziehung auf die Schlacht durch mehrere vorliegende Entwürfe bedeutsam verstärkt wird ${ }^{8}$ ), vereint antike Schlachtfeldsage von immer wieder erneuertem Streit der Geisterheere der Gefallenen in gro\&artiger Weise mit dem gefühlsschweren Bild nächtlich banger Beiwacht. Wie in Shakespeares Heinrich V. lastet die Finsternis über nahgerückten Heeren, glühen die Zeilen der Wachtfeuer auf, schwanken Gestalten im halben Licht des Monds. Wie Richards III. und Richmonds leibhaft erblickter Schlachttraum die mit dem Morgen anbrechenden Führerschicksale schneidend trennt, so träumt Pompejus trughaft ,früher Größe Blütentag", indessen Caesar vor der Größe der nahenden Entscheidung den Schlaf nicht finden kann. Magisch blau leuchten pharsalische Feuer im Schwinden des Trugbilds, magisch blau brennt König Richards Kerze. In derselben aniiken Schlachtwelt überblickt Klingers Helen den nächtigen Kreis des sich dehnenden Zeltlagers, wo Erichtho das Tal von grauer Zeltwoge weithin überbleicht sieht. Dem gehcimnisvoll dämonischen Vorwurf ringt auch Schiller in Wallensteins Schlachttraum vor Lützen klangtiefe Verse von eigentümlich dichter Spannung ab : „Die Feuer/Des Lagers brannten düster durch den Nebel,/Der Waffen dumpfes Rauschen unterbrach,/ Der Runden Ruf einförmig nur die Stille." Goethe krönt die poetische Entwicklung dieses Kriegsmotivs. Er greift zu einer Entscheidungsstunde welthistorischen Gewichts, er gibt ihr die symbolische Geltung ewig wiederkehrender Kampfprozesse. Er ist in aller Anschauungskraft der zauberisch tastbaren Vision umfassender, durchgeistigter als die Vorgängcr.

dazu Pandora 951 ff. Meer und Schwimmer beobachtet: Pandora $997 \mathrm{ff} . ;$ Hafengewimmel: Lynceus II 143 ff. Sternenhimmel: Mephisto mit den Sphinxen 7125 ff.; Wolke: Faust 10043 ff.; Mlcteorsturz: Anaxagoras $7924 \mathrm{ff}$. Brand: grandios Lynceus $11304 \mathrm{ff}$., Faust $11378 \mathrm{ff}$.; Pandora $819 \mathrm{ff}$. Flammengaukelspiel: Herold $5920 \mathrm{ff}$.

7) Düntzer 2,130 f. u. Erläut. 20/21 S. 139 f. E. Schmidt in Jubil. Ausg. 14, 335; v. Loepers Faustausgabe', Berlin 1879, 2, XLVIII.

8) Besonders die Paralipomena 123-25; 123 läßt (Werke 15 II, 206) gespenstische Kohorten von Pompejanern und Cäsareanern erstehen, vgl. Morris² 1. 195; zu 125 (Werke 15 II, 216) das. S. 194-98 u. die feinsinnige Würdigung im Rahmen der Beleuchtungsphänomene S. 191. 


\section{Die Schlacht des IV. Aktes.}

Die Teichoskopic erfährt ihre breiteste Ausgestaltung in der großen Kaiserschlacht. Der Kriegsakt ist der sachlichste, symbolisch unbeschwerteste und darum eindeutigste Teil des ganzen Werks. Aber in seiner rein gegenständlichen Haltung für dic eigentliche Fausthandlung, die Förderung des Problems, zugleich auch der leerstc ${ }^{9}$ ). Das bloße Verbindungsmotiv, Faust das Lehen vom grenzenlosen Strande zu verschaffen, hätte die Breitenausdehnung der Schlacht nicht erfordert. Fast möchte es scheinen, daß die Kriegsdarstellung Goethe hier zum Selbstzweck auswachse. Den Weg in den Gedankengang der Generalidee weist der Verlauf des Kampfes, der von eingehend gegebener Feldzugsrealität in dämonische Entfesselung der Naturgewalten hineinführt. Hier fand Mephisto das Feld zu übermächtigem Spuk, hier konnte der höllische Helfer das Meisterstück diabolischer Gaukelei leisten, hier Faust unlösbar in Magie verstrickt werden, die er umsonst von seinem Pfad zu entfernen sucht.

Man hat triftig bemerkt, wie schlecht dabei der Krieg als solcher besteht. Im Epimenides noch zurückgedämmte Ablehnung manifestiert sich endgültig. Faust tritt widerwillig an ihn heran: .,Schon wieder Krieg! der Kluge hörts nicht gern" - und überninmt nur äußerlich, gedrängt von Mephisto, die Regie der Schlacht. Dafür findet sich dieser, je heißer sie aufflammt, so wohliger im eigensten Element, schlürft gierig den Greuel chaotischen Zusammenpralls und führt mit satanischem Behagen die äußerste Verwirrung herauf. Krieg ist das rechte Teufelsfest, das wüste Bacchanal sinnloser Zerstörung.

Aber es bleibt nicht zu überschen, wie staunenswert treu der greise Dichter diesen Krieg zu zeichnen vermag. Das Treffen vird so wohl gegründet, so wirklichkeitsnah und sachkundig angelegt wie sonst nur bei Kleist. Neben dem ausgeführten, erschöpfenden Bild der Schlacht beweisen Skizzen (Paralipomenon 181, 183) noch ganz ausdrücklich, wie viel Goethe darauf ankam, die kriegerische Situation klar und eingehend zu disponieren. Die Feldzugserfahrung der Kampagne in Frankreich trägt reichste Früchte. Es wird scharf geschieden zwischen .,Motiven der beiden Flügel, und der Mitte", und aus sorgfältigstem Aufbau des Kampfgeländes eine dreigeteilte schiefe Schlachtordnung entwickelt. Sie ist nach der Dreizahl der in den .Gewaltigen" versinnbildlichten Kriegskräfte gegliedert und wird am hnappsten in deren Aussendung überblickt. Bei verhaltenem linkem Flügel im schwer zu bezwingenden Felsgeklipp steht das starke Zentrum auf flachem Wiesenplan und folgt wuchtig dem Angriff, der vom rechten, dem Offensivflügel, über welliges, vor Reiterei gesichertes Terrain auf ansteigenden Gegner geführt wird. Der Stoß dér im Verlauf nach rechts vereinten Hauptkraft dringt siegreich vor, aber die.

T Vgl. R. M. Meyer, Coethe", Berlin 1913. S. 502. 
Defensivflanke hält übermächtigem Andrang nicht stand und droht den Erfolg des Tages zu verscherzen, bis Zauberei entscheidet.

Goethe besetzt die Szene in modernem Sinne mit dem schlachtregierenden Generalstab, dem kaiserlichen, dann dem höllischen Schlachtenlenker. Die Ausschau von hohem Vorgebirg erfolgt aus dem geistigen Schwerpunkt der Aktion, aus dem Bezirk, mit Kleist zu reden, ,wo sich der kühne Schlachtgedank' ersinnt." Sie ist damit leitend mehr denn schildernd. Nur im Eingang baut der Obergeneral bloß informierend vor dem Kaiser die Schlachtfront auf, wie vorher Mephisto mit prüfendem Kennerblick die Lage erwägt. Doch zeigt gerade dieser eindringend darstellende Teil am feinsten, wie aktionell die Teichoskopie von Grund auf gedacht ist. Nicht als Zustand, sondern als Material des künftigen Vorgangs, nicht ruhend, sondern in kriegerischer Tätigkeit, abwehrend, schützend oder angriffsbereit wird das Gelände gesehen. Als wehrhafter Freund tritt es den in den Räumen sich tummelnden Truppen zur Seite. Diese selbst sind statt in Stellung in Bewegung erfaßt, waffenfunkelnd die Besatzung der Felsbastion, imposant der Kraftgehalt der Hauptmacht. flimmerndes Pikenmeer über dem dunkelwogenden Quadrat der Phalanx. Jedes einzelne, Mann wie Hügel und Berg deutet kommendes Geschehen vor, glüht auf große Tat. In eigenartiger, glücklichster Durchdringung von Handlung und Schilderung fertigt dann Faust zugleich mit den Befehlen des Obergenerals die drei Tüchtigen $a b$, und vollends zum selbstherrlichen Anordner wirft sich Mephisto auf, sobald er die Gewalt höchsten Kommandos an sich reißt. Jetzt hat die Beobachtung, in des Kaisers und seiner Helfer, schließlich in Fausts und des Teufels Hand, nur noch dem Aufruf und der Beschwörung in wachsender Eile zu folgen, die Maschinerie zu zeigen, die der Hexenmeister dramatisch glanzvoll in Bewegung setzt. Sie weitet hier nun am willkommensten den Raum nach dem Bedürfnis des Dichters. Sie gibt das Übernatürliche der losgelassenen Schlacht der Elemente, sie schildert das schlechthin Undarstellbare und formt zugleich die sichtbare Entfaltung breiten Theatralapparates zu eindrucksmächtigen Visionen.

Die stufenweis ansteigende höhere Einwirkung, das Spuk- und Zauberhafte ist das ganz Besondere dieser Teufelsschlacht. Fausts rüstige Gesellen bezeichnen seinen ersten Grad. Zunächst noch fast natürlich als zusammengeballte urwüchsige Bergeskraft vorgestellt, werden sie erst späterhin, als Raufebolds niedersausender Arm gespenstisch sich vervielfältigt, in die Trugatmosphäre gehoben. Sie kennzeichnen scharf die kühne Mischung des zauberischphantastischen Elementes mit dem Wirklichen, am meisten die Beuteszene Habebalds und seiner gierig plündernden Buhle. Mit festem Zugriff in die Realität des rohen Krieges wird niedrige Habsucht des Heergesindels gestaltet, mit grimmigem Humor die Gleichung des diebischen Raubs und soldatisch 
redlicher .Kontribution" aufgestellt, aber zugleich der prall gegenständliche Auftritt in geisterhafte Luft gehüllt: den Trabanten tritt vor den unerbetenen Gästen, auf die sie nicht einzuschlagen vermögen, das seltsam schwanke Nebelwerk des ganzen Schlachttags abschließend ins Bewußtscin ${ }^{10}$ ).

Dunkle Künste nehmen mit Mephistos Hinzutreten überhand. Das geharnischte Geisterheer quillt aus Felsschlünden hervor, die gespenstische Streitmacht, dic aus keckem Museumsscherz zu großdichterischer Bedeutung emporwächst. Das lockende Motiv unheimlich selbstagierender Rüstung, des hohlen Gehäuses menschlicher Formen ohne menschlichen Kern - geniale Skizzen Menzels gehören hierher - wirft vor allem akustischen Ertrag ab. Der blechklappernde Rumor der scheinlebendigen Eisenmänner ist erste Begleitung der schemenhaft sich jagenden Schlachtgesichte "). Der Tumult breitet sich aus, es erwacht die dämcnische Natur. "Der Fels, der Wald, die Atmosphärc. / Der ganze Himmel mischt sich ein." Höllisches Kampfgetöse, furchtbarer Posaunenschall von oben akkompagnicrt, hüpfendes St. Elmsfeuer vergeistert die Speerspitzen inmitten magischer Verdüsterung des Raumes, 'homerisch-shakespearisches Vorzcichen. Kampf von Adler und Greif in den

$\left.{ }^{10}\right)$ Es ist soviel ich sehe nicht bemerht, wie nahe Goethes Trabantenspuk der Szene Kotzebues in ..Schutzgeist" (II, 2. o. S. 232 f.) steht, den er ciner sorgfätigen Bearbeitung (1817) für wert hiclt und nach K. W. Müllers Bericht (Gespräche ${ }^{2} 4,455$, dazu 5. 183) noch in den letzten Stunden im Sinn gehabt hätte. Das Atmosphärische der beiden Auftritte ist überraschend ähnlich, es finden sich gemeinsame Züge ungewissen Sehens mil florbedeckten Augen, des Summens vor dern Ohr, des blinden Tappens, der Unsicherheit über das Vorgehende, des lastenden Sruks. Das fesselnde und schon von Kotzebue unverächelich behandelte Motiv mochte im Gedächtnis. des Vorgängers gereimte Jamben im Ohr des Bearbeiters haften und den Meister dramatischer Zauberei zu eigener, endgültiger Gestaltung reizen. Es ist lehrreich, die Dichte. Tonschwere und im besonderen die magische Anspannung der Wortkunst Goethes an dem wahrscheinlichen Anreger zu messen. Statt eines lecren Verses Kotzebues: .Es summt, Mir vor dem Ohr, es flüstert cine Stimme" - entfesselt er in einer cinzigen Zeile die ganze Hexenmusik: .Dann summt's und saust's und zischt im Ohr," Es berührt den Sachverhalt nicht, daß Gocthes Bearbeitung (Werke 13 II: 1, 10-12) die Schildwachepisode Kotzebues gerade nicht enthäht: sie muBte (an Zelter 9. März 1817) kürzen und das Notvendige zusammenfassen. Vgl. über sic G. Stenger, Coethe u. A. v. Kotzebue $S .75-81$, der im folg. auch die übrigen Bearbeitungen kotzebuescher Stücke durch Coethe, S. 75 die Epimenides-Angelegenheit u. S. 109 1. u. 168 weitere Bezichungen behandelt.

11) Die Rüstkarnmercindrücke (Kügelgens Bericht Gespräche² 2. 182; Düntzer. Coethe u. Carl August? Leipzig 1888, S. 180; zu E. Schmidts Hinweisen. Jubil. Ausg. 14. 384 noch Coethes ..Winckelmann". Werke 46. 49 f.: ,.Rüstkammern, Galerien und Muscen ... haben etwas Grab- und Gespensterartiges") durchdringen sich mit den ('berlielerungen geisterhafter Hecre. wozu $v$ Loeper ${ }^{2}$ 2. 261 vgl. S. XLVIII das meiste und Morris² 1, 109-1II das wichtigste beibringt. 
Lüften deutet auf gewissen Sieg. Aber es fehlt zur dramatischen Schlacht noch die Krise: "Gewöhnlich gehts am Ende scharf" - und der diabolische Feldherr führt sie, souverän mit dem Geschehen schaltend, selbst herauf und übertreibt sie hitzig, um dann zur Entscheidung als gewaltigstes Kriegsinstrument die entbundene Naturkraft einzusetzen. Die Heerfürsten treten ab, nur ncch der Meister, in seiner Rabentraulichkeit unheimlich sich aufreckend, hält die Szene. Der natürliche Krieg geht unter in der Phantasmagorie. Auge und Ohr und alle Sinne sind ihr verfallen. Schäumender Wasserspuk, sinnverwirrender Feuerzauber und satanisches Schreckgetën schlagen über dem Feindesheer zusammen und einen sich in wildem Schlachtgewitter ,bis in den allerletzten Graus." In einer einzigartigen Gestaltung wird hier die Natur, seit Shakespeare zum Kriegsgeschehen mannigfach herangezogen, vordeutend, stimmend, dem Eindruck nach (zuletzt bei Kleist) den Kampf entscheidend, selbst zur zermalmenden Kriegsmacht. Coethes Faustschlacht setzt damit einen Schlußstein: der menschliche Zusammenprall endet in übermenschlicher Sphäre in grandioser Symphonie der Elemente. 


\section{Ergebnisse.}

Der lange tieg von der Schaubiahne Cottscheds bis zum vollendeten Faust Suhre uber Höhen und durch Nirderungen auf (ipfel, die rine weite Uberschau gewatren. Man erkensut riskllickend lesser die Wëgzeichen. die im ruhigen Fortzang des Plades schuichterner, an scharfen Windungen sprechender die Richtung weisen. V'on Elias Schlegels betangener: Hermannschilacht, won Cöz zu den Raubern und an dit: Edelform der achtziger Jahre, an den Abwegen handfester Theatralik und halttoser Romantik vorboi gelangt das deutsche Kriegsedrama zu endgultigen Formungen Schillers. Kleists und Gouthes.

Die Eunzelforschung hat sich höhere Zicle zusetzen ais nur die Durchackeruag ciner bestimmen Materialmasse. Sie dart von ihren Gegenständen niche lass.n bis sie ihnen jene Einsichten in den Cang der Dinge im ganzen abgewonnen hat, die sith der treuen duffassung planwoll begrenzter Phanomene aen sichersten zu crschliebers scheinen. Hier sollee in der Darstellung von Karrof und Krieg ein Kapited dramatischer Caeschichte durchschritten werden und die Sonderfraw sum (Okular fur scharfe Betracheung ihses allgemeinen Luuf s dienen.

Der gewistesgeschichetiche Prozel' zwischen Phantasie und Ratio vollziche

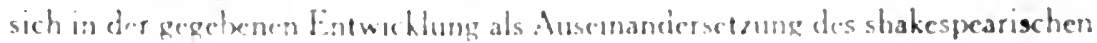
mit dem framzosischen Tragendienideal. Linuersohnlich stehen sich zunächst

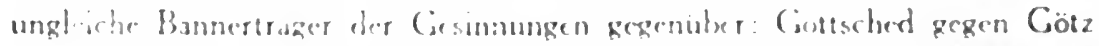
von Berhiehingen. Es war zu engen, wie sich aus weltherarischen Polaritaten die deutsche Form langeann heranbildet. Blicke main auf die kriegerischen Sacinotive, so ubereshattet Shakesprease unsere Bahn his ans Ende. Man

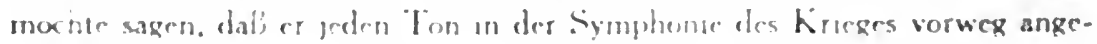
schlagen haler. Aber formal herrscht er nur rone. Sirerke welt. und die deut seche

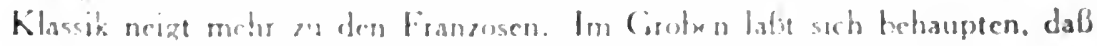
deren gesclidossene form gencitet wird hos dee Sachfulle. Shakespeares in sie

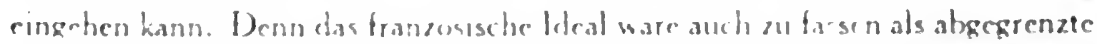

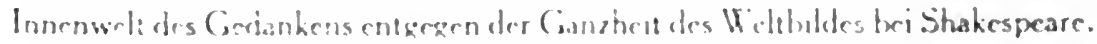

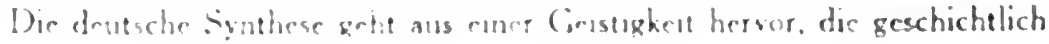


schon einmal, in Griechenland, gegeben war. Wir verfolgten die Übereinstimmung in einer wichtigen Crundlage der dramatischen Gestaltung: der Auffassung des Raumes. Für die Kriegsdarstellung ergab sich, daß die strenge Gesinnung hier wie dort den sichtbaren, getümmelfrohen Krieg vom Schauplatz verbannt. Die neue Klassik nähert sich damit, von Shakespeare abrückend, der gehaltenen Würde des antiken Theaters. Aber sie widersetzt sich der Verengung, der die griechische Tragödie auf französischem Boden anheimfällt. Sie leistet nicht wie der Rationalismus auf den Krieg Verzicht. In langer Lehrzeit bildet sie das antike Kunstmittel der Teichoskopie zum starken Träger ihrer Kriegsdarstellung aus und findet dabei eine neue, eigenste Aufgabe. In der Antike noch nicht gegeben und zugleich der shakespearischen Ungebundenheit fremd, der neuen angestrafften Form vorbehalten ist die spezifisch dramatische Organisierung des Krieges. Bei den Griechen ist er episch gerichtet, bei Shakespeare und dem ihm folgenden Sturm und Drang entlädt sich gewitterartig seine Ereignisfülle. Jetzt wird er in das Gefüge der gegenwirkenden Kräfte und Spannungen eingeordnet.

Das kriegerische Erlebnis, das den Untergrund der ganzen Entwicklung bildet, fehlt durchaus der früheren Zeit. Sie bringt mit sklavischem Anschluf an fremde Form kein Opfer eigenen Fühlens. Es gewinnt zuerst Gestalt im Siebenjährigen Krieg und erstarkt mächtig in der radikalen Neugeburt der Geister, die wir Sturm und Drang heißen, obwohl gerade diese Jahre äußerlich den friedlichsten Habitus tragen: so glatt geht die Geistesgeschichte in die politische Geschichte nicht auf. Es bleibt wach in die Revolutionskriege hinein und empfängt - in Kleist - seinen mächtigsten Anstoß aus den Feldzügen Napoleons. Neben den realen Grundlagen aber steht die Geistesmacht, die trotz allem Einspruch gegen „literarischen Einfluß" ihnen an Gewicht gleichkommt: Shakespeare. Nicht papieren als Buch genommen, sondern als der unerschöpfliche Bildungsstoff, der aus dem halben Jahrhundert seiner frischesten, leidenschaftlichsten Aufnahme am wenigsten wegzudenken ist. Das kriegerische Erlebnis der Zeit wird im ganzen durch Shakespeare wohl entscheidender bestimmt als durch die geschichtlichen Tatbestände. Jedenfalls erhält es durch ihn seine besondere Prägung. Aus dem Primat des shakespearischen Geistes fließt dann seine Einwirkung auch auf das Einzelste.

Als grundsätzlich geschiedene Typen der Kriegserfassung traten die pathetische Schillers und die sachliche Goethes einander entgegen. Noch in dem gewaltigen Vorwurf der Faustschlacht, wo sich Schiller mit der höchsten Idealität von Sprache und Bild gerade genug getan hätte, beharrt der Dichter des Götz auf seinem trotz machtvollster Steigerung der Ausdrucksmittel unweigerlich schlichten Ton. Kleist steht hier zwischen den Weimarern, or ist kühn realistisch mit Goethe, aber auch schwungvoll gehoben, grandios mit 
Schiller, und führt beides bis an die letzten Grenzen. Wir fanden Beispicle in Penthesilea.

Dies ist Kleists, des ausschließlichsten Kriegsdramatikers im deutschen Dreigestirn. Stellung überhaupt. Man hat versucht, sein Schaffen als den Gipfel des formalen Aufsticges deutscher Dramatik darzutun. Kaum mit Recht. Historisch erreicht die formale Auseinandersetzung in Schiller ihren Scheitelpunkt. Kleist greift sic leidenschaftlich noch einmal auf. Im Zusammenhang der ganzen Kunstentwicklung gesehen, zeigen sich seine Werke als geniale, aber für jeden einzelnen Fall insbesondere gefundene, ganz eigenrichtige und einmalige Formsynthesen. Die vorwiegend klassische Penthesilea neben der vorwiegend shakespearischen Hermannsschlacht zeugt dafür am lautesten. Kaum ein anderes Schaffen schwankt so stark, kaum ein anderes fordert vor jedem ncuen Werk soviel zugegebene Prämissen. Darüber darf kein Zwcifel sein: was dem Guiskard an Formalabsichten zugeschrieben wird, war mit seinem Scheitern gescheitert und ist nie erreicht worden.

Kleist ist gegen Goethe und Schiller der Sohn einer neuen Generation in seiner Anschauung vom Kriege. Die vorgoethische Pericde nimmt im Tieferen nicht Stellung, sie erlebt den Krieg noch nicht; der Sturm und Drang zunächst nur bejahend, freudig. Hier taucht dann das Problem auf, erst noch angeknüpft an das Kriegswerkzeug, nichi den Krieg selbst: an die Armee. Es scheidet sich der reine Gestalter, Goethe, von den Reformern, Lenz und Schiller. Eine Wertbetonung bleibt Schiller eigentümlich, er verherrlicht, im Wallenstein, oder er verdainmt, im Tell; er wägt Krieg und Frieden gegeneinander ab in der Braut von Messina - alles auf Grund der Kriegsauffassung der Humanität. Diese spricht absichtloser, aber gültig aus den Alterswerken Goethes. Dagegen setzt nun Kleist ein völlig abweichendes Denken vom Krieg. Er ist trotz einem schroffsten Tendenzstück überall sonst reiner Gestalter wie Gocthe. Aber er schlägt durch den immanenten kriegerischen Gehalt seiner Schöpfungen die Anschauung der Klassiker in Stücke. Er führt cine andere Zeit herauf. 


\section{Anhänge.}

Neue Gesinnung erweist sich sprechend am Kleinwerk. Ein paar Querschnitte nach sachlichen Gesichtspunkten mögen zum Schlusse zur Übersicht über die weitschichtige Entwicklung beitragen und zugleich manches im Lauf der Darstellung Angedeutete in seinen Zusammenhang rücken.

\section{Die Waffe.}

Der Wandel der Zeitanschauung spiegelt sich in der wechselnden Auffassung des kriegerischen Rüstzeugs. Nach der inneren Leere der Cottschedschule ist Lessing der erste, der im Philotas die Waffe eindringlich erfaßt, im Anschluß an die Antike, der er dann im Laokoon (cap. XV; XVI ; XVIII f.) die Gesetze homerischer Waffenbeschreibung abgewinnt. Wie der gefangene Jüngling sich ein Schwert verschaft, ist die einzige äußere Handlung des Einakters. Bedeutungsvoll spricht er die listig errungene Waffe an und findet tiefsinniger Aufmerksamkeit daran schon wert, „,daf es ein Schwert ist". Von allen Seiten wird das köstliche Werkzeug betrachtet, geprüft, gerühmt, auf seine Eignung versucht, um endlich der befreienden Tat zu dienen.

Die eigentümliche Spannung in diesem Verhältnis zur Wehrbildet Klops tock zu einem besonderen "Waffengestus" aus, dem gedankenschweren Kult mit Schild und Lanze, den seine Germanen umständlich verrichten. Eine bedeutsame Geste wird bemerkt und fragend unterstrichen. Man blickt seine Lanze mit besonderem Lächeln an (Hermannsschlacht $\mathrm{Sz} .3 \mathrm{~S}$. 77), gibt ihr sprechenden Ausdruck schon durch die Art, wie man sie hält (Sz. 5 S. 90), bewegt sie auf eigenartige, deutbare Weise (Sz. $11 \mathrm{~S} .118)$. Sie ist der Gegenstand zärtlicher Verehrung und wird vom Dichter liebevoll angeschaut. Mit seiner „,blanken“, ,leichten Lanze“" verlangt der Opferknabe in die Schlacht (6 S. 98) und trauert sterbend seiner "kleinen schönen Lanze" nach (8 S. 107). Emphatisch werden die Waffen geküßt (Hermann und die Fürsten Sz. 3 S. 227; 7 S. 281 u. 287 usw.), Schwertschwüre geleistet (Hermannsschl. 6 S. 91), daneben allerhand Gebräuche verwertet (Hermann und die Fürsten 7 S. 292). Erst die blutige Waffe ist schön (Hermannsschl. 3 S. 77), und darum brachte es Siegmar (7 S. 104) als Jüngling kaum über sich, das Blut vor dem Siegesmahl nach der Vorschrift von der Lanze zu spülen (11 S. 114). Die eigene Waffe ist köstliches, reichverziertes Gut (6 S. 99), sie muß bei dem gefallenen Krieger liegen (8 S. 109). Die Feindeswaffe ist ersehnte Trophäe. In der Betrachtung des erbeuteten Varusschildes läßt Klopstock durch Thusneldas Mund sein 
stimmungsvollstes Waffenwort sprechen: „So groß, und hat doch nicht gerettet" (II S. 116; ähnlich Kleists Kurfürst, Homburg II, 10, über die erbeutete Schwedenfahne mit der Inschrift Per aspera ad astra: „Das hat sie nicht bei Fehrbellin gehalten"). Eine reiche Anschauung des Rüstwerks beginnt sich hier zu entfalten, ein wacher Sinn auf die Gegenständlichkeit zu achten.

Klopstocks Waffengestus wirkt auf Klinger (Pyrrhus I, Dramat. Jugendwerke 2, 362 f. "Was spielst du im Staube mit dem SpieB?", anschließend genaue Erörterung seiner zweckmäBigsten Form, Laokoongesetze erfüllend an seiner Tätigkeit im Gefecht demonstriert), wie Klopstock überhaupt - eine neue Beziehung zur jungen Generation - die schwärmerische Waffenverehrung des Sturm und Drangs eröffnet. Sie ist, wenn auch der Götz die Motive überall vorbildet, am ausgesprochensten bei den pathetisch gerichteten Stürmern, bei Klinger und dem jungen Schiller. Der Waffenkult der Klingerschen Helden geht bis ins Bombastische. Er trägt klopstockische Farben noch im Aristodemos (SchluB der ersten Fassung), im Damokles (Werke 2. 379 u. 346, wo der die Jugend verlockende Zauber der Waffen, des bewehrten Sichfühlens ähnlich erfaßt ist wie in der Szene des Rudenz und Attinghausen im Tell II, I: .. Ich sehe dich gegürtet und gerüstet" usw.) und in der Medea auf dem Kaukasus (Werke 2, 278 u. 303 usw.). Der Speer trinkt Feindesblut (das. 2, 278) wic Klopstocks Lanzen. Aus den Räubern gehört das aufdringlich verwendete blutbeschriebene Schwert Karls (II, 2) hierher, wohl Leisewitz nachgebildet, der im Julius von Tarent IV, 6 ganz ähnlich einen blutigen Degen überschicken läßt. Mit Emphase wird in der Räuberbande insbesondere der Dolch verehrt, den etwa Schweizer dem alten Moor (IV. 5) weiht. An Beispielen übersteigerten Schwertkults ist der Fiesko überreich; die Klingen der Verschworenen werden der geschändeten Bertha in feierlichem Cestus zu Füßen gelegt $(I, 12)$, die blutige Waffe nach vollzogener Rache der Braut zugefertigt $(V, 3)$.

Das Schwert wird dem Sturm und Drang zum Symbol der Tat, Helm und Rüstung zum wahren Kleid des Mannes. „Auch leg' ich nicht gern die Waffen ab; ich scheine mir halb", sagt Klingers Alexander im Pyrrhus (I S. 359), wie später zugespitzter der Tell (v. 1538): „Mir fehlt der Arm, wenn mir die Waffe fehlt". Der kriegerische Mann ist wie die Waffe: "Seh ich ein Schwert, ein Waffenstück oder sonst etwas Männliches, so denk ich an Otto", heißt es bei Babo (Otto III S. 130). Dem Rüstzeug horcht noch Tiecks Karl von Berneck ganz im Sinne der Stürmer die Aufforderung zur Tat ab: .Wenn ich im Waffensaale auf- und abgehe, so ist es, als wenn jedes Schwert und jeder Schild mich verhöhnte“" (Schriften 11, 17); in der Rüstkammer: „Wie schlägt mein Herz, da ich hier die Schwerter und die Panzer aller meiner Ahnherrn vor mir sehe. - Hier sprechen mich Taten und Geister an" (11, 82). Zur großartigen Inkarnation tätigen Lebens wird die Waffe dann in des Prometheus Aufforderung an die Schmiede bei Goethe (Pandora 305 ff.): „Nur Waffen schafft! Geschaffen habt ihr alles dann./Auch derbster Söhne übermäß'gen Vollgenuß!" 
Das Schwert ist beseeltes, fühlendes Wesen. Hier gibt Klinger Tiefempfundenes. Sein Otto (II, 10) verhüllt sein Schwert, das nicht schlagen darf im Mantel, es widerstrebt, seine Tränen fallen darauf. Helens Schwert (Pyrrhus V S. 395) trauert unter den Tränen des Herrn und erwidert seinen Abschiedskuß. Derbkräftig spricht ein Bürger Längenfelds (Ludwig IV. C IV, 2) zu seiner Klinge: „Heraus du alter Vielfraß! thu dir heute weidlich Guts nach so langer Fasten".

Eine besondere Form der fast religiösen Vcrehrung des Schwertes läBt sich im Knabenmotiv seit Lessing verfolgen. Philotas „wählte unter den Schwertern meines Vaters, dem ich gewachsen zu sein glaubte" (Sz. 2). Götzens Georg schwingt vorzeitig das Schwert seines Vaters. Die stürmerische Pathetik steigert Dimension und Gewicht der Waffe, den Zentnerworten ihres Stils entspricht die zentnerschwere Rüstung eines Alcim bei Klinger. Dem Unerwachsenen ist damit das Schwert zu schwer, er vermag es noch nicht zu führen. Alcim (Pyrrhus II S. 376) ruft den Buben, der die Waffe holen soll, zurück: er kann sie doch nicht tragen. Helen (das. I S. 360) hüpft vor Freude unbändig, da er den Schild eines alten Helden so leicht tragen konnte. Die Motive wirken fort. Den Schuliern des Tieckschen Karl von Berneck $(11,17)$ ist der größte Harnisch nicht zu schwer, die gewaltigsten Schwerter und Streitäxte sind ihm ein Spiel. Bayard bei Kotzebue IV, I rät seinem Knappen Miranda, das leichteste Schwert zum Lohn zu wählen und erhält die Antwort: „O mit dem leichten habt $\mathrm{l}$ hr nicht gefochten". Wie den Halbwüchsigen, ist die Waffe Frauen zu schwer. Schillers Leonore (Fiesko V, 5) wägt sie: „Ein schweres Schwert, meine Bella! Doch schleppen kann ich's noch wohl".

Die Tatsehnsucht der Stürmer und Dränger gewinnt eindrucksvoll Gestalt in der Waffensehnsucht ihrer Knabenfiguren. Das Motiv kündigt sich an im Philotas, den Söhnen Ugolinos bei Gerstenberg und in Klopstocks Opferknaben, die „den Tag der ersten Waffen" als Glückstag herbeisehnen. Dann entwickelt sich eine reiche Tradition vom Georg im Götz zu Klinger (Gebhardt im Otto II, 6 u. 9, Helen im Pyrrhus V S. 394, den der strafweise Entzug der Waffen im Tiefsten trifft) und v. Soden (Heinrich IV: I, 4), durch Niederungen wie der Ausschlachtung in Hübners Camma (II S. 44 ff. usw.). zu Tiecks Karl von Berneck (11, 17, 70 u. 82) und dem Heinrich Kotzebues im Grafen von Burgund I, 1. Kleists Rosenmädchen (Penthesilea v. $928 \mathrm{ff}$.) fühlt den Arm dem sanften. Werk des Kränzewindens entwachsen und für Wurfspieß und Schleuder erstarkt. In die Reihe gehört als liebenswürdigste Figur Goethes Elpenor, der am Abschiedstag das Schlachtschwert und den lange still begehrten Bogen zum bedeutungsvollen Geschenk erhält; er ist Aufgabe für ihn, er wird ihn erst als Mann spannen können, und soll ihn nur nach würdigen Zielen richten.

Die neue Sinnlichkeit der Geniezeit war am Kriegsbild des Cötz von Berlichingen zu erweisen. Hier zuerst wird die Waffe auf ihre sinnlichen Qualitäten hin gesehen. „Fürchterlich schön“ leuchtet den Kriegern Klingers 
cine gigantische Rüstung im Mondlicht (Pyrrhus I S. 360). Klopstock geht bedeutsann voran, schon er hat Augen für Glanz und Schimmer der Waffe und horcht insbesondere auf ihre Akustik. Schönaich nagelt die kühne Neuerung im .Neologischen Wörterbuch" (DLD 70/81 S. 218) an Versen des Messias fest: ..... Eherne Kricger; sie rauschen mit eisernem wilden Getöse/ Üher die Felsen, und krachen, und donnern, und töten von ferne". Klinger folgt Klopstock auch darin am engsten (s. o. S. 96). Noch spät begegnet im Dumokles (Werke 2, 346) eine Stelle wie „rauschest du mit dem Kriegsgetön durch Rhodos Straß3en". Klopstocks kriegsakustischer Lieblingsausdruck "rasseln" wird ein Kraftwort der Stürmer, das bei Klinger reich zu belegen ist. Es heftet sich vorzüglich an das Geräusch der Rüstung: in gespanntem Hinhorchen hören Schillers Verschworene (Fiesko IV, II) „dumpfes Rasseln wie von Harnischen, die sich ancinander reiben". Dragoner rasseln (,In einer Bataille") in den Feind. Das Ritterstiick gab diesen Waffenlärm dem Theatermeister anheim, und so konnte Tieck es mit dem Kemwort selbst geißeln: „Auf der Bühne rasselten Panzer und Helm des Götz, ohne dessen Verstand und Gemüt" (Einleitung zu Lenz" Werken I, LXXIV). Sein eigener Karl von Berneck $(11,89)$ lauscht in der Rüstkammer geheimnisvollem Geräusch: "Horch, wie seltsam diese Panzer und Schilde aneinander klirren Wie der Anfang cines wunderbaren Gesprächs". Aus solcher Belebung der Ristung im gewaltigen Maßstab erwächst das satanische Schreckgetön der Filustschlacht: ,Da droben klappert's, rasselt's lange schon/Ein wunderbarer falscher Ton!"

Die Akustik der Waffe wie ihre körperliche Erfassung überhaupt gipfelt in Kleist. Er erneuert das Kraftwort der Ceniezeit, dem Achilles wird die .Quadriza rasselnd" geschickt (Penthesilea 1472), wis des Varus Todeswagen bei Klopstock Walhalla vorbeirasselt. Die Karren in der ArtillerieAnekdote (Werke 4, 191) protzen im Regen der feindlichen Kanonenkugeln von allen Sciten rasselnd ab. Umrasselt von der erznen Rüstung schmettert Penthesilea nieder (1561 f.), rasselnd steigt im Käthchen I, I der erzgepanzerte Graf vom Pferd. 'Troilus trifft dem Peliden ,mit einem tück'schen Schlag die Rüstung prasselnd" (176f.). Hermann will mit sorglosem Ausdruck (Hcrmannsschl. 332) cinen Krieg entflammen, .,der in Deutschland rasselnd./ Gleich einem dïrren Walde, um sich greifen soll" (Des "Tempels Pforten öffnen sich Penth. 1641 , des Elysiums Pforten 2215 rasselnd, wic sich rasselnd die Tore des Fehrbelliner Schlosses im Homburg, nach 77 u. 182 schließßen). Gehör und Gesicht achten gleich angespannt auf das Rüstzeug: „Dem Schild aufdonnem, daß die Funken sprüher", heißt es Penth. 2492 konzis vom bornbastischen Fechter, mit grimmigem Gleichnis wird die Barbare:sprache (Hermannsschl. 1898) klanglich charakterisicrt: ,als schlüg' ein Stecken/An einen alten, rostzerfreßnen Helm" - der zugleich in voller Kürperlichkeit dasteht. Vomblenden en Glanz der Rüstungen, schimmerndem Err und funkel:ndem $\mathrm{K}$-iensschmuck ist Penthesilea erfültt.

Statt vieler Beispiele kleistischer Waffenerfassung (die Belege für seine 
Lieblingsvorstellung, die Keule, sind gesammelt bei Minde-Pouet S. 206 f.) diene das eine, bedeutendste, der leitmotivisch gebrauchte Bogen des Amazonenstaates. Er wird gezeichnet als „,der große, goldene des Reichs“ (1973, 1996), er bestimmt die Gestalt der einherschreitenden Kriegsfurie (2612), er wird im entscheidenden Schuß mit unfehlbarer Sicherheit gesehen: „Und spannt ... / Den Bogen an, daß sich die Enden küssen, / Und hebt den Bogen auf und zielt und schießt" (2646 ff.; bei Shakespeare: "Zicht Schützen, zieht die Pfeile bis zum Kopf!"). "Den Bogen siegreich auf der Schulter tragend“, blickt Penthesilea nach der Tat bildhaft starr „, in das Unendliche hinaus und schweigt" (2698 f.). Ihn ,festlich schulternd", schreitet die Cräßliche heran (2708). Er wird gehört, wie er (1995 f.) vor Tanais schwirrend niederstürzt, von der Marmorstufe klirrt (2159 f.: „Den Bogen gab man mir, / Den klirrenden, des Amazonenreichs") und sich stumm wie der Tod zu ihren Füßen legt. Er wird endlich, die Geschichte des Amazonenstaates symbolisch schließend, gehört und gesehen, wie er der Hand der Königin entgleitet, ,klirrt, und wankt, und fällt," und als beseeltes Wesen am Boden zuckend stirbt (2769 ff.).

Es ist merkwürdig, wie nahe sich Penthesileas bedeutsames Spiel mit den Pfeilen mit klopstockischem Waffengestus berührt. Das Pfeilmotiv ist in „Hermann und die Fürsten“ vorgebildet, wo Herminone in Szene 14 ihren Köcher absichtsvoll mustert, die Geschosse um sich her streut und sie betrachtet: „Du, oder du, oder auch du“ — bei Penthesilea (3022): „Denn dieser hier - nicht? Oder war es dieser?" Es keimt ihr die Absicht auf, einen als Todeswaffe zu brauchen wie der Amazonenkönigin: „Zwar reizend wärs von einer Seite" - ; sie richtet ihn gegen die Brust und heißt ihn sehnsüchtig lockend willkommen: „Senke dich, senke dich, blanker Pfeil!" Er wird ihr rasch entwunden, Penthesilea kommt Prothoes stiller Bitte freiwillig nach. Es liegt hier mehr als eine zufällige Berührung: eine gemeinsame Empfindung vor.

Die sinnlichere Phantasie Kleists, die geistigere Schillers ließe sich an ihrem Verhältnis zur Waffe auseinandersetzen. Kleist gibt ihre Körperlichkeit in geballtem Ausdruck, er charakterisiert schlagend .,der Schwerter wetterflammendstes" (Penth. 843), er empfindet noch den ,Windzug eines Streiches" (710). Bei Schiller stehen mehr gedachte als geschaute Bilder: „Das Schwert ist kein Spaten, kein Pflug“ (Wall. Lager 917), die Waffe wird ihm unter Verflüchtigung der sinnlichen Qualität zum gedanklichen Symbol: ,Zum letzten Mittel, wenn kein andres mehr / Verfangen will, ist ihm das Schwert gegeben" (Tell $1285 \mathrm{f}$.).

Ein Seitentrieb der Dingfreude der Sturm und Drangः ist die liebhabermäBige Erfassung des Waffenwerks, die wiederum in der Geistigkeit der Romantik einen reichen Nährboden findet. Strato im Philotas (Sz. 8) versteht sich „mehr auf den Stahl als auf die Arbeit", das kostbare Heft von Philotas' Schwert spielt seine Rolle. In Paul Werners persischem Kriegsprojekt (Minna von Barnhelm 1, 12) locken diamantenbesetzte Türkensäbel, 
wofür der subalterne Packknecht Just kein Gefühl zeigt. Goethes Knechte am Rüstschrank wählen kundig unter den Büchsen. Der Waffenkenner, man möchte sagen der Sammler, spricht aus Maler Müllers Schloßhauptmann (Genovefa III. 3): .,Mir ist der Säbel lieber als fünf Morgen Weinberg. Betrachtet den Griff, Meister, das Klingenwerk; solche Arbeit macht man hienum im Lande nicht. Die Schwertfeger von Straßburg sind bekannt; aber so wie das gearbeitet - bei Leibe! Ich will Euch gleich eine Ofenschraube herunterhauen, ohne daß es der Kling' eine Scharte läßt. Man muß es den Türken lassen, in der Sach" zu arbeiten verstehn sie sich gut". Die Mägde der Genovefa weisen der Herrin die blitzblank gescheuerten Waffen ihres Gemahls, mit den Knechten zetert der Burgvogt, weil sie Sättel. Zeug und Gewehr ohne Sorgfalt hin und wider tragen (I, 3). Schwerfälliger, aber mit redlichem Bemühen hängt Jakob Maier dieser Richtung an; er gibt im Fust von Stromberg $(V, I)$ - im Saal Jaxthausens werden Kugeln gegossen - eine fürderhin häufigere Werkstattszene: die Waffe in Arbeit, die Zurüstung des Kriegsgeräts. In Theobalds Heilbronner Werkstatt läßt sich dann Wetter vom Strahl eine losgegangene Schiene einrenken. Unter einer Reihe von Schwertern wählt prüfend Adelungen in Spieß Klara von Hoheneichen I, 5 und rühmt Griff und Klinge. Einen Rüstkammereindruck nützt Längenfeld (Ludwig IV.B III, I) zu gutem, spaßhaftem Bild: „,So herzustehn wie ein gestopfter Küras, während dort alles drunter und drüber geht."

Der romantische Waffenfreund ist Tieck. In der Zwiesprache, die Karl von Berneck (11.82) mit den ,reliquienteuren Waftenbildungen" seiner Väter hält, versenkt er sich in Alter und Arbeit: .Welches dieser Schwerter mag wohl das älteste sein? - Dieses mit der wunderbaren Handhabe, mit der fein getriebenen Goldarbeit?" Köstliche Beutestücke, ein funkelnder Mohrensäbel und reichgewirktes Wehrgehenk werden in der Genoveva liebreich betrachtet $(2,79)$. Verschimmeltes Eisenzeug. Krebs und Beinharnisch vergangener Zeiten aus der Rumpelkammer dient zu Florens' Wafinung im II. Teil des Octavian (1, 262 f.). Hier bereitet sich leis wehmütige Lust am antiquarischen Waffenkram ein besonderes Fest. Zum schartigen, in seinem Gehäuse eingerosteten Schwert, das unbedenklich .blank" getragen werden kann: „Es ist so schwarz, man denkt es ist die Scheide" - tritt der bös zugerichtete Spieß: ..denn die Hühner haben lange / Darauf gesessen, solch Gesindel achtet / Nicht sehr, obs eine Lanze ist, ob Stock" - tritt der Helm, ..voll Spinneweben, Mäuse sind / Drin ein und ausgegangen, und an Glanz / Ist nicht zu denken - recht ein Bild des Friedens / Sind Mãus im Helm" - und einzig das Riemenwerk am Harnisch ist noch lobenswert im Stand: ..Solch Lederzeug hält lange".

Aus dem Kult der Waffe in der Geniezeit, der einen starken Zug ins Geheimnisvolle trägt, aus der schon bei Lessing und Klopstock bemerkten Spannung. womit sie fast scheu verehrt wird, und zugleich aus der Beseelung des toten Geräts geht die spätere Schicksalswaffe hervor. Die entscheidende Stelle steht in den Räubern (IV, 5). Schweizer wirft das Messer über den erstochenen. 
Spiegelberg, und Moor erkennt den „Finger der rachekundigen Nemesis“: „Weihe dies Messer der dunklen Vergelterin! - das hast du nicht getan, Schweizer." Schon ganz im Sinne des Schicksalsdramas ist dann das Schwert das Unheilsinstrument, das verhängnisvolle Requisit in Tiecks Karl von Berneck, ein Mörderstahl, von dem man abrät, ,,ein gefährliches, furchtbares Eisen“", das fast wie von selbst, nachdem es einmal Blut getrunken, zum Mord schreitet.

Den dramatischen Anlaß, den Gehalt des Rüstzeugs auszuschöpfen, bietet am meisten die Waffnungsszene. Götz wappnet sich im Aufbruch mit Helm und Lanze, Bruder Martin empfindet ihm das Behagen wohligen Sichentwaffnens nach getaner Kampfarbeit vor, das er dann, Weislingen einbringend, zu Jaxthausen genießt. Der Auftritt wiederholt sich mehr cder minder lebendig durch das ganze Ritterstück, $\epsilon r$ gerät in undramatische Breite in Tiecks Florens-Szene, er empfängt die straffste Fassung bei Kleist. Käthchen versieht in der Verwirrung des Überfalls statt Gottschalks den Dienst des Knappen beim Grafen vom Strahl (III, 8 vgl. IV, I), der auch im Sylvesternachtstraum zum Aufbruch nach Helm, Harnisch und Schwert verlangt, wie im Schloßgarten der erwachende Prinz von Homburg. Machtvoll wird Guiskard im Wappnen beobachtet, gewaltig reckt sich der Kriegsheld Achill (Sz. 16 u. 17) aus Rosenketten auf, im Erzgewand jäh ein Anderer, Schrecklicher. Solche Großheit der Auffassung führt auf Shakespeare zurück, der des Antonius Waffnung und Entwafnung zum Symbol heldischen Auf- und Niedergangs erhöht (IV, 4 u. 14). „Wer das aufschnallt bevor es uns gefällt / Es abzutun zur Ruh, den trifft ein Wetter," spricht der Held im Vollgenuß schwellender, eisengepanzerter Glieder zu der flink ihn rüstenden Frau und feiert aus kriegjauchzender Brust das Mannesfest der Waffenführung: „O Liebe, / Sähst du heut meine Kämpfe und verstündest / Das königliche Handwerk, sähest du / Drin einen Meister". Der Gebrochene, Sterbende dann legt die Wehr hin: „Eros, schnall $a b$ ! Das lange Tagwerk ist / Getan. Wir müssen schlafen ... - Schartige Stücke, geht / Ihr wart edel getragen“".

\section{Die Wunde.}

a) Dichterische Auffassung. Shakespeare emeuert die Vorstellung der Alten von der ruhmvollen Wunde. In der deutschen Entwicklung bricht wiederum Lessing den Bann der Gottschedischen und wertet das Motiv charakterisierend aus. Philotas staunt den wundenbedeckten Veteranen Parmenio an (Sz. 5), der der Kürze halber statt der verwundeten lieber die Glieder aufzählt, an welchen er es nicht ist. In der ersten Szene klagt der junge Prinz: „Und nur eine Wunde, nur eine!" Wie einen Kult der Waffe, so bildet Klopstock einen Kult der Wunde aus. Aus einer falschen Lesart des Tacitus erwächst seine Vorstellung vom Saugen der Wunden bei den Germanen (,,Sauget, Mütter und Weiber, das schöne Blut der Schlacht", im Bardenchor, Hermannsschl. Sz. 2 S. 64 u. oft), die noch bei Kleist (A. Fries, Forschungen S. 20) beiläufig auftaucht. Klopstock achtet eingehend auf die 
Pflege der Verletzungen: „Die kühlsten Quellen sind die besten für die Wunden". äußert Hermann (II S. 114). Siegmars Lanzenwunde wird im Bach gekühlt (6 S. 95). In „Hermanns Tod". der hinter der Schlachtlinie im Bereich der Nichtkombattanten spielt, findet sich gar ein entwickelter, anachronistischer Sanitätsdienst. Ehrfürchtige Verehrung gilt der Todeswunde, Siegmars, des Opferknaben, und diese gefühlsschwere Auffassung macht sich Klinger zu eigen: „Laßt bluten meine Wunden. Todeswunden sind es, doch Wunden fürs gerettete Vaterland", spricht feierlich der König im Aristodymos (I790 S. 90): Medea crblickt in schauerlicher Vision (Werke 2, 308), wie ihre ermordeten Kinder auf die fortblutenden Todeswunden zeigen. Still phantasierend, sieht Schillers Leonore (Fiesko IV, 14) den Gemahl ,an tiefen, tödlichen Wunden zu Boden fallen". Lessing ist dagegen kühl, dialektisch: "Sie ist nicht tödlich, sagte der Arzt, und glaubte mich zu trösten. - Nichtswürdiger, sie sollte tödlich sein!", erwägt Philotas in Anblick seiner leichten Verletzung.

$\mathrm{Zu}$ Kranzgebinden der festlichen Schlacht werden die tiefen Male in Kleists bildnerischer Phantasie. "Die Stirn bekränzt mit Todeswunden" will Achill (v. 614) die Feindin sehen, die dann , die blut'gen Rosen", den „Kranz von Wunden um sein Haupt" (2908) vor seiner Leiche schmerzvoll betrachtet. Die Wunde ist hier nicht allein als ruhmvoll, als erhaben, sondern vor allem als schön angeschaut, wie schon Klopstock das schöne Blut und die schöne Wunde zelebriert. ,Dir stehn die Worte wie die Wunden schön", sagt Shakespeares Duncan (Macbeth I, 2) zum berichtenden Soldaten, und grandios Antonius vor rauschendem Fest über seine Kriegsgesellen (III, II): „Ich muß heut Nacht / Den Wein in ihren Narben schaun". Solcher Preis schöner Wunde und schöner Narbe ist dem pathetischen Sturm und Drang gemäß. Der Räuber Moor wischt Schweizers Gesicht ab (III, 2): ,.Sonst sieht man ja die Narben nicht, die die böhmischen Reuter in deine Stirne gezeichnet haben - dein Wasser war gut, Schweizer - diese Narben stehen dir schön”. (Philotas Sz. 2: „Dein Gesicht voll Narben ist freilich ein schöners Gesicht - "). Im Don Carlos II, 5 vergleicht Alba das schimmernde Blut mit dem Glanz des Edelgesteins: „An der Krone funkeln / Die Perlen nur, und freilich nicht die Wunden, / Mit denen sie errungen ward." „Blut glänzt schöner am Mann als Cold”", übersetzt Lenz, Werke 3, 416 aus Shakespeares Coriolan 1, 3, aus der Szene, worin die kriegerische, starkgeistige römische Matrone der weichmütigen Frau entgegentritt, die vor dem Gedanken an aie blutige Stirn ihres fechtenden Gemahls zurückschaudert. „Ach was, ihr Närrin! Das ziert mehr den Mann / Als Coldtrophäen. Der Busen Hekubas / Beim Säugen Hektors war nicht reizender / Als Hektors Stirn, wenn sie, mit Griechenschwertern / Im Streite, Blut hervorspie." Charakteristisch finden selbst die männischen Frauen des Sturm und Drangs, gleich Shakespeares Volumnia, die blutige Wunde und die Narbe schön und liebkosen sie. "Hast du Wunden, wilder Strabo?", fragt das Weib den Kricger bei Klinger (Pyrrhus I S. 365), wenn er aus Staub und Schweiß der Schlacht 
kommt. „Und hatt' ich sie, sprang sie freudiger; der Küsse bekam ich mehr." Für Elfriedens Mutter $(I, 2)$ war es ein Tag stolzer Freude, als ihr Gemahl ,aus dem Schottenkrieg kam, und sie zum erstenmal die Narbe einer Wunde auf seiner Wange küßte." Don Brankas' Mutter (Der Günstling II, I) küßt stolz den heimkehrenden Helden: „Wie, ich möchte lächeln, und dem Mauren danken, der diese Narbe so kühn über deine hohe Stirne gezogen hat."

Feierlich werden die Ehrenmale gewiesen, und ihr Anblick hat über die Gemüter Gewalt. „Vergißt man Wunden so bald ?", mahnen die Räuber (V, 2) den wankenden Hauptmann und reißen ihre Kleider auf: ,Schau her, schau! Kennst du diese Narben? Du bist unser! Mit unserem Herzblut haben wir dich zum Leibeigenen angekauft", und Moor ergibt sich ihnen: „Die Narben, die böhmischen Wälder! Ja! ja, dies mußte freilich bezahlt werden." Oder es wird im Fiesko I, 5 gefragt: „Hat darum Herzog Andreas seine Narben geholt in den Schlachten dieser Lumpenrepublikaner?" Klingers Feldherr Don Brankas (Der Günstling IV, 2) fragt: ,,Soll ich meine Brust öffnen, Euch zeigen wie oft der Tod um Euretwillen mich angefallen hat?" (Ähnlich, nach antiker Quelle, Collins Coriolan II, 3: „Entblößen will ich nun / Die Brust; sie ist der tiefen Wunden voll"). Gebhard wiederum bei Klinger (Otto II, 6) bewundert emphatisch eine gewaltige Narbe: "Wie ihm das überm Auge steht - 'nein gehauen tief" - und findet an seinem Helden die antike Forderung erfüllt, das sprechende Zeugnis der Tapferkeit abgelegt: „Da steht er, so, so, - . . zerfetzt, und alle Wunden vorn". So ist Siwards (Macbeth V, 7) erste Frage bei der Meldung vom Tod seines Sohns: "Sind die Wunden alle vorn?", und er feiert auf die Antwort : , Ja, auf der Stirn" ", klaglos sein heldisches Ende.

Aber die pathetische Auffassung der Wunde ist nicht die einzige bei Shakespeare. Sachlich, schlicht, ohne jede Spannung sagt etwa Antonius (IV, 7) zu seinem Kampfgenossen: „Du blutst tüchtig“, und Scarus stellt darauf ohne alle Gefühlsbetonung fest: „Hier hatt' ich eine Wunde wie ein T/ Doch jetzt ward sie ein H." Es läßt sich beobachten, wie in der Geniezeit die Hohes und Gewöhnliches universal einschließende Auffassung Shakespeares sich in zwei Richtungen teilt, wie sich, um die typischen Erscheinungen gegeneinander zu stellen, die Geistigkeit des jungen Schiller von der Geistigkeit des jungen Goethe trennt. Auf die fadenscheinige Aufmunterung des Heilbronner Rates: „Gibt euch eure Liebe zu eurem Kaiser nicht mehr Mut?", antwortet Götz natürlich-derb und nennt das Ding beim Namen: „Nicht mehr als ihnen der Kaiser Pflaster gibt, die Wunden zu heilen, die sich ihr Mut holen könnte" - wo die Räuber getragen ihre Narben und Wunden anrufen. Lerse hieb bei erster Begegnung Cötzens Panzerärmel durch, „daß es ein wenig gefleischt hatte", während Moors Gesellen in poetischer Aufhöhung von vergossenem Herzblut sprechen, womit sie ihren Führer sich zu eigen verpflichteten. Gewiß geht daneben der kräftige, zupackende Sturm- und Drangstil durch. Der Stürmer Schiller ist wie der Stürmer Klinger noch weit davon entfernt, in Bild und Sprache sorglich auszuwählen. Die wackeren Söldner 
Dorias wollen, ein Wort Parmenios (Philotas Sz. 5: ., Wozu hat man die Knochen anders, als dass sich die feindlichen Eisen darauf schartig hauen sollen") aufnehmend, mit ihren teutschen Knochen Scharten in die genuesischen Klingen schlagen. Aber die Anspannung, der Drang zur Geste, leiclit bramarbasierend, ist in der nur scheinbar dem Götzstil nahen Ausdrucksweise zu spüren.

Es lassen sich im Gang der Entwicklung Vermittler zwischen der pathetischen und der realistischen Auffassung von Wunde und Narbe namhaft machen. Der junge Tieck feiert gleich Klinger das kriegerische Mannesideal aus Frauenmund. Einen tapferen, männlichen Mann mögen im Karl von Berneck (I. Schriften 11, 12) alle Frauen gern. Doch wird zugleich gegenläufig zum Kult der Geniezeit die Narbe nicht mehr als schön gepriesen, sondern als entstellend in Kauf genommen: .Schön ist er nicht, denn Narben in Schlachten und Zweikämpfen erhalten, entstellen sein Gesicht." Es ist von der .großen Schmarre" die Rede (11,22), die sein Antlitz verunziert. Beide Richtungen zu Ende geht Kleist. Neben den hochfestlichen Bildern der wundbekränzten Stirnen in Penthesilea steht der blutige Horror der zerfetzten Leiche Achills, die nackte, furchtbar aufrichtige Anschauung grausig zerfleischter Glieder. Dazwischen auch die schlichte Betrachtung: "Schau'! Eine Wund', und das recht tief! Du Arme!", womit Prothoe jene Verletzung Penthesileas mustert (v. 282l), dic unter allen dramatischen Verwundungen am meisten disputiert worden ist.

Der Träger bleibender Kriegsverletzung, der Invalide, wird im Soldatenstück zur rührsamen oder komischen Figur, Narben und Blessuren im ganzen sind der Anlaß der fortgeerbten Ruhmredigkeit des Cloriosus (vgl. Stockmayer S. 46 u. 5 f.). Von der komischen Seite zeichnet etwa Kotzebue im Grafen von Burgund IV, 3 den Invaliden, cinen angejahrten, arg zusammengehauenen Kriegskumpan, der als Brautwerher auftritt. Es klingt wie Spott auf die kriegsbegeisterten Frauen Klingers, daß er zum Brautvater, der seine Gebresten als Zeugen seiner Tapferkeit bewundert, skeptisch äufert: „Guter Vater! Ein glattes Kinn ist den Weibern lieber, als cin glatter Kopf. Wenn ein Arm richt mehr vermag sich um ihren Nacken zu schlingen, so fragen sie wenig darnach, ob er von Sarazenen steif gehauen worden!" Eine noch weit "fragmentiertere" Gestalt treibt bei Tieck im Prolog des Fortunat (Schriften 3, 14 f.) unter den Anklägern der Fortuna ihr Wesen, .,cin Auszug, ein Epitome eines Menschen, eine abgekiirzte Ubersicht, eine philosophische Reduktion", deren Leiblichkeit so dick vernarbt ist wie die Rinde einer alten Eiche. Dem entgegen steht die menschliche, barmherzige Auffassung, die aus einem schlichten Lied Schubarts, dem ."Bettelsoldat". ergreifend spricht und dem rohen Spott der Gasse über dic Bresthaften das soziale Elend dieser Ärmsten entgegenhält. So wird etwa Jean Paul im ..Hesperus“ (Werke 8, Berlin 1826, S. 29) ein Scherz über die Physiologie und Diätetik der Kriegskasse zur bitteren Anklage. Sentimentalisiert treten diese Figuren in das Rührstück ifflandischer Prägung ein.

Ein paar bedeutende Invalide der ernsten kriegerischen Dramatik sind vor 
allem sachlich, ohne Tendenz und Rührseligkeit gesehen. Feinfühlig behandelt Lessing Tellheims steifen Arm; prachtvoll kräftig, mit einem Einschlag grimmigen Humors, Goethe das Paar Götz-Selbitz, in Kaiser Maximilians Ausruf: „Heiliger Gott! Heiliger Cott! Was ist das? Der eine hat eine Hand, der andere nur ein Bein, wenn sie denn erst zwo Hände hätten und zwo Beine, was wolltet ihr dann tun?" Bewundernd faßt Bruder Martin Götzens eiserne Rechte, und der wackere Selbitz hat sich possenhafte Züge, die seiner nicht würdig sind, erst in der Theaterbearbeitung gefallen lassen müssen. In diese Reihe gehört auch der ,würd'ge Holzgebein" Kleists, „,der seinen Stock im Militär geführt“, der flüchtig als Evchens Werber im Zerbrochenen Krug auftaucht.

b) In der theatralischen Darstellung der Wunde behauptet sich die krude Blutblase der englischen Komödianten (darüber Devrient ${ }^{1}$ I, 168 f., vgl. 405; Creizenach DNL 23, LXXXVIII f. und am reichsten S. Mauermann, Palaestra Bd. 102, 113-15) bis weit in das 18. Jahrhundert hinein (Devrient ${ }^{1} 2$, 366; 408; Petersen S. 358 u. 365). Noch heute wird sie beispielsweise im chinesischen Schauspiel gebraucht. Die regelmäßige Tragödie verabscheut dann in ängstlicher Opposition alles Blutvergießen schlechthin. Erst die lessingische Theorie (Dramaturgie 9. Stück, Petersen S. 36j) erfaßt den entscheidenden Gesichtspunkt. Sie verlegt Vorgänge dieser Art aus der Realität in die Illusion und nimmt damit ohne Zugeknöpftheit die Partei des feineren Gefühls. Statt der abstoßenden Wirklichkeit von Blut und Wunde soll die Phantasie des Zuschauers in Bewegung gesetzt werden. Es bedarf dazu nur einiger Anweisungen, nicht der vollständigen, naturalistischen Wiedergabe. Diese kommt ohnehin ohne hinweisendes, unterstreichendes Wort nicht aus, wenn sie sich nicht gleich den blutrünstigen Hinrichtungen und Marterszenen der Komödianten zur nervenaufpeitschenden Blutszene auswachsen will. Denn es handelt sich zumeist um kleine, schlecht wahrnehmbare Vorgänge, die dem Zuschauer durch den Dialog erst sichtbar gemacht werden müssen. (Als Beispiel diene Shakespeare, I Heinrich VI: I, 4, Talbot über den getroffenen Salisbury geneigt: "Ein Aug' und halb die Wange weggeschmettert“.) Wie weit daneben das leibliche Auge des Publikums befriedigt werden soll, ist zumeist eine Frage des darstellerischen Taktes, die nicht aus der einzelnen Stelle, sondern aus der Gesamtstimmung eines Werkes zu lösen ist. Das Theater des Sturm und Drangs hat ganz andere Maßstäbe als etwa dasjenige der Klassik. Die Räuber wissen noch nichts von der poetischen Dignität, die eine Verwundung des jungen Piccolomini gar nicht mehr verstattet, weil sie unschön wäre und das dichterische Bild seines Todes nach der Anschauung des Klassikers Schiller störte. Kleist wiederum sieht auch dem Grauenvollen furchtlos ins Auge. Aber es ist nicht mehr die Liebe zum Krassen schlechthin, wie sie das unausgegorene Stürmergeschlecht regiert. Die Amazone erblickt in der Entstellung noch immer ehrfurchtsvoll auch den hehren Tempel der Glieder Achills, und anderwärts schlägt die poetische Aufhöhung durch scheinbar rein sachliche, theatralisch notwendige Mitteilungen durch. „Blut füllt, 
vom Scheitel quellend, ihm den Mund", heißt es im Käthchen (II, 8 , Fries, StvglL 4, 240 u. Forschungen S. 18 f.). Man steht damit der Art Schillers nahe, dessen Talbot mit getragener Geste dem Blutstrom seiner Wunde freien Lauf gibt: .,So strömet hin, ihr Bäche meines Bluts". Weit über das theatergerechte Sichtbarmachen der Vorgänge hinaus wird damit eine dichterische Gestaltung gegeben.

\section{Das Pferd.}

a) Dichterische Auffassung. Wie neuartig sich die Sturm-und Dranggesinnung zu den Dingen der Außenwelt stellt, tut sich sprechend in ihrem Verhältnis zum Pferd kund. In dem wilden Reiterideal der Geniezeit liegt der Kern ihres Lebensgefühls, alles Junge, Ungestüme, Verwegene beschlossen. ist die gültige Vorstellung vom Manne niedergelegt, wic ihn der Stürmer erträumt: als den kriegerischen, reisigen Tatmenschen, der das Schwert zu führen und das Roß zu tummeln weiß. In einer umfassenden Monographie über .,Roß und Reiter in Leben und Sprache, Glauben und Geschichte der Deutschen" setzt Max Jähns (2, 272 ff. u. 284 ff.) auseinander, wie um die Mitte des 18. Jahrhunderts der kecke Geist des Kampagnereitens die abgemessene, kunstgerechte Schulreiterei der alten Zeit verdrängt. In die Dichtung (worauf Jähns in dieser Periode weniger als in früheren achtet) tritt das neue Ideal im Zusammenhange des ganzen Erlebniswandels mit dem Götz ein. Noch bei Lessing etwa wird beiläufig (Minna III, 2) von Martin dem vortrefflichen Kutscher erzählt, dem die Pferde im vollen Rennen auf Burr! standen wie die Mauern: das ist Dressur, gegen die Natur mühevoll erreichtes Zirkelwesen gleich der französischen Gartenkunst und der korrektsteifen Tracht. die jetzt unwillig abgeworfen wird. So erhält auch das Pferd seine Freiheit. Nicht mehr die wohlgezogene, knechtisch gedrillte Kreatur, sondern das wild sich bäumende, unbändige Roß liebt der Sturm und Drang. Wenn dieses Pferd in scinem dahinbrausenden Eigenwillen vom überlegenen Manne beherrscht und seine rohe Kraft sinnvoll geleitet wird, dann genießt er, wie in einem prachtvollen Gleichnis des jungen Goethe (An Herder, Juli 1772) oder dem Herzenswunsch einer Amazone Klingers (Elfriede Akt II S. 354). das Hochgefühl vollendeter Meisterschaft, das stolze Bewußtsein freier Virtuosität. Wie Klingers ritterlicher König (Elfriede IV, 2) es faßt: „Endlich fühl" ich, daß ich meine Leidenschaften wie meinen Tartar lenke."

$\mathrm{Da} B$ dic Geniezcit ihr eigenes Empfinden, das überschäumende Temperament und die ungebärdige Kraft in das Tier legt. setzt voraus, daß man mit ihm fühlen gelernt hat und es versteht. Nicht zufällig kommt zu der gleichen Zeit, die in der Dichtung ein enges Band der Kaneradschaft von Mann und Roß (Klingers Otto, o. S. 93), ein Verhältnis auf du und du zeigt, in der hippologischen Literatur (Jähns 2.315) die psychologische Betrachtungsweise auf. Das Pferd, das Tier überhaupt tritt als besceltes Wesen unmittelbar neben den Menschen. Wieviel Früheren verschlossenes Gefühl spricht aus knappen Versen Mephistos, der im Kerker zum Aufbruch mahnt: .Unnützes Zagen! 
Zaudern und Plaudern! / Meine Pferde schaudern, / Der Morgen dämmert auf"!

Die junge Dichtergeneration lebt mit dem Pferd; man braucht an Sesenheim und Werther, an die Werthertracht (Jähns 2,312) nur zu erinnern. Goet he betont nach in Dichtung und Wahrheit, wie das frische Reiten jener Jahre die melancholischen Fußwanderungen glücklich verdrängt habe. Klinger, in allen Kavalierkünsten voran, ist ein vortrefflicher Reiter, Maler Müller (o. S. 113) ein besorgter Pferdefreund. Den Räubern und dem Fiesko zum mindesten, mit ihrem Kult des Pferdes, und der an Bildern von Roß und Reiter reichen Sprache Schillers (herausgegriffen sei nur Piccolomini I, 2) sieht man die Qualifikation des Karlsschülers: „Reuten schlecht" nicht an. Was Lady Milfort in Kabale und Liebe II, 1 in der Erregung befiehlt: „Man soll mir den wildesten Renner herausführen, der im Marstall ist. Ich muß ins Freie - Menschen sehen und blauen Himmel und mich leichter reiten ums Herz herum" - kennzeichnet erschöpfend, was der Sturm und Drang im Tummeln des Pferdes sieht, so wie sie dann sein Pferdeideal umschreibt: „Es ist verdrießlich, ein Roß zu reiten, das nicht auch in den Zügel beißt."

Wo der kriegerische Sturm- und Drangheld in der Fülle seiner kraftvollen Schönheit vorgestellt werden soll, wird er durchweg gezeichnet, wie er stolz zu Pferde sitzt. Es gibt kaum ein Stück in dieser Zeit, das nicht einen Einzug seines Helden zu Pferd oder dergleichen aufwiese. (Eine Zusammenstellung darüber bei Minor u. Sauer S. 276 f.). Als Prototyp kann eine Stelle des Fiesko (II, II) dienen: „Ich sah ihn durch die Stadt galoppieren. Nie sah ich unsern gnädigen Herm so schön“, schwärmt Bella von Fiesko. „Der Rapp prahlte unter ihm und jagte mit hochmütigem $H$ uf das andrängende Volk von seinem fürstlichen Reiter." Alba bei Coethe beobachtet vom Zimmer aus Egmonts Einreiten in den Hof, Klärchen erinnert die Mutter daran, wie sie Egmont am Fenster vorbeireiten sahen und er heraufgrüßte. Kaspar der Thorringer wird beim Einreiten in die Stadt (II, I) wie ein Kaiser geehrt und umdrängt, das Volk küßt seine Hände, seine Sporen und selbst sein Pferd. Das reiterliche Mannesideal feiert am höchsten Klinger. Hingerissen bewundern seine Mädchen und Frauen (Otto I, 8; Elfriede III, 6) den Mann, der das Tier voilendet beherrscht, und selbst die Frau erscheint am hehrsten als kühne Reiterin (Die neue Arria III, I; Grisaldo III, 4). Köstliche Pferde, deren Wuchs und herrliche Gestalt begeistert gepriesen wird, sind das vornehmste Geschenk nicht allein unter Männern (Zwillinge I, 4) sondern auch für die Geliebte. Die Verehrung für das Pferd geht so weit, daß Grisaldo als Zeugnis seiner Liebe in zwei Jahren der Abwesenheit (III, 4) allein anführen darf: „Hab ein Pferd für dich gefangen, es war meine tägliche Sorge. Ich sah dich reiten." Völlig mit seinem Pferd verwachsen ist der heißblütige Halbsarazene Heinrich von Kastilien im Konradin; er schwört bei seinem Roß, seinem Araber, seinem wilden Pferd (I, 4).

Die reiterliche Sorge für den treuen Gefährten lernten wir in Klingers Otto und beim Maler Müller kennen. Das einzige, was Grisaldo $(I, I)$ anordnet, 
Wrvor er zur lielwesnacht nit der Maurenprinzessin alxpeht, ist: . Reitet zum Heer, und songet meine hraven Rosse". Der Rauber Meor (II. 3) heibe Schweizer scinen Rappen mit Wein waschen, wic Kleists Achill scin erhitztes Cespann (v. 53 i). Von Satteln, Zaumen, Futtern und Tranken ist im wirklichkeitsnahen (imiedrama vielfach die Rede. Das Ritterstück rechnet dann alle diese Dinge zu scinem festen Motivbestand. Nur ab) und zu finden sich wärmere, aus crenem Fublen geschopte Toune, so bei J. Maier eine scherzhafe Unzerhaltung uiker den Charakter des Tieres (Sturm 2. Fassung I, 3), oder eine Interweisung in Dienst des Reiters (Fint I. 2). Coröbere Innigkeit spriche wiesterum aus der Tieckschen Dramatik. Hialseh tut sich jungritterliche Unberubretheit von Franenminne im Karl son Berneck kund, wo Reinhard (S.hriften 11. 13) gesteht: ..Bis jetzt ist mir mein Streitroß immer noch schöner vorgekommen, als jedes weibliche (ieschopf, das ich sah." Sein keckes Dahinsprengen gehort wie Colos wildes Reiten. Sprung und Sturz auf herrlichem Tier (Cenoveva. Schriften 2.9 ff.) z.u dem Reiterideal des Sturm und Drangs. Danclen wendet sich Tiecks verweilende Betracheung des Cegenstädichen auch dem P'ferd zu. Fir schildert im Octavian (1, 200) aus anpreisendem Händlermund cinen stattichen Hengst und lafie den jungen Forens das Hochgefühl des kiihnen Reitens vorweg genicken - in der behaglichen Ausfuhrlichkeit cincs dramatisierten Pferdemarktes, aber auch letendig und eindringlich. Er kehrt zu der Figur eines Rolkamms zurück im Fortunat (I. Teil. 3. 134 f.). wo sleicherweise ein junger. unerlahrener Käuler in den Schlingen des ausgelernten Pferdehandels gefangen wird.

Die proctische Erfassung des Rosses gipfele in Kleist. und zwar nach ihren beiden Richtungen, der intimen Einfluhlung in das Tier sowohl wie seiner grobulichterischen Gestaltung. Der kundige Reiter spricht schon aus jener hildkraftigen Schilderung der Jagd zu Pferde in den Schroffensteinem (1. 1). die mit dem Ausgreiten. Vorschießen und Durchgehen eines erregten Pferdes aus dem Rolgewimmel des Jagdgeschwaders so treu nicht sein könnte. wenn sie niche erlebt wäre. Fur die intime Tierdarstellung brauche an die unvergleichlich gebildeten Rappen des Kohlhass, an denen keine kleinste Regung cines Muskels, keine leiseste Veranderung in ihrem Habitus verloren gehe. wur erinnert zu werden. Dern grenzenlosen Mitleid mit ihrem jammervollen Zumtand mag nach dem Simne des Robhandters die ganze Welt aufge-

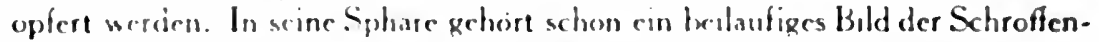
striner (818 ff.) wom ehrlechen P'fereickaut, wie wherhaupt im Bildschatz der kleistuschen Surache die Pferdekennerschaft des Dichters vielfach offenbar

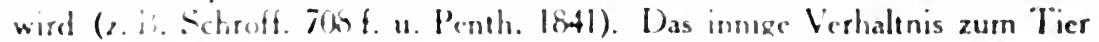
zeigt am mesten das Kathehen. In der Szene am Bach. wo Gottschalks un-

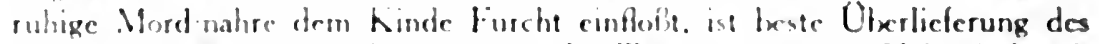
Ruttrstucks zartsinnig anfecnommen. In Traum unter dem Holunderbusch

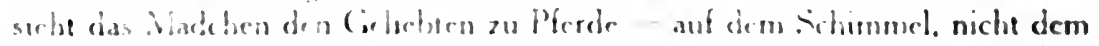
Fuchs - und es beschushege den wermemthet Nostengenden, der nach dem

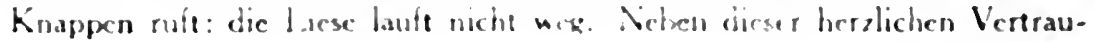


lichkeit bricht aber auch die pathetische Auffassung des Tieres durch. Das arme Kind nächtigt bei dem gleichgültigen Grafen auf der Streu, ,die seinen stolzen Rossen untergeworfen wird" ( $(1,1)$, und diese bildhafte Prägung klingt leitmotivisch durch das Stück fort. Kunigunde wird mit der Begeisterung Klingers für reitende Frauen als Amazone im hochfestlichen Einzug zu Pferde geschildert (II, 6), wie sie, „einer Fabel gleich, von den Rittern des Landes umringt" einherzieht, daß selbst die Kiesel, die unter ihr Funken sprühen, sie bewundern. Das sind Bilder aus der Welt Penthesileas, aus jener blendenden, sinnbetörenden Pracht des Krieges, die über die skamandrischen Ebenen ausgeschüttet wird, und die auch das kriegerische Roß zu höchstem Glanze übergoldet. Kleists Blick für Pferd und Reiter läßt sich die Vorstellung des berittenen Achill trotz Homer nicht entgehen: „Auf einem Hügel leuchtend steht er da, / In Stahl geschient sein Roß und er" - (v. 1037 f.), ganz ähnlich wie später (Homburg 540 f.) der Kurfürst angeschaut wird: ,Auf einem Schimmel herrlich saß er da / Im Sonnenstrahl, die Bahn des Siegs erleuchtend". Neben diese statuenhaften Reiterbilder tritt das Meisterstück dichterischer Schilderung bewegter Rosse, dahinstürmender Renner: Achills Wagenfahrt (v. 356 ff.), vom Auftauchen seines Gespanns am Horizont über die jagende Hast sich überstürzender Verfolgung bis zum Vollgenuß des Sieges, worin der Lenker Automedon , die Rosse schrittweis, / Die dampfenden“", an Achills Seite führt gleichsam die dramatische Erfüllung dessen, was der junge Coethe als freies poetisches Bild gestaltet hatte. Zu einem Doppelwesen höherer Art, zum völligen Einssein wird Roß und Männin verschmolzen in dem Bild der königlichen Amazone, der jungfräulichen Reiterin, deren triumphale Erscheinung zu Pferde Kleists Auge rastlos umbuhlt. Zuerst zu Roß, an der Spitze ihrer Jungfrauen aufgepflanzt, tritt Penthesilea vor unser geistiges Gesicht: „Und seine Gold- und Purpurtroddeln regend, / Zerstampft ihr Zelter unter ihr den Grund" (61). Es ist ohne Beispiel, wie dieses Tier, das ,gefleckte Tigerpferd“" (224), der "Schecke" oder auch "der Tiger" schlechthin genannt, angeschaut und unablässig charakterisiert wird, wie der Dichter immer wieder einen neuen bestimmenden Zug der Erscheinung, ein Merkmal, eine Bewegung wie im Sprunge hascht. Das edle Roß wird gesehen im ungeduldigen Harren $(61 ; 619)$, im stolzen, geflügelten Sichbäumen in die freie Luft $(1020 ; 1065)$, im unruhig suchenden Trabe (302), der äußersten Schnelle der Hetzjagd, "wenn sich ganz aus die Dogge streckt" (399ff.), in den Wendungen des Fechtens (190) und im schmetternden Sturz (325 ff.; 427 ff.). Wie die Häupter, "geschmückt mit Blessen", von Achills Roßgespann, erblickt man den Hals, "den mähnumflossenen, des Schecken" und sieht ihn in den Goldzaum beißen (189f.). So wird die Reiterin beobachtet, wie sie sich ,mit einer zuckenden Bewegung" biegsam vom Rücken des Pferdes schwingt (72), und nicht übersehen, wie sie dabei die Zügel weggibt. Oder sie wird geschildert, wie sie im Kampf das Roß souverän tummelt, dem Mordhieb ausweichend wendet und zum blitzschnellen Enteilen die Zügel schießen läßt (190f.). Wo wäre der eingewachsene Sitz zu Pferde zwingender geformt als mit den Worten: „Seht! 
wie sie mit den Schenkeln / Des Tigers Leib inbrünstiglich umarmt!" - wo die letzte Willensanspannung im sausenden Dahinjagen leidenschaftlicher gegeben als in dem Bilde: "Wie sie, his auf die Mähn' herabgebeugt. / Hinweg die Luft trinkt lechzend, die sie hemmt!" Es ist hier ein Höchstes an prall gesättigter Anschauung und zugleich dichterischer Sublimierung von RoB und Reiter geleistet.

b) Das Pferd auf der Bühne. Kommt man von Kleist, so wird init aller Schärfe klar, wie weit die reale Verwendung von Pferden im Theater dem Eindruck nach notwendig hinter der dichterischen Vorstellung zurückbleiben ınuß. Es tritt dazu die stets fühlbare Störung der Illusion - wozu es nicht jener anstößigen Äußerung unbefangener Tiernatur an den unpassendsten Stellen bedarf, woran sich zahlreiche Theateranekdoten ergötzen (von Unzelmann erzählen Kleists Abendblätter eine. Werke 4, 198; von Nestroy FlögelBauer, Geschichte des Grotesk-Komischen 1. 363) - die vielmehr schon gegeben ist mit dem bloßen Erscheinen des Tiers, das aus einer andern, aus der alltäglichen Realität in die fiktive der Bühne hineinstößt. Dieser Zwiespalt war auf der antiken Bühne, wenn nicht aufgelöst, so doch bei weitem geringer, weil sie unter dem wirklichen Himmel, nicht abgesondert von der Natur, sondern in der Natur stand. Damit war sie zugleich vor den Zufällen geschützt, die sich im modemen Theater beim Aufziehen Berittener aus dem bretternen Bühnenboden und dem luftigen Pappenwerk der Kulissen so leicht ergeben. Die Steinfliesen und der gewachsene Boden der Orchestra ertrugen den Schlag wirklicher Hufe, die festgehaltene Naturhaftigkeit des Theaters die schwere Fülle wirklicher Pferdeleiber. Eine Verletzung der tragischen Würde war demnach nicht zu besorgen, um so weniger, als man die Verwendung der Rosse, wie W. Schlegel bei der Behandlung dieser Frage hervorhebt (Dramat. Kunst u. Litt. ${ }^{2}$ 3, 208), auf feierliche Aufzüge beschränkte und sie nicht ,in der wilden Unordnung eines Gefechtes" sehen ließ. Dagegen vermeidet die Bühne Shakespeares die Pferde grundsätzlich und durchbricht die Konsequenz darin durch keinerlei Konzession an das Publikum (o. S. 79). Es kennzeichnet das untheatralische Geniedrama. daß3 es in dieser Beschränkung seinem Meister nicht folgt, nicht dem Publikum zu Gefallen, sondern weil es die Natur selbst anstatt ihrer theatralischen Spiegelung zu geben sich unterfängt. Die technischen Prozeduren, das Auftreten der Pferde zu umgehen, allerhand motivierende Vorwände um sic hinter der Szene zu halten und zu verdecken, kommen damit erst später zu Ehren. Dic frühen Kampfpantomimen eines Törring und Längenfeld zeigen noch so unbekümmert wie Cötzens Reiteraktion ganze Scharen von Berittenen, während allerdings zu gleicher Zeit der Maler Müller schon den anderen Weg einschlägt.

Auf einem andern Blatte steht die Verwendung von Pferden aus theatralischer Spekulation (vgl. dazu Petersen 256 f.). Treffend bernerkt W. Schlegel (3. 208), die Erfahrung lehre, ,daß, wenn man Gefechte der Reiterei anbringt. die Menschen neben den vierfüBigen Schauspielern bald zu Nebenpersonen werden" - aber das besondere Interesse an den Vierfüßlern ist es gerade. 
worauf die Unternehmer bauen. Der Hund des Aubry spielt in der weimarischen Theatergeschichte eine symbolische Rolle, auf die Wiener Verhältnisse zielt eine Anekdote aus Schröders Mund (Fr. L. Schmidt, Denkwürdigkeiten I. 196), wonach Reitfertigkeit erstes Erfordernis für einen Schauspieler gewesen wäre, der dort engagiert sein wollte. Es ist die allgemeine Stimme des naiven Publikums, die Tieck in den Zwischenaktsunterhaltungen des "Gestiefelten Katers“" (Schriften 5, 200 f.) zu Wort kommen läßt: „Es sind die Leute selten so dreist, Pferde aufs Theater zu bringen, - und warum nicht? Sie haben oft mehr Verstand als die Menschen... Ich möchte wohl ein ganzes Stück von lauter Husaren sehn - ich mag die Kavallerie so gern." Die Oper geht mit prunkvollen Aufzügen von Reitern und Wagen voran, und das Pferdespektakel, wie es sich zumeist an den Namen Schikaneder knüpft, steht in einer viel älteren Tradition als man denken' möchte. Das mittelalterliche Turnier lebt noch im 17. Jahrhundert als "Karusel" (Jähns, RR 2, 224) fort, der kunstgerechten Darstellung eines Reitergefechtes, und auch zum „Reiterballet" hat das Pferdewesen, das sich am behaglichsten auf der Wiener Bühne breitmacht, die „Roßkomödie“" (Devrient ${ }^{1}$ 3, 317; v. Komorzynski S. 25 u. 58; Kilian, Dramaturg. Blätter I, 177 ff.) starke Beziehungen. Das Ritterdrama vor allen andern mußte den Handlungsvorwand zur Entfaltung der Zirkuskünste hergeben, und W. Schlegel konnte mit Grund über die ganze Gattung klagen: „Aus Ritterstücken sind wahre Reiterstücke geworden, die zuletzt mehr von Pferden als von Menschen aufgeführt zu werden verdienen." So fragte sich in späteren Jahren Grillparzer vor einem verschwenderischen Pariser Pferdespektakel (Tagebuch auf der Reise nach Frankreich und England, Werke, Cottasche Weltlit. 20,63), ob die Schauspieler zugleich Kunstreiter, oder die Kunstreiter zugleich Schauspieler seien, weil die Hauptpersonen des Stücks so halsbrecherische Dinge zu Pferde machten. Das Wesentliche spricht Tieck (Krit. Schriften 4, 368) aus, der in einem eigenen Theater für Seiltänzer und Pferdekünste in Southwark den Gipfel aller Roßkomödie, einen unmöglich scheinenden Burgsturm zu Pferde mitansah: „Wohl der Stadt, die dazu eine eigene Bühne hat, und also nicht alles auf das sogenannte Nationaltheater nehmen darf. Das Tolle und Abgeschmackte wird um vieles gemildert, wenn es sich in einer ihm eigentümlichen Bahn bewegt, und weder die $\mathrm{Er}$ wartung getäuscht wird, noch das Widersinnige sich die Miene der Kunst und Bildung gibt." 


\section{Hauptsächlichste Literatur.}

(Die Vertasser aller beiläufiger herangezogenen Schriften siehe im Register, das jeweils die Stelle nachweist, wo die betr. Arbeit zuerst genannt und bibliographisch verzeichnet ist.)

1. Mit Namen abgekürzi zitierte Literatur.

Bellermann = Ludwig Bellermann, Schillers Dramen, 1. Auf., Berlin 1888-91. 2 Bde.

Berger $=$ Karl Berger. Schiller, Scin Leben und seine Werke, 5. Auf., München 1910-11. 2 Bde.

Beyträge Beyträge zur critischen Historie der deutschen Sprache, Poesie und Beredsamkeit, hrsg. von einigen Mitgliedern der Deutschen Cesell. schaft in Leipzig. 1732-44, 8 Bde.

Biedermann KarlBiedermann, Deutschland im 18. Jahrhundert, Leipzig $1854-80$. 5 Bde.

Brahm Ritt. = Otto Brahm, Das deutsche Ritterdrama des 18. Jahrhunderts. Studien über Jos. Aug, von Törring, seine Vorgänger und Nachfolger. Straß burg 1880 (Quellen und Forschungen 40).

Devrient Eduard Devrient, Geschichte der deutschen Schauspielkunst, 1. Aufl, Leipzig 1848-74, 5 Bde.

Gervinus $=$ G. G. Gervinus, Geschichte der deutschen Dichtung. 5. Auf., hrsg. von K. Bartsch, Lcipzig 1871-74, 5 Bde.

Gundolf - Friedrich Cundolf, Shakespeare und der deutsche Geist, Berlin 1911.

Haym = Rudolf Haym. Die romantische Schule, 3. Aufl., hrsg. von O. Walzel. Berlin 1914.

Heinsius - W. Heinsius. Allgemeines Bücherlexikon.

Herrigs Archiv $=$ Archiv für das Studium der neueren Sprachen und Literaturen. begründet von Ludwig Herrig. 1846 ff.

Holzmann u. Bohatta Michacl Holzmann und Hanns Bohatta, Deutsches AnonymenLexikon. Weimar 1902-09, 5 Bde.

Jähns KW. Max Jähns. Geschichte der Kriegswissenschaften vornehmlich in Deutschland. München und Leipzig 1890-91. 3 Bde. (Geschichte der Wissenschaften in Deutschland, hrsg. durch die histor. Kommission der kgl. bayer. Akadenic der Wiss.: Neucre Zeit. Bd. 21).

Jähns RR - Max Jähns, RoB und Reiter in Leben und Sprache, Glauben und Ceschichte der Deutschen. Eine kulturhistorische Monographie. Leipzig 1872. 2 Bde. 
Jördens $=$ Karl Heinrich Jördens, Lexikon deutscher Dichter und Prosaisten, Lejpzig 1806-11, 6 Bde.

Jonas $=$ Schillers Briefe. Hrsg. und mit Anmerkungen versehen von Fritz Jonas. Kritische Gesamtausgabe. Stuttgart usw. o. J. [1892-96], 7 Bde.

Kayser $=$ Ch. C. Kayser, Vollständiges Bücherlexikon.

Koberstein = Aug. Koberstein, GrundriB der Geschichte der deutschen Nationalliteratur. 5. umgearbeitete Auf. von K. Bartsch, Lejpzig 1872-73. 5 Bde.

Kühnemann = Eugen Kühnemann, Schiller, 3. Auf., München 1908.

Legband $=\mathrm{Paul}$ Legband, Münchener Bühne und Literatur im 18. Jahrhundert, München [1901-]1904. (Oberbayer. Archiv für vaterländische Geschichte 51).

Lohmeyer $=$ Walter Lohmeyer, Die Dramaturgie der Massen, Berlin u. Leipzig 1913.

Meusel Lex. $=$ Joh. Georg Meusel, Lexikon der vom Jahr 1750 bis 1800 verstorbenen teutschen Schriftsteller, 1802-16, 15 Bde.

Minor = Jakob Minor, Schiller. Sein Leben und seine Werke. Berlin 1890 . Bd. I u. 2.

Minor u. Sauer = Jakob Minor und August Sauer, Studien zur Coethe-Philologie, Wien 1880.

Muncker $=$ Franz Muncker, Friedrich Gottlieb Klopstock. Geschichte seines Lebens und seiner Schriften. Stuttgart 1888, 2. [Titel-]Aufl., Berlin 1900.

Petersen $=$ Julius Petersen, Schiller und die Bühne. Ein Beitrag zur Literatur- und Theatergeschichte der klassischen Zeit. Berlin $1904\left(\mathrm{~Pa}_{\mathbf{a}}\right.$ laestra 32).

Rabany = Charles Rabany, Kotzebue, sa vie et son temps, ses Euvres dramatiques. Paris-Nancy 1893.

Rieger $=$ Max Rieger. Friedrich Maximilian Klinger. Sein Leben und seine Werke. Darmstadt 188C-96, 2 Bde. (Klinger in der Sturm- und Drangperiode, und Klinger in seiner Reife, mit einem Briefbuch).

Scherer $=$ Wilhelm Scherer, Geschichte der deutschen Literatur, 12. Aufl, Berlin 1910.

Schlegel, Dramat. Kunst u. Litt. = August Wilhelm Schlegel, Ueber dramatische Kunst und Litteratur. Vor'esungen. 2. Aufl., Heidelberg 1817, 3 Bde.

Schmid, Chronol. = Christian Heinr. Schmid, Chronologie des deutschen Theaters (1775). Neudruck von Paul Legband, Berlin 1902 (Schriften der Gesellschaft für Theatergeschichte 1).

Schmidt, Lessing = Erich Schmidt, Lessing. Ceschichte seines Lebens und seiner Schriften. 2. veränderte Auff, Berlin 1899, 2 Bde.

Schnorrs Archiv = Archiv für Literaturgeschichte. Jahrg. 1 u. 2 hrsg. von Gosche, folg. von Schnorr von Carolsfeld, 1870-85.

Schütze $=$ Joh. Friedrich Schütze, Hamburgische Theatergeschichte, Hamburg 1794. 
Stockmayer $=$ Karl Hayo von Stockmayer. Das deutsche Soldatenstück des 18. Jahrhunderts seit Lessings Minna von Barnhelm. Weimar 1898 (Literarhistor. Forschungen von Schick u. Waldberg 10).

Waniek = Gustav Waniek. Gottsched und die deutsche Literatur seiner Zei:. Leipzig 1897.

WeiBenfels = Richard WeiBenfels. Cocthe im Sturm und Drang. Bd. I, Halle 1894.

Weltrich $=$ Richard Weltrich. Friedrich Schiller. Geschichte seines Lebens und Charakteristik seiner Werke. Bd. I. Stuttgart 1899.

Wurzbach $=$ Constantin von Wurzbach. Biographisches Lexikon des Kaisertums Österrcich. Wien 1856-91.60 Bde.

\section{Siglen.}

$\mathrm{ADB}=$ Allgemeine Deutsche Biographie, Leipzig $1875 \mathrm{ff}$.

AfdA $=$ Anzeiger für deutsches Alterturn, Leipzig u. Berlin $1876 \mathrm{ff}$.

$D_{j} \mathrm{C}=$ Der junge Coethe. Neue Ausgabe in sechs Bänden besorgt von Max Morris, Leipzig 1909-12.

DLD $=$ Deutsche Literaturdenkmale des 18. und 19. Jahrhunderts, hrsg. von B. Seuffert und A. Sauer. Heilbronn, Stuttgart, Berlin $1882 \mathrm{f}$.

DNL $=$ Deutsche National-Litteratur, hrsg. von Joseph Kürschner, Berlin u. Stuttgart o. J. [1882-99], 222 Bde.

$\mathrm{DWb}=$ Deutsches Wörterbuch. (begründet) von Jakob und Wilhelm Grimm. Leipzig 1854 ff.

Euph. = Euphorion, hrsg. von A. Sauer. Wien 1894 ff.

$\mathrm{GGr}=\mathrm{Karl}$ Coedeke. Grundri $\mathrm{B}$ zur Geschichte der deutschen Dichtung. 2. u. 3. Aufl., Leipzig $1884 \mathrm{ft}$.

StvglL $=$ Studien zur vergleichenden Literaturgeschichte, hrsg. von Max Koch. Berlin 1901 ff.

$V_{j s} L=$ Vierteljahrsschrift für Literaturgeschichte, hrsg. von B. Seuffert, 1885-93.

$\mathrm{ZfdPh}=$ Zeitschrift für deutsche Philologie, Halle $1868 \mathrm{ft}$.

ZvglL = Zeitschrift für vergleichende Literaturgeschichte, hrsg. von Max Koch. Berlin $1886 \mathrm{ff}$.

\section{Gesamtausgaben.}

Comeille, Euvres $=$ Eurres de Pierre Corneille, éd. Marty-Laveaux. Paris 1862-68 (Grands Ecrivains).

Coethe. Werke = Goethes Werke, hrsg. im Auftrage der CroBherzogin Sophie von Sachsen, Weimar 1887 f.. I. Ableilung.

Coethe, Tagebuicher $=$ dass. III. Abteilung.

Coethe, Briefe $=$ dass. IV. Abteilung.

Coethe, Gespräche $=$ Coethes Gespräche. Begrindet von W. Frhr. v. Biedermann. Zweite durchgesehene und stark vermehrte Auf.. Leipzig 1909-10, 5 Bde. 
Kleist. Werke $=H$. von Kleists Werke. Im Verein mit G. Minde-Pouet und R. Steig hrsg. von Erich Schmidt, Lejpzig u. Wien o. J. [1904 f.] (Meyers Klassikerausgaben), 5 Bde.

Klinger, Werke $=F$. M. Klingers Werke, Königsberg 1809-15, 12 Bde.

Klinger, Dramat. Jugendwerke $=$ F.M. Klingers Dramatische Jugendwerke, hrsg. von $\mathrm{H}$. Berendt und K. Wolff, Leipzig.1912-13, 3 Bde.

Kotzebue, Werke $=$ A. v. Kotzebues Sämtliche dramatische Werke, Leipzig 1828-29, 44 Bde.

Lessing, Schriften = G. E. Lessings Sämtliche Schriften, hrsg. von K. Lachmann, 3. Auff., besorgt durch F. Muncker, Stuttgart $1886 \mathrm{fl}$., 22 Bde.

Ludwig. Schriften $=$ Otto Ludwig, Gesammelte Schriften, hrsg. von A. Stern und E. Schmidt, Leipzig 1891 f., 6 Bde.

Schiller, Werke $=$ Schillers Werke, hrsg. von Ludwig Bellermann, Leipzig u. Wien o. J. [1895] (Meyers Klassikerausgaben), 14 Bde.

Schiller, Säkularausg. = Schillers Sämtliche Werke, Säkularausgabe, hrsg. von E. von der Hellen, Stuttgart u. Berlin o. J. [1904-05], 16 Bde.

Schiller, Gespräche $=$ Schillers Gespräche. Berichte seiner Zeitgenossen über ihn hrsg. von Julius Petersen, Leipzig 1911.

W. Schlegel, Werke $=$ A. W. Schlegels Sämtliche Werke, hrsg. von E. Böcking, Leipzig $1846-47,12$ Bde.

Shakespeare, Werke $=$ Shakespeare in deutscher Sprache. Hrsg., zum Teil neu übersetzt von Friedrich Gundolf, Berlin $1908 \mathrm{ff} .$, bis jetzt 9 Bde. Für die noch nicht erschienenen Teile: Übersetzt von A. W. Schleg el und L. Tieck, Ausgabe der deutschen Shakespeare-Gesellschaft, hrsg. von W. Oe chelhäuser. Zitate nach Wieland, Zürich 1762-66, 8 Bde. (in Wielands Gesammelten Schriften, hrsg. von der deutschen Kommission der kgl. preuB. Akademie der Wiss., II. Abt., Bd. 1-3, Berlin 1909-11) sind als solche kenntlich gemacht.

Tieck, Schriften $=$ Ludwig Tiecks Schriften, Berlin 1828-54, 28 Bde.

Voltaire, CEuvres $=$ Voltaire, CEuvres completes, éd. Mol and, Paris 1877-83, 52 Bde. 


\section{Register.}

Einfache Ziffern weisen aut die ganze Seite, Ziffern mit * aut die Anmerkungen allein. LV aut das Literaturverzeichnis.

\section{Personenregister.}

\section{A}

Ackermann, K. E. 107*.

Addison 11, 44, 46*.

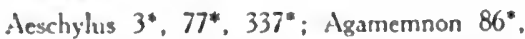
Perser 25* $1 ., 63,64,91,337,359 ;$ Sieben gegen Theben 26, $60-6 \% 3,68,115^{*}, 226$. $331,347$.

Albrecht, K. 3*.

Anquetil 297*.

Antoniewicz, J. v. 12* u. o.

Appell. J. W. 201* u. ö.

Aristophanes 359.

Aristoteles 9*, 12*, 17, 33, 66.

Ayrenho:9 37, 74, 315*; Hermanns Tod 6tif.; Kleopatra $67^{*}$.

\section{B}

Baader, $\mathrm{Cl}, \mathrm{A} .114^{*}$.

Babo 101, 114*, 135. 137, 176, 194*: Arno 123, 153*; Dagobert der Frankenkönig 123. 125: Oda oder die Frau von zween Männern 122*: Otto von Wittelsbach 114*, 123, 124. $13 ;-1 \% 6,129,133^{*}, 176^{*}, 177,209^{*}, 396$; Dic Römer in Teutschland 123-124. 125. $358^{\circ}$.

Bacchtold, J. 64".

Bamberg. F. 325*.

Battcux 22", 25".

Baumgart. H. 299".

Behrmann, G. 20.

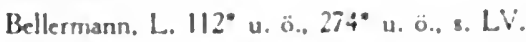
Belloy, de, Le siege de Calsis 21 ". 107. 333".
Bélouin, G. $16^{*}$ u. ō.

Berger, K. 57* u. ö., s. LV.

Bernhardi, A. F. 238*.

- Fr. v. 168*.

Bertin, E. $381^{*}$.

Bertuch, Fr. J. 60*, 258*.

Biedermann, F. . 325*.

- K. 85* u. ö.. s. LV.

-W. v. $208^{*}$ u. ö.

Bielschowsky. A. 185*

Bienenfeld. E. 212*.

Birt, Th. $143^{*}$.

Blacse, B. 94*.

Blaimhofer s. Blumhofer.

Blücher 383.

Blümner, H. 37*.

Blumauer, A. Enwine von Steinheim 12\%-123, 134.

Blumhofer, M. (Blaimhofer), Dic Luftschiffer 147*: Die Schweden in Bayern 131-132. 225, 333*.

Bode. Fir. 3*.

Bodmer 12, 21*; Karl von Burgund 64.

Böhı, Jolı. 9*.

Böhtlingk. A. $+6^{*}$ u. ö.

Bötriger, k. ^. 306.

Bohatta, H. $47^{\circ}$ u. ö., s. LV (Holzmann).

Boilean 4, 9*2 $21^{*}$.

Bonaventura. Nachiwachen 245.

Bormann. W. 152*.

Boxberger, R. 156* u. ö., $295^{*}$ u. ö.

Bräker. M. (Arme Mann im Toggenburg) 140*. 
Brahm, O. 2, 101 u. ö., s. LV, $234^{*}$ u. ö., $325^{*}$ u. ö.

Braitmaier, Fr. 10* u. ö.

Brandes, J. Chr. 35* f.; Der Schiffbruch :13, $217^{*}, 224^{*}, 240,241^{*}$.

Brandl, A. 94*.

Brawe 57, 74; Brutus 41-46, 49, 153*; Freygeist $39 \mathrm{f}$.

Brentano 47*, 207; Gustav Wasa $74^{*}, 212$, 223 f., 238, 240.

Breymann, H. $357^{*}$.

Brodnitz, K. 256* u. o.

Brotanek, R. 72* u. ö.

Brümmer, F. 201*.

Büchmann, C. $279^{*}$ u. ö.

Büchner, G. Wozzek 142*; Der Hessische Landbote 146*.

Bülow, E. v. $325 \mathrm{f}$.

Bürger, G. A. 357.

Bulthaupt, H. 299* u. ö.

Burdach, K. $60^{*}$.

\section{C}

Calderon 76*, 245*, 248*, 333*, 35\%.

Campe, J. H. 279* u. ö.

Campistron, Arminius 23, 43*.

Carl August 314*.

Caroline (Schlegel) 146*, 304.

Cervantes $76^{*}$.

Chateauneuf 336*.

Clavel 33*.

Collin, H. J. v., Coriolan 301*, 308*, 31.j*, 403; Regulus 315*.

Conrad, H. 329*.

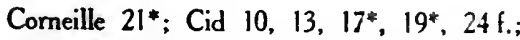
Horace 17*, 18*, 20, 348; Trois Discours $9^{*}, 21^{*}, 24$ f., 39, 55, 129*.

Costenoble, C. L. 87*.

Cramer, C. G., Das Turnier zu Nordhausen 19, 202-203.

Creizenach, W. $8^{*}$ u. ö., 47*.

Cronegk 39, 50; Codrus 40 f.; Olint und Sophronia $21^{*}$.

Curtius Rufus 297*.

Scberrer, Kampf im deurchen Drama.
Dante 65.

Degen, J. F. 61*.

Desceltes, M. 107*.

Devrient, E. $19^{*}$ u. ö., s. LV.

Diderot 24*.

Dingelstedt, Fr. 272*.

Dryden $11^{*}, 31$.

Düntzer, H. 146* u. ö., $381^{*}$ u. ̈., $390^{*}$.

Dyk, J. C. $53^{*}, 210$.

\section{E}

Eckermann 380, 383, 384.

Eelking, M. v. $145^{*}$ u ö.

Einzing, Einzinger von, Die Erobenung der

Stadt Jerusalem 13:, 333*.

Ellinger, G. 139*.

Eloesser, A. $325^{*}$ u. ö.

Erdmann, O. 151*, 171*.

Erfurth, P. 3*.

Eschenburg, J. J. 15*, 98 f.

EBlair, F. 289*.

Euripides, Phönissen 62, 222, 322*.

\section{$\mathrm{F}$}

Fielitz, W. $304^{*}$ u. ö.

Fischer, O. $57^{*}, 326^{*}$ u. ü., $358^{*}$ u. ö.

Fleck, J. F. 289*.

Flögel-Bauer 410 .

Fouqué 325.

Franck, J. 202*.

Freye, K. $76^{*}$ u. ö., $77^{*}$ u. ö.

Freytag, C. $24^{*}$ u. ö., 140* u. ö.

Friedrich d. Gr. $43,48^{*}, 49,52,140^{*}, 145,307^{*}$, $334^{*}, 368^{*}$.

- Th. 66*.

Fries, A. 330* u. ö.

Funk, K. W. F. v. 335.

- Z. (K. F. Kunz) 289*.

G

Gärtner, K. Ch. 30*.

Galfried von Monmouth 336.

Gaudig, H. $325^{*}$ u. ö.

Geiger, L. $207^{*}$ u. ö. 
Gellert 75 f.

Gellius, J. G. $47^{\star}$.

George, Stefan 383.

Gerstenberg 56, 57 f., 59*, 60*, 70, 74, 326*, $337^{*}$ : Ugolino 55*, 88*, 98, 108, 338*, 397.

Gervinus, G. G. $22^{*}$ u. ö., s. LV.

Gierke, W. $87^{*}$.

Gilow. H. 370*.

Gleim 52*, 56*; Grenadierlieder 43.

Glück, C. $229^{*}$ u. ö., $230^{*}$.

Goedeke, K. 13* u. ö., s. LV.

Goethe 2, 89, 147*, 158, 194, 206, 271, 281*, $344^{*}, 392,406,409$; Kriegsauffassung $149 f$., 153. 183 f., 344, 380-381, 383-384, $388,393-394$; Urteile wher andere $26 f$., 27 f., 103*, 207, 208*, 217*, 224*, 267; Cassar 183; Clavigo 190. 191: Egmont 183-187, 188, 190, 191, 210, 216*, 237*, 289*, 319*, 351, 369, 380, 381*, 407; Epimenides Erwachen 381, 382-384, 385. 388, 390: Faust I 95, 153, 184*, 185*. 190-193, 234, 381, 406 f.; Faust II 2. $186^{*}$ f., 195, 210, 233, 372*, 380-391, 392. 393. 398; Götz von Berlichingen 37. $64,66^{*}, 69,70-73,76,77-88,96,116$. $118,119^{*}, 120,122,136,138,144,148$. 149 f., 155, 156 f., 159, 183, 184, 186, 187. $188,190,203,216,245,246,247,252,254$, $315,328,339,346,380$ f., 383, 384, 385. $386,392,396,397,400,401,403,404,405$. 406. 410: (Nachwirkung) 89, 90, 921 . 100, 101 f., 103f., 105, 106, 107, 108 f. $110 \mathrm{f.}, 113,117,123-133$ passim. 135. 137, 151, 156f., 162, 176*, 189, 198*, 202. 301*, 354, 355, 356, 357*; (Selbitzszenc) $56^{*}, 80-\$ 2,112,133,173,218,228,246$. 256, 308 f., 313, 317\%, 321f. $368 \mathrm{f}$; (Theaterbearbeitung) 101, 118, 133*, 234 bis 237: Jahrmarktsfest $34,35^{*}$; Iphigenic 187-189, 190, 302*, 314, 316, 381, 386; Das Neueste von Plundersweilern 147"; Pandora 280*, 381, 38\%, 384, 386, 387". 396: Prometheus 328: Tasso 74", $112^{\circ}$. 187, 159-190, 266, 386; Dichtung und
Wahrheit 1, 76*, 139. 247, 407; Kampagne in Frankreich 381, 388; Wilhelm Meitter 191: Zuin Schakespears-Tag 73, 78; Werther 407.

Goldhagen, J. E. $60^{*}$.

Golz, B. $112 *$ u. ö.

Cottsched 2, 8-19, 21 f., 24f., 29 f., 31, 33. $39,43,46,47,48,49,55,56,66,103,107$. $124,189,195,238,259,314,322,346,348$, 392, 395, 401; Agis 15, 18; Bluthochzeit 15. 17 f., 22: Cato 10, 14, 18, 44, 46, 85.

- Frau 11: Panthea 14, 15, 19, 20.

Grabbe 2, 3*, 52, 142*, 203, 313, 346; Hermannsschlacht 23.

Gräf, H. C. 184*.

Graf-Lomtano. J. 72*.

Graft, Jörg 77*.

Grandaur, Fr. 123* u. ö.

Grillparzer 411.

Grimm. F. M., Banise 15f., 33*

Cubitz, F. W. 271*.

Günther, H. 202* u. ö.

- K. 332*.

Cuibert, Comte de $141^{*}, 168^{*}$.

Cundolf, Fr. $55^{*}$ u. ö., s. I.V.

\section{H}

Hachtmann, O. $176^{*}$ u. :

Hadlich, H. 299*.

Hafner, Ph. 34.

Hagedorn 15*.

Hagemann, F. G. 197*

Hahn. L. Ph., Der Aufruhr zu Pisa 98-100, 105, 106, 129, 158* : Robert von Hohenecken 100, 101, 10\%, 105-106, 114, 135*, 316. Hamel, R. 52* u. ö.

Hampe, K. 167*.

Hart, J. $367^{\circ}$.

Hauffer, A. $101^{*}$ u. o., 208* u. 8.

Hauptmann, C. Florian Geyer 104*

Hausen, Fr. $3^{*}$.

Haym, R. 212* u. ö., s. LV.

Hayn, H. 114*.

Hebbel, Fr. 337 f. 
Hédelin d'Aubignac 21*, 24.

Heitmüller, F. 20*.

Hellen, E. von der $80^{*}$.

Hensler, K. F. 37*.

Herder 46, 48, 65*, 78; Von deutscher Art und Kunst 70 f., 73.

Herold, Th. 216*.

Herzog, W. 325* u. ö.

Hettner, H. $16^{*}$.

Heymach, F. 107* u. ö.

Hippe, M. $87^{*}$.

Hirzel, S. $77^{*}$.

Hoffmann, E. T. A. 357.

Hoffmeister, K. $275^{*}$ u. ö.

Holbein, Fr. v. 357.

Holstein, H. 271*.

Holtei, K. v. $238^{*}$.

Holzgraefe, W. $330^{*}$ u. ö.

Holzmann, M. $47^{*}$ u. ö., s. LV.

Homer 26*, 62, 395; Ilias 12*, 91, 227*, 254, $295,301,302,303,306^{*}, 352^{*}$.

Horaz 6 f., 9, 10, 17, 47*, 54, 74, 87*.

Horn, Fr. 202*.

Hübner, Lorenz 197; Camma 128, 130-131, 397; Hainz von Stain 128-130, 135, $194^{*}$.

' Hutten, U. v. 76.

\section{J}

Jacobowski, L. 90*.

Jacobs, M. $47^{*}$ u. ö.

Jähns, M. $85^{*}$ u. ö., $204^{*}$ u. ö., $140^{*}$ u. ö., 3. LV.

Ibsen 127*.

Jean Paul 404.

Iffland $47^{*}, 207,245^{*} \mathrm{f}, 271-272,404$; Albert von Thurneisen 198*; Friedrich von Österreich 196, 198-201, 231, 316; Theatralische Laufbahn 134, 214*, 242.

Immermann, K. 154, 289*, 293.

Jördens, K. H. 13* u. ö., s. LV.

Jonas, Fr. 22* u. ö., s. LV.

Jungfer, Joh. $367^{*}$.

Juvenal $307^{*}$.
Kästner, A. G. 29 f.

Kaltwasser, J. Fr. S. $297^{*}$.

Kannegießer, P. 143*.

Kant 384.

Kaper, E. 325* u. ö.

Kapp, Fr. 145* u. ö.

Karl Wilhelm Ferd. v. Braunschweig 57*.

Kawerau, W. 87*.

Kayser, Ch. G. $61^{*}$ u. ö., s. LV.

Keith, James Graf 277*.

Keller, E. 143* u. o.

Keller, Gottfr. 149.

Kempner, A. (Kerr) $224^{*}$.

Kettner, G. $112^{*}$ u. ö., $282^{*}$ u. ö.

Kilian, E. $37^{*}$ u. ö.

Klee, C. 247 u. ö.

Kleist. E. v. 43, 44, 49, 75, 76 f., 138.

- H. v. 2, 20*, 27, 102, 160, 192, 314, 325 bis $379,382,388,392,393,398$ f., 408-410; Als Soldatenkind 77, 138, 325-327, 339; Kriegsauffassung 327-330, $334 \mathrm{f}$., 350 f., 354 f., 359 f., 379, 393-394; Amphitryon 35, 338*, 354; Robert Guiskard 95*, 180*, 326, 327, 331-341, 344, 346 f., 351, 353, $354,363,377,379,389,394,401$; Hermannsschlacht $23,26,73,110,118^{*}, 124,170$. $180,328,329,342,350,352^{*} 356,359$ bis $366,367,369,372,379,391,324,398,401$ : Der Prinz von Homburg 2, 115, 151*, 169 , $170^{*}, 171,172,173,200,282^{*}, 285,296^{*}$. $326,327,329,335^{*}, 336,339,341,342$, 348, 351, 352-365 passim. 366-379, 386, 396, 398, 401, 409; Käthchen von Heilbronn 121, 128, 148*, 329, 354-358, 398, 400, 401, 405 f., 408 f.; Der zerbrochene Krug 147*, 185*, 354, 376, 405: Leopold von Österreich 364-365; Penthesilea 43, 73, 118*, 148*, 214*, 29**,327. $328,329,332,336,337,341-353,354$, $357,358,359^{*}, 361,365,394,397,398$. 399, 401, 402, 404, 405, 408, 409 f.; Familie Schroffenstein 148*, 245, 318, 322 , $326,327,328,329-331,334^{*}, 340^{*}, 345$, 
346 f. 349, 354f,. 359, 408: Prosaschriften 354, 359 f.. 376. 398, 410; Germania 359; Kateclisınus 359: Michael Kohlhaas 109* 1., 328, 408.

Klinger, F. M. 60*, 89-98, 102,112, 118, 1.1. 156. 194, 355, 404, 407, 409; als Soldat 36 f., 89, 138, 146*; Aristodernos 171*. 1is-181, 187, 396, 402; Die neue Arria 407; Damocles 175*, 182, 3\%, 398; Elfriede 76. 92, 97*, 117*f., 175*, 18\%, 403, 406. 407: Der verbannte Göttersolin 338*; Simsone Grisaldo 97, 182, 201*, 407; Der Günstling 1\$1 f., 297*, 403; Konradin 98. $115,16 \%-175,177,179,210,311^{*}, 31 \%$. 357, 368, 407; Medea in Korinth 95*, 96*, $173^{*}, 175^{*}, 233^{*}, 297^{*}$. 338*: Medea auf dem Kaukasus 171*, 173*, 39, 402; Otto $89-93,95,97,100,101,102,109,110$., $116,125,137,148,151^{*}, 167,169,171$, 176, 177, 187, 364, 397, 403, 405, 407; Pyrrhus 89, 93-96, 98, 137, 169, I81. 183, 246, 263, 287*, 33i-339, 345, 372*, 387, 396, 397, 398, 402; Roderico 144"; Die falschen Spieler 139*; Stilpo 92*, 97 f., 99. 158*, 159; Sturn und Drang 89 . $146^{*}$; Die Zwillinge 97, 407; Orpheus 242*. Klöden, K. Fr. v. 140*.

Kloffler $211^{*}$.

KlopReisch. J. 213*.

Klopstock. Hermannsschlacht 23, 52-67, 68, $69,70,71,74,78,79,80,81,82,88^{*}, 93$. 96, 103*, 110, 115, 123 1., 130, 131, 148*. $155,1 \div 1,173,178,179,181,198^{*}, 228$, 256, 271, 279*, 313, 316, 321, 3:3, 349 . $359.360,362,365,366,392,395$ f., 397. 398, 400, 401 1.: Hermann und dic Fürsten is f., 112*. 168*, 395, 399; Hermanns Tod 68, 402: Salomo 60*: Messias 148* 398.

Klotz. Chr. A. 58*, 59*.

Koberstein, A. $47^{*}$ u. ö., s. LV.

Koch, H. C. 80.

-M. 101* u. ö.. 207* u. ö., 224*. 239*.

Käpke, R. 205 u. ö."

Körner. Th. $333^{\circ}, 336^{\circ}, 380$.
Köster, А 147", 280* u. ö.

Kohlrausch, R. $367^{*}$ u. ö.

Komorzynski, E. v. 34* u. 8 .

Kotzebuc, A. v. 2, 47*, 121*, 19, 206-234, 237, 238, 244, 293, 314, 319*; Adelheid von Wulfingen 209; Bayard 209*, 216 bis 218. 229, 230, 397; Graf Beniowski 117*. 228*; Klcopatra 34, 36; Der Graf von Burgund 209, 222*, 397, 404: Hugo Grotius 208 f., 209*, 224*, 231-23\%, 233 f.; Die Hussiten vor Naumburg 216, 221*, 225-2:26, 235, 333*; Johanna von Montfaucon $128^{*}, 129,197^{*}, 202-216,217$, 218, 220, 224*, 226, 235, 238, 304; Die Kreuzfahrer 197*, 210, 217*, 218-222. $224^{*}, 225,236^{*}, 295,304^{*}, 333^{*}$; Octavia 36, 210, 226-228, 230, 231; Pandorens Büchse 242*; Heinrich ReuB 210 f.. 222 bis 223, 225, 233*, 239, 333*; Rudolf von Habsburg 218, 230, 307*. 372*: Der Schutzgeist 209*, 229-230, 231, 232 f., 390): Die Spanier in Peru 228-229. 231. 232* : Sultan W'ampum 233*; Ubaldo 234*; Custav Wasa 197*, 209*, 212, 2\%3-225, $236^{*}, 240,241^{*}, 273^{*}$.

Kotzebue, W. v. $207^{*}$ u. ö.

Kralik, R. v. 333*.

Krell, M. 140".

Kretychmann, K. F., Dic Belagerung 333*. Kronfeld, E. M. 143*.

Krüger. Ben. Ephr., Mahomed IV. 15, 16, 30; Vitichab und Dankwart 19, 20, 29 f.

Krüger, Joh. Chr. 16*.

Kügelgen. W. v. 390*

Kühn. W. $346^{\circ}$.

Kühnemann, E. 269* u. ö., s. LV.

Küttner, K. A. $41^{\circ}$.

Kurz, J. (Bernardon) Prinzessin Pumphia 33-38, 67. 85*. 99, 238; Weiber- und Bulsenbataille $34^{\circ}$.

Ladendorf, O. 30*.

Längenfeld (Lengesfelder). J. N., Ludwig IV. 
114-117, 118, 123, 126, 171, 195, 321, 368, 397, 400, 410; Die neuen Vestalinnen $114^{*}$.

Lanson, G. 23* u. ö., 258*.

Lappenberg. J. M. $56^{*}$ u. ö.

Legband, P. $34^{*}$ u. ö., s. LV.

Leibecke, O. 3*.

Leisewitz, Julius von Tarent 9S, 182, 307*, 396.

Lenz, J. M. R. 76, 138, 244, 373, 394, 402: Der Engländer 142*; Die Freunde machen den Philosophen 76, 117; Die Soldaten 76, 89, 138, 142, 143; Der tugendhafte Taugenichts 142*, 250*; Anmerkungen übers Theater $65 \mathrm{f}$; Über Götz von Berlichingen 72; Über die Soldatenehen 76*. 138-139, 140-141, 142-146 passim. $168^{*}, 186,187,272^{*}$; Der Waldbruder 146*.

Lessing, G. E. 27, 30, 31*, 39, $41^{*}, 44,46-49$, 64, 181*, 277*, 319*; Emilia Galotti 27 f., 86, 97*, 98; Kleonnis 46, 48, 161, 358*; Minna von Barnhelm 49, 117*, 139-140, $141,142,148,183,326,378,399$ f., 404, 406; Miß Sara Sampson 40; Nathan 55, $86^{*}, 219^{*}$; Philotas $46,48 \mathrm{f.}, 74,88^{*}, 168 \mathrm{f}$., $184,395,397,399,400,401,402,404$; Hamburgische Dramaturgie $21^{*}, 65,70$, 129*, 405; Laokoon 395, 396; Literaturbriefe 10, 13, 14*, 46 f., 74; Rettungen 74*.

- K. G. $41^{*}, 206^{*}$.

Liebe, G. 140*.

Lindau, P. 346*.

Lindner, W. 201*.

Litzmann, B. 87*.

Livius 297*, 368*.

Lobe, J. Ch. 121*, 206*.

Loeper, v. $384^{*}$ u. ö.

Logau 74.

Lohenstein $124^{*}$.

Lohmeyer, W. 3 u. ö., s. LV.

Lope de Vega $76^{*}$.

Ludwig XVIII. 279*.

- Chr. G., Banise 15; Ulysses 13*, 15, 28; „Abhandlung" 12-14.
Ludwig, O. 274*, 281, 283*, 283*, 287, 290, $291^{*}, 292^{*}$.

Lukan 387.

\section{M}

Mahlmann, S. A., Herodes vor Bethlehem 225*, $226^{*}$.

Maier, Jakob 118, 119, 123, 128, 220, 281 : Fust von Stromberg 103, 13\%-135, 136, 198*, 281, 400, 408; Sturm von Boxberg $92^{*}, 101,10 \%-106,108,113,121,122$. 132, 133*, 135-136, 156, 157, 194*, 281*, 408.

Manuel, Niklaus 77*.

Mason, W., Caractacus (60), 61 f., 65; Elfrieda 60.

Mauermann, S. $8^{*}$ u. ö.

May, Karl 149.

Meißner, G., Johann von Schwaben 111.

Mendelssohn, M. 23, 27, 39, 58, 71.

Menzel, A. 390.

Mercier, S., Der Deserteur 139*, 243*.

Meszlény, R. 250*.

Meusel, J. G. 13* u. ö., s. LV.

Meyer, C. F. 217*.

- F. L.W. 206*.

- Rich. M. 388*.

Meyer-Benfey, H. 325* u. ö.

Milton 44, 47.

Minde-Pouet, G. $348^{*}$ u. ö.

Minor, J. 39* u. ö., 79* u. ö., s. LV, 147* u. ö., 3. LV, 149* u. ö., 208* u. ö., 212*, 246* u. ö., $260^{*}$ u. ö., $306^{*}, 333^{*}$ u. ö., $358^{*}$.

Möller, H. F., Graf Walltron 123*, 204-205, $211^{*}$.

Möser, J., Arminius 32.

Molière, Amphitryon 35, 354.

Monsigny 206*.

Montag, W. 66*.

Morel, L. 107*.

Morris, M. $77^{*}$ u. ö., $386^{*}$ u. o.

Morsch, H. 384*.

Müller, C. 272*.

- Fr. (Maler M.), Golo und Genovefa $111-113,115,117,118,120,122,123$. 
$133.135,137.136 .246 .250-252.2344 . .351$. 355, 400, 407, 410: Soldatenabschied 143.

- Hans v. $357^{\circ}$.

- K. W. 390.

Müller-Fraureuth. K. 201* u. ö.

Muncker, F. $21^{*}$ u. ö., $52^{\circ}$ u. ö., s. LV. 60*, $183^{\circ}$ u. ö.. 299*.

Mylius, Chr. 29 f.

\section{$\mathrm{N}$}

Nagel. Anton, Der Bürgeraufruhr in Landshut 126-128. 131, 158*.

Napoleon I. 279*. 326, 393.

Nestroy 410.

Nicolai, Fr, 30 f., 32, 33, 39, 114*, 126*. 205, $238^{\circ}$.

Niejahr, J. $343^{*}$ u. ö.

Nieten, O. 3*.

Nietzsche, Fr. 212".

Ohlert, K. $190^{*}$ u. ö.

Opitz 74.

Ossian 130.

Pausanias 178.

Pelzel. J. B. 333".

Peppmüller, R. 295* u. ö.

Perrault, Ch. 256-258.

Petersen, J. 3 u. ö., s. LV. 263*, 294* u. ö., $332^{*}, 384^{*}$.

Petscl., R. $308^{*}, 328^{\circ}$.

Pfister. A. 143*.

Pfuel. E. v. 326, 341, 364 f.

Philipp, R. 89*.

Pitschel. Th. L., Darius 15, 16, 18f., 20, 28.

Plautus 242.

Plutarch 45*, 95*, 148*, 168*, 297*, 334, 387.

Pniower, O. $367^{\circ}$ u. ö., $384^{\circ}$.

Pope 44*.

Pröhle. H. 43*.

Pyrker. J. L. $333^{\circ}$.

\section{R}

Raab. F. 33* u. ö

Rabany. Ch. $208^{*}$ u. z. s. LV.
Rabener, G. W. 75.

Racine 13. 21*: Phedre 18*, 281*.

Rahmer, S. $326^{\circ}$.

Ramler, K.W. $41^{*}$.

Ramond de Carbonnieres, Hugo VII.107-111, $113,115^{*}, 119,120,125,127,128,129$. 197, 246, 321, 333, 356, 364.

Ranftl, J. $245^{\circ}$ u. ö.

Recke, E. von der $128^{\circ}$.

Reichel, E. 14*.

Rentsch. J. 22* u. ö.

Retz, Kardinal 163.

Riccohoni 14*.

Rieger, M. $60^{\circ}$ u. ö., s. LV.

Riffert, J. E. $21^{*}$ u. ö.

Rist. Joh. 359.

Rößler, C. $336^{*}$.

Roctteken. H. $343^{\circ}$ u. ö.

Rohwedel, v. 87*. 333*.

Rostand. E., Cyrano de Bergerac 191. 275*.

Rubens 342, 357.

\section{S}

Sacchini, Calliroë 206

Sachs, Hans 192, 333*.

San Marte (Alb. Schulz) 336".

Sauer, A. $33^{*}, 40^{*}$ u. ö., $43^{*}, 79^{*}$ u. ö., s. LV (Minor), $111^{*}, 205^{*}$.

Schacht, R. 12* u. ö., 332*.

Scheible, J. $34^{*}$.

Scherer, W. $49^{\circ}$ u. ö., s. LV. $382^{\circ}$.

Schikaneder 34, 153. 196, 203-205, 206. 207, $211^{\circ}, 240^{\circ}, 313,411$; Hanns Dollinger 203. Der Grandprofos 205, Graf Schembera 205" : Die Schweden vor Brünn 2015.

Schiller, Charlotte v. 260.

- Fr. 2, 52, 103, 178, 181, 208*, 217, 224*, 230, 244, 349, 350, 361, 369, 370, 392. 399 ; als Soldatenkind 77, 137 f., 147, 163. 260 f., 325: als Kriegsdichter 57, 102. $143^{*}, 261$. 327: Kriegsauffassung 149-153, 32i-330. 344. 359, 393-394: Braut von 
Messina 117*, 275*, 285, 302*, 313*, 314*, 319*, 323, 394; Don Carlos 98, 163*, $166,189,264,286 \mathrm{f}, 302^{*}, 329,402$; Demetrius 274*, 299*, 319 f., 323; Fiesko $144^{*}, 151^{*}, 155^{*}, 158-166,167,186$, $191,194^{*}, 227^{*}, 232,261,319,340,396$, 397. 398, 402, $403 f$., 407; Die Jungfrau von Orleans $20^{*}, 44^{*}, 92^{*}, 167^{*}, 171,210$, $214^{*}, 218^{*}, 221,223^{*}, 224^{*}, 229,254,261$, $264^{*}, 266,273^{*}, 275,279^{*}, 281^{*}, 286$, $293-324,327,330-331,335,342,344$, 347, 349, 351-353, 357*, 358*f., 363 , $364,368,371,373,386,406$; Kabale und Liebe 144*, 145-146, 165*, 166, 407; Macbeth 280*, 282*, 295*; Maria Stuart $112^{*}, 158^{*}, 165^{*}, 264^{*}, 281^{*}, 293,319^{*}$, 329; Phönizierinnen $322^{*}$; Die Räuber 2 , $44^{*}, 76,111,137 \mathrm{f}, 142,143-145$, 147-158, 164, 165 f., 167, 174, 180, 186, $194,198^{*}, 200,203,236^{*}, 250^{*}, 261,265$, 267, 268, 270 f., 274, 288, 298*, 299*, $307^{*}, 313^{*}, 316,32 \pi, 340,344^{*}, 351$, $392,396,400 \mathrm{f}, 402,403,405,407,408$; Wilhelm Tell 220, 224*, 241*, 2i3*, 307*, $309^{*}, 313^{*}, 319^{*}, 323,327,328,394,396$, 399; Wallenstein 22, 143*, 224*, 260-292, 293, 294, 306, 323, 327, 330*, 331f., $336 \mathrm{f}, 338,340 \mathrm{f}, 362,364,376,377$, 378, 385, 394; (Lager) 95*, 105, 158, 216*, 219, 233, 260, 262, 267-272, 273, 274, 277 f., 281*, 285*, 286*, 292, 294, 327, 334 f., 339, 340 f., 381, 399; (Piccolomini) $50,233,260^{*}, 273^{*}, 275-278,284,287$ f., $334^{*}, 335^{*}, 353^{*}, 362$ f., 407; (Tod) 148*, $158^{*}, 160^{*}, 217^{*}, 233^{*}, 260^{*}, 263-267$, 268, 272-275, 288-292, 296, 297*f., $315,316,334^{*}, 335,349,352^{*}, 353,363^{*}$. 371, 387, 405; Die Flibustiers 223*, 240*; Die Malteser 286*; Das Schiff 240*; Das Seestück 223*, 240* f.; In einer Bataille 152, 261, 311*f., 398; Craf Eberhard der Greiner 152*; Hektors Abschied 227*; Die Glocke 224*; Ritter Toggenburg 297*; Geschichte des Abfalls der Niederlande
187*, 261 f., 316-318; Geschichte des Dreißigjähr. Kriegs 262. Kreg . Schink, J. Fr 123*, 131, 195*. 3i Schlegel, A. W. 3, 5*, 6, 7, $25 \mathrm{f}, 31^{*}, 60^{*}$, $63^{*}, 64,76,131,195,212,238,302^{*}, 306^{*}$. $323,365,368,410,411$ s. LV; Ehrenpforte $128^{*}, 195,209,212,215,238-357^{*}$.

- Elias 13*, 14, 15, 48, 57; Canut 28f.; Dido 14f., 22, 28, 42; Hermann 15, 19. $20-28,30,32,41,52-55$ passim. 61 , $62,64,65,68,69,93,115,123,179,180$. $316,319^{*}, 360,365,392$; Orest und Pylades 28*; Die Trojanerinnen 22; Von der Nachahmung 29.

- Fr., Alarcos 251*f.

- J A. 30*.

- J. H. 22, 28.

Schlenkert, Graf Wiprecht von Groitzsch 196, 201-202, 203.

Schlözer, A. L. 145*.

Schmid, Chr. H. 13*, 16* u. ö., s. LV, 60*. Schmidt, Erich 48* u. ö., s. LV, 60* u. ö., 76*, $107^{*}$ u. ö., 109* u. ö., 146* u. ö., 190* u. ö.

- Fr. L. 206*, 271*, 333*, 411; Der Sturm von Magdeburg $87^{*}$.

Schneider, H. $328^{*}$ u. ö.

Schöll, A. 147*.

Schönaich $30-33,37,40,42,43,50,66,74$, 124; Mariamne 31; Thusnelde 31,33,69, $124^{*}$; Zarine 31, 32, 66; Zayde 31; Hermann 32, 43; Neologisches Wörterbuch 279*, 398.

Schröder, Fr. L. 80, 97*, 206*, 411.

Schröter, M. v. 204*.

Schubart, Chr. Fr. 98, 142 f., 145, 146*, 151*, 404.

- L. 143.

Schüddekopf, C. $381^{*}$.

Schütze, J. F. $121^{*}$ u. ö., s. LV.

Schulze, Berthold $118^{*}$ u. ö.

Schumann, Val. 77*.

Schummel, J. G., Die Eroberung von Magdeburg $86-88,127,132,225,333^{*}$.

Servaes, Fr. 325*. 
Seuffert, B. 12* 11. ̈., 101*.111* 11. \%。.

Sexau, R. 13*.

Shakespeare 8, 11, 17*, 21, 23, 31*, 44, 48*. $49,51,58,59,60^{*}, 65 \mathrm{f}, 67^{*}, 69,70-33$, 89, 93, 96, 100, 109, 111, 119, 127, 159. 176. 195. 24i-250, 251, 253, 254, 259. 274, 275, 291, 306 f., 308, 391, 399, 401, 410; als Kriegsdichter $+f .6,25,72 f .0$ 77, 245, 260, 285 f., 294 f., 301, 323. 3.j0 f., 392-393; Kampltechnik 53, 83. $90,97,160,177,249$ f., 293, 299, 301, 310, 313 f., 315, 318, 324, 343, 360 f., 369, 372; (Kanpfgetümmel) 47, 72f., 116, 302; Kriegerische Stimmungsszenen 27, 65. 155 f., 169, 246, 248, 362, 364f., 387; Behandlung des Ortes 32, 44, 55, $70 \%$. 78, 79. 161, 323; der Zeit 305; Teichoskopie 59. 80, 81, 96 f.. 99*, 173; Botenempfang 174: Nachruf 90-92, 129, 230, 247, 306. $307^{*}$; Postenszenen 71. 73, 94, 98 f. 109. 119. 129, 162-164, 231: Sterberede 192, 218, 247, 306, 309; Antonius und Cleopatra $26,36,45^{*}, 73,81,84^{*}, 91^{*}, 92^{*}$, $94,95,152^{*}, 155^{*}, 168^{*}, 174^{*}, 178^{*}, 226$, $228^{*}, 231^{*}, 248^{*}, 249^{*}, 262$ f., 286*, 290. $307^{*}, 364,372,401,402,403$; Julius Caesar 11 f., 26, 45, 80, 81, 82, 91, 94, 110, 119*. $155^{\circ}, 168^{\circ}, 170^{\circ}, 173,180,214^{\circ}, 228$.

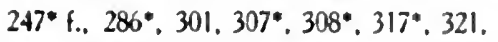
352*, 364, 369; Coriolan 90*, 91*, 94*. 126*, 161*, 337, 402; Hamlet 71, 73, 88, 94. 98, 109, 113, 126*, 129, 163 f., 191. 232, 239, 295": Heinrich IV., 1. Teil $44^{\circ}$. $90^{\circ}, 91^{\circ}, 99,145^{\circ}, 168^{*}, 174^{*}, 248^{\circ}, 250^{*}$, $307^{*}, 310^{*}, 311^{*}, 372^{*}: 2$. Teil 168*, 174*: Heinrich V. 4,.. 26, 73, 79*, 81*, 91, 126*. $250^{\circ}, 325,365^{\circ}, 372^{*}$. 387; Heinrich VI., 1. Teil $83^{\circ}, 90^{\circ}, 91,92^{*}, 94^{\circ}, 110^{*}, 126^{*}$, $156^{\circ}, 223^{\circ}, 232^{\circ}, 248^{\circ}, 295^{\circ}, 296^{*}, 300$. $302^{\circ}, 306^{*}, 307^{*}, 309^{*}, 310,311$, 3331.. 351", 405: 2. Teil 91*, 112": 3. Teil 90*.

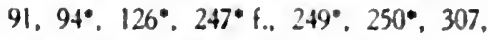
309*, 311*: Falstaff 38, 73, 91, 99, 144. 242, 2:30: Heinrich VIII. 73: König Johann
$94^{*}, 126^{*}, 308^{*}, 309^{*}$ : Lear $65^{*}, 81^{*}, 99^{*}$, $112^{*}, 176$; Macbeth 79*, 84, 90*. 91, 113 . $174^{*}, 191^{\circ}, 233^{\circ}, 249^{*}, 292,295^{\circ}, 312$. $344^{*}, 358^{*}, 364^{*}, 402,403$; Othello 350* f.; Richard 11. 112*, 126*: Richard III, 25. $79^{*}, 90^{*}, 92,94,95^{*}, 146^{*}, 155^{*}, 174^{*}$, $248^{\circ}, 249^{\circ}, 250^{\circ}, 291,292,313,364,372^{\circ}$, 387; Romeo und Julia 51, 239; Der Sommernachtstraum 233*; Der Sturm 338*; Troilus und Cressida 81, 227*, 255*.

Sittard. J. 206*.

Soden, J. v., Franz von Sickingen 177": Heinrich IV. 144*, 175-178, 397; Kleopatra $1 \pi^{*}$ f., $372^{*}$.

Soliman 334.

Sonnenfels, J. v. $44^{*}$ f.: Briefe über die wien. Schaubuibne 18*,37*, 66*, 6i.

Sonnenthal, A. 289*.

Sophokles $60^{*}, 65^{*}, 334,340^{*}$.

Speidel, L. 289*.

Spieß, Chr. H., Klara von Höheneichen $117^{*}$. 196-198, 199, 200, 210, 400.

Spinola 333*.

Spörken. v. 206*.

Spontini, Ferdinand Cortez 206.

Stä:dlin, G. Fr. 21*.

Steele, R. 11.

Stenger, G. $208^{*}$ u. ö.

Stephanie d. jg. $77^{\circ}, 206^{\circ}, 243$.

Stern, A. 43*.

Stich, H. 12*.

Stocknzayer, K. H. v. 2 u. o., s. LV.

StrauB. D. Fr. $1+6^{\circ}$.

\section{T}

Tacitus 279*, 297", 401 .

Tasso $118^{\circ}, 334$ f., $350^{\circ}$.

Teichmann, J. V. $272^{\circ}$.

Teller, Fr. 332* u. ö.

Thimme, A. 269".

Tieck 2, 111", 195, 238-259, 260, 283, 289". $308,351,359^{\circ}, 366,367^{*}, 398,411$ : Blaubart $8,242^{\circ}, 243^{\circ}, 247^{\circ}, 249,250,256-258$. 259. 317; Düunchen 243*. 258-259. 
Fortunat 251*, 404, 408; Genoveva 117*, 209, 245-25*, 253, 255*, 259, 280*, 303, 307, 30s-311, 333 f., 356, 372*, 400, 408; Der Gestiefelte Kater 240*, 243, 411; Karl von Berneck 128, 209, 239-240, 251. 255*, $257^{*}, 396,397,398,400,401,404,403$; Octavian 185*, 248*, 251, 252, 253-256, 259, 303, 317, 400, 401, 408; Die verkehrte Welt 174*, 238-243, 244, 248*, 249, 250, 259; Prinz Zerbino 34, 35, 243-245, 333*; Fermer der Ceniale 202*; Die Heymonskinder 256* f.; Phantasus 205*, 206*. 256*; Der junge Tischlermeister $79,80,153 \mathrm{f}$. Tittmann, J. 8*.

Törring, J. A. v. 101, 114*, 124, 125, 127, 135, 137, 176, 194*, 195; Agnes Bernauerin 119-122, 123-126 passim. 134, 157, $206^{*}, 356$.

Törring-Seefeld, A. v., Die Belagerung der Stadt d'Aubigny 131, 333*.

Treitschke, H. v. 269*, 379.

Tyrtäus 181.

\section{U}

Üchtritz, F. v. 333*.

Unzelmann, Fr. 215*.

- K.W. 410.

Urlichs, L. $260^{*}$.

Uther Pendragon 336.

\section{V}

Varrentrapp, C. $367^{*}$.

Vischer, Fr. Th. 299* u. ö.

Voltaire $5^{*}, 6 \mathrm{f}, 8,10,17^{*}, 18^{*}, 71,189$. 295*; Adelaide du Guesclin 18*.

VoB, J. H. 279*.

- Jul. v. 139.
Waetzoldt, W. 331*.

Wagner, R., Lohengrin 134.

Walz, J. A. $60^{*}$ u. ö.

Walzel, O. 75*.

Waniek, G. 13* u. ö., s. LV.

Weidmann, P. 333*.

Weincck, F. 304*.

Weiße, Chr. F. 41*, 49-51: Die Betreiuns Thebens 50, 87 f., 158*; Krispus 50: Mustapha 50; Richard III. 49 f.; Romeo und Julia 51.

Weißenfels, R. 78* u. ö., s. LV.

Weltrich, R. 138* u. ö., s. LV.

Wendt, H. 234*.

Werder, R. 269* u. ö.

Werner, R. M. 98* u. ö., 101* u. ö., 306*.

Werthes, Fr. A. Cl. 333*; Ba ard 216*.

Westenrieder, L. 67*, 123*, 124*.

Widmann, W. 143*.

Wieland $7^{*}, 49,74^{*}, 77,98,225^{*}$.

Wilbrandt, A. 325*.

Windisch, E. 336*.

Winter, Fr. 79* u. 0.

Wohlwill, A. 146*.

Wolff, E. 22* u. ö., 329*.

Wolzogen, Caroline v. 271, 278.

- L. v. 280 f., 282.

Wukadinowič $180^{*}$ u. ö.

Wurzbach, C. v. 122* u. ö., s. LV

\section{Z}

Zickel, M. 253*.

Ziegler, F. W. 197*.

Zolling, Th. 325*.

Zorn, J. 122*.

Zschokke, H., Abällino 194, 279*: Graf Monaldeschi 194*. 


\section{Sachregister.}

\section{A}

Aktion $31-$ i3, 245, 350 f.

Aktschluß 19, 27.

Angriff 168, $349 \mathrm{f}$.

Aufführbarkeit 55, 79, 80*.

\section{B}

Belehlen 341.

Belagerungsstück 35, 87, 131 f., 219 f., 225 f. 252. 294 f., 333.

Beobachtung von Vorgängen hinter der Szene s. Teichoskopie.

Berufssoldat 75, 138, 140-14i, 149, $164 f$. 186 f., 232, 250, 261, 270, 272, 293f. 276 f., 326 f., 378 f.

Besorgnisszenen 19, 27, 45*, 46, 61, 88*, 89 . 131, 210, 213,227, 229, 230.

Botenbericht bei den Theoretikern 9*, 12, 16. 58: Stärker als Vorführung 40; Bericht und Beobachtung 54, 346; In der griech. Tragödic 3; in der frz: Tragödie 4, 9. 17. 18. 21, 54, 263: im deutschen Drama 17. 18 f., 19, 20, 26, 40, 44, 45 f., 50 f.. 58, 59, 61, 62, 83, 88, 103, 160, 161 f., 175*. 199, 222, 227. 258 f.; (Klassik) 92, 263 f.. 281-283, 291-297, 300, 346-349, 361: parodiert 35 f.: Botenempfang 174; Falschbericht 20. 151 f.. 199. 348: Teilbericht $20,28,54,229,348$.

Bühnenanweisungen 79, 116. 253०。

Burgenstück 108, 111, 120 f., 125*, 128, 197. 209, 214, 251, 258.

\section{C}

Combattement 36f., fif f. 103, 116, 213. 222. 235, 239. 266; Ansätze 16, 18, 23. $30.31 \mathrm{f}$.

D

Deserteur 142*, 243, 354.

Dichter und Soldat i.t-ii, 89, 137 f.. 261.
278, 315, $326^{\circ}$. 379; Militärische Kenntnisse der Dichter 26, 49, 56, 57, 76 f, 163. $278-280$.

Disziplinproblcm 147, 165, 186, 233, 261, $270,274,278,339$ 1., 351, 366 f., 372-375, $337-378$.

Drama, Deutsches 5, 7, 8 f., 10, 16, 39, 54 .. 70, 137, 178f., 187f.; (klassisches) 262-268. ?9:, 330 f., 39!\%-394; Englisches 3 f., 5. 6. 8, 11, 30 ศ.. 32. 39; Französisches (tragédie classique) 4, 5, 8 f., 13, 14 f., 16 .. 18, 21, 23, 31, 39, 46 f., 52 f., 54 f., 57. 6i3, 65, 71, 81, 91, 107, 1781., 187, 189. $190,227,263,314,322,348,392$ f.; Griechisches $3 f ., 60-6 i, 81,91,393,410$; Spanisches 31., 6, 76 f., 245*, 253, 259.

E.

Einheit des Ortes 9, 12, 32, 41, 44, 50, 53. 54, 3i, 70, 78, 80, 129, 132, 159, 345 f. - der Zeit 12, 24 \%., 53, 78, 127.

\section{F}

Feldherr 73, 260, 274, 286-292, $30.5 \%$ 33:-341, 312-36.4.

Frau, kriegerische 182, 185, 351-353, 402.

C

Glückwechsel 20, 35*, 65, 174, 199, 228 f. 320. 349.

H

Heer 260, 269, 272, 275, 277 f., 339 f., 375 f. 378 f., 382.

Heerlager 219, 279, 387.

Hypothetische Kampfschilderung 27, 28, 48. 54, 86. 161, 227, 228, 319 f.

I

Illusion 3-6, 54, 63 \&., 79, 240 f., 315. 405. 410 .

Illusionistische Mittel 6, 53, 63, 110, 184, 188 
$299^{*}, 302^{*}, 314$; Getöse 32, 119, 237, $265,302,304,390 \mathrm{f}$.

Invalide $404-405$.

\section{$\mathrm{K}$}

Kampfabgang 19, 27*, 35, 46, 59, 157, 217, 221, 227.

Kampfbefehl 34f., 61, 169, 249.

Kampfmorgen 248, 3i2.

Kampfmusik 53 f., 172, 184, 205, 210-2i3, 227, $304 £ ., 314$.

Kampfpantomime 116, 118, 129, 158, 160, 177, 189, 195, 205 f., 211f., 225 f., 302.

Kampfschilderung 42, 43, 46, 74*, 280-283, $294-297,342,349$.

Kampfspektakel 7, 72 f., 135 f., 137, 153, 195 f., 203-206, 207, 324, 411.

Kampftempo 14, 78, 82, 322.

Kampfvorführung im neueren Drama 3; in der frz. Tragödie 9; bei Shakespeare 12, 90; Shakespeare darüber $4 \mathrm{f}$.; in Gottscheds Theorie 10-12, 47; rationalistische Einwände $4 f ., 6,10,11,12,13,31,67$; Satire (Theatralgefecht) 36-38, 238-242; im bürgerl. Drama 40; bei Schiller 293, 294, 299-312; bei Kleist 348; Kampfgetümmel $11,16,18,31,47,48,54,67^{*}$, 73, 158, 217; Blutvergießen 8, 10, 13, 405.

Kampfzeit 23f., 28, 61, 78, 305, 312*, 321. Komparserie 11, 37 f., 55, 206, 314.

Krieg als Erlebnis 43, 45, 49, 51, 56, 59 , $65,72,74-77,84,86,89,93 \mathrm{f.,} 102$, $113,138,168 \mathrm{f} ., 170 \mathrm{f.,} \mathrm{181,} 183$ f., 207, 245 f., 252, 259, 325-330, 344 f., 349, 350 f., 354 f., 359 f., 380-381, 383-384, 388, 393-394; als dramatischer Vorwurf 3-7, 313-315, 368, 369 f., 381-385, 393; als theatralischer Vorwurf 7, $153 \mathrm{f.}$ 194-196; Pathetische und realistische Kriegsauffassung 149f., 283-287, 393 bis 394; Sentimentalisierung 216, $225 \mathrm{f}$.

Kriegshistorische Gelehrsamkeit 56, $103 \mathrm{f}$, 132 f., 134, 280-283, 285, 294 f., 297, 370.
Kriegslyrik 43, 51, 56, 152.

Kricgsmann 73, 242.

1.

Lokal 5j f., 58, 63, 30f., 78, 79, 82, 109. $111,125,200,3,36$ !.

$\mathrm{Mi}$

Masse $5,11,16,31,32,47,48^{*}, 50,54,55$, 66, 206, 262, 264 f., 266 f., 286*, 301, 302. $342 \mathrm{f.;}$ parodiert 37.

Miles gloriosus 34, 35, 242, 404.

\section{N}

Nachruf 90-9\%, 129, 247 f.

Nachtkampf 93-95, 246.

\section{$\mathrm{P}$}

Parteiwechsel 32, 53, 84, 249, 299*.

Pferd 7, 63, 79, 80, 92 f., 112, 113, 125, 133. 202, 203, 204f., 251, 278, 350, 356, 406 bis 411; „Roßkomödie" $79^{*}, 411$.

Postenszenen 98, 99, 109, 115, 131, 162-164, 192, $200 \mathrm{f}, 231-233,239,273^{*}$; bei Shakespeare 71, 73, 94, 98, 129.

\section{$\mathrm{R}$}

Raumvorstellung 54, 63 f., 79 f., 159, 254, 312*, 346, 356, 386, 393.

Reservestellung 24, 115, 171, 368.

Ritterstück 86, 101-13\%, 158, 159, 176, 177 , 194-204, 209-223, 239, 258, 294*, $324,328,329,333,354 f ., 356-358,411$.

\section{$\mathrm{S}$}

Schießen 17, 18, 67*, 153-155, 162, 184, 204, $205,223,224^{*}, 237,242,265,281,282$, 311, 371; anachronistisch 11*, 295*.

Schlacht, als dramatischer Vorwurf 3*, 313 bis $31 \mathrm{~J} ; 21,41 \mathrm{f} ., 52,65,66,68,169 \mathrm{f}$., $179,213-215,246-254,259,280$ f., 293 , $296-324,360-362,368-372,388-391$; satirisch 240-252; Motivierung des Aus- 
gangs $20,25 f ., 45,65,94,169$ f., 172. 180, 29s f., 343, 364 f., 370, 372.

Sihlachiberatung $168,300 \mathrm{f}$.

Soldatenhandel 145-14\%.

Soldatenstïck 2, 49, 76 f., 91*, 123, 130 f., 139, 153*, 2034., 206*, 208, 233, 326*. $333^{*}, 366,376$.

Soldatentum 18:3 f., 186 f., 192 f., 268, 269 bis $280,292.378$.

Soldatica 84 f., 231, 232, 233, 338-341 ; Bleisoldaten 245.

Spannung 68, 121 f.. 126, 15j-15s, 172, 257.

Stimmungsszenen u. Stimmungselensente 27. $41,53,54,61,65,84,934,96,124,155$. 161, 169 f., 221 f., 245, 2.16-24!, 251 f. 259. 312, 36t-366, 371 6., 387.

Symbolische Parteiung 312-324, 330-331. 347.

Szenenwechsel 120, 249*, 303, 323.

\section{$\mathrm{T}$}

'Teichoskopic 54, 56-59, 60*, 61, 62, 63, 66,68 f., 80, 81-83, 86, 88*, 96 f., 103. $110,112,113,115,121,127,130,133$. $160 \mathrm{f} ., 171-133.177,179,199,217 \mathrm{f}$. $222,224,226,228,229$ f., 235, 254-258. 264f., 294, 299*. 313, 315-323, 330 f., $338,346-349,368$ f., 371, 356. 389. 393; als unrationalistische Form 4, 57: Ansàtze 50: Akustische Beobachtung 133\% $158^{*}$. $161,254^{\circ}, 265^{*}, 319$.

Tod aut der Bühne 12 f, 250.

Turnier 11\%, 122 \%. 125 \%., 134, 201-204. $251 * 358$.

Uberfall 14, 401.

\section{IV}

Waffe u. Rüstung $85,95,96,113,125,131$. 133, 190, 239, 251, 350, 395-401.

W'ehrverfassung 76 f., 138-147, 242 f., 243 His 24i, 259, 261, 272.

Welt friede 384.

Werber 142*, 144f., 147*, 354.

Wortschatz, kriegerischer 89, 165 f.: ..Kriegsgefährte” 279; .,entscharen" $296 \mathrm{f.}$. "Gendarmen" 322": .rasseln" 398.

Wunde $68,283,343,401-406$; Blutblase 8 . 405.

\section{Z}

Zweikampf (Duell) 10, 13f, 15, 16, 28 f., 30 . 31, 37, 40, 98, 187, 189-192, 220, 239. 254-2.56, 303 f., 310, 358; Zweigefecht 90.214 f., 249, 253 f., 301, 315, 318, 361. Zwischenakt für Kämpfe verwendet 24 f, 28 , 46. 66, 89, 300 . 


$$
\text { - }
$$




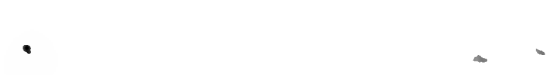





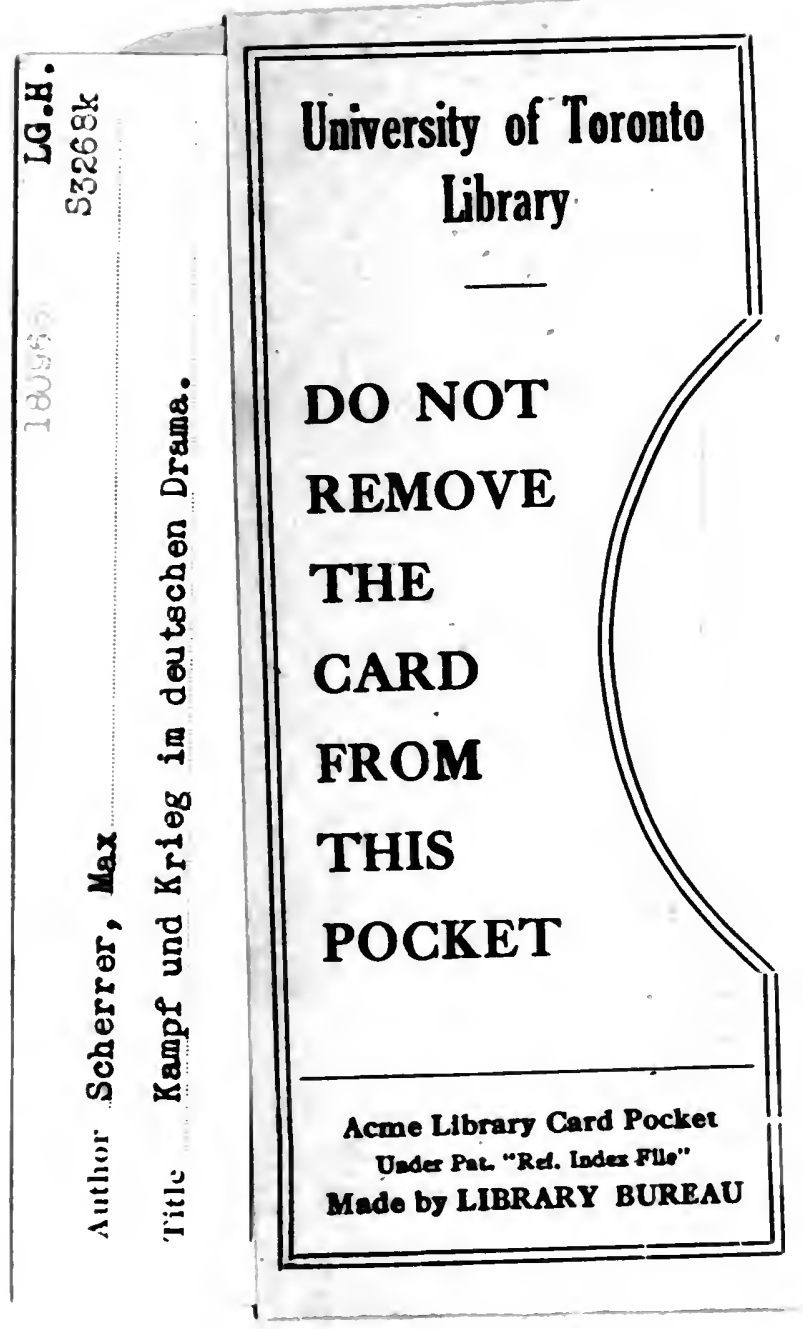


